\title{
Analysis of the Potential Impacts on Surface Water Quality Resulting from the Proposed Use of the San Luis Drain to Transport Agricultural Drainage through the Northern Grasslands
}

\author{
Nigel W.T. Quinn \\ Earth Sciences Division \\ Lawrence Berkeley Laboratory \\ University of California \\ Berkeley, California 94720
}

May 1992

This work was supported in part by the U.S. Bureau of Reclamation, under U.S. Department of the Interior Interagency Agreement No. 0-AA-20-09410, through U.S. Department of Energy Contract No. DEAC03-76SF00098. 


\section{Table of Contents}

1. Background

1.1 Purpose of report and scope of study

1.2 Water supply and drainage in the Grassland area prior to 1985

1.3 Present use of Grassland channels for drainage conveyance

1.3.1 Blake-Porter bypass

1.3.2 Agatha / Camp 13 Flip - Flop

1.4 Alternative Water Supplies $\quad 8$

1.5 Grassland drainers proposed use of the San Luis Drain 8

1.6 Water quality objectives for the San Joaquin River, Mud and Salt Sloughs 10

2. Study design 12

$\begin{array}{lll}2.1 & \text { Conceptual framework } & 12\end{array}$

$\begin{array}{lll}2.2 & \text { Data requirements } & 13\end{array}$

2.3 Data sources and limitations 13

3. Analysis of operations and impacts on flow and water quality 15

$\begin{array}{lll}3.1 & \text { Land use and water requirements } & 15\end{array}$

$\begin{array}{lll}3.2 & \text { Wetland water management practices } & 15\end{array}$

3.3 Water budget and mass balances on salts and trace elements 16

$\begin{array}{lll}3.4 & \text { Scenarios } & 16\end{array}$

3.5 Assumptions in wetland return flow analysis 26

3.6 Contaminants in wetland return flows 27

3.7 Agricultural retum flows and contaminant loads 28

3.8 Losses of boron,selenium and TDS in ponds and channels 44

4. Analysis of impacts 46

$\begin{array}{lll}4.1 & \text { Scenario development } & 47\end{array}$

4.2 Development of the with-project scenarios 48

4.3 Calibration of contaminant flows and loads (without project) 49

4.3.1 Contaminant flow and concentration data 49

4.3.2 Selenium uptake and effect of using San Luis Drain 51

4.3.3 Projected mass loading of boron, selenium and TDS 53 
4.4 Effect of proposed project on boron concentrations

4.4.1 1988 data 53

$\begin{array}{lll}4.4 .2 & 1986 \text { data } & 54\end{array}$

4.5 Effect of proposed project on selenium concentrations 54

$\begin{array}{lll}4.5 .1 & 1988 \text { data } & 54\end{array}$

$\begin{array}{lll}4.5 .2 & 1986 \text { data } & 61\end{array}$

4.6 Effect of proposed plan on TDS concentrations 61

$\begin{array}{lll}4.6 .1 & 1988 \text { data } & 61\end{array}$

$\begin{array}{lll}4.6 .2 & 1986 \text { data } & 62\end{array}$

4.7 Effect of proposed action on the maintenance of water quality objectives 62

4.8 Effect of proposed project on boron and selenium loads 66

4.9 Options for restoring the San Joaquin River to pre-project conditions 66

4.10 Supplemental water supply requirements to match without-project water 69

quality concentrations and meet SWRCB objectives

5. Conclusions 97

5.1 Summary of findings $\quad 97$

$\begin{array}{lll}5.2 & \text { Study limitations } & 99\end{array}$

$\begin{array}{ll}\text { 6. References } & 100\end{array}$

$\begin{array}{lll}\text { Appendix A } & \text { Monthly Water Quality Concentrations and Load-Flow Factors. } & 102\end{array}$

(A - 1 -thru A - 11 : Years 1986 - 1990)

$\begin{array}{lll}\text { Appendix } B & \text { TDS, Boron and Selenium Mass Loading and Flow Data for } 1988 & 115\end{array}$

Hydrology With and Without the Proposed Project. (B -1 thru B - 28)

Appendix C TDS, Boron and Selenium Mass Loading and Flow Data for 1986

Appendix D Flow, Salt and Trace Element Monitoring Data Collected by Summers 203 Engineering Inc. and the CRWQCB.

Appendix E Detailed Maps of Water Supply Facilities in the State and Federal Wildlife 209

$\begin{array}{lll}\text { Appendix F } & \text { Land Use Data for management areas defined in GRASDIN model. } & 215\end{array}$

Appendix G Monitoring locations and constituent sampling frequency for the Grassland area. 222 


\section{List of Tables}

Table 1 Water budget and contaminant load-flow factors - San Luis NWR.

Table 2 Water budget and contaminant load-flow factors - Kesterson NWR. 18

Table 3 Water budget and contaminant load-flow factors - Los Banos WA. 19

Table 4 Water budget and contaminant load-flow factors - Volta WA. 20

Table 5 Water budget and contaminant load-flow factors - Grassland RCD and WA. 21

Table 6 Grassland wetland retum flow and contaminant discharge : Without project. 22

Table 6 (continued) 23

Table 7 Grassland wetland return flow and contaminant discharge : With.project 24

Table 7 (continued) 25

Table 8. Input-output analysis of boron loading in the Grassland area 39

Table 9 Input-output analysis of selenium loading in the Grassland area 40

Table $10 \quad$ Input-output analysis of TDS loading in the Grassland area 41

$\begin{array}{lll}\text { Table } 11 & \text { Frequency of exceeding SWRCB water quality objectives } & 67\end{array}$

Table 12 Summary of boron and selenium loads in the San Joaquin River with and without 68

Table 13 Volume of supplemental water supply required to meet SWRCB boron objectives for the San Joaquin River at Newman : Scenario 1. 1988 hydrology.

Table 14 Volume of supplemental water supply required to meet SWRCB boron objectives for the San Joaquin River at Newman : Scenario 2.1988 hydrology.

Table 15 Volume of supplemental water supply required to meet SWRCB boron objectives for the San Joaquin River at Newman : Scenario 3. : 1988 hydrology.

Table 16 Volume of supplemental water supply required to meet SWRCB boron objextives for the San Joaquin River at Newman : Scenario 3. : 1986 hydrology.

Table 17 Volume of supplemental water supply required to meet SWRCB boron objectives for the San Joaquin River at Newman : Scenario 3. : 1986 hydrology.

Table 18 Volume of supplemental water supply required to meet SWRCB boron objectives for the San Joaquin River at Newman : Scenario 3. : 1986 hydrology.

Table 19 Volume of supplemental water supply required to meet SWRCB selenium objectives for the San Joaquin River at Newman : Scenario 1. : 1988 hydrology.

Table 20 Volume of supplemental water supply required to meet SWRCB selenium objectives for the San Joaquin River at Newman : Scenario 2. : 1988 hydrology

Table 21 Volume of supplemental water supply required to meet SWRCB selenium objectives for the San Joaquin River at Newman : Scenario 3. : 1988 hydrology

Table 22 Volume of supplemental water supply required to meet SWRCB selenium objectives for the San Joaquin River at Newman : Scenario 1. : 1986 hydrology 
Table 23 Volume of supplemental water supply required to meet SWRCB selenium objectives for the San Joaquin River at Newman : Scenario 2.: 1986 hydrology

Table 24 Volume of supplemental water supply required to meet SWRCB selenium objectives for the San Joaquin River at Newman : Scenario 3.: 1986 hydrology 


\section{List of Figures}

Figure 1. Location of Grasslands relative to west-side agricultural water districts

Figure 2. Location of state and federal refuges and the perimeter of Grassland RCD 4

Figure 3. Canal network within the south-eastern and north-western Grassland areas 6

Figure 4. Schematic of the water supply and drainage network in westem Grassland. 7

Figure 5. Monthly agricultural drainage flows into Grassland for $1985-1989$ (Summary of Simmers Engineering and CRWQCB data).

Figure 6. Boron concentrations in monthly drainage flows from agricultural water districts measured at four monitoring sites in South Grasslands for the period 1986-1987

Figure 7. Boron concentrations in monthly drainage flows from agricultural water districts measured at four monitoring sites in South Grasslands for the period 1988-1989

Figure 8. Selenium concentrations in monthly drainage flows from agricultural water districts measured at four monitoring sites in South Grasslands for the period 1986-1987

Figure 9. Selenium concentrations in monthly drainage fiows from agricultural water districts measured at four monitoring sites in South Grasslands for the period 1988-1989

Figure 10 Effect of averaging the CRWQCB boron monitoring data and the data collected by Summers Eng. Inc. 1986

Figure 11 Effect of averaging the CRWQCB boron monitoring data and the data collected by Summers Eng. Inc. 1987

Figure 12 Effect of averaging the CRWQCB boron monitoring data and the data collected by Summers Eng. Inc. 1988

Figure 13 Effect of averaging the CRWQCB boron monitoring data and the data collected by Summers Eng. Inc. 1989

Figure 14 Effect of averaging the CRWQCB selenium monitoring data and the data collected by Summers Eng. Inc. 1986

Figure 15 Effect of averaging the CRWQCB selenium monitoring data and the data collected by Summers Eng. Inc. 1987

Figure 16 Effect of averaging the CRWQCB selenium monitoring data and the data collected by Summers Eng. Inc. 1988

Figure 17 Effect of averaging the CRWQCB selenium monitoring data and the data collected by Summers Eng. Inc. 1989

Figure 18 Shallow groundwater quality zones in Grassland area

Figure 19 Input-output analysis showing the percent gain in boron and TDS load and the percent reduction in selenium load between the drainage monitoriing sites and Mud and Salt Slough (1988 data)

Figure 20 Input-output analysis showing the percent gain in boron and TDS load and the percent reduction in selenium load between the drainage monitoriing sites and 
Mud and Salt Slough (1986 data)

Figure 21 Estimated effect of project on boron concentrations in Salt Slough : 1988

Figure 22 Estimated effect of project on boron concentrations in Mud Slough : 1988

Figure 23 Estimated effect of project on boron concentrations in the San Joaquin River : 1988

Figure 24 Estimated effect of project on selenium concentrations in Salt Slough : 1988

Figure 25 Estimated effect of project on selenium concentrations in Mud Slough : 1988

Figure 26 Estimated effect of project on selenium concentrations in the San Joaquin River : $1988 \quad 56$

Figure 27 Estimated effect of project on TDS concentrations in Salt Slough : 1988

Figure 28 Estimated effect of project on TDS concentrations in Niud Slough : 1988

Figure 29 Estimated effect of project on TDS concentrations in the San Joaquin River. 1988

Figure 30 Estimated effect of project on boron concentrations in Salt Slough : $1988 \quad 58$

Figure 31 Estimated effect of project on boron concentrations in Mud Slough : 1988

Figure 32 Estimated effect of project on boron concentrations in the San Joaquin River : $1988 \quad 58$

Figure 33 Estimated effect of project on selenium concentrations in Salt Slough : 1988

Figure 34 Estimated effect of project on selenium concentrations in Mud Slough : 1988

Figure 35 Estimated effect of project on selenium concentrations in the San Joaquin River : $1988 \quad 59$

Figure 36 Estimated effect of project on TDS concentrations in Salt Slough : $1988 \quad 60$

Figure 37 Estimated effect of project on TDS concentrations in Mud Slough : $1988 \quad 60$

Figure 38 Estimated effect of project on TDS concentrations in the San Joaquin River: $1988 \quad 60$

Figure 39 Estimated effect of boron concentration in the San Joaquin River : 1988

Figure 40 Estimated effect of selenium concentration in the San Joaquin River : 1988

Figure 41 Estimated effect of boron concentration in the San Joaquin River : 1986

Figure 42 Estimated effect of selenium concentration in the San Joaquin River : 1986

Figure 43 Monthly supplemental flows required to restore the San Joaquin River at Newman 75 to pre-project boron concentrations (1988 hydrology)

Figure 44 Monthly assimilative capacity of the San Joaquin River or monthly volume of 76 supplemental water required to meet SWRCB objective : 1988 hydrology

Figure 45 Monthly supplemental flows required to restore the San Joaquin River at Newman 80 to pre-project boron concentrations (1986 hydrology)

Figure 46 Monthly assimilative capacity of the San Joaquin River or monthly volume of suppiemental water required to meet SWRCB boron objective : 1986 hydrology

Figure 47 Monthly supplemental flows required to restore the San Joaquin River at Newman to pre-project selenium concentrations (1988 hydrology)

Figure 48 Monthly supplemental flows required to restore the San Joaquin River at Newman to pre-project selenium concentrations (1986 hydrology)

Figure 49 Monthly assimilative capacity of the San Joaquin River or monthly volume of supplemental water required to meet SWRCB selenium objective : 1988 hydirology 
Figure 50 Monthly supplemental flows required to restore the San Joaquin River at Newman to pre-project selenium concentrations (1986 hydrology)

Figure 51 Monthly supplemental flows required to restore the San Joaquin River at Newman to prs-project selenium concentrations (1986 hydrology)

Figure 52 Monthly assimilative capacity of the San Joaquin River or monthly volume of supplemental water required to meet SWRCB selenium objective : 1986 hydrology

Figure 53 Monthly supplemental flows required to restore the San Joaquin River at Newman to pre-project TDS concentrations (1988 hydrology)

Figure 54 Monthly supplemental flows required to restore the San Joaquin River at Newman to pre-project TDS concentrations (1986 hydrology) 


\section{Acknowledgements}

This project was funded by the US Bureau of Reclamation under U.S. Department of the Interior Interagency Agreement No. 0-AA-20-09410. I would like to thank Donald Swain, of Donald G. Swain and Associates, for his assistance in the original study report which formed the basis for this report and to Mike Delamore, MP-405, U.S. Bureau of Reclamation for providing the funding for the project. Thankyou also to Sally Benson and Tetsu Tokunaga at Lawrence Berkeley Laboratory who reviewed the draft report and provided helpful comments. 


\section{Background}

\subsection{Purpose of report and scope of study}

An Environmental Assessment and Initial Study for the interim use of a portion of the San Luis Drain for conveyance water through the Grassland Water District and adjacent Grassland areas was conducted by Summers Engineering Inc. for a coalition of Grassland Drainage entities. These entities include the Panoche Drainage District, Firebaugh Canal Water District, Central California Irrigation District, Broadview Water District, Pacheco Water District, Charleston Drainage District and the City of Los Banos. The project proposes the use of 18 miles of the San Luis Drain for the conveyance of agricultural drainage water for a period of five years and the elimination of agricultural drainage discharges from 76 miles of existing channels in and adjacent to the Grassland Water District.

Review of the study document by the Natural Resources Defence Council, the Environmental Defence Fund and the Fish and Wildlife Service resulted in the request by these organizations for more detailed analysis of potential environmental impacts of the project and a more detailed accounting of project benefits. A report by Swain and Quinn (March,1991) was prepared to (a) quantify the potential project effects on surface water quality within Salt and Mud Sloughs and the San Joaquin River using currently available data, and (b) to improve the understanding of existing water supply and drainage operations within the Grassland area. After submission of the original report it was brought to the attention of one of the co-authors that the database on selenium and boron concentrations in drainage water, compiled by the Environmental Defence Fund (EDF), did not include the water quality data collected by the Regional Water Quality Control Board (CRWQCB). In addition, the US Bureau of Reclamation (USBR) requested further examination of Grasslands hydrology to estimate the quantity of supplemental water that would be needed to restore the San Joaquin River to the same TDS and trace element concentrations prior to implementation of the project. This report addresses these issues and incorporates additional analysis in response to some of the review comments of the March, 1991 (Swain and Quinn, 1991) report .

Some of the March 1991 report will be repeated in this report to produce a stand-alone document. Only two years of Grassland area hydrology are considered, however, as an expedient. These years are considered to be representative of wet (1986) and critically dry (1988) years. The years 1987 and 1989 were also considered critically dry - the 1988 results for monthly selenium and boron loads to the San Joaquin River appear to be intermediate between the 1987 and 1989 results. The updated database does not change the results significantly from those presented in the March, 1991 report. The reader is referred to the March, 1991 report for the analysis of with project and without project scenarios for hydrologies similar to the 1987, 1989 and 1990 water years.

\subsection{Water supply and drainage in the Grassland area prior to 1985}

A detailed description of the water resources of the Grassland area is containtd in the Report on Water Supply Investigations (USBR,1989) and in the San Joaquin Valley Drainage Program Report on Fish and Wildlife Resources and Agricultural Drainage in the San Joaquin Valley (SJVDP, 1990a). 
The Grassland area shown in Figure 1 is typically divided into two subareas, the northwestern Grassland and the Southwestern Grassland. The northwestern Grassland is approximately 130,000 acres in area and is bounded by State Sighway 140 to the north, State Highway 152 to the south, the San Joaquin River to the east and Ingomar Grade to the west. The southwestem Grassland area covers a smaller area of approximately 50,000 acres and is bounded by State Highway 152 to the north, the Outside Canal to the south, State Highway 53 to the east and State Highway 165 to the west (SJVDP, 1990a).

The Grassland Resource Conservation District (RCD) covers an area of approximately 75,000 acres and is the largest institutional entity within the combined northeastern and southwestern Grassland areas (Figure 2). The lands contained within the Grassland area sustain multiple lind uses including seasonally flooded inland marshes, permanent pasture, seasonally flooded native pasture and agricultural crops. The Grassland RCD includes 60,000 acres of privately owned duck clubs, 12,000 acres of land owned by the State and Federal governments and 3,000 acres of cropland. The Federal and State owned refuges include Kesterson National Wildlife refuge, Volta Wildlife Management Area and Los Banos Wildlife Management Area. The San Luis National Wildlife Refuge lies to the east of the northwestern Grassland area (USBR,1989).

Within the non-refuge areas of Grassland RCD $70-80 \%$ of the acreage is managed to provide habitat for wintering waterfowl (USBR,1989). Most agricultural land with in the RCD is in permanent pasture or field crops such as sugar beets, alfalfa and cotton. Wetland areas which have been converted to agricultural uses are no longer eligible to receive Central Vallizy Project (CVP) water, which is made available through the Grassland Water District. Hence today, as weili as prior to 1985 , agricultural land is entitled only to drainage return flows as an irrigation water supply. The firm CVP allocation of 50,000 acre-ft per year has been insufficient to meet demand from the wetland areas within Grassland area - hence agricultural return flows and operationa' pills from agricultural areas outside the Grassland area and pumpage from groundwater wells within the Grassland area have been used to supplement water supplies in the Federal and State refuges and in the private duck clubs (USBR, 1989). The fraction of annual wetland water requirements met by groundwater pumping is difficult to assess owing to the lack of monitoring data and the variable water quality underlying the Grassland area. Private duck clubs, within the Grassland RCD, but outside the boundaries of the Grassland Water District, rely heavily upon alternative sources of water other than project deliveries, as well as on interim contracts for water with neighbouring water districts.

The Grassland area conveys agricultural drainage produced by entities known as the "exchange contractors" including the Central California Irrigation District (CCID), the San Luis Canal Company and the Firebaugh Canal Company and by water districts within the San Luis Unit which include the Panoche Water District, the Broadview Water Districh, the San Luis Water District and the Pacheco Water District. The mass load of selenium entering the Grassland area is mostly contributed by the Federal water contractors within the San Luis Unit. The channels contributing these contaminated flows enter the Grassland area from the south. These contaminated drainage return flows mix with return flows with lower selenium concentrations in transit through south and north Grasslands. Prior to 1985, these drainage return flows were utilized to supplement water deliveries to wetlands and refuges within the Grassland areas. 


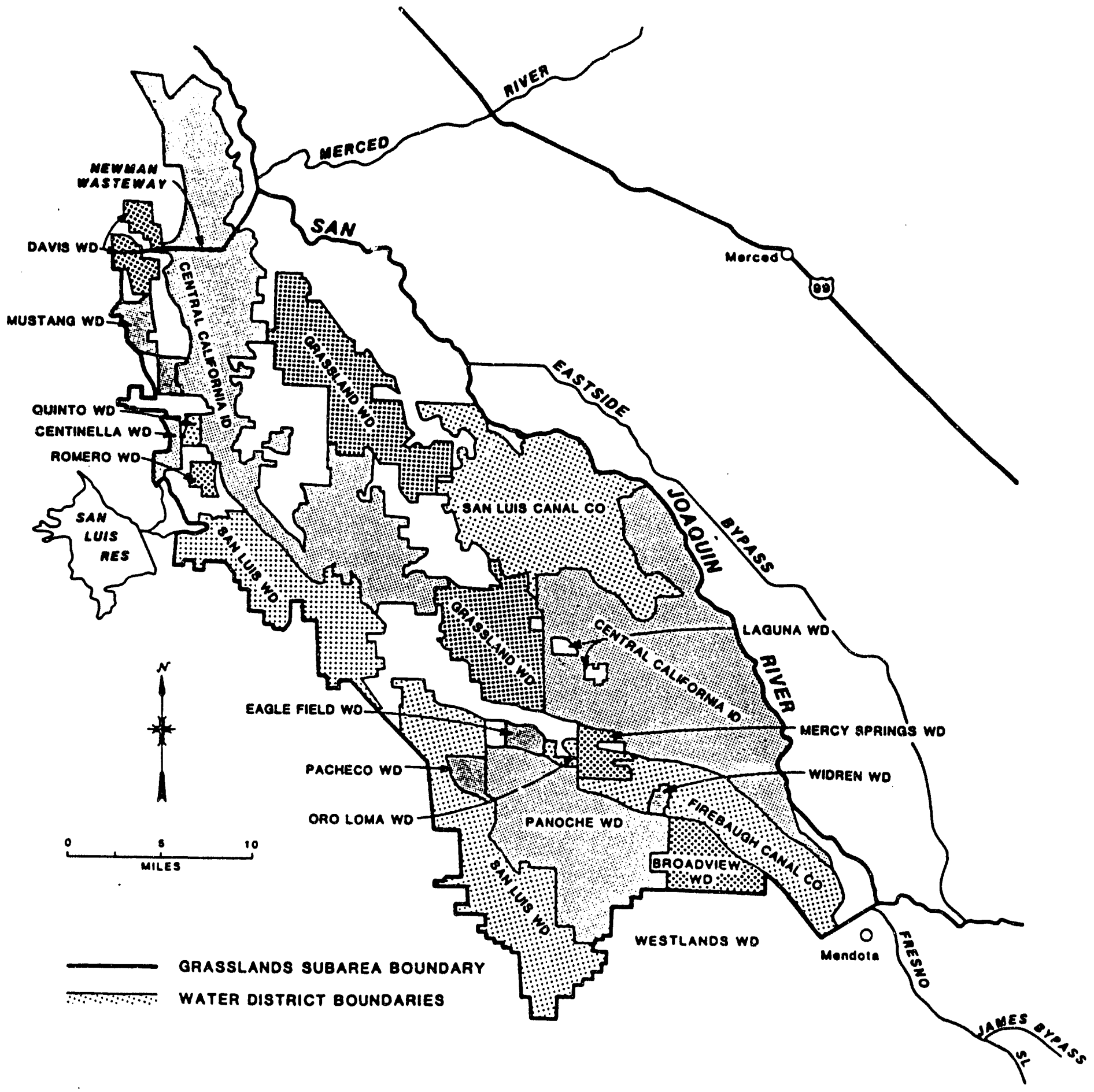

Figure 1. Location of Grassland area relative to west-side agricultural water districts 


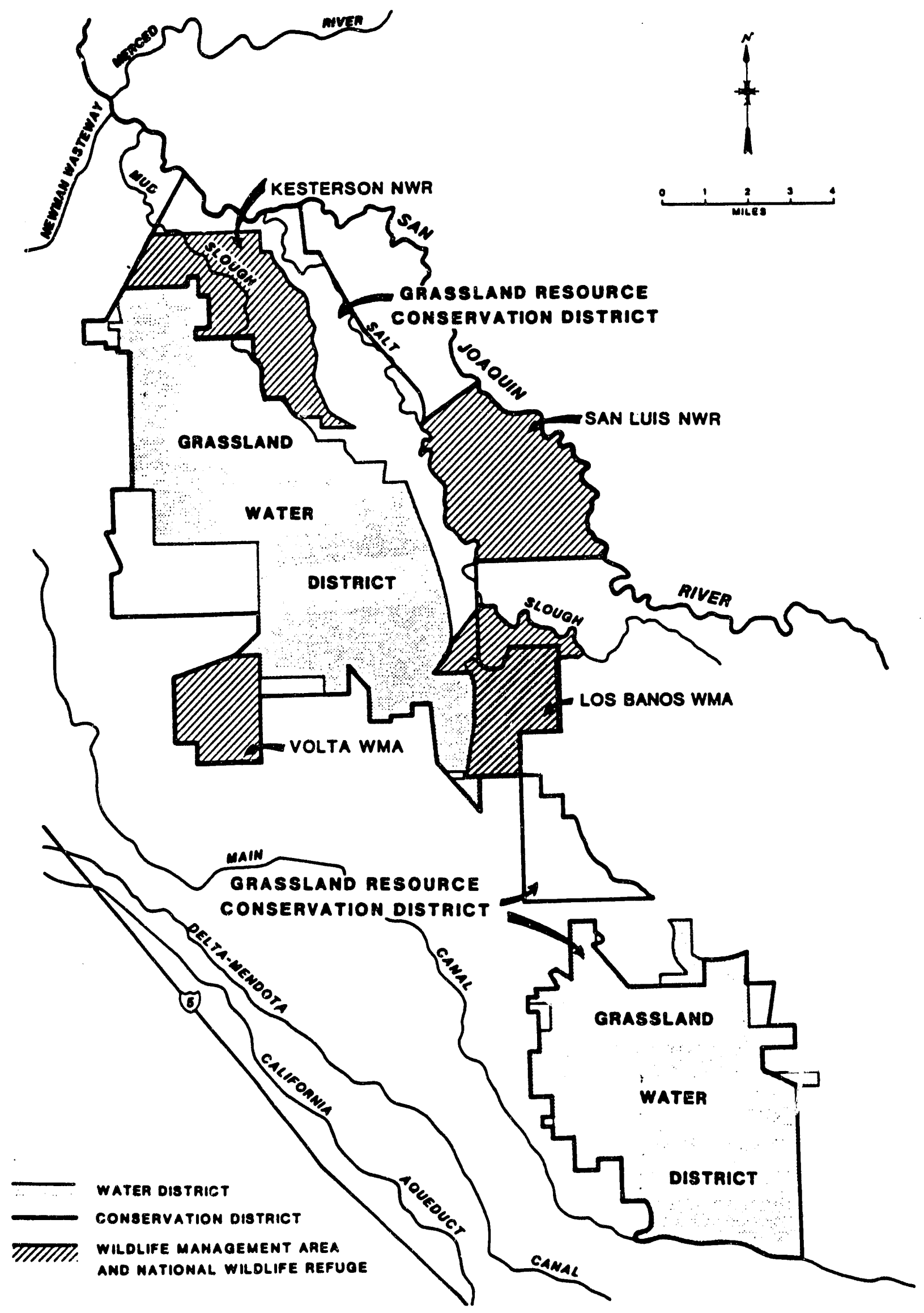

Figure 2. Location of state and federal refuges and the perimeter of the Grassland Resource Conservation District. 
In 1985, after the closure of the twelve 100 acre ponds of Kesterson Reservoir due to selenium poisoning of waterfowl, use of tile drainage flows from the Westlands Water District was also discontinued. Westlands is located to the south and east of Broadview , San Luis and Panoche Water Districts in the San Luis Unit. To the Grassland area, this change in operation constituted a loss of approximately 90,000 acre-ft of firm water supply (USFWS, 1988). Although the Bureau of Reclamation has, since 1986, made available up to 100,000 acre-feet of interim project water, the cost of this water supply (\$12/acre-ft) has precluded its widespread use (USBR,1989). In addition, capacity limitations within the Delta-Mendota canal have hampered efforts to deliver this water on a continuing basis.

\subsection{Present use of Grassland channels for drainage conveyance}

The major difference between pre-1985 and present use of the channels and drainage ditches for surface water conveyance within Grassland area, is the elimination of the use of turnouts along these channels to diven drainage return flows into the refuges. The non-availability of these drainage return flows for use in refuges has ce nrely decreased operational flexibility related to delivery and distribution of fresh water supplies within the Grassland area. This has resulted in several of the channels, such as the Agatha Canal and Camp 13 ditch, within southern Grassland being alternately used to convey fresh water supplies and agricultural drainage flows at various times during the water year (Figures 3 and 4). Although field studies have determined minimum flushing flows necessary to minimize contamination of fresh water supplies by residual volumes of contaminated drainage water, such a practice creates scheduling difficulties and leads to a potential loss of water supply.

Water supplies to the northem area are delivered by Garzas Creek in the northwest, Volta Wasteway and San Luis Wasteway in the southwest, the Santa Fe Canal and Eagle Ditch in the central portion (Grassland Water District) and the San Luis Canal on the east side of the Grassland area (Figure 4). CVP water can be delivered from the Delta Mendota Canal, either through the Mendota Pool or Wolfsen Bypass to the CCID Main Canal which then flows into Garzas Creek, or from the Delta Mendota Canal directly into Volta Wasteway. Water supplies to the southem area are routed through the CCID Main Canal and CCID Helm Canal. The Camp 13 Ditch and the Agatha Canal/Geis Canal are the primary conveyances for delivering CVP water from the Delta Mendota Canal by way of the CCID Main Canal.

A number of control and diversion structures have been constructed in the Grassland area since 1985 to allow the separation of contaminated drainage flows from those flows of more suitable quality for use in refuges (Figure 4). These include :

\subsubsection{Blake-Porter Bypass}

This control structure was scheduled to be discontinued in 1990 by agreement with the San Luis Canal Company. The bypass diverts contaminated drainage flows, which passes through tie Camp 13 and Agatha Canals, directly into Mud Slough (south) and hence to the San Joaquin River by way of Salt Slough. Use of the bypass has allowed freshwater deliveries to be made using the San Luis Canal to refuges in the northem Grassland RCD. The 


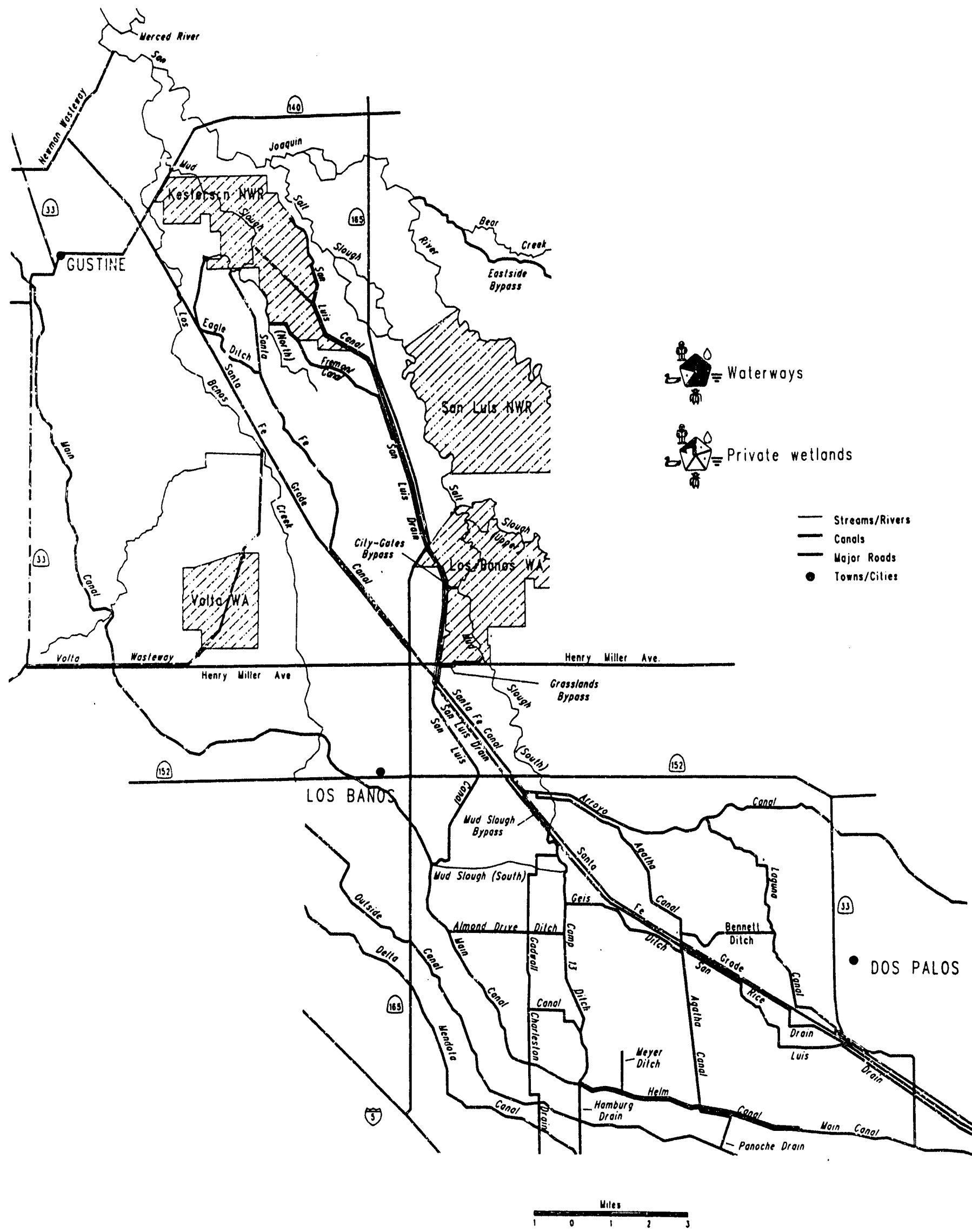

Figure 3. Canal network within the south-eastern and north-western Grassland areas. 


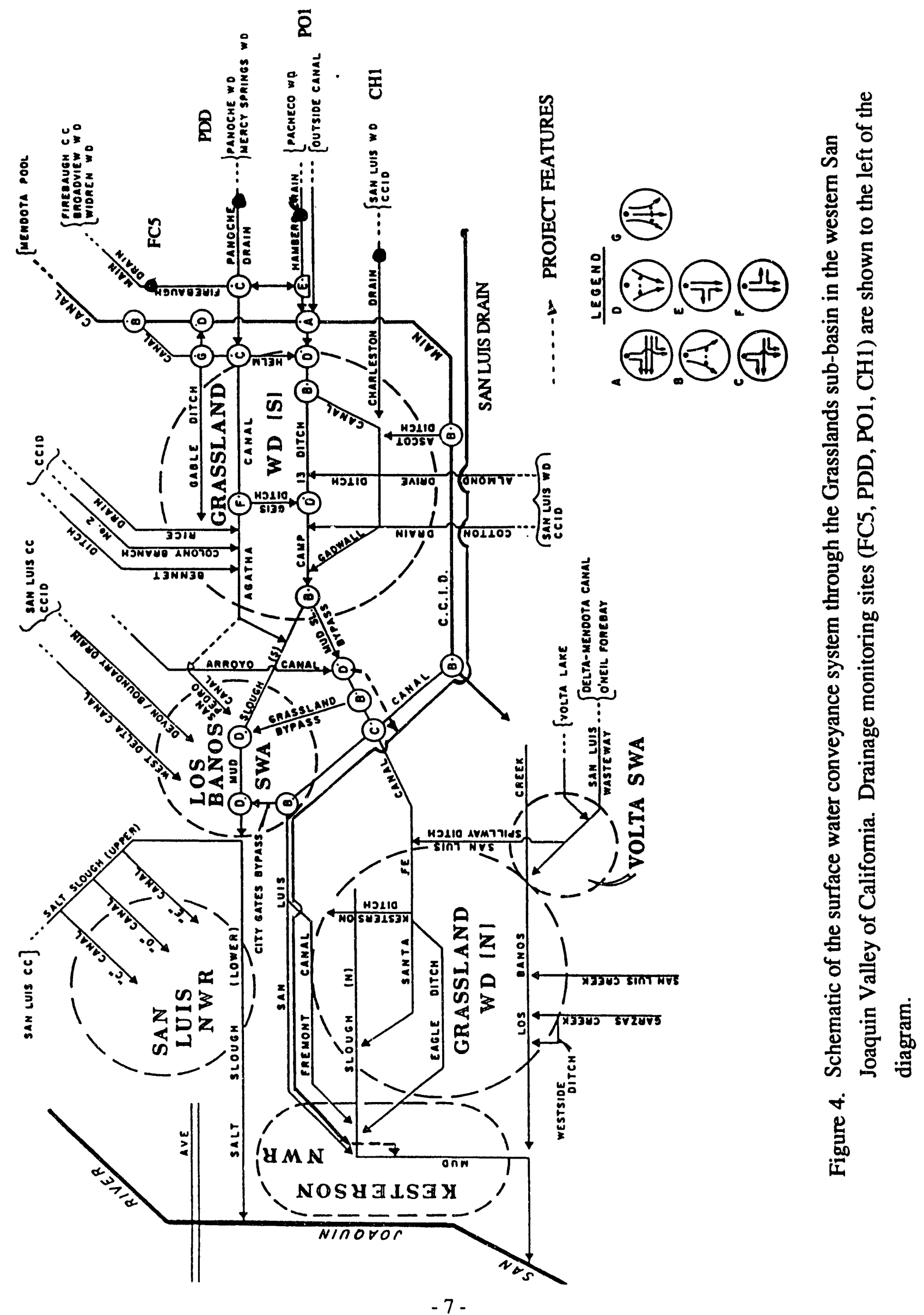


potential effect of discontinuing use of this system, without use of an alternative means of flow separation, is the contamination of some portions of the northem Grassland RCD area (USBR, 1988). In this study an assumption is made that after August 1991 use of the bypass will continue, in the absence of the current proposed plan. Hence drainage from Camp 13 Ditch and Agatha Canal will be combined in Mud Slough (South) and will primarily be diverted through 23 miles of Salt Slough to the San Joaquin River. Some agricultural drainage flows would be carried to the San Joaquin River by Mud Slough (North). This is similar to the without project assumption, made in the Environmental Assessment study (Summers Engineering, 1990), which assumed that the Santa-Fe Canal / Mud Slough bypass would be continued to be operated in violation of the agreement with San Luis Canal Company.

\subsubsection{Agatha / Camp 13 Flip-Flop}

This system was designed to allow Grassland Water District to alternate the conveyance of fresh water between the Agatha and Camp 13 Canals. When fresh water is diverted along the Agatha Canal, adjacent marshlands can be flooded and irrigated, while agricultural drainage is diverted along the Camp 13 Canal to Mud Slough and vice-versa. By alternating (flip-flopping) fresh water and drain water in each of these canals, the southern portion of the Grassland RCD wetlands can receive water of acceptable quality. However, because some agricultural drainage is present within the system at all times, there is some potential degradation of water quality and possible water wastage, in particular if flushing flows are required prior to the delivery of refuge fresh water supply. The need for flushing can detract from the flexibility of conveyance operations and the ability to deliver water at the time it is nooded.

\subsection{Alternative water supplies}

Groundwater pumping is used for supplemental water supply in as many as 15 of the 165 private duck clubs within the Grassland RCD. High pumping costs, poor groundwater quality and insufficient well yield preclude the use of these wells beyond use as a supplemental supply. Pump yields range from $675-2,100$ gallons per minute and confined aquifer pumpage has an average TDS of 2000 ppm (USBR, 1989; USFWS, 1978). Safe yield for areas outside the State and Federal refuges has been estimated by the USBR at 71,500 acre-ft - however actual groundwater pumping within the Grassland area is typically less than 2000 acre-ft/year.

\subsection{Grassland drainers proposed use of the San Luis Drain}

Several variations of the Zahm-Sansoni-Nelson plan have been considered by the Grassland entities. Previous versions of the plan included use of segments of the San Luis Drain for separate conveyance of CVP water and agricultural drainage. The current proposed action is to use the San Luis Drain to convey agricultural drainage from a point approximately 1.3 miles south of Highway 152 to the terminus of the San Luis Drain at the north of Kesterson Reservoir, a distance of 18 miles (Summers Eng., 1990). Agricultural drainage would continue to be routed through the southern Grassland Water District via the existing Camp 13/Agat!ha Canal system and discharge 
into the San Luis Drain at the point of intersection with Mud Slough. Structural changes would be necessary in Mud Slough (south) to permit gravity discharge into the San Luis Drain. At the terminus of the San Luis Drain an existing short channel would be enlarged to allow the agricultural drain flows to enter Mud Slough (North) and then be conveyed a short distance to the San Joaquin River (Figure 4).

The effect of the project would be to divert contaminated agricultural drainage flows (drainage high in TDS, selenium and boron), which currently flow into both Mud and Salt Sloughs, entirely into Mud Slough. Eliminating these discharges would reduce the flow in Salt Slough. Flows in Salt Slough would derive from seepage, runoff and reservoir releases from adjacent refuges and agricultural drainage flows from water quality zone $A$, as described by the SJVDP plan (SJVDP, 1990b). It is assumed that San Luis NWR and Los Banos WA contribute flow mainly to channels tributary to Salt Slough and that Kesterson NWR and Volta WA contribute flow mainly to channels tributary to Mud Slough. Grassland RCD contributes to both Salt and Mud Sloughs.

The most important potential beneficial features of the project as stated by Summers Engineering (1990) are as follows :

(a) Isolation of unusable agricultural drainage water from usable and fresh water supplies in the Northem Grassland area.

(b) Improvement in the operational flexibility of existing facilities and improvements in the efficiency of water delivery to wetland areas.

(c) Improvement in water quality in many of the existing channels within Grassland RCD and in Salt Slough.

(d) Reduction in selenium and boron uptake by aquatic vegetation and invertebrates in the channels no longer carrying contaminated agricultural drainage.

(e) Improved habitat quality for warm-water resident fish in Salt Slough.

The significant potential environmental consequences of the project and important potential negative impacts, as noted by Summers Engineering (1990) and reviewers of the Environmental Assessment and Initial Study document, are the following :

(a) Increased flows in Mud Slough reducing the habitat available for fish species such as sunfish, bass and carp which prefer low velocity water.

(b) Increased contaminant load in Mud Slough and increases in the concentrations of TDS, selenium and boron.

(c) Necessity for regulation of agricultural drainage discharges to meet SWRCB and CRWQCB objectives for selenium, boron and TDS in Mud and Salt Sloughs and in the San Joaquin River (although this may come to pass with or without the proposed action). 
(d) Potential negative impacts on fish and invertebrates due to increased duration of exposure and higher ambient concentrations in the six mile segment of Mud Slough from the point of discharge to the point of discharge into the San Joaquin River.

(e) Fossible disturbance of contaminated sediments in Mud Slough due to an increase in flow within Mud Slough.

(f) Likelihood of increased sediment deposition in Salt Slough because of reduced discharges.

(g) Potential increase in selenium, boron and TDS loading to the San Joaquin River if there is no reduction in drainage discharges from Grassland drainers.

\subsection{Water quality objectives for the San Joaquin River, Mud and Salt Sloughs}

Water quality objectives have been established for selenium and boron by the State Water Resources Control Board (SWRCB) and the California Regional Water Quality Control Board (CRWQCB), for Mud and Salt Sloughs, for the San Joaquin River near the mouth of the Merced River at Newman and by the USBR for TDS downstream of the Stanislaus River near Vernalis. Since less than 50\% of the TDS load to the San Joaquin River is conveyed hrough the project study area, adherence to the TDS objective at Vernalis is an issue that concerns a much larger contributing area. Monitoring and regulation of TDS loading from Mud and Salt Sloughs is still important, however, because of the large total mass of salts added to the San Joaquin River by these sources. Selenium and boron are more important elements of concern, because more than $70 \%$ of the total load of these constituents in the San Joaquin River during a normal or dry year are contributed by Mud and Salt Sloughs (SWRCB, 1987). Analyses performed by the SWRCB (1987) have shown that the selenium objective of $2 \mathrm{ppb}$ in Mud and Salt Sloughs is the most difficult to meet and hence the limiting constituent in these tributaries to the San Joaquin River. At Newman, the CVRWQCB boron objective of $0.8 \mathrm{ppm}$ from March 15 - September 14 and $1.0 \mathrm{ppm}$ from September 15 to March 14 (1.3 ppm in a critical year) limits drainage discharge to the San Joaquin River. At Vernalis, the limiling TDS water quality objective is $450 \mathrm{ppm}$, the result of an agreement between the US Bureau of Reclamation and the South Delta Water Agency. The SWRCB objective is $500 \mathrm{mg} / \mathrm{l}$. Both objectives have been difficult to meet in dry and critically dry water years, even with releases from New Melones Reservoir. The SWRCB has adopted new objectives for Vernalis, which should go into effect in 1996. The new objectives are $0.7 \mathrm{mmhos} / \mathrm{cm}$ (April through August) and $1.0 \mathrm{mmhos} / \mathrm{cm}$ (September - March) and assume an TDS /EC conversion factor of $590 \mathrm{mg} / \mathrm{TDS}$ per unit of EC) (EC is measured in $\mathrm{mmhos} / \mathrm{cm}$ ).

Of direct relevance to this study and to the environmental assessment of the impacts of the proposed use of the San Luis Drain are the objectives for selenium and boron for Mud and Salt Sloughs and for the San Joaquin River. These are as follows : 
Mud and Salt Slough Objectives :

boron

$2 \mathrm{ppm}$

(CVRWQCB 88-195)

$2 \mathrm{ppm}$

(SWRCB, 1987)

selenium

$10 \mathrm{ppb}$ (CVRWQCB 88-195)

San Joaquin River Objectives near Newman (CVRWQCB 88-195):

boron

$0.8 \mathrm{ppm}$

March 15 - September 15

$1.0 \mathrm{ppm} \quad$ September 16 - March 14

$1.3 \mathrm{ppm} \quad$ critical year

selenium

$5 \mathrm{ppb}$

$8 \mathrm{ppb}$ critical year 


\section{Study design}

\subsection{Conceptual framework}

The Grassland area contains complex and diverse terrestrial and aquatic ecosystems. Any change in the inputs to these ecosystems, either in the quantity or quality of water deliveries can have impacts on the suitability of the ecosystem to support biota at each level of the food chain. Assessing the impacts of these seasonal changes cannot be performed adequately without intensive study and the collection of field-level data, neither of which are currently available. The approach that has been taken in this study is limited in scope to conservation of mass with respect to flows of water and contaminants. Contaminants are defined as those dissolved constituents in water that have been shown to cause damage to the aquatic and terrestrial ecosystems through the processes of bioaccumulation and that degrade the utility of the surface water resource as an irrigation supply for agricultural uses downstream. Selenium, boron and total dissolved solids (TDS) have been chosen as the primary contaminants of concern.

It is important to note that the analysis which follows utilizes historical data and hence treats surface and subsurface drainage flows within the Grassland area as substantially unregulated flows. In this sense the analysis is conservative and portrays a worse case scenario for the two years considered $(1986,1988)$. It is envisaged that any use of the drain through authorization of the project would require considerable monitoring and regulation of discharges from each of the upslope agricultural water and drainage districts. Current monitoring sites have been chosen by Summers Engineering Inc. and the Grasslands Water District to allow the flow and contaminant load from each of these five entities to be infividually estimated. Figure G-1 (Appendix G) shows the location of current monitoring sites within the Grassland area (Summers Engineering, 1991). Aslo contained in Appendix $G$ is a table which describes the location of the monitoring sites shown in Figure G-1 and which also lists the sampling frequency of the major constituents EC, selenium and boron.

A current effort, spearheaded by the Water Quality Subcommittee of the San Joaquin River Management Program, is investigating the telemetering of electrical conductivity (EC) of flows at Newman and at other stations along the San Joaquin River. Once in place, this would provide real-time TDS concentrations along various reaches of the river, allowing east-side reservoir releases to be scheduled at times when TDS concentrations exceeded the SWRCB water quality objectives. Telemetering of drainage flows and TDS at each of the monitoring sites and the development of regression equations, relating seasonal TDS to selenium and boron concentrations at these sites, would allow greater water district control over drainage discharges. Additional research will be required to develop better predictors of selenium concentrations from flow and TDS data. Use of the San Luis Drain for conveyance of subsurface drainage would enhance the ability to control releases of contaminated drainage water to Mud Slough and the San Joaquin River. With water district co-operation and involvement of State and Federal agencies in data acquisition, analysis and dissemination the project could play a significant role in helping to improve water quality for TDS, selenium and boron in the San Joaquin River. 


\subsection{Data requirements}

As previously noted, there is a paucity of historical data that provide concurrent records of flow and contaminant concentrations within the network of channels and ponds that make up the Grassland RCD. To perform a mass balance analysis, concurrent measurements of flow and concentration data are necessary at a sampling frequency that allows short term fluc'suations in these levels to be observed. A weekly and sometimes even a daily sampling frequency would be required to perform realistic mass balances.

\subsection{Data sources and limitations}

Monitoring of flows and contaminants within the Grassland area has been undertaken by a number of State and Federal Agencies, as well as local agencies. The most comprehensive database has been compiled by Summers Engineering, a local engineering consulting firm, under contract with the Department of Water Resources and the Grassland drainage entities (Figure G-1 and Appendix G). The USGS has been monitoring flows and a wide range of common salts and trace elements between June,1984 and October, 1988 within Salt and Mud Sloughs and the San Joaquin River. Data collected on contaminant loading entering the Grassland area is limited in its accuracy by virtue of the fact that the flow and concentration measurements are grab samples, taken once or twice per month. Flow volumes along the Grassland channels are subject to considerable variation, especially luring the pre-irrigation and regular irrigation seasons when drainage flows in the channels can change dramatically in the space of a few days. The USGS monitoring stations utilize continuous recorders - hence the flow measurements are likely to provide an accurate accounting of monthly flow volume. Data from three of these stations were used to analyse the effect of the proposed actions. These include Salt Slough at Highway 165, Mud Slough at Highway 140 and the San Joaquin River near Newman.

Analysis of monthly selenium and boron concentrations show significant correlation between monthly values of successive years - giving some confidence that grab samples of contaminant concentrations in channels within the Grassland area may be somewhat indicative of mean monthly contaminant concentrations. However, grab samples taken within the San Joaquin River may vary more markedly from the mean monthly average concentration of selenium, boron or TDS.

At the outset of this study there was some confusion regarding the use of the contaminant data from the Newman gauging station. The station is located on the west bank of the San Joaquin River, a short distance downstream of the confluence with the Merced River. This distance is not considered sufficient to allow adequate mixing of discharges from Salt and Mud Slough and the high quality Merced River flow. Crows Landing monitoring station is located approximately 6 miles downstream from the Newman gauge and is presently used to estimate TDS, selenium and boron concentrations in the San Joaquin River at the Newman site. Although Orestimba Creek occasionally discharges into the River between these two sites, these flows are not considered to be significantly large to invalidate the assumption that the flows at Newman and Crow Landing are equal. The Crows Landing data is used in this study for 1989 and 1990 river hydrology. These data were obtained from the California Regional Water Quality Control Board (CRWQCB,1990, 1991). 
During the period 1986 - 1988, the USGS monitoring program was active. The USGS used a sampling technique that allowed contaminant concentrations to be measured at various depths and at several locations across the river. Using a flow weighting technique, the USGS was able to obtain a more realistic measurement of contaminant loading within the river. These samples were taken between two and six times per month. In this study, the USGS data for the period 1986 - 1988 was considered to be the most reliable, and hence was used in preference to other published data. 


\section{Analysis of operations and impacis on flow and water quality}

\subsection{Land use and water requirements}

Land use practices within the wetlands and wildlife refuges, managed by the Departments of Fish and Game and the Fish and Wildlife Service, have been surveyed - hence it is relatively simple to determine water requirements within these areas. In the predominantly privately owned areas (southwestern Grassland), data on land use practices are harder to obtain, and there is a greater variety of land use, making estimation of water requirements considerably more difficult. The Report on Water Supply Investigations (USBR, 1989) was used to obtain the annual estimates of available water supply and the initial estimates of the monthly distribution of wetland water requirements.

In a previous SJVDP study an attempt was made to subdivide the area in to land units according to the source of water supply for the 1988 water year (Quinn, 1990, Phillips and Quinn, 1990). The Grassland area was divided into a number of subareas according to maps provided by F. Paveglio of the Fish and Wildlife Service, which delineated areas that were serviced with water supply through common turnouts and managed as units by the District Watermaster. The State and Federal wildlife areas were each considered as single subareas for water budgeting purposes. A map of these delineated subareas is provided in F-1 (Appendix F). The database of agricultural crops, pasture and managed wetlands for the 1988 water year, obtained from a survey of land use within each of the subareas, is included in Appendix A1. These land use estimates were used to estimate the wetlat:d area drainage contribution to Salt and Mud Sloughs.

\subsection{Wetland water management practices}

Management practices differ between the subareas as a function of land use and refuge operation in those subareas with substantial areas of seasonal and permanent wetland. The most important impact of these practices from the standpoint of water quality in Grassland channels is :

(a) the timing of water deliveries to seasonal and permanent wetlands during the fall flooding period; (b) the timing of spring-time wetland releases to the channels (typically during March or April) in preparation for emergence of vegetation within the wetland areas and irrigation of these areas for wildlife food supply.

The schedule of wetland make-up water deliveries to offset direct evaporation and seepage losses can also affect the periods during which the channels contain water of good quality. The complicated schedule of water deliveries to wetlands and water releases from wetlands at different times of the year make a determination of monthly operations difficult to ascertain with confidence. Average monthly estimates of water deliveries have been determined for the 
State and Federal refuges and private lands, based on hisioric operations and on perceived management strategies (USBR,1989; SJVDP, 1990b). These data are presented in Tables $1-5$.

\subsection{Water budget and mass balances on salts and trace elements}

Water budgets and trace element balances are also presented in Tables 1 - 5 for San Luis National Wildlife Refuge, Kesterson National Wildlife Refuge, Los Banos Wildlife Area, Volta Wildlife Area and Grassland RCD Wildlife Area. In each of these Tables the budgets and balances are performed for scenarios without the proposed action (without-project) and with the proposed action (with-project). These tables contain some small changes, which differ from the numbers tabulated in the March, 1991 report (Swain and Quinn, 1991), mostly to correct minor inconsistencies between the methodology described to calculate remaining wetland storage and the tabular values.

Refuge water supply quantities for the without-project scenario are based on current firm annual water supplies to these refuges, obtained from data complied by the SJVDP and Reclamation (SJVDP, 1990a and USBR, 1989). The with-project scenario is more complicated because of the large number of different State and Federal Agency estimates of water supplies required for optimal operation of these wetland areas.

The total water supply assumed available to each management area includes:

(a) the existing firm annual water supply (SJVDP, 1990a, 1990b)

(b) the surface return flows from wetland areas and agricultural drainage from operational spills of usable quality, made available as a result of the proposed action.

\subsection{Scenarios}

With-project scenarios can be developed with different sets of assumptions. Three scenarios are analyzed in this report which consider different operations utilizing three combinations of these sources of wetland water supply. These are as follows :

(a) Contaminated agricultural retum flows are diverted to the San Luis Drain. Existing fresh water supplies to wetlands are supplemented by use of useable quality water in Salt Slough, improved in quality as a result of the project. Annual wetland drainage flows are increased by 27,000 acre-ft to 65,300 acre-ft. - (Scenario 1)

(b) Contaminated agricultural return flows are diverted to the San Luis Drain. Existing fresh water supplies to wetlands are not supplemented by use of useable quality water in Salt Slough due to a moratorium on increased diversions. A portion (80\%) of the surface return flows and operational spills are routed directly to the San Joaquin River via Salt Slough. Total annual wetland drainage flows remain at approximately 38,300 acre-ft similar to the current condition. - (Scenario 2). 

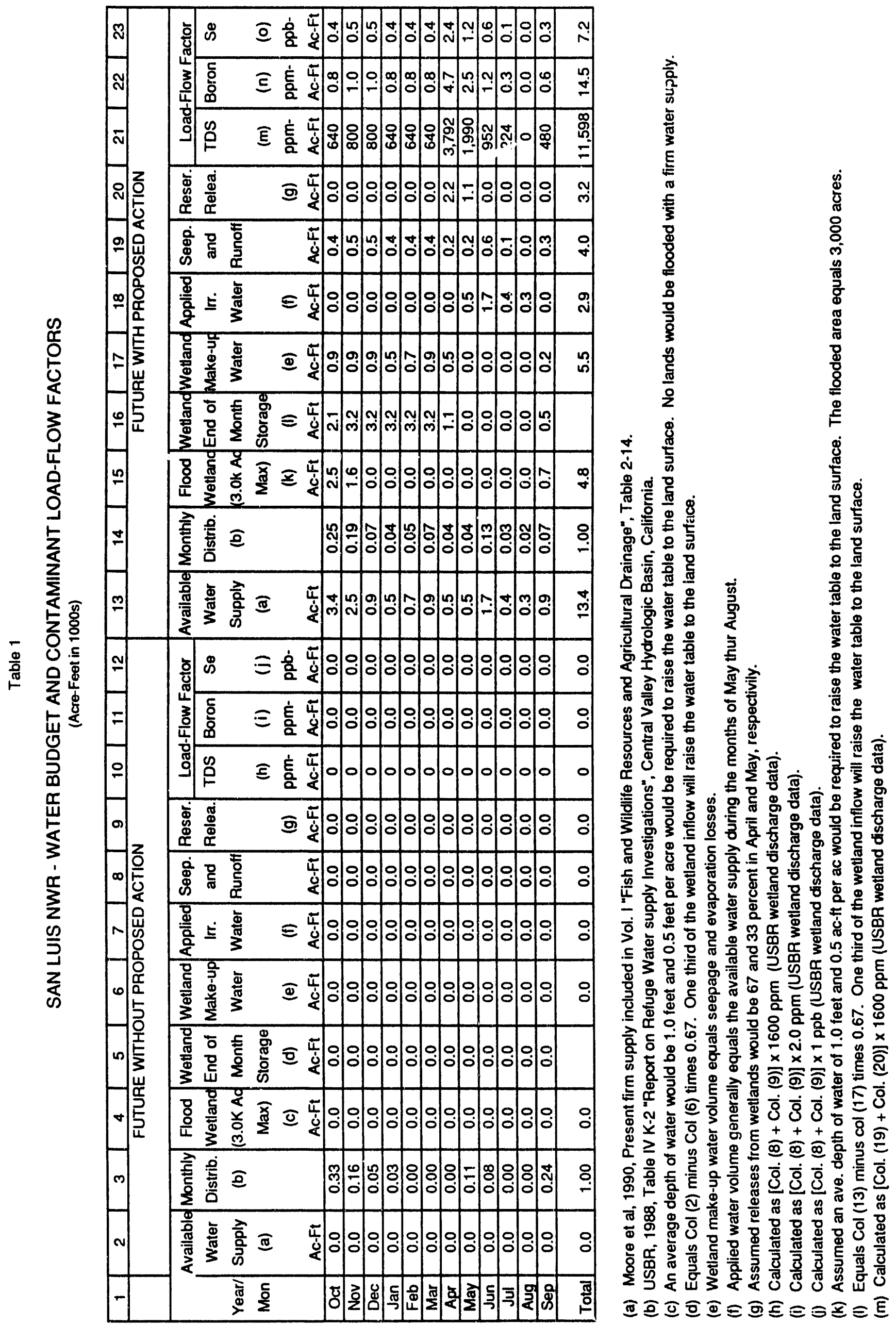


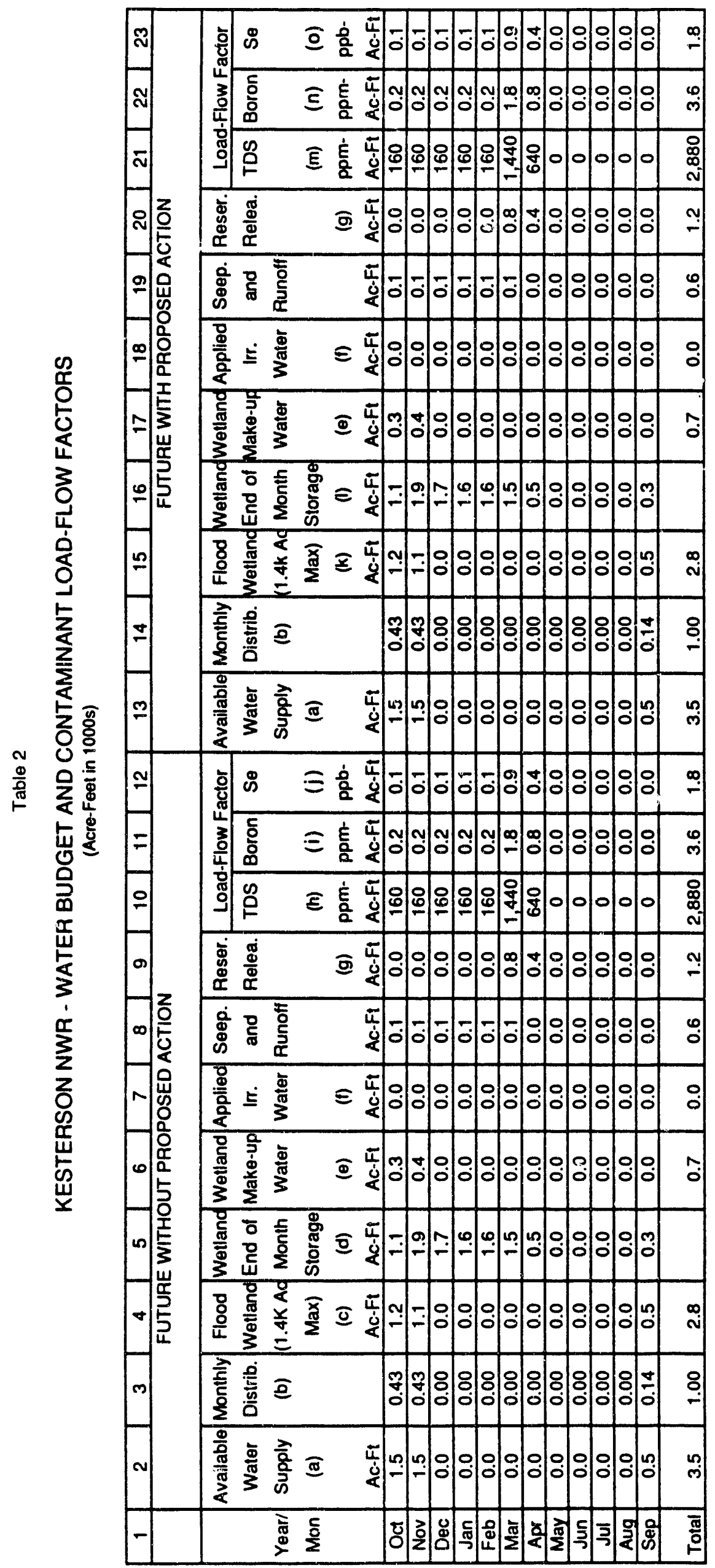

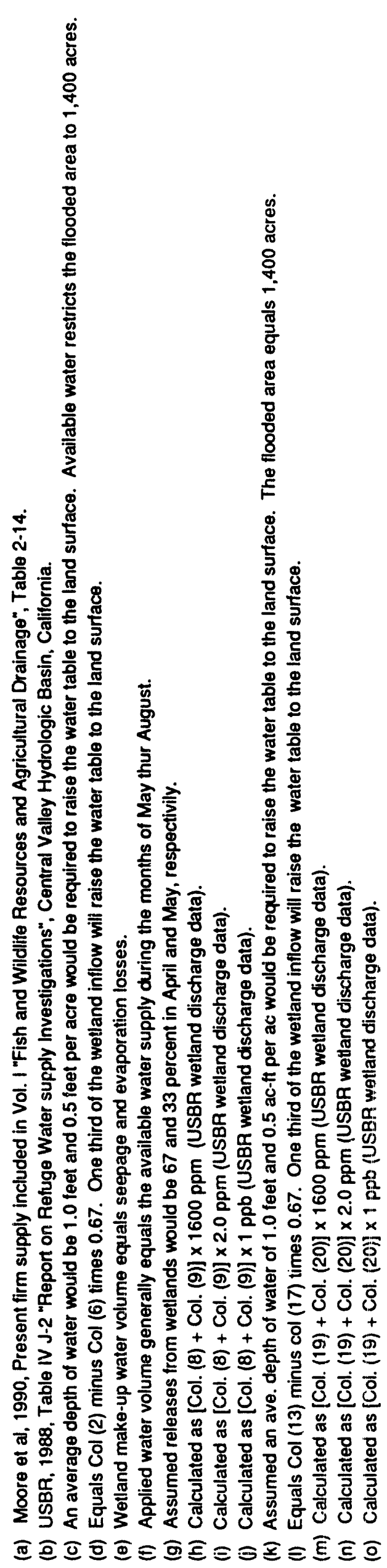




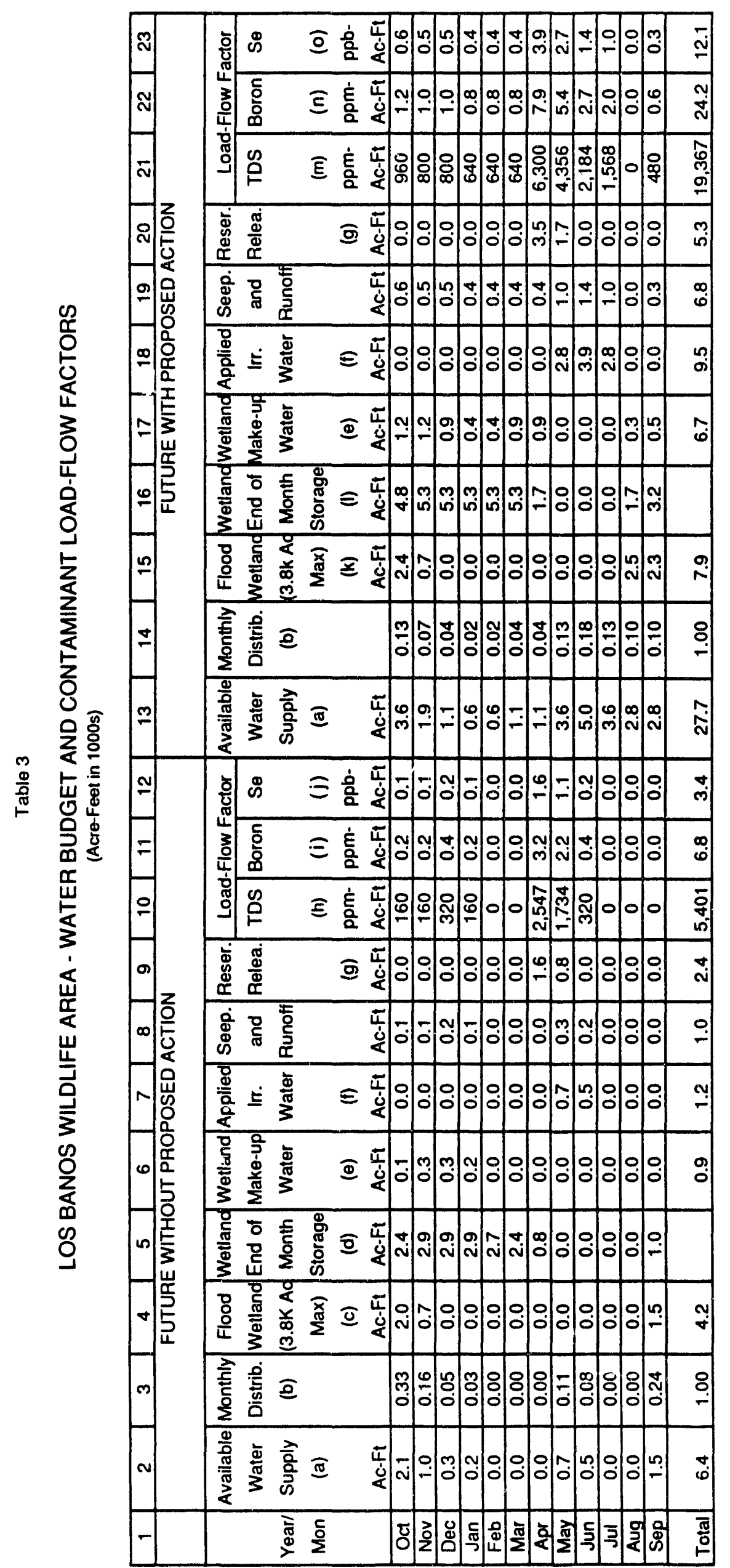

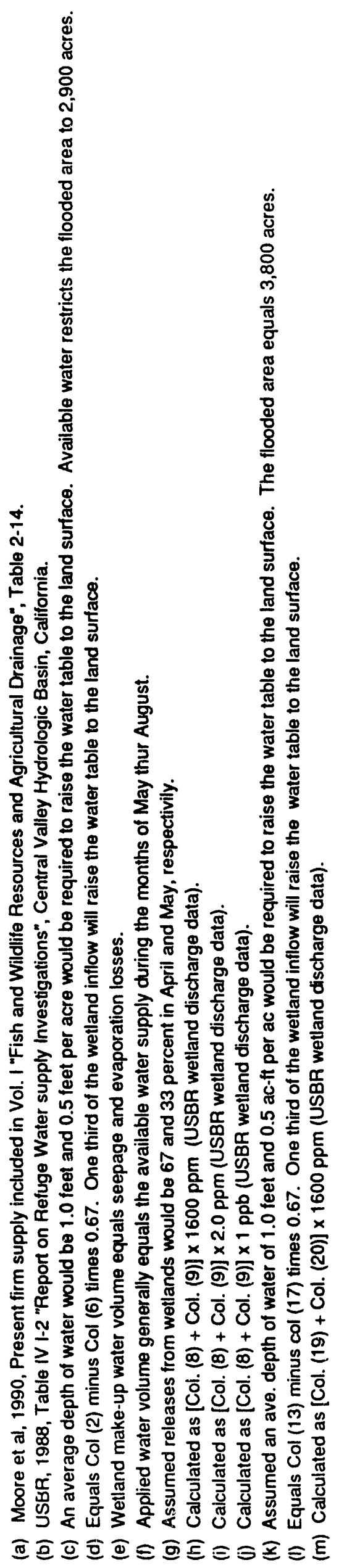




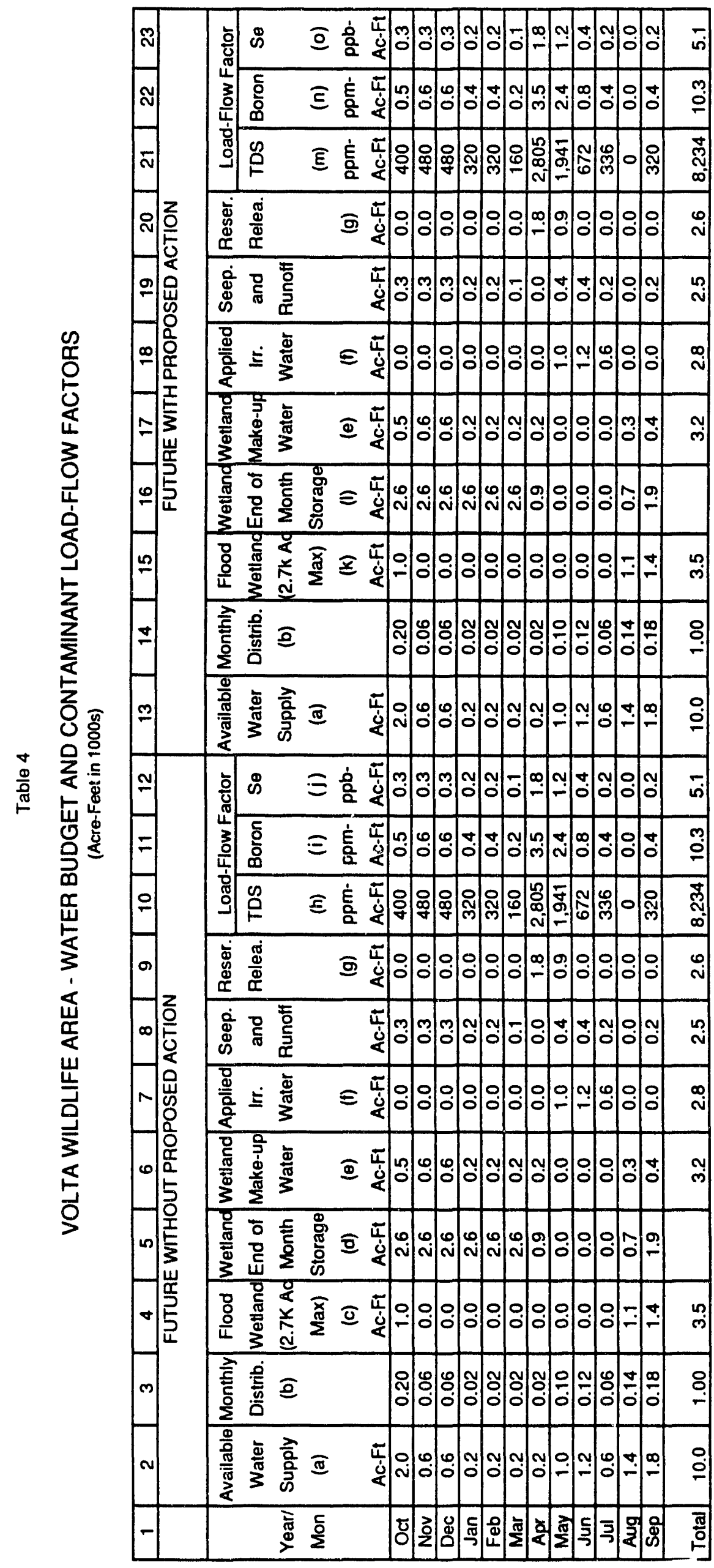

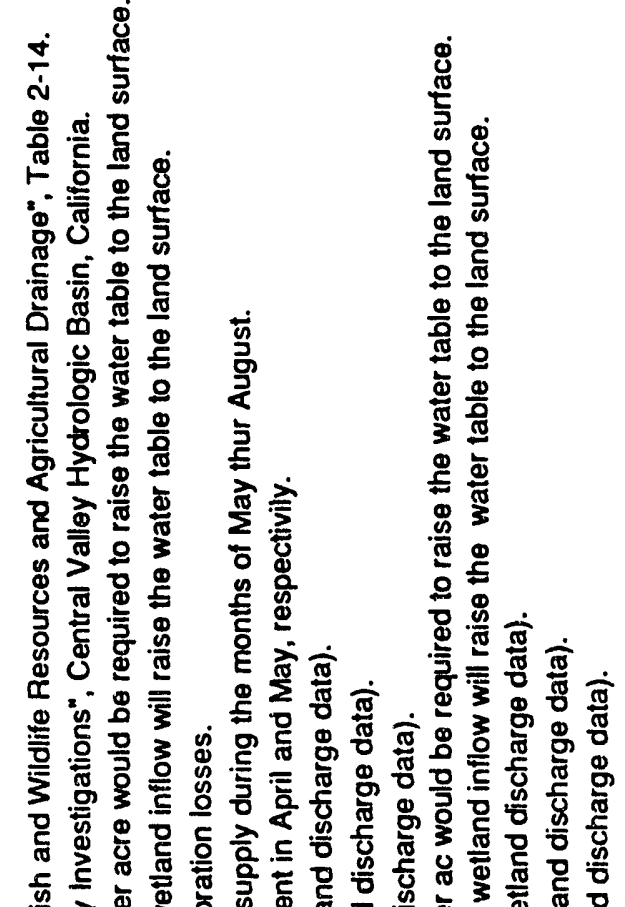

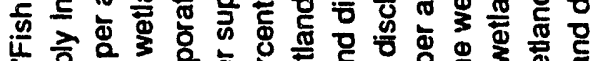

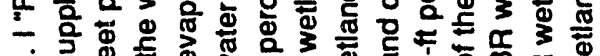
कं के

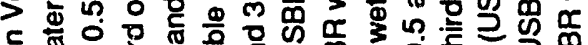

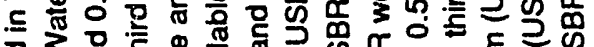
उ 융 긍 웡

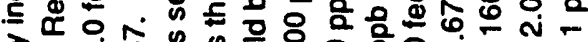
군은

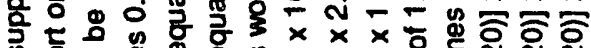
की 은 हैं

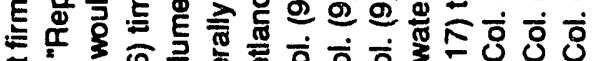
范

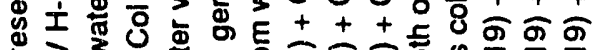
远 $\geq 3$ os

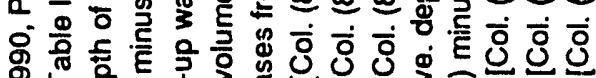

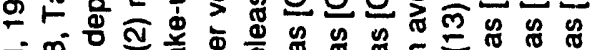
ส 西

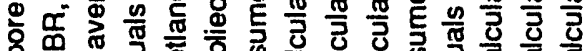

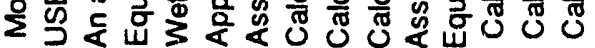

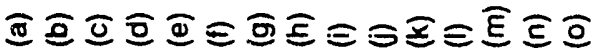



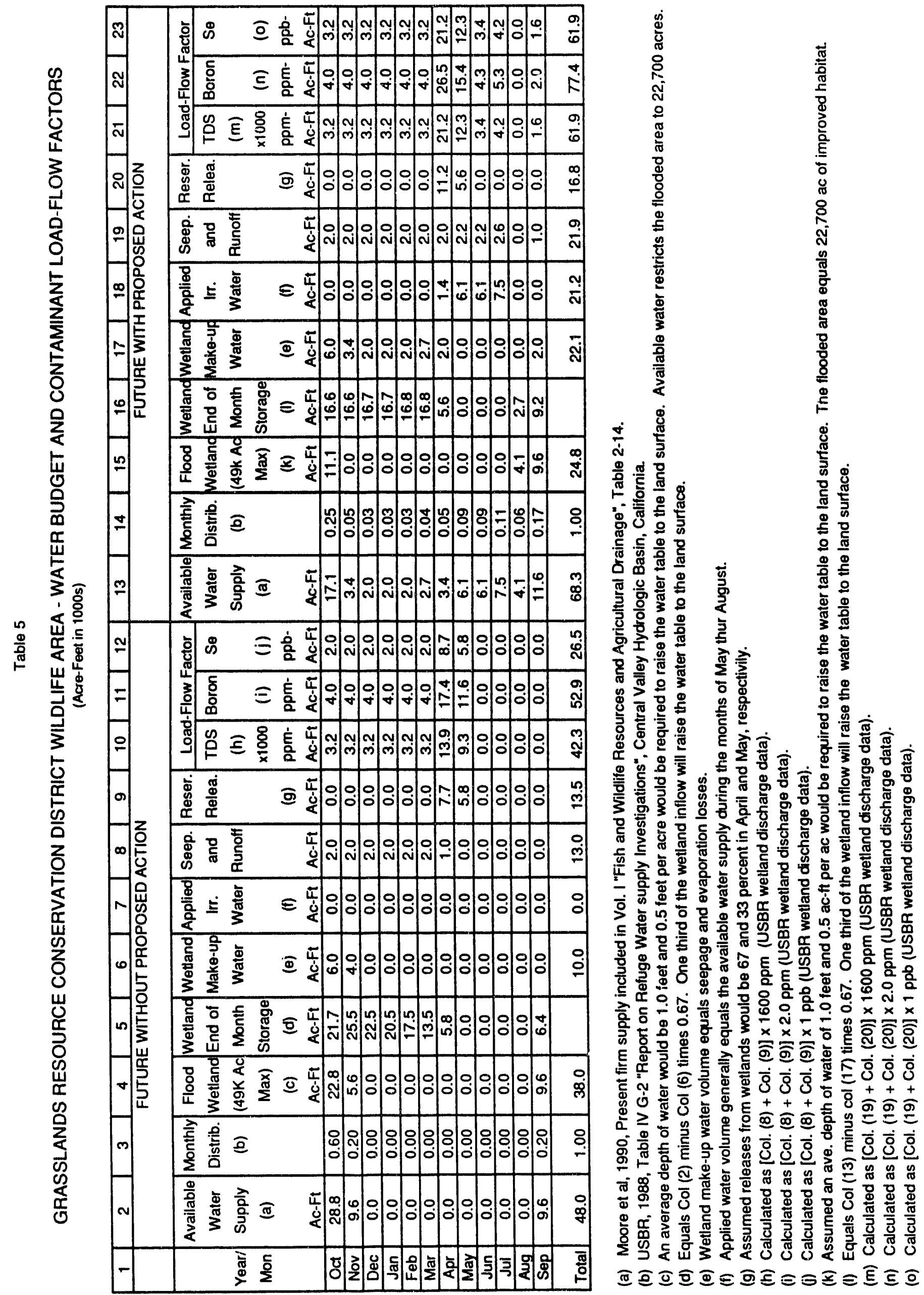

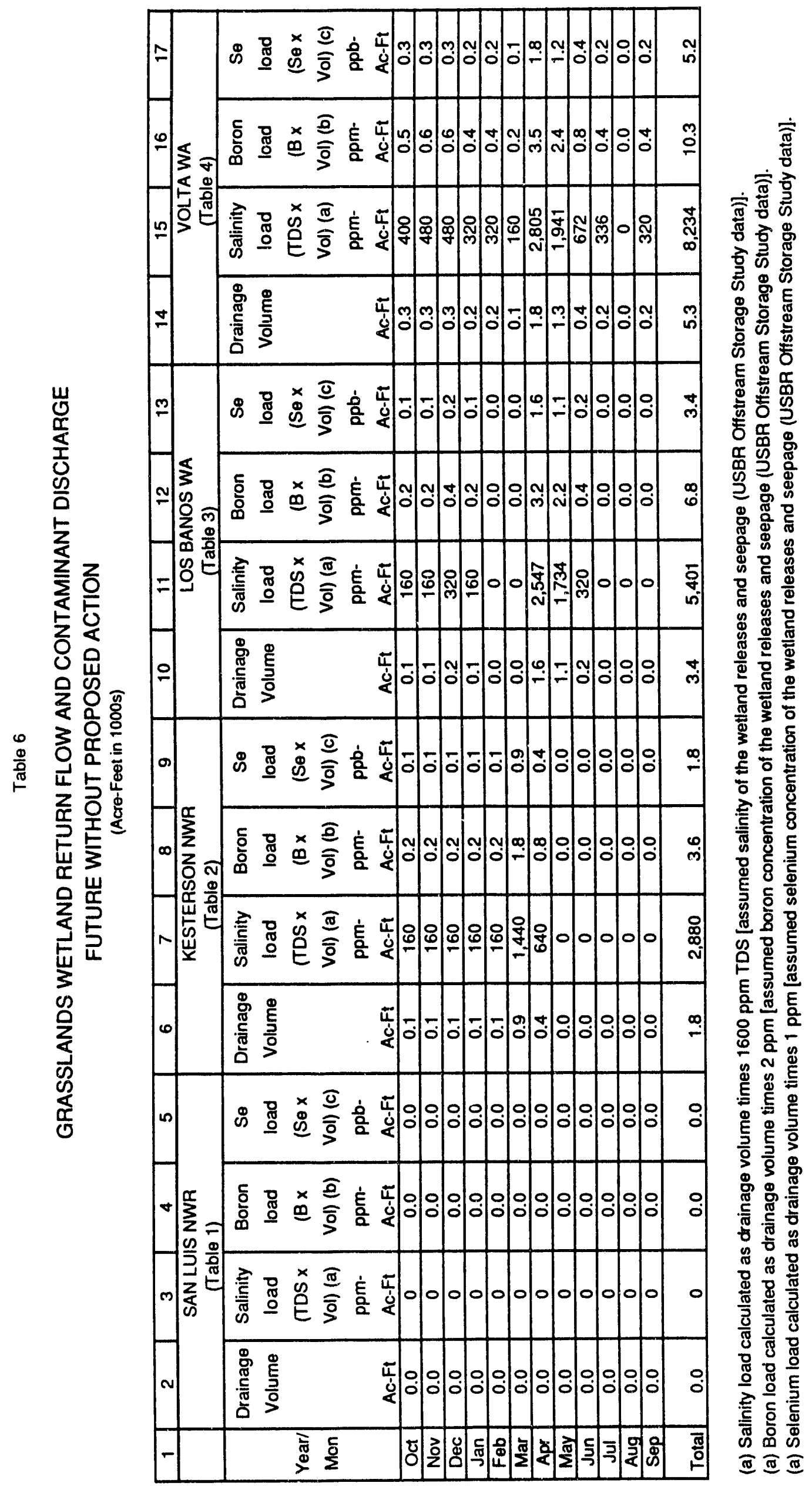


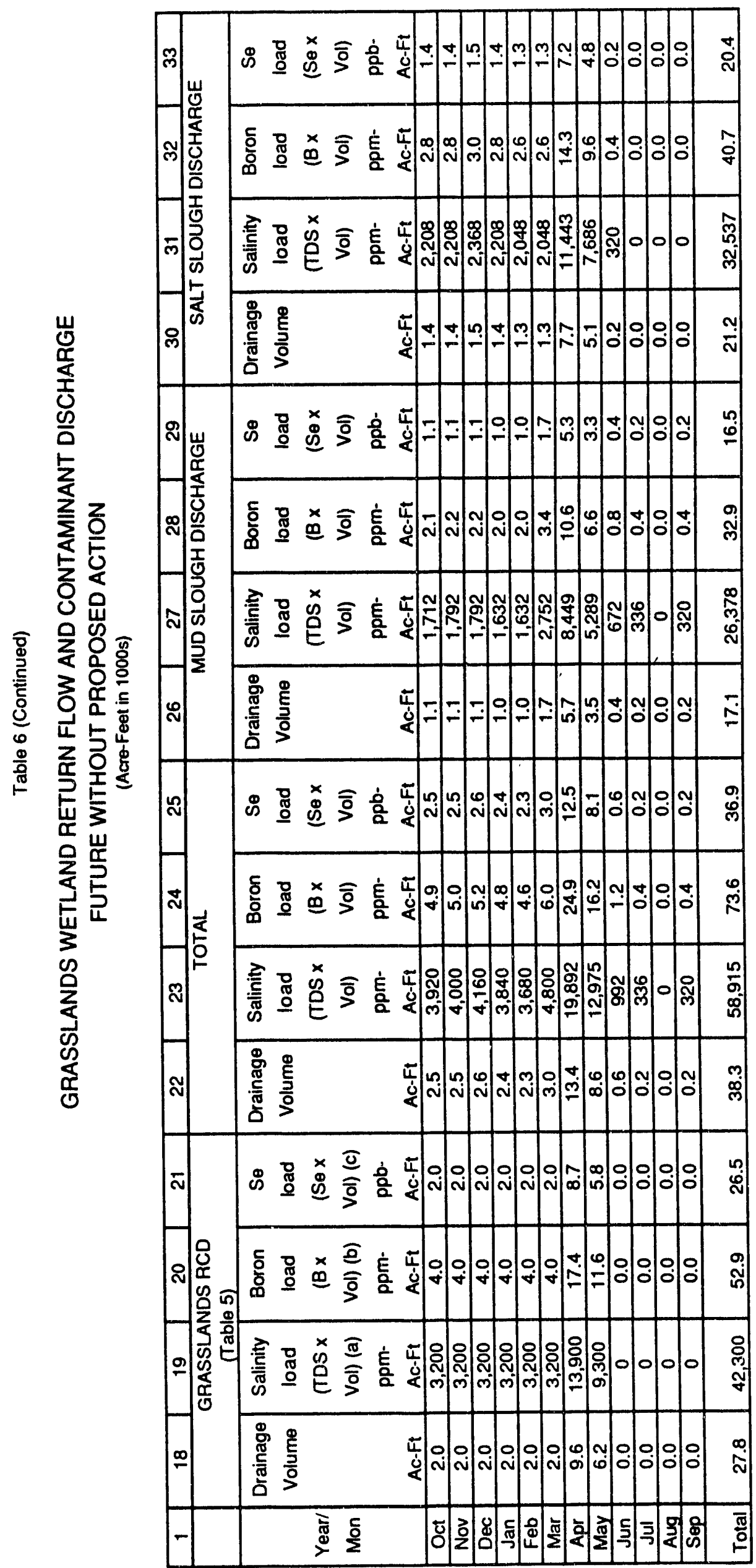

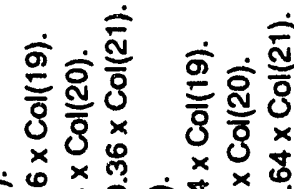

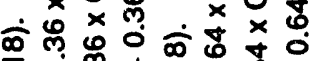
言0 $0+0$

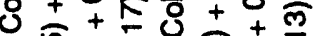

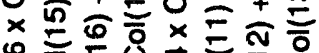
过 $=08$ 员 0 8 웅 8 \% $+++0++0$

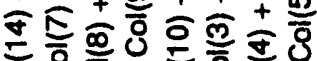

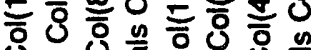
0

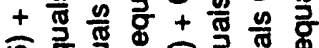

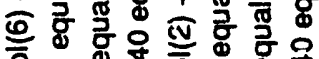

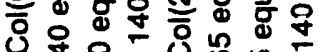
品定

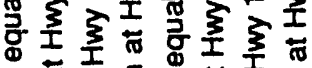

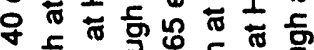

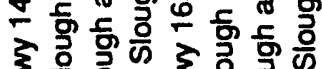

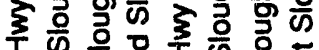

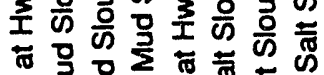

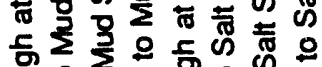

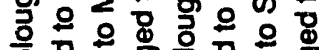
क 造 8 施 枹

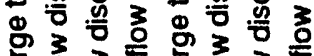
흐은 둥응 등 은

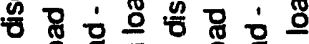
으 을

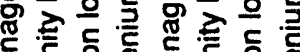

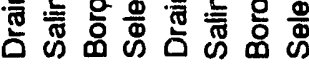

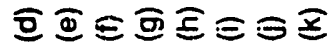




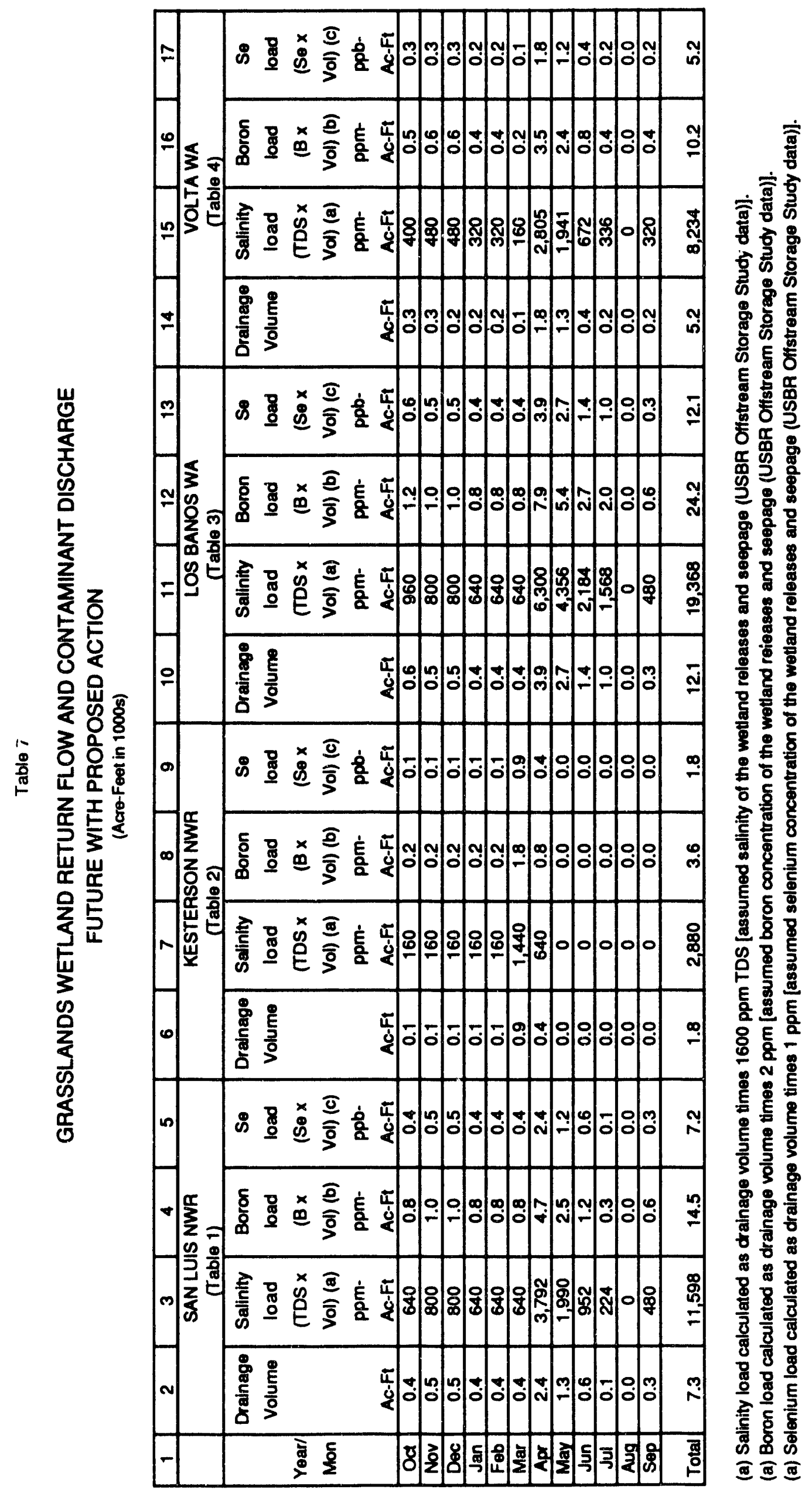




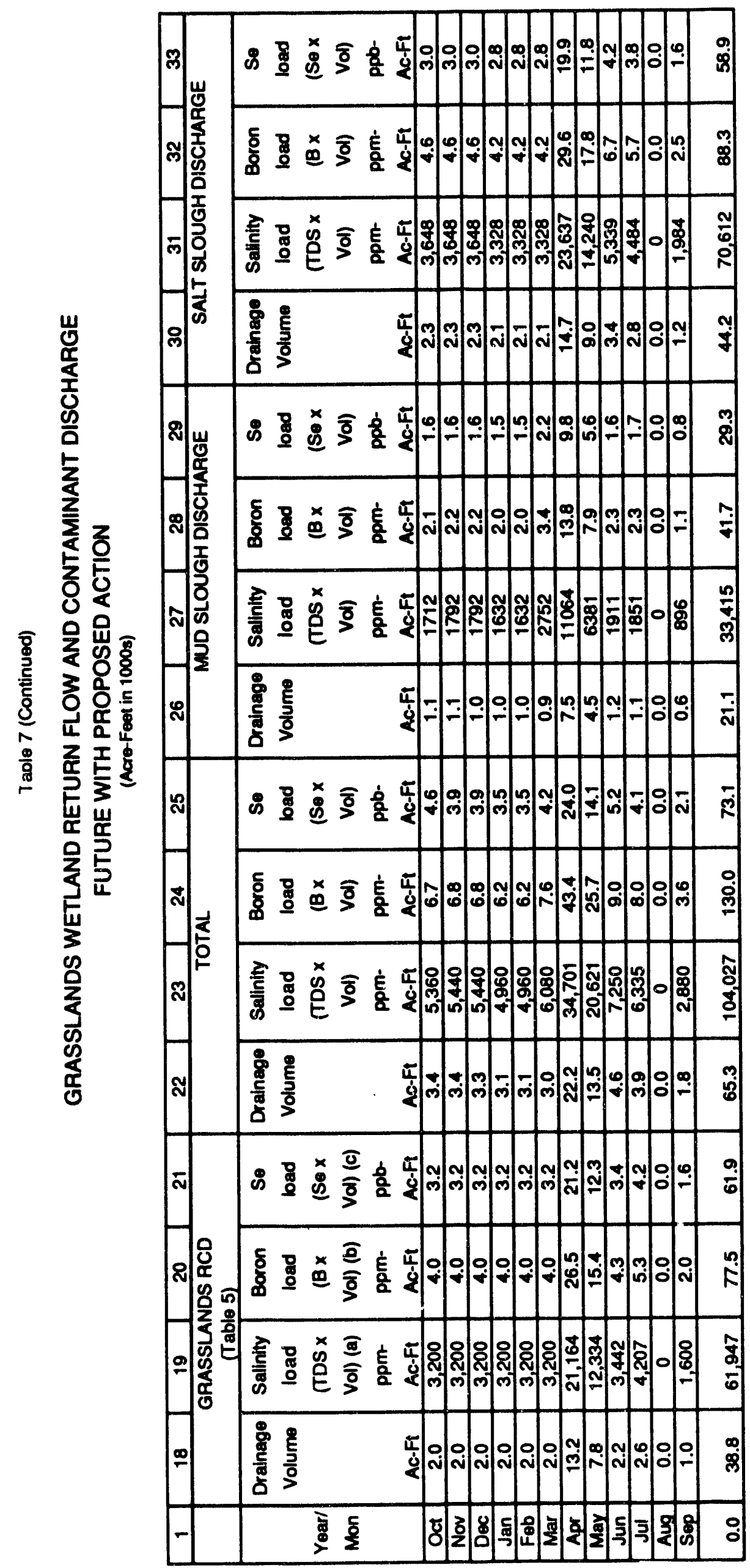

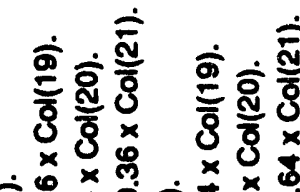

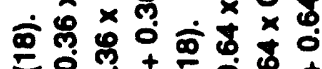

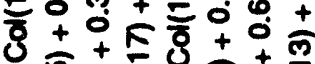

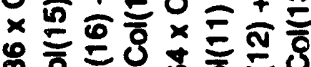

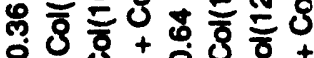
$++\mathcal{1}+0+8+$ +

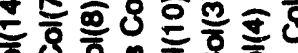

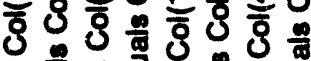

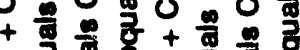

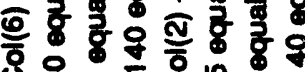

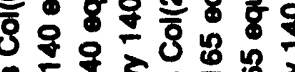

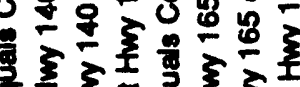

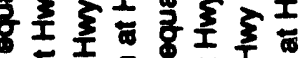
워

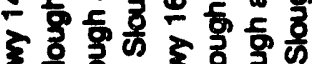

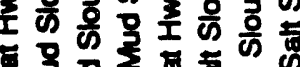

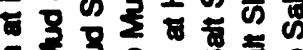
5 응 9 웅용 क \& \% \% \&

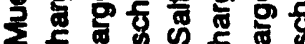

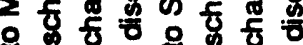

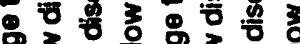

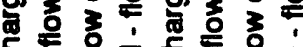

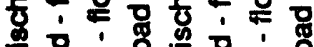

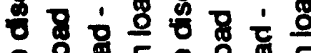

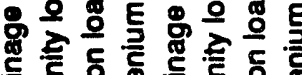
急 总 드트모토포 
(c) Contaminated agricultural return flows are diverted to the San Luis Drain. Wetland water supply is supplemented with an additional 55,000 acre-ft of interim supply due to increased operational flexibility in the Grassland basin. Wetland drainage flows are identical to those in (a) and $80 \%$ of the surface return flows and operational spills are routed directly to the San Joaquin River via Salt Slough as in (b). - (Scenario 3).

\subsection{Assumptions in wetland return now analysis}

Moore et al. (1990) describe the historical use of surface and subsurface return flows in the Grassland area. The annual volume of these return flows made available for wetland use was estimated by the SJVDP (SJVDP, 19906) to be 55,000 acre-ft. Estimates of likely increases in wetland water supplies, the volume of wetland return flows and constituent loads in these return flows, resulting from the proposed action, are shown in Tables 1 - 5. The average water use for these wetlands was assumed to be 4.2 acre-ft / acre. Allowance was also made for seepage losses from these wetland areas. Seepage losses were assumed to account for up to $30 \%$ of the annual surface applied irrigation water.

The monthly supply was obtained, as previously noted, by multiplying the annual total available water supply by the monthly distribution percentage, as described for each wetland management area (USBR, 1988). This monthly distribution of water requirements varies from area to area because of differences in management objectives and in the mix of seasonal pasture, permanent pasture and agricultural crops in each refuge ( Tables 1- 5 : column 3 ). The wetland flood - up period typically occurs between the months of September and November each year. To raise the water table to shooting depth, approximately one and one half feet of water were assumed necessary ( Tables $1-5:$ column 4 ). This would provide 0.5 feet of water to raise the water table to the land surface. This estimate is based on a water table at $5.0 \mathrm{ft}$ and a specific yield of the shallow groundwater aquifer of $0.1 \mathrm{ft} / \mathrm{ft}$.

In months when water supply is available for flooding wetland, make-up water is supplied to the wetland to keep the water table at shooting depth. Make-up water is generally the sum of evaporation losses and seepage losses throughout the hunting season and until April when the seasonal wetlands are de-watered. The amount of water available to flood wetland is the difference between the available supply and the required volume of make-up water. During the months of May through August the applied irrigation water is generally equal to the available monthly water supply as estimated by the USBR and the Fish and Wildlife Service (USBR, 1989). Seasonal wetlands and a portion of the permanent ponds are dewatered in anticipation of emergence of plants preferred by waie: fowl as a food supply. Releases from wetlands into the drainage channels within the Grassland area are assumed to be $67 \%$ and $33 \%$ of the total reservoir release in the months of April and May respectively.

Drainage releases from these ponds are calculated according to the following algebraic equation where :

$$
\mathrm{REL}_{\mathrm{i}}=\mathrm{STOR}_{\mathrm{i}-1}-\mathrm{EVAP}_{\mathrm{i}}+\mathrm{AIW}_{\mathrm{i}}-\mathrm{SP}_{\mathrm{i}}-\mathrm{RO}_{\mathrm{i}}-\mathrm{STOR}_{\mathrm{i}}
$$

Where: $\quad$ ATW $\quad-\quad$ applied irrigation water in month $i$ 


$\begin{array}{lll}\text { EVAPi } & - & \text { evaporation loss during the month } i \\ \text { RELi } & - & \text { monthly wetland return flow in month } i \\ R_{i} & - & \text { runoff in month } i \\ S_{i} & - & \text { seepage losses in month } i \\ \text { STORi-1 } & - & \text { previous month wetland storage month }(i-1) \\ \text { STORi } & - & \text { storage in month } i \\ \text { MUWi } & - & \text { wetland make-up water in month } i \text { (equal to EVAP } i+S_{i} \text { ) }\end{array}$

In the case of the San Luis NWR, the refuge currently has no firm fresh water supply, hence the available water supply numbers in column 2 are shown equal to zero. Both th.? Volta WA and Kesterson NWR are limited in the firm water supply and were assumed to have access to surface drainage water of usable quality. Hence the available water supply to these refuges, with the project, is assumed to equal the firm water deliveries available under existing conditions.

\subsection{Contaminants in wetland return flows}

The load- flow factor, calculated in Tables 1-5, is the product of (a) the volume of seepage, runoff and drainage releases from managed wetlands into channels within Grasslands and (b) the concentration of the chemical contaminants dissolved in these flows. The load-flow factor is a parameter used to compare mass loading of contaminants. This parameter is expressed in units of acre-ft - ppm (TDS and boron) or acre-ft - ppb (selenium) for ease of analysis (flow $\mathrm{x}$ contaminant concentration).

Direct evaporation from wetland channels and from the ponded wetlands do not affect the mass of contaminants in the Grasslands but can have a significant effect on contaminant concentrations at various points within the system. Even though evaporation losses are lower in the winter months (when water is ponded) than in the summer months (when the seasonal wetlands are drained) evaporative concentration of the salts and trace elements dissolved in the influent water supply takes place. During the summer months evaporative concentration and precipitation of salts in the near surface soils occurs as water is drawn to the soil surface through capillarity and strong matric gradients. Salts are also concentrated in the root zone due to evapo-transpiration losses from native vegetation, during the growing season. Some of the salts precipitated in surface soils are resolubilized during the flooding period. Data collected during an off-stream storage experiment conducted by the Boyle Engineering Corp. for the USBR (Boyle, 1987) shows effluent concentrations of approximately $1600 \mathrm{ppm}$ for TDS, $2.6 \mathrm{ppm}$ for boron and less than $1 \mathrm{ppb}$ for selenium. These concentrations were assumed for the combined runoff, seepage and wetland reservoir releases during the flooding and irrigation seasons. It is likely that seepage into the network of shallow surface channels would contain high concentrations of salts and certain trace elements due to the high concentrations of these contaminants in the shallow groundwater. The mean TDS concentrations of these flows were estimated to be $3200 \mathrm{ppm}$. 


\subsection{Agricultural return nows and contaminant loads}

Mass loadings of return flows from the wetland areas co-mingle with agricultural drainage return flows from the upslope water and drainage districts. The total mass loading of boron, selenium and TDS from each of the wetland areas is summarized for the without project scenario in Table 6 and for the with project scenario in Table 7. Monthly flow and concentration data of agricultural drainage discharged from several upslope water and drainage districts have been collected by Summer's Engineering Inc., the CRWQCB and local entities. The monitoring sites were chosen such that each site could be assumed to represent the flow and loading originating from certain water or drainage districts (Figure G-1, Appendix G)). The assignment of these monitoring sites to the districts is shown schematically in Figure 4 using the symbols FC5, PDD, PO1 and CH1. The flow and water quality monitoring data are grab samples, taken once or twice a month, and are used to represent the average contaminant level of drainage outflow from each entity for that month. There has been little analysis to check the validity of this sampling frequency to estimate monthly loads of TDS, boron and selenium to the San Joaquin River.

USGS water quality and flow monitoring sites on Mud and Salt Sloughs and the San Joaquin River were used to determine the impact of the proposed action. The Mud and Salt Slough monitoring sites located at Highways 140 and 165 , respectively, generally correspond to the lower boundary of the wetland area and the San Joaquin River, near the Newman site, coincides with the Hills Ferry Basin Plan control station. Tables C1 through C11 in Appendix C include the mean monthly flow and water quality data for electrical conductivity, TDS, boron and selenium. Data in Appendix C : Tables C1 - C5 for the years 1986 - 1988 include USGS published monthly flow data and calculated mean monthly water quality data from unpublished USGS grab sample data. Tables C6 - C11 for the years 1989 and 1990 represents published USGS flow data and mean monthly water quality data calculated from the California Water Quality Control Board water quality grab sample data.

In the previous report (Swain and Quinn, 1991) monthly TDS concentrations were estimated using boron data and a regression equation. The regression equation was developed by the SJVDP from field data, collected during the period the Water Districts were freely discharging their drainage water through the Grassland area. In this report, actual TDS data was obtained from CRWQCB records and substituted for the estimates based on boron concentrations, except for the period October - December, 1986, for which no records were obtained and for which the boron-based estimates were retained. In most cases the measured TDS concentrations, used as monthly averages, were greater than those estimated from boron concentrations. As noted in Section 1, the previous database, compiled by the Environmental Defence Fund (EDF) did not include the selenium and boron data collected by the CRWQCB. These data were compiled and a simple mean was taken of the mean concentration values from both data sets.

The monthly flow data for the period October 1985 - December 1989 is graphed in Figure 5. Monthly concentrations of boron and selenium for the same period are graphed in Figures 6 through 9. It should be noted that the monthly concentration values in these graphs are arranged according to calendar year - the spreadsheets, described in the next section, have the monthly sequence organized by water year (October 1 - September 30 ). The drainage flow, selenium and boron loading are recorded at each of four drains flowing into the Grassland area. The 
CDD : Charleston Water District

FCWD : $\quad$ Firebaugh, CCID and Broadview Water Districts

PWD : Pacheco Water District

PDD : Panoche Drainage District

口CDD-F $\square$ FCWD-F $\square$ PWD-F $\square$ PDD-F

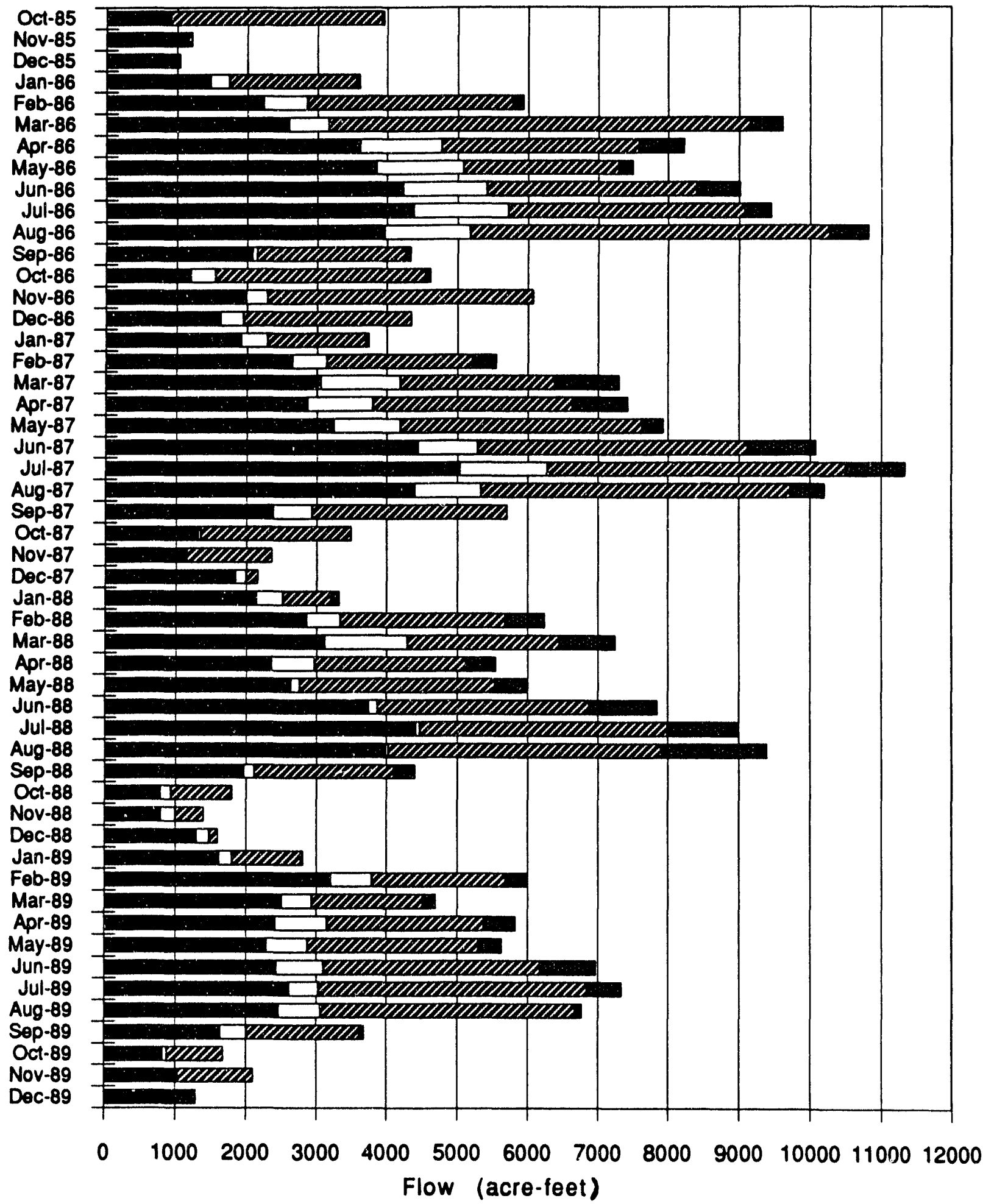

Figure 5. Monthly drainage flows from agricultural and water districts measured at four monitoring sites in South Grasslands for the period $1985 \cdot 1989$. 


\begin{tabular}{|llll}
\hline PDD & II PWD & FCWD & CDO \\
\hline
\end{tabular}
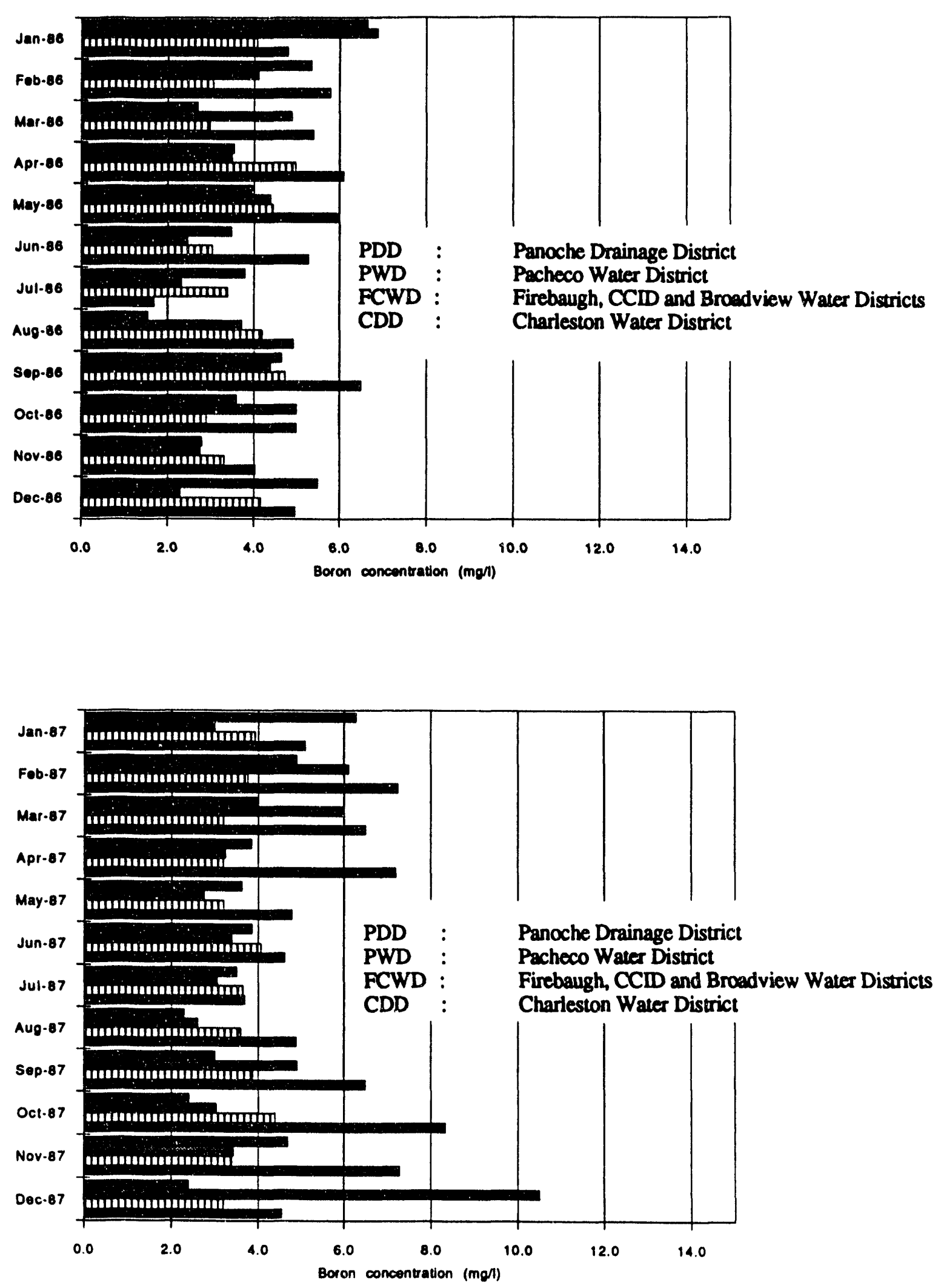

Figure 6. Boron concentrations in monthly dralnage flows from agricultural and water districts measured at four monitoring sites in South Grasslands for the perlod 1986 - 1987. 


\begin{tabular}{|llll|}
\hline PPD & ⿴囗十 PWD & FCWD & CDD \\
\hline
\end{tabular}
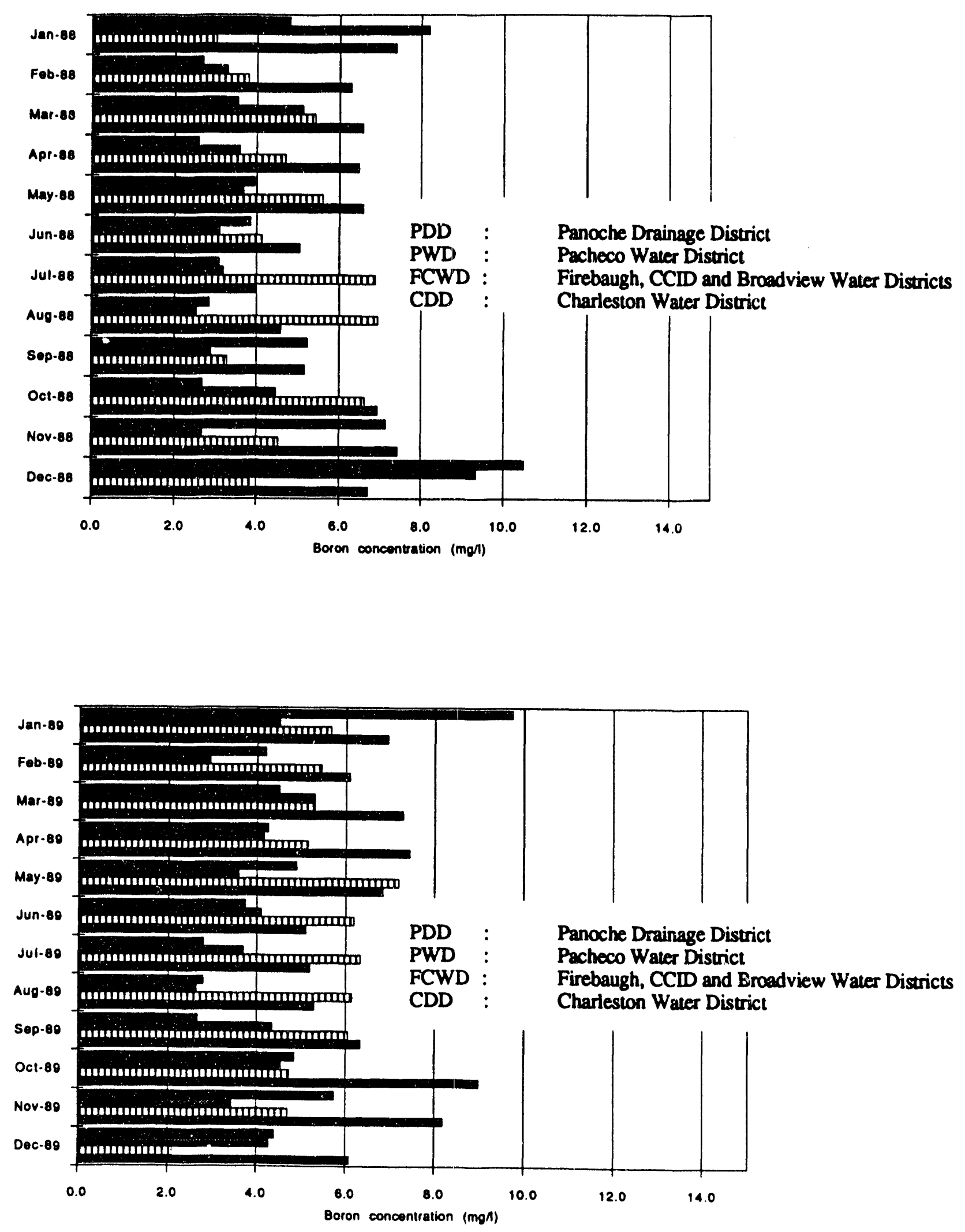

Figure 7. Boron concentrations in monthly drainage flows from agricultural and water distrlcts measured at four monitoring sltes in South Grasslands for the perlod 1988 - 1989. 


\section{PDD UD PWO $\square$ FCWD}
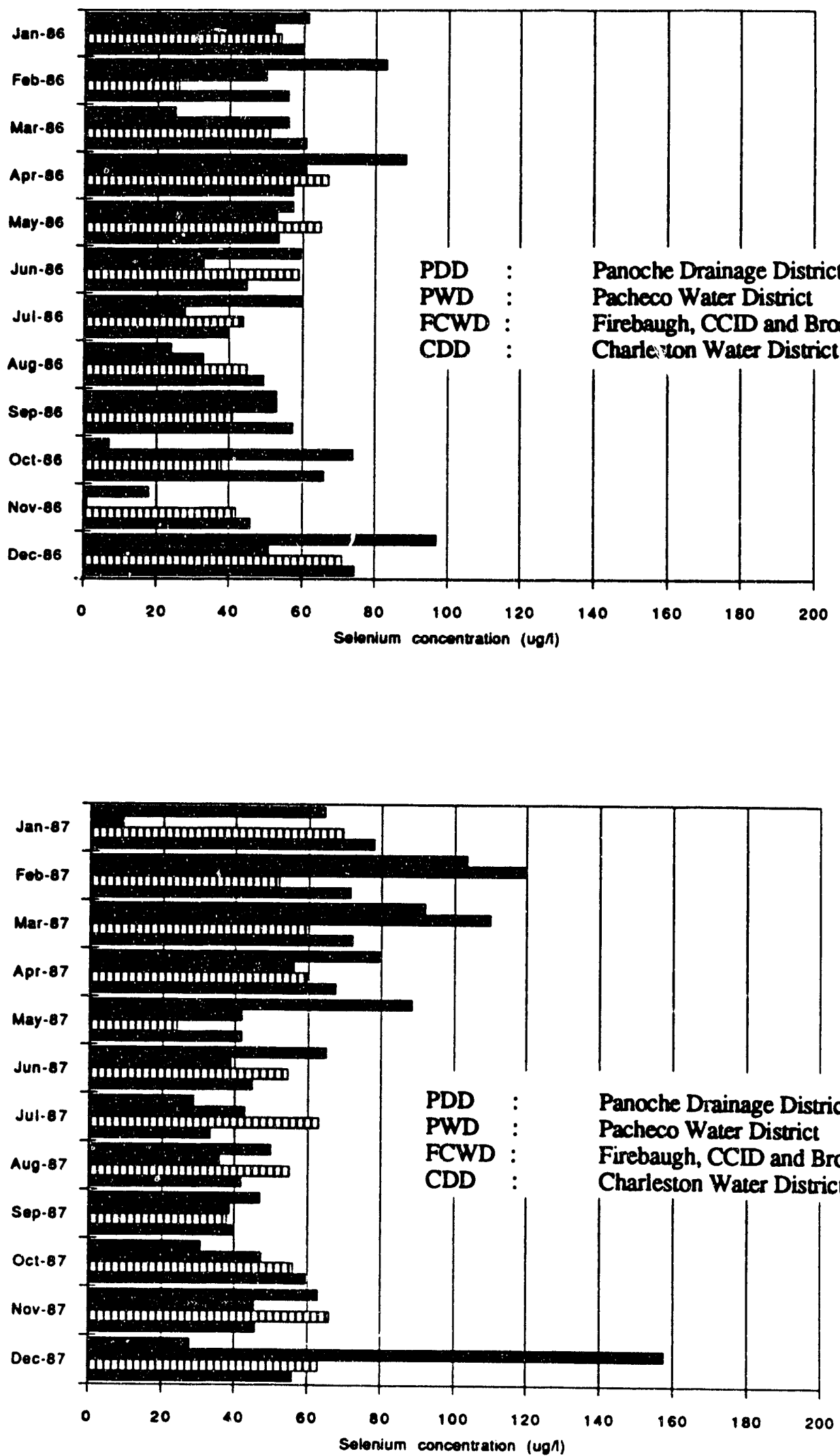

Figure 8. Selenlum concentrations in monthly dralnage flows from agricultural and water districts measured at four monitoring sites in South Grasslands for the perlod 1986 - 1987. 


\begin{tabular}{|llll|}
\hline PDD & W PWD \\
\hline
\end{tabular}
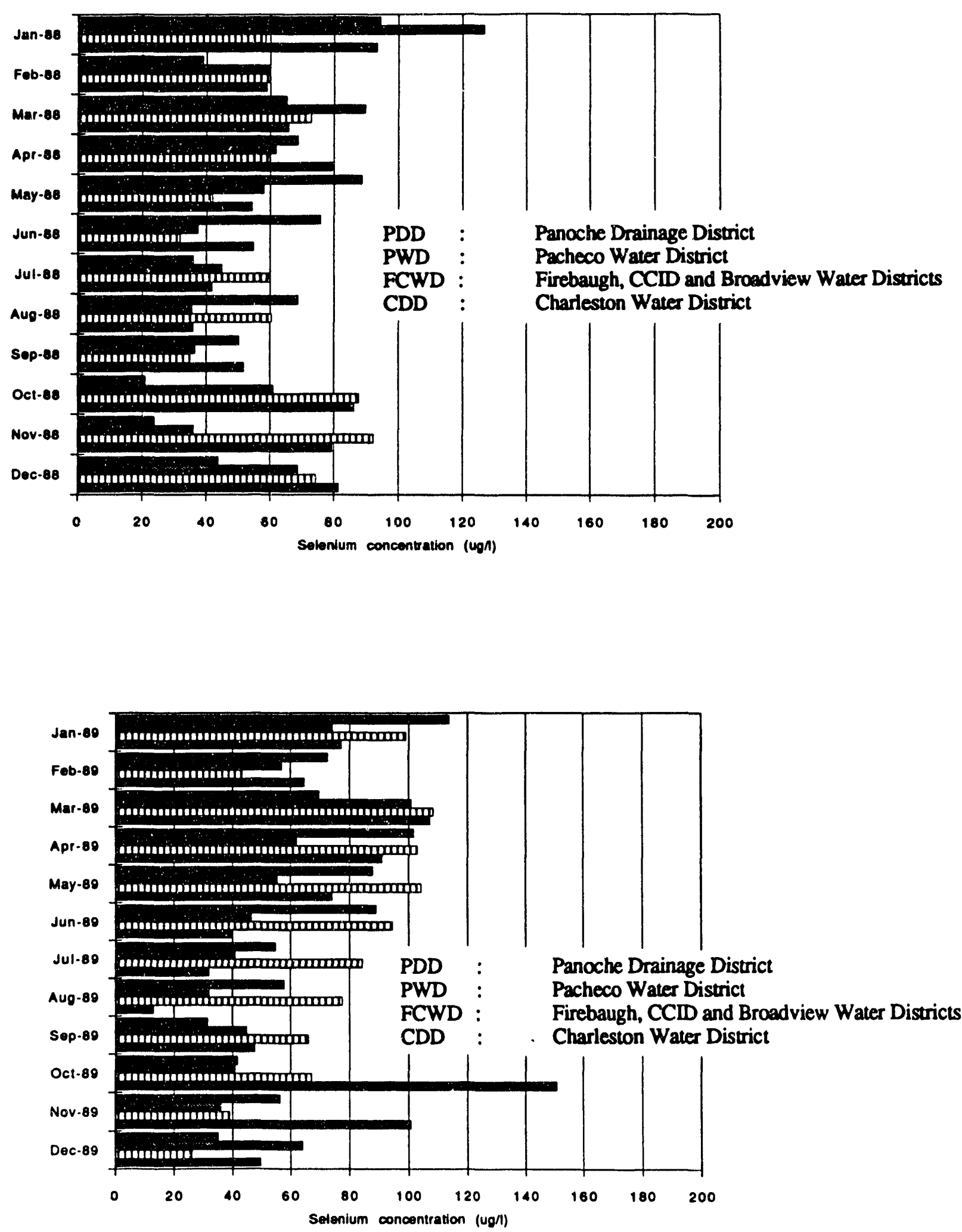

Figure 9. Selenium concentrations in monthly drainage flows from agricultural and water districts measured at four monitoring sites in South Grasslands for the period 1988 - 1989. 


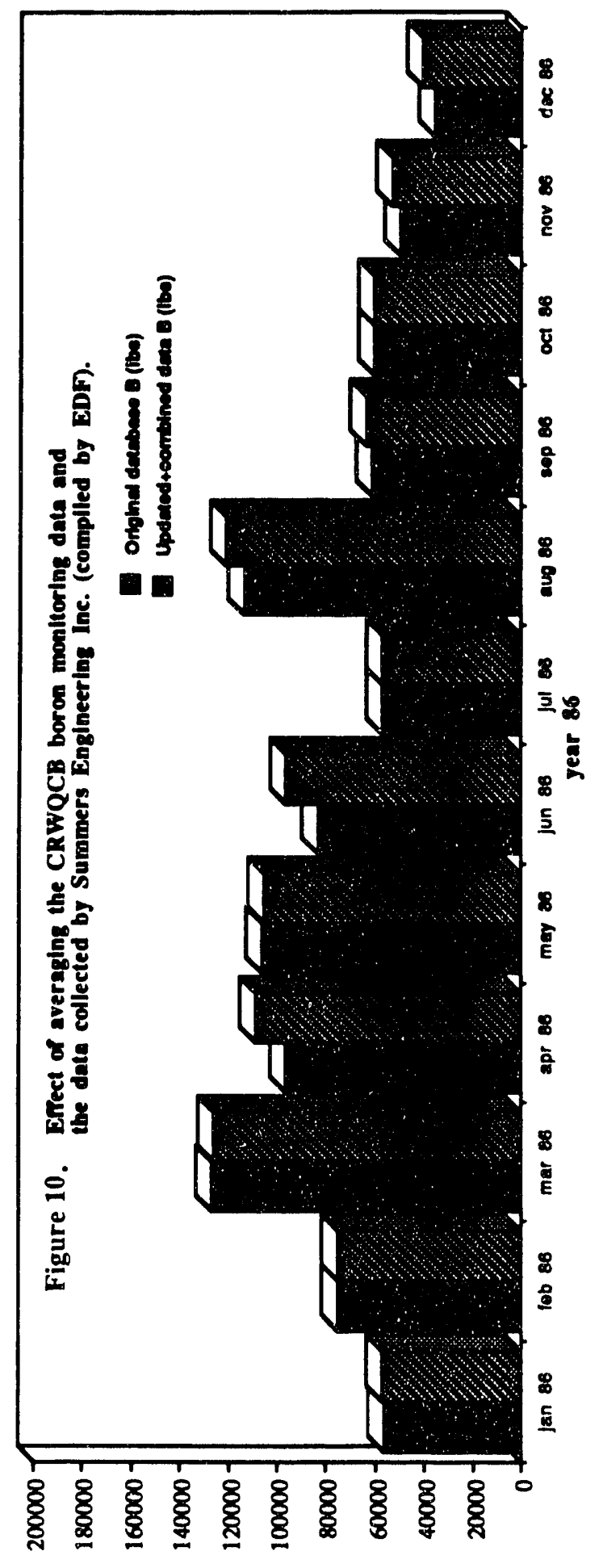

(ma1) $v$ owor daAfs wods pool wosog

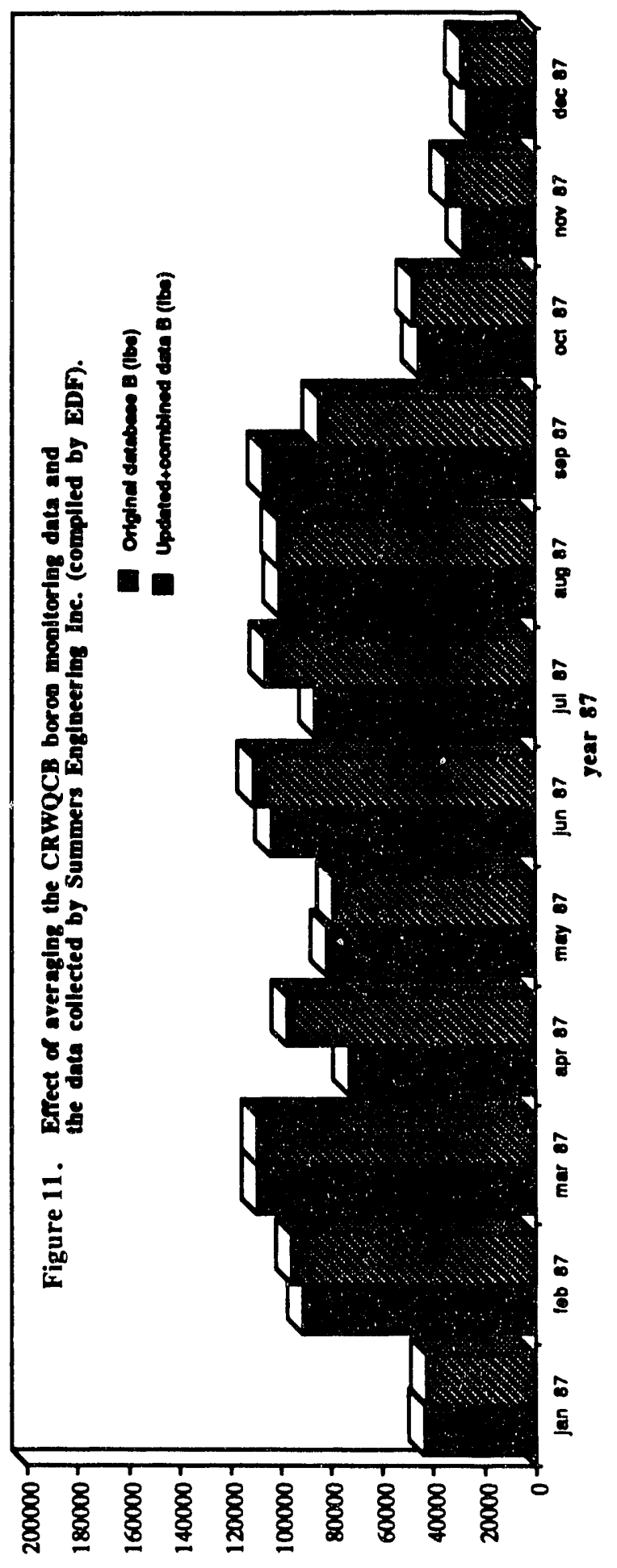

(wql) v owor danfs wods prol vosog 

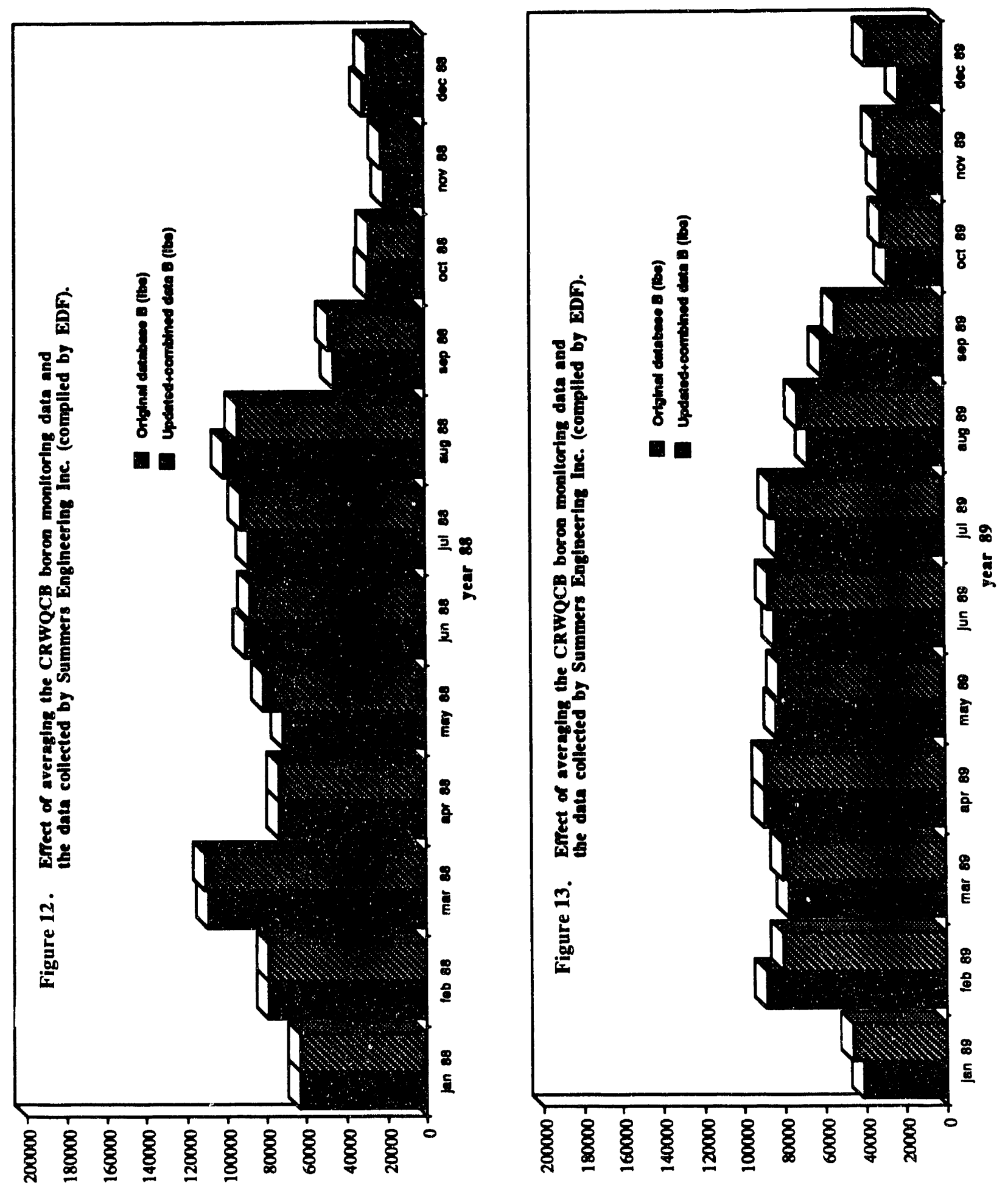

(eq1) V ouoz daAfS mods prop wosog

(mq1) V owor dOAfS wody prof rosog 


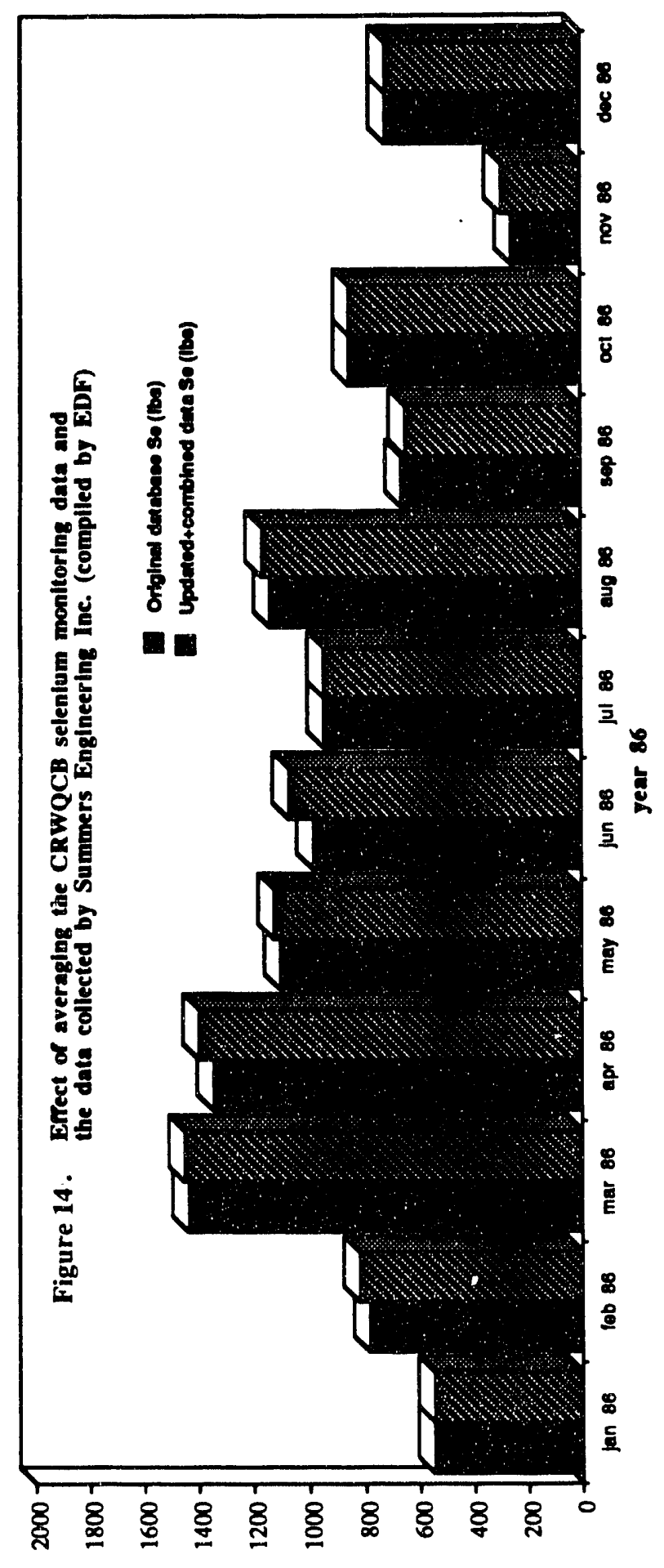

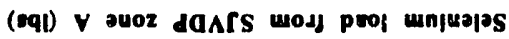

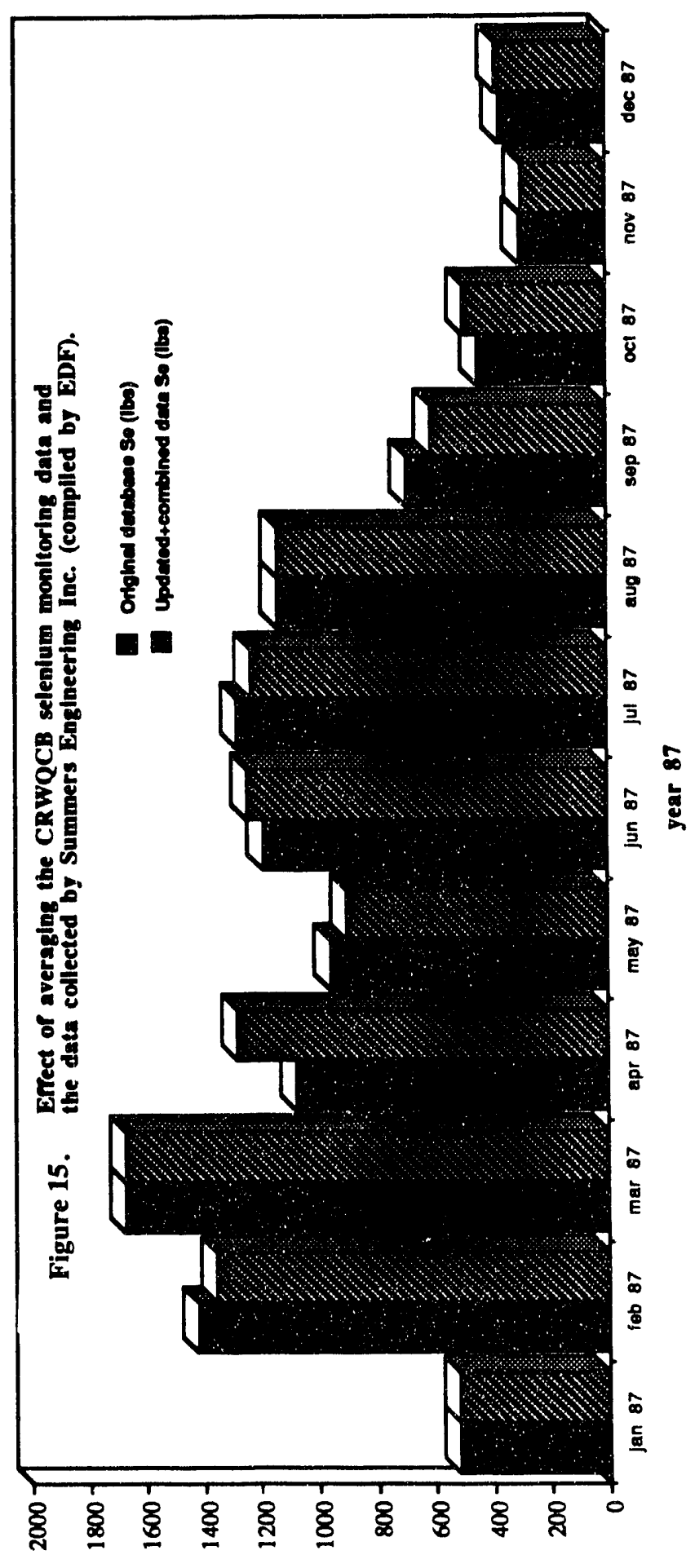

(4q1) $v$ awoz daAfs wos, prof mnjupas 


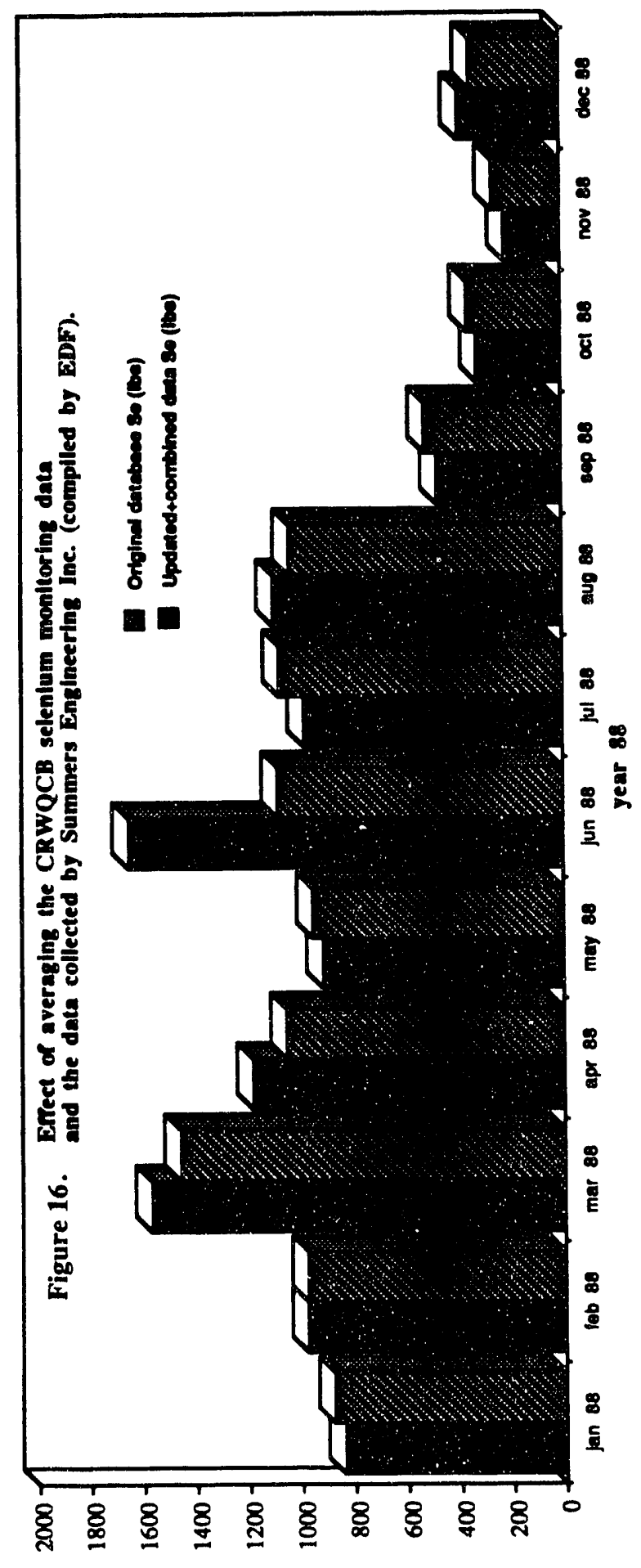

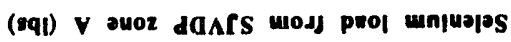

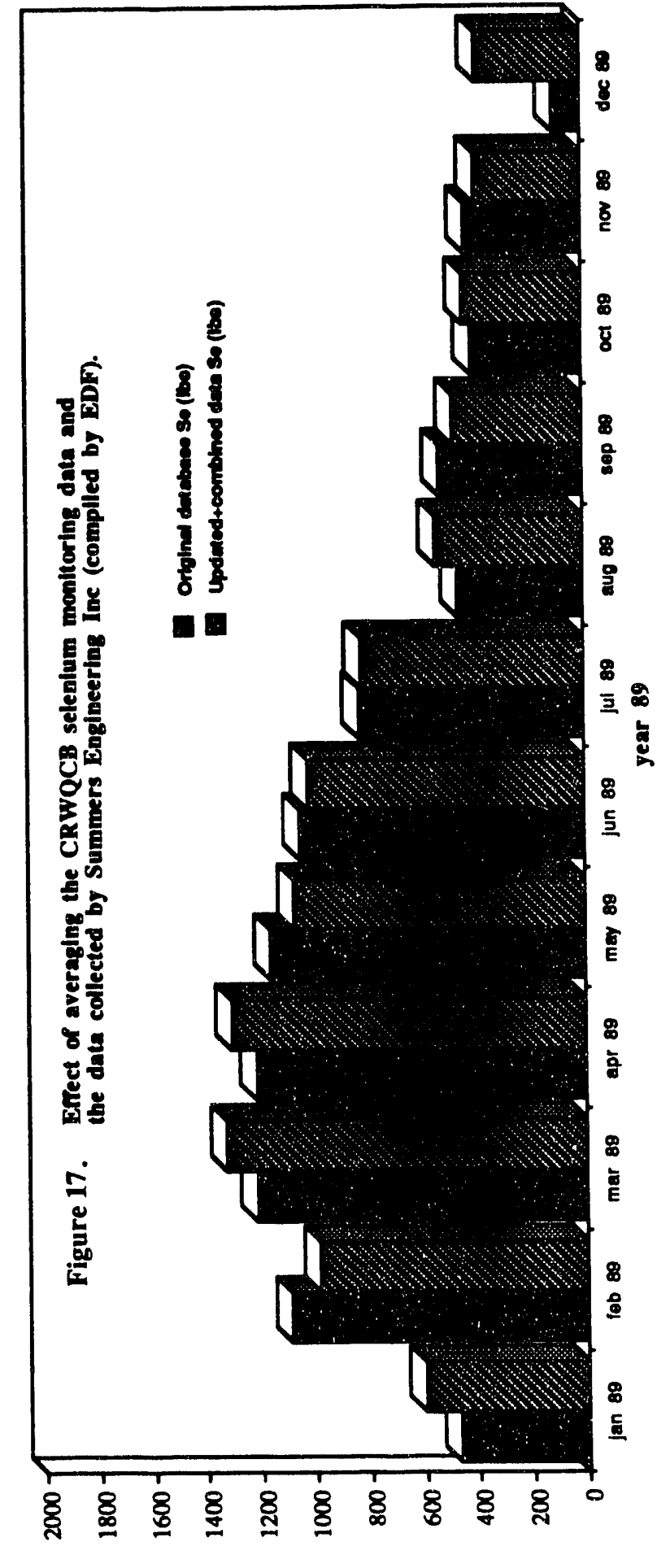

(ยq1) V owor daAfs mods peof wnjuops 
Figure 18. Shallow groundwater quality zones in Grassland area.

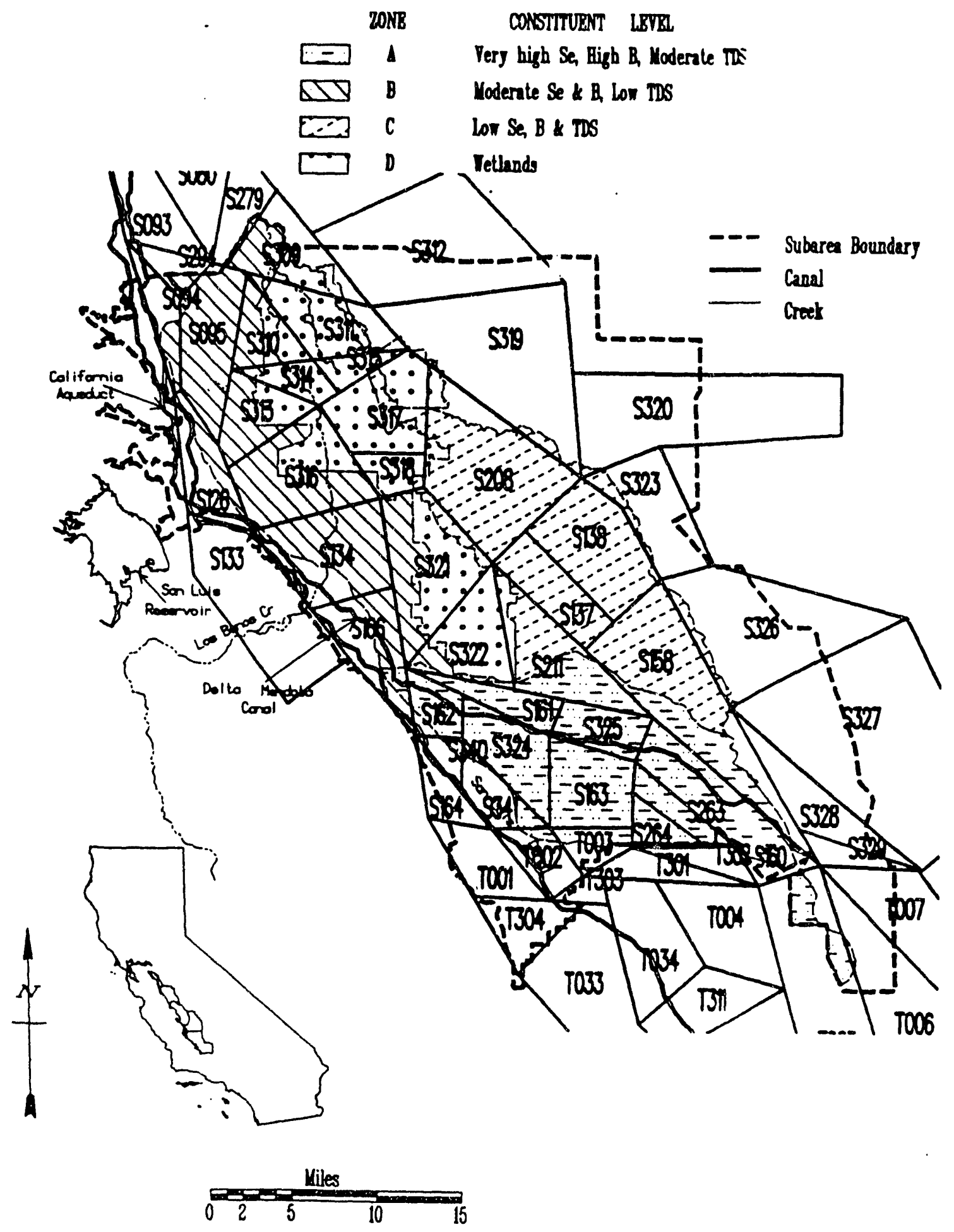

San Joaquin Palley Drainage Program 


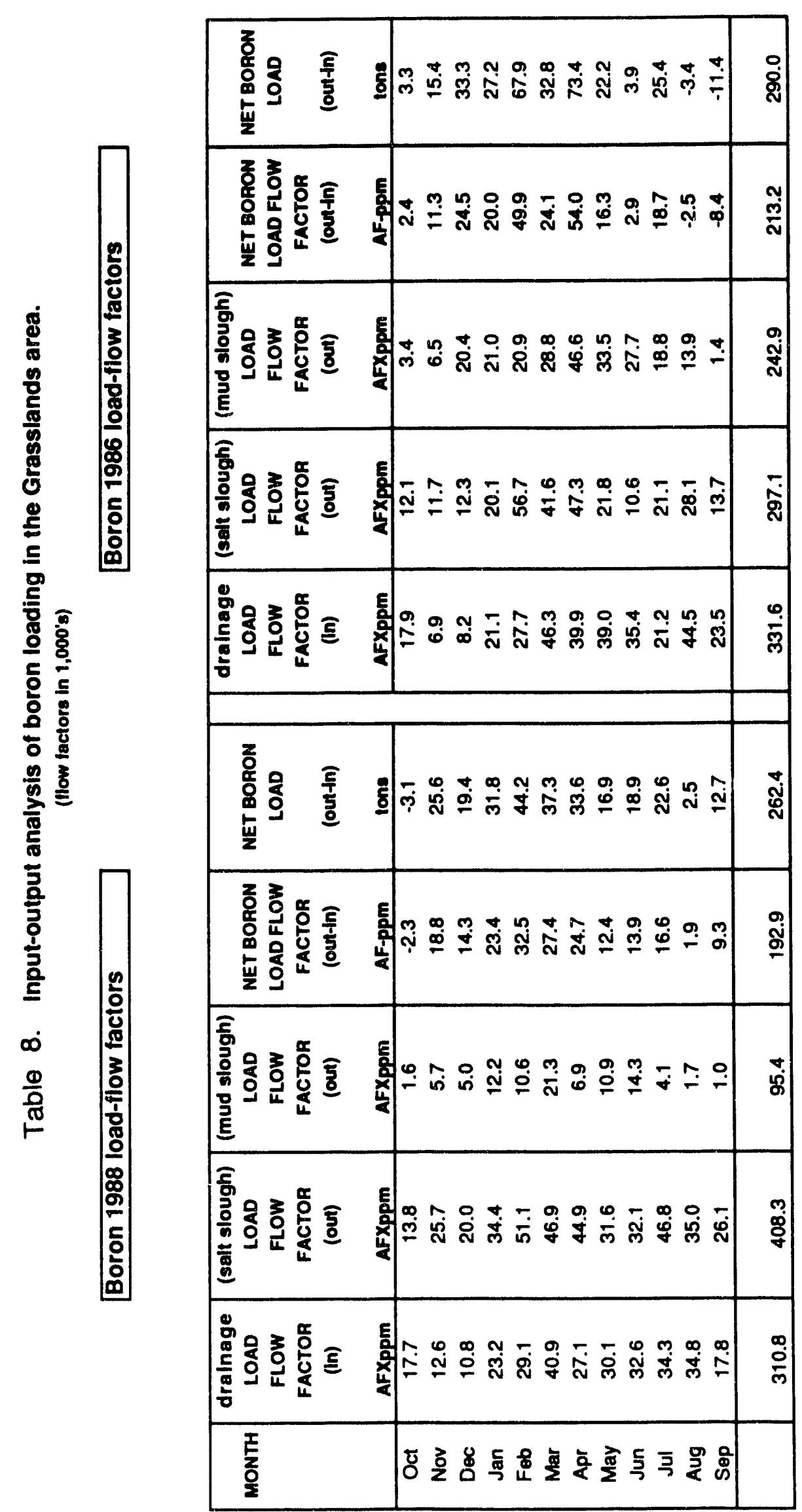




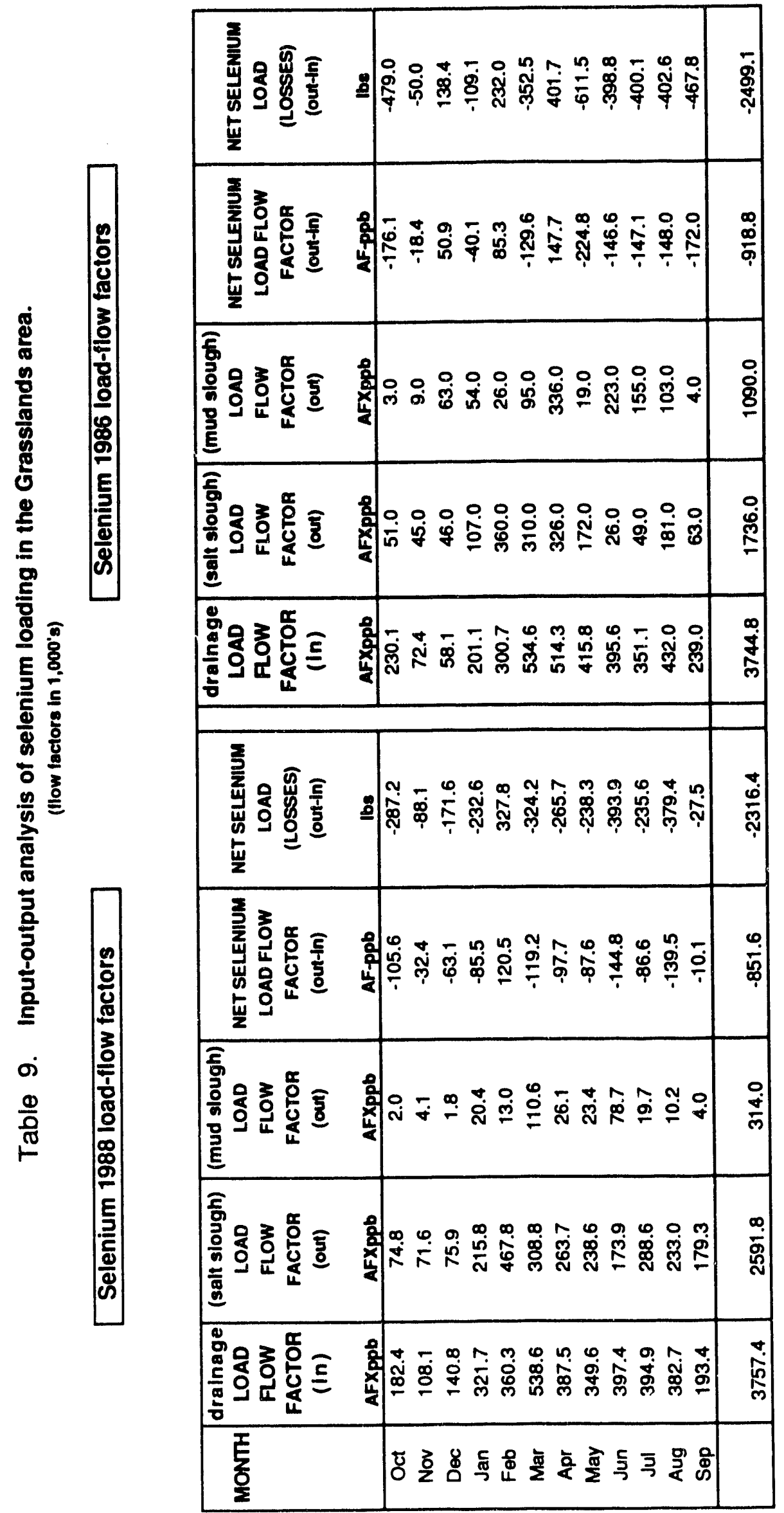




\begin{tabular}{|c|c|c|c|}
\hline \multirow{4}{*}{ 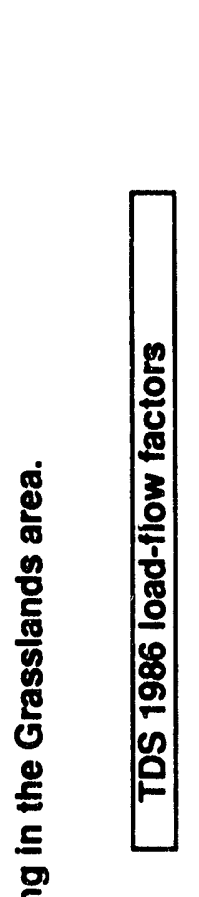 } & 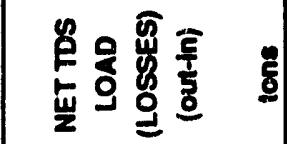 & 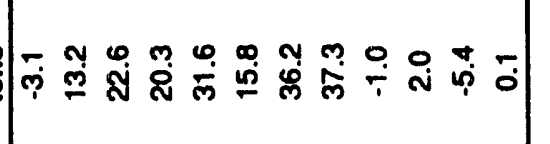 & 㤩 \\
\hline & 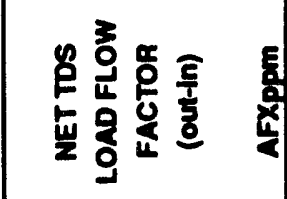 & 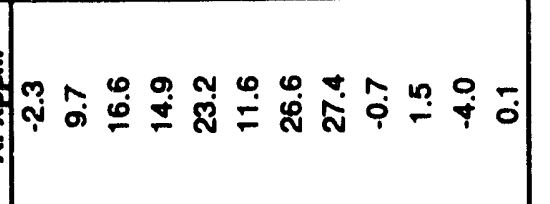 & \\
\hline & 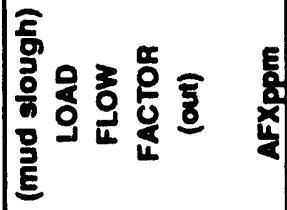 & 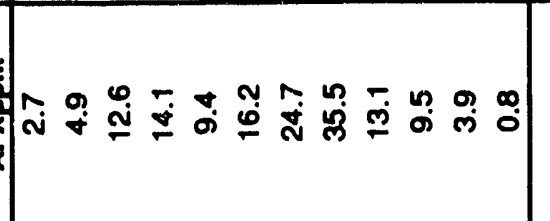 & $\dot{I}$ \\
\hline & | & 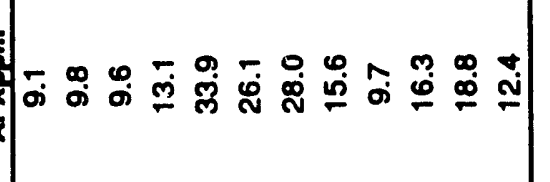 & :ेّ \\
\hline \multirow{7}{*}{ 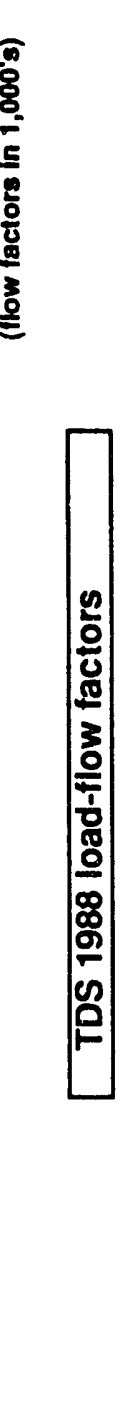 } & 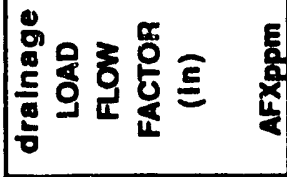 & 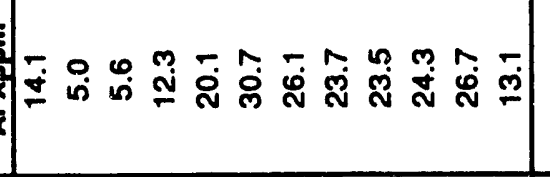 & ูำ \\
\hline & 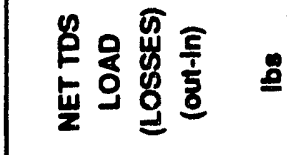 & 푸 & $\frac{\stackrel{0}{0}}{n}$ \\
\hline & 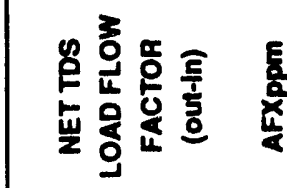 & 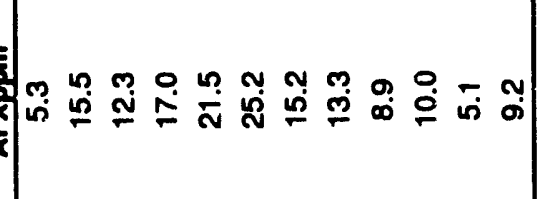 & 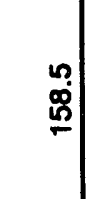 \\
\hline & 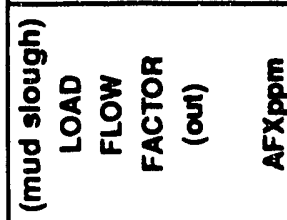 & 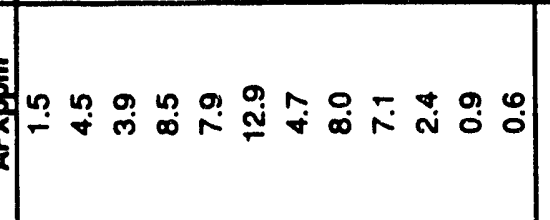 & ণั่ \\
\hline & 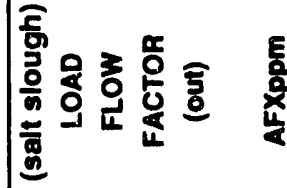 & 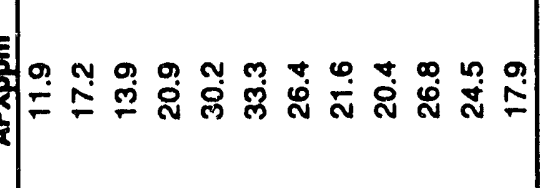 & 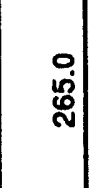 \\
\hline & 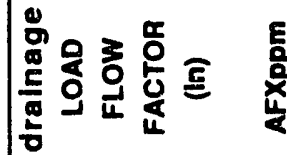 & 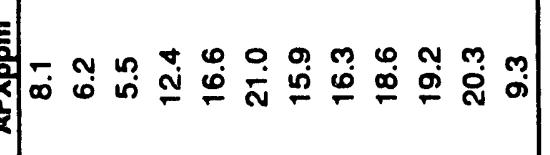 & \\
\hline & \begin{tabular}{|l|}
\multicolumn{1}{c}{} \\
$\underline{\Sigma}$
\end{tabular} & 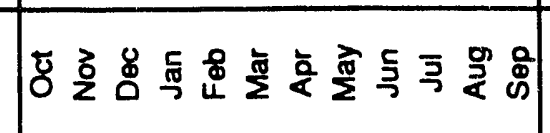 & \\
\hline
\end{tabular}




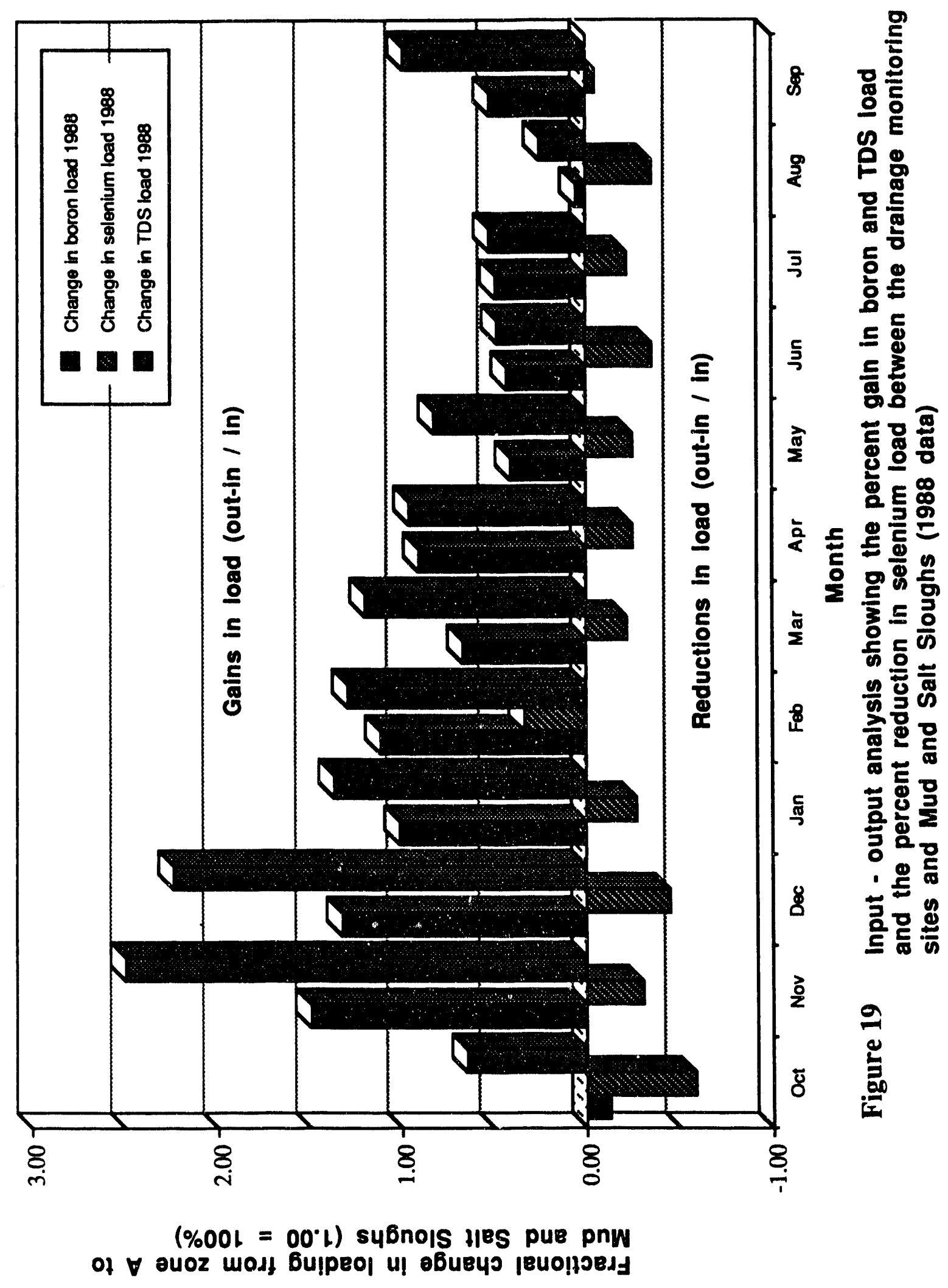




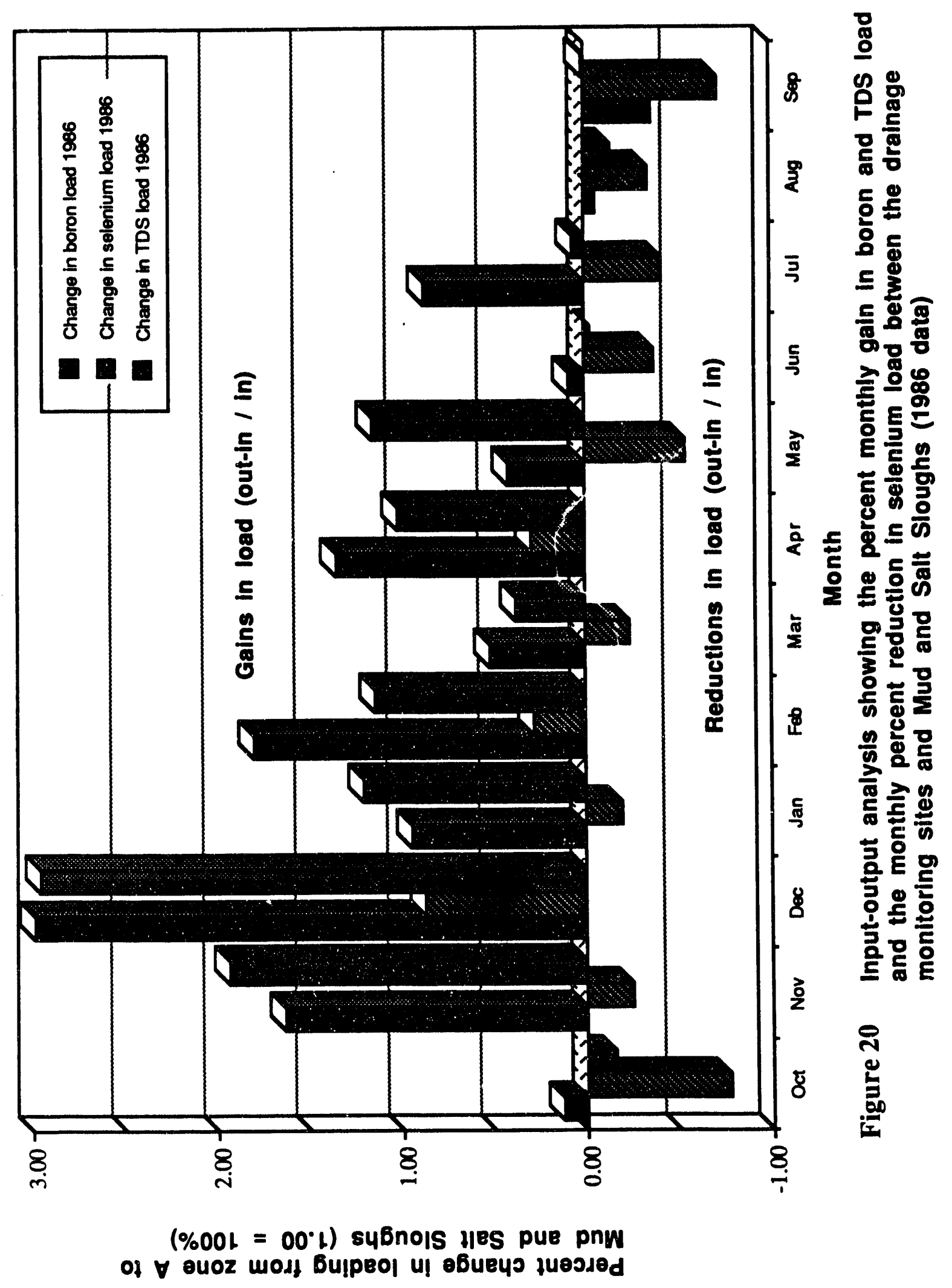


four drains (CCD, FCWD, PWD and PDD) correspond to the the four drainage monitoring sites shown in Figure 4. Each histogram is labelled according to the relative contribution from each source. The total flow shown in Figure 5 is equal to the :otal agricultural drainage flow into the Grassland area.

Examination of Figure 5 reveals that monthly flows from the agricultural water and drainage districts (SJVDP water quality zone A) have decreased by as much as $20 \%$ between 1985 and 1989 . Since contaminant concentrations in these flows have not changed to the same extent (Figure 6), with the exception of San Luis Water District (SLWD) and Central California Irrigation District (CCID), cuntaminant loads of TDS, selenium and boron passing into the Grassland area would appear to have decreased correspondingly. If analyzed by calendar year ; boron loads decreased from 514,132 lbs in 1987 to 432,904 lbs in 1989 (16\% reduction); selenium loads decreased from 4,835 lbs in 1987 to $4253 \mathrm{lbs}$ in 1989 (12\% reduction); and TDS decreased from 113,891 tons in 1987 to 96230 tons in 1989 (16\% reduction). This decrease in load may be attributed to increased subsurface drainage recycling and improvements in on-farm water management practices. The year 1988 is intermediate in boron, selenium and TDS drainage loads compared to years 1987 and 1989, which were also designated as critically dry .

To gauge the significance of enlarging the database by inclusion of the CRWCB data and the effect on the conclusions drawn in the March 1991 report (Swain and Quinn, 1991), the EDF and the combined EDF and CRWCB datasets are contrasted in Figures $10-17$. These figures are for boron and selenium concentrations and cover the period 1986 - 1989. The differences in mean values are small and not very significant for the boron data . In the case of the selenium data there appears to be more variability in the data. This may be ascribed to differences in laboratory protocols responsible for analyzing the samples - and inherent difficulties in measurement of concentrations in the parts per billion range in the case of selenium. Major discrepancies in the data were only evident in 1988, where the mean of the two data sets reduced the June mean monthly concentration by approximately $30 \%$.

\subsection{Losses of boron, selenium and TDS in ponds and channels}

Agricultural return flows pass though vegetated and earth-lined channels in their passage through the Grasslands area. Mass balance analyses of input loads and export loads from the Grassland area have revealed substantial selenium losses between the points of entry into the Grassland area and the USGS monitoring sites in Salt and Mud Sloughs and along the San Joaquin River (Figures 19 and 20 ; Table 9). In Figures 19 and 20 the combined mass loadings of boron, selenium and TDS at Mud and Salt Sloughs are subtracted from the combined agricultural drainage mass loading of these constituents, as measured at the four previously described monitoring sites. In this report the mass loadings at these import and export sites were chosen without including the estimated return flows and loads from SJVDP zones B and C (as was perfomed by Swain and Quinn, March, 1991) so as to utilize only measured data. SJVDP zones $B$ and $C$ include those areas which moderate and low levels of boron, selenium and TDS in the Grassland area and are delineated in Figure 18. The tables and graphs in Figures 19 and 20 show that both boron and TDS loads increase in transit through Grasslands, resulting from the co-mingling of surface and subsurface return flows from SJVDP zones B and C and wetland return flows from within Grasslands itself. This 
increase in load also results in a decrease in boron and TDS concentratious, since the mixing flows contain lower concentrations of TDS and boron than the agricultural drainage discharge from SJVDP zone A (Figure 18).

Selenium loads, conversely, decrease in most months for both 1988 and 1986 water years. The observation that selenium loads do not increase can be explained by the low concentrations of selenium (typically less than $1 \mathrm{ppb}$ ) in return flows from SJVDP zones B and C and the wetland return flows. Selenium losses may result from activity by a variety of biochemical mechanisms including uptake by vegetation, invertebrates, algae and other biota within the Grassland ecosystem. Volatilization may take place along channels and within earth-lined canals that support fungi and other microbes capable of reducing selenium into volatile organic compounds such as dimethylselenide. Selenium reduction to $\mathrm{Se}(\mathrm{IV}), \mathrm{Se}(0)$ and $\mathrm{Se}(-\mathrm{II})$ in boutom sediments may also contribute to decreases in selenium load (Tokunaga, 1991, personal communication).

Although some boron uptake may occur in vegetation growing within and along the sides of channels both boron and TDS loads are expected to be largely conserved during passage through the Grassland area. In the scenarios examined in Section 4 of this reporh, surface return flows from SJVDP zones B and C are utilized by wetlands to supplement water supply and hence some reduction in boron and TDS load may occur due to precipitation of salts and deposition in the pond sediments. Mass balances of all three contaminants of concern will be examined in more detail in Section 4. 


\section{Analysis of Impacts}

An analysis of project impacts must consider both the within and between season variations in contaminant loads and flows entering the Grassland area from the upslope drainage districts as well as the within and between season seepage flows, runoff and refuges and agricultural drainage discharges within the Grassland area. Retwrn flows from CCID, SLCC and other drainers adjacent to the Grassland area (SJVDP zones B and C) are of sufficient quality for wetland use and are considered to be a water resource, which presently is used either to blend with and dilute agricultural drain flows before discharging into the San Joaquin River, or is used as a supplemental water supply for re-use in the wetlands themselves. With the proposed action, more of this water is likely to become available for other uses.

Return flows from wetlands, which include seepage, uncontrolled runoff and drainage releases are returned to the natural and man-made system of channels, ultimately reaching the San Joaquin River by way of Salt and Mud Sloughs. The geographic proximity of San Luis NWR and Los Banos WA to Salt Slough suggests that most of the retum flows from these refuges discharge into Salt Slough. Likewise, Kesterson NWR and Volta WA are closest to Mud Slough (Northi which is likely to receive the most of the return flows produced by these wildlife management areas. Grassland RCD, including the Grassland WD and the private duck clubs in southwest Grassland, is a large contiguous area and likely contributes to both Sloughs. To determine the distribution of flow and contarninant load from the privately operated wetland to each of the Sloughs, an area weighting procedure was used. The areas of permanent and seasonal wetlands (land uses 20 and 21 in Appendix A) were summed and the acreages within the Grassland subareas shown in Figure 5 were allocated as tributary either to Salt Slough or Mud Slough (see the following tabulation). 


\begin{tabular}{rrrrr} 
& Salt Slough & \multicolumn{3}{c}{ Mud Slough } \\
Subarea & Area (acres) & Subarea & Area (acres) \\
206 & $(50 \%)$ & 1.5 & 203 & 3.8 \\
207 & 1.5 & 204 & 1.5 \\
209 & 1.7 & 205 & 8.1 \\
201 & 6.3 & $206(50 \%)$ & 1.5 \\
200 & 2.6 & 223 & 1.1 \\
215 & 5.3 & TOTAL & 16.0 \\
216 & 0.9 & & \\
218 & 3.1 & & \\
219 & 3.0 & & \\
220 & 2.2 & & \\
221 & 1.1 & & \\
222 & 0.8 & & \\
TOTAL & 30.0 & &
\end{tabular}

The ratio of wetland areas contributing to Salt and Mud Sloughs flows is approximately $2: 1$. Therefore the retum flow volume discharged to Salt Slough is assumed to be approximately twice as large as that discharged to Mud Slough. Wetland return flows to these two sloughs with and without the proposed action are illustrated in Figure 20.

\subsection{Scenario development}

The analysis which follows considers the with project scenarios outlined in the previous section. The first and most likely scenario (scenario 1) is that wetland managers take advantage of the improved water quality in Salt Slough and divert surface return flows and water district operational spills to supplement the firm water supply delivered from the Federal CVP. This will reduce the average annual volume of flow along Salt Slough as well as change the monthly schedule of flow and mass loading of TDS, selenium and boron to the San Joaquin River. Releases from wetlands during the spring will generally be larger and contain higher salt loads. The analysis which follows (4.2) attempts to quantify the volume and mass loading of these discharges.

The second scenario (scenario 2) assumes that no diversions into the adjacent wetlands will occur. In this scenario the hydrologic analysis is comparatively simple since the major impact of the project would be to divert the existing agricultural drainage flows into the San Luis Drain and then to Mud Slough (North). In this scenario boron and TDS loads to the river will be largely unchanged and should closely match the monthly distribution of contaminant load from the water districts. The only impact will be on selenium, which is not expected to experience the same losses due to plant and microbial uptake in the Drain that occurred within the Grassland channels. A comparison is made of these scenarios in Section 4.3. 
A third scenario, which is not part of the proposed project, is analyzed nevertheless. In this scenario (scenario 3) the amount of water that is diverted by wetlands and refuges in scenario 1 is supplied from other sources. The rationale for this scenario is both practical and political. In order to ensure that no Salt Slough diversions occur to wetlands, with implementation of the project, additional water , equivalent in volume and quality to the zone B and $\mathrm{C}$ drainage is assumed to be found. This supply could as easily be supplied from groundwater pumpage. The USBR has estimated safe yield within the Grassland area of greater than 55,000 acre-f $\mathrm{f} /$ year. Water quality considerations, however, may account for the small annual amount of groundwater pumped within the Grassland area. The surface return flows and operational spills from SJVDP designated zones $B$ and $C$ continue to be diverted mostly (80\%) down Salt Slough. The wetland releases continue to be discharged down both Mud and Salt Sloughs in the ratio of approximately $1: 2$ (i.e. 33\% into Mud Slough and 66\% into Salt Slough) as in the other withproject scenarios. Hence, in this scenario, the total flow leaving Mud and Salt Sloughs is increased by a volume equal to the additional discharge from wetlands.

\subsection{Development of the with-project scenarios}

Tables 6 and 7 showed the return flow volumes and contaminant loads from each of the wetland management areas. The flow volumes were obtained by combining the volumes of seepage and runoff and the volume of reservoir release expected from each of the five refuges and wetland areas (Tables 1-5). The major differences between the without -project (Table 6) and the with-project scenarios (Table 7) are in the flow volumes assumed for San Luis NWR, Los Banos WA and Grassland RCD. The increase in the estimated return flows from each area is in direct proportion to the increased water supplies assumed to be available to these refuges resulting from the capability of separating usable retum flows from contaminated agricultural return flows. Summing the volume of return flows for the with-project scenario, and subtracting these from the summed flow volumes for the without-project scenario, yields the total increased return flow volume from the wetlands of approximately 27,000 acre-ft. Additional inflow to these areas was approximately 55,000 acre-ft. Of these increased return flows it is assumed that approximately 23,000 acre-ft would be directed down Salt Slough and the remaining 4,000 acre-ft down Mud Slough.

To determine the effects of the proposed action on the loads of boron, selenium and TDS at Mud and Salt Sloughs, the refuge return flows are combined with agricultural drainage flows from the upslope water and drainage districts. These agricultural drainage flows are from two main sources as recognized in the SJVDP Final Report (SJVDP, 1990) and in the Technical Appendix to the SJVDP Final Report (Swain, 1991). SJVDP zones B and C (Figure 18) are sources of relatively good quality retum flows and include agricultural drainage from parts of CCID and San Luis Canal Company. Zone A is the source of agricultural drainage, identified by the SJVDP as problem water, which derives from Firebaugh Water District (Canal Company), Broadview Water District, Panoche Water District, Pacheco Water District and San Luis Water District.

Tables B1 - B27 and C1 - C27 in Appendices B and C describe the effect of the combined flows (measured or estimated) on the concentrations of boron, selenium and TDS, with and without the proposed action for hydrologic years 1988 and 1986. The with-project analysis contrasts scenarios 1,2 and 3. The logic of the spreadsheet format 
is discussed for one example, contrasting the without project and the with project cases (scenario 1) using Tables B1 and B2 in Appendix B (hydrologic year 1988 ). The same logic used to construct Tables B1 and B2 apply to all other tables in this report. The following assumptions apply to the construction of these tables:

(a) The USGS continuous flow recorded in Salt and Mud Sloughs can be used as a standard against which the hydrology upstream of these gauges can be calibrated.

(b) The USGS TDS, boron and selenium grab sample data are representative of average monthly concentrations and can be used to estinate mean monthly loads of constituents for 1986 and 1988.

(c) There are flows and contaminant loads unaccounted for in the mass balance analysis. These flows may be greater or lower than the annual figures calculated for each year of the 1986 and 1988 hydrology database used in the analysis. Adjustments were made to these flows, and to the loads of contaminants carried by these flows, in order to calibrate against the contaminant loads in Mud and Salt Sloughs for the existing or no-action condition. These adjustments can also be applied to the hydrology of the with project scenario.

(d) Adjustments should be made to flows first, given the greater reliability of the data.

(e) Grab samples taken by the CVRWQCB on the west bank of the San Joaquin River at Newman, tends to underestimate the effect of the Merced River. For this reason, the CVRWQCB water quality measurements at Crows Landing for TDS, boron and selenium taken during 1989 and 1990 were used to estimate the mean monthly load at Newman. For the years 1986 and 1988 which are the subject of this analysis the Newman data were used, complete CRWQCB data not having been available. (The San Joaquin River is assumed to be completel! mixed at Crows Landing.) The flow measured at Newman is assumed to be similar that measured at Crow Landing, since both are downstream of the Merced River and there are no major tributary inflows or river accretions between these sites. An adjustment factor could be applied between these sites to correct contaminant concentrations for the small differences in flow, if the data were available.

\subsection{Calibration of contaminant flows and loads (without project)}

\subsubsection{Contaminant flow and concentration data}

Monthly flows and boron concentrations for the gauging station near Newman are shown in each of the water and contaminant budgets (Table B1: columns 2 and 3). The integrated flow weighted water sampling procedure used by the USGS from October 1985 through September 1988 was assumed to improve data reliability at the Newman site. Boron load, expressed as a boron load-flow factor, is determined by multiplying the figures in columns 2 and 3. This is equivalent to multiplying the monthly averaged flow and concentration data as described by the following equation :

$$
C \quad=1 / t \int_{0}^{m} \mathrm{C}(\mathrm{t}) \mathrm{dt}
$$


$Q=\int_{0}^{m} Q^{*} d t$

$\mathrm{L}=\mathrm{C} \mathrm{Q}$
2.

3.

Where : $\quad \begin{array}{lll}\mathbf{C} & = & \text { time averaged concentration } \\ \mathbf{C} & = & \text { sampled concentration at time } \mathrm{t} \\ \mathbf{Q} & = & \text { monthly flow volume } \\ \mathrm{Q}^{*} & = & \text { flow rate at time } \mathrm{t} \\ \mathrm{m} & = & \text { month index } \\ \text { d } & = & \text { delta time }(\mathrm{t} \text { expressed in days or weeks) } \\ \mathrm{L} & = & \text { constituent load (expressed in load-flow units) }\end{array}$

Tokunaga (Tetsu Tokunaga, LBL : personal communication, 1991) has questioned the validity of this procedure, in the case where $C$ and/or $Q^{*}$ vary with time. Unfortunately, flow and concentration data for constituents other than TDS, are not collected concurrently, as part of the current Grassland and San Joaquin River monitoring programs. Neither boron or selenium can be determined directly, except by chemical analysis in the laboratory. Regression relationships between TDS (or EC) and the trace elements selenium and boron, as previously noted, are not entirely reliable. The regression coefficient for the relationship between TDS and boron is typically higher than that for TDS and selenium. The time averaged concentration data was considered more accurate than the regression derived concentration data and was therefore utilized in this study.

The flows and estimated loads (load-flow factors), contributed by Salt and Mud Sloughs were subtracted from the flow and estimated boron load-flow factor near Newman(columns 11 and 12) to estimate the concentration of boron in river accretions between the Mud and Salt Slough monitoring stations and the San Joaquin River monitoring station near Newman. The calculated monthly value of boron concentration, obtained by dividing the boron loadflow factor by the flow, should be a positive number. However, most of the load-flow factors values are negative indicating a reduction in boron load somewhere between Salt and Mud Sloughs and the San Joaquin River monitoring station. If these monthly residuals are compared for water years 1986 through 1990 , it appears that the error in the calculated mass balance is not systematic. The error does not appear to be consistent between months of different years or for a particular water year type (i.e wet or critically dry). It is possible that random error, associated with the water quality sampling procedure at Newman and in Mud and Salt Sloughs, is rather large and that the sample values are not good estimators of the monthly mean.

A calibration procedure was adopted to distribute the error in this load-flow factor by adjusting first the flows, then the contaminant load-flow factors in Mud and Salt Sloughs, so that the total of the flows and loads from each of the source areas balances with the flow and load measured at the Newman monitoring station. These source areas include the wetlands and refuges (columns 14 and 15), SJVDP agricultural drainage discharge zones B and C 
(columns 16 and 17) and agricultural discharge zone $A$ (columns 18 and 19), the source of most of the high boron, selenium and TDS.

The wetland return flows are all assumed to have a boron concentration of $1 \mathrm{ppm}$, a selenium concentration of $1 \mathrm{ppb}$ and a TDS concentration of $1600 \mathrm{ppm}$. The boron, selenium and TDS concentration assumptions are based on limited data, obtained during the USBR's of fstream storage study, conducted in the Northern Grassland area, and from the USBR agricultural drainage monitoring data from SJVDP zones B and C (Appendix D), obtained during the period 1984 - 1987.

In columns 20 to 23 the flows and load-flow factor numbers are calculated from the wetland retum flows and the agriculural drainage monitoring data from SJVDP water quality zones A, B and C, including that collected by Summers Engineering. In all years, and for most months the load-flow factors for the reconstructed data exceed the monitored data load-flow factors at the Salt and Mud Slough, USGS stream gauging sites. However, the calculated flows are less than those recorded by the USGS. The calculated values were adjusted by increasing or decreasing the accretion sufficiently to match the recorded value. This adjustment factor was assumed to be independent of the proposed action and was used to adjust the predicted flows both with and without the proposed action. In columns $24-27$, the flow discrepancy between the measured and the calculated values was determined for both Salt and Mud Sloughs and the contaminant concentration of these accretions assumed to be equal to the surface drainage water quality from the San Luis Canal Company which is : TDS - $1000 \mathrm{ppm}$; boron - $1.0 \mathrm{ppm}$; selenium - $1.0 \mathrm{ppb}$. In columns 28 -31 the reconstructed load-flow factors (boron load in wetland releases + boron load agricultural retum flows from zones A, B and C) were added to the adjusted low boron load-flow estimates and from this sum was subtracted the load flow factors estimated from the records at Mud and Salt Sloughs. The calculated difference is the in-transit boron adjustment, which when added to the reconstructed Mud and Salt Slough load-flow factors produces the figure in column 33, the load flow factor for boron in the San Joaquin river. If the load flow factor in column 33 is divided by the recorded flow at Newman monitoring station, the monthly boron concentrations in column 2 are reproduced. These same adjustments are then applied to each of the with project scenarios.

The calibration procedure, that has just been described, was duplicated for both the without project and with project analyses for the 1986 and 1988 water year hydrologies and for the three contaminants. In evaluating the impact of the proposed project, the calibrated TDS, selenium and boron loading data were used as base conditions for the impact analysis.

\subsubsection{Selenium uptake and effect of using San Luis Drain}

The conclusions drawn from analysis of Figures 19 and 20 were that, whereas boron and TDS mass loads appeared to be largely conserved in transit through Grassland channels, selenium experienced a significant loss. Mechanisms responsible for the reduction in selenium mass loading between the drainage monitoring sites and the points of discharge into the San Joaquin River along Mud and Salt Sloughs may include the following : 
(a) Uptake by vegetation in unlined canals.

(b) Direct volatilization of selenate and selenite from wetted soils.

(c) Uptake by algae and other biota and immobilization in channel sediments.

In Swain and Quinn (1991) the assumption made was that the selenium losses, which were calculated for the no-action condition, would be reduced by a certain percentage due to the diversion of highly contaminated drainage water from Salt and Mud Sloughs to the San Luis Drain. This percentage reduction was correlated with the residence time that the drainage contaminants had to interact with vegetation and biota. This reduction was assumed to correlate directly with the length of earth lined channel through which the drainage would pass - since the length of earth lined channel is reduced with the use of the San Luis Drain, the selenium uptake would likely decrease. To obtain an estimate of the percentage change in residence time, the reduction in the length of vegetated channel was measured and used as a weighting factor. This weighting factor was applied to correct for selenium accumulation in vegetation and biota that would no longer take place with the proposed action. This simple weighting factor was used as a first approximation and is not based on field concentration data or from a detailed knowledge of channel cross - sections or ve'ocities. More intensive study of selenium transformations within the Grassland basin will be necessary to address this deficiency.

In Tables B9, B11 and B13 the effect of the project on selenium loading in Salt and Mud Sloughs is calculated in columns 28 - 31. Column 29 contains the selenium load in-transit adjustment adjusted for the assumed reduction in selenium losses and/or uptake due to diverting the drain flows from the Grassland channels into the San Luis Drain. By adjusting the in-transit adjustment load factor downward - the net effect is an increase in net selenium load compared to the without project scenario. The reduction in selenium losses and/or uptake within the Grassland distribution system was calculated to be $49 \%$ in the report by Swain and Quinn (1991) since conveyance along the San Luis Drain was assumed to reduce the vegetated channel residence time by $49 \%$. Selenium losses were assumed to be primarily due to uptake by vegetation growing in the channels. Hence the selenium load increase due to the proposed action was estimated in Table B9, B11, B13 and B15 as 49\% of the selenium load adjustment necessary to reconstruct the San Joaquin River selenium concentrations (Table B8).

During a field trip organized by the Grassland Water District, after the completion of the report by Swain and Quinn (March, 1991), it was observed that water flowing along the Camp 13 and Agatha Canals did not contact aquatic and terrestrial vegetation to the extent initially assumed. During this tour it was also learned that channels were cleared and sediments were removed from the channels every 2 - 3 years as part of routine maintenance by the Grassland Water District (Don Marchioci; personal communication, 1991). Although no data exists to verify selenium uptake or removal mechanisms, it may more reasonable to assume that the majority of the selenium loss may be through uptake by algae and phytoplankton than by vegetal uptake (Alex Horne, U.C. Berkeley : personal communication, 1991). Selenium taken up in this fashion would likely eventually end up in channel sediments, where it could become immobilized in the reducing environment of the detrital layer. Deposition and immobilization of selenium could occur equally in the San Luis Drain as in Grassland channels. The intial estimate of selenium in-transit loss adjustment of $51 \%$ was decreased to 
$10 \%$ - resulting in a smaller net increase in selenium load entering Mud Slough as a result of the projech compared to the without project scenario. The $10 \%$ in transit loss adjustment assumption of $10 \%$ may be conservative if algal uptake, deposition and immobilization are the primary mechansims for selenium losses from the Grassland system. However, because this assumption has no scientific basis, a range of in-transit selenium reduction (uptake) assumptions were made $-0 \%, 10 \%, 20 \%$ and $51 \%$. The spreadsheet analysis performed for scenario 1 is made using each of these four assumptions. Scenarios 2 and 3 were analyzed using only the $10 \%$ uptake assumption.

The importance of this assumption of selenium uptake mechanism will be evident in the analysis that follows. Field research to verify this assumption should be undertaken as a matter of some urgency.

\subsubsection{Projected mass loading of boron, selenium and TDS}

After calibrating flows in both Salt and Mud Sloughs to match measured data, a separate mass balance analysis was performed to estimate the effect of the project on concentrations of the contaminants in Mud Slough, Salt Slough and in the San Joaquin River.

The effect of the proposed project on selenium flows and loads at Salt Slough, Mud Slough and the San Joaquin River near Newman are presented in Columns 35 - 43. In each case, since the majority of the agricultural drainage flows containing high loads of contaminants are routed and discharged into Mud Slough (north), above the monitoring site at Highway 140, the contaminant concentrations increase within Mud Slough (north) and decrease along Salt Slough. The volume of flow within Salt Slough is significantly depleted by virtue of the redirection of contaminated drainage and the increased diversions from the Slough of good quality drainage return flows to adjacent wetlands. The general effect of the proposed action is described in Figures 21 through 26 for contaminants boron, selenium and TDS and for the years 1988 and 1986. In the graphs which follow the 1988 results (crtitically dry year) are presented before 1986 results (wet year) to remain consistent with the previous report by Swain and Quinn

(1991). The three graphs on each page, labelled (a), (b) and (c), describe the effects on Salt Slough, Mud Slough and the San Joaquin River at Newman respectively. In order to make the graphs easy to interpret, only scenario 1 (with increased use of Salt Slough flows by wetlands - S1) and scenario 2 (without increased use of Salt Slough flows by wetlands - S2) were compared with the without project scenario.

\subsection{Effect of proposed project on boron concentrations}

\subsubsection{8 data}

The effect of the proposed project on monthly boron concentrations is similar to the effect of the project on TDS. This is expected, since both boron and TDS appear to be conserved in transit through the Grassland area. In 1988, boron concentrations are most elevated above the without project scenario concentrations in Mud Slough for the months of November through April (Figure 22), and may be close to $100 \%$ higher in the months of December, January and February for both Scenarios 1 and 2. Conversely, in Salt Slough, boron loads are reduced throughout the year with the greatest improvement occurring in January and February when most of the high boron loads are being diverted to Mud Slough. There does not appear to be much difference in boron concentrations between 
scenarios 1 and 2 (with and without wetland use of Salt Slough flows, respectively), although in every month, wetland diversions cause slightly higher concentrations of boron in both sloughs. Wetland releases during April and May do not add significantly to the total boron load - hence concentrations change very liule.

Boron concentrations in the San Joaquin River at Newman are elevated only slightly, in Scenario 1, over the without project scenario. As expected, since Scenario 2 involves only re-routing of agricultural drainage flows along Salt and Mud Sloughs, there is little discernable difference in San Joaquin River concentrations.

\subsubsection{6 data}

Figures 30 and 31 show the same general pattern of lower boron concentrations, in the months December through April in Salt Slough, compared to the without project scenario. The converse is true of Mud Slough, which exhibits higher concentrations of boron, during the same period, as a result of the project, and lower concentrations of boron between the months April and Septsmber. Boron concentrations are always higher in Salt Slough under scenario 1, where wetland return flows to Sialt Slough contain higher concentrations of boron than the return flows within Salt Slough. There appears to be little effect of the project on boron concentrations in the San Joaquin River. The major difference between the wet year and critically dry year hydrologies for boron is manifested in lower boron concentrations in both Mud and Salt Sloughs, with the greatest percentage reduction, during the summer months. This is probably a result of improved quality of subsurface returns from the upslope agricultural areas due to a higher proportions of tailwater in the combined flow.

\subsection{Effect of proposed project on selenium concentrations}

The monitoring data for the 1986 - 1989 period suggest that under the existing operation of the Grassland system significant losses of selenium occur in transit through the vegetated channels and unlined ditches. The precise magnitude of these losses have been difficult to quantify, because the monitoring program that has been conducted since 1985 has been more concerned with assessing compliance with water quality objectives and less with analysis of selenium losses through the Grassland system. An attempt has been made in the analysis, previously described, to correct for ungaged flows into the Grassland system and for errors in loads, resulting from using grab sample data as average monthly selenium concentration values.

In Salt Slough the selenium concentration was assumed to remain at $1 \mathrm{ppb}$ or less for the entire year. This assumption was based on monthly monitoring of Wetland return flows during the Reclamation's Offstream storage study, the assumed quality of fresh water delivered and/or spilled through Salt Slough and monthly monitoring of subsurface and surface drainage from agricultural lands east of Salt Slough by Reclamation and state and local agencies. For example the offstream storage monitoring program indicated that wetland releases did not contain selenium concentrations greater than $5 \mathrm{ppb}$ during three years of water quality sampling and were typically lower than $1 \mathrm{ppb}$.

\subsubsection{8 data}

In Figure 24 the analysis suggests a dramatic increase in selenium concentrations in Mud Slough as a result of the project. During the year, selenium levels could increase from less than $5 \mathrm{ppb}$ to over $40 \mathrm{ppb}$ in the months of October, 
Figure 21. Estimated effect of project on boron concentrations in Salt Slough. S1 - Increased wetland use of Salt Slough flows permitted S2 - No increase in wetland use of Salt Slough flows fwo - without project : tw - with project

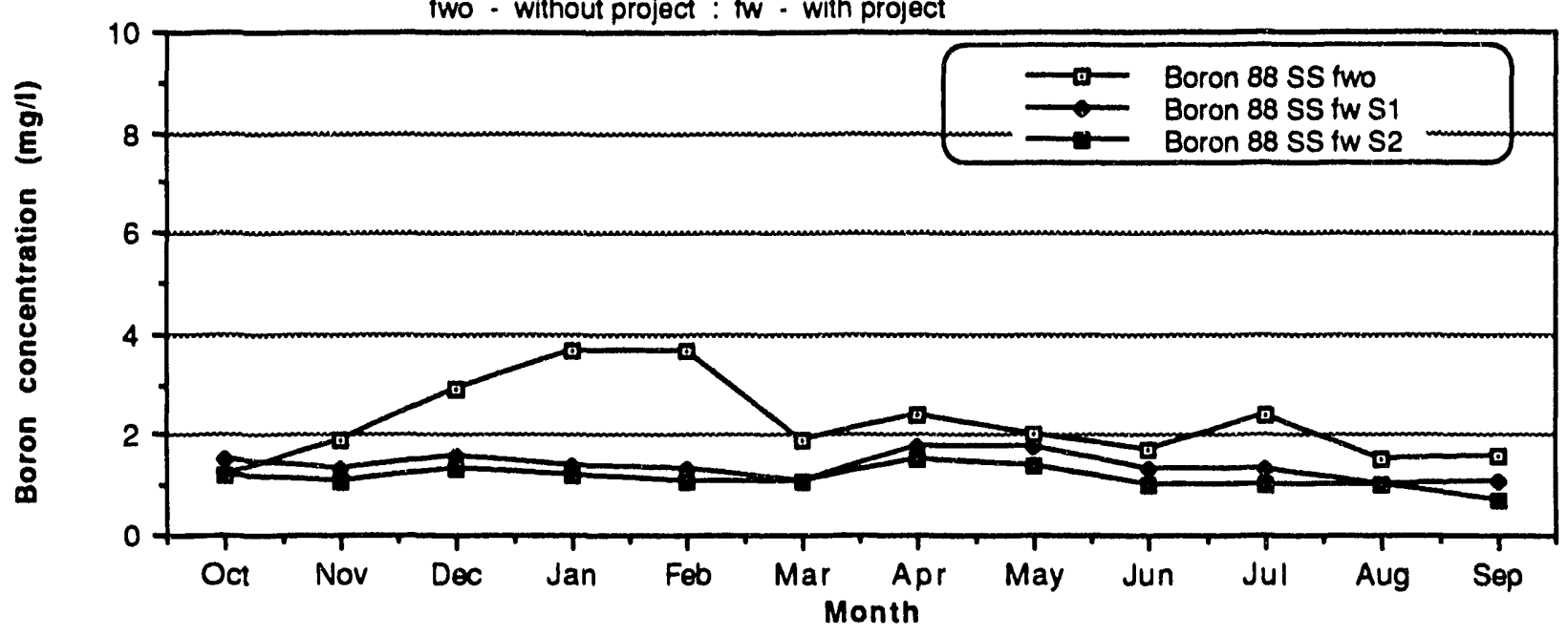

Figure 22. Estimated effect of project on boron concentratlons In Mud Slough. S1 - Increased wetland use of Salt Slough flows permitted S2 - No increase in wetland use of Salt Slough flows fwo - without project : fw - with project

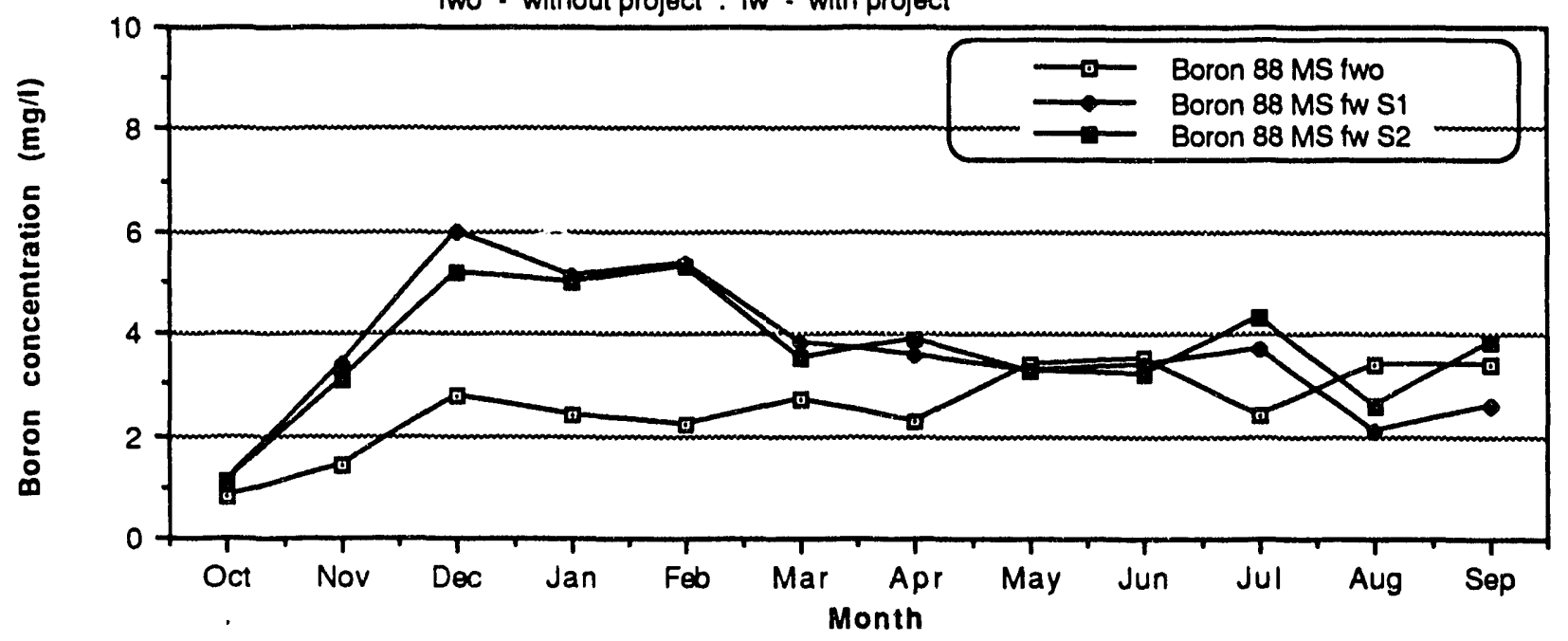

Figure 23. Estimated effect of project on boron concentrations in the San Joaquin River. S1 - Increased wetland use of Salt Slough flows permitted S2 - No increase in wetland use of Salt Slough flows two - without project : tw - with project

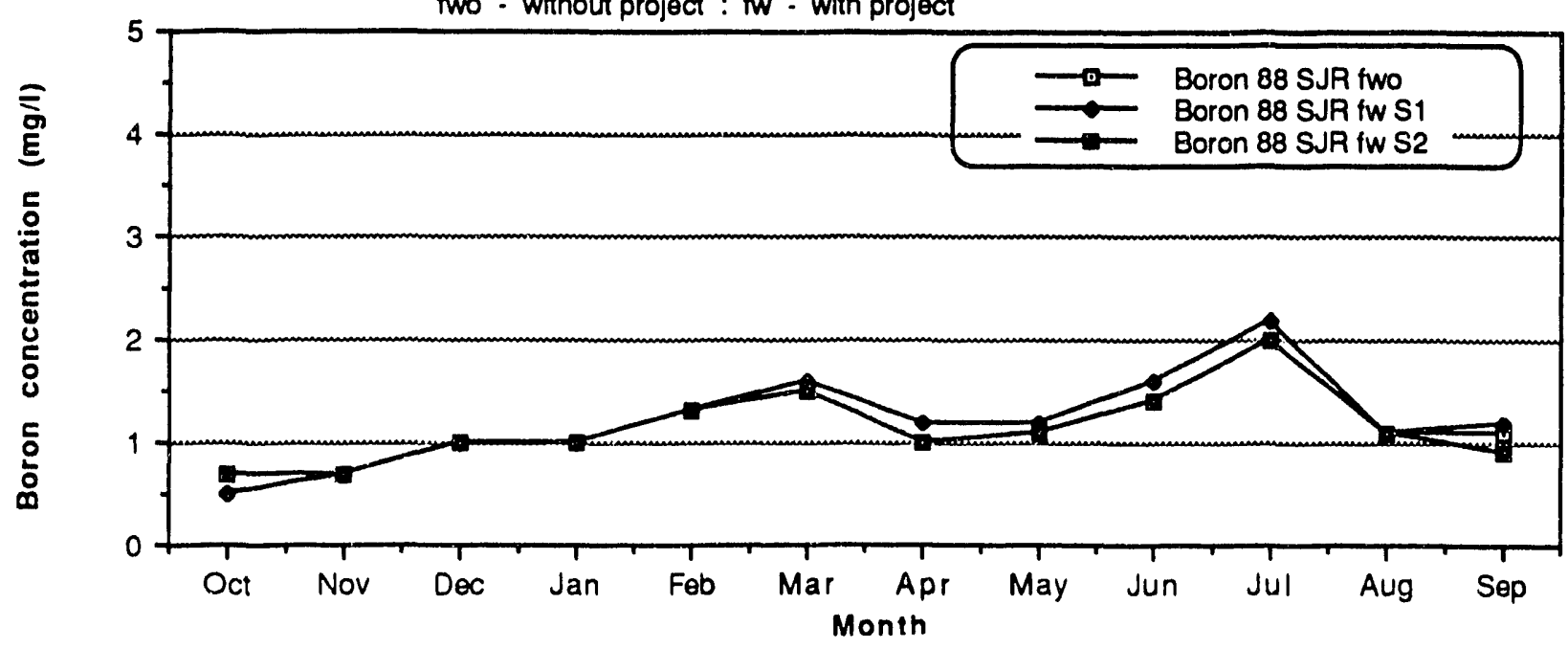


Figure 24. Estimated effect of the project on selenium concentrations in Salt Slough. S1 - Increased wetland use of Salt Slough flows permitted S2. No increase in wetland use of Salt Slough flows two - without project : tw - with project

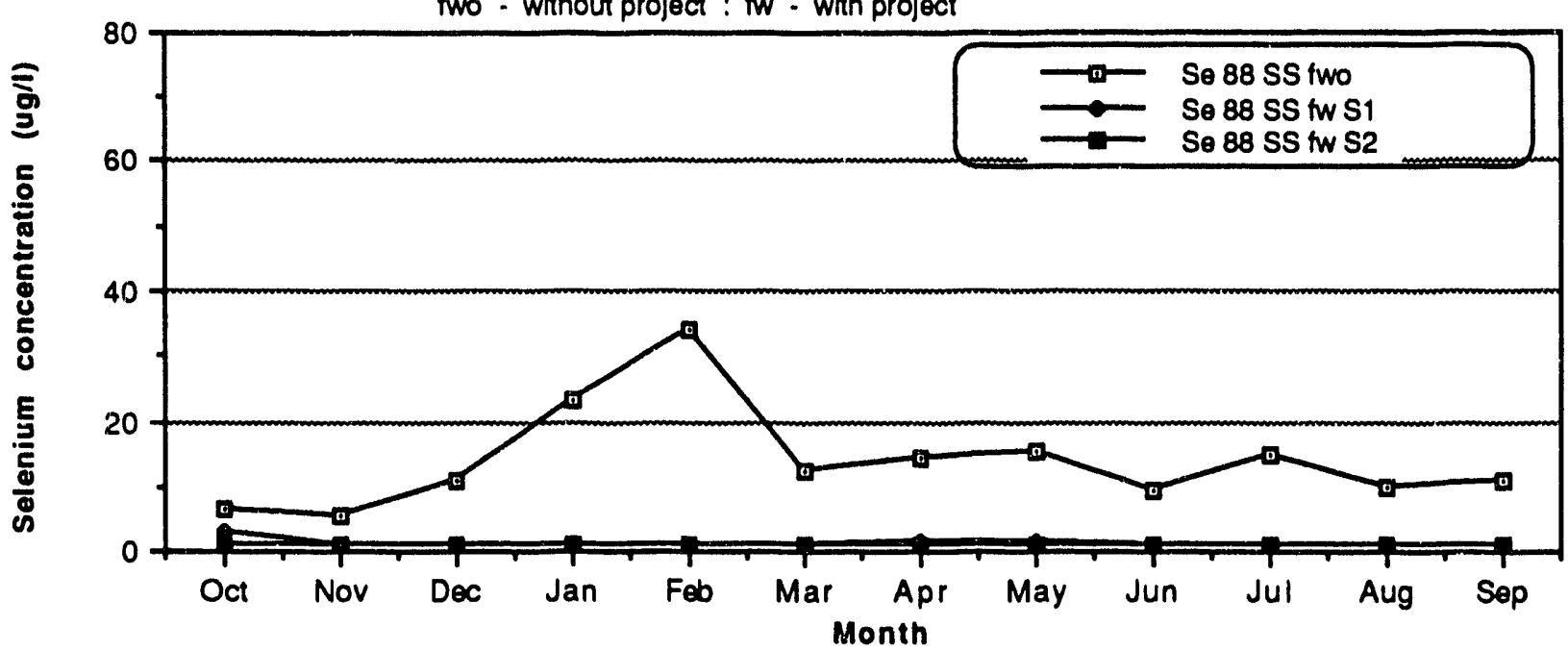

Figure 25. Estimated effect of the project on selenium concentrations in Mud Slough. S1 - Increased wettand use of Salt Slough flows permitted S2 - No increase in wetland use of Salt Slough flows fwo - without project : fw - with project

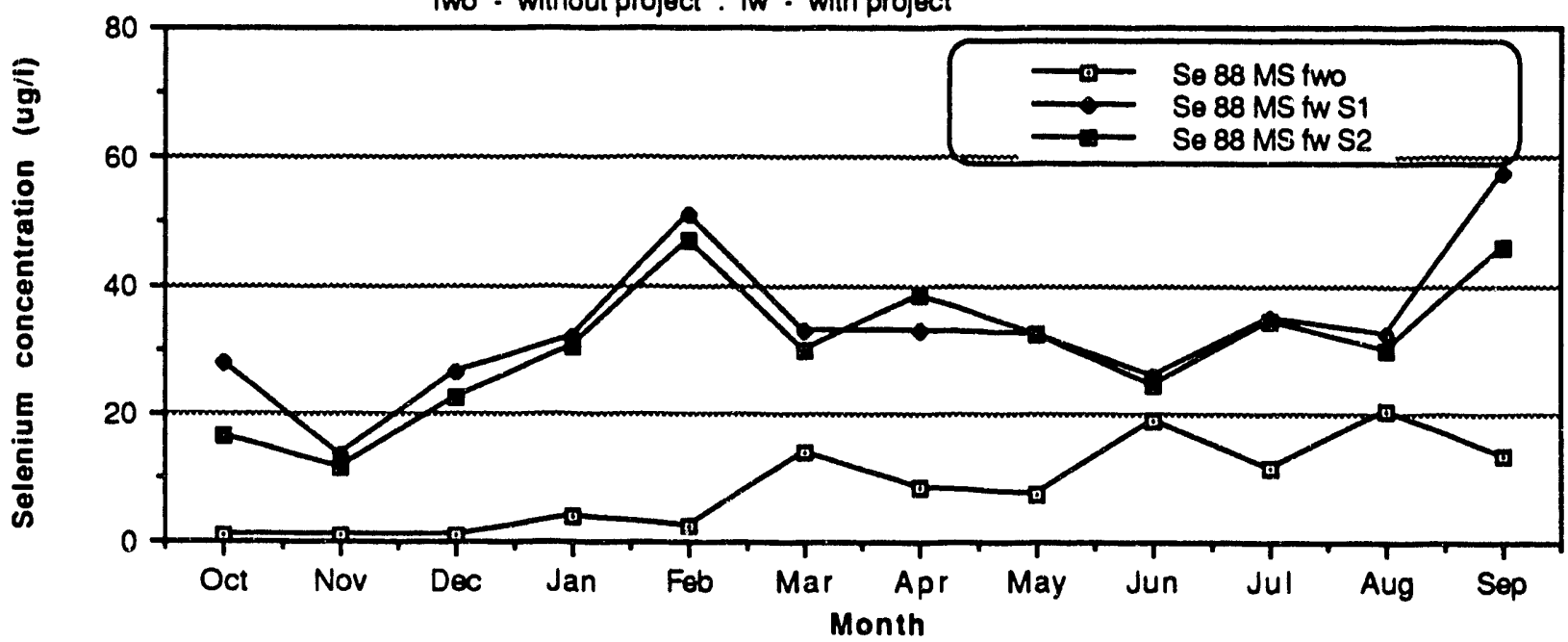

Figure 26. Estimated effect of the prolect on selenium In the San Joaquin River. S1 - Increased wetland use of Salt Slough flows permitted S2 - No increase in wetland use of Salt Slough flows

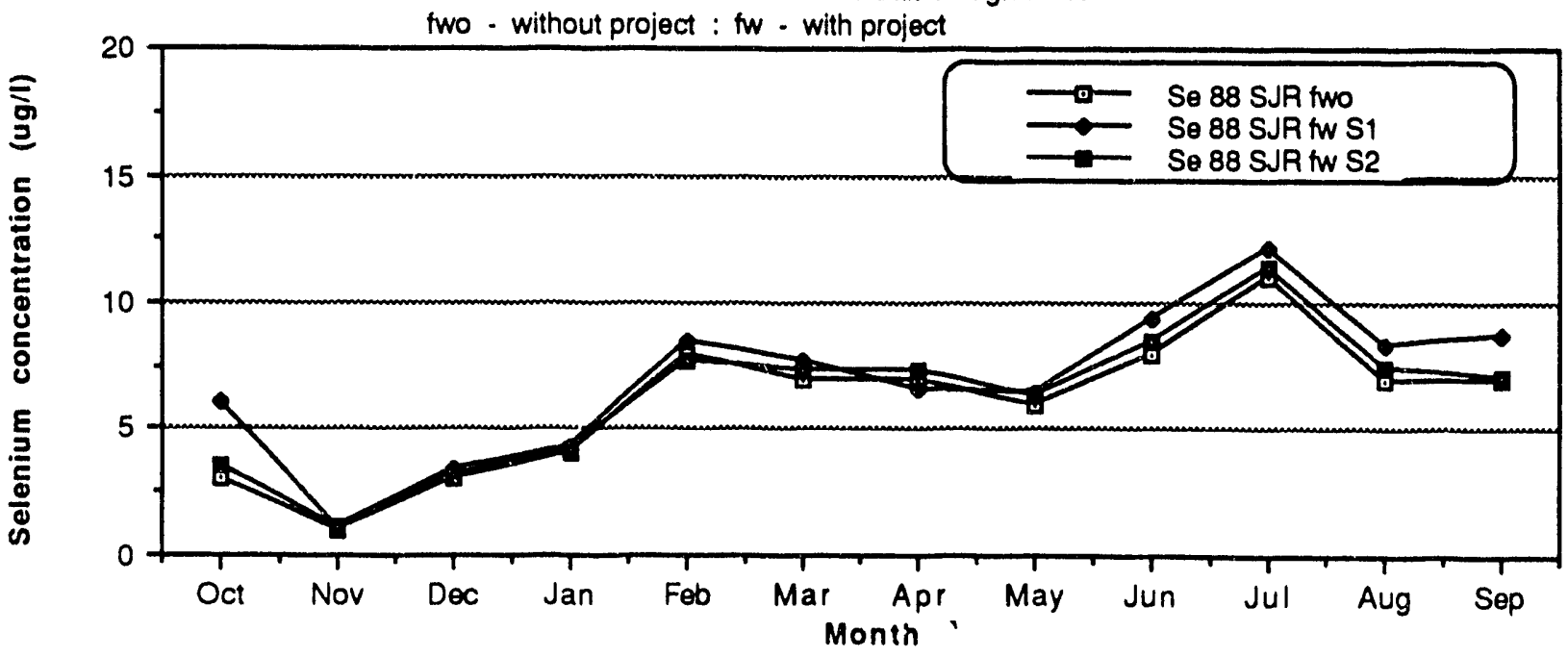


Figure 27. Estlmated offect of projoct on TDS concentratlons in Salt Slough S1 - Increased wettand use of Salt Slough flows permitted

S2 - No increase in wetland use of Salt Slough flows

two - whthout project : fw - with project

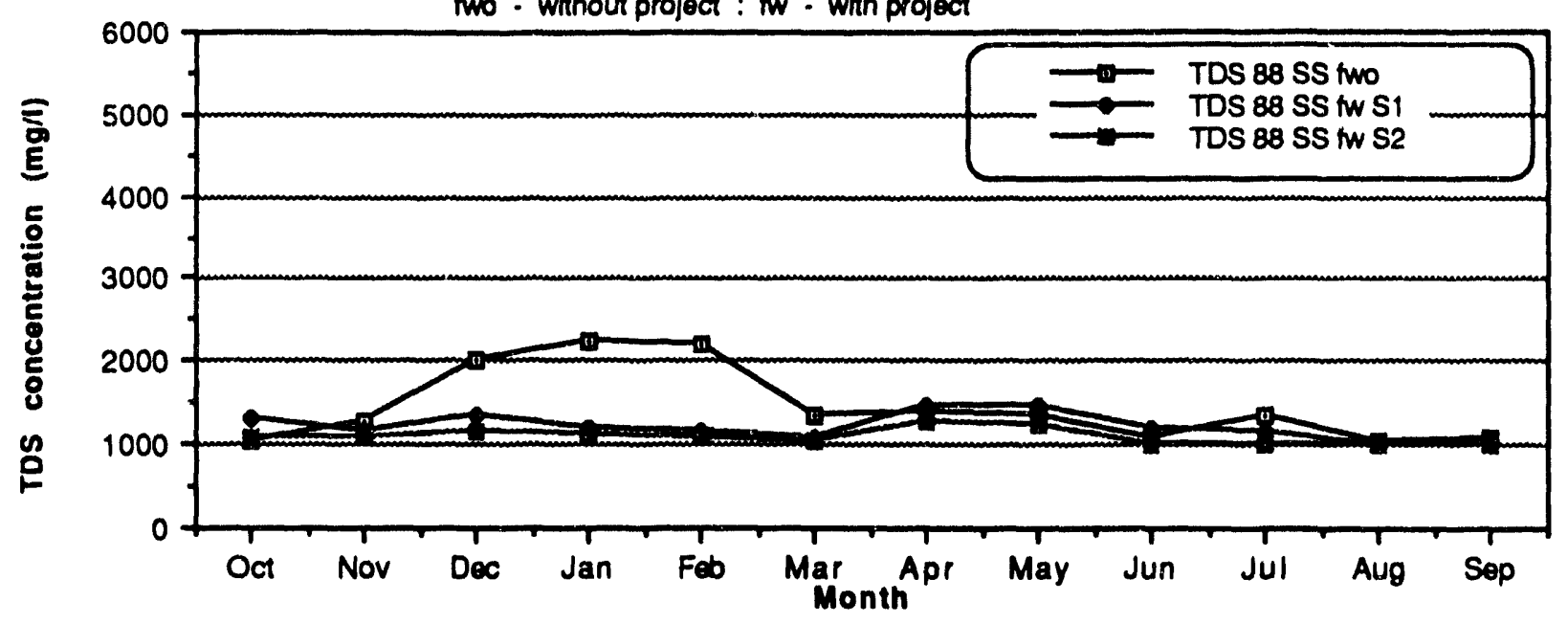

Figure 28. Estimated effect of project on TDS concentration In Mud Slough. S1 - Increased wetland use of Salt Slough flows permitted S2 - No increase in wetland use of Salt Slough flows

fwo - without project : fw - with project

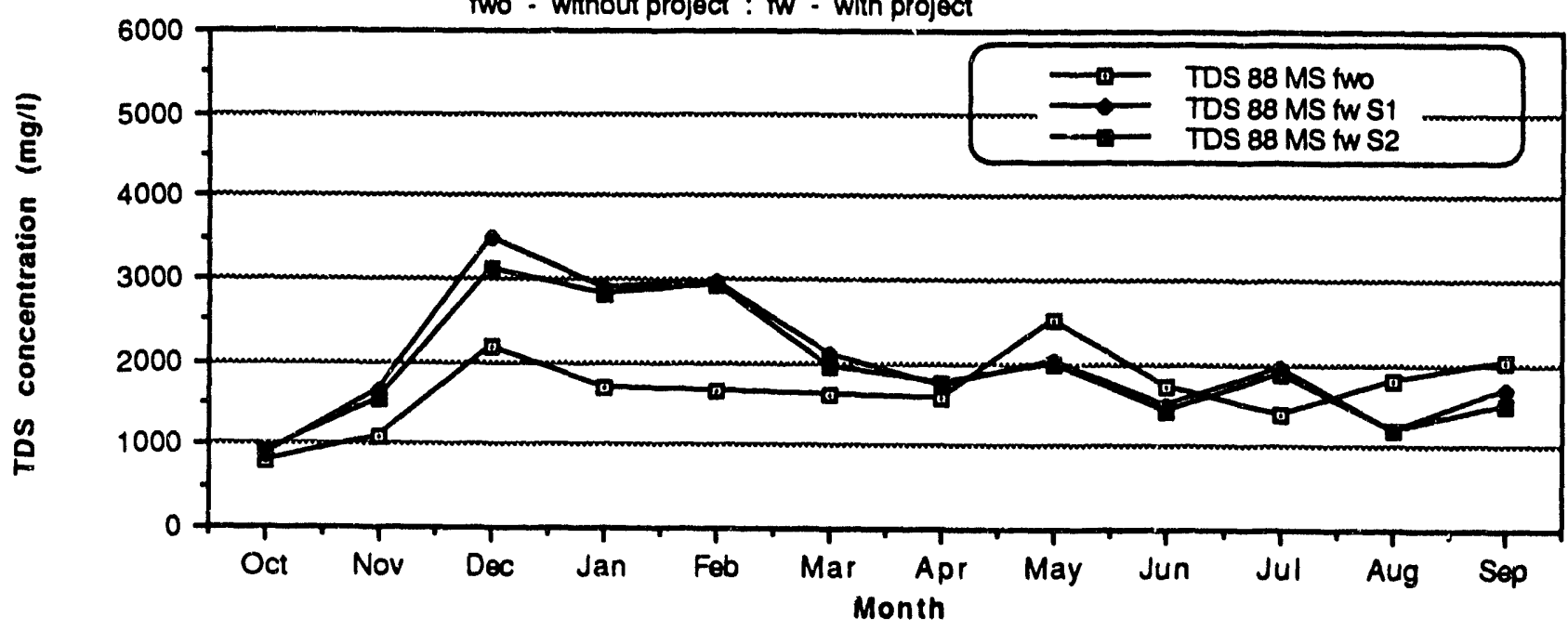

Figure 29. Estimated effect of project on TDS concentrations In the San Joaquin River. Si - Increased wetland use of Salt Slough flows permitted S2 - No increase in wetland use of Salt Slough flows

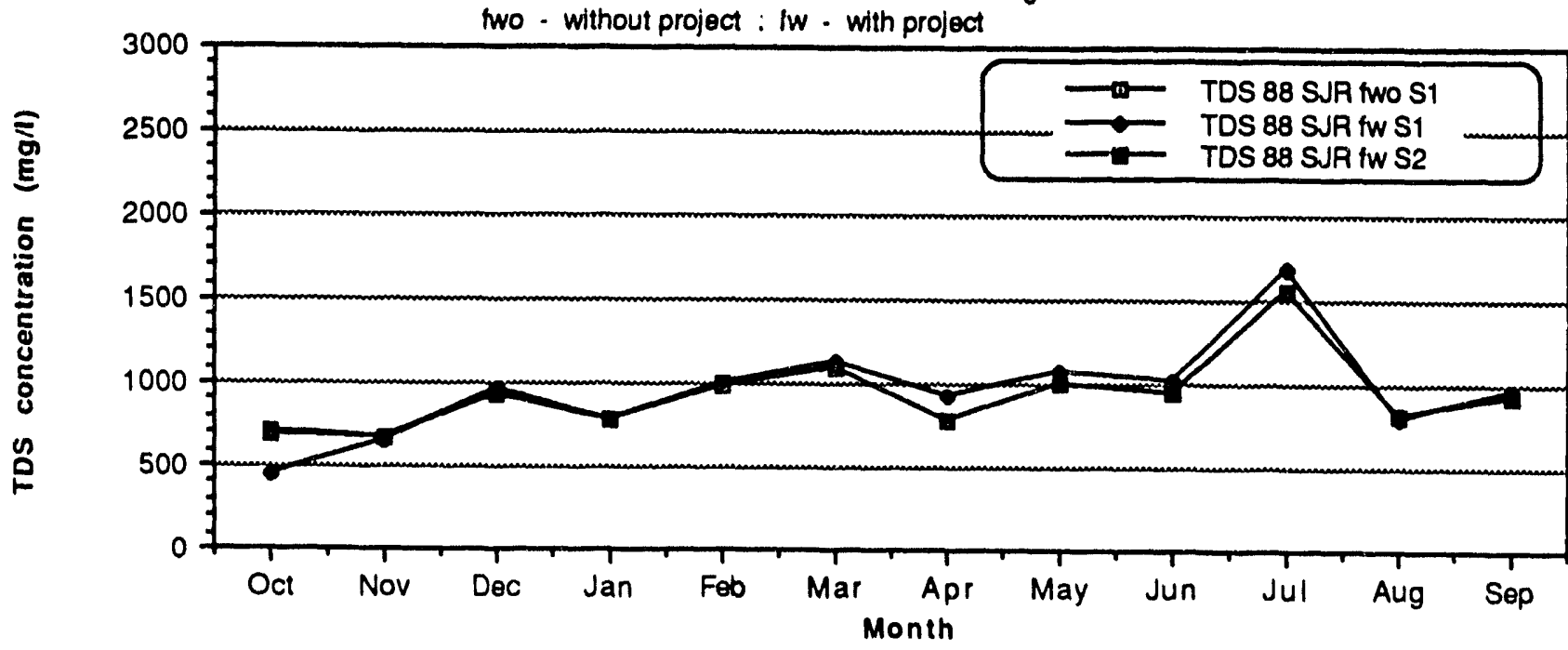


Figure 30. Estimated offect of project on boron concentrations in Salt Slough S1 - Increased wetland use of Salt Slough flows permitted S2. No increase in wetland use of Salt Slough flows two - without project : tw - with project

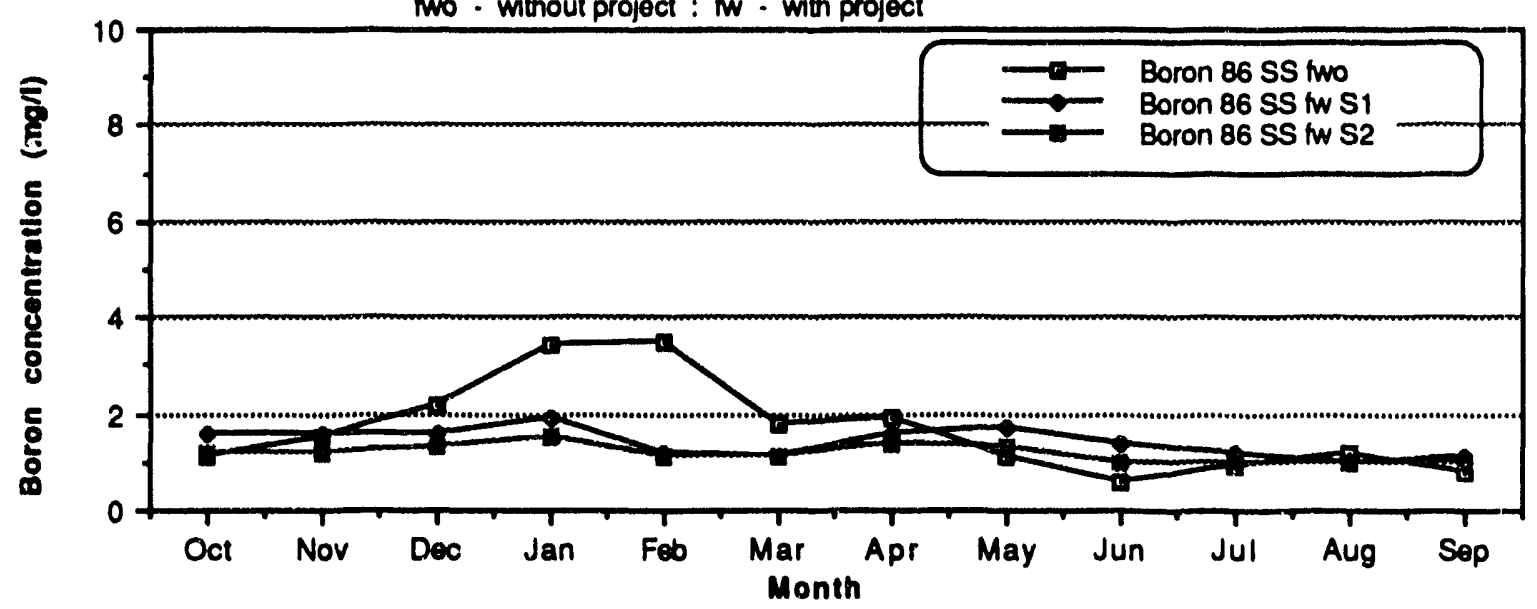

Figure 31. Estimated effect of the project on boron concentrations in Mud Slough

S1 - Increased wetland use of Salt Slough flows permitted

S2 - No increase in wetland use of Salt Slough flows

two - without project : tw - with project

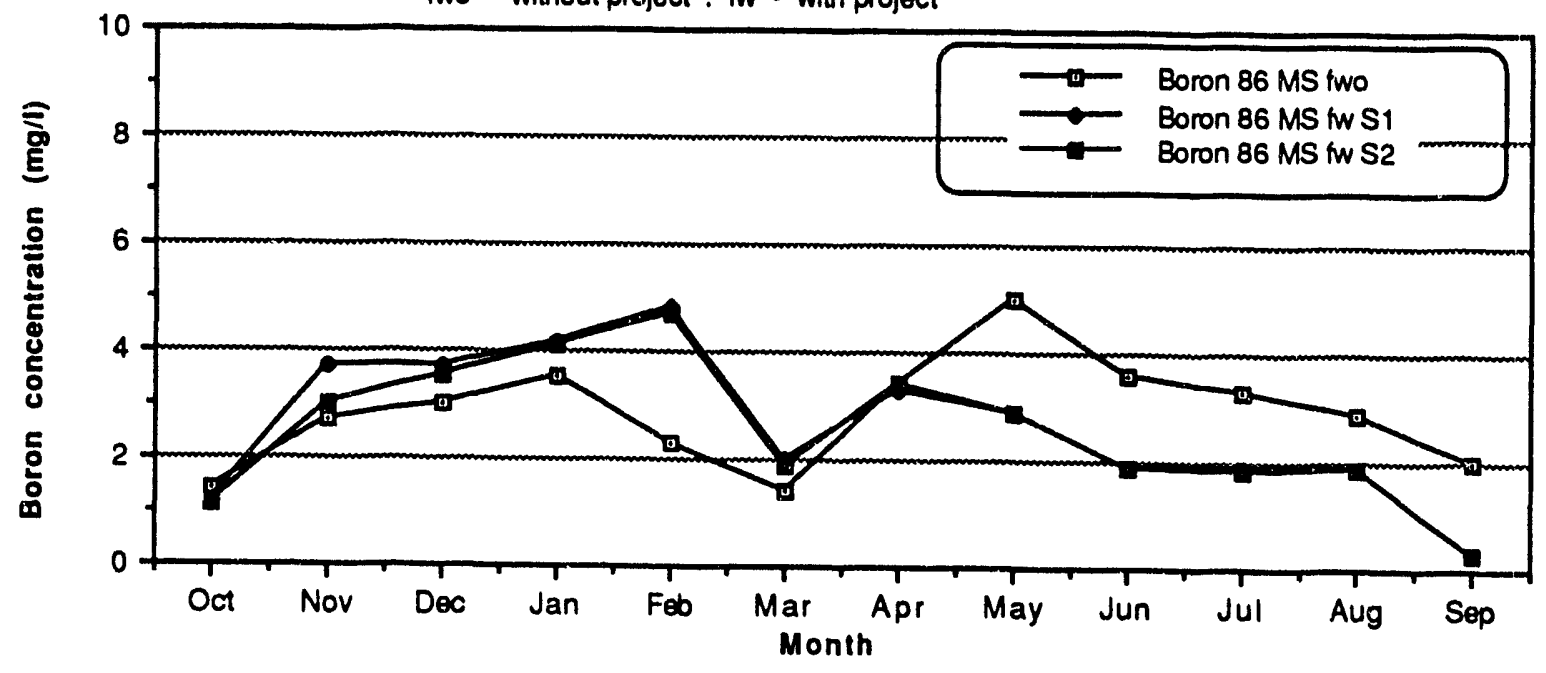

Figure 32. Estimated effect of the project on boron concentrations in the San Joaquin River S1 - Increased wetland use of Salt Slough flows permitted

S2 - No increase in wetland use of Salt Slough flows

two - without project : tw - with project

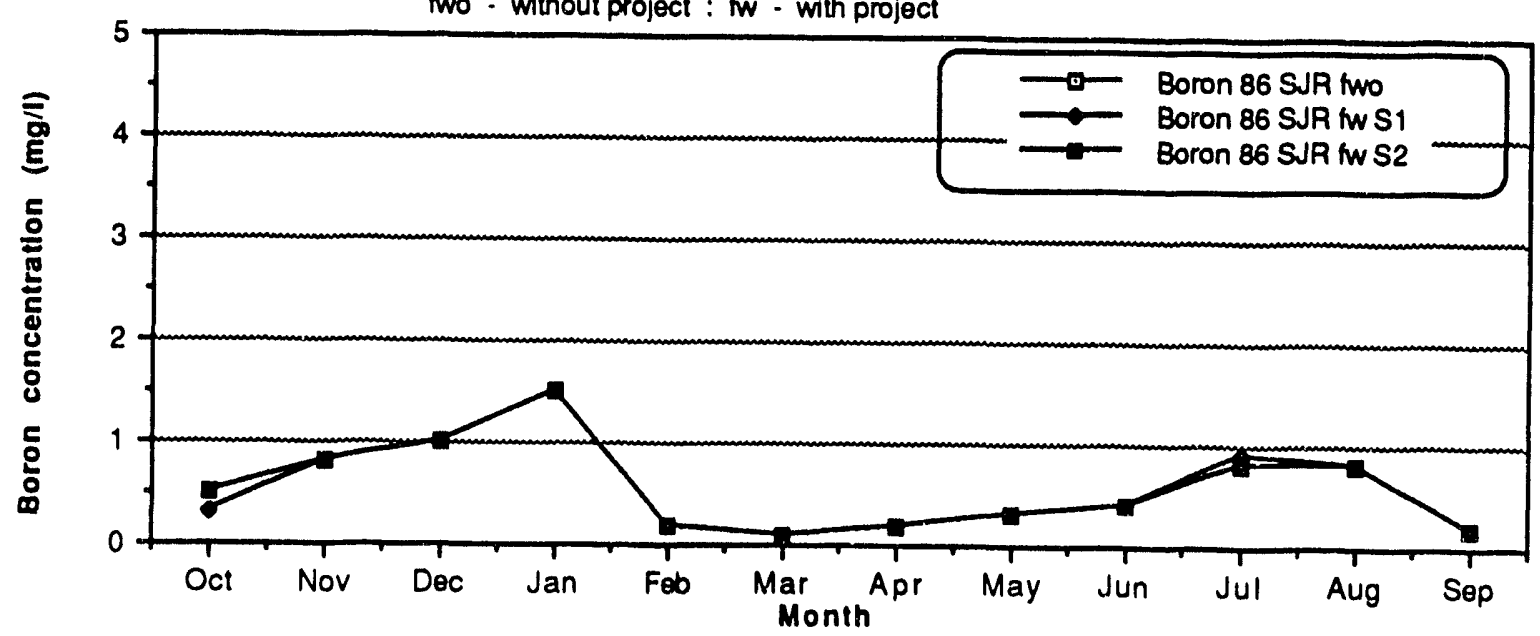


Figure 33. Estimated effoct of the project on selonlum concentrations in Salt Slough S1 - Increased wetland use of Salt Slough flows permitted S2 - No increase in wetland use of Salt Slough flows

two - without project : fw - with project

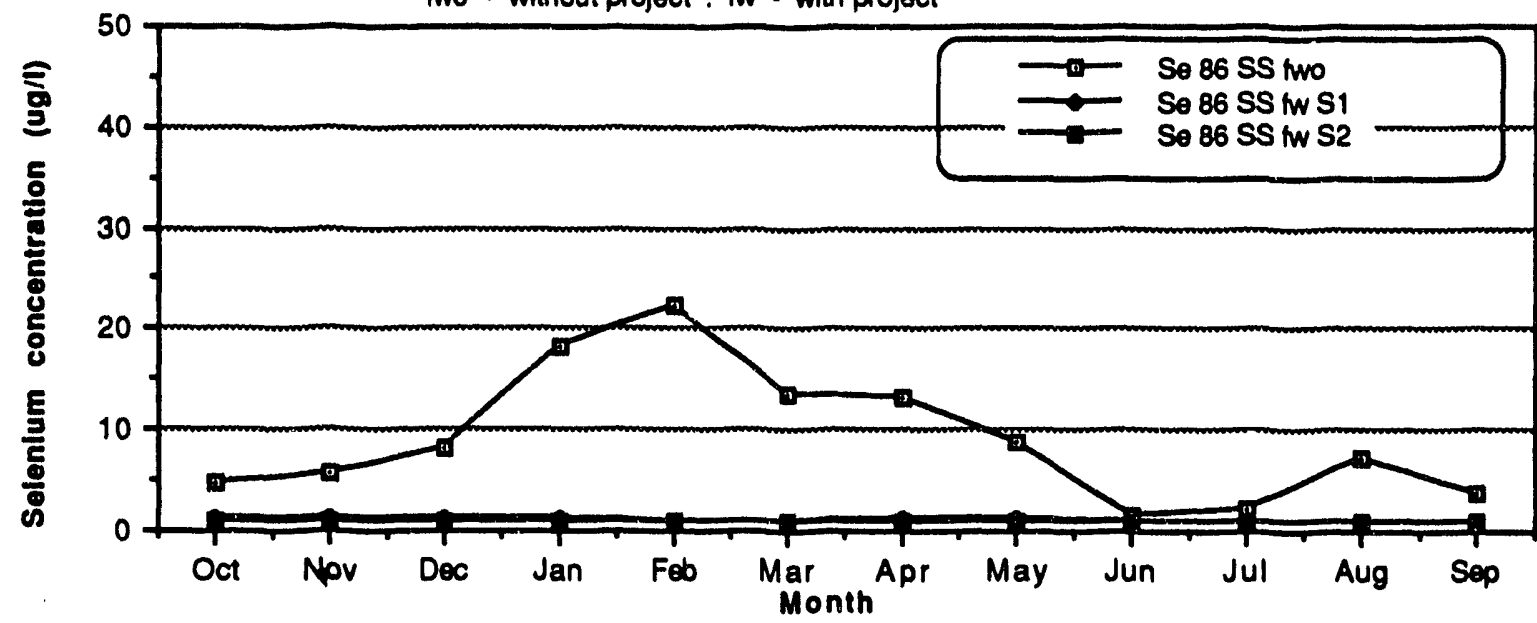

Figure 34. Eatimated effect of the project on selenlum concentrations ir. Mud Slough S1 - Increased wetland uze of Salt Slough flows permitted S2 - No increase in wettand use of Salt Slough flows

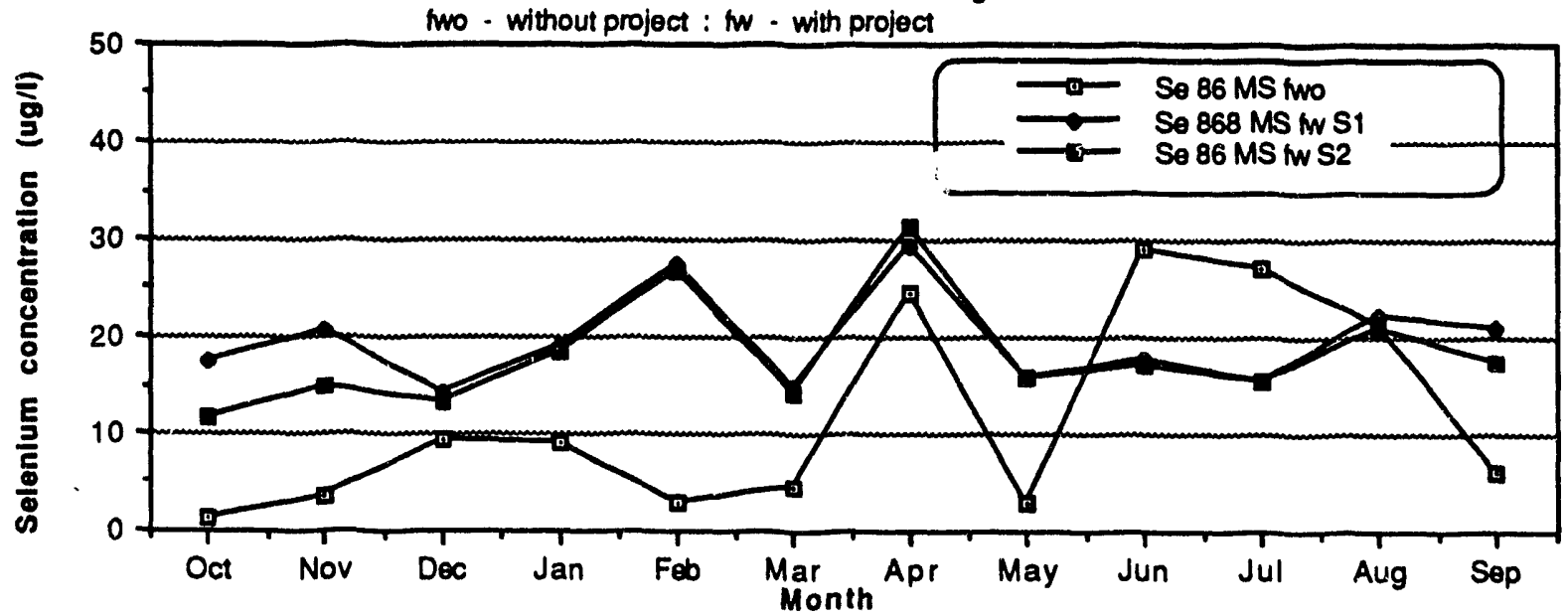

Figure 35. Estimated effect of the project on selenium concentrations in the San Joaquin River. S1 - Increased wetland use of Salt Slough flows permitted S2 - No increase in wetland use of Salt Slough flows two - without project : tw - with project

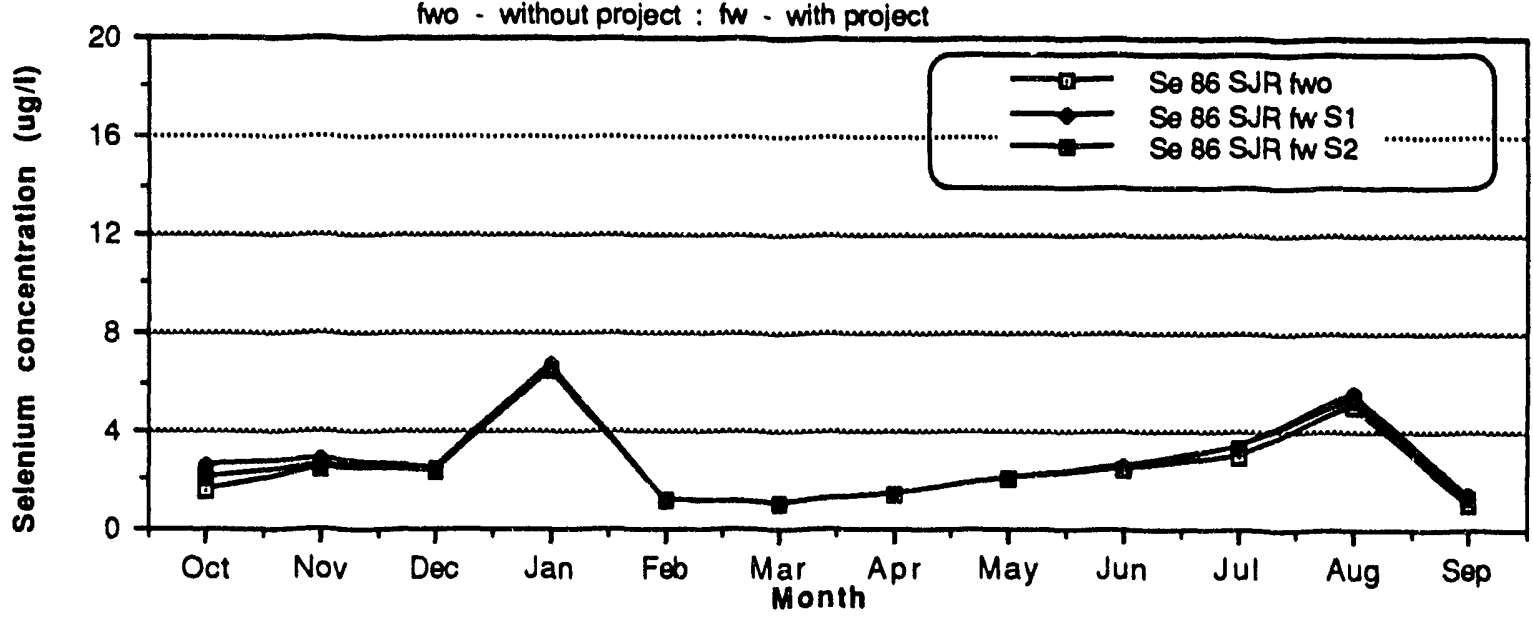


Figure 36. Estimated effect of project on TDS concentrations in Salt Slough. S1 - Increased wetiand use of Salt Slough flows permitted S2 - No increase in wettand use of Salt Slough flows two - without project : tw - with project

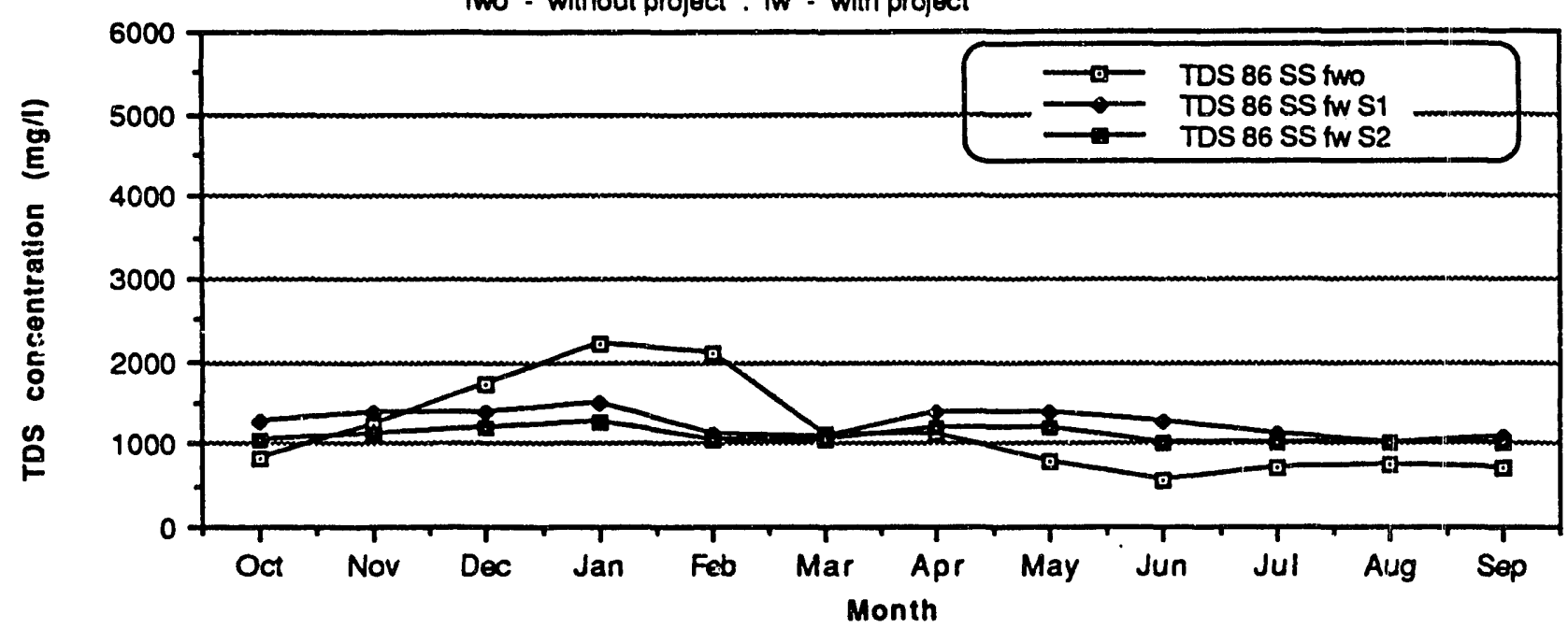

Figure 37. Estimated effect of project on TDS concentrations In Mud Silough. S1 - Increased wetland use of Salt Slough flows permitted S2 - No increase in wetland use of Salt Slough flows two - without project : fw - with project

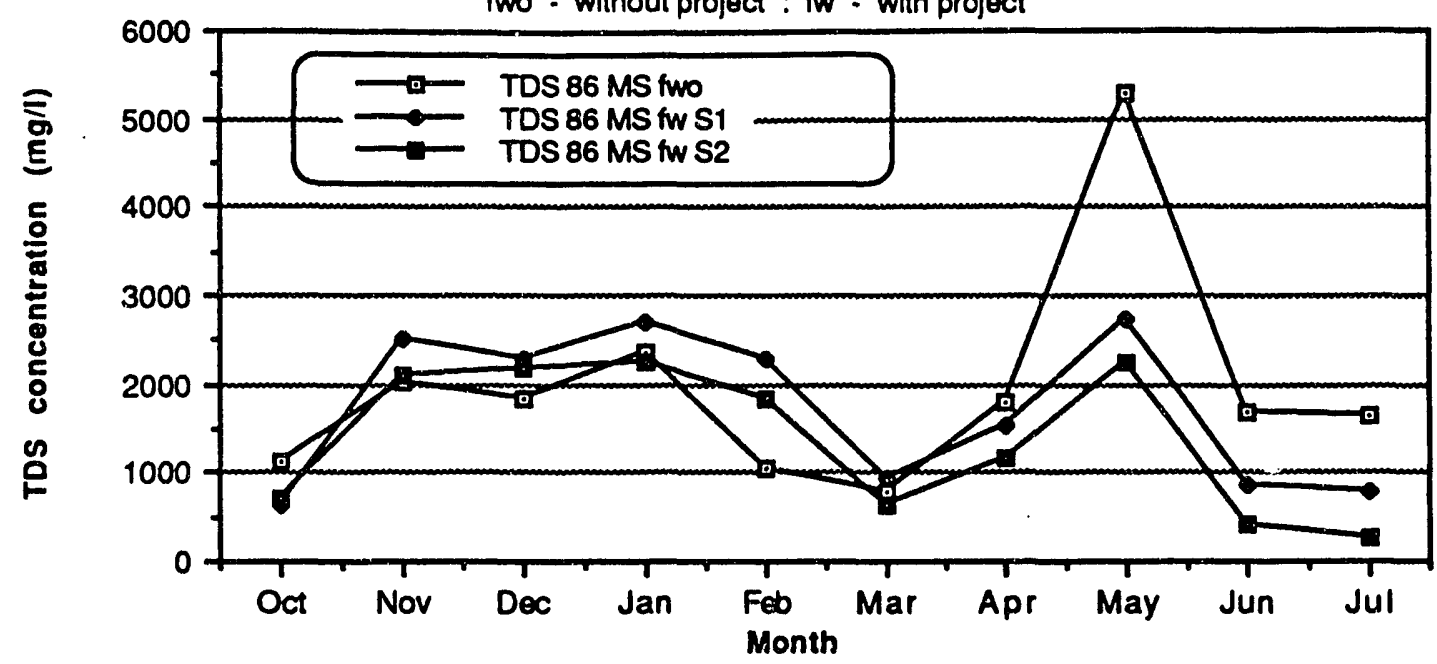

Figure 38. Estimated effect of project on TDS concentrations in the San Joaquin River. S1 - Increased wetland use of Salt Slough flows permitted S2 - No increase in wetland use of Salt Slough flows

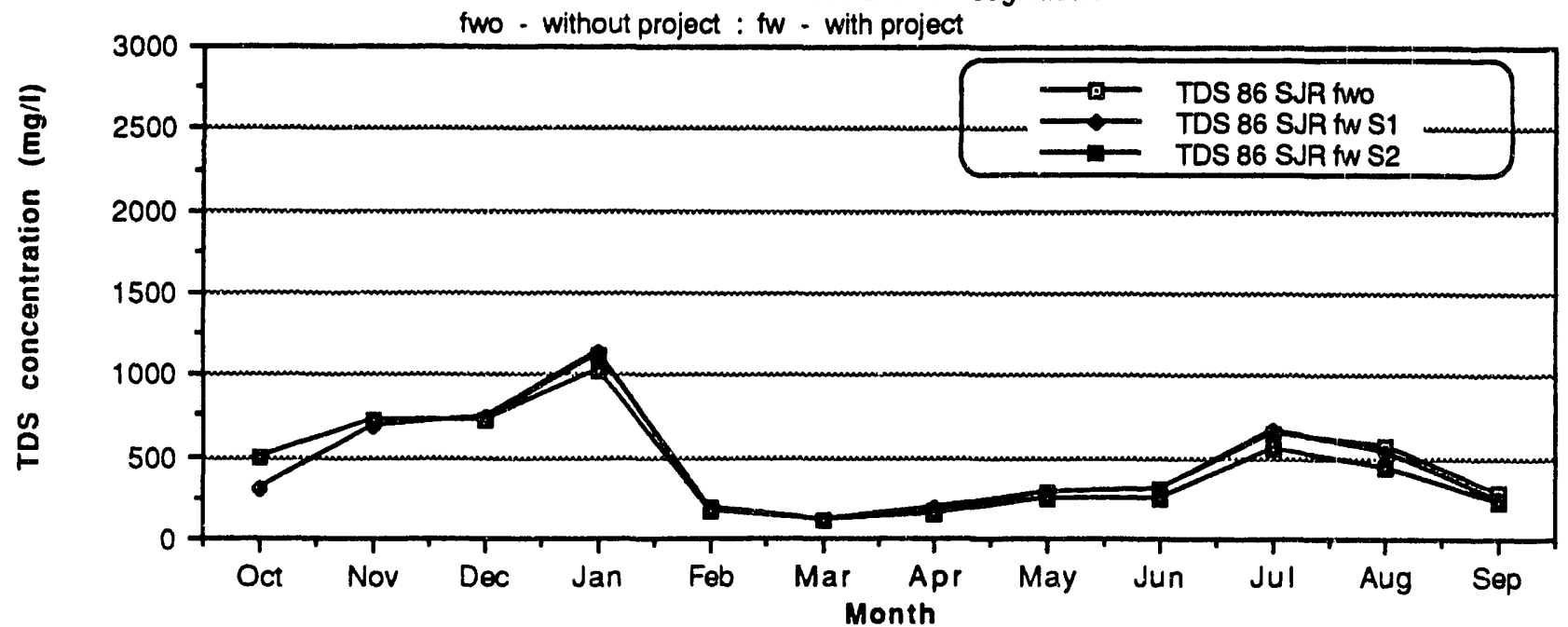


December, January ard February and by more than $50 \%$ in the months of March through October. The peak concentrations between January and March in Mud Slough, that result from the project, appear to offset the high concentrations of selenium in the without project scenario, in Salt Slough. Mud Slough concentrations resulting from Scenario 1 are, in most months, elevated over selenium concentrations for Scenario2, due to evaporative concentration of selenium in the ponded wetlands. In the San Joaquin River selenium concentrations are slightly higher for each month with the project than without the project. This is, in part, due to the assumption that $10 \%$ of the in-transit losses (uptake) of selenium, in the without project scenario, were added to the selenium load for the with-project scenarios. A $\mathrm{n}$ uptake assumption of $0 \%$ for selenium would result in a smaller increase in San Joaquin River selenium concentrations. A $51 \%$ uptake assumption for selenium, on the other hand, would result in much higher San Joaquin River selenium concentrations, relative to the without project scenario and the other with-project scenarios.

\subsubsection{6 data}

The 1986 data presented in Figure 34 shows a marked difference from the 1988 data in the concentration of selenium in Mud Slough as a result of the project. In 1988, the peak concentrations in February and September are $50.8 \mathrm{ug} /$ and $57.4 \mathrm{ug} / \mathrm{l}$ - in 1986, the February and September selenium concentrations are $27.3 \mathrm{ug} /$ and $21.1 \mathrm{ug} /$ respectively. The unusually high runoff in March and April of 1986 , combined with the high selenium load in wetland releases during April and May may help to explain the sawtooth nature of Figure 34 between February and

June. In contrast to 1988, selenium concentrations are lower in June and July in Mud Slough, with the project, than without the project. Inspection of the San Joaquin River selenium concentration at Newman for these two months shows little difference between the without and the with project scenarios. The likely result of the lower Mud Slough selenium concentrations associated with the project is therefore the wetland releases of 4600 acre-ft and 3900 acre-ft during the months of June and July, which helped to dilute seienium levels in Mud Slough flows.

In 1986, a wel year, the effect of the project scenarios 1 and 2 on selenium concentrations in the San Joaquin River is smaller than experienced during 1988, a critically dry year. As for boron, the lower selenium concentrations in the combined agricultural return flows entering the Grassland area during 1986 helps to reduce the overall water quality impact of the project.

\subsection{Effect of proposed project on TDS concentrations}

The analysis of mass loading in to and out of the Grassland area suggests that there was no significant net accumulation of salts in the Grassland. Hence the major impact of the project would be a reapportioning of the TDS loads to Mud and Salt Sloughs, with a resulting change in the average monthly TDS concentrations and loads in the Sloughs. In the case of Salt Slough this is due to increased wetland diversions of Salt Slough flows.

\subsubsection{8 data}

Figure 28 shows that TDS concentrations in Mud Slough could increase by as much as $80 \%$ in December, to approximately $3500 \mathrm{ppm}$, and increase by between $30 \%$ and $80 \%$ between the months of November through March. 
The salinity of the flows generally are reduced after April due to the increased volume of water released from wetlands storage into Mud Slough.

The major benefit of the project in Salt Slough would appear between the months of December and March, when the TDS concentrations are reduced by between $25 \%$ and $50 \%$ of those levels representative of conditions without the project. This period corresponds with the highest expected increase in Mud Slough TDS concentration. One of the effects of the project on contaminant levels in the San Joaquin River near Newman would be an average annual increase in TDS concentrations. In Figure 29, the average estimated increase in TDS concentration is 3.5\%, from a mean value of $928 \mathrm{ppm}$ without the proposed project, $10960 \mathrm{ppm}$ with the project. This small increase in concentration is a direct effect of increased consumptive use of water and storage of salts within the wetlands in the Grassland area. These return flows typically have concentrations of $1000 \mathrm{ppm}$ TDS when diverted to the wetland areas and $1600 \mathrm{ppm}$ when they are returned as drainage flows in the spring. The timing of these releases has a direct bearing on their TDS upon discharge to Mud and Salt Sloughs. Increasing levels of evaporation from the wetlands, as mean daily temperatures rise during the early Spring, can elevate concentrations of TDS, boron and selenium. Although the increase in TDS concentrations of return flows from these wetlands can be largely explained by the process of evapoconcentration of salts, part of this increase could also result from increased levels of organic materials suspended in the return flows, a fraction of which would be salts.

\subsubsection{6 data}

Figures 36 and 37 summarize the effect of the project on TDS in Salt and Mud Sloughs respectively. Figure 36 shows the same trend as Figure 27, with lower TDS concentrations in Salt Slough in the October - March period offset by higher TDS concentrations during the same period in Mud Slough. The last two months of data are not included in Figure 37 - since both were negative and hence unrealistic. Hence the August and September numbers in Figure 38 may also be in error. The negative numbers result from the calibration procedure and may arise from either (a) unreliable monthly TDS estimates from monitoring data or (b) a poor assumption for the TDS concentration of the flows used in the flow adjustment procedure during calibration. Scenario 1 produces higher TDS concentrations in both Salt and Mud Sloughs than in the case of Scenario 2.

As expected, and consistent with the boron analysis, the effect of the project on TDS in the San Joaquin River is less marked in the wet year (1986) than in the critically dry year (1988).

\subsection{Effect of the proposed project on the maintenance of water quality objectives}

Figures 39, 40, 41 and 42 show monthly variations in boron and selenium concentrations in the San Joaquin River for the years 1986 and 1988 for the without and the with project conditions. The wet and critically dry year objectives for Mud and Salt Sloughs and the San Joaquin River were previously described in Section 1.6.

Mud and Salt Slough Objectives :

boron $2 \mathrm{ppm}$ monthly mean $\quad 5.8 \mathrm{ppm}$ maximum $\quad$ (CVRWQCB 88-195) 
$\begin{array}{lll}\text { selenium } & 10 \mathrm{ppb} \text { monthly mean } & 26.0 \mathrm{ppb} \text { maximum } \\ \text { (CVRWQCB 88-195) }\end{array}$

San Joaquin River Objectives near Newman (CVRWQCB 88-195):

boron $\quad 0.8 \mathrm{ppm}$ monthly mean March 15 - September 15

$1.0 \mathrm{ppm}$ monthly mean September $16-$ March 14

$1.3 \mathrm{ppm}$ monthly mean critically dry year

selenium $5 \mathrm{ppb}$ monthly mean

$8 \mathrm{ppb}$ monthly mean critically dry year

For 1988 the boron objective of $1.3 \mathrm{ppm}$ for the San Joaquin River (critically dry years) is violated in March, June and July both with the project, under scenarios 1, 2 and 3 and without the project. In all cases scenario 2, in which Salt Slough flows are diverted for use on wetlands, shows the highest boron concentrations. The selenium objective for the San Joaquin River of $8 \mathrm{ppb}$ (critically dry year) is exceeded once without the project and five times under scenario 2. For Scenario 2, in which Salt Slough is not utilized, the objective is violated twice, in both June and July. For Scenario 3, which allows for the provision of additional tailwater return flows, equal to the volume that would be taken from Salt Slough and used in wetlands, only one violation of the SWRCB objective occurs. Although there is a large difference in the number of monthly violations between the with (Scenario 1) and without project scenarios, inspection of Figure 40 shows that the objective for selenium concentrations is very close to being violated without the project in both February and June.

In 1986 the boron and selenium objectives for the San Joaquin River at Newman are lower and are violated only once without the project, in January, and twice with the project (Scenario 1) - in January and July for boron, and in January and August for boron (Figures 41 and 42). Both Scenario 2 and Scenario 3 result in a lower frequency of exceeding the boron and selenium objectives than Scenario 1. Unlike the 1988 hydrologic year there are very small differences between the scenarios in the case of boron and only small differences in the case of selenium. The large volume of San Joaquin River flow in the spring months tends to dampen the effect of the much smaller volume of boron and selenium contaminated retum flows.

Table 11. is a summary of the frequency of exceeding the SWRCB objectives for both selenium and boron for both 1988 and 1986 hydrologic years. This table should be used with Figures 21 - 40 to assess the magnitude by which the objective was exceeded or how the close the objective was to being exceeded in any one month. Inspection of the monthly frequency of exceeding the objectives for Salt and Mud Sloughs shows that the sum of monthly violations for both Sloughs actually decreases for each of the with-project Scenarios. The water quality data for 1988 and 1986 for Salt Slough shows that the SWRCB objectives were violated five times in 1988 and three times in 1986 for boron; the objectives were violated eight times in 1988 and four times in 1986 for selenium. By diverting most of the subsurface agricultural drainage flows to Mud Slough, in each of the with-project scenarios, violations of the SWRCB objectives in Salt Slough are largely eliminated. However, as was shown in Figures 21 38, the resulting Mud Slough concentrations of boron and selenium not only violate the objectives with greater 
Figure 39. Estimated effect of boron concentration In the San Joaquin River (1988 - critically dry year)

S1 - Increased wetland use of Salt Slough flows permitted

S2 - No increase in wetland use of Salt Slough flows

S3 - No increase in wetland use of Salt Slough flows : Additional water supply supplied.

fwo - without project : fw - future-with project

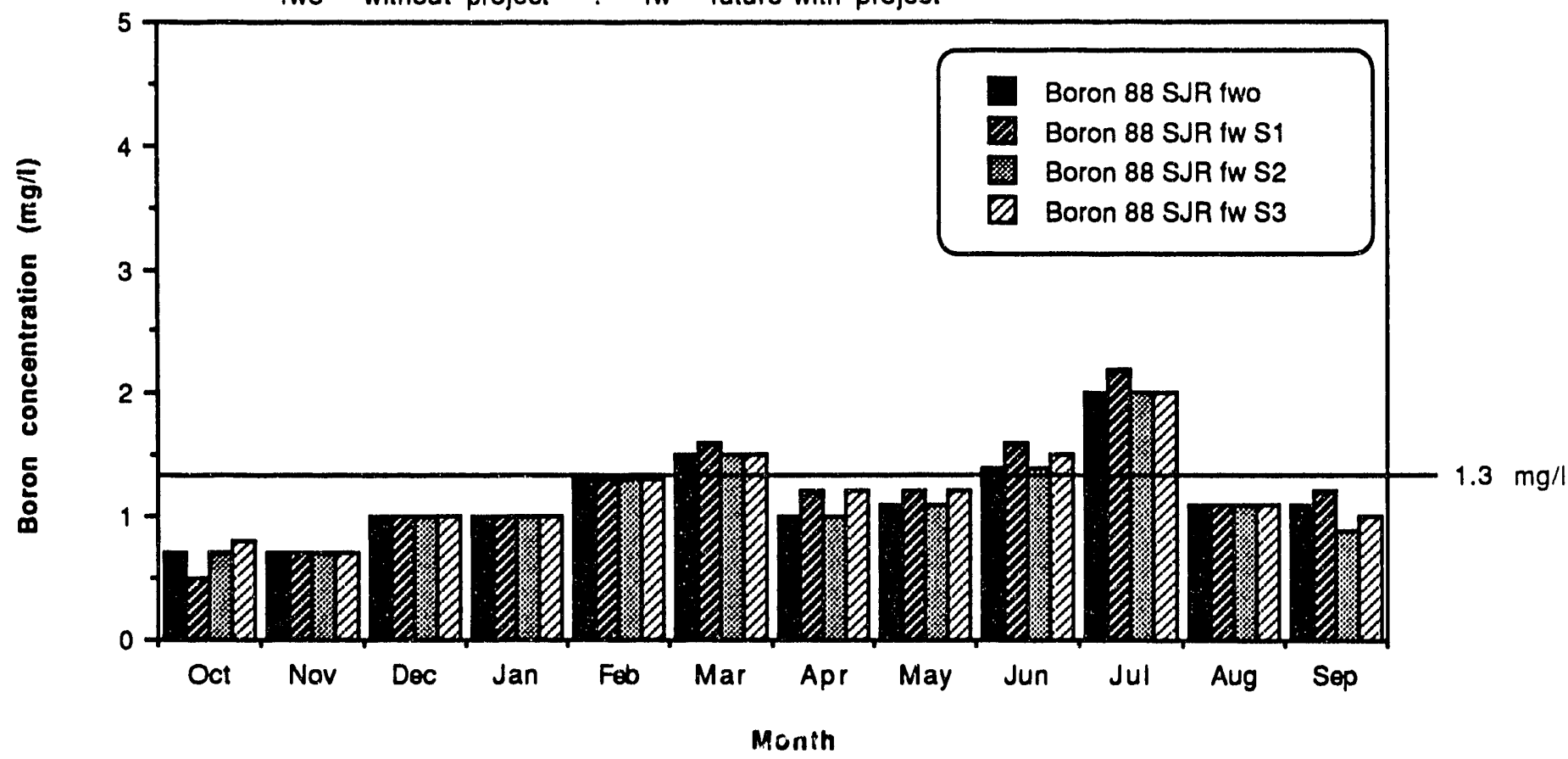

Figure 40. Rstimated effect of project on selenlum concentrations in the San Joaquin River. (1988 - critically dry year)

S1 - Increased wetland use of Salt Slough flows permitted

S2 - No increase in wetland use of Salt Slough flows

S3 - No increase in wetland use of Salt Slough flows : Additional water supply supplied.

fwo - without project : tw - future-with project

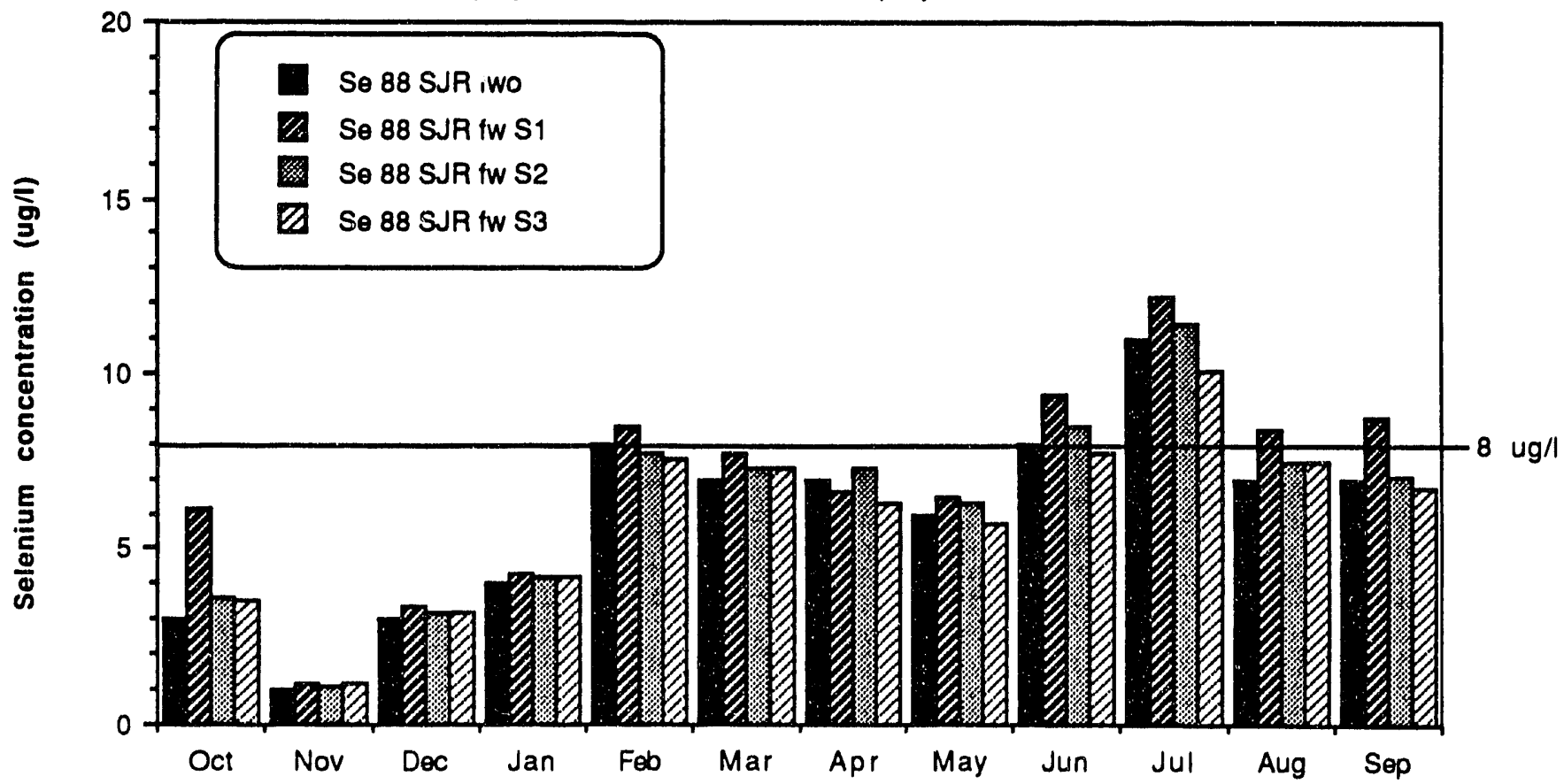

Month 
Figure 41. Estimated effect of boron concentration In the San Joaquin River. (1986 - wet year)

S1 - Increased wetland use of Salt Slough flows permitted

S2 - No increase in wetland use of Salt Slough flows

S3 - No increase in wetland use of Salt Slough flows : Additional water supply supplied. fwo - without project : fw - future-with project

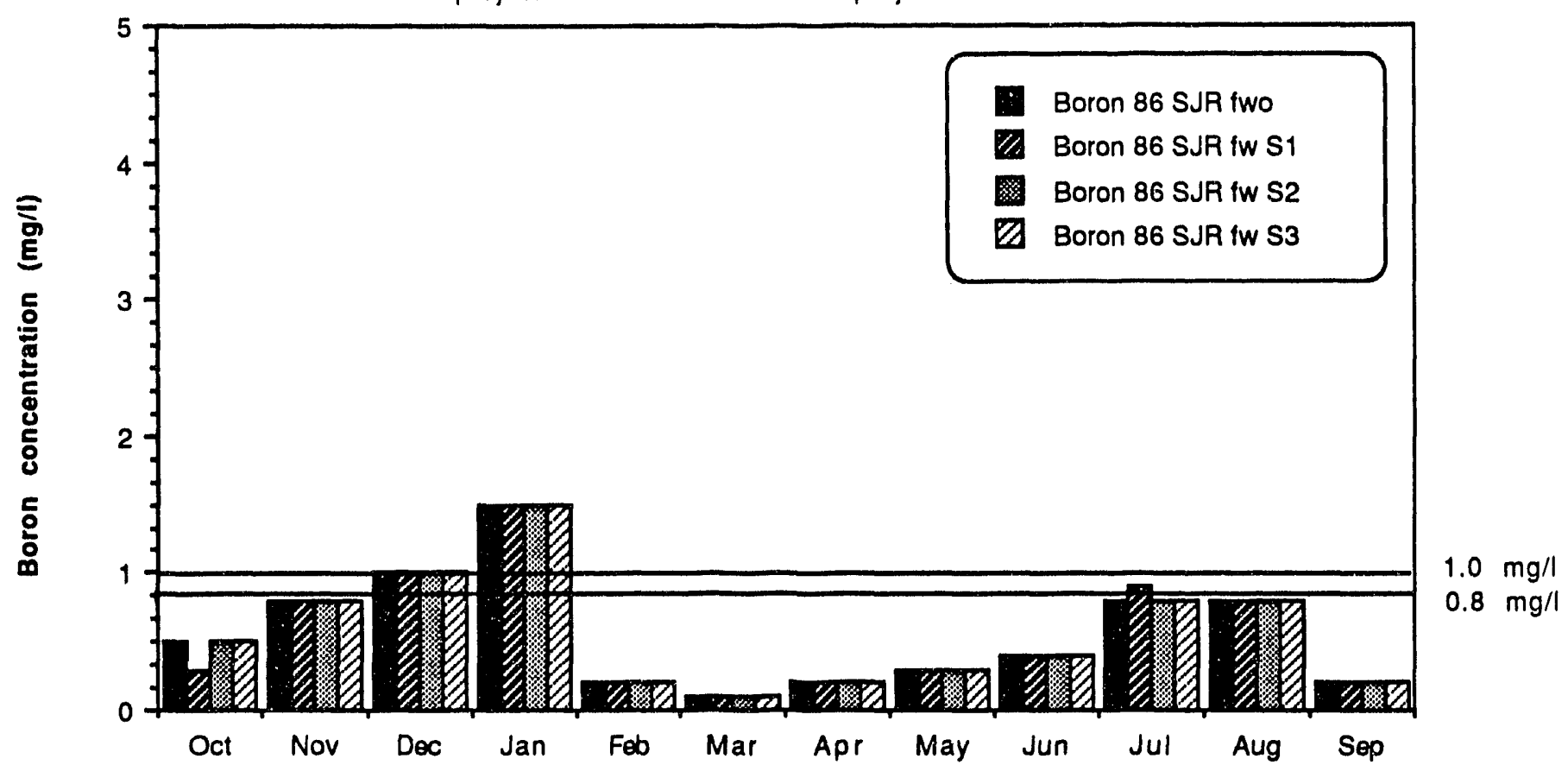

Month

Figure 42. Estimated effect of project on selenium concentrations in the San Joaquin River. (1986 - wet year)

S1 - Increased wetland use of Salt Slough flows permitted

S2 - No increase in wetland use of Salt Slough flows

S3 - No increase in wetland use of Salt Slough flows : Additional water supply supplied. fwo - without project : iw - future-with project

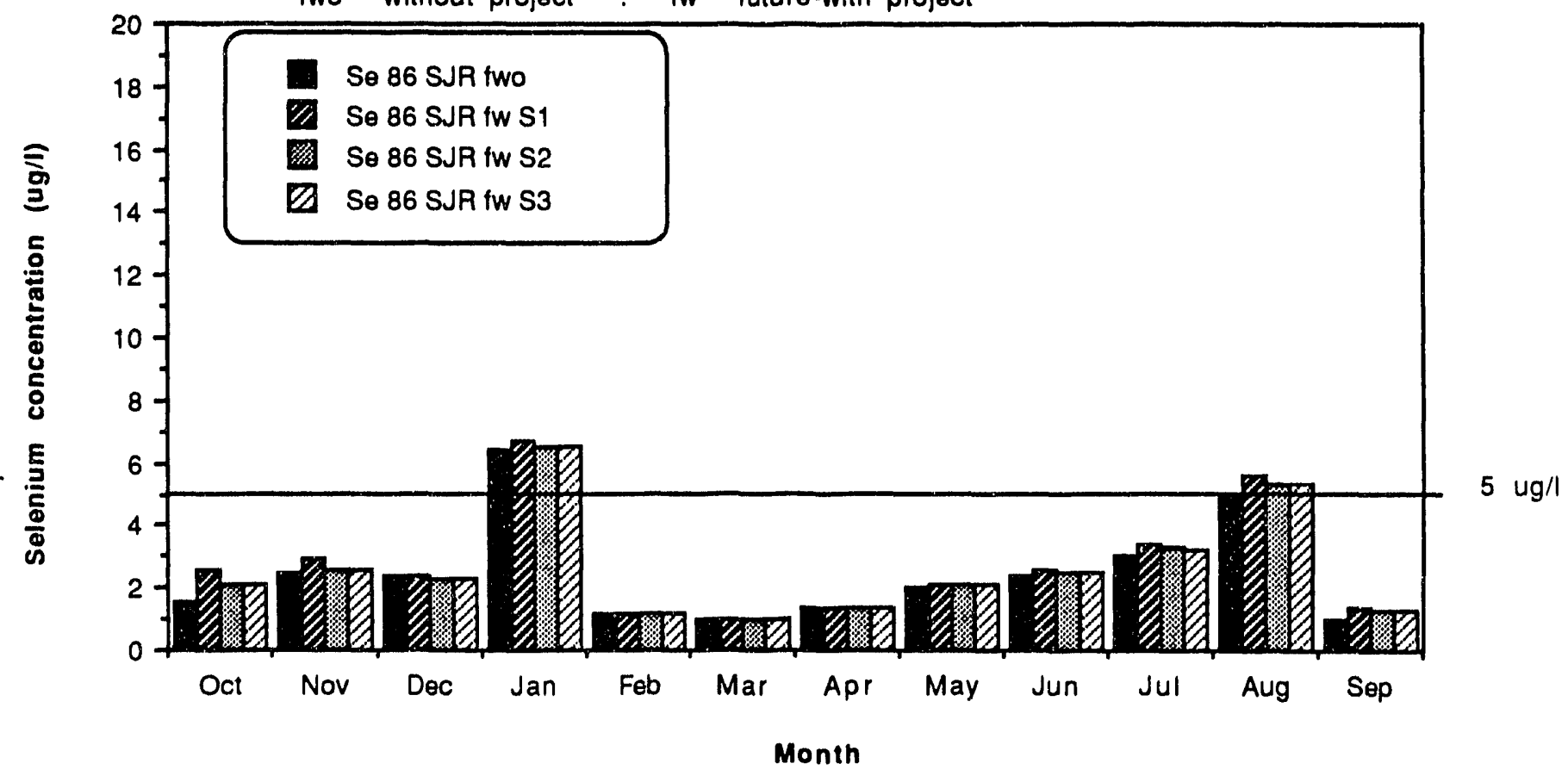


frequency, but also exceed more frequently the $5.8 \mathrm{ppm}$ and $26.0 \mathrm{ppb}$ maximum concentration limits, set by the CRWQCB for boron and selenium respectively. The maximum boron concentration of $5.8 \mathrm{ppm}$ was not exceeded in either 1988 or 1986, in the without project scenario, whereas it is exceeded once in Mud Slough, in Scenario 1. The maximum selenium concentration of $26.0 \mathrm{ppb}$ was exceeded once in 1988 (Salt Slough) and twice in 1986 (Mud Slough) for the without project scenario. In Scenario 1 this maximum concentration was exceeded in Mud Slough ten times in 1988 and twice in 1986.

\subsection{Effect of the proposed project on boron and selenium loads}

The major difference between each of the project scenarios 1,2 and 3 is in the use of Salt Slough flows and in the release pattern of wetland returm flows. Table 12. is a summary of the boron and selenium loads for the San Joaquin River at Newman expressed as load-flow factors and taken from column 33 of the spreadsheet analysis. The conversion factor to change load flow factors to tons of boron and to pounds of selenium appears below Table 12.

Inspection of Table 12. shows that boron loads generated by the project are not significantly different between Scenarios 1 and 2 and the without project scenario. The largest difference of 2700 AF-ppm between Scenario 2 and the without project scenario in 1988 is equivalent to an annual difference of 3.7 tons of boron. A larger difference occurs between Scenario 3 and the without project scenario - in this case 53,800 AF-ppm, which is equivalent to 73.2 tons of boron annually. In Scenario 3, the boron load contained in the additional water supply supplied to wetlands, accounts for the higher boron load. It should be noted that the assumption was made that this water was of the same quality as the return flows from SJVDP water quality zones B and C. However, since this increased load is associated with higher return flows down Mud and Salt Slough, the overall effect on boron, selenium and TDS concentrations in the San Joaquin River was very small, as was shown in Figures 39 - 42 The higher runoff and return flows generated in 1986 account for the approximately $25 \%$ - 30\% difference in annual boron loading between the two years.

The assumption that was made regarding selenium uptake in the Grassland area account, in large part for the differences between the project scenarios 1, 2 and 3 and the without project scenario. Again, the increased selenium load contained in the additional water supply accounts for the differences in total annual load between Scenario 3 and Scenarios 1 and 2. The largest difference in selenium loading between the Scenarios 1 and 3 in 1988 (90.8 lbs) is smaller than the difference between Scenario 1 and the without - project scenario for 1988 (415.8lbs). This contrasts with $149.6 \mathrm{lbs}$ between Scenarios 1 and 3 and $445.8 \mathrm{lbs}$ for the without - project scenario in 1986.

\subsection{Options for restoring the San Joaquin River to pre-project conditions for boron, selenium and TDS}

A number of options exist to mitigate the effect of the project on the San Joaquin River. These options fall into two major categories : (a) those options that reduce the load of contaminants in agricultural return flows from SJVDP water quality zone A; and (b) those options which provide supplemental flows of fresh water for blending 


\begin{tabular}{|c|c|c|c|c|c|c|c|c|c|c|c|}
\hline \multirow{10}{*}{ 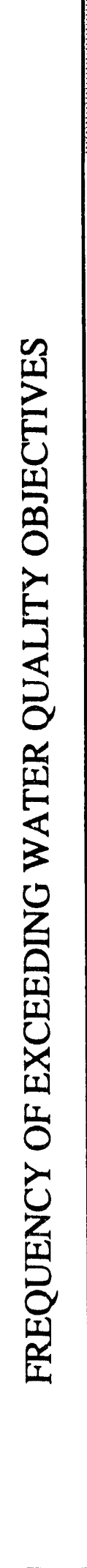 } & \multirow{5}{*}{ (a) } & \multirow{4}{*}{ 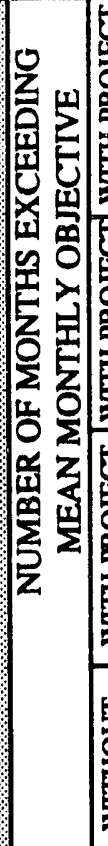 } & 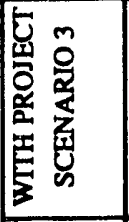 & & 0 & $\simeq$ & - & & 0 & $\approx$ & - \\
\hline & & & 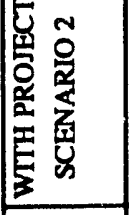 & & 0 & $\cong$ & $N$ & & 0 & $\simeq$ & $N$ \\
\hline & & & 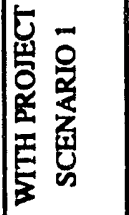 & & 0 & $\simeq$ & $n$ & & 0 & $\simeq$ & $N$ \\
\hline & & & $\begin{array}{l}5 \\
5 \\
0 \\
0\end{array}$ & & $\infty$ & $n$ & - & & $\nabla$ & $N$ & - \\
\hline & & 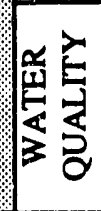 & 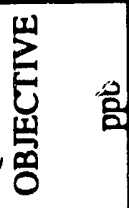 & & 오 & 으 & $\infty$ & & 오 & 으 & $n$ \\
\hline & \% & 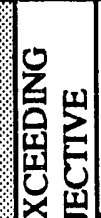 & 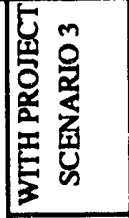 & & 0 & $\exists$ & $m$ & ? & 0 & 0 & - \\
\hline & z. & 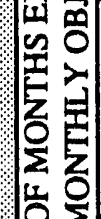 & 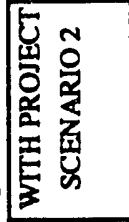 & i. & 0 & 인 & $m$ & & 0 & 0 & - \\
\hline & $\mid \begin{array}{l}\alpha \\
z \\
u \\
z \\
z \\
u \\
z\end{array}$ & 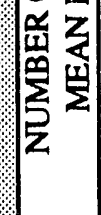 & 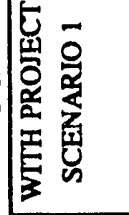 & 19. & 0 & $a$ & $m$ & & 0 & 0 & $N$ \\
\hline & 容 & & 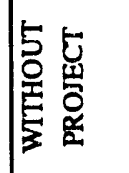 & 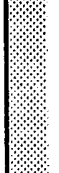 & $n$ & 요 & $m$ & & $m$ & $n$ & - \\
\hline & $1 \%$ & 委 & 密 & & 范 & $\stackrel{ }{i}$ & $\dddot{2}$ & & $\stackrel{i}{i}$ & $\stackrel{\text { i }}{\text { in }}$ & 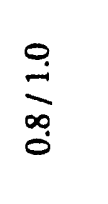 \\
\hline & $\frac{1}{4}$ & 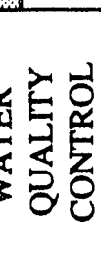 & 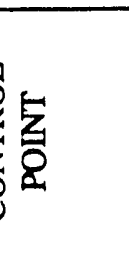 & 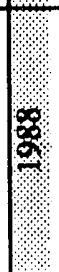 & 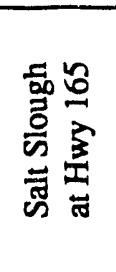 & 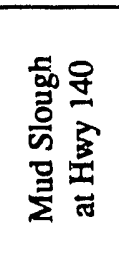 & 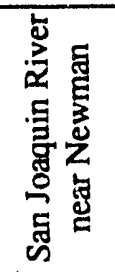 & 8 & 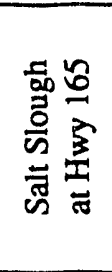 & 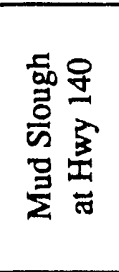 & 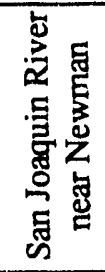 \\
\hline
\end{tabular}




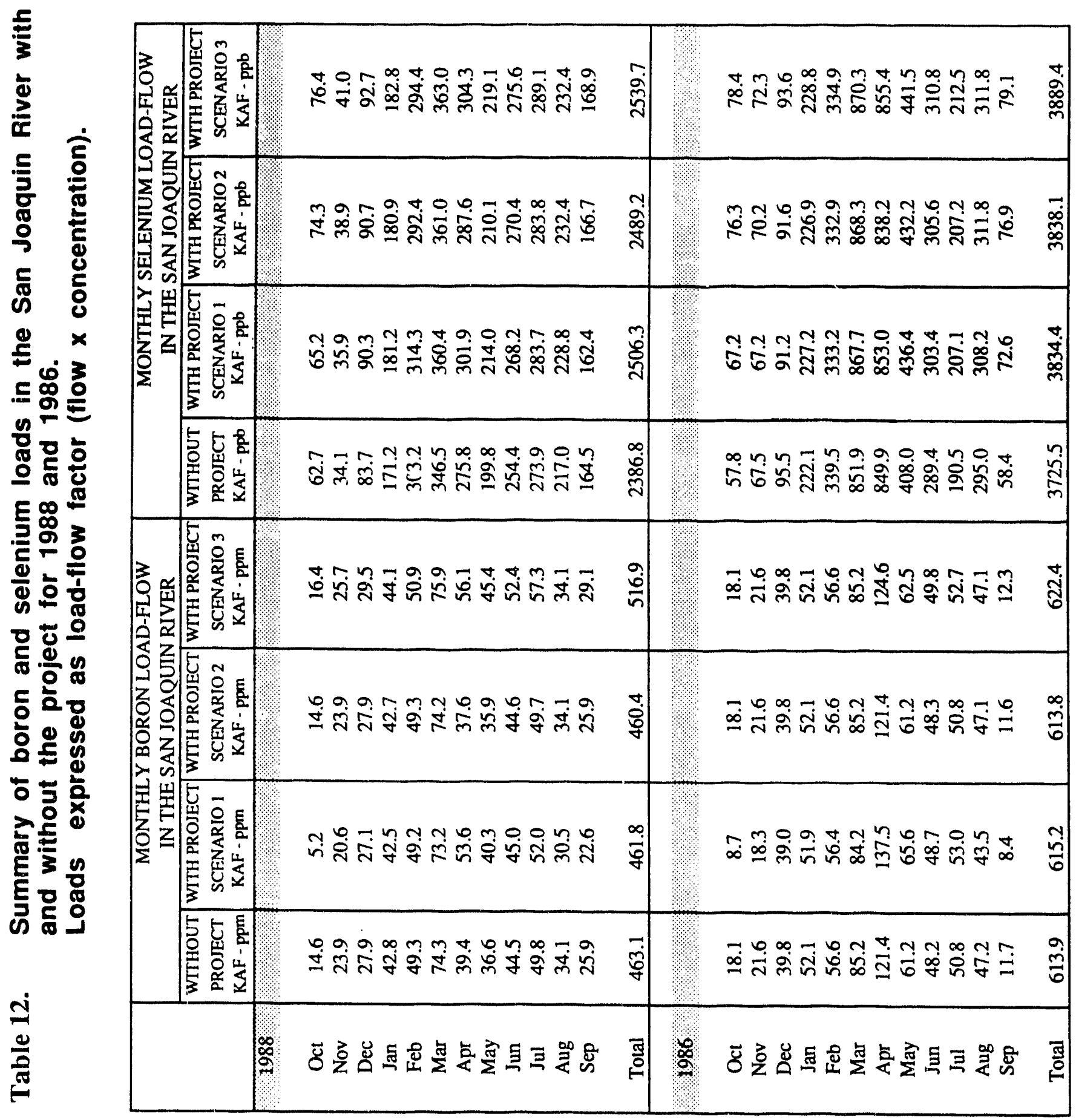


purposes during those periods when water quality either exceeds the without-project concentration or exceeds the State Water Resources Control Board objectives for selenium and boron.

(a) On-farm water management options for controlling drainage at its source include water conservation through adoption of improved irrigation and drainage technologies, tail water and subsurface drainage recycling and changes in agronomic practices. Some of these options may result in little change in contaminant load, such as can happen with subsurface drainage recycling, whereby a reduction in subsurface agricultural drainage flows is associated with an increase in the contaminant concentration of these flows. Improved management practices, aided by the current proposed project, could increase flexibility of water delivery and discharge operations and hence enhance the ability to control the timing of contaminated subsurface drainage discharges to Salt and Mud Sloughs and to the San Joaquin River. Current inititiatives by the SWRCB, the CRWQCB and the San Joaquin River Management Program to measure real-time flow and water quality data at designated monitoring stations along the San Joaquin River should substantially enhance information flow between river managers and the upslope agricultural water districts, making it easier to meet San Joaquin River water quality objectives.

(b) Supplemental flows, provided for blending with contaminated flows within Mud Slough to improve water quality in the San Joaquin River, could potentially be aquired from a number of sources depending on the availability of water supplies, the ability to pay for the water and the ability to convey water from the diversion point to the place of delivery. The Federal and State Project facilities to the west of the Grassland area can provide Delta water through the Delta Mendota,Canal or the Califormia Aqueduct or by transfer along the Main or Outside Canals, water supplies can also be made available along the San Joaquin River, either through releases from Mendota Pool or through some future reoperation of Friant Dam. Additional surface return flows from SJVDP water quality zones B and C, which currently return to the river via Orestimba Creek, if available, could also be used for blending purposes, though the higher boron and TDS concentrations in these return flows would increase the volume of this supply that would be needed for blending purposes. Timing of supplemental water supplies for blending would rely heavily on a real-time monitoring system for provision of water quality information and flexible and coordinated water supply management by the State and Federal Water Purveyors and the Grasslands Water Master.

\subsection{Supplemental water supply requirements to match without-project water quality concentrations and meet SWRCB objectives.}

One means of mitigating the impact of the project is to attempt to restore the San Joaquin River to the same water quality prior to implementation of the project. This is only feasible where the quality of the water used for blending purposes is lower in TDS, boron or selenium concentration than the without project, San Joaquin River concentration. If the water supply has a higher concentration than the target concentration this option would not be feasible, since, theoretically, even an infinite volume of water would fail to exactly satisfy the criterion. In practical 
terms, a very large volume of water could concievably provide sufficient dilution to meet the criterion, owing to numerical round-off, since the SWRCB objective is an integer number in the case of selenium and rounded to the first decimal place in the case of boron .

In Appendices B and C, the supplemental water requirements have been determined for each with-project scenario, for boron, selenium and TDS and for 1988 and 1986 hydrologies. The volume of supplemental (dilution) water was calculated using the following algorithm :

$$
V_{s}=V_{f w}\left(\left(C_{f w}-C_{f w+s}\right) /\left(C_{f w+s}-C_{s}\right)\right)
$$

$\begin{array}{lll}\text { Where : } & \mathrm{V}_{\mathrm{s}} & \text { volume of supplemental water required to match without project conc. } \\ \mathrm{V}_{\mathrm{fw}} & - & \text { flow in the San Joaquin River with the project } \\ \mathrm{C}_{\mathrm{fw}}+\mathrm{s} & - & \text { concentration of the San Joaquin River without the project } \\ \mathrm{C}_{\mathrm{fw}} & - & \text { concentration of the San Joaquin River with the project } \\ \mathrm{C}_{\mathrm{s}} & - & \text { concentration of the supplemental water supply }\end{array}$

Tables 13 - 24 and Figures 43 - 54 show the monthly supplemental water supply needed to (a) restore the San Joaquin River to pre-project concentrations and; (b) meet SWRCB objectives for the San Joaquin River. Preproject conditions are the concentrations reported in column 3 of the spreadsheets. In the case of boron, Scenario 1 and 1988 hydrology, meeting the SWRCB objectives requires a greater volume of supplemental water supply (39,518 acre-ft/year) than the volume required to restore the San Joaquin River to the without-project boron concentration $(28,113$ acre-ft/yr). Tables $13-15$ and Figure 43 also show that only in Scenarios 1 and 3 is supplemental water needed to restore boron concentrations to pre-project concentrations. This result is also true of the 1986 hydrology.

In Figure 44 both the supplemental water requirement and the assimilative capacity of the San Joaquin River is shown. Assimilative capacity is a concept that was utilized by the San Joaquin Valley Drainage Program to describe the maximum contaminant load that the river can accept and still meet the existing Basin Plan water quality objectives for selenium and boron, developed to protect beneficial uses of the San Joaquin River. The assimilative capacity of the San Joaquin River at Newman can be calculated by first reconstructing the flow and calculating the load-flow factor within the San Joaquin River without the contaminated flows from zone A. The reconstructed San Joaquin River flow is multiplied by the Basin plan objectives which produces the maximum allowable load-flow factor. Finally the reconstructed load-flow factor at Newman is subtracted from the maximum allowable load-flow factor to obtain the assimilative capacity. The allowable discharge by drainers is calculated by dividing the allowable load-flow factor by the concentration of each of the contaminants, selenium and boron, for the with-project condition.

The allowable discharge can be calculated using the following algorithm : 


$$
V_{d}=V_{f w}\left(\left(C_{f w} \cdot C_{s W R C B}\right) /\left(C_{S W R C B} \cdot C_{d}\right)\right)
$$

\begin{tabular}{|c|c|c|}
\hline \multirow[t]{5}{*}{ Where : } & $\mathbf{V}_{\mathbf{d}}$ & - volume of discharge allowed without exceeding SWRCB objectives. \\
\hline & $V_{f w}$ & - volume of flow in the San Joaquin River \\
\hline & $C_{\text {sWRCB }}$ & - SWRCB objective for the San Joaquin River at Newman \\
\hline & $C_{\text {fw }}$ & - existing concentration of the San Joaquin River \\
\hline & $\mathbf{C}_{d}$ & - concentration of the discharge into San Joaquin River \\
\hline
\end{tabular}

The assimilative capacity of the river can vary widely between months and between years depending on the flow volume. In the past four years the drought has caused significant reductions in monthly flow volume in the San Joaquin River - hence the assimilative capacity of the river has been relatively low (Figure 44), whereas during 1986, high river flow volumes during the months of February, March and April provided a very large assimilative capacity (Figure 46).

Only by making use of the assimilative capacity of the river can the requirement for supplemental water supply to meet SWRCB water quality objectives be reduced, since, for boron the SWRCB objectives are more restrictive than the requirement to recreate pre-project boron concentrations. To make use of the river assimilative capacity , temporary storage of subsurface agricultural drainage is necessary to permit these drainage discharges to enter the river during those times when flows are high relative to boron loads.

In contrast to boron, the volume of supplemental water required for selenium to restore the San Joaquin River to pre-project conditions is, in most cases, greater than the volume required to meet SWRCB objectives. The magnitude of the supplemental flows are highly dependent on the assumptions made of selenium uptake within the Grassland system. Figure 47 and Tables B10-B16 and C10-C16 in the Appendix show the magnitude of the differences in monthly supplemental water requirement, if the assumption varies between a minimum of $0 \%$ uptake to a maximum of 51\% uptake, using 1988 hydrology. In Figure 47 scenario 1 and scenario 2 are compared as far as the monthly volume of supplemental water supply required to retum the river to pre-project selenium concentrations. Five different levels of selenium uptake are assumed in scenario in the analysis of supplemental water requirements to meet SWRCB objectives. Only the 10\% selenium uptake level is considered in scenario 2. The reader is reminded that "uptake" refers to the total selenium system losses assumed in the without-project scenario that are due to conveyance in the vegetated Grassland channels. It is assumed that these losses do not occur when the project is implemented, hence these losses must be added to selenium load that occurs in the no-action scenario.

In Figure 50 the same range of selenium uptake assumption values is applied to 1986 San Joaquin River hydrology. The high flows in the San Joaquin River during the spring months make it more difficult to match preproject selenium concentrations - hence a much larger volume of supplemental water is required. In several cases where the San Joaquin River selenium concentrations were equal or lower than the assumed selenium concentration of the supplemental water - an infinite volume of supplemental water would be required - an infeasible solution. 


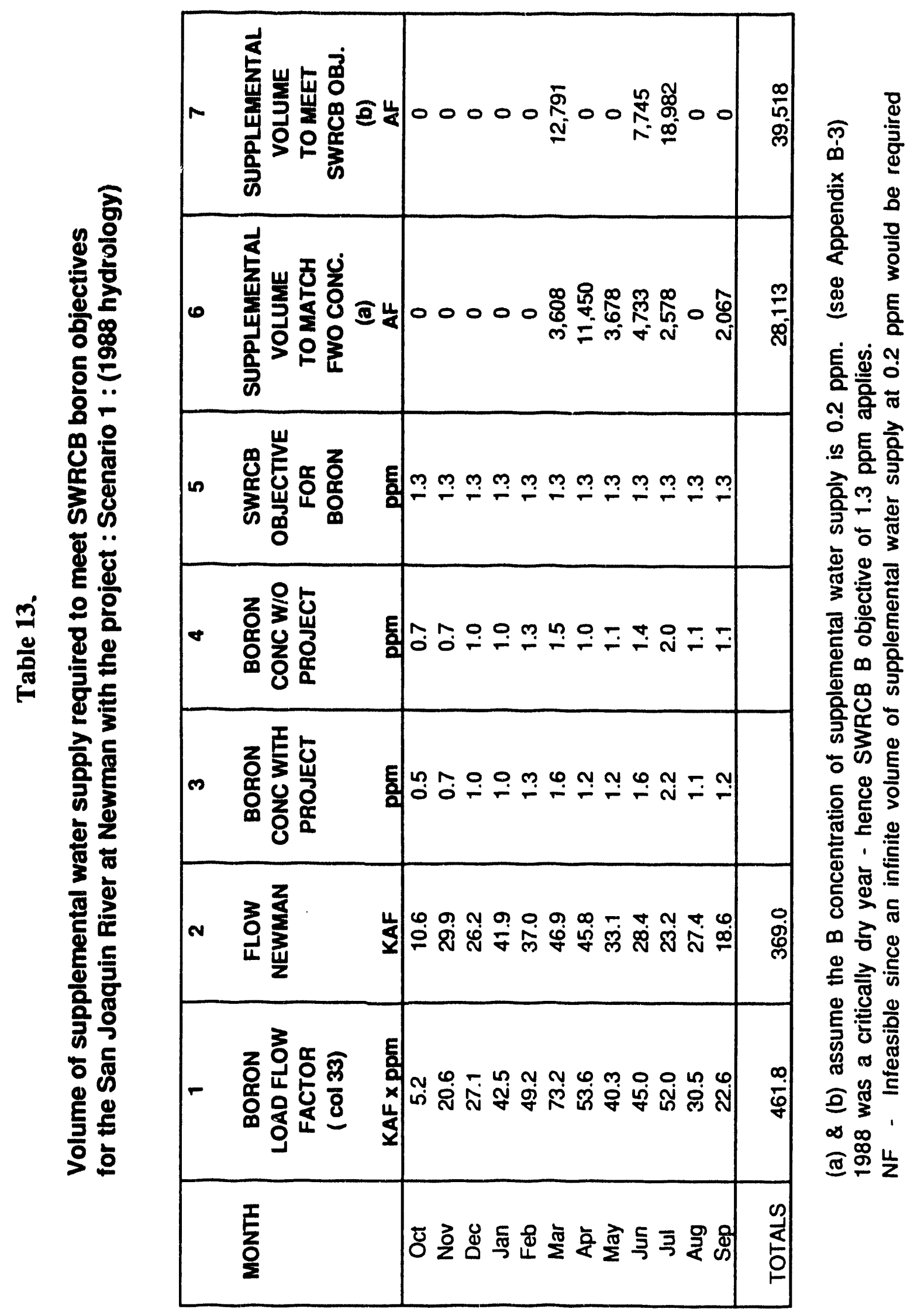




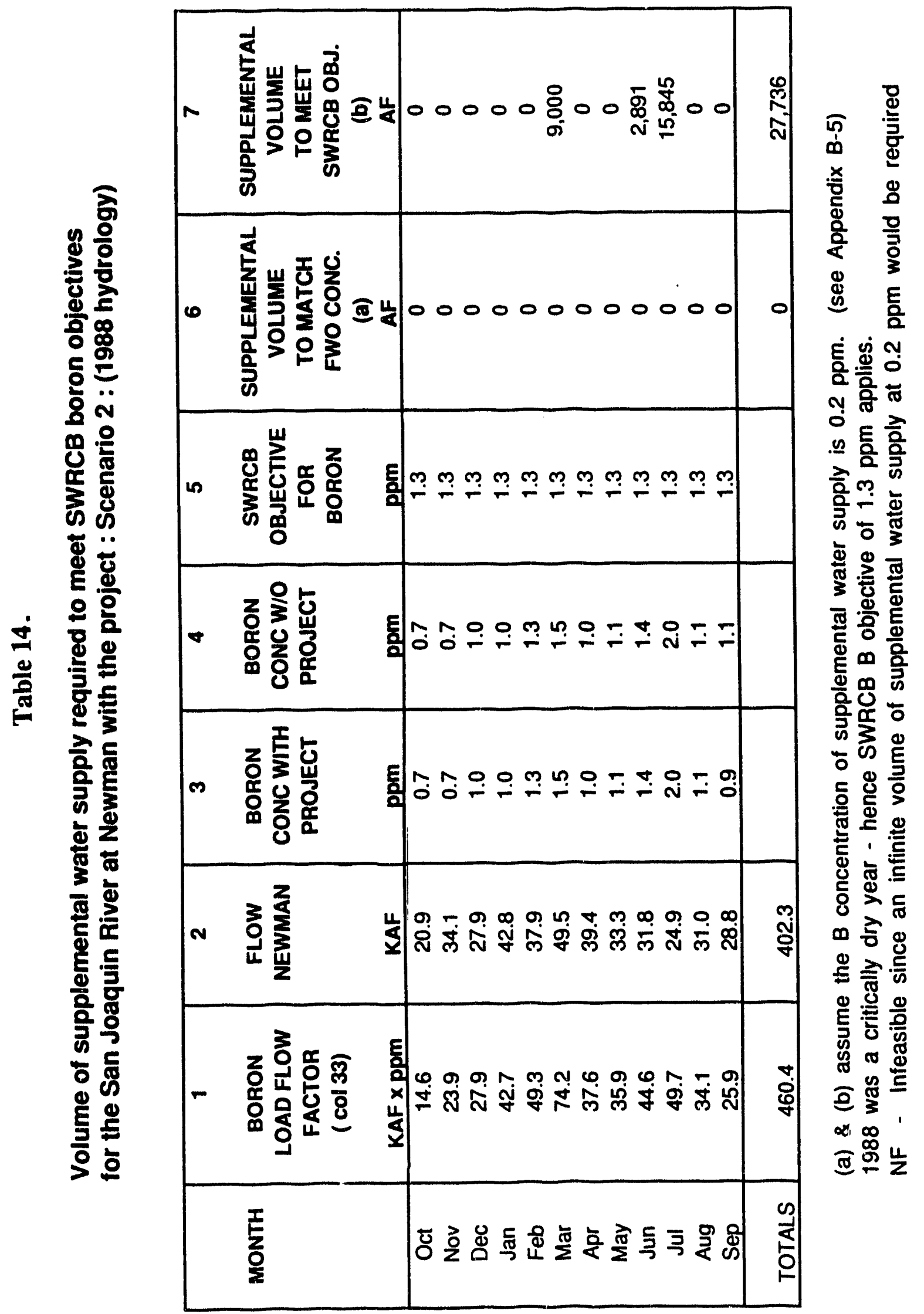




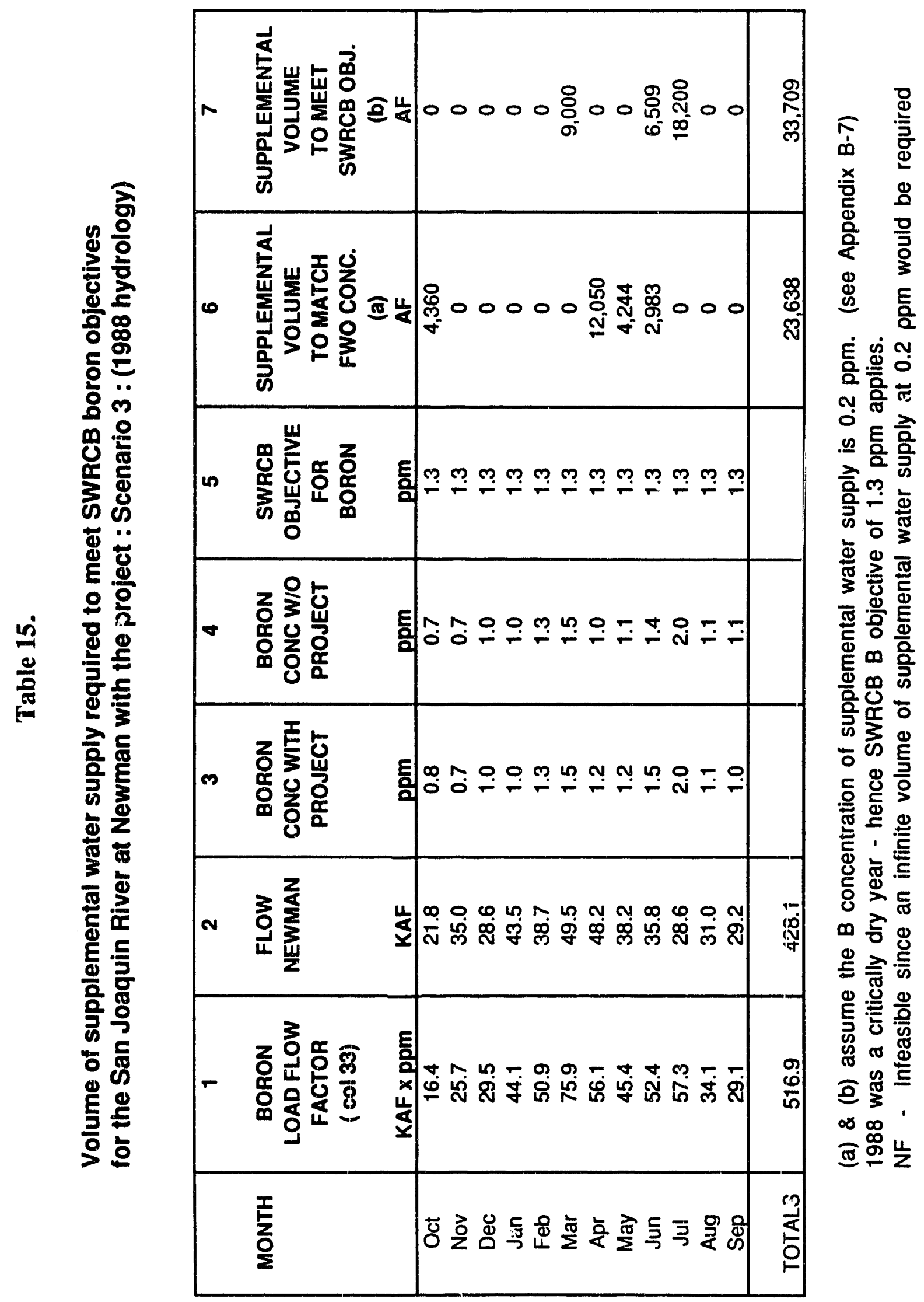




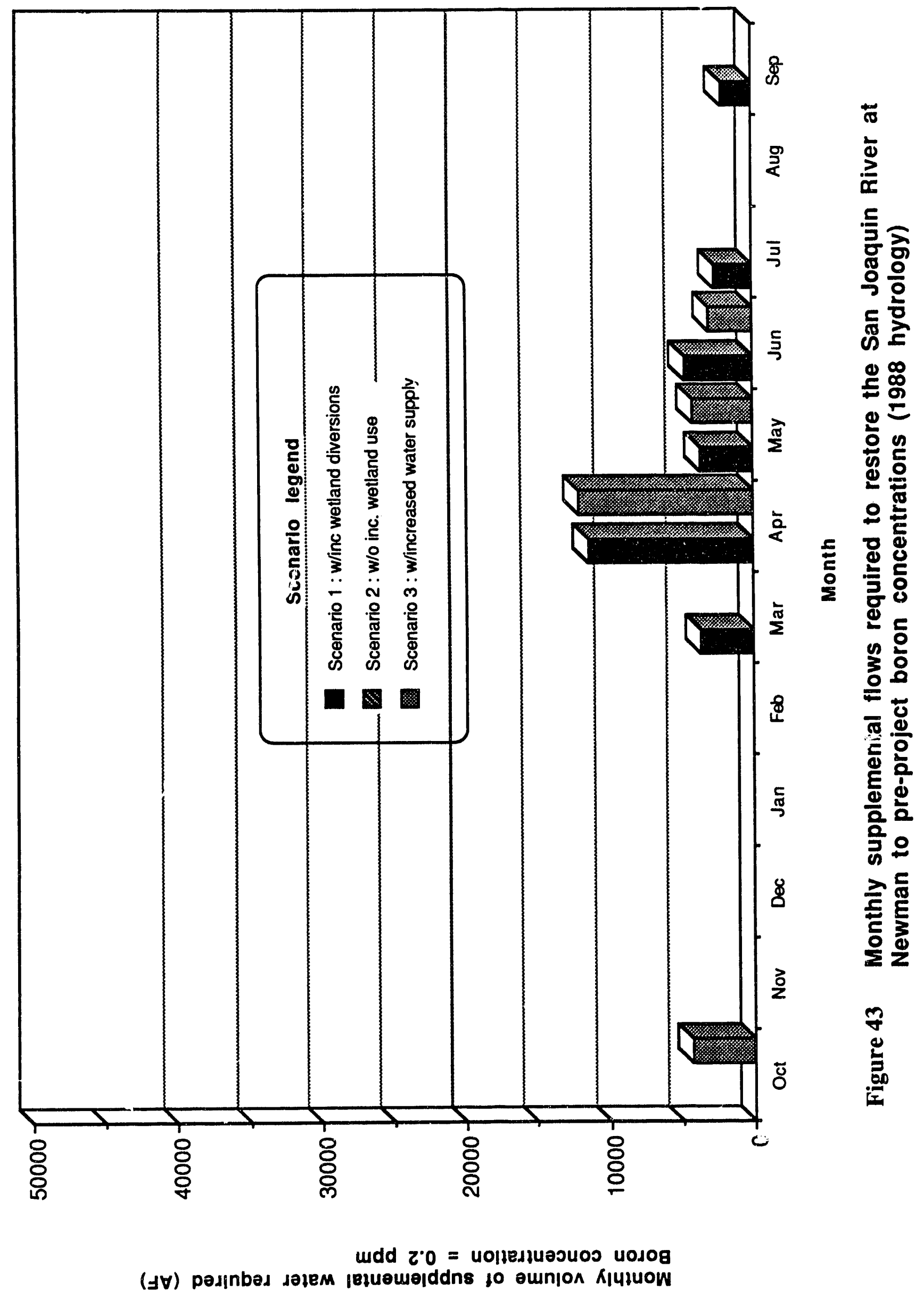




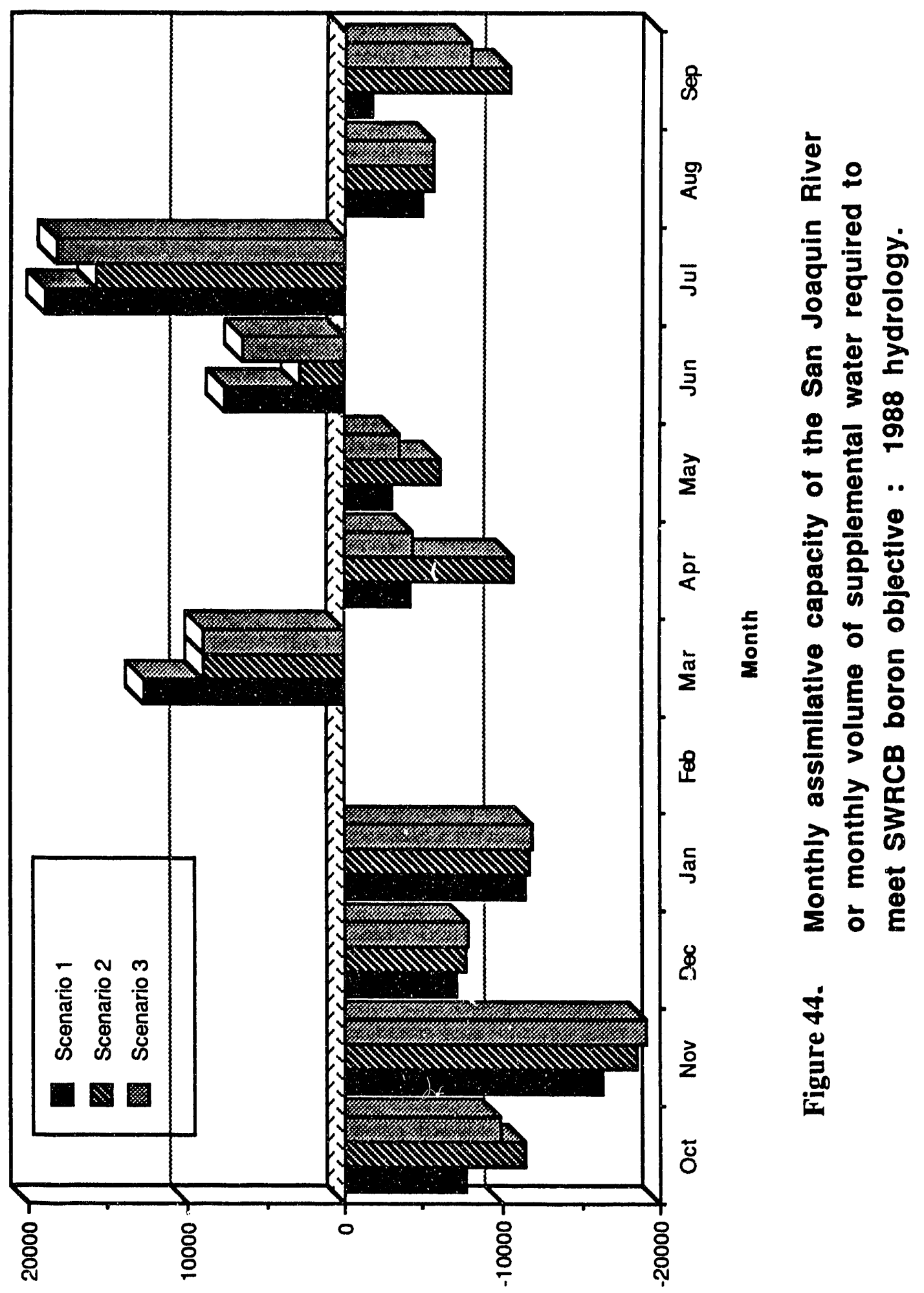

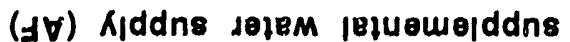

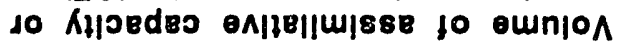




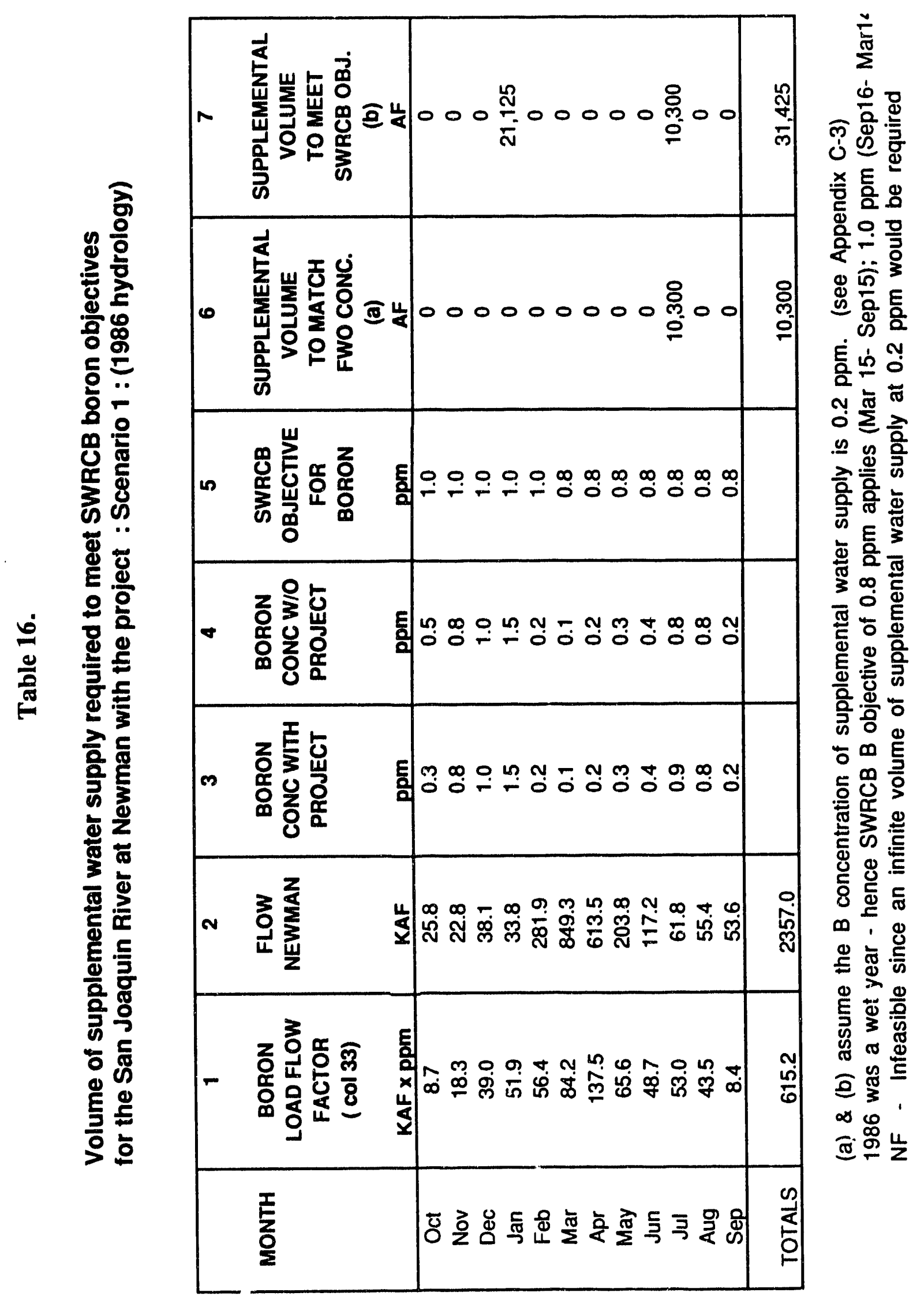




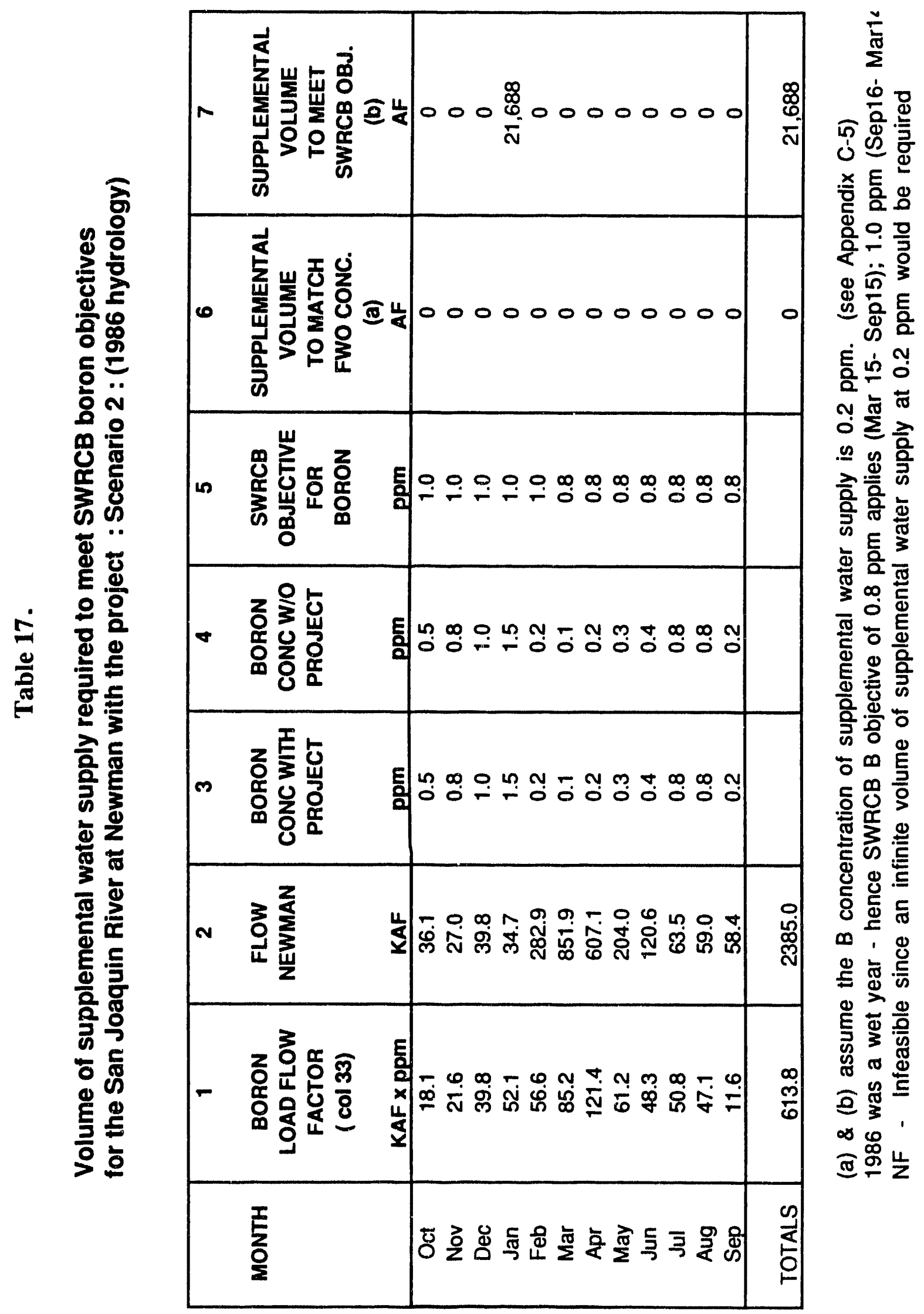




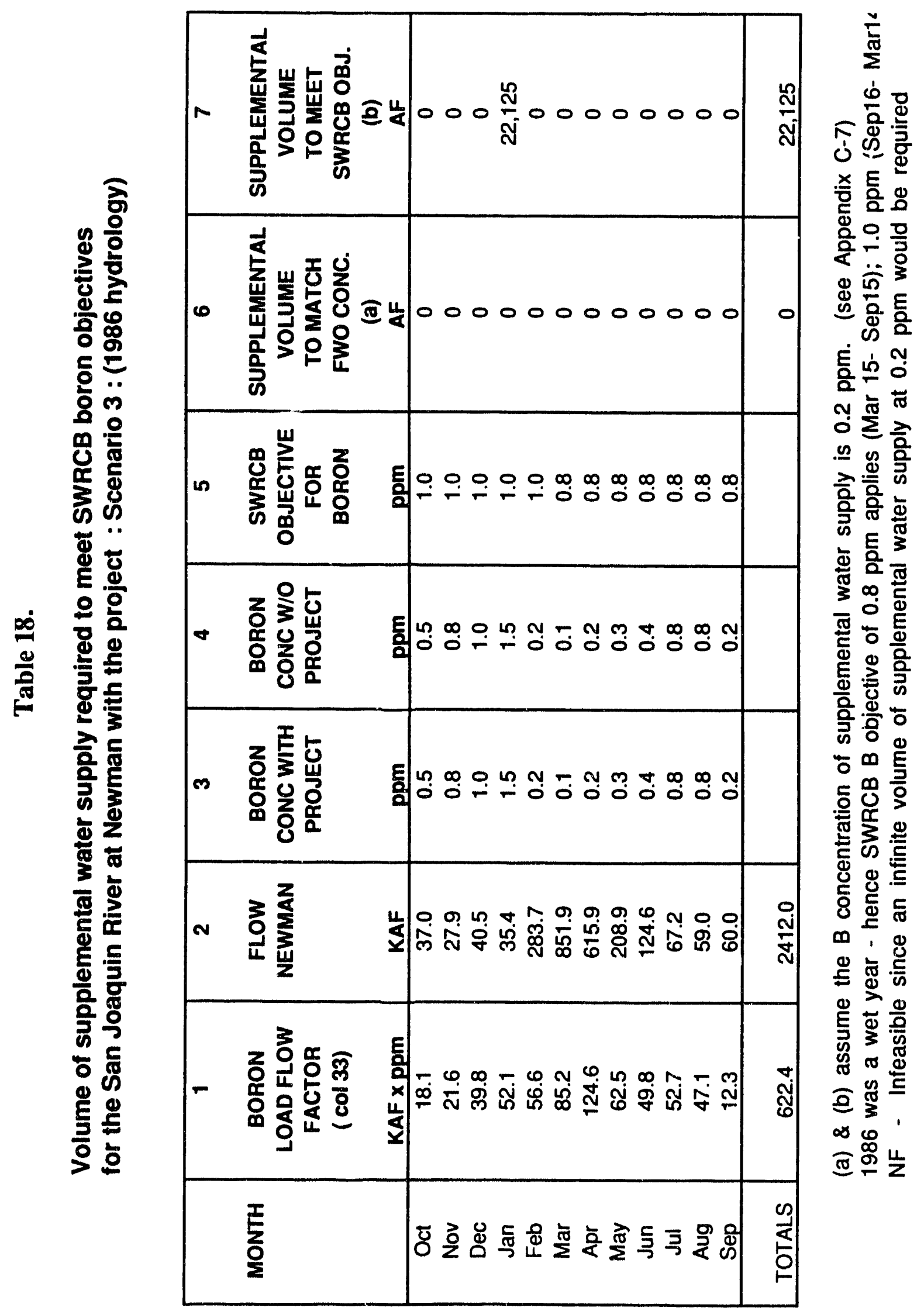




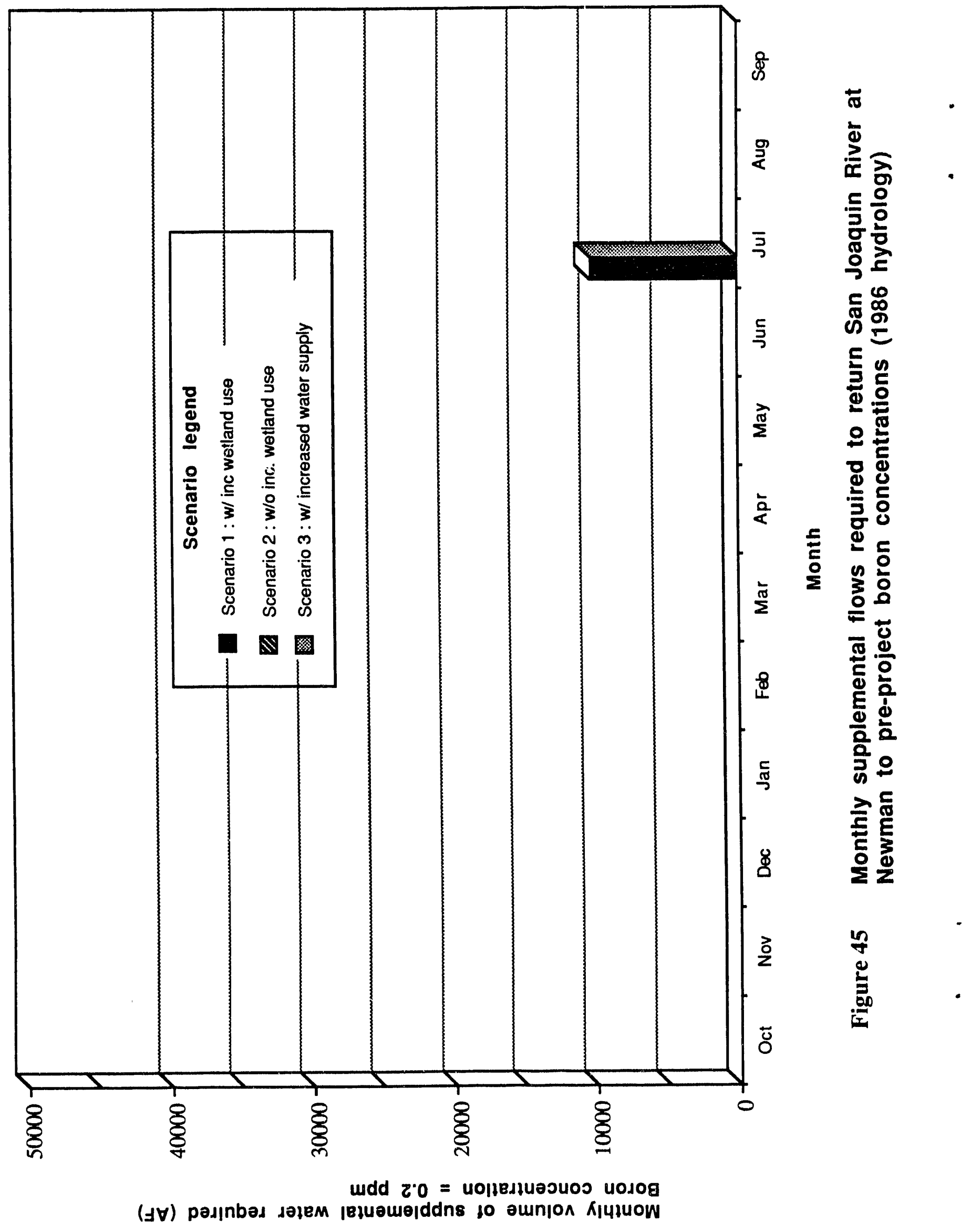




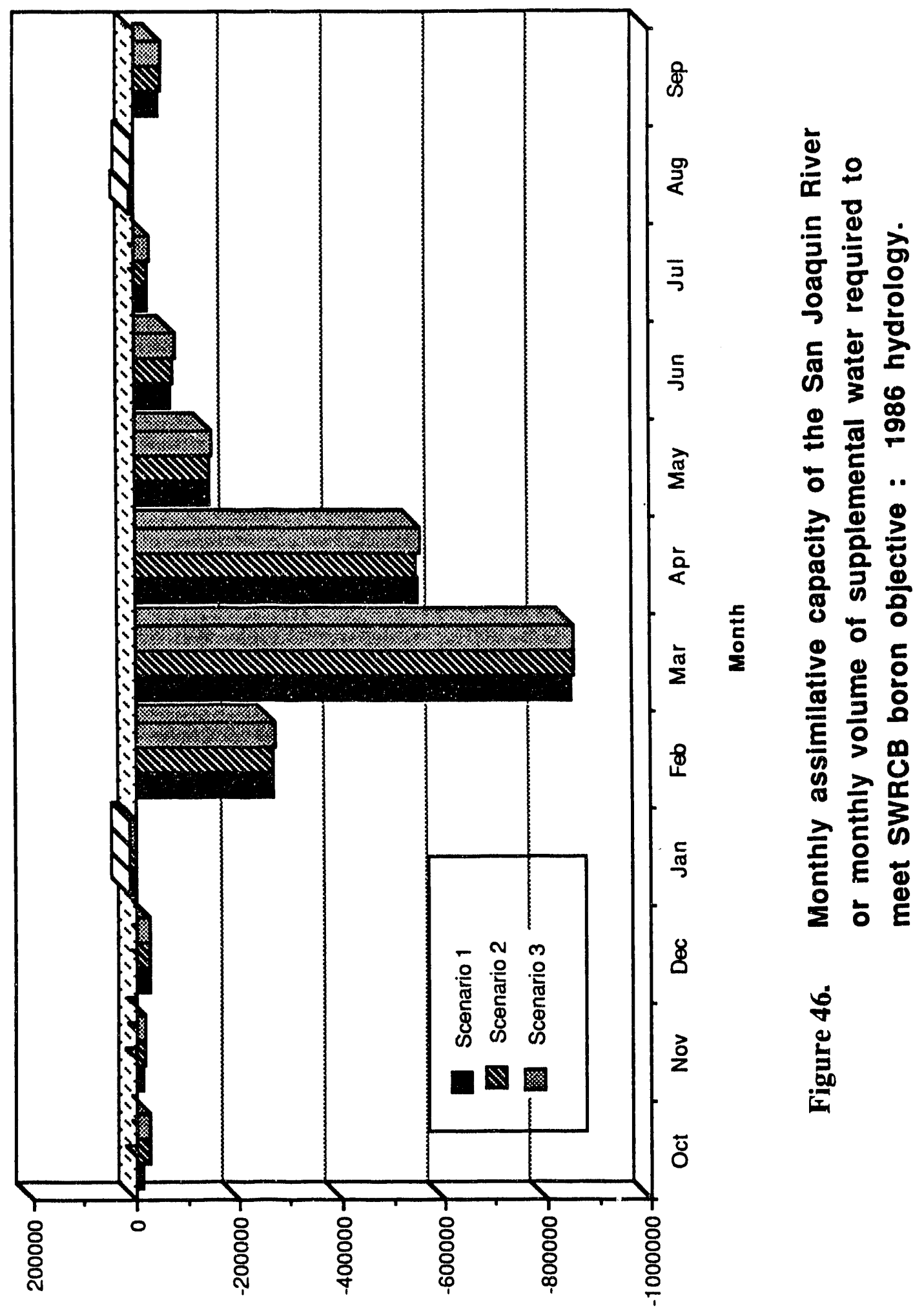

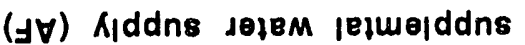

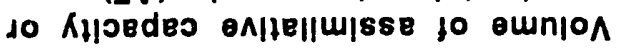




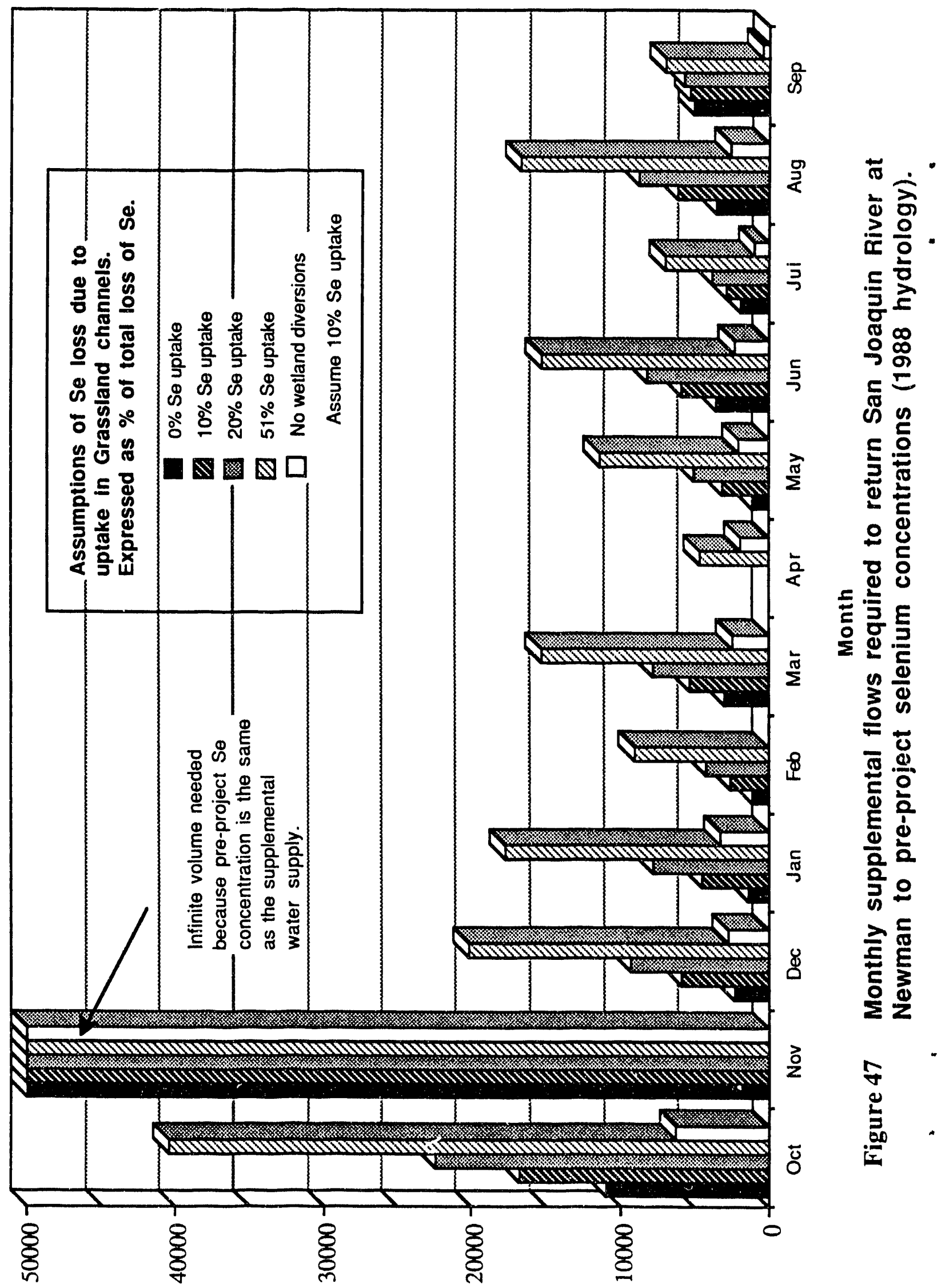

(qdd $L=$ uolıedłuəsuos əs)

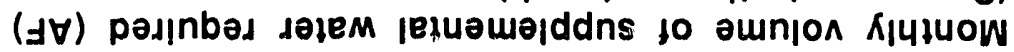




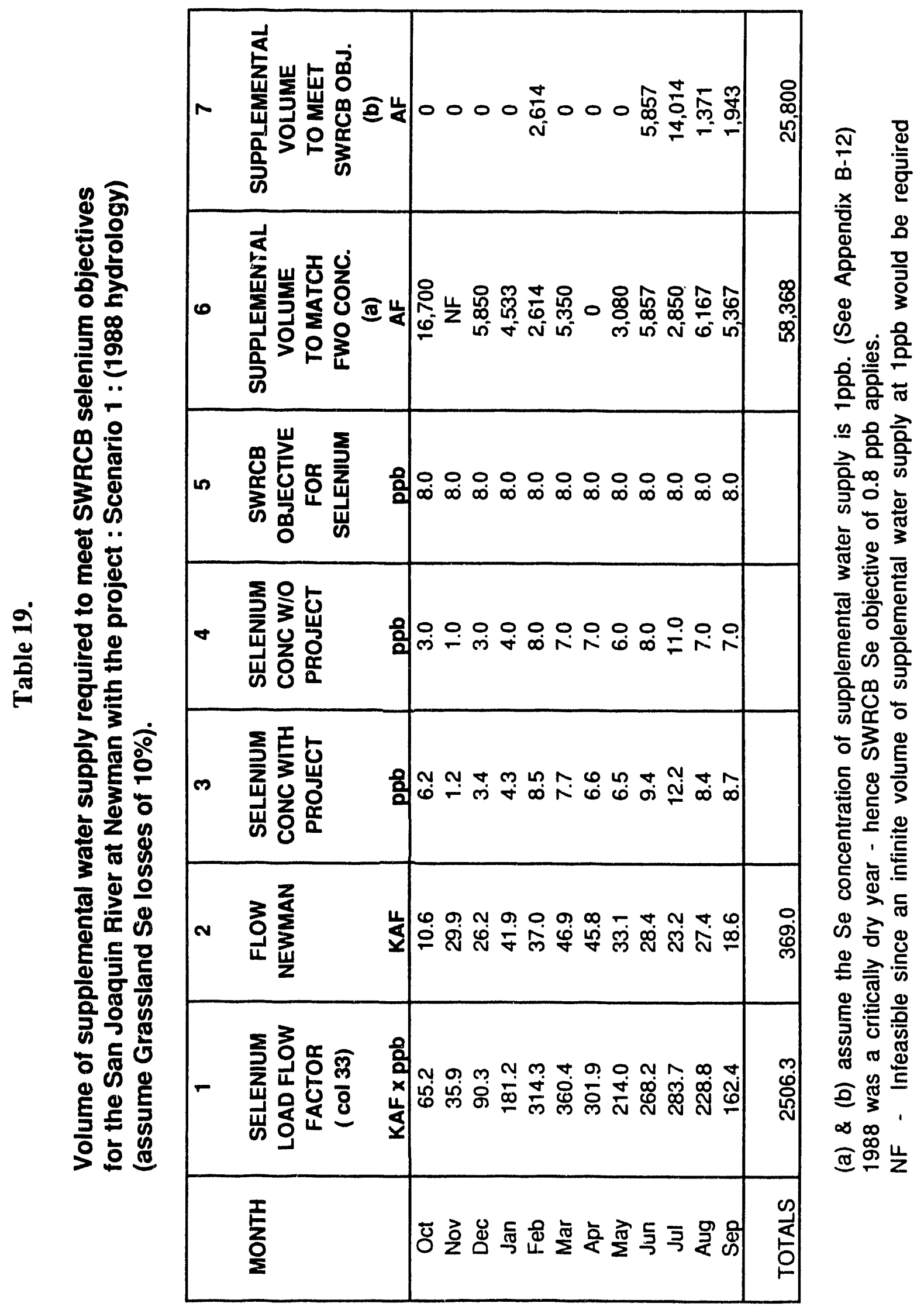




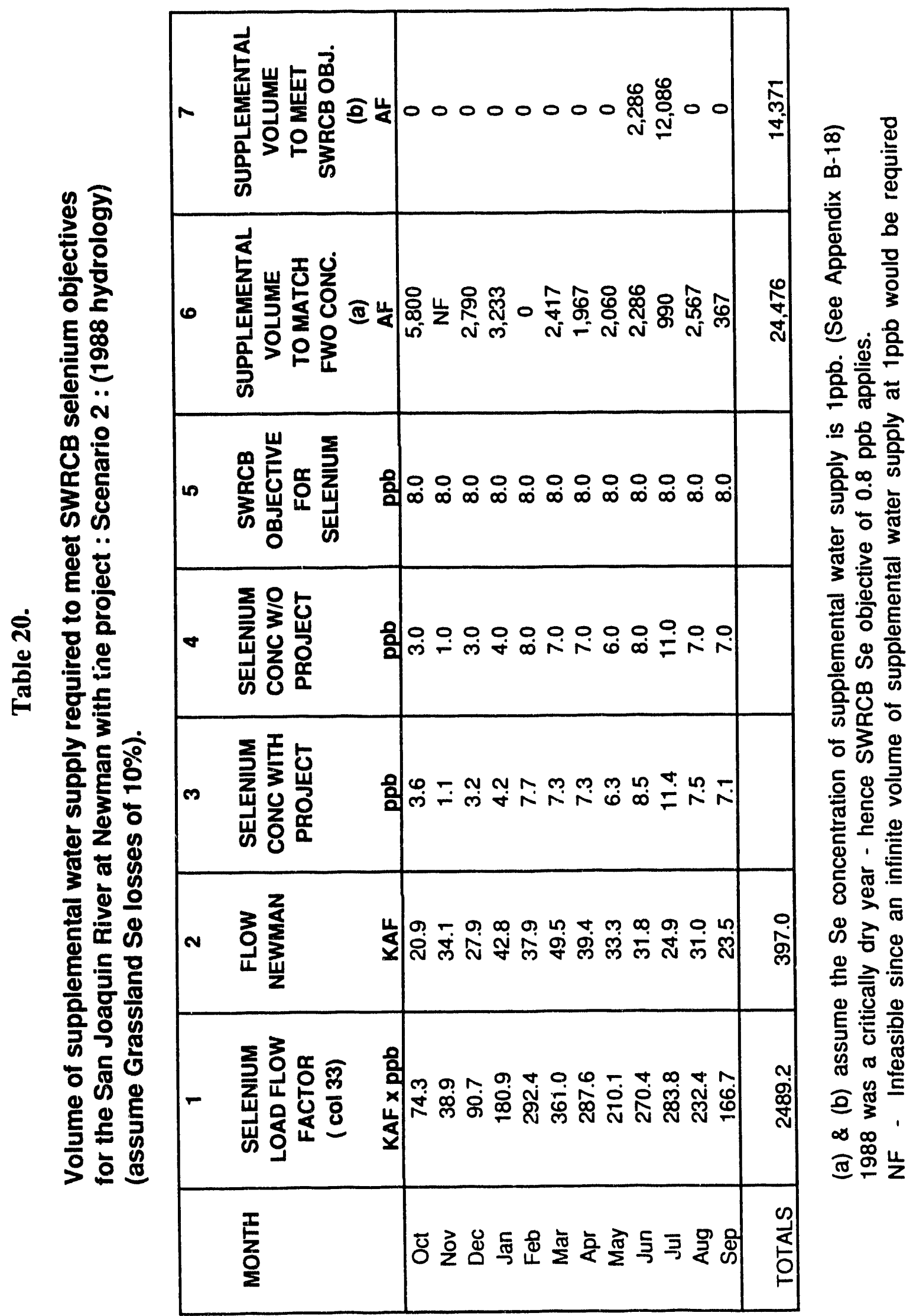




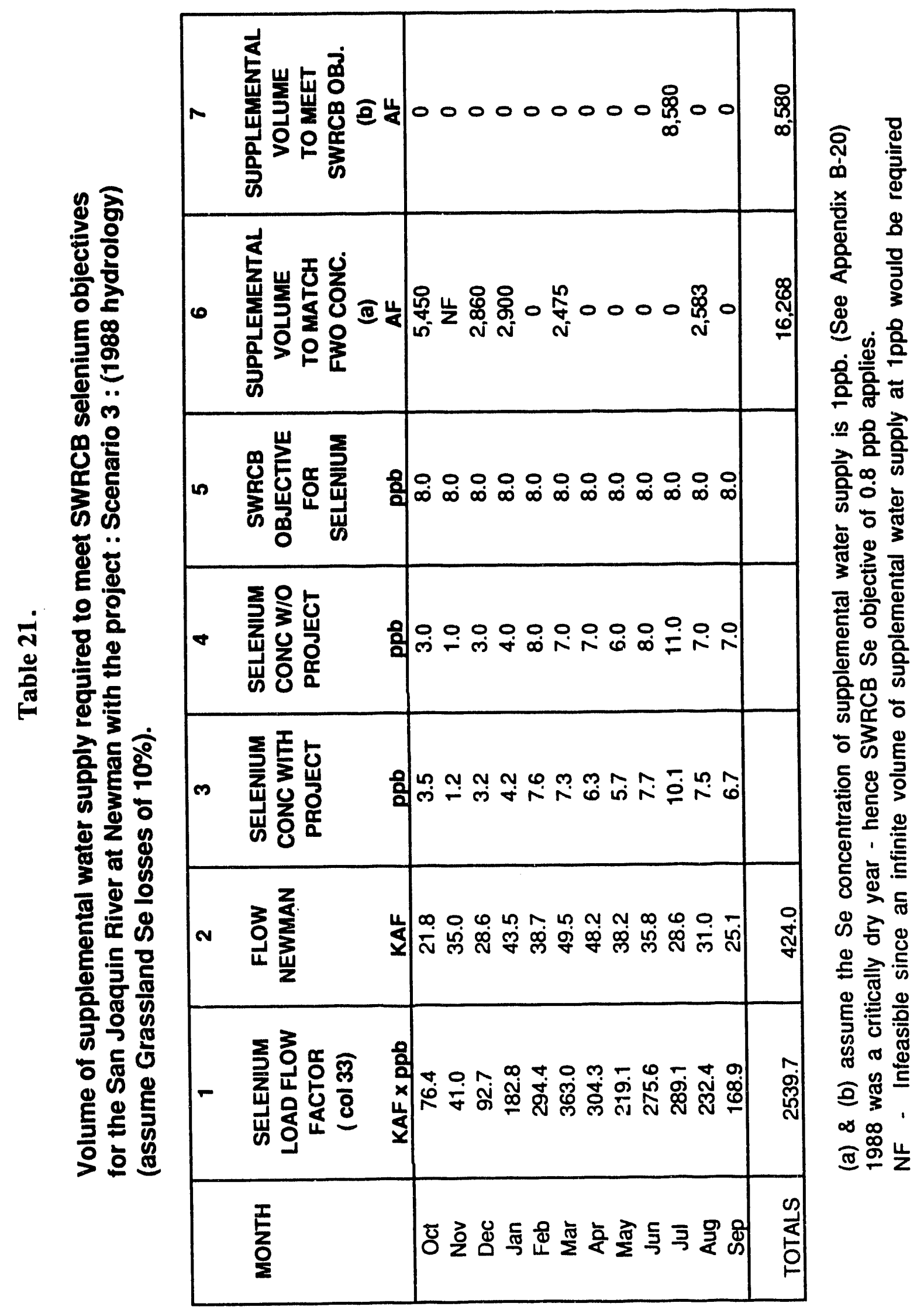




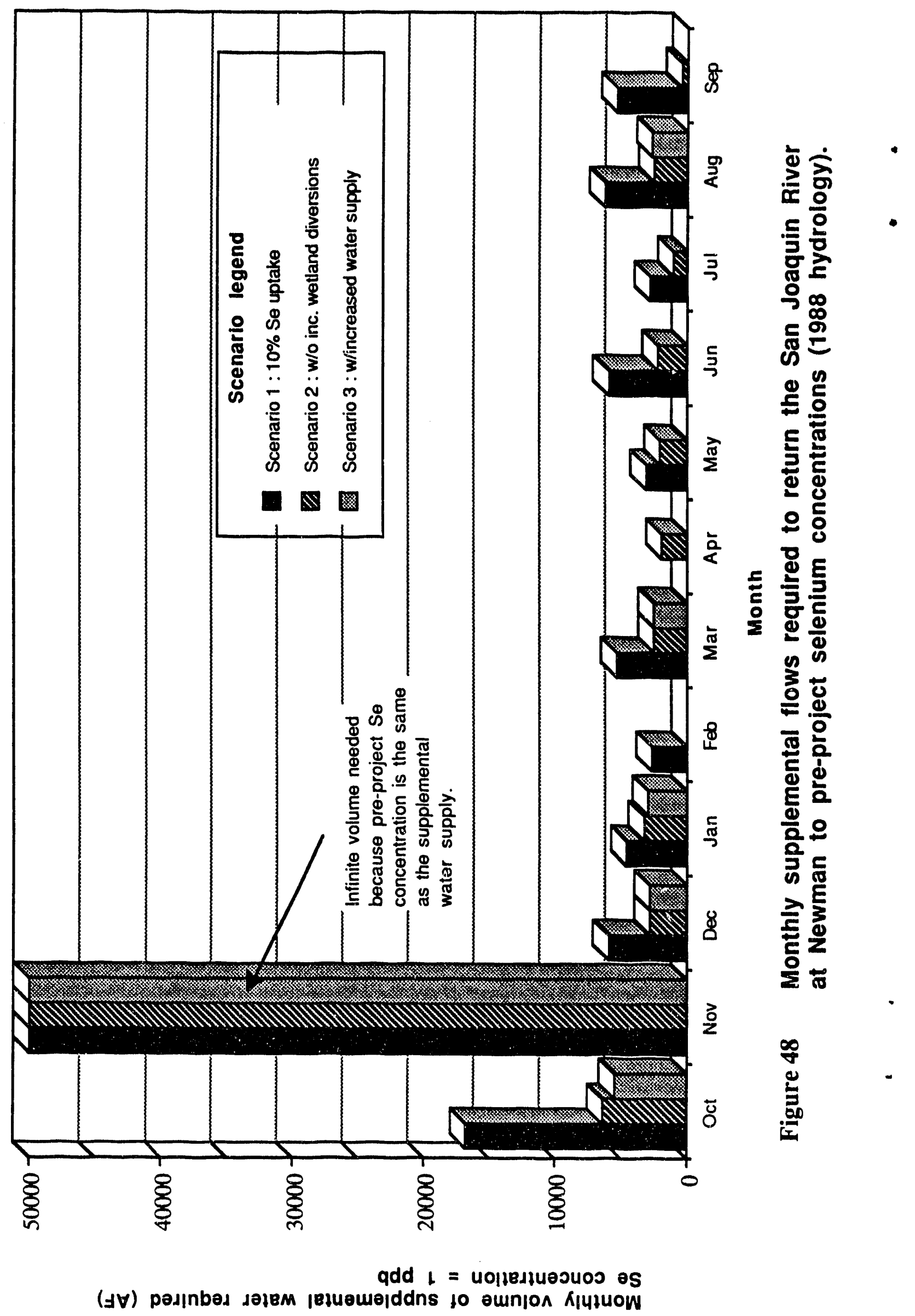




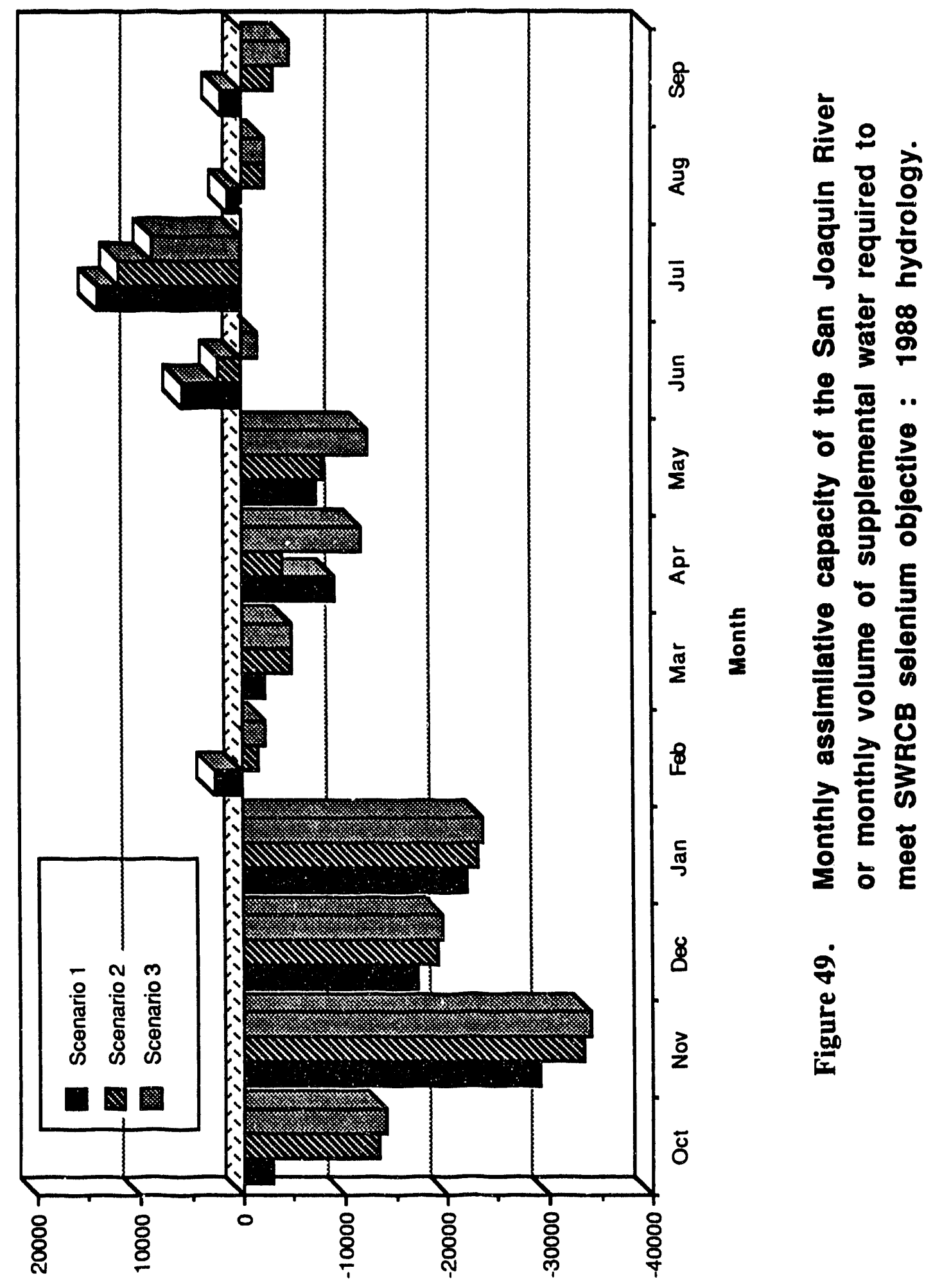

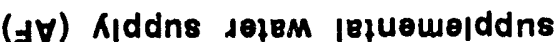

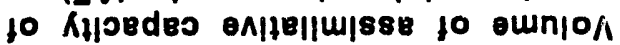




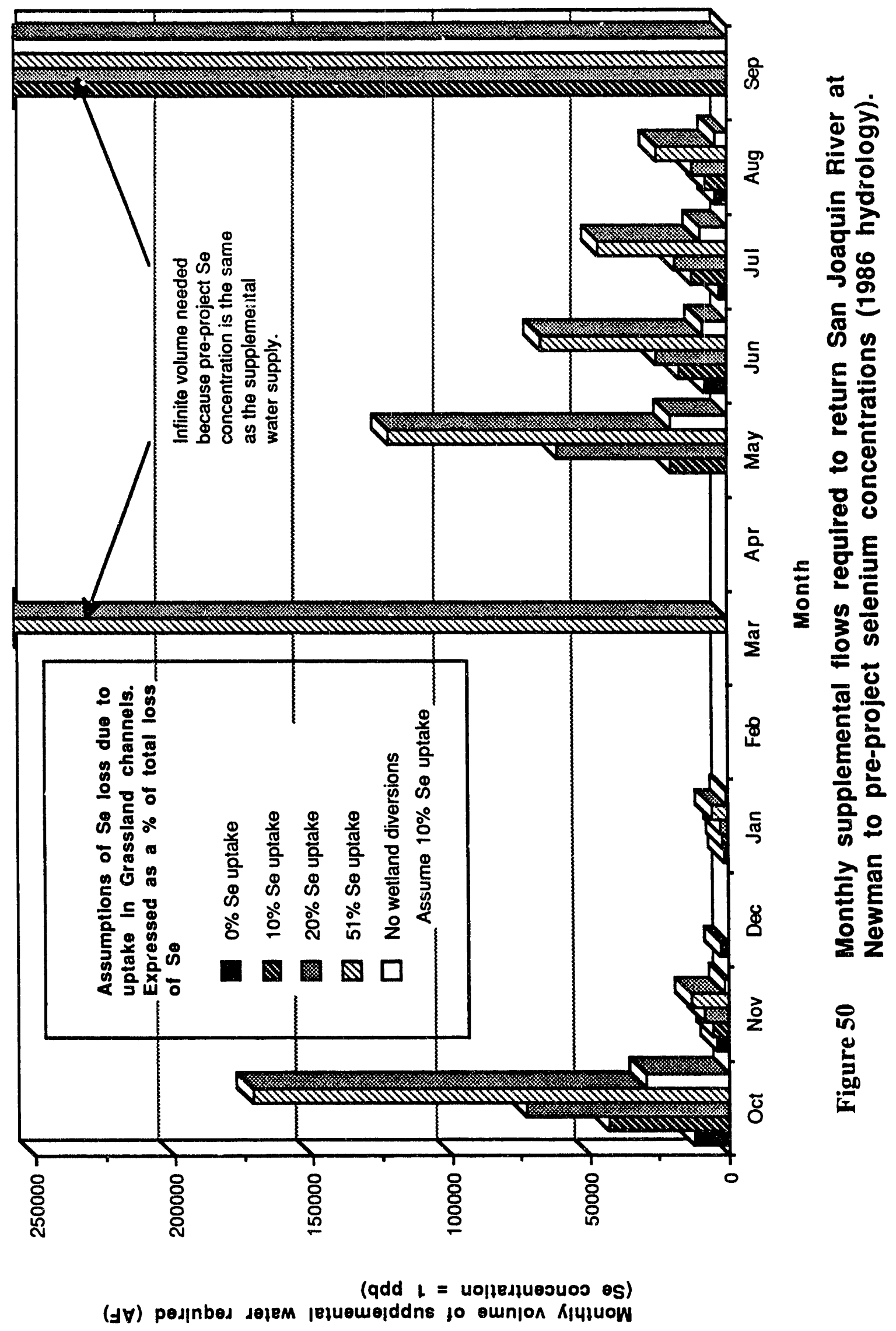




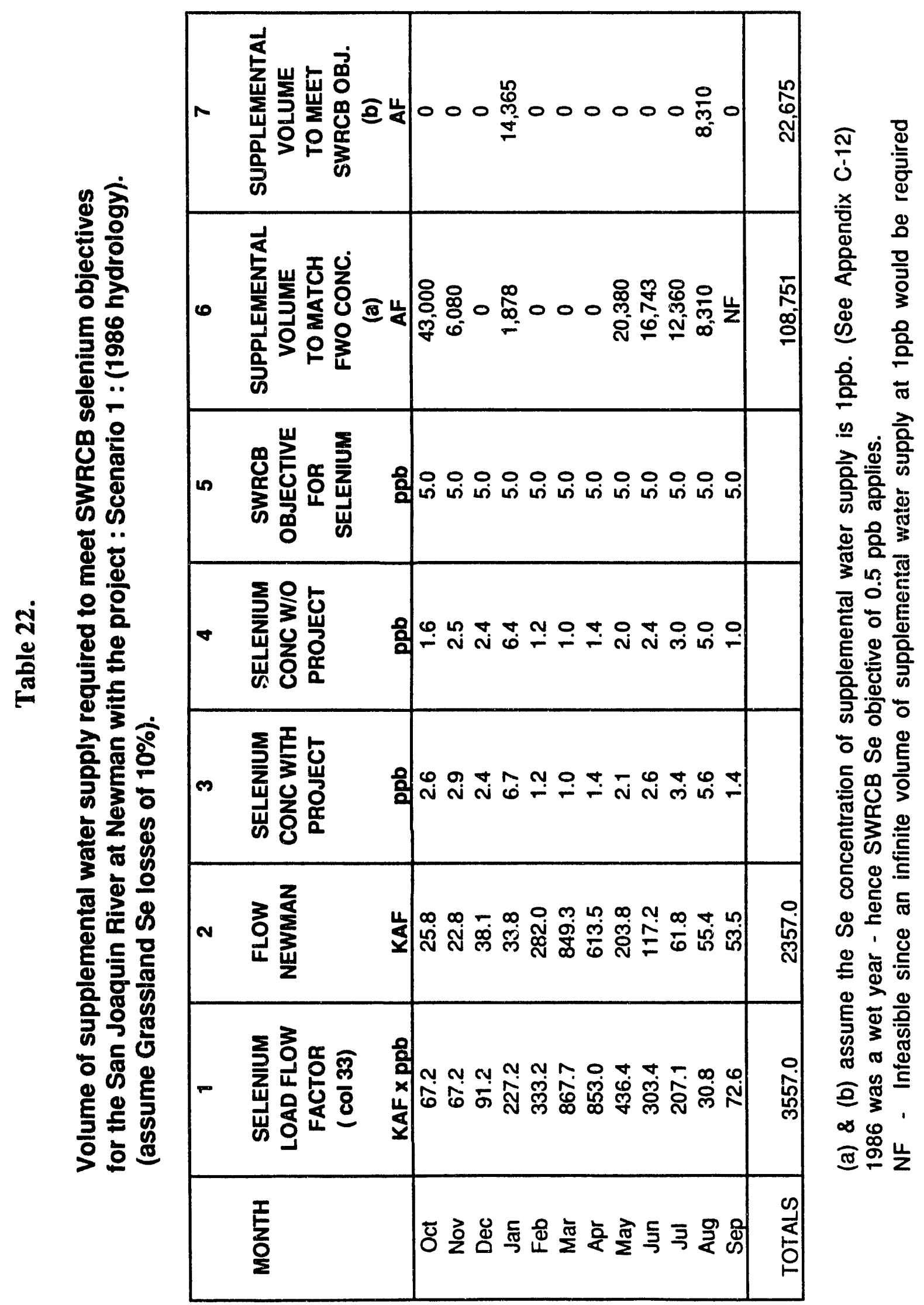




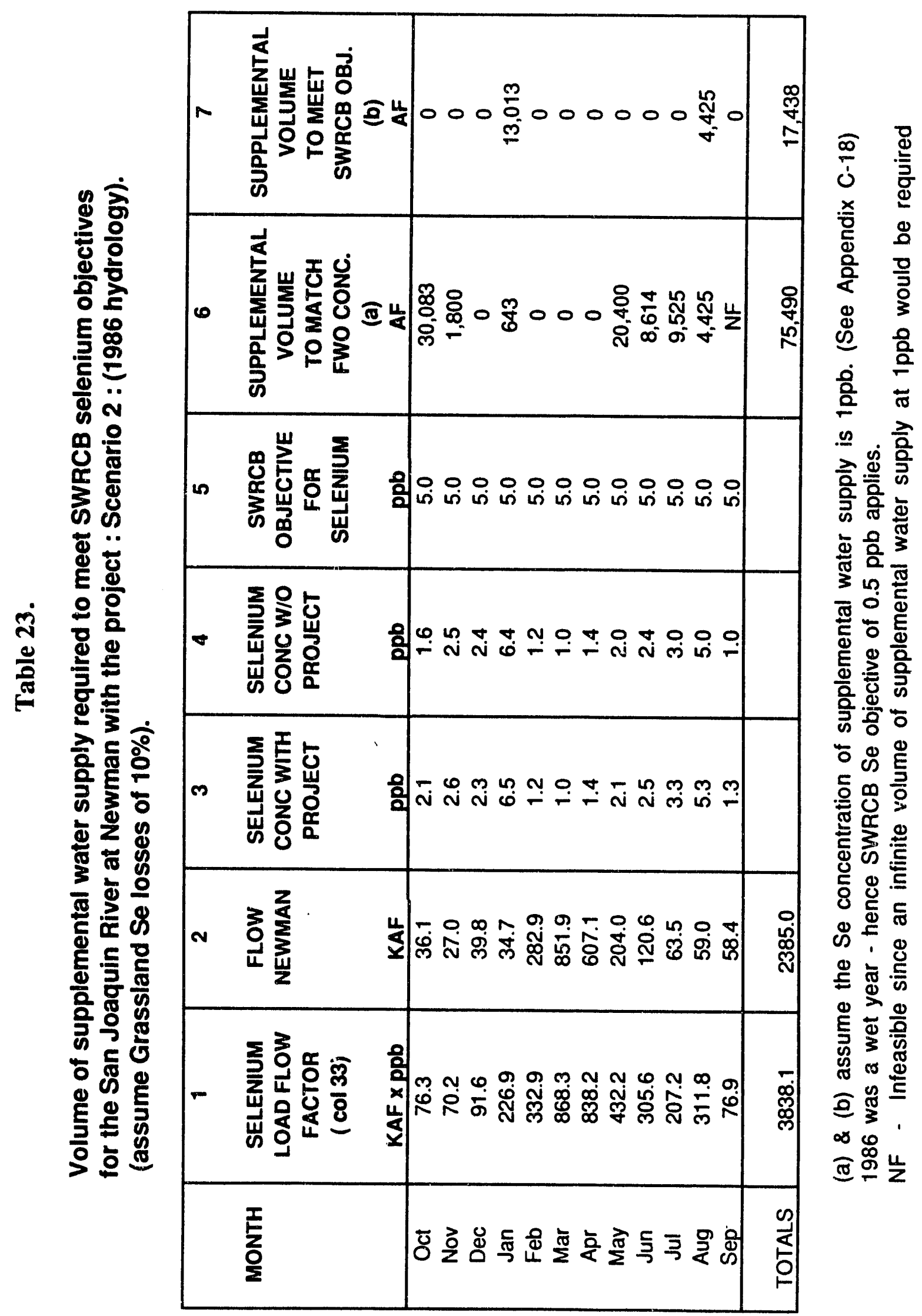




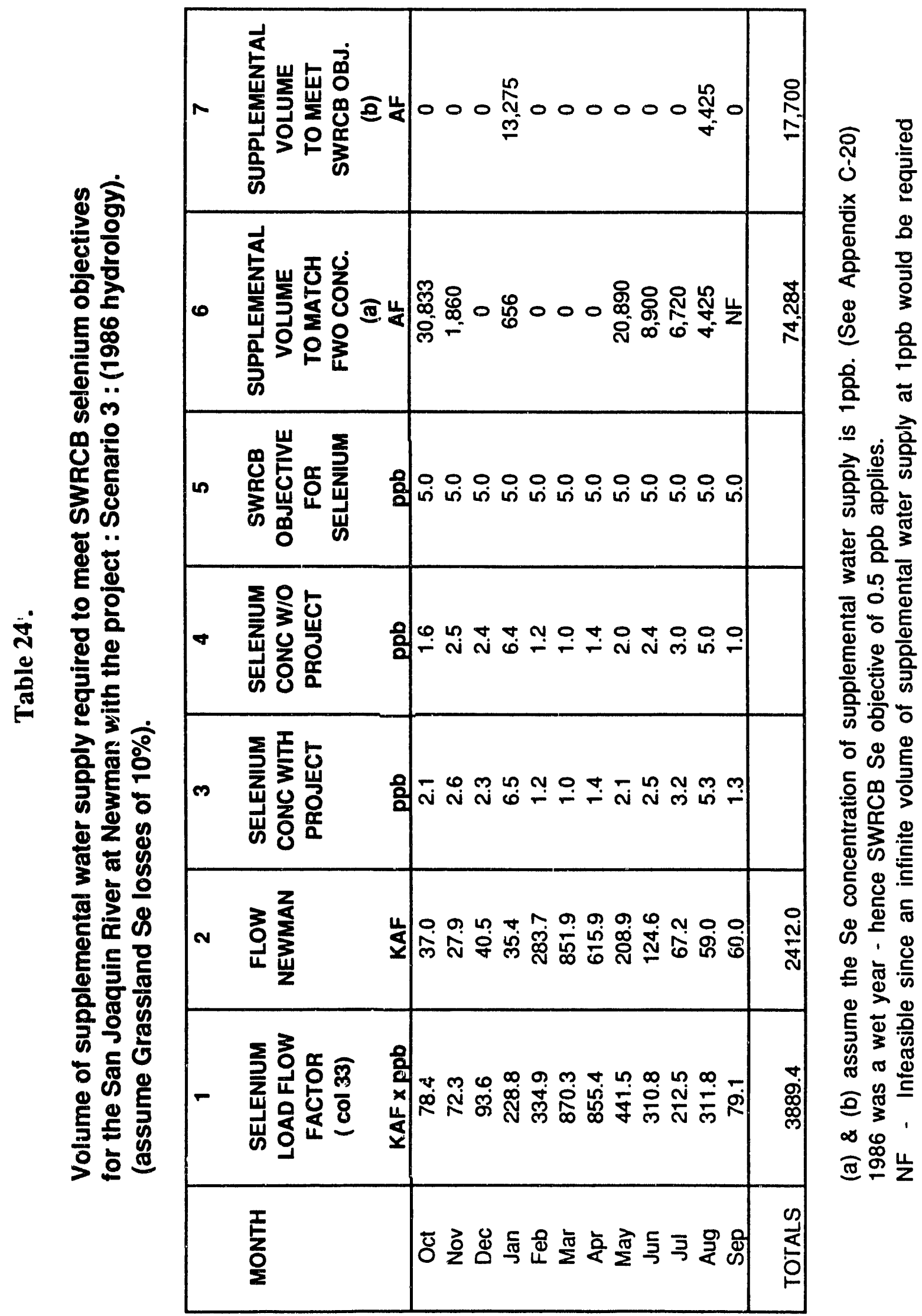




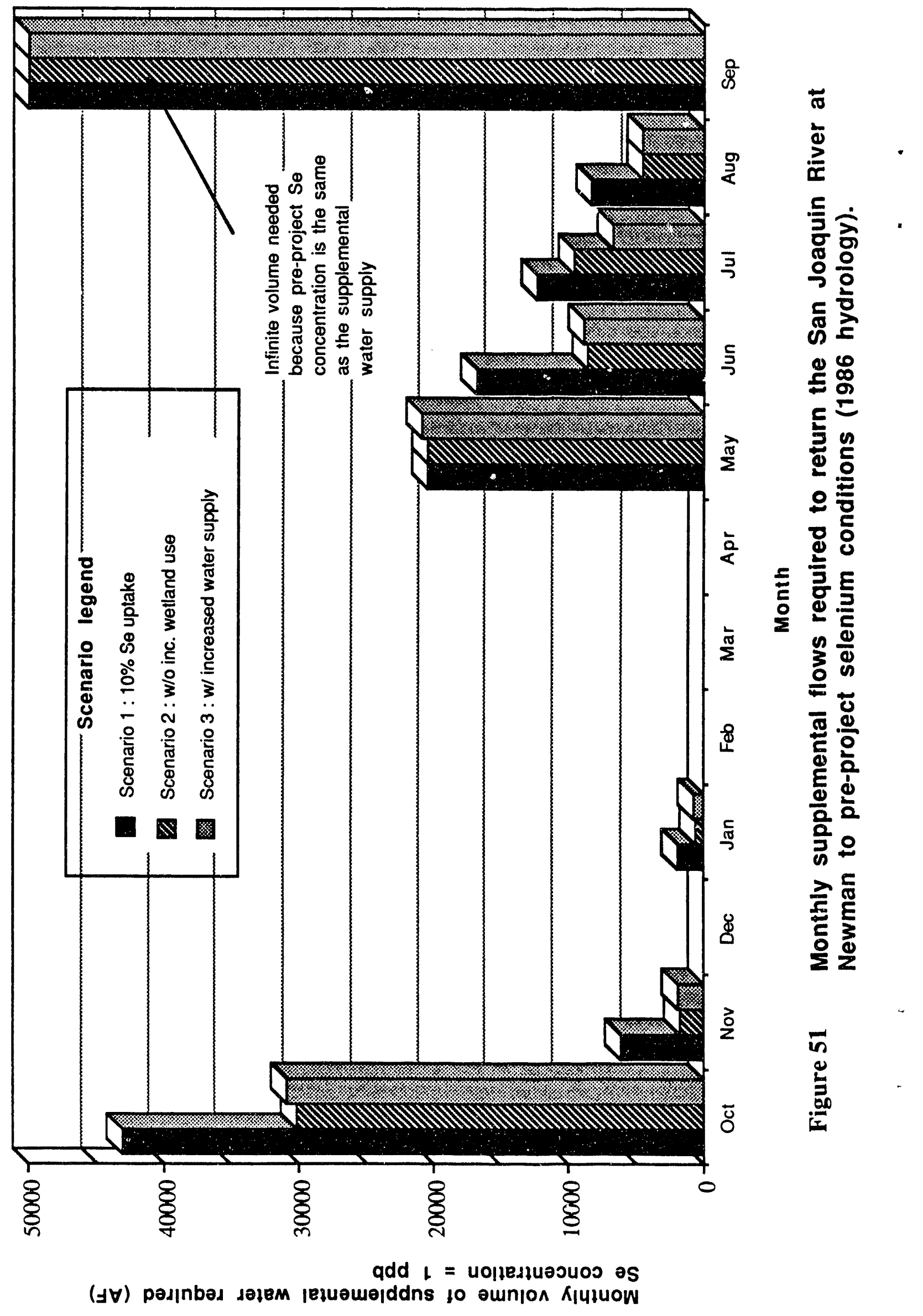




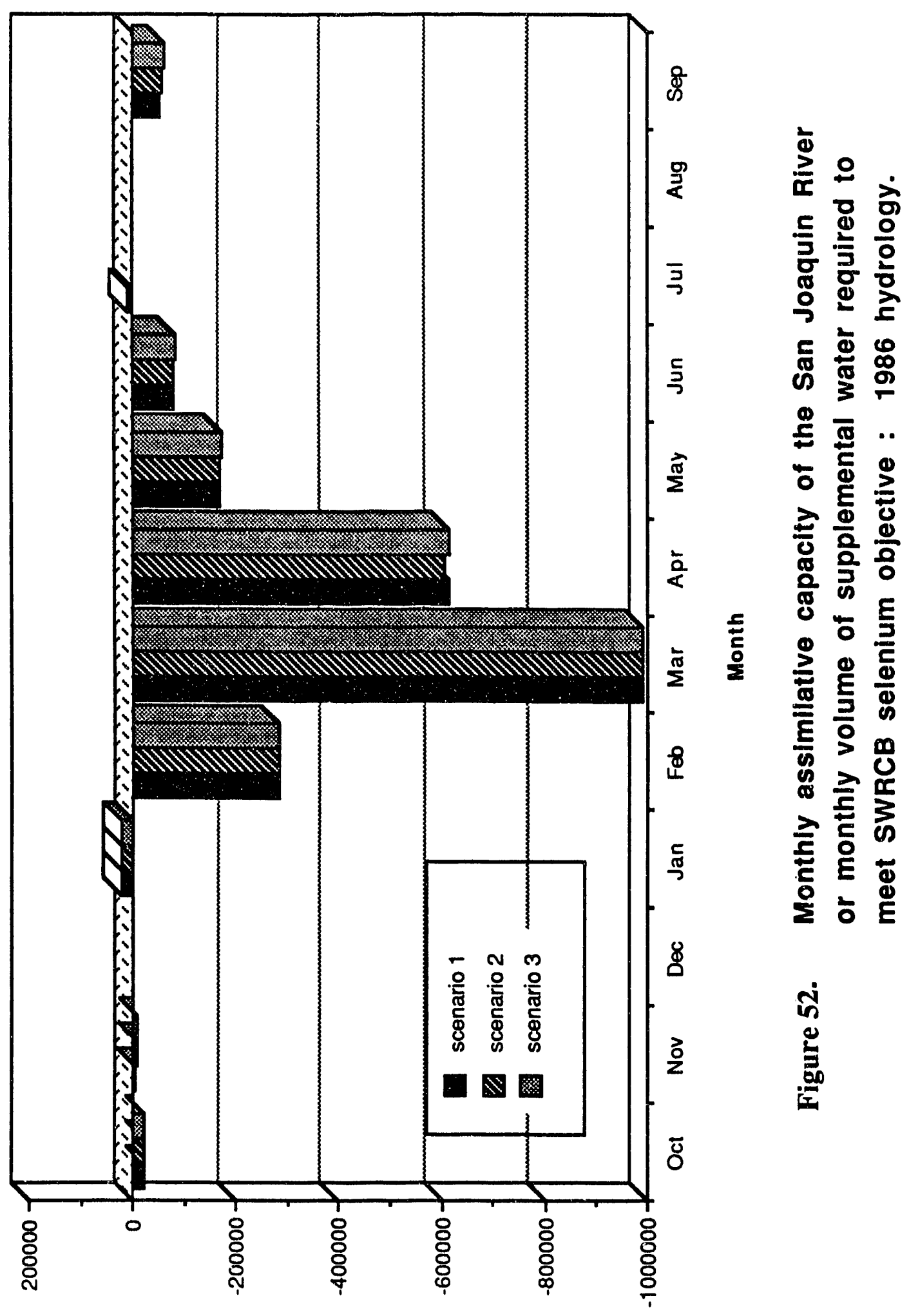

(AV) K/ddns dejeM |ejuewejddns

do Kyjedeo on|le||W|sse to ounjon 


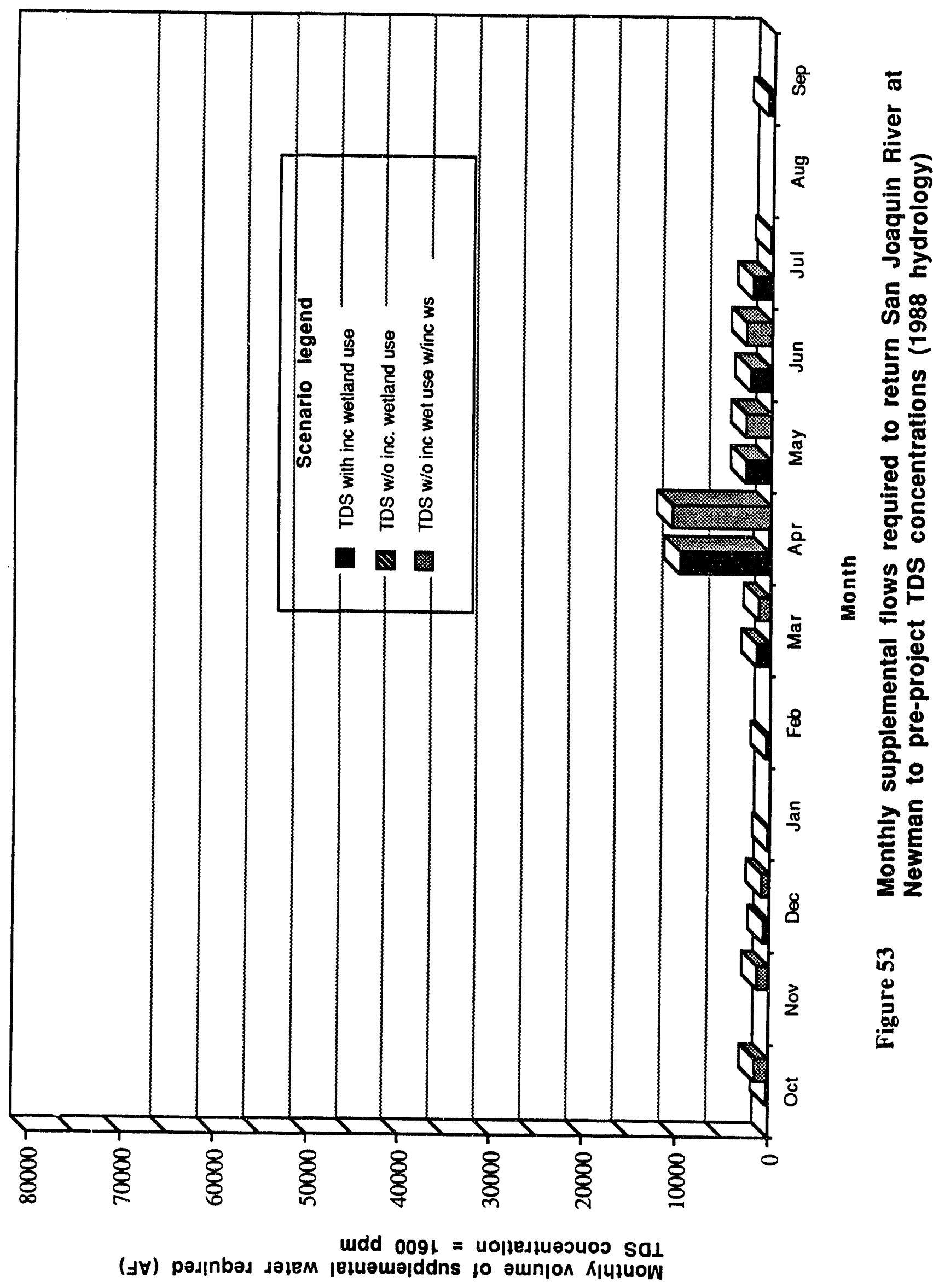




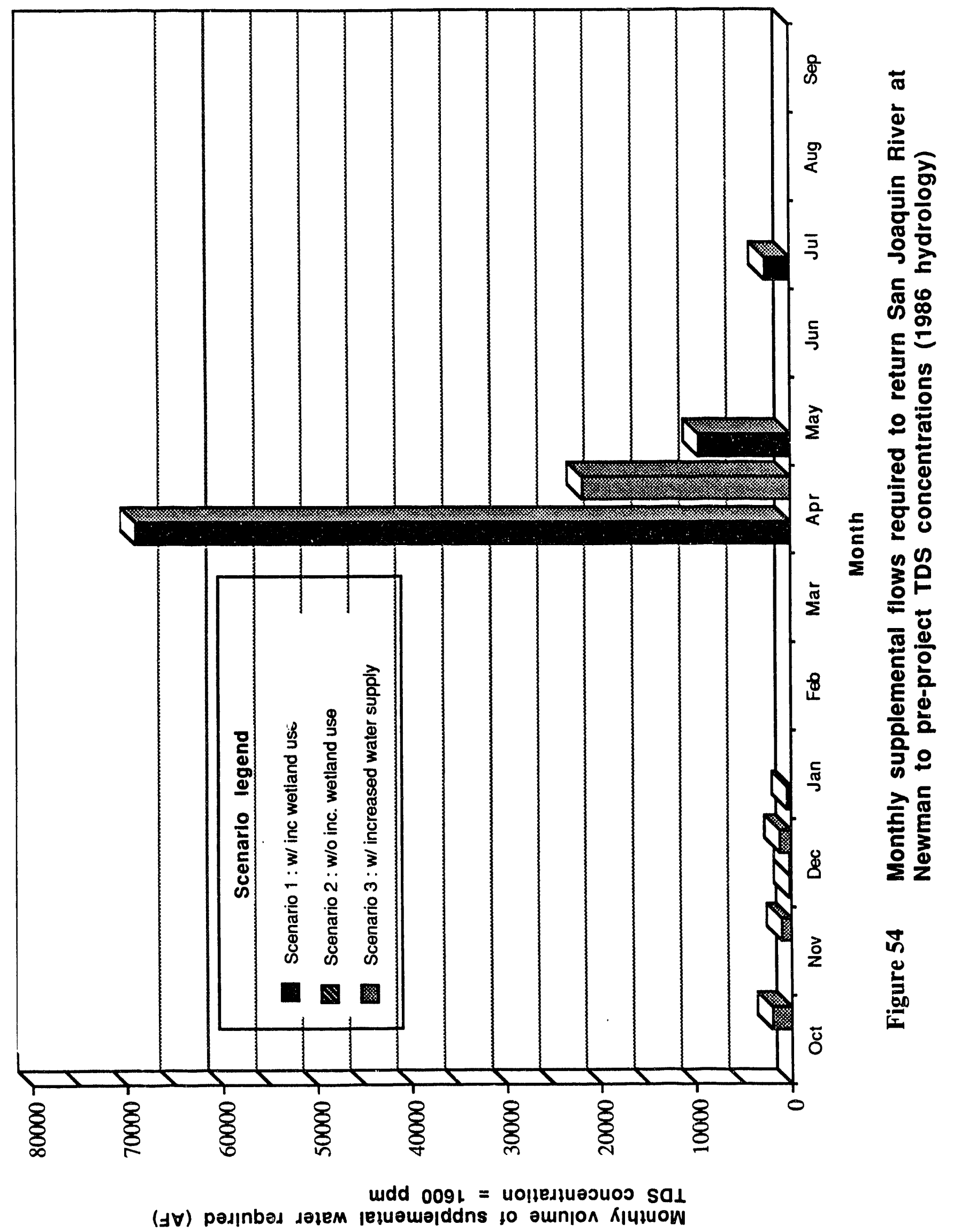


Although a greater volume of supplemental water appears to be required using the 1986 hydrology, the number of months for which supplemental flows are needed is reduced.

Figures 49 and 52 and Tables 18 - 23 can be used to contrast the monthly supplemental flows required to meet SWRCB objectives for selenium in 1988 and 1986 respectively. Figure 49 shows that total supplemental water requirements of 25,800 AF/yr , 14,371 AF/yr and 8,580 AF/yr are needed in Scenarios 1, 2 and 3 respectively (assuming a 10\% selenium uptake). In a wet year (1986) these requirements are 22,675 AF/yr , 17,438 AF/yr and $17,700 \mathrm{AF} / \mathrm{yr}$. In 1988 the highest supplemental water requirements occurred in the months of June and July, whereas for 1986 the highest requirement occurred in January. Although not apparent from Figure 52 because of the scale of the ordinate, substantial assimilative capacity occurs in the river during the months October through December for all three project scenarios in 1986. Similarly in 1988 the months October through January combined produce an assimilative capacity ranging from more than 75,000 AF for Scenario 1 to more than $95,000 \mathrm{AF}$ for Scenario 2. In all cases, considering only these months, the total assimilative capacity of the river exceeds the volume of supplemental water required - unfortunately this assimilative capacity does not coincide with the period of greatest selenium load to the river, which typically runs from February through July.

In Figure 52, the high volumes of spring runoff produced exceptionally high river assimilative capacities in the months February through June, as high as $1 \mathrm{MAF}$ in March of 1988 , when applied to all three of the potential project scenarios. Hildebrand (personal communication, 1990) and others have advocated the utilization of this assimilative capacity in wet years by pumping shallow groundwater - hence reducing shallow groundwater tables and the annual production of tile drainage high in toxic trace elements in succeeding years. Recent work by Swain (personal communication, 1991) and CH2M-Hill (Grant Davids, personal communication, 1991) has shown that a system of improved irrigation management, combined with drainage recycling and temporary storage of subsurface drainage, can be developed to take better advantage of river assimilative capacity for boron and selenium in the San Joaquin River.

Figures 53 and 54 and Tables B21-B28 and C21 - C28 show the supplemental flows required to restore the San Joaquin River to pre-project TDS concentrations for 1988 and 1986 respectively. Since there is no SWRCB objective for TDS at Newman, and meeting the Vemalis objective is outside the scope of this study this was the only analysis performed. Total supplemental water requirements for 1988 range from 20,227 AF/yr for Scenario 1 , $590 \mathrm{AF} / \mathrm{yr}$ for Scenario 2 and 20,864 AF/yr for Scenario3. In Scenarios 1 and 3 wetland return flows add TDS load to Mud Slough, which require dilution to return them to the pre-project TDS concentrations. In 1986, the high volumes of stream flow during the spring months tended to damp out the effect of the wetland return flows - hence only $50 \%$ of the 1988 Scenario 1 supplemental flows were required to restore the San Joaquin River to pre-project conditions. No supplemental water was required for either Scenario 2 or Scenario 3 in 1986. 


\section{Conclusions}

\subsection{Summary of findings}

The major effects of the proposed action under scenarios 1,2 and 3 were summarized in Tables 11 and 12 . The major effect of the project under each of the three scenarios described in this document are to increase the load and concentration of boron, selenium and TDS in Mud Slough while reducing the load and concentration of these contaminants in Salt Slough. Other observations are as follows :

- Violations of the SWRCB mean monthly concentration objectives for boron in Salt Slough, which currently occur, and which would continue to occur in the future, under the without - project scenario, would likely be eliminated with implementation of the project. Violation of the SWRCB monthly maximum concentrations for selenium, which occur infrequently in Salt Slough in dry years, such as 1988, are also likely to be eliminated with implementation of the project.

- SWRCB mean monthly boron concentration objectives for boron in Mud Slough which are currently violated in both critically dry and wet years would continue to be violated in both the without project and with project scenarios. The monthly maximum boron concentration level of $5.8 \mathrm{ppm}$ was violated once using the 1988 hydrology in Scenario 1, whereas no violations occurred in the without-project scenario. Selenium concentrations in Mud Slough, which currently exceed the mean monthly objective for more than one third of the year in both critically dry and wet years, would violate the objective throughout the year with implementation of the project. Maximum monthly selenium concentrations were violated in June and July of the wet year,1986, in Mud Slough but not in the critically dry year,1988. It would be more likely that these SWRCB maximum monthly selenium concentrations would be violated with implementation of the project, especially in critically dry years.

- Implementation of the project causes boron, selenium and TDS loads and flows to decrease during every month of the year in Salt Slough and increase for every month of the year in Mud Slough. During the spring and late summer months these changes can be greater or smaller by a factor of greater than $100 \%$.

In every scenario the water quality for TDS, boron and selenium improves in Salt Slough and deteriorates in Mud Slough. The timing of the highest loads in Salt Slough in the without project scenario generally corresponds to the timing of the highest flows - these occur during preirrigation and the regular season irrigations within the upsiope water districts. Diversion of these high loads by the project into Mud Slough, during the high flow months of February - April and July - August, produces a corresponding bimodal load distribution. The concentrations of contaminants tend to be highest oetween December and February for TDS and boron in Salt Slough in the without project scenario and in Mud Slough in the with-project scenarios, when 
flows are low. Selenium concentrations, on the other hand are influenced, not only by the timing of wetland releases, but also by opportunities for uptake by aquatic vegetation and biota.

- The water years 1986-1990 show a trend of decreased flows of agricultural drainage water from the upslope agricultural water districts. This reduction in flow is the result of improvements in water conservation and irrigation practices and an increase in tailwater and subsurface drainage recycling. As a result, the corcentrations of TDS, boron and selenium within the drainage water from these water districts have increased during the same period. If the flows and the concentrations are multiplied together, a small reduction in contaminant loading to the Grassland area appears to be taking place for TDS, boron and selenium. The encouragement of water conservation and drainage reduction practices in the upslope agricultural areas would appear to make it more difficult for these entities to comply with water quality objectives for selenium and boron in Mud and Salt Sloughs. However, the reductions in boron and selenium loads should make it easier to comply with SWRCB water quality objectives for the San Joaquin River at Newman. During drought periods such as the present one, smaller volumes of Merced River water may be available to dilute the discharges from Mud and Salt Sloughs. Tailwater drainage flows and operational spills are also substantially reduced, diminishing the available water supply for dilution purposes.

- The toron objective is generally more restrictive than the selenium objective in the San Joaquin River at Newman for the with-project scenarios. This occurs even though selenium concentrations are expected to increase by a greater percentage than boron concentrations a I result of the project. The ramification of this finding is that selenium levels would be expected to fall below the objective during those months where the assimilative capacity of the river with respect to boron was met but not exceeded.

- Annual supplemental water requirements are generally higher for boron than they are for selenium for both 1988 and 1986 hydrologies to meet SWRCB objectives for the San Joaquin River at Newman. Conversely, supplemental water requirements are greater for selenium than they are for either boron or TDS in order to restore the San Joaquin River to pre-project concentrations.

- Wetland retum flows often have boron concentrations exceeding the SWRCB objectives for Mud and Salt Sloughs. Delivering additional water to wetlands, such as was analyzed in Scenario 3 to discourage use of Salt Slough flows, increases total boron loading to the San Joaquin River but does not have a significant affect on boron concentrations ir, the river for either 1988 or 1986 hydrologies. Although boron and selenium loading to the San Joaquin River is similar in Scenarios 1 and 2, boron and selenium concentrations are almost always higher in Scenario 1 because of the use of Salt Slough to provide supplemental wetland water supply . 
- Considerable opportunity exists to make use of the assimilative capacity of the San Joaquin River through creative management of subsurface agricultural drainage that contains high levels of potentially toxic trace elements. Pumping of the shallow semi-confined aquifer and discharge of contaminated water high in these trace elements during wet years and times of large river assimilative capacity can help to lower water tables and thus reduce the flow and load of contaminated agricultural return flows during nomal and dry years. Changes in drainage management practices to accomodate this strategy would be made easier with the implementation of the proposed project.

\subsection{Study Limitations}

Besides the data limitations, which were discussed in Section 2, the major weakness of this study lies in the use of recent hydrology data to represent the without-project scenario pre-1985 conditions before the development of the Blake-Porter bypass and its use to divert contaminated drainage flows from Camp 13 and Agatha Canals directly into Mud Slough (South) and Salt Sough for eventual delivery to the San Joaquin River. A calibration procedure was devised to allow reconstruction of the monthly flow records, so as to account for the effects of these diversions and on the conditions manifested without the proposed action. The paucity of data, especially replicate data, makes it impossible to test some of the assumptions made in this analysis or to develop confidence intervals for the flow, load and concentration data. As a result, there are unexplained gains and losses of TDS, boron and selenium within the study area.

The mechanisms responsible for selenium losses that have been shown to occur within the Grassland area are not well understood. Hence, there is no means to predict with confidence the effect of diverting the contaminated agricultural drainage flows into the San Luis Drain - hence reducing the total residence time in the vegetated channels within the Grassland area. If uptake by vegetation is the primary mechanism responsible for selenium uptake then the net gain in selenium load with implementation of the project could be as large as $51 \%$ of the total annual system losses of selenium. On the other hand, if algae and phytoplankton are the responsible agents for the loss of selenium in the system, then the losses experienced by the current routing of contaminated drainage flows could quite easily be replicated in the San Luis Drain. The long - term effects of selenium immobilization and accumulation within Mud Slough are also unknown. This research question deserves to be examined in more detail. 


\section{References}

Boylc Engineering Corporation, 1987. An Evaluation of Wetland Habitat for Offstream Storage : Final Report. US Buraeu of reclamation, CA. November, 1987.

CRWCB, 1990. Agricultural Drainage Contribution to Water Quality in the Grassland Area of Westem Merced County, California. October 1988 through September 1989. Water Year 1989. November 1990.

CRWCB, 1991. Agricultural Drainage Contribution to Water Quality in the Grassland Area of Western Merced County, California. October 1989 through September 1990. Water Year 1990. November 1991.

Phillips A. and N.W.T. Quinn. 1989. Grassland Fresh Water Supply and Drainage Model Preliminary Draft Report. September, 1989.

Quinn, N.W.T. et al. 1990. Overview of the Use of the Westside Agricultural Drainage Economics Model (WADE) for Plan Evaluation. Technical Information Record. August, 1990.

SJVDP, 1990a. Fish and Wildlife Resources and Agricultural Drainage in the San Joaquin Valley, California. October 1990.

SJVDP,1990b. A Management Plan for Agricultural Subsurface Drainage and Related Problems on the Westside San Joaquin Valley. September 1990.

State Water Resources Control Board, 1987. Regulation of Agricultural Drainage to the San Joaquin River. Final Report. August, 1987.

Summers Engineering, 1990. Environmental Assessment and Initial Study. Proposed Use of the San Luis Drain for Conveyance of Drainage Water through the Grassland Water District and Adjacent Grassland Areas.

Summers Engineering, 1991. Monitoring Program Map, 1991.

Swain D.G., 1990. Documentation of the Use of Data, Analysis and Evaluation Process that Riesulted in the SJVDP Recommended Plan. Technical Information Record. September, 1990.

Swain D.G. and N.W.T. Quinn, 1991. Analysis of the Potential Water Quality Impacts Resulting from the Proposed Use of the San Luis Drain by Grassland Drainers. In : Supplemental Environmental assessment and Draft Finding of No Significant Impact. USBR, April, 1991.

USBR, 1989. Report on Refuge Water Supply Investigations. Central Valley Hydrologic Basin, California. March 1989.

USGS Watstore database. 


\title{
Appendix A
}

\author{
Monthly water quality data \\ Concentrations and load-flow factor
}

San Joaquin River, Mud Slough, Salt Siough

$1986-1990$

A1 - A11 


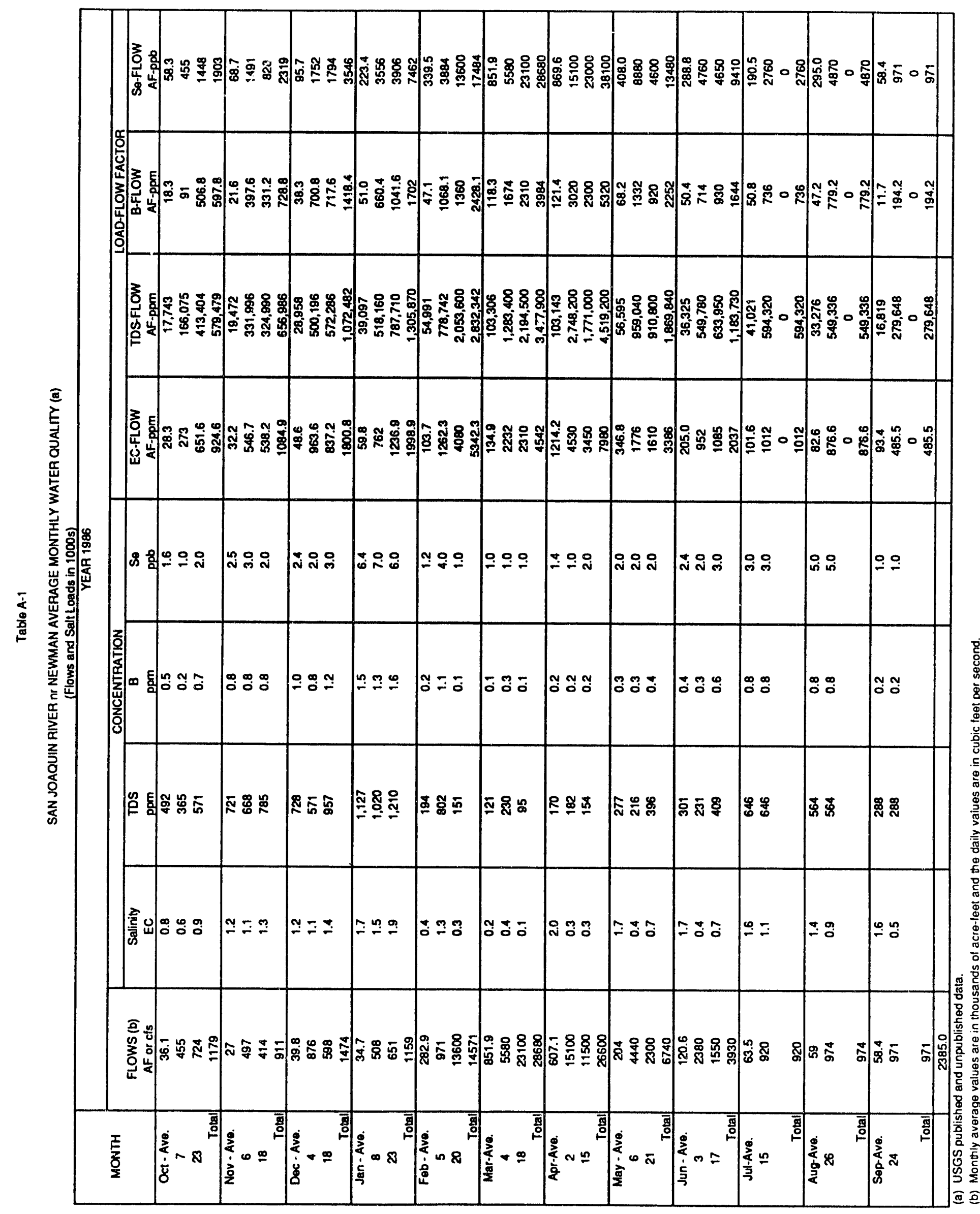




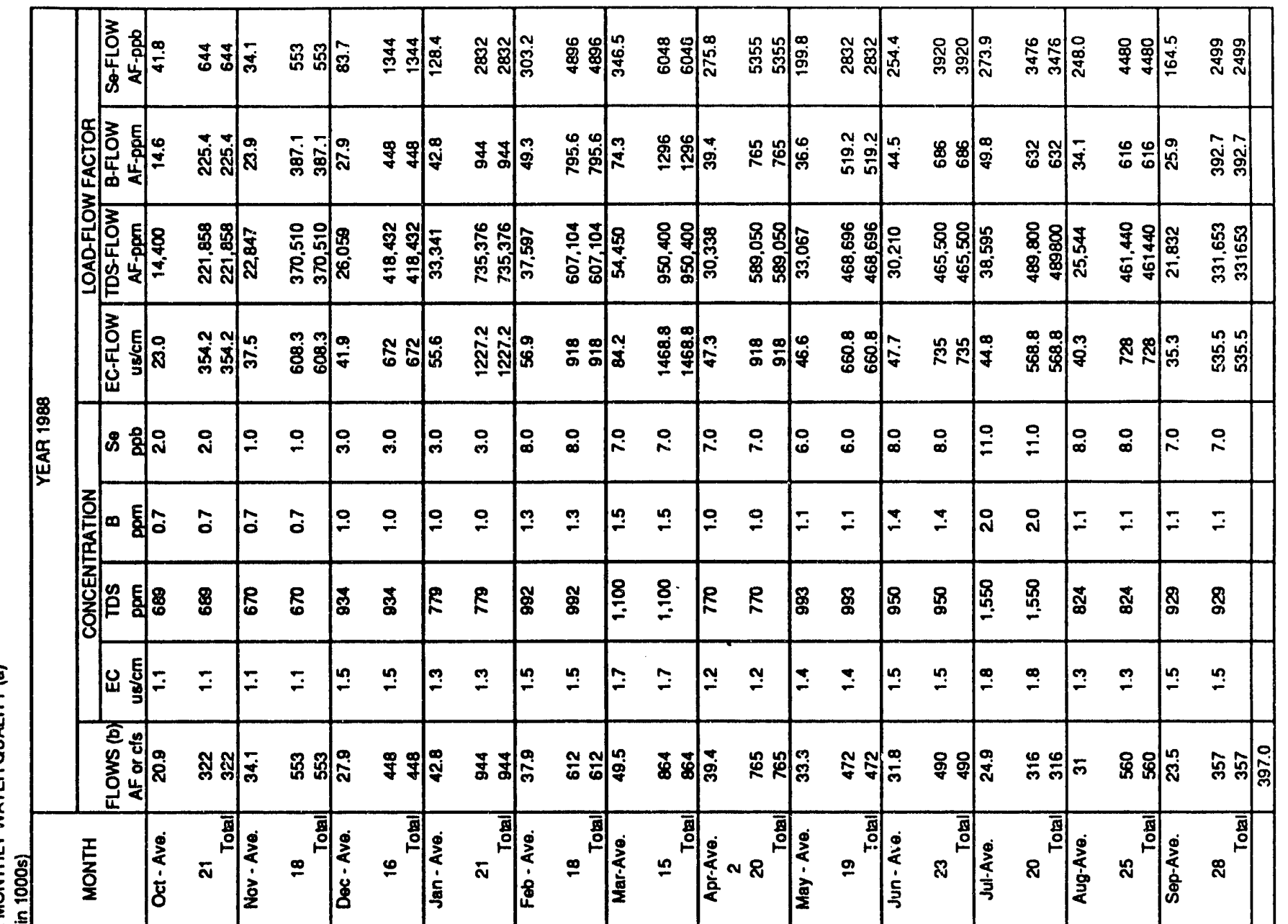

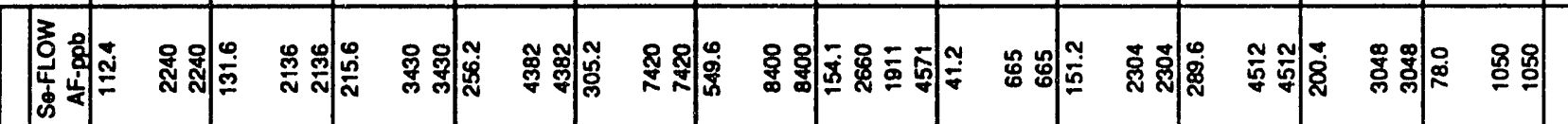

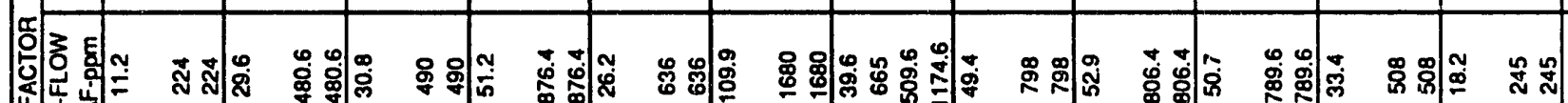

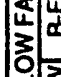

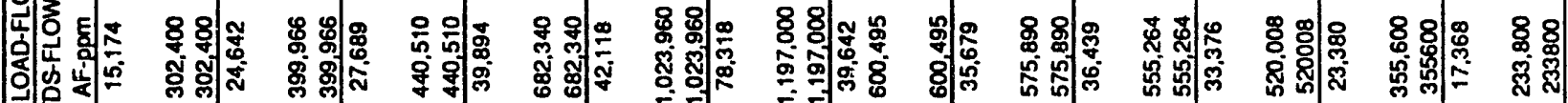

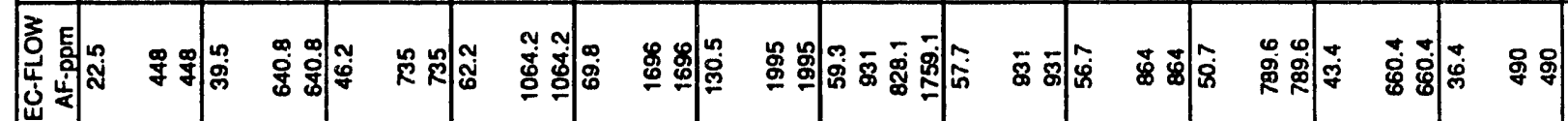

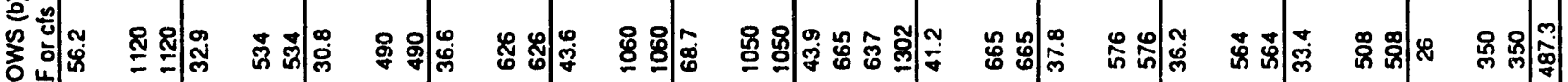

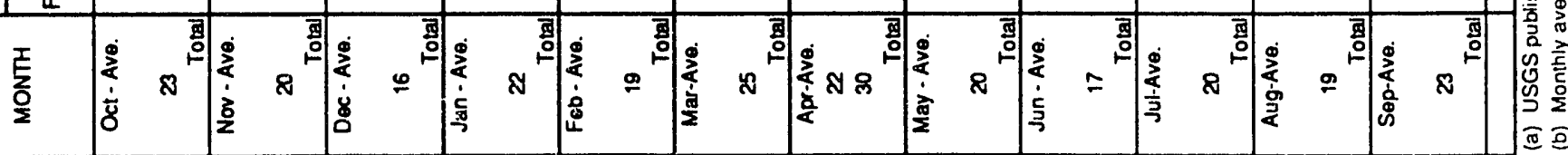




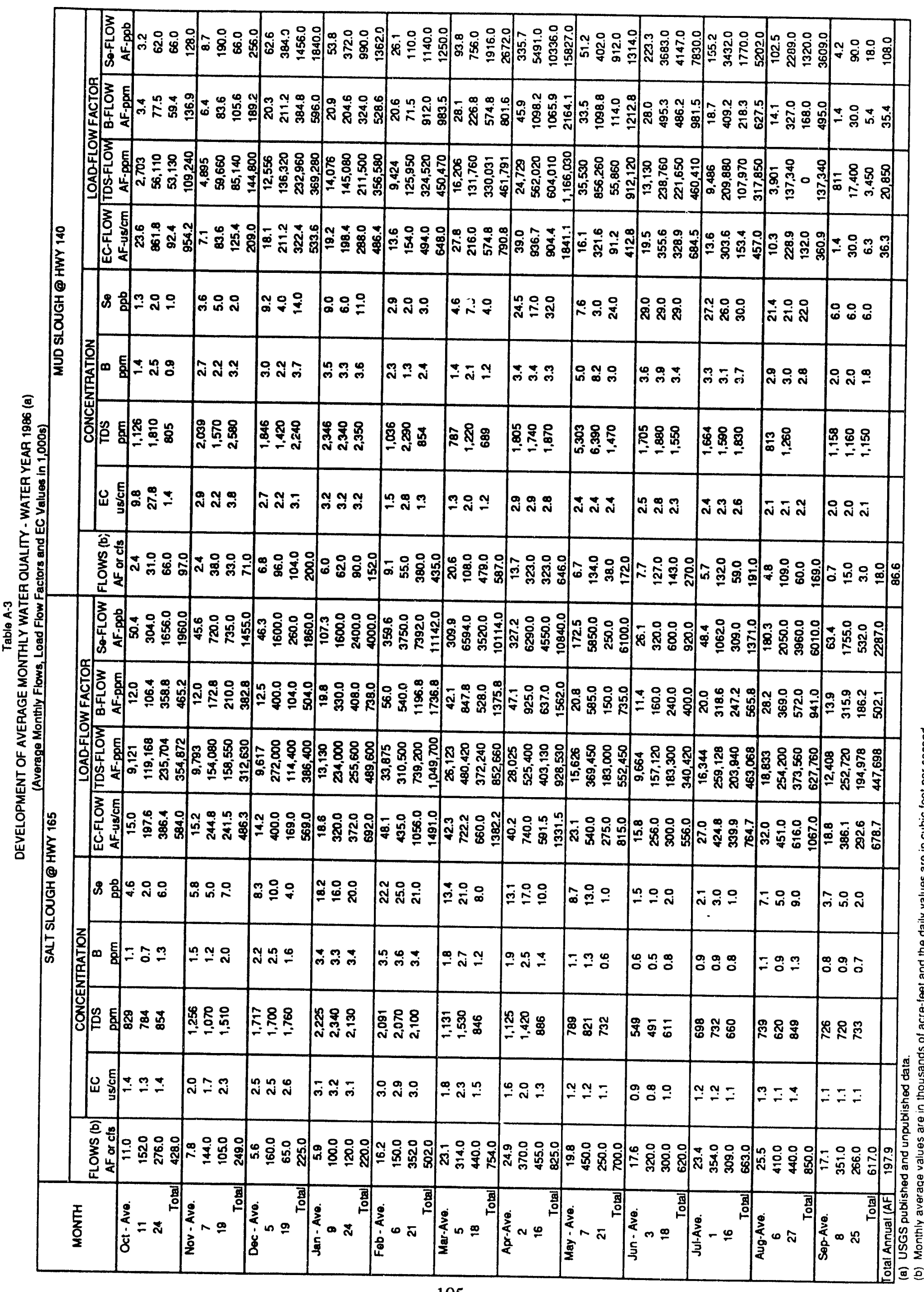




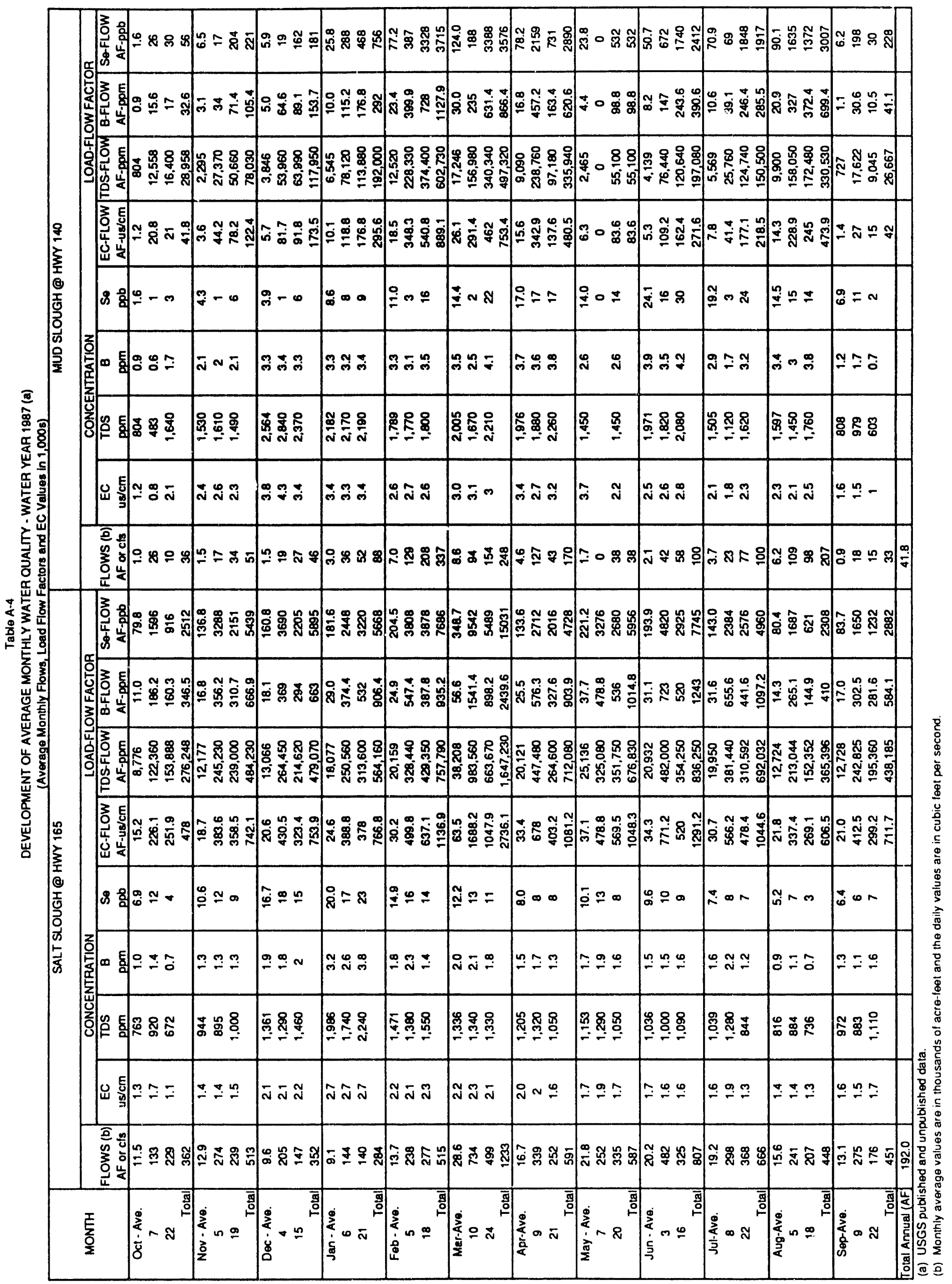




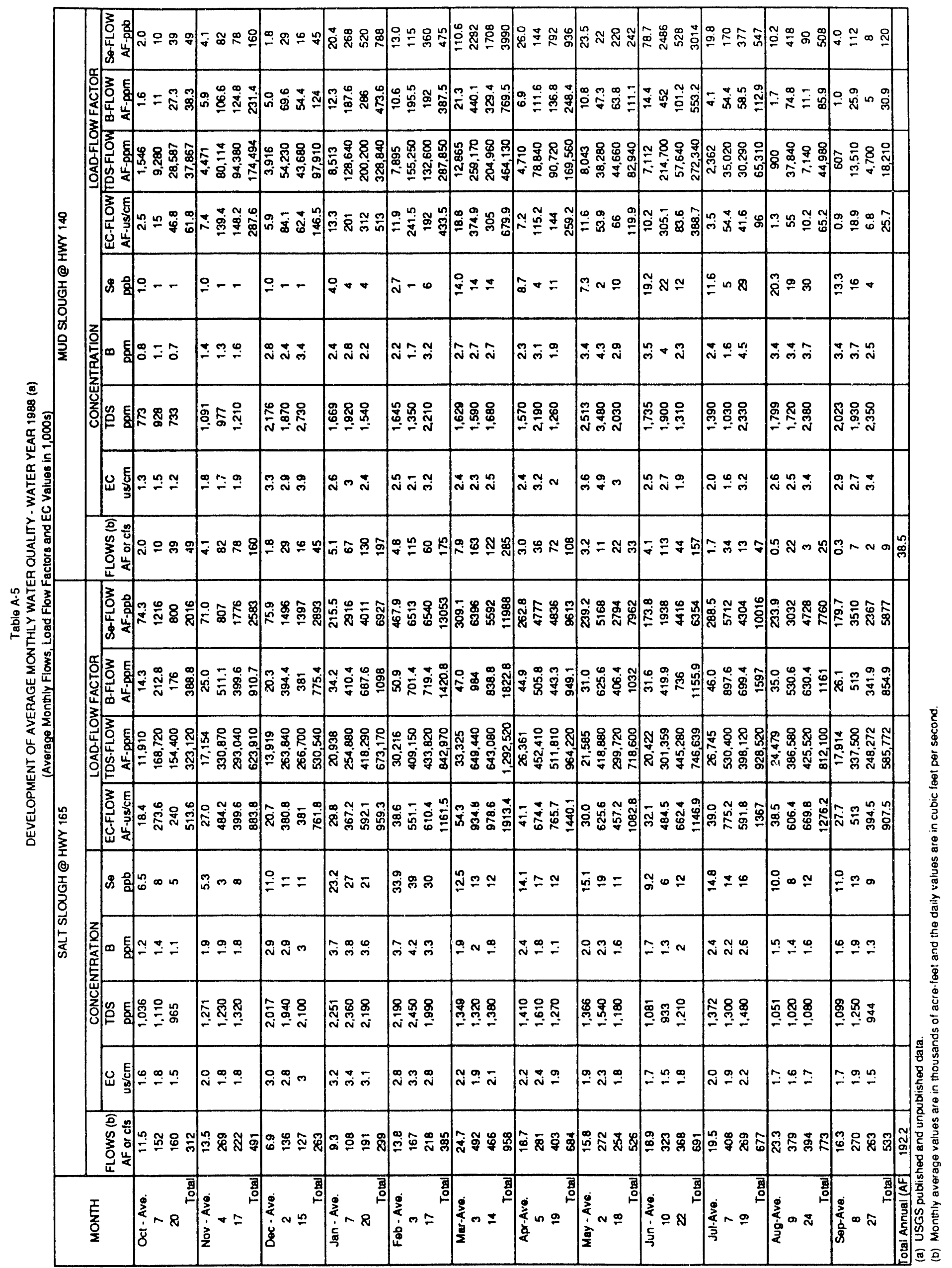


Table A-6

SAN JOAQUIN RIVER nT NEWMAN AVERAGE MONTHLY WATER QUALITY - WATER YEAR 1989(a) (Flows and Salt Loads in 1000s)

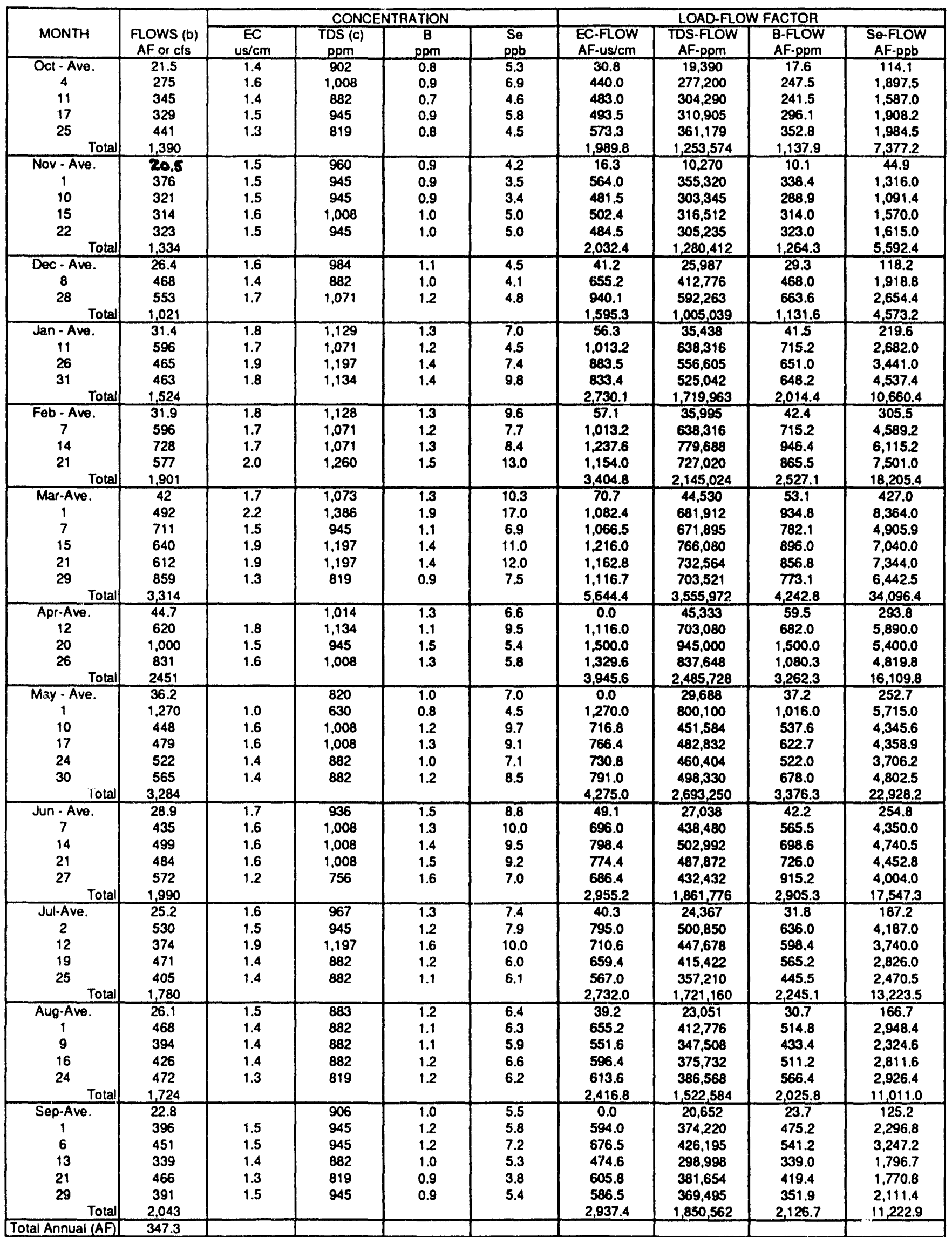

(a) USGS flow data near Newman and Calif. RWCCB water quality data at Crows Landing from their December 1990 report on the lower San Joaquin River.

(b) Monthly average values are in thousands of acre-leet and the daily values are in cubic leet per second.

(c) Daily TDS values calculated as 0.63 times the recorded EC values measured at the Crows Landing CVAWOCB monitoring station. The 0.64 EC to TOS conversion factor was determined from the 1987 and 1988 USGS data obtained at the Newman station. 
Table A.7

SALT SLOUGH AT HWY 165 AVERAGE MONTHLY WATER QUALTTY - WATER YEAR1989 (a)

(Average Monthly Flows, Load Flow Factors and EC Values in 1,000s)

\begin{tabular}{|c|c|c|c|c|c|c|c|c|c|}
\hline \multirow[b]{2}{*}{ MONTH } & \multirow[b]{2}{*}{$\begin{array}{c}\text { FLOWS (b) } \\
\text { AF or cts }\end{array}$} & \multicolumn{4}{|c|}{ CONCENTRATION } & \multicolumn{4}{|c|}{ LOAD-FLOWFACTOA } \\
\hline & & $\begin{array}{c}\text { EC } \\
\mathrm{us} / \mathrm{cm}\end{array}$ & $\begin{array}{l}\text { TDS } \\
\text { ppm }\end{array}$ & $\begin{array}{c}\text { B } \\
\mathrm{ppm}\end{array}$ & $\begin{array}{r}\text { Se } \\
\text { ppb }\end{array}$ & $\begin{array}{l}\text { EC-FLOW } \\
\text { AF-Us/cm }\end{array}$ & $\begin{array}{l}\text { TDS-FLOW } \\
\text { AF-ppm }\end{array}$ & $\begin{array}{l}\text { B-FLOW } \\
\text { AF-ppm }\end{array}$ & $\begin{array}{c}\text { So-FLOW } \\
\text { AF-ppb }\end{array}$ \\
\hline Oct-Ave. & 15.6 & 1.5 & 958 & 1.0 & 7.9 & 23.0 & 14,945 & 15.7 & 122.8 \\
\hline 4 & 236 & 1.7 & 1.105 & 1.3 & 15.0 & 401.2 & 260,780 & 306.8 & $3,540.0$ \\
\hline 11 & 245 & 1.4 & 910 & 0.8 & 7.5 & 343.0 & 222,950 & 196.0 & $1,837.5$ \\
\hline 17 & 247 & 1.3 & 845 & 0.7 & 2.7 & 321.1 & 208,715 & 172.9 & 666.9 \\
\hline 25 & 295 & 1.5 & 975 & 1.2 & 6.8 & 442.5 & 287,625 & 354.0 & $2,006.0$ \\
\hline Total & 1023 & & & & & $1,507.8$ & 980,070 & $1,029.7$ & $8,050.4$ \\
\hline Nov - Ave. & 10.7 & 2.0 & 1,264 & 1.5 & 7.6 & 21.1 & 13,521 & 15.8 & 81.6 \\
\hline 1 & 272 & 1.6 & 1,024 & 1.1 & 6.2 & 435.2 & 278,528 & 299.2 & $1,686.4$ \\
\hline 10 & 162 & 2.1 & 1,344 & 1.6 & 7.0 & 340.2 & 217,728 & 259.2 & $1,134.0$ \\
\hline 15 & 167 & 2.0 & 1,280 & 1.5 & 6.7 & 334.0 & 213,760 & 250.5 & $1,118.9$ \\
\hline \multirow{2}{*}{ Total } & $\begin{array}{l}147 \\
748\end{array}$ & 2.5 & 1,600 & 2.0 & 12.0 & 367.5 & 235,200 & 294.0 & $1,764.0$ \\
\hline & 748 & & & & & $1,476.9$ & 945,216 & $1,102.9$ & $5,703.3$ \\
\hline $\begin{array}{c}\text { Dec - Ave. } \\
8\end{array}$ & 9.7 & 2.4 & 1,634 & 2.1 & 9.1 & 23.7 & 15,854 & 20.7 & 88.4 \\
\hline & 174 & 2.0 & 1,340 & 1.6 & 5.4 & 348.0 & 233,160 & 278.4 & 939.6 \\
\hline 28 & 166 & 2.9 & 1,943 & 2.7 & 13.0 & 481.4 & 322,538 & 448.2 & $2,158.0$ \\
\hline Total & 340 & & & & & 829.4 & 555,688 & 726.6 & $3,097.6$ \\
\hline Jan-Ave. & 8.6 & 3.0 & 1,965 & 3.1 & 25.5 & 25.6 & 16,898 & 26.9 & 219.3 \\
\hline 11 & 140 & 2.8 & 1,960 & 2.8 & 15.0 & 392.0 & 274,400 & 392.0 & $2,100.0$ \\
\hline 26 & 126 & 3.4 & 2,176 & 3.4 & 33.0 & 428.4 & 274,176 & 428.4 & $4,158.0$ \\
\hline 31 & 150 & 2.8 & 1.792 & 3.2 & 29.0 & 420.0 & 268,800 & 480.0 & $4,350.0$ \\
\hline Total & 416 & & & & & $1,240.4$ & 817,376 & $1,300.4$ & $10,608.0$ \\
\hline Feb-Ave. & 13.2 & 2.7 & 2,097 & 2.5 & 22.2 & 35.5 & 27,679 & 33.2 & 293.3 \\
\hline 7 & 224 & 2.8 & 2,184 & 2.7 & 23.0 & 627.2 & 489,216 & 604.8 & $5,152.0$ \\
\hline 14 & 293 & 2.4 & 1,872 & 2.2 & 18.0 & 703.2 & 548,496 & 644.6 & $5,274.0$ \\
\hline & 281 & 2.9 & 2,262 & 2.7 & 26.0 & 814.9 & 635,622 & 758.7 & $7,306.0$ \\
\hline Total & 798 & & & & & $2,145.3$ & $1,673,334$ & $2,008.1$ & $17,732.0$ \\
\hline Mar-Ave. & 18.0 & 2.7 & 1.630 & 2.5 & 24.1 & 48.1 & 29,341 & 44.8 & 434.4 \\
\hline 1 & 195.0 & 3.4 & 2,074 & 3.9 & 38.0 & 663.0 & 404,430 & 760.5 & $7,410.0$ \\
\hline 7 & 228.0 & 2.9 & 1,769 & 2.7 & 24.0 & 661.2 & 403,332 & 615.6 & $5,472.0$ \\
\hline 15 & 269.0 & 2.9 & 1.769 & 2.5 & 20.0 & 700.1 & 475,861 & 672.5 & $5,380.0$ \\
\hline 21 & 287 & 2.8 & 1,708 & 2.7 & 31.0 & 803.6 & 490,196 & 774.9 & $8,897.0$ \\
\hline 29 & 434 & 2.0 & 1,220 & 1.6 & 16.0 & 868.0 & 529,480 & 694.4 & $6,944.0$ \\
\hline Total & 1413 & & & & & $3,775.9$ & $2,303,299$ & $3,517.9$ & $34,103.0$ \\
\hline Apr-Ave. & 18.7 & 2.3 & 1,490 & 2.4 & 19.9 & 43.5 & 27,870 & 44.9 & 372.8 \\
\hline 5 & 251 & 2.9 & 1,856 & 2.5 & 30.0 & 727.9 & 465,856 & 627.5 & $7,530.0$ \\
\hline 12 & 370 & 2.1 & 1,344 & 1.8 & 17.0 & 777.0 & 497,280 & 666.0 & $6,290.0$ \\
\hline 20 & 371 & 2.3 & 1,472 & 2.5 & 18.0 & 853.3 & 546,112 & 927.5 & $6,678.0$ \\
\hline 26 & 374 & 2.2 & 1,408 & 1.9 & 18.0 & 822.8 & 526,592 & 710.6 & $6,732.0$ \\
\hline Total & 1366 & & & & & $3,181.0$ & $2,035,840$ & $2,931.6$ & $27,230.0$ \\
\hline May-Ave. & 17.0 & 2.1 & 1,508 & 2.2 & 19.1 & 35.6 & 25,634 & 37.2 & 324.4 \\
\hline 1 & 266.0 & 2.5 & 1,800 & 2.7 & 28.0 & 665.0 & 478,800 & 718.2 & $7,448.0$ \\
\hline 10 & 235.0 & 2.2 & 1,584 & 2.4 & 22.0 & 517.0 & 372,240 & 564.0 & $5,170.0$ \\
\hline 17 & 277.0 & 2.2 & 1,584 & 2.2 & 18.0 & 609.4 & 438,768 & 609.4 & $4,986.0$ \\
\hline 24 & 326 & 1.7 & 1.224 & 1.6 & 14.0 & 554.2 & 399,024 & 521.6 & $4,564.0$ \\
\hline 30 & 356 & 2.0 & 1,440 & 2.2 & 16.0 & 712.0 & 512,640 & 783.2 & $5,696.0$ \\
\hline Total & 1460 & & & & & $3,057.6$ & $2,201,472$ & $3,196.4$ & $27,864.0$ \\
\hline Jun - Ave. & 19.9 & 1.9 & 1,235 & 2.1 & 19.1 & 38.4 & 24,574 & 42.1 & 380.0 \\
\hline 7 & 257 & 2.5 & 1,600 & 2.6 & 27.0 & 642.5 & 411,200 & 668.2 & $6,939.0$ \\
\hline 14 & 290 & 2.1 & 1,344 & 2.2 & 19.0 & 609.0 & 389,760 & 638.0 & $5,510.0$ \\
\hline 21 & 347 & 2.1 & 1,344 & 2.4 & 19.0 & 728.7 & 466,368 & 832.8 & $6,593.0$ \\
\hline 27 & 482 & 1.4 & 896 & 1.6 & 15.0 & 674.8 & 431,872 & 771.2 & $7,230.0$ \\
\hline Total & 1376 & & & & & $2,655.0$ & $1,699,200$ & 2.910 .2 & $26,272.0$ \\
\hline Jul-Ave. & 20.5 & 1.7 & 1,200 & 1.8 & 12.4 & 35.7 & 24,600 & 37.6 & 254.1 \\
\hline 5 & 308 & 1.9 & 1,311 & 2.0 & 13.0 & 585.2 & 403,788 & 616.0 & $4,004.0$ \\
\hline 12 & 314 & 2.0 & 1.380 & 2.2 & 16.0 & 628.0 & 433,320 & 690.8 & $5,024.0$ \\
\hline 19 & 363 & 1.5 & 1,035 & 1.5 & 10.0 & 544.5 & 375,705 & 544.5 & $3,630.0$ \\
\hline 25 & 321 & 1.6 & 1,104 & 1.7 & 11.0 & 513.6 & 354,384 & 545.7 & $3,531.0$ \\
\hline Total & 1306 & & & & & $2,271.3$ & $1,567,197$ & $2,397.0$ & $16,189.0$ \\
\hline Aug-Ave. & 22.5 & 1.5 & 960 & 1.5 & 9.0 & 33.8 & 21,605 & 34.6 & 203.6 \\
\hline 1 & 495 & 1.3 & 832 & 1.2 & 7.4 & 643.5 & 411,840 & 594.0 & $3,663.0$ \\
\hline 9 & 322 & 1.7 & 1,088 & 1.8 & 11.0 & 547.4 & 350,336 & 579.6 & $3,542.0$ \\
\hline 16 & 351 & 1.6 & 1,024 & 1.7 & 9.4 & 561.6 & 359,424 & 596.7 & $3,299.4$ \\
\hline 24 & 431 & 1.5 & 960 & 1.6 & 9.2 & 646.5 & 413,760 & 689.6 & $3,965.2$ \\
\hline Total & 1599 & & & & & $2,399.0$ & $1,535,360$ & $2,459.9$ & $14,469.6$ \\
\hline Sep-Ave. & 15.7 & 1.6 & 1,065 & 1.6 & 12.9 & 25.7 & 16,713 & 24.5 & 201.8 \\
\hline 1 & 312 & 1.6 & 1,040 & 1.6 & 11.0 & 499.2 & 324,480 & 499.2 & $3,432.0$ \\
\hline 6 & 323 & 1.6 & 1,040 & 1.5 & 10.0 & 516.8 & 335,920 & 484.5 & $3,230.0$ \\
\hline 13 & 269 & 1.5 & 975 & 1.4 & 12.0 & 403.5 & $26 \%: 275$ & 376.6 & $3,228.0$ \\
\hline 21 & 250 & 1.7 & 1,105 & 1.6 & 14 & 425.0 & $27 f \cdot, 250$ & 400.0 & $3,500.0$ \\
\hline 29 & 280 & 1.8 & 1.170 & 1.7 & 18 & 504.0 & $32 ;, 600$ & 476.0 & $5,040.0$ \\
\hline Total & 1434 & & & & & $2,348.5$ & $1,526,525$ & $2,236.3$ & $18,430.0$ \\
\hline tal Annual (AF) & 190.1 & & & & & & & & \\
\hline
\end{tabular}

(a) USGS published and unpublished data and Calif. Reg. Water quality Control Board data from December 1990 report on the lower San Joaquin River.

(b) Monthly average values are In thousands of acre-teet and the dally values are in cublc foet per second. 
MUD SLOUGH AT HWY 140 AVERAGE MONTHLY WATER QUALTY - WATER YEAR1989 (a) (Average Monthly Flows, Load Flow Factors and EC Values in 1,000s)

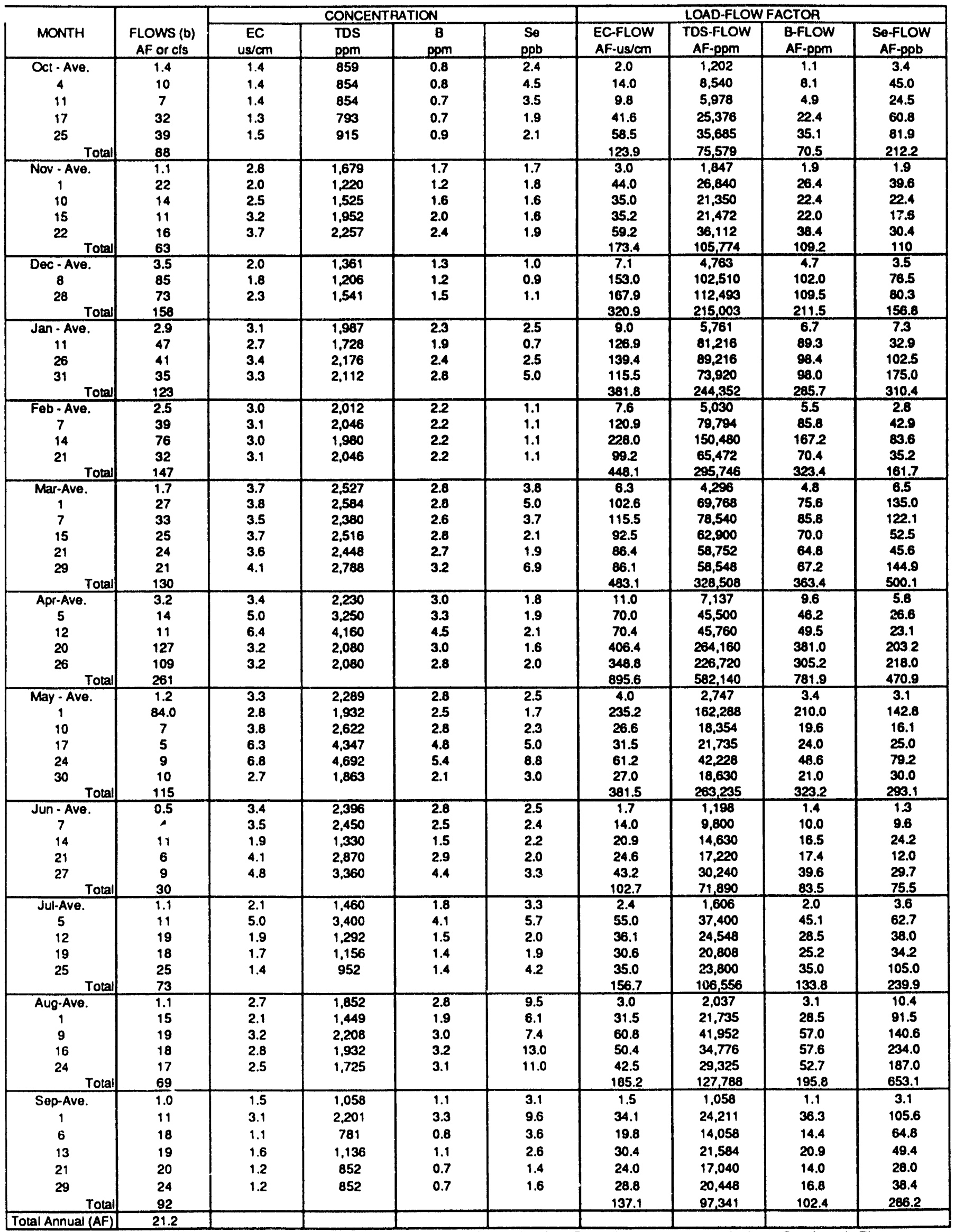

(a) USGS published and unpublished data and Callf. Reg. Water quality Control Board data from December 1990 report on the lower San Joaquin River.

(b) Monthly average values are in thousands of acre-feet and the daily values are in cublc feet per second. 
Table A-9

SAN JOAOUIN RIVER nr NEWMAN AVERAGE MONTHLY WATER QUALITY - WATER YEAR 1990(a)

(Flows and Salt Loads in 1000s)

\begin{tabular}{|c|c|c|c|c|c|c|c|c|c|}
\hline \multirow[b]{2}{*}{ MONTH } & \multirow[b]{2}{*}{$\begin{array}{l}\text { FLOWS (b) } \\
\text { AF or cts }\end{array}$} & \multicolumn{4}{|c|}{ CONCENTRATION } & \multicolumn{4}{|c|}{ LOAD.FLOWFACTOR } \\
\hline & & $\begin{array}{c}\text { EC } \\
\mathrm{us} / \mathrm{cm}\end{array}$ & $\begin{array}{l}\text { TDS (c) } \\
\mathrm{ppm}\end{array}$ & pom & $\begin{array}{l}\text { Se } \\
\text { ppb }\end{array}$ & $\begin{array}{l}\text { EC-FLOW } \\
\text { AF-us/cm }\end{array}$ & $\begin{array}{l}\text { TDS-FLOW } \\
\text { A:-ppm }\end{array}$ & $\begin{array}{l}\text { B.FLOW } \\
\text { AF-ppm }\end{array}$ & $\begin{array}{c}\text { So-FLOW } \\
\text { AF-pob }\end{array}$ \\
\hline $\begin{array}{c}\text { Oct - Ave. } \\
6 \\
13 \\
20 \\
30 \\
\\
\end{array}$ & $\begin{array}{c}27.8 \\
378 \\
348 \\
395 \\
621 \\
1742 \\
\end{array}$ & $\begin{array}{l}1.3 \\
1.6 \\
1.2 \\
1.2 \\
1.2\end{array}$ & $\begin{array}{c}811 \\
1.008 \\
756 \\
756 \\
756\end{array}$ & $\begin{array}{l}0.9 \\
1.0 \\
0.7 \\
0.8 \\
0.9\end{array}$ & $\begin{array}{l}3.6 \\
5.9 \\
4.0 \\
2.1 \\
2.8\end{array}$ & $\begin{array}{c}35.8 \\
604.8 \\
417.6 \\
474.0 \\
745.2 \\
2,241.6 \\
\end{array}$ & $\begin{array}{c}22,537 \\
381,024 \\
263,088 \\
298,620 \\
469,476 \\
1,412,208 \\
\end{array}$ & $\begin{array}{c}23.9 \\
378.0 \\
243.6 \\
316.0 \\
558.9 \\
1,496.5 \\
\end{array}$ & $\begin{array}{c}98.8 \\
2,230.2 \\
1.392 .0 \\
829.5 \\
1,738.8 \\
6,190.5 \\
\end{array}$ \\
\hline 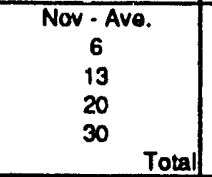 & $\begin{array}{l}35.8 \\
568 \\
613 \\
584 \\
652 \\
2417\end{array}$ & $\begin{array}{l}1.3 \\
1.3 \\
1.3 \\
1.3 \\
1.3\end{array}$ & $\begin{array}{l}819 \\
819 \\
819 \\
819 \\
819\end{array}$ & $\begin{array}{l}0.9 \\
0.9 \\
0.8 \\
0.9 \\
0.9\end{array}$ & $\begin{array}{l}3.5 \\
3.9 \\
2.9 \\
3.9 \\
3.5\end{array}$ & $\begin{array}{c}46.5 \\
738.4 \\
796.9 \\
759.2 \\
847.6 \\
3,142.1\end{array}$ & $\begin{array}{c}29,320 \\
465,192 \\
502,047 \\
478,296 \\
533,988 \\
1,979,523 \\
\end{array}$ & $\begin{array}{c}31.3 \\
511.2 \\
490.4 \\
525.6 \\
586.8 \\
2,114.0 \\
\end{array}$ & $\begin{array}{c}126.7 \\
2,215.2 \\
1,777.7 \\
2,277.6 \\
2,282.0 \\
8,552.5 \\
\end{array}$ \\
\hline 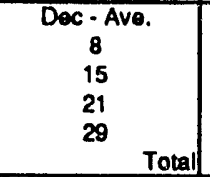 & $\begin{array}{l}36.2 \\
614 \\
604 \\
593 \\
553 \\
2364 \\
\end{array}$ & $\begin{array}{l}1.5 \\
1.3 \\
1.5 \\
1.6 \\
1.6\end{array}$ & $\begin{array}{c}943 \\
819 \\
945 \\
1,008 \\
1,008\end{array}$ & $\begin{array}{l}1.0 \\
0.9 \\
1.0 \\
1.1 \\
1.1\end{array}$ & $\begin{array}{l}5.7 \\
3.9 \\
5.5 \\
5.8 \\
7.9\end{array}$ & $\begin{array}{c}54.2 \\
798.2 \\
806.0 \\
948.8 \\
884.8 \\
3,537.8\end{array}$ & $\begin{array}{c}34,130 \\
502,866 \\
570,780 \\
597,744 \\
557,424 \\
2,228,814\end{array}$ & $\begin{array}{c}37.0 \\
552.6 \\
604.0 \\
652.3 \\
608.3 \\
2.417 .2\end{array}$ & $\begin{array}{c}207.1 \\
2,394.6 \\
3,322.0 \\
3,439.4 \\
4,368.7 \\
13,524.7\end{array}$ \\
\hline \begin{tabular}{cc|} 
Jan - Ave. & \\
5 & \\
11 & \\
19 & \\
26 & \\
& Total \\
\end{tabular} & $\begin{array}{c}34.8 \\
530 \\
540 \\
622 \\
552 \\
2244 \\
\end{array}$ & $\begin{array}{l}1.8 \\
1.8 \\
1.9 \\
1.7 \\
2.0\end{array}$ & $\begin{array}{l}1.163 \\
1.134 \\
1.197 \\
1.071 \\
1.260\end{array}$ & $\begin{array}{l}1.3 \\
1.2 \\
1.3 \\
1.2 \\
1.5\end{array}$ & $\begin{array}{c}8.9 \\
8.4 \\
8.3 \\
7.2 \\
11.0\end{array}$ & $\begin{array}{c}64.2 \\
854.0 \\
1,026.0 \\
1,057.4 \\
1.104 .0 \\
4,141.4 \\
\end{array}$ & $\begin{array}{c}40,462 \\
601,020 \\
646,380 \\
666,162 \\
695,520 \\
2,609,082 \\
\end{array}$ & $\begin{array}{c}45.2 \\
636.0 \\
702.0 \\
746.4 \\
828.0 \\
2.912 .4 \\
\end{array}$ & $\begin{array}{c}310.5 \\
4,452.0 \\
5,022.0 \\
4,478.4 \\
6,072.0 \\
20,024.4 \\
\end{array}$ \\
\hline \begin{tabular}{cc|} 
Fob-Ave. \\
2 \\
2 \\
9 \\
19 \\
26 & \\
& Total \\
\end{tabular} & $\begin{array}{c}37.4 \\
575 \\
625 \\
827 \\
693 \\
2720 \\
\end{array}$ & $\begin{array}{l}1.8 \\
1.8 \\
1.9 \\
1.8 \\
1.8\end{array}$ & $\begin{array}{l}1,148 \\
1,134 \\
1,197 \\
1,134 \\
1,134\end{array}$ & $\begin{array}{l}1.5 \\
1.4 \\
1.6 \\
1.5 \\
1.6\end{array}$ & $\begin{array}{l}12.0 \\
13.0 \\
12.0 \\
12.0 \\
11.0\end{array}$ & $\begin{array}{c}68.2 \\
1,035.0 \\
1,187.5 \\
1,488.6 \\
1,247.4 \\
4,958.5 \\
\end{array}$ & $\begin{array}{c}42,953 \\
652,050 \\
748,125 \\
937,818 \\
785,862 \\
3,123,855 \\
\end{array}$ & $\begin{array}{c}57.1 \\
805.0 \\
1,000.0 \\
1,240.5 \\
1,108.8 \\
4,154.3 \\
\end{array}$ & $\begin{array}{c}47.2 \\
7,475.0 \\
7,500.0 \\
9,924.0 \\
7,623.0 \\
32,522.0 \\
\end{array}$ \\
\hline 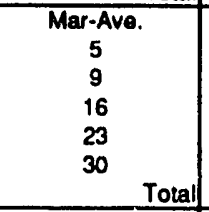 & $\begin{array}{c}38.1 \\
677 \\
637 \\
634 \\
609 \\
503 \\
3060 \\
\end{array}$ & $\begin{array}{l}2.0 \\
1.9 \\
1.9 \\
2.0 \\
2.0 \\
2.0\end{array}$ & $\begin{array}{l}1,233 \\
1,197 \\
1.197 \\
1.260 \\
1,260 \\
1,260\end{array}$ & $\begin{array}{l}1.5 \\
1.7 \\
1.4 \\
1.3 \\
1.4 \\
1.5\end{array}$ & $\begin{array}{c}11.0 \\
12.0 \\
12.0 \\
11.0 \\
9.9 \\
10.0\end{array}$ & $\begin{array}{c}74.6 \\
1,286.3 \\
1,210.3 \\
1,268.0 \\
1,218.0 \\
1,006.0 \\
5,988.6 \\
\end{array}$ & $\begin{array}{c}46,975 \\
810,369 \\
762,489 \\
798,840 \\
767,340 \\
633,780 \\
3,772,818 \\
\end{array}$ & $\begin{array}{c}55.7 \\
1,150.9 \\
891.8 \\
824.2 \\
852.6 \\
754.5 \\
4.474 .0 \\
\end{array}$ & $\begin{array}{c}420.9 \\
8,124.0 \\
7,644.0 \\
6,974.0 \\
6,029.1 \\
5,030.0 \\
33,801.1 \\
\end{array}$ \\
\hline \begin{tabular}{cc|} 
Apr-Ave. \\
6 \\
12 \\
20 \\
27 & \\
& Total \\
\end{tabular} & $\begin{array}{c}30.1 \\
454 \\
465 \\
567 \\
487 \\
1973 \\
\end{array}$ & $\begin{array}{l}2.0 \\
2.0 \\
1.9 \\
2.0 \\
2.0\end{array}$ & $\begin{array}{l}1.245 \\
1.260 \\
1.197 \\
1.260 \\
1.260\end{array}$ & $\begin{array}{l}1.4 \\
1.4 \\
1.3 \\
1.7 \\
1.3\end{array}$ & $\begin{array}{l}7.9 \\
8.8 \\
7.8 \\
8.6 \\
6.5\end{array}$ & $\begin{array}{c}59.5 \\
809.0 \\
883.5 \\
1.134 .0 \\
974.0 \\
3.899 .5 \\
\end{array}$ & $\begin{array}{c}37,479 \\
572,040 \\
556,605 \\
714,420 \\
613,620 \\
2,456,685 \\
\end{array}$ & $\begin{array}{c}43.3 \\
635.6 \\
604.5 \\
963.9 \\
633.1 \\
2.837 .1 \\
\end{array}$ & $\begin{array}{c}239.0 \\
3,995.2 \\
3,627.0 \\
4,876.2 \\
3,165.5 \\
15,663.9\end{array}$ \\
\hline 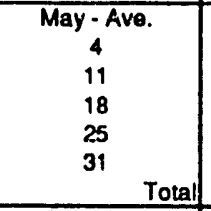 & $\begin{array}{c}25.6 \\
397.0 \\
306.0 \\
306.0 \\
384 \\
733 \\
2126 \\
\end{array}$ & $\begin{array}{l}1.7 \\
1.8 \\
1.8 \\
1.9 \\
1.9 \\
1.5\end{array}$ & $\begin{array}{c}1.089 \\
1.134 \\
1.134 \\
1,197 \\
1,197 \\
945\end{array}$ & $\begin{array}{l}1.3 \\
1.3 \\
1.4 \\
1.6 \\
1.5 \\
1.0\end{array}$ & $\begin{array}{c}9.4 \\
9.4 \\
10.0 \\
12.0 \\
11.0 \\
7.2\end{array}$ & $\begin{array}{c}44.3 \\
714.6 \\
550.8 \\
581.4 \\
729.6 \\
1,099.5 \\
3,675.9 \\
\end{array}$ & $\begin{array}{c}27,886 \\
450,198 \\
347,004 \\
366,282 \\
459,648 \\
692,685 \\
2,315,817 \\
\end{array}$ & $\begin{array}{c}33.0 \\
516.1 \\
428.4 \\
489.6 \\
576.0 \\
733.0 \\
2.743 .1 \\
\end{array}$ & $\begin{array}{c}240.4 \\
3,731.8 \\
3,060.0 \\
3,672.0 \\
4,224.0 \\
5,277.6 \\
19,965.4 \\
\end{array}$ \\
\hline $\begin{array}{c}\text { Jun - Ave. } \\
8 \\
15 \\
22 \\
28 \\
\\
\\
\end{array}$ & $\begin{array}{c}21.5 \\
313 \\
294 \\
303 \\
269 \\
1179 \\
\end{array}$ & $\begin{array}{l}1.7 \\
1.8 \\
1.8 \\
1.9 \\
1.4\end{array}$ & $\begin{array}{c}1.093 \\
1.134 \\
1.134 \\
1.197 \\
882\end{array}$ & $\begin{array}{l}1.4 \\
1.1 \\
1.5 \\
1.7 \\
1.2\end{array}$ & $\begin{array}{l}7.4 \\
8.4 \\
7.6 \\
9.4 \\
3.7\end{array}$ & $\begin{array}{c}37.3 \\
563.4 \\
529.2 \\
575.7 \\
376.6 \\
2,044.9 \\
\end{array}$ & $\begin{array}{c}23,493 \\
354,942 \\
333,396 \\
362,691 \\
237,258 \\
1,288,287\end{array}$ & $\begin{array}{c}29.6 \\
344.3 \\
441.0 \\
515.1 \\
322.8 \\
1,623.2 \\
\end{array}$ & $\begin{array}{c}158.8 \\
2,629.2 \\
2,234.4 \\
2,848.2 \\
995.3 \\
8,707.1 \\
\end{array}$ \\
\hline \begin{tabular}{cc|} 
Jul-Ave. & \\
6 & \\
13 & \\
20 & \\
27 & \\
& Total \\
\end{tabular} & $\begin{array}{c}20.1 \\
384 \\
225 \\
289 \\
332 \\
1230 \\
\end{array}$ & $\begin{array}{l}1.5 \\
1.6 \\
1.8 \\
1.5 \\
1.3\end{array}$ & $\begin{array}{c}965 \\
1,008 \\
1,134 \\
945 \\
819\end{array}$ & $\begin{array}{l}1.3 \\
1.4 \\
1.5 \\
1.2 \\
1.1\end{array}$ & $\begin{array}{l}5.9 \\
6.8 \\
6.1 \\
6.2 \\
4.5\end{array}$ & $\begin{array}{c}30.8 \\
614.4 \\
405.0 \\
433.5 \\
431.6 \\
1,884.5 \\
\end{array}$ & $\begin{array}{c}19,401 \\
387,072 \\
255,150 \\
273,105 \\
271,908 \\
1,187,235 \\
\end{array}$ & $\begin{array}{c}25.9 \\
537.6 \\
337.5 \\
346.8 \\
365.2 \\
1,587.1\end{array}$ & $\begin{array}{c}119.0 \\
2,611.2 \\
1,372.5 \\
1,791.8 \\
1,507.3 \\
7,282.8\end{array}$ \\
\hline \begin{tabular}{cc|} 
Aug-Ave. & \\
3 & \\
9 & \\
16 & \\
24 & \\
31 & \\
& Total \\
\end{tabular} & $\begin{array}{c}20.6 \\
299 \\
317 \\
333 \\
311 \\
258 \\
1518 \\
\end{array}$ & $\begin{array}{l}1.5 \\
1.9 \\
1.5 \\
1.3 \\
1.4 \\
1.6\end{array}$ & $\begin{array}{c}965 \\
1,197 \\
945 \\
819 \\
882 \\
1.008\end{array}$ & $\begin{array}{l}1.1 \\
1.3 \\
1.3 \\
0.9 \\
0.9 \\
1.2\end{array}$ & $\begin{array}{l}6.1 \\
7.4 \\
6.3 \\
4.8 \\
5.5 \\
6.8\end{array}$ & $\begin{array}{c}31.5 \\
568.1 \\
475.5 \\
432.9 \\
435.4 \\
412.8 \\
2,324.7 \\
\end{array}$ & $\begin{array}{c}19,875 \\
357,903 \\
299,565 \\
272.727 \\
274,302 \\
260,064 \\
1,464,561 \\
\end{array}$ & $\begin{array}{c}22.9 \\
388.7 \\
412.1 \\
299.7 \\
279.9 \\
309.6 \\
1,690 \\
\end{array}$ & $\begin{array}{c}125.8 \\
2.212 .6 \\
1,997.1 \\
1,598.4 \\
1.710 .5 \\
1,754.4 \\
9.273\end{array}$ \\
\hline $\begin{array}{|cc|}\text { Sep-Ave. } & \\
7 & \\
14 & \\
21 & \\
28 & \\
& \text { Total } \\
\end{array}$ & $\begin{array}{l}13.6 \\
264 \\
249 \\
180 \\
255 \\
948 \\
\end{array}$ & $\begin{array}{l}1.3 \\
1.3 \\
1.3 \\
1.2 \\
1.2\end{array}$ & $\begin{array}{l}790 \\
819 \\
819 \\
756 \\
756\end{array}$ & $\begin{array}{l}0.8 \\
0.8 \\
0.8 \\
0.7 \\
0.8\end{array}$ & $\begin{array}{l}3.4 \\
3.5 \\
2.8 \\
1.6 \\
5.3\end{array}$ & $\begin{array}{c}17.1 \\
343.2 \\
323.7 \\
216.0 \\
306.0 \\
1.188 .9 \\
\end{array}$ & $\begin{array}{c}10,745 \\
216,216 \\
203,931 \\
136,080 \\
192,780 \\
749,007 \\
\end{array}$ & $\begin{array}{c}10.6 \\
211.2 \\
199.2 \\
126.0 \\
204.0 \\
740.4 \\
\end{array}$ & $\begin{array}{c}46.8 \\
924.0 \\
697.2 \\
288.0 \\
1,351.5 \\
3,260.7 \\
\end{array}$ \\
\hline Total Annual (AF) & 341.6 & & & & & & & & \\
\hline
\end{tabular}

(a) USGS flow data near Nowman and Calit. RWOCB water quality data at Crows Landing from their December 1990 report on the lower San Joaquin Fliver.

(b) Monthly average values are in thousands of acre-feot and the daily values are in cubic feet per second.

(c) Daily YDS values calculated as 0.63 times the recorded EC values measured at the Crows Landing CVAWCCB monitoring station. The 0.64 EC $w$ TDS conversion factor was determined from the 1987 and 1988 USGS data obtained at the Newman station. 
Table A-10

SALT SLOUGH AT HWY 165 AVERAGE MONTHLY WATER QUALITY - WATER YEAR1990 (a)

(Average Monthly Flows, Load Flow Factors and EC Values in 1,000s)

\begin{tabular}{|c|c|c|c|c|c|c|c|c|c|}
\hline \multirow[b]{2}{*}{ MONTH } & \multirow[b]{2}{*}{$\begin{array}{l}\text { FLOWS (b) } \\
\text { AF or cfs }\end{array}$} & \multicolumn{4}{|c|}{ CONCENTRATION } & \multicolumn{4}{|c|}{ LOAD-F'OW FACTOR } \\
\hline & & $\begin{array}{c}E C \\
\mathrm{Us} / \mathrm{cm}\end{array}$ & $\begin{array}{l}\text { TDS } \\
\text { pgm }\end{array}$ & Bpm & $\begin{array}{l}\text { Se } \\
\text { ppb }\end{array}$ & $\begin{array}{l}\text { EC-FLOW } \\
\text { AF-us/cm }\end{array}$ & $\begin{array}{l}\text { TDS-FLOW } \\
\text { AF.ppm }\end{array}$ & $\begin{array}{l}\text { B-FLOW } \\
\text { AF-pom }\end{array}$ & $\begin{array}{l}\text { Se-FLOW } \\
\text { AF-ppb }\end{array}$ \\
\hline Oct - Ave. & 15.8 & 1.6 & 1,014 & 1.3 & 6.7 & 24.6 & 16,019 & 20.6 & 105.8 \\
\hline 6 & 246 & 1.6 & 1,040 & 1.3 & 8.7 & 393.6 & 255,840 & 318.8 & $2,140.2$ \\
\hline 13 & 193 & 1.4 & 910 & 1.1 & 5.4 & 270.2 & 175,630 & 212.3 & $1,042.2$ \\
\hline 20 & 212 & 1.6 & 1,040 & 1.5 & 9.2 & 339.2 & 220,460 & 318.0 & $1,950.4$ \\
\hline 30 & 309 & 1.6 & 1,040 & 1.3 & 4.2 & 494.4 & 321,360 & 401.7 & $1,297.8$ \\
\hline Total & 860 & & & & & $1,497.4$ & 973,310 & $1,251.8$ & $6,430.6$ \\
\hline Nov - Ave. & 16.4 & 1.8 & 1.131 & 1.4 & 8.5 & 29.0 & 18,554 & 23.5 & 139.8 \\
\hline 6 & 286 & 1.7 & 1,088 & 1.4 & 9.4 & 486.2 & 311,168 & 400.4 & $2,688.4$ \\
\hline 13 & 286 & 1.7 & 1,088 & 1.2 & 7.2 & 486.2 & 311.168 & 343.2 & $2,059.2$ \\
\hline 20 & 235 & 1.9 & 1,216 & 1.7 & 9.8 & 446.5 & 285,760 & 399.5 & $2,326.5$ \\
\hline Total & $\begin{array}{l}237 \\
1044\end{array}$ & 1.8 & 1,152 & 1.5 & 7.7 & $\begin{array}{c}426.6 \\
1,845.5\end{array}$ & $\begin{array}{c}273,024 \\
t, 181,120\end{array}$ & $\begin{array}{c}355.5 \\
1,498.6\end{array}$ & $\begin{array}{l}1,824.9 \\
8,899.0\end{array}$ \\
\hline Dec-Ave. & 12 & 2.3 & 1.569 & 2.0 & 14.1 & 28.1 & 18,828 & 24.4 & 169.2 \\
\hline 8 & 212 & 2.1 & 1.407 & 1.7 & 7.2 & 445.2 & 298,284 & 360.4 & $1,526.4$ \\
\hline 15 & 224 & 2.1 & 1.407 & & 11.0 & 470.4 & 315,168 & & $2,464.0$ \\
\hline 21 & 178 & 2.6 & 1.742 & 2.1 & 17.0 & 462.8 & 310,076 & 373.8 & $3,026.0$ \\
\hline & 166 & 2.7 & 1,809 & 2.4 & 24.0 & 448.2 & 300,294 & 398.4 & $3,984.0$ \\
\hline Total & 780 & & & & & $1,826.6$ & $1,223,822$ & 1,133 & 11,000 \\
\hline Jan-Ave. & 10.9 & 3.2 & 2,106 & 2.8 & 27.3 & 35.2 & 22,960 & 30.7 & 297.5 \\
\hline 5 & 175 & 2.8 & 1,960 & 2.3 & 22.0 & 490.0 & 343,000 & 402.5 & $3,850.0$ \\
\hline 11 & 183 & 3.1 & 1,984 & 3.0 & 26.0 & 567.3 & 363,072 & 549.0 & $4,758.0$ \\
\hline 19 & 181 & 3.0 & 1.920 & 2.9 & 27.0 & 543.0 & 347,520 & 524.9 & $4,887.0$ \\
\hline 26 & 158 & 4.1 & 2,624 & 3.1 & 35.0 & 647.8 & 414,592 & 489.8 & $5,530.0$ \\
\hline Total & 697 & & & & & $2,248.1$ & $1,468,184$ & $1,866.2$ & $19,025.0$ \\
\hline Fob-Ave. & 15 & 2.6 & 2,049 & 26 & 28.1 & 39.4 & 30.728 & 39.6 & 421.3 \\
\hline 2 & 211 & 3.0 & 2,340 & 2.9 & 36.0 & 633.0 & 493,740 & 611.9 & $7,596.0$ \\
\hline 19 & 306 & 2.5 & 1,950 & 2.6 & 30.0 & 765.0 & 596,700 & 795.6 & $9,180.0$ \\
\hline & 318 & 2.5 & 1,950 & 2.5 & 21.0 & 795.0 & 620,100 & 795.0 & $6,678.0$ \\
\hline Total & 835 & & & & & $2,193.0$ & $1,710,540$ & 2.202 .5 & $23,454.0$ \\
\hline Mar-Ave. & 19.1 & 2.6 & 1,611 & 2.6 & 22.3 & 50.5 & 30,776 & 48.9 & 426.8 \\
\hline 5 & 366 & 2.3 & 1.403 & 2.1 & 19.0 & 841.8 & 513,488 & 768.6 & $6,954.0$ \\
\hline 9 & 293 & 2.8 & 1,708 & 2.6 & $\mathbf{2 9 . 0}$ & 820.4 & 500,414 & 761.8 & $8,497.0$ \\
\hline 16 & 278 & 2.8 & 9,708 & 3.1 & 24.0 & 778.4 & 474,824 & 861.8 & 6,6720 \\
\hline 23 & 306 & 2.5 & 1,525 & 2.2 & 18.0 & 765.0 & 466,650 & 673.2 & $5,508.0$ \\
\hline 30 & 217 & 3.0 & 1,830 & 3.1 & 23.0 & 651.0 & 397,110 & 672.7 & $4,991.0$ \\
\hline Total & 1460 & & & & & $3,856.6$ & 2352,526 & 3.738 .1 & $32,622.0$ \\
\hline Apr-Ave. & 18.8 & 2.7 & 1,696 & 2.4 & 18.2 & 49.8 & 31,885 & 45.1 & 3424 \\
\hline 6 & 214 & 3.0 & 1,920 & 2.6 & 24.0 & 642.0 & 410,880 & 556.4 & $5,136.0$ \\
\hline 12 & 199 & 2.7 & 1,728 & 2.2 & 16.0 & 537.3 & 343,872 & 437.8 & $3,184.0$ \\
\hline 20 & 269 & 2.3 & 1,472 & 2.4 & 14.0 & 618.7 & 395,968 & 645.6 & $3,766.0$ \\
\hline & 187 & 2.7 & 1,728 & 2.6 & 20.0 & 504.9 & 323,136 & 486.2 & $3,740.0$ \\
\hline Total & 869 & & & & & 23029 & $1,473,856$ & $2,126.0$ & $15,826.0$ \\
\hline May-Ave. & 129 & 2.5 & 1,767 & 2.4 & 21.4 & 31.7 & 22.789 & 30.9 & 275.9 \\
\hline 4 & 165 & 2.7 & 1,944 & 27 & 28.0 & 445.5 & 320,760 & 445.5 & $4,620.0$ \\
\hline 11 & 175 & 2.7 & 1.944 & 2.8 & 31.0 & 472.5 & 340,200 & 480.0 & $5,425,0$ \\
\hline 18 & 153 & 2.9 & 2,088 & 3.0 & 25.0 & 443.7 & 319,464 & 459.0 & $3,825.0$ \\
\hline 25 & 236 & 2.0 & 1,440 & 1.6 & 14.0 & 472.0 & 339,840 & 377.6 & $3,304.0$ \\
\hline 31 & 293 & 2.3 & 1,656 & 2.3 & 16.0 & 673.9 & 485,208 & 673.9 & $4,688.0$ \\
\hline Total & 1022 & & & & & 2507.6 & $1,805,472$ & $2,446.0$ & 21,8620 \\
\hline Jun-Ave. & 10.9 & 2.7 & 1,699 & 3.0 & 17.3 & 28.9 & 18,518 & 324 & 188.1 \\
\hline 8 & 151 & 2.9 & 1,856 & 2.3 & 21.0 & 437.9 & 280,256 & 347.3 & $3,171.0$ \\
\hline 15 & 185 & 2.8 & 1.792 & 3.4 & 18.0 & 518.0 & 331,520 & 629.0 & $3,330.0$ \\
\hline 22 & 178 & 2.8 & 1,792 & 3.7 & 19.0 & 488.4 & 318,976 & 658.6 & $3,382,0$ \\
\hline 28 & 162 & 2.1 & 1,344 & 2.3 & 11.0 & 340.2 & $: 17.728$ & 372.6 & 1,7820 \\
\hline Total & 676 & & & & & $1,794.5$ & $1,146,480$ & $2,007.5$ & $11,665.0$ \\
\hline Jul-Ave. & 16.1 & 2.0 & 1,373 & 2.2 & 10.6 & 320 & 22,100 & 35.1 & 171.3 \\
\hline 6 & 273 & 2.0 & 1,380 & 2.2 & 12.0 & 546.0 & 376,740 & 600.6 & $3,276.0$ \\
\hline 13 & 157 & 2.4 & 1,656 & 3.0 & 13.0 & 376.8 & 250,992 & 471.0 & $2,041.0$ \\
\hline 20 & 240 & 1.8 & 1,242 & 1.8 & 8.2 & 432.0 & 288,080 & 432.0 & $1,968.0$ \\
\hline 27 & 245 & 1.9 & 1.311 & 2.0 & 10.0 & 465.5 & 321.195 & 490.0 & 2.450 .0 \\
\hline Total & 915 & & & & & $1,820.3$ & $1,256,007$ & $1,993.6$ & $9,735.0$ \\
\hline Aug-Ave. & 18.4 & 1.6 & 995 & 1.5 & 8.4 & 28.6 & 18,300 & 28.0 & 154.1 \\
\hline 3 & 237 & 1.9 & 1,216 & 2.4 & 10.0 & 450.3 & 288,192 & 568.8 & $2,370.0$ \\
\hline 9 & 274 & 1.7 & 1,088 & 1.7 & 9.6 & 465.8 & 298,112 & 465.8 & $2,630.4$ \\
\hline 16 & 298 & 1.4 & 896 & 1.1 & 6.3 & 417.2 & 267,008 & 327.8 & $1,877.4$ \\
\hline 31 & 215 & 1.2 & 768 & 0.9 & 7.9 & 258.0 & 165,120 & 193.5 & $1,698.5$ \\
\hline Total & 1024 & & & & & $1,591.3$ & $1,018,432$ & $1,555.9$ & $8,576.3$ \\
\hline Sep-Ave. & 122 & 1.8 & 1,202 & 1.5 & 11.8 & 226 & 14,668 & 18.5 & 143.9 \\
\hline 2 & 245 & 2.9 & 1,885 & 2.8 & 27.0 & 710.5 & 461,825 & 686.0 & $6,615.0$ \\
\hline 7 & 201 & 2.0 & 1,300 & 1.1 & 6.3 & 402.0 & 261,300 & 221.1 & $1,266.3$ \\
\hline 14 & 133 & 1.2 & 780 & 0.8 & 3.6 & 159.6 & 103,740 & 106.4 & 478.8 \\
\hline 21 & 165 & 1.3 & 845 & 1.2 & 9.1 & 214.5 & 139,425 & 188.0 & $1,501.5$ \\
\hline 28 & 201 & 1.3 & 845 & 1.1 & 6.4 & 261.3 & 169,845 & 221.1 & $1,286.4$ \\
\hline Total & 845 & & & & & $1,747.9$ & $1,136,135$ & $1,432.6$ & $11,148.0$ \\
\hline Total Annual (AF) & 178.5 & & & & & & & & \\
\hline
\end{tabular}

(a) USGS published and unpublished data and Calif. Reg. Water quality Control Board data from December 1990 report on the lower San Joaguin River.

(b) Monthly average values are in thousands of acre-leet and the daily values are in cubic feet per second. 
Table A-11

MUD SLOUGH AT HWY 140 AVERAGE MONTHLY WATER QUALTY - WATER YEAR1990 (a)

(Average Monthly Flows, Load Flow Factors and EC Values in 1,0008)

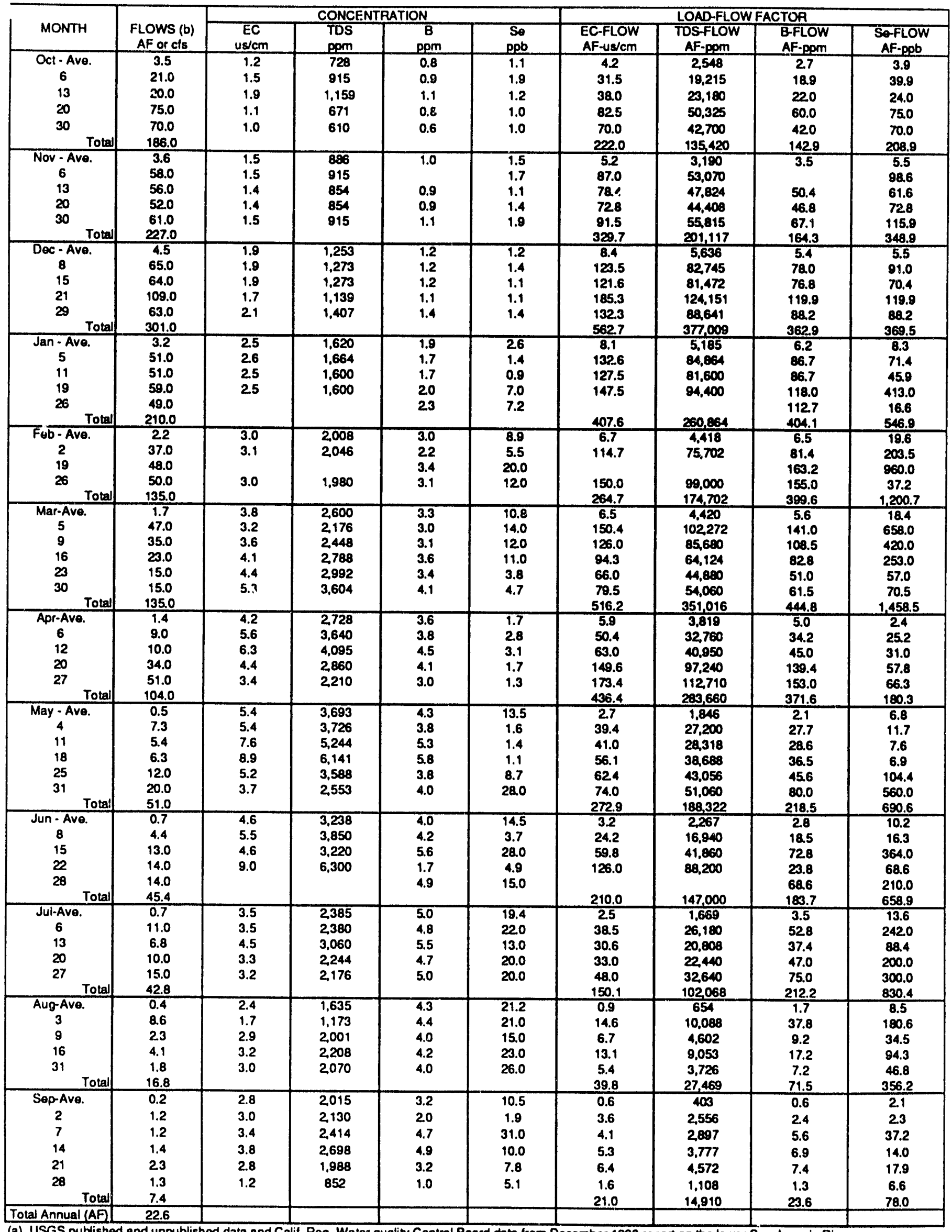

(a) USGS publishod and unpublished data and Calif. Reg. Wator quality Control Board data from December 1990 report on the lower San Joaquin Piver.

(b) Monthly average values are in thousands of acre-feet and the daily values are in cubic feet per second. 


\section{Appendix B}

Mass balance analysis for
boron, selenium and TDS

1988 hydrology

B1 - B28 


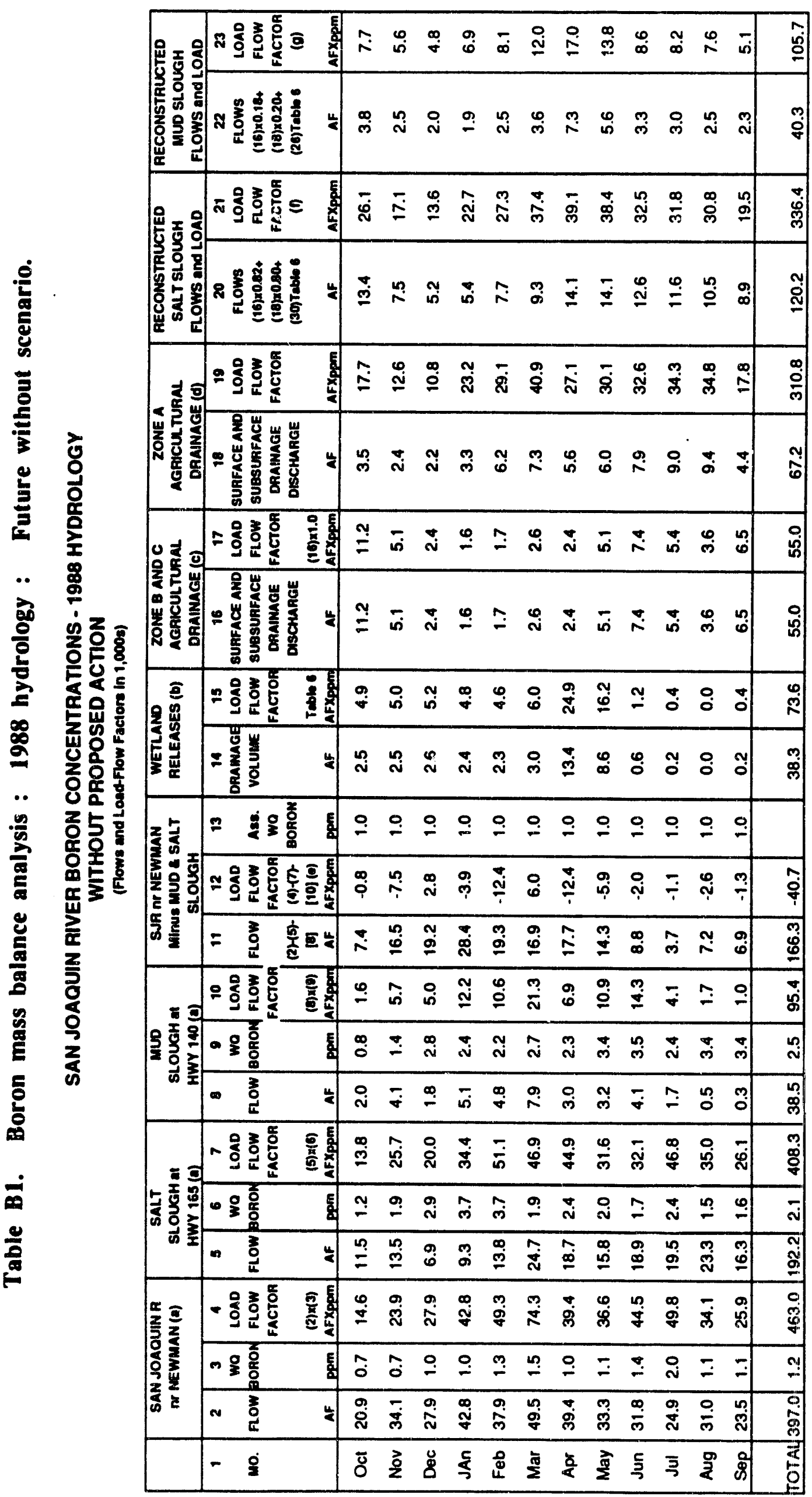

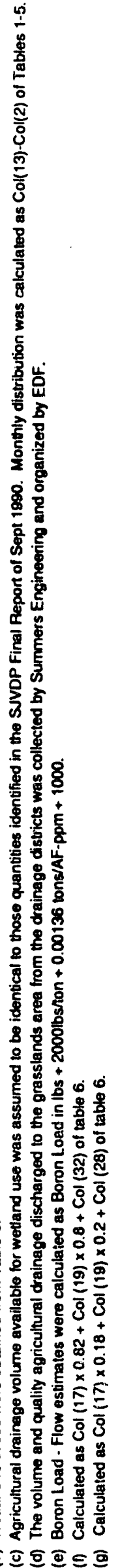




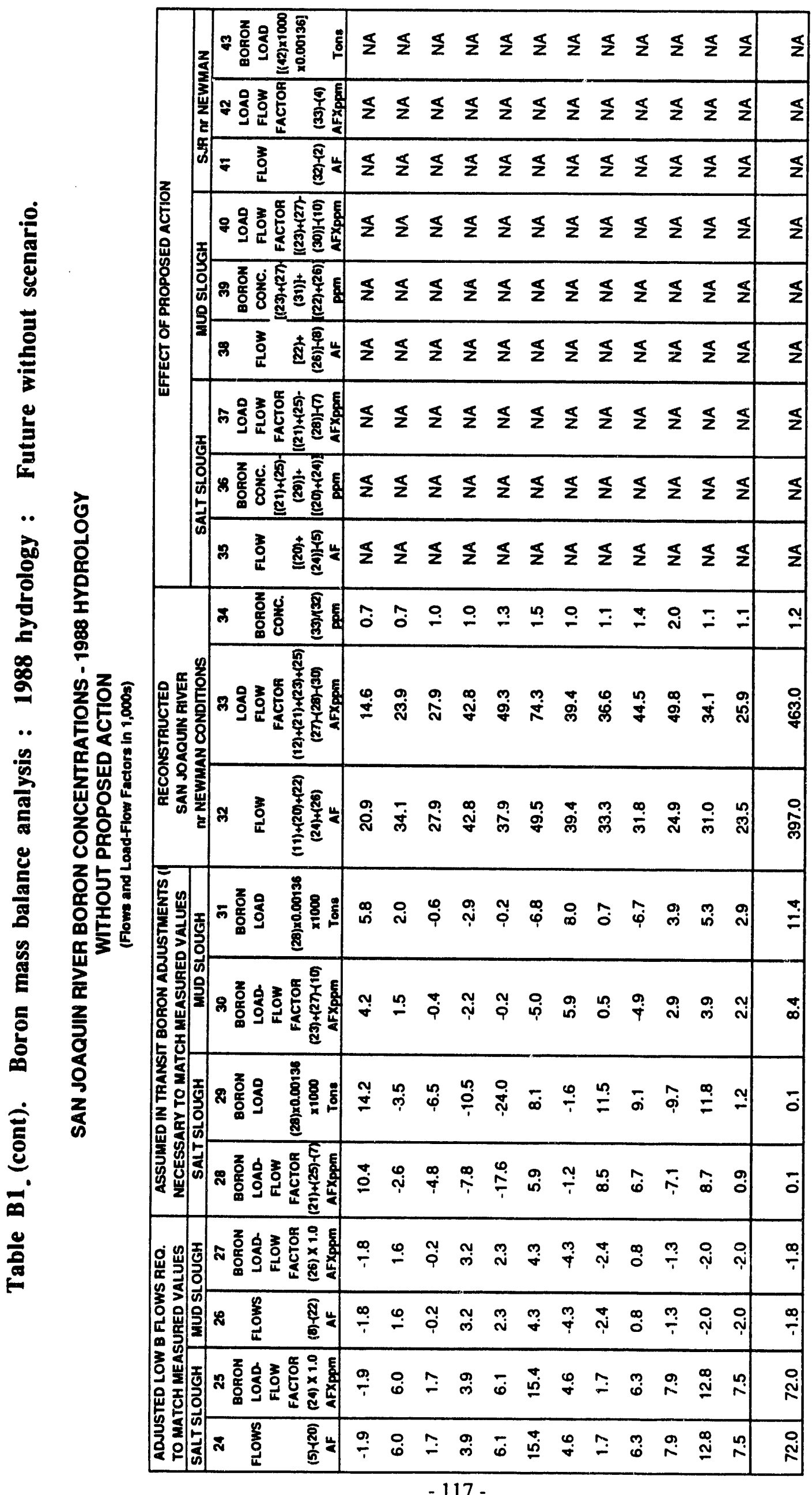




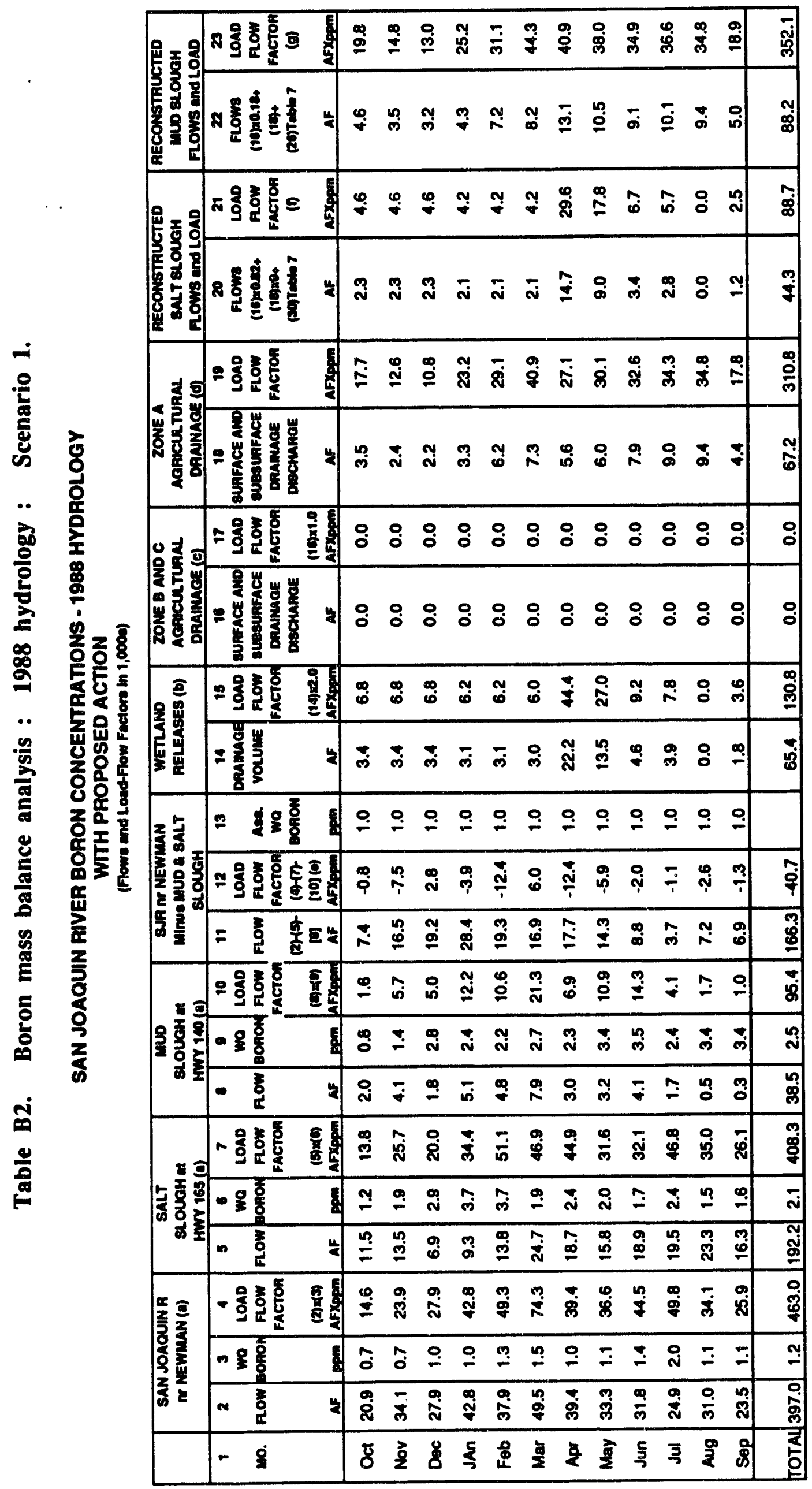

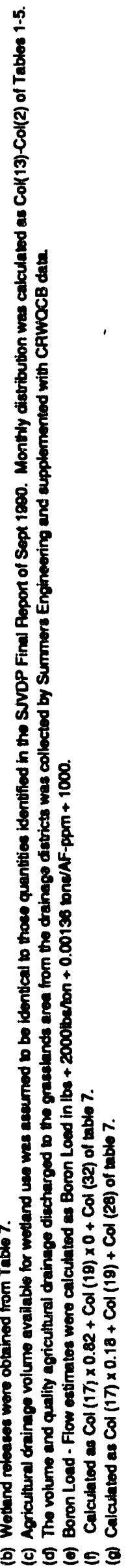




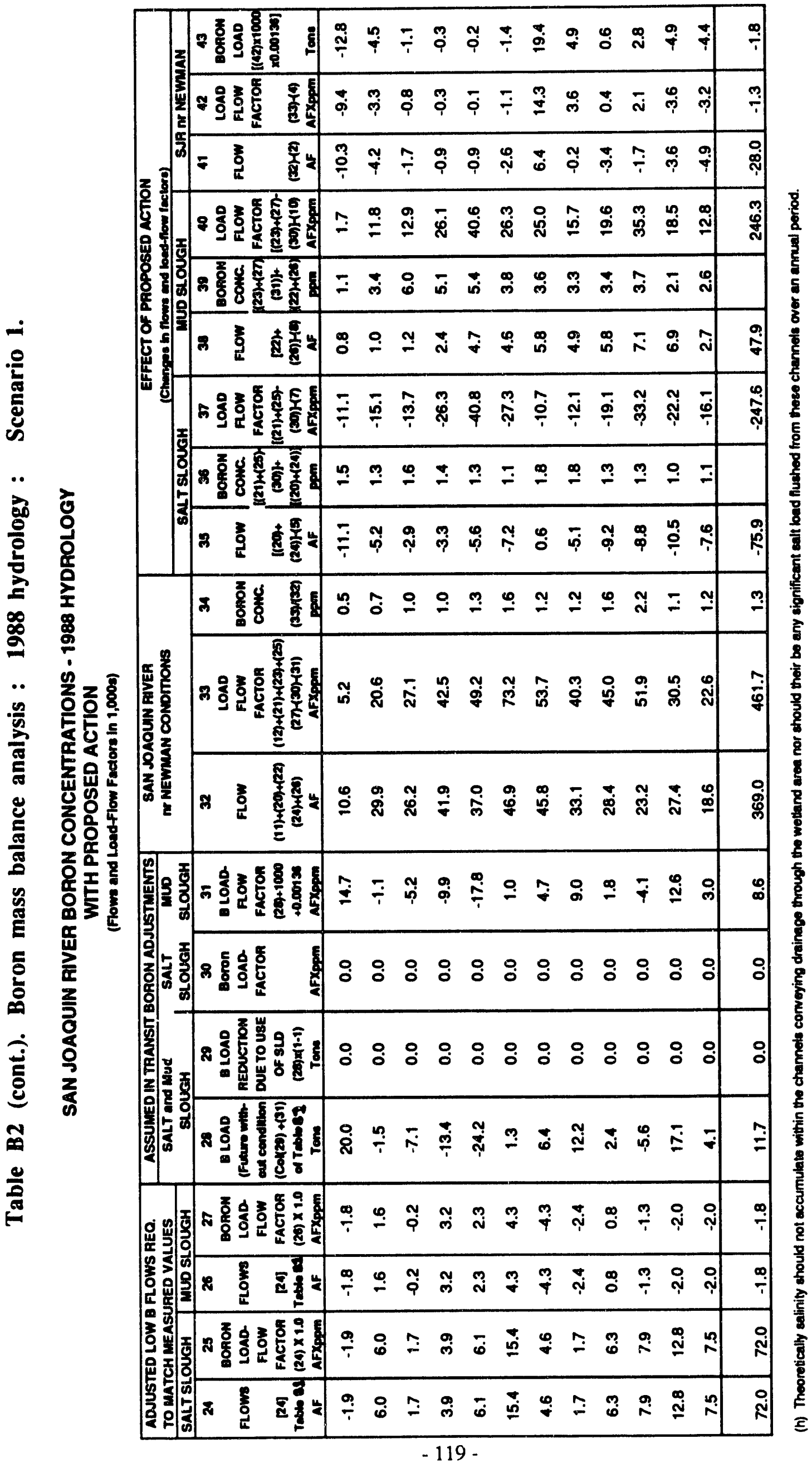




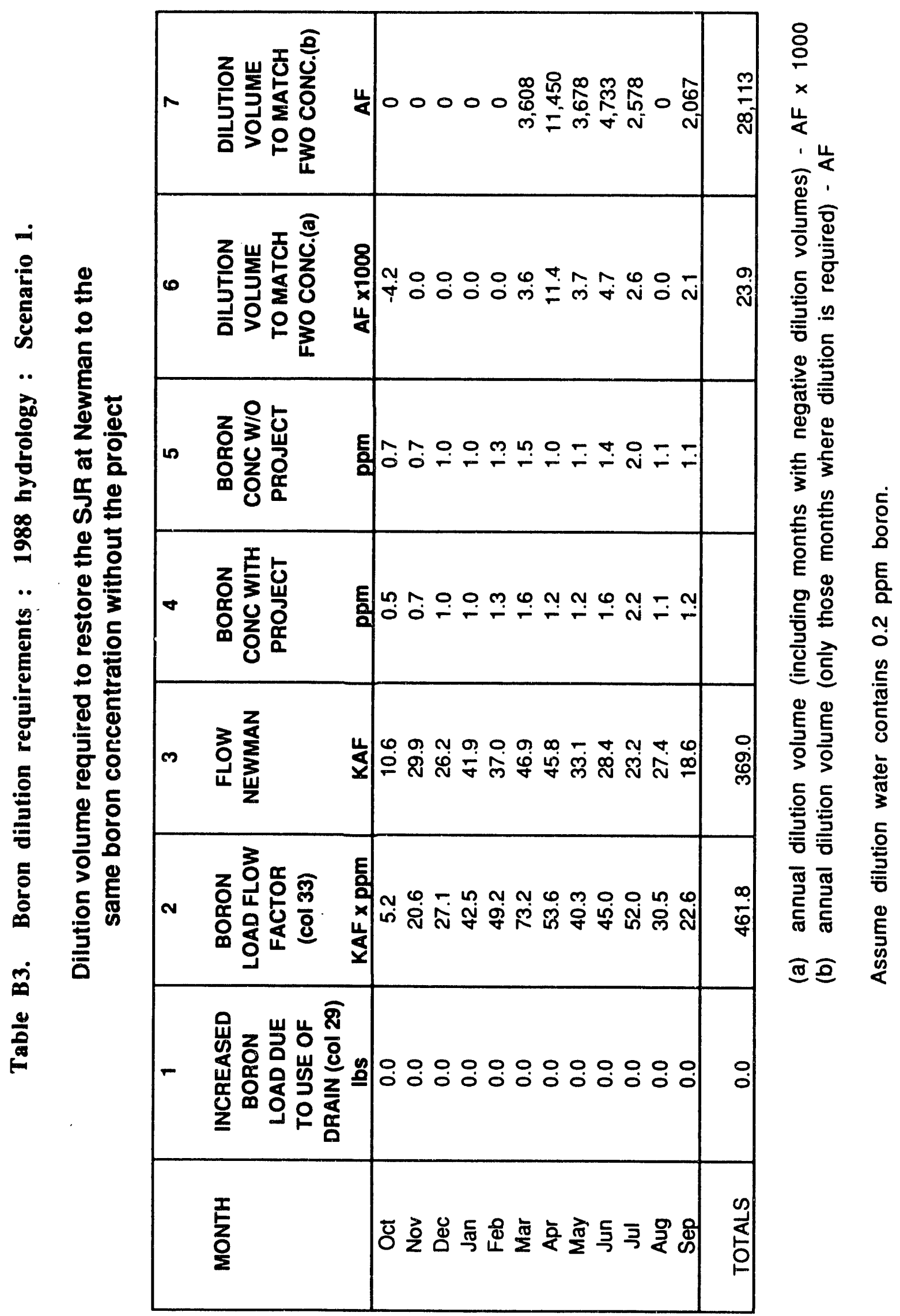




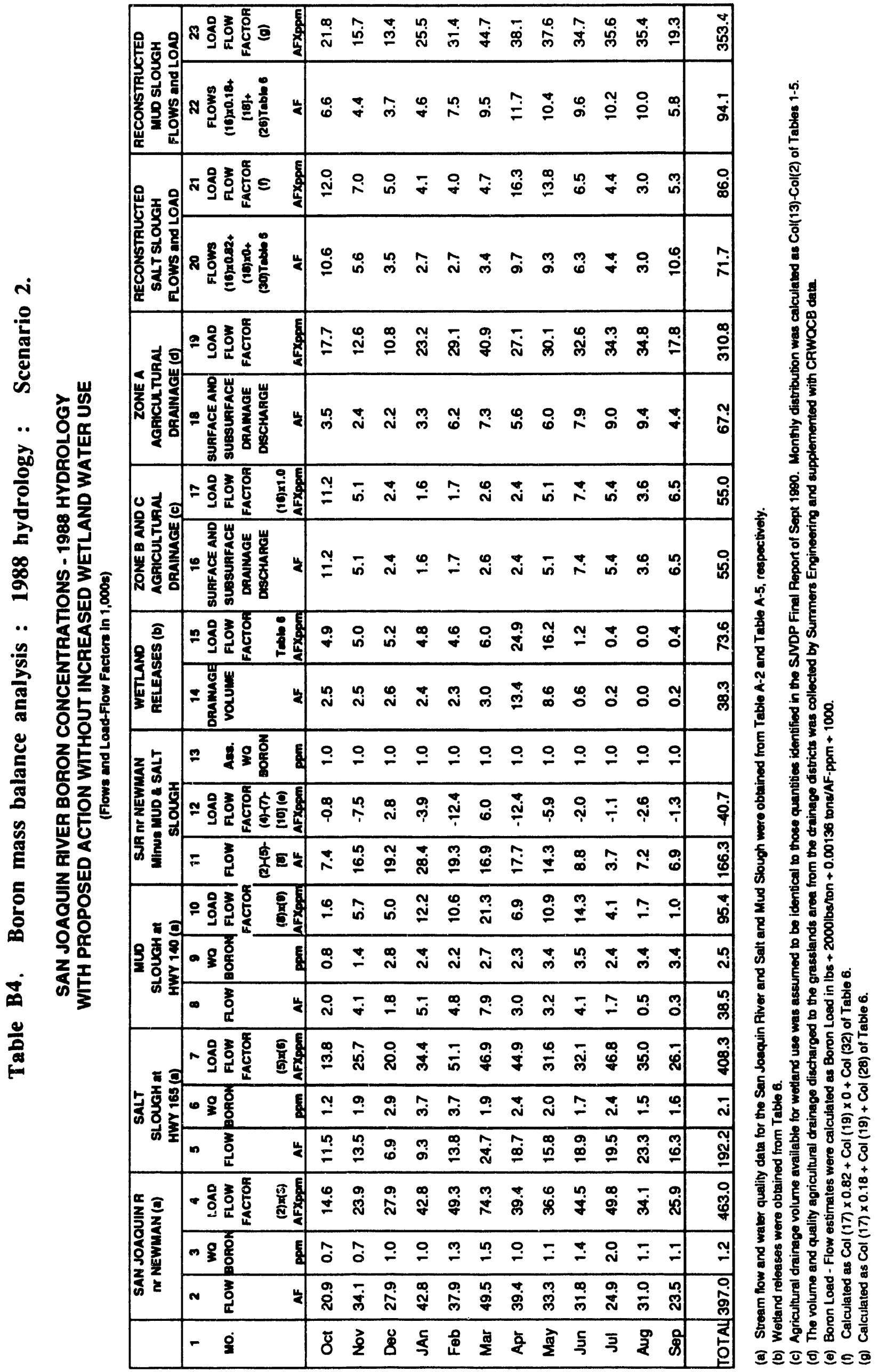




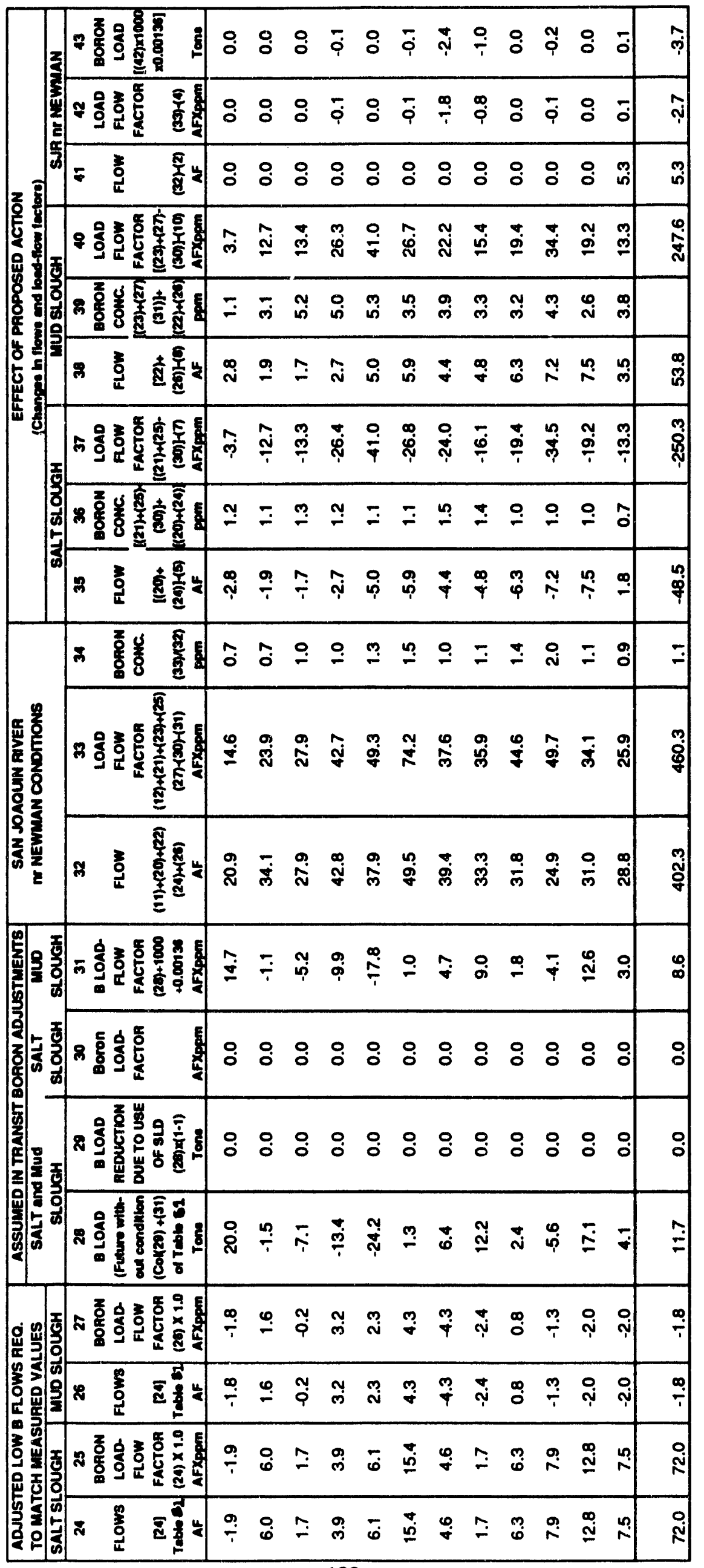




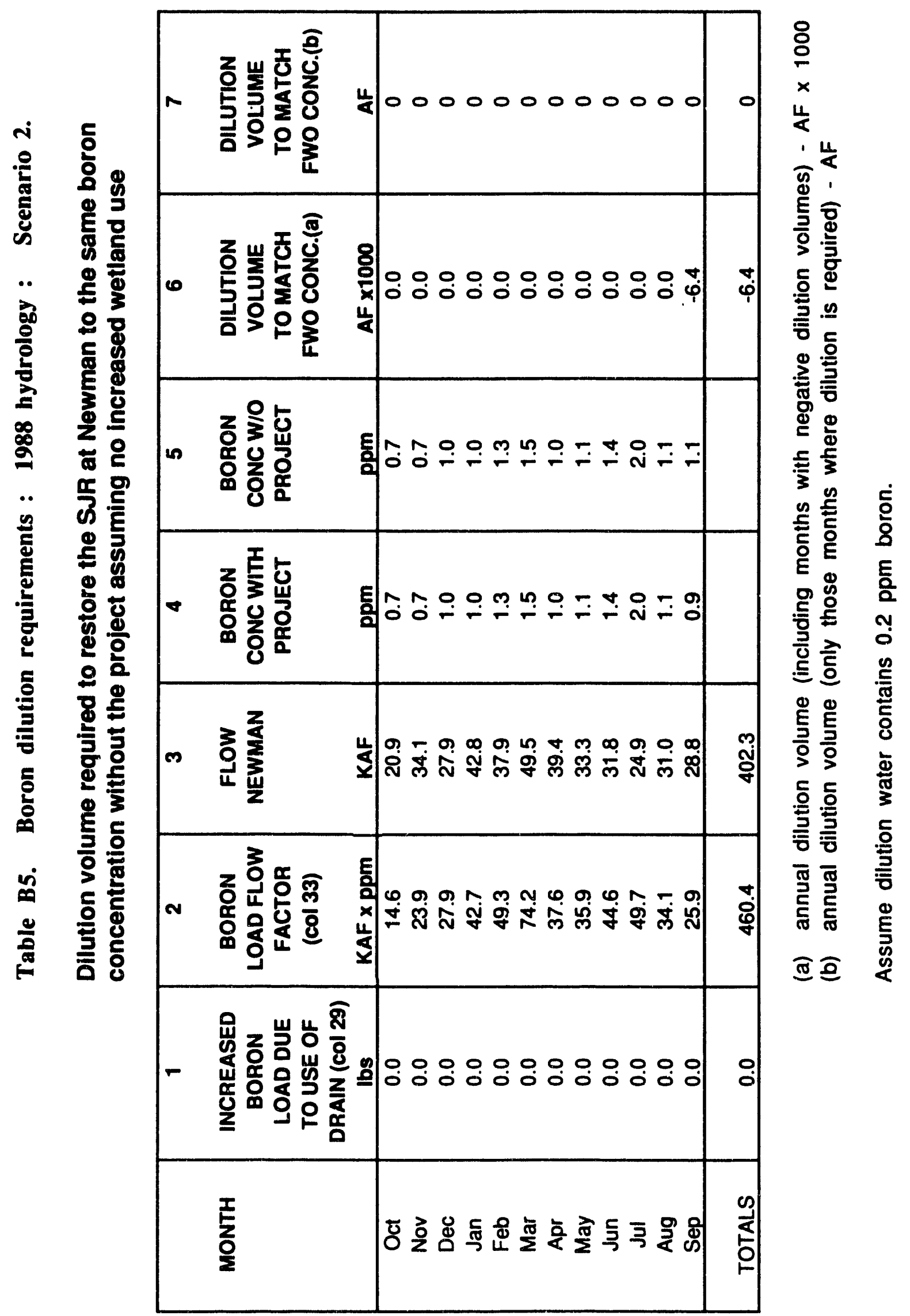




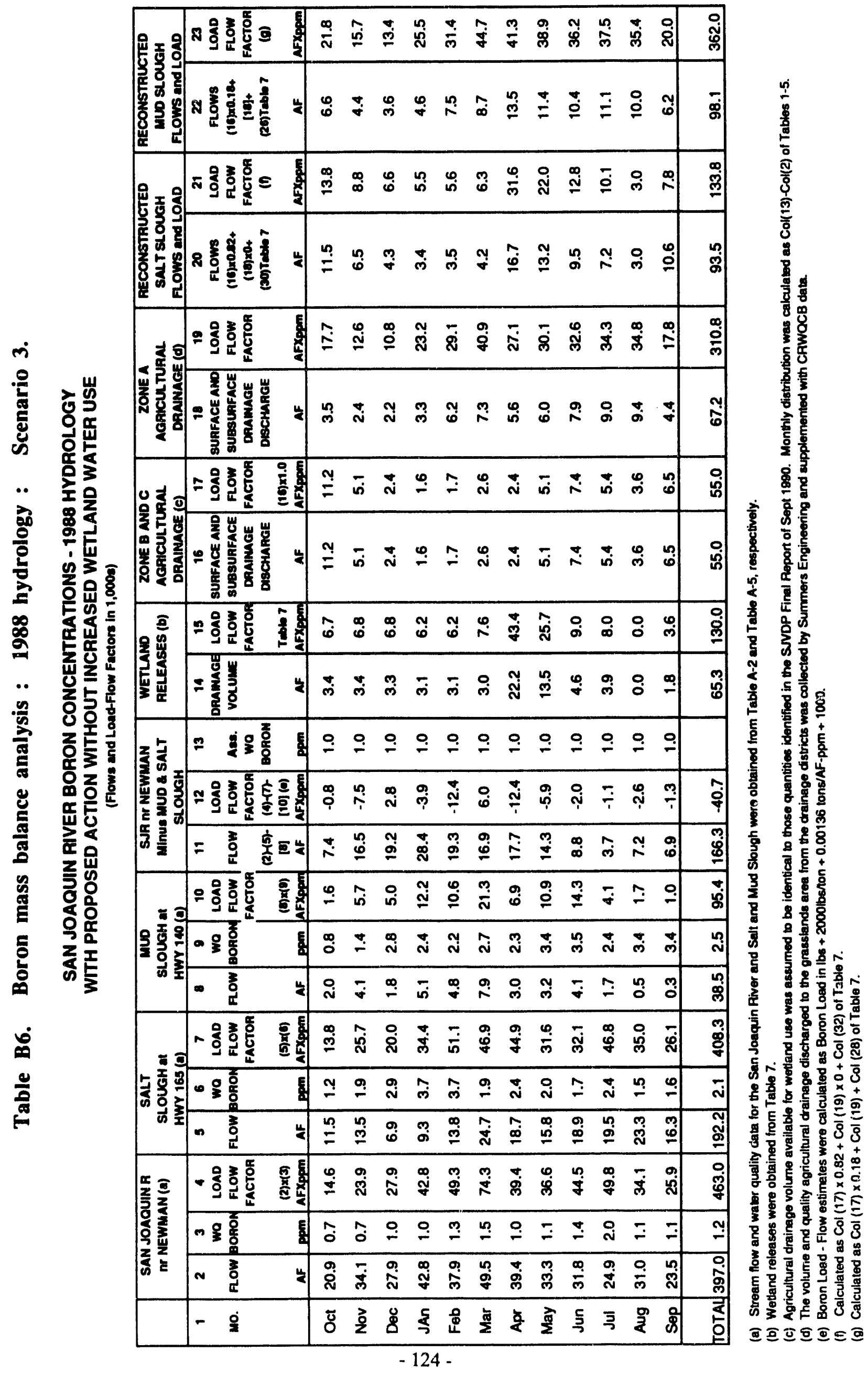




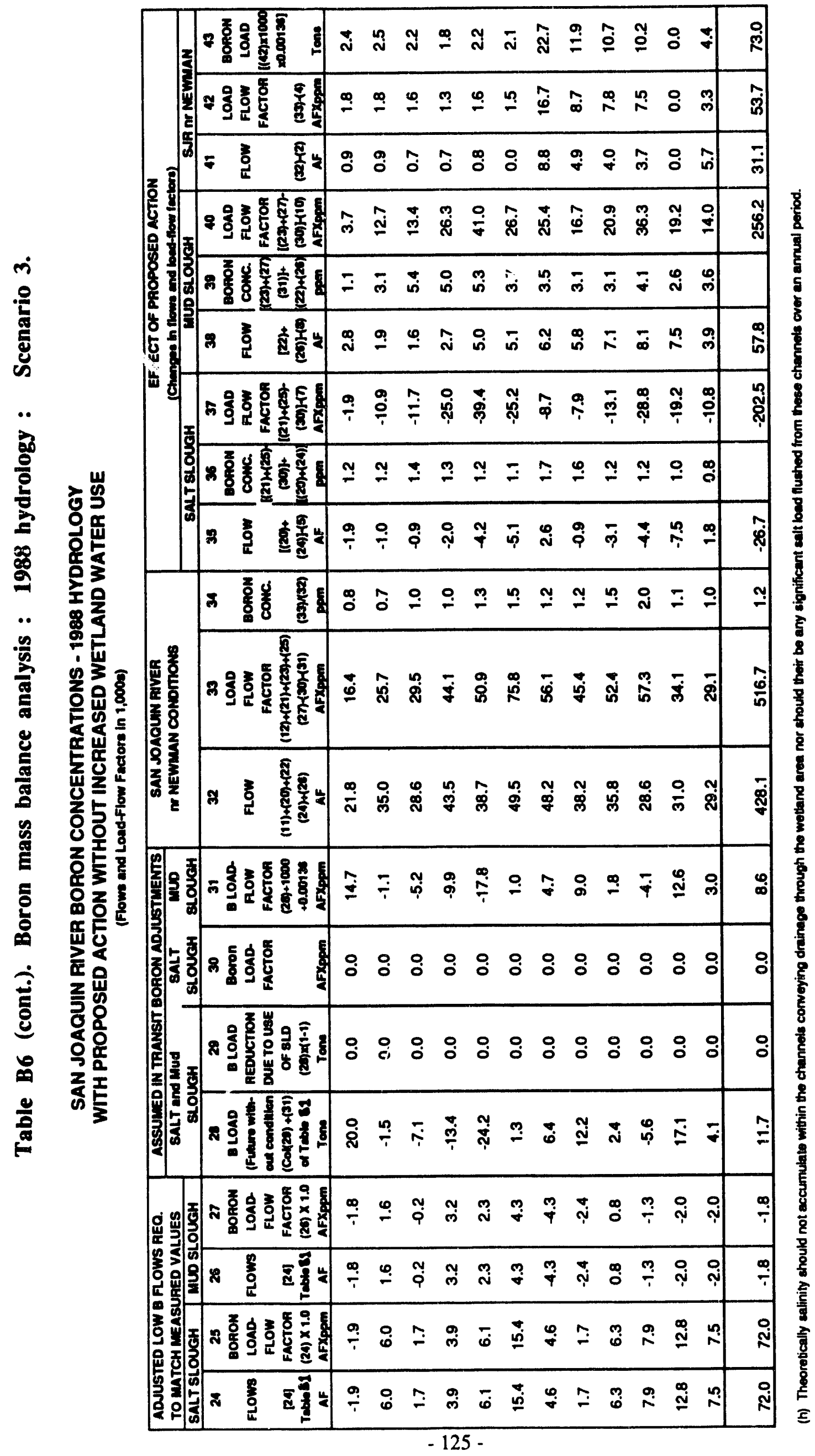




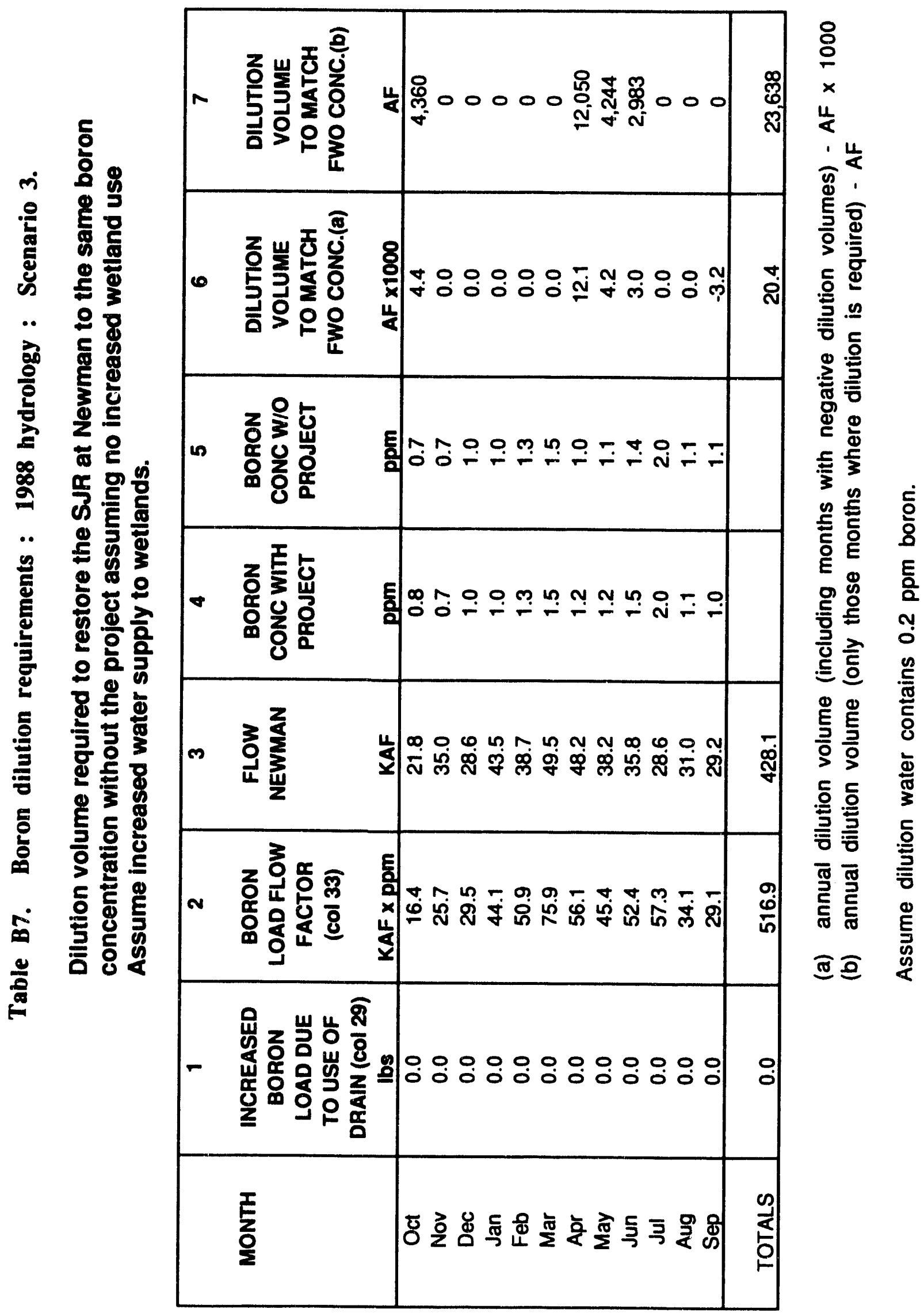




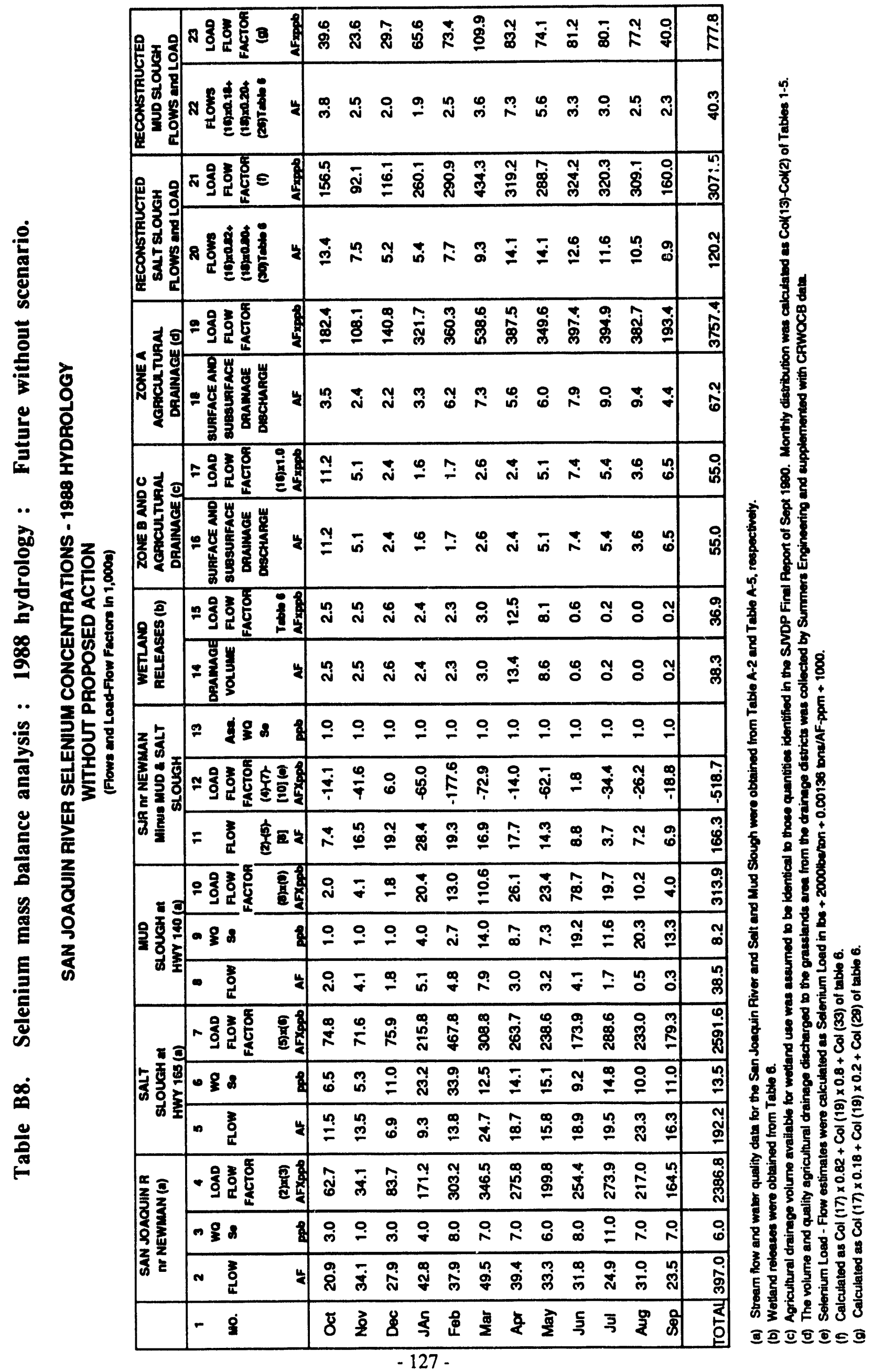




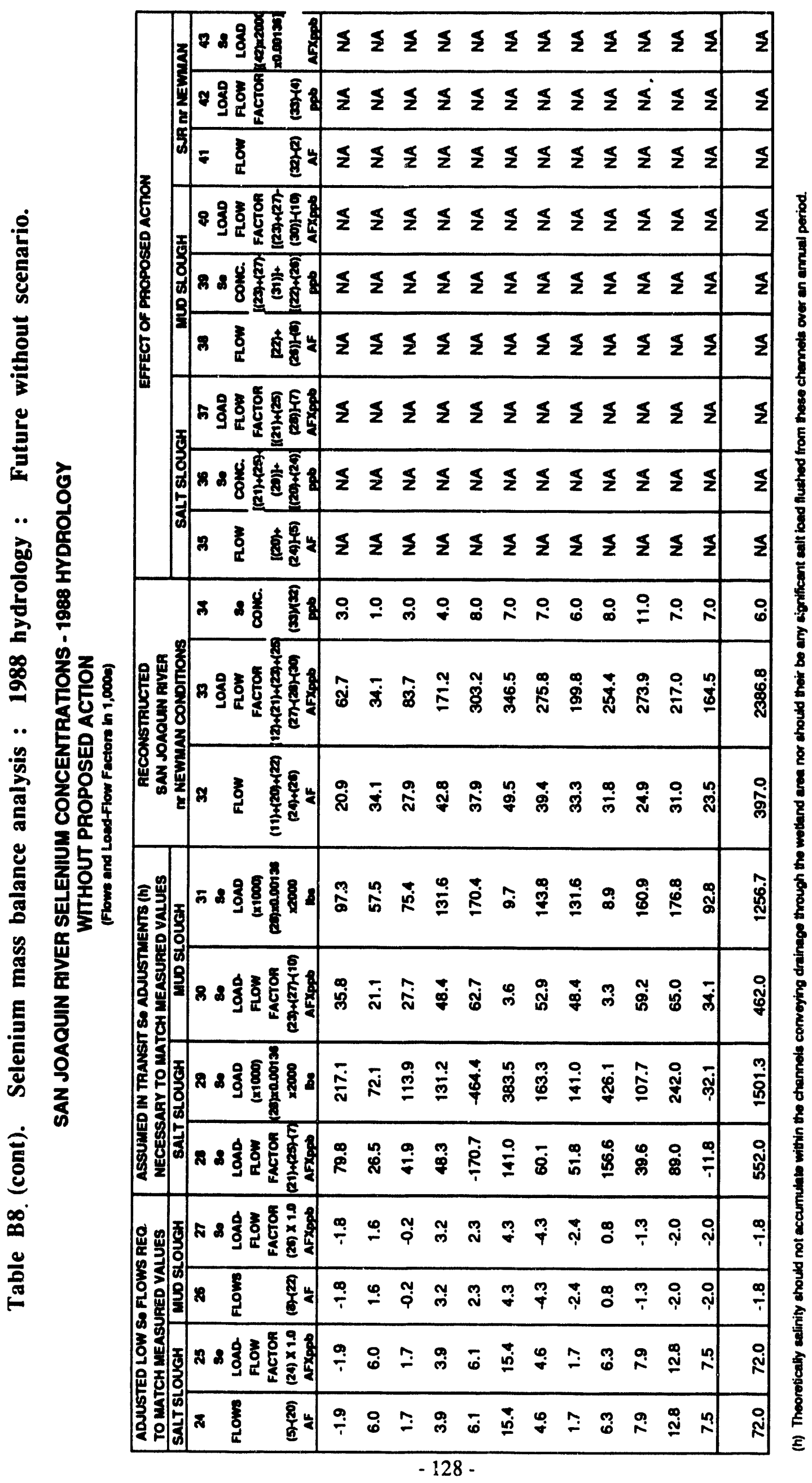




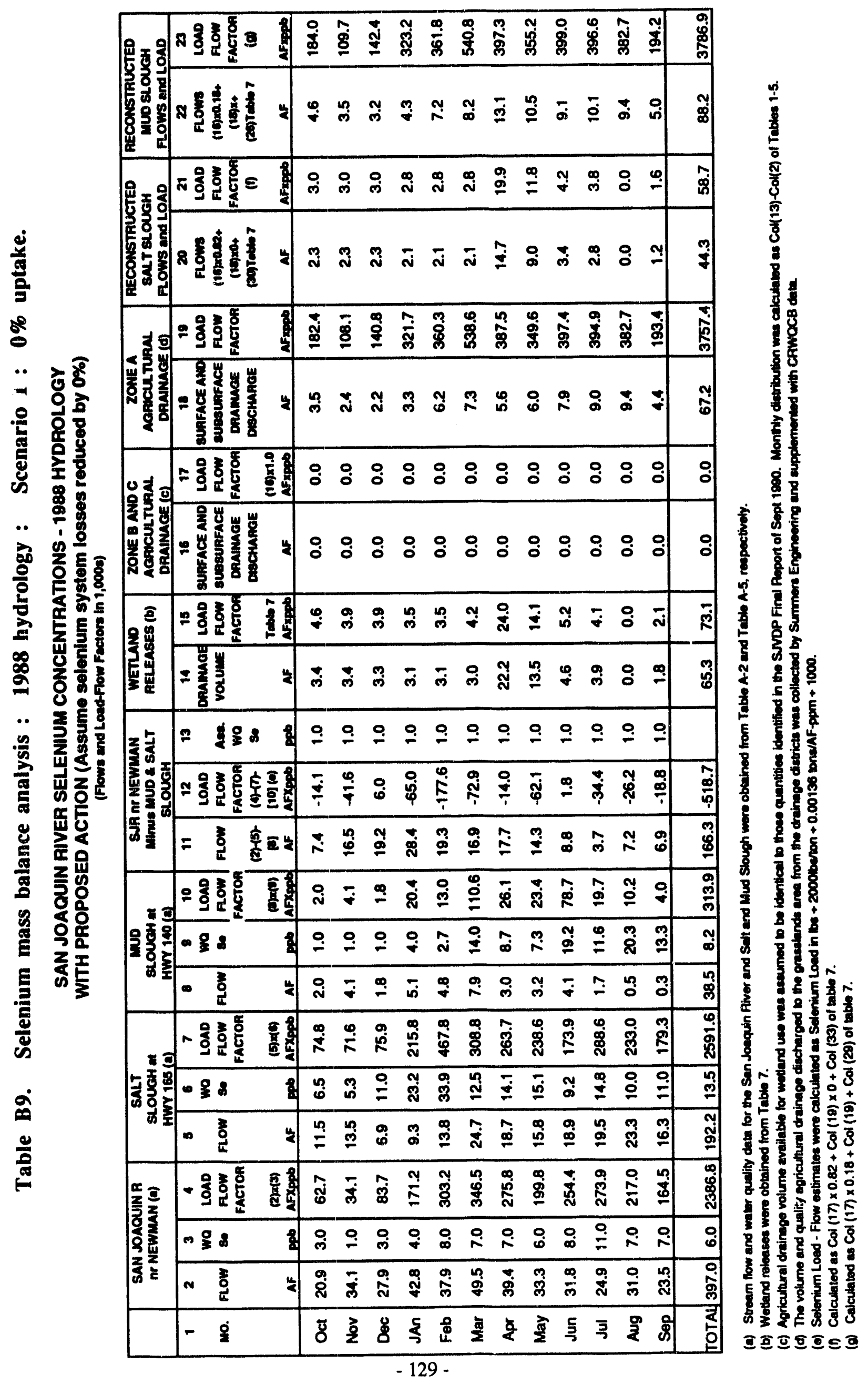




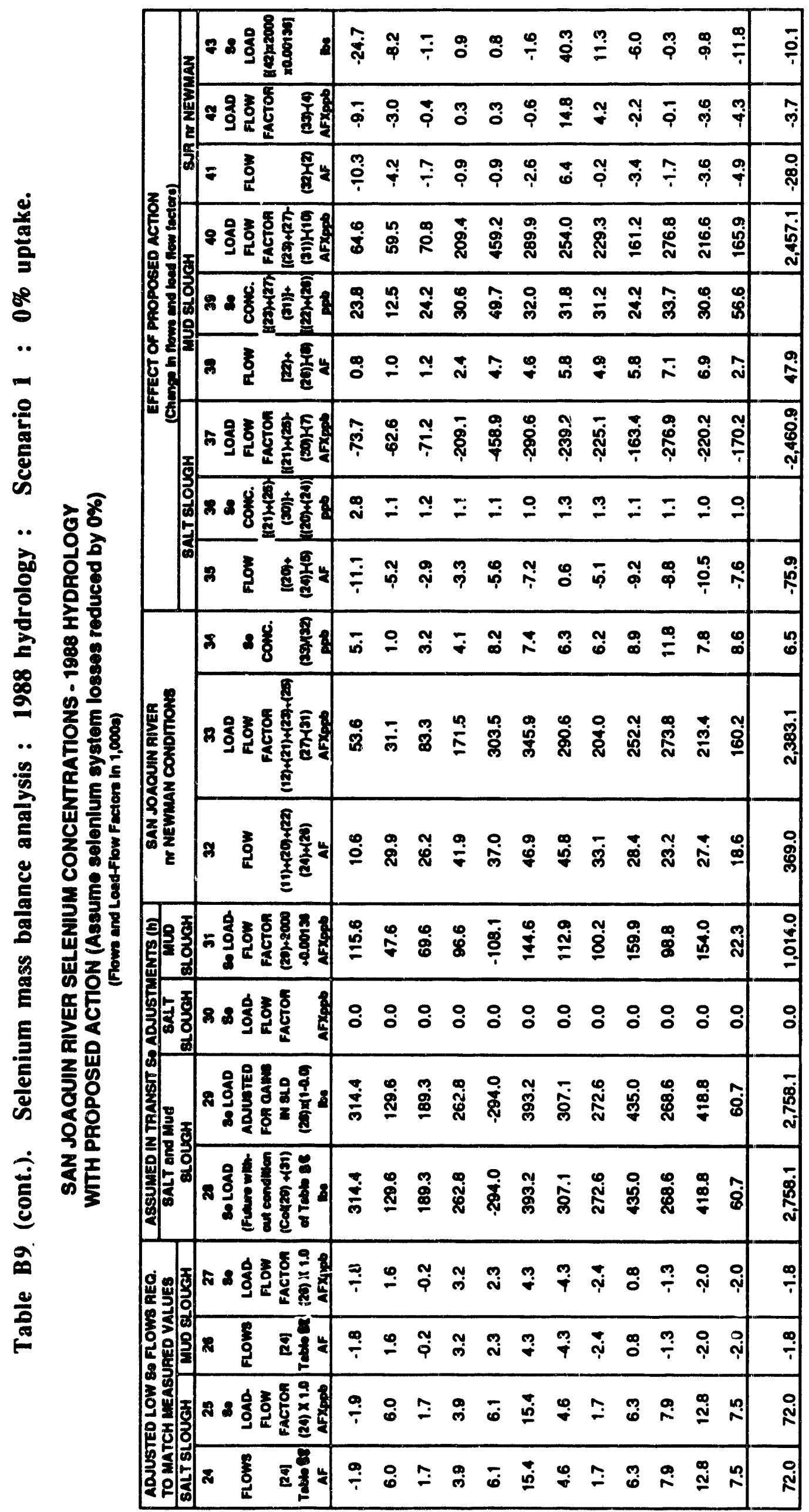




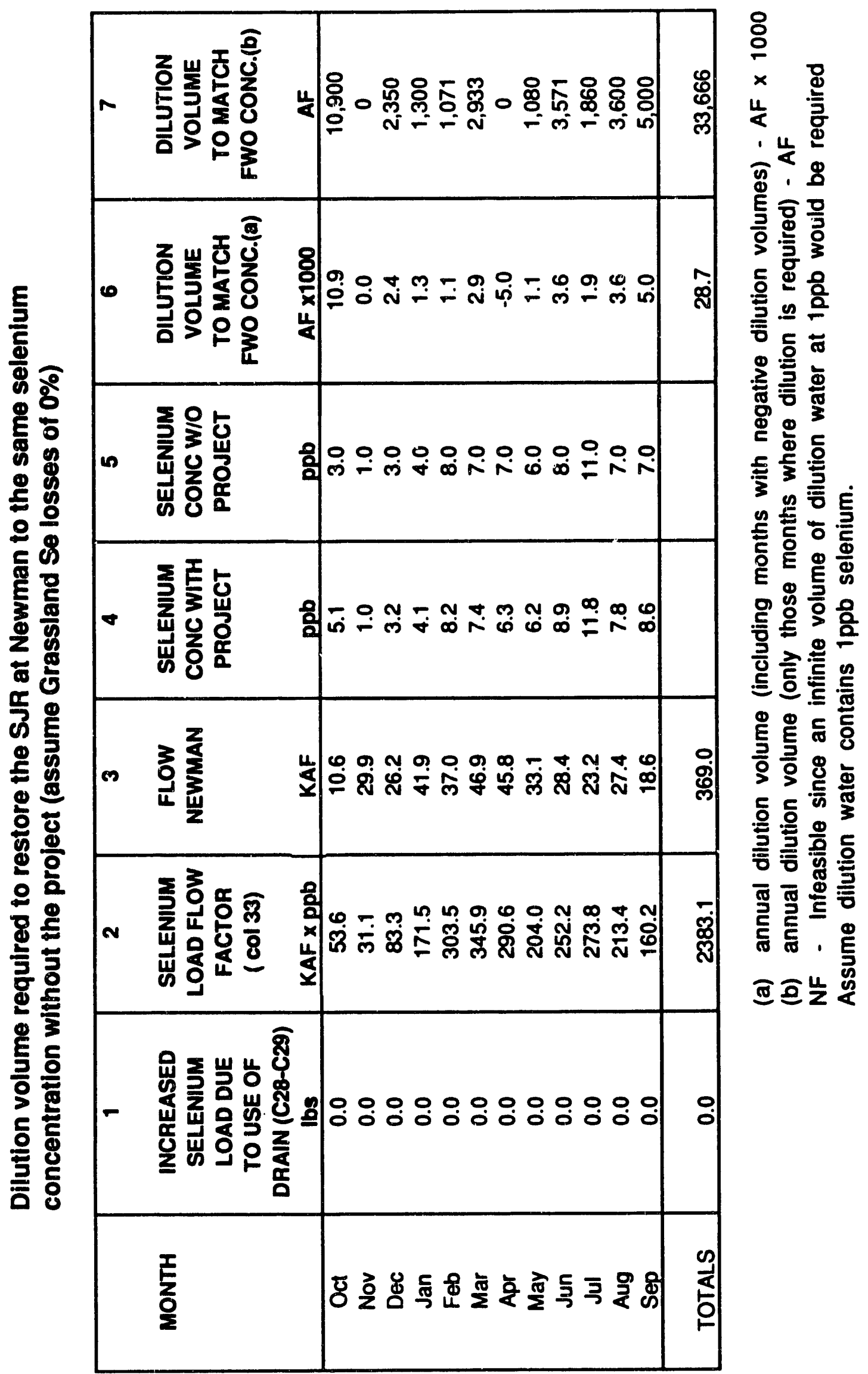




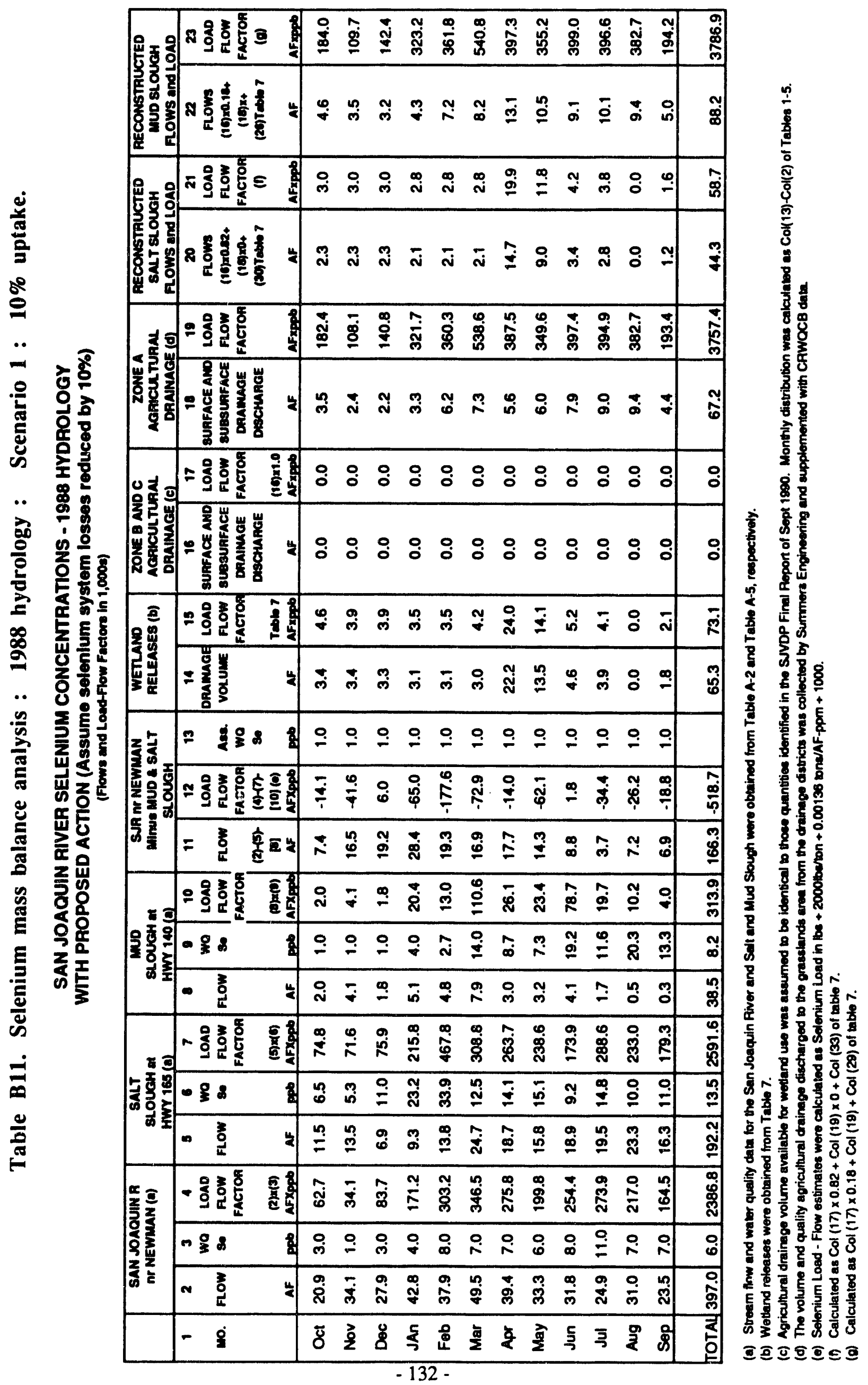




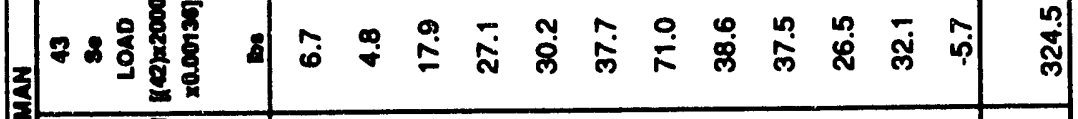
爱 ₹

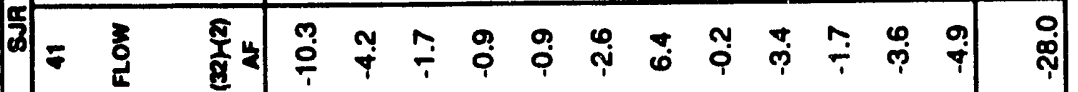

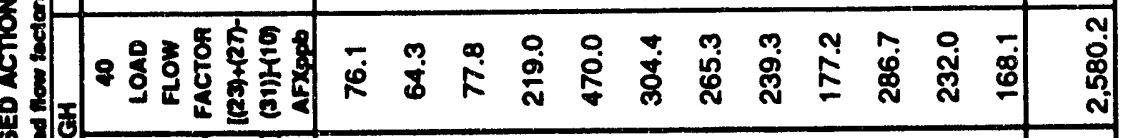
8 若

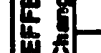

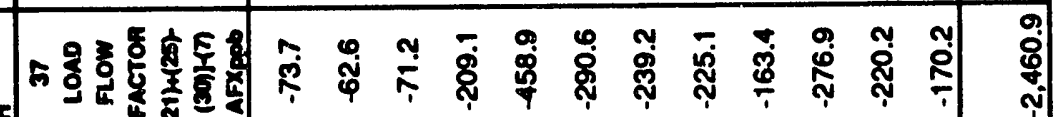
苞

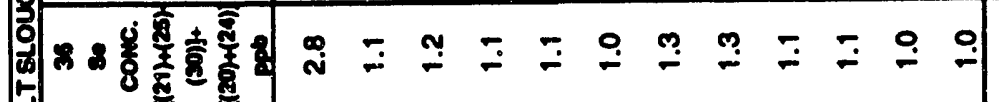
20

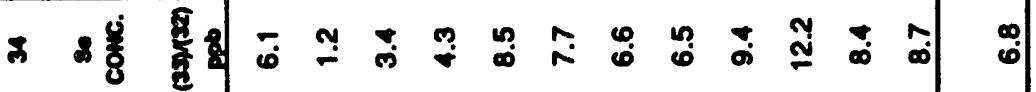
..

은

$\frac{2}{5}$ है

宽 을

霝

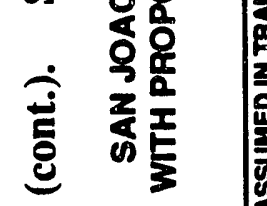

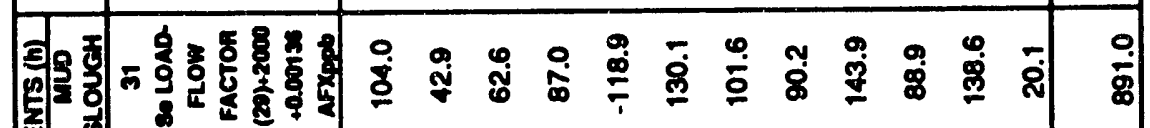

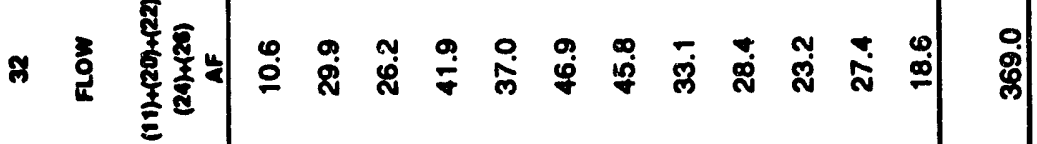

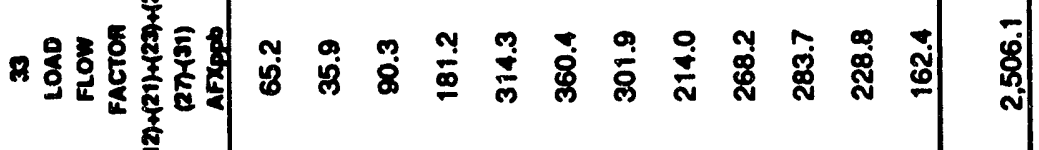
要专

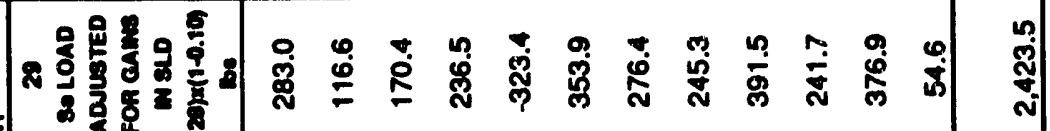
골

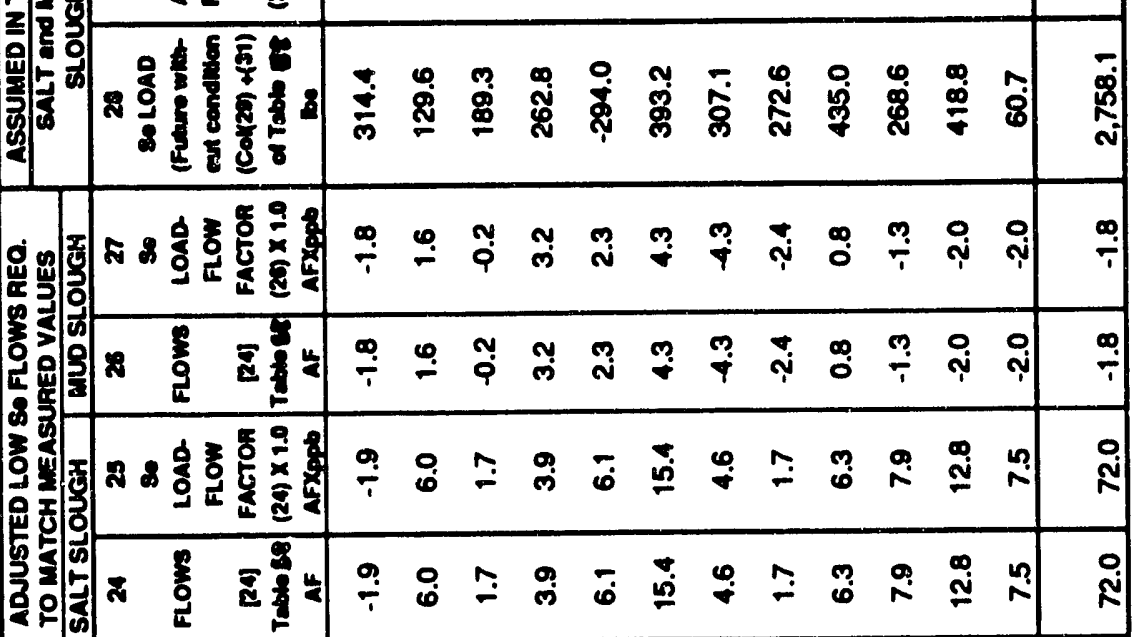


勇

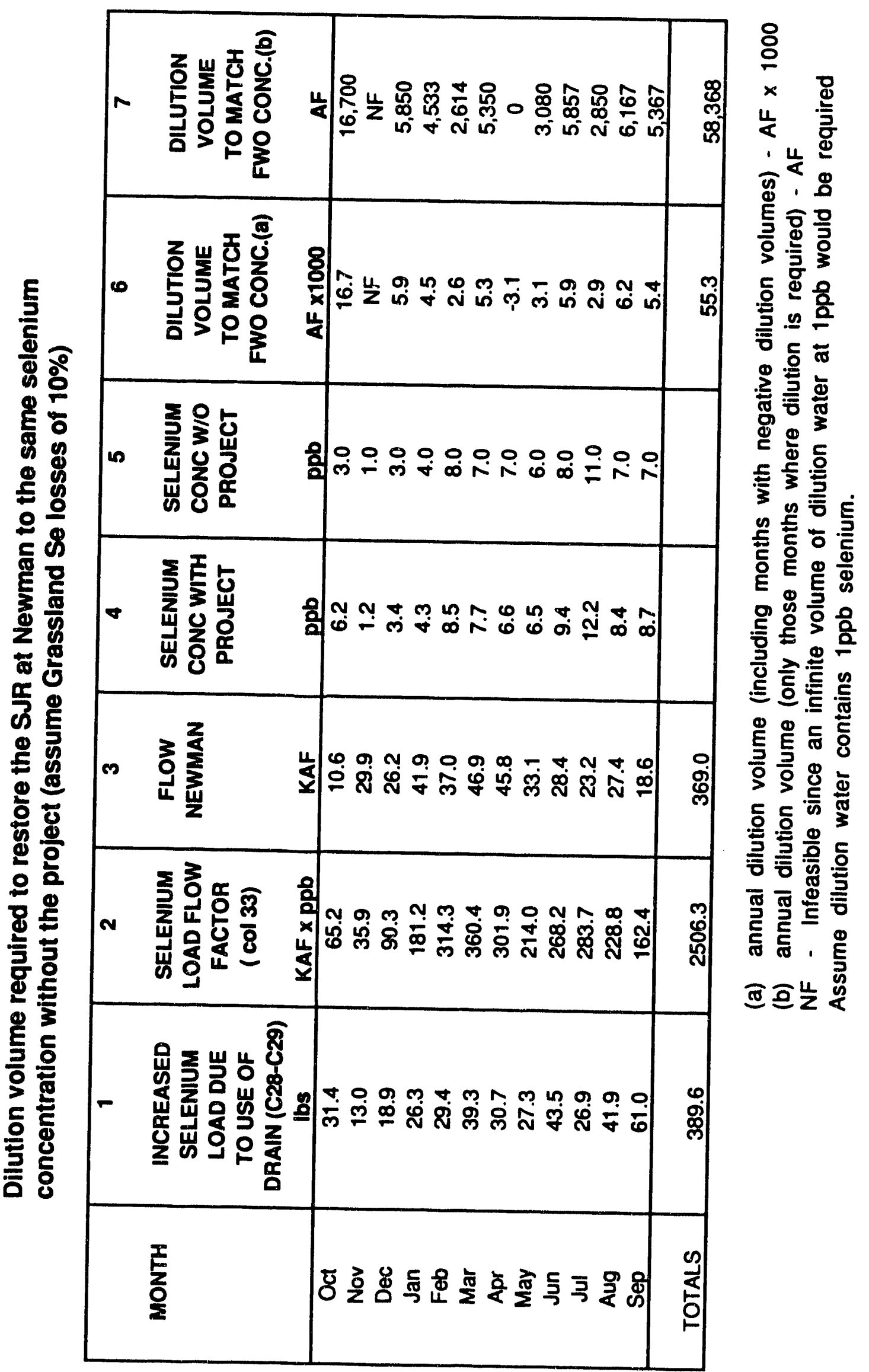




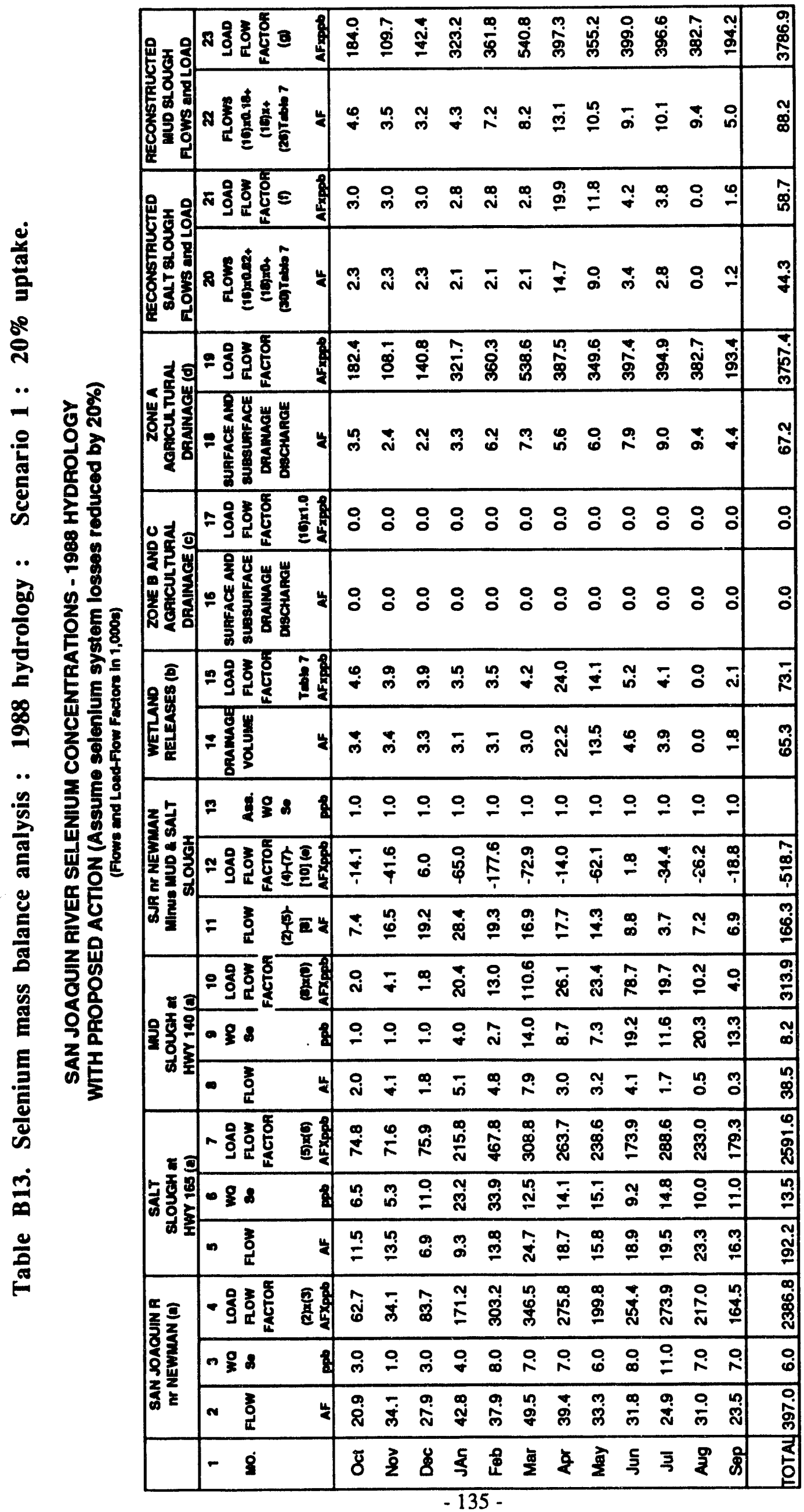

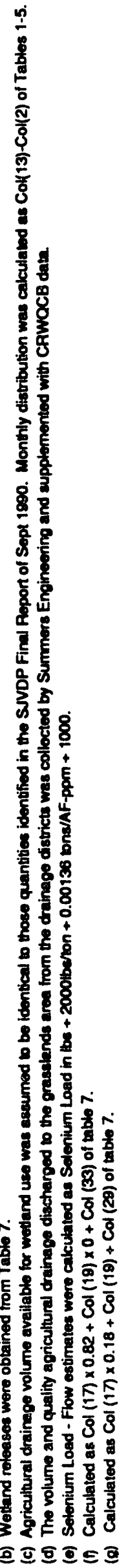




\begin{tabular}{|c|c|c|c|c|c|c|c|c|c|c|c|c|c|c|c|}
\hline$z$ & $720 \frac{8}{8}$ & & $\underset{\infty}{\mathscr{g}}$ & $\stackrel{શ}{\leftrightarrows}$ & $\begin{array}{l}\infty \\
\dot{g}\end{array}$ & में & $\begin{array}{l}\stackrel{0}{\circ} \\
\stackrel{\leftrightarrow}{\circ}\end{array}$ & $\stackrel{\leftrightarrow}{\dot{K}}$ & $\underline{0}$ & $\stackrel{9}{80}$ & $\frac{0}{\infty}$ & 落 & $\stackrel{0}{i}$ & $\dot{0}$ & ס्. \\
\hline है & 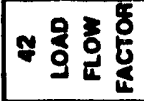 & 矛量 & $\stackrel{\circ}{ \pm}$ & $\mathscr{0}$ & $\stackrel{n}{\ddot{m}}$ & $\stackrel{\circ}{\mathscr{Q}}$ & $\frac{0}{N}$ & 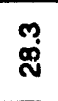 & 灾 & N̦ & $\stackrel{\infty}{\&}$ & 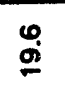 & 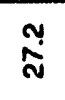 & 5 & ปึ. \\
\hline & $=\frac{7}{2}$ & 毅 & $\stackrel{9}{\circ}$ & $\stackrel{\Upsilon}{+}$ & $\stackrel{9}{\square}$ & $\stackrel{\leftrightarrow}{\varphi}$ & $\stackrel{\leftrightarrow}{\rho}$ & $\stackrel{\leftrightarrow}{\leftrightarrow}$ & $\overrightarrow{0}$ & ִִ & চ্் & 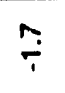 & 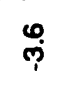 & ְִ & జ్రీ \\
\hline
\end{tabular}

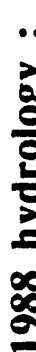

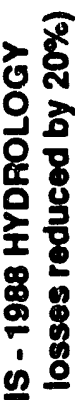

造得

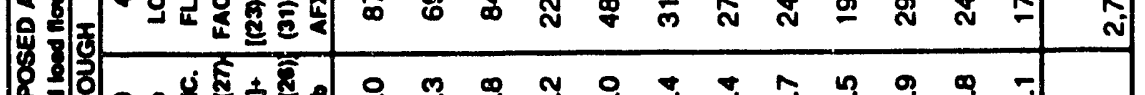

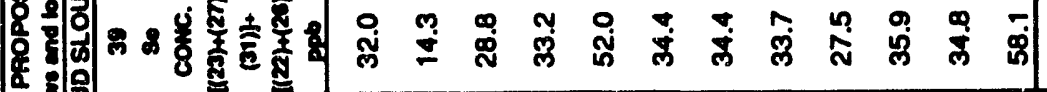

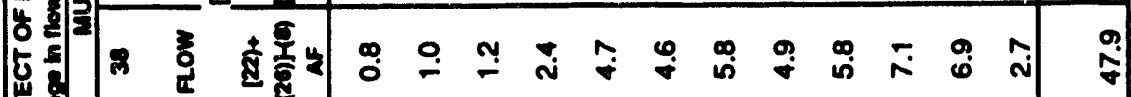

竞势

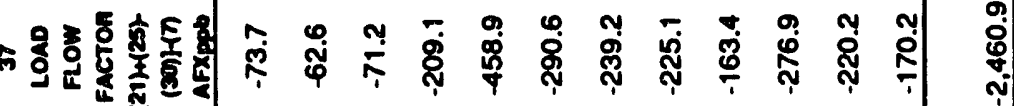

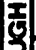

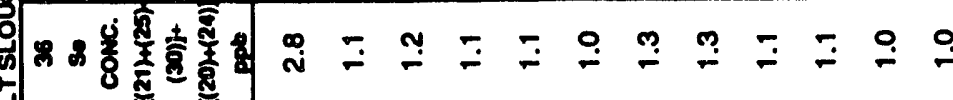

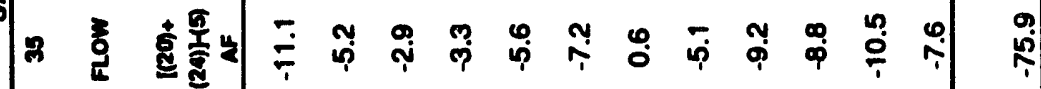

\$ 2 害

(1)

일

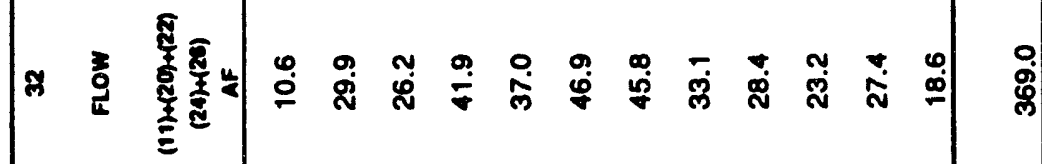

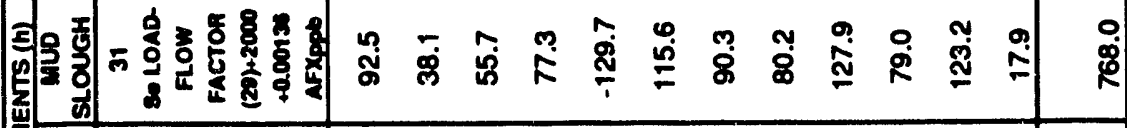

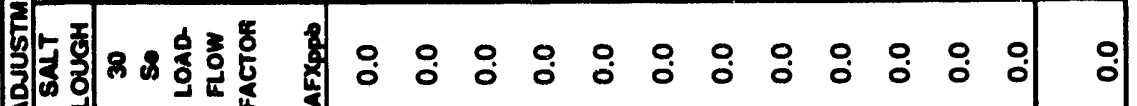

要它

वर

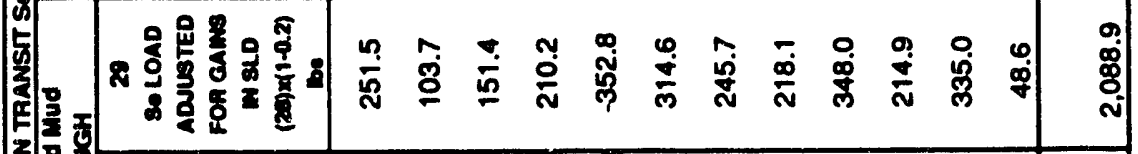

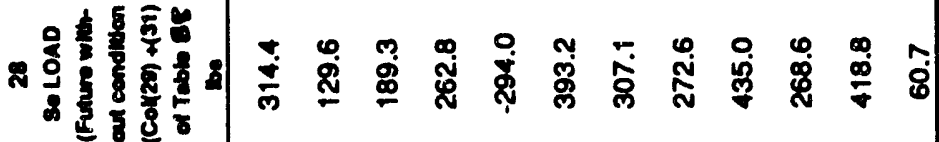

$\ddot{\theta}$

$\frac{0}{0}$ 


\begin{tabular}{|c|c|c|c|}
\hline & $\mid$ & 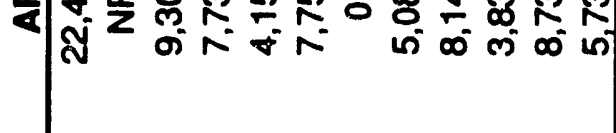 & ฌे \\
\hline$\underline{\underline{\partial}}$ & 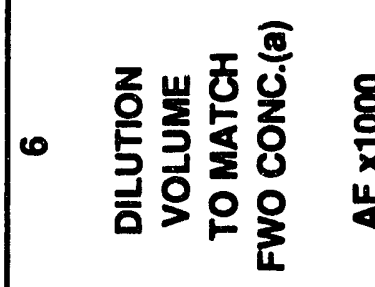 & 象 & 茄 \\
\hline 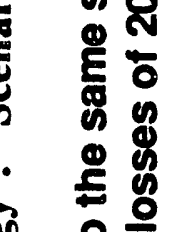 & 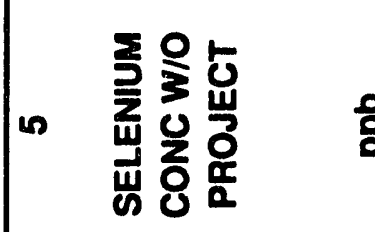 & 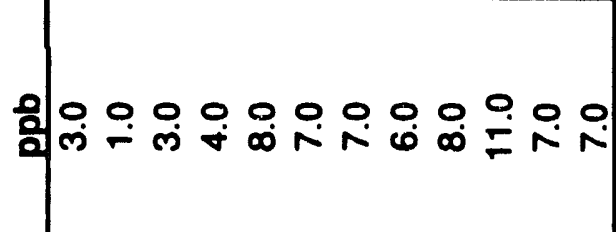 & \\
\hline 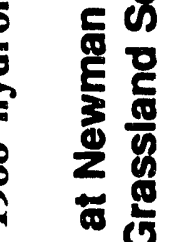 & 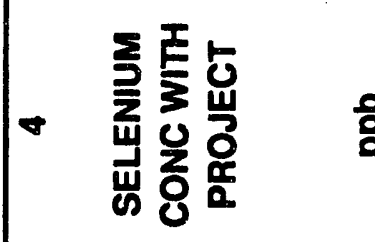 & 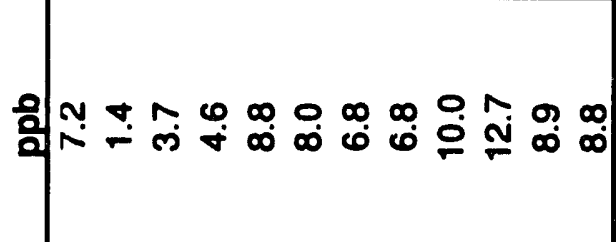 & \\
\hline 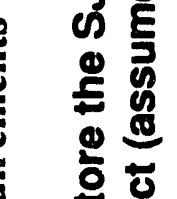 & os & 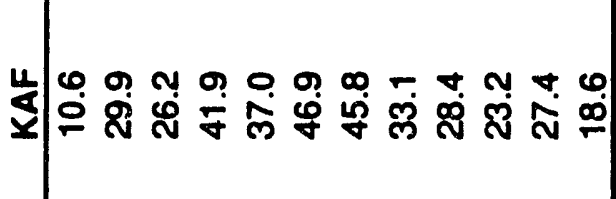 & 영 \\
\hline 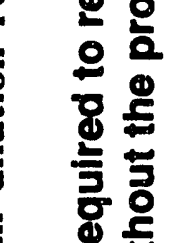 & 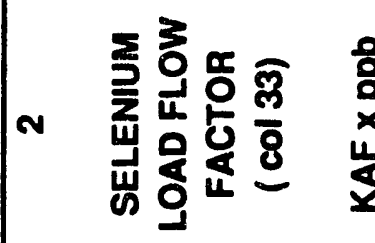 & 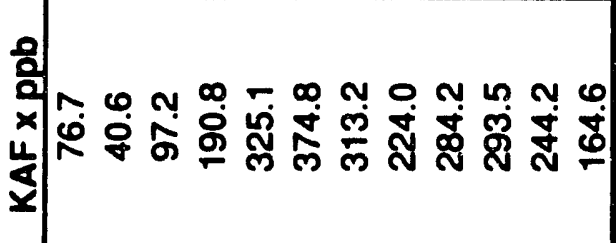 & 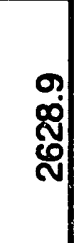 \\
\hline 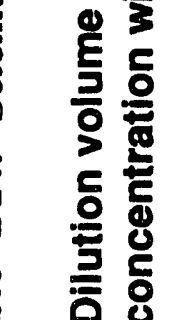 & 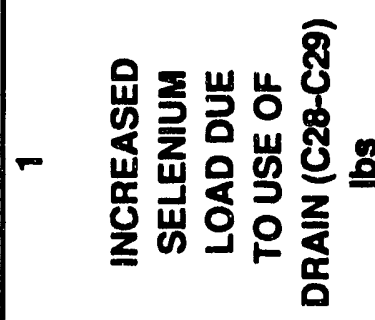 & 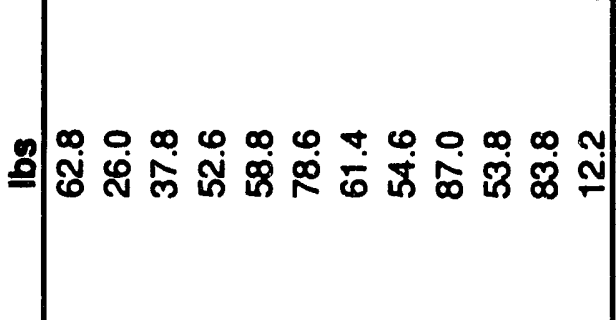 & : \\
\hline & $\begin{array}{l}\text { T } \\
\text { 夏 } \\
\text { O }\end{array}$ & 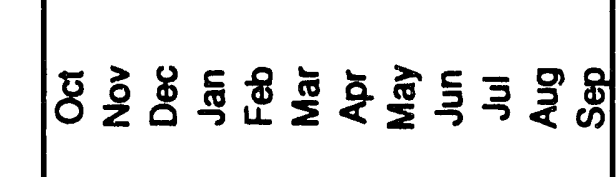 & 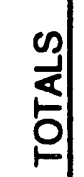 \\
\hline
\end{tabular}

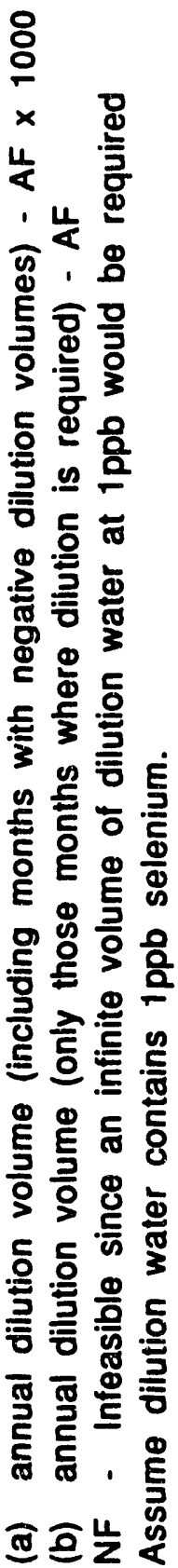




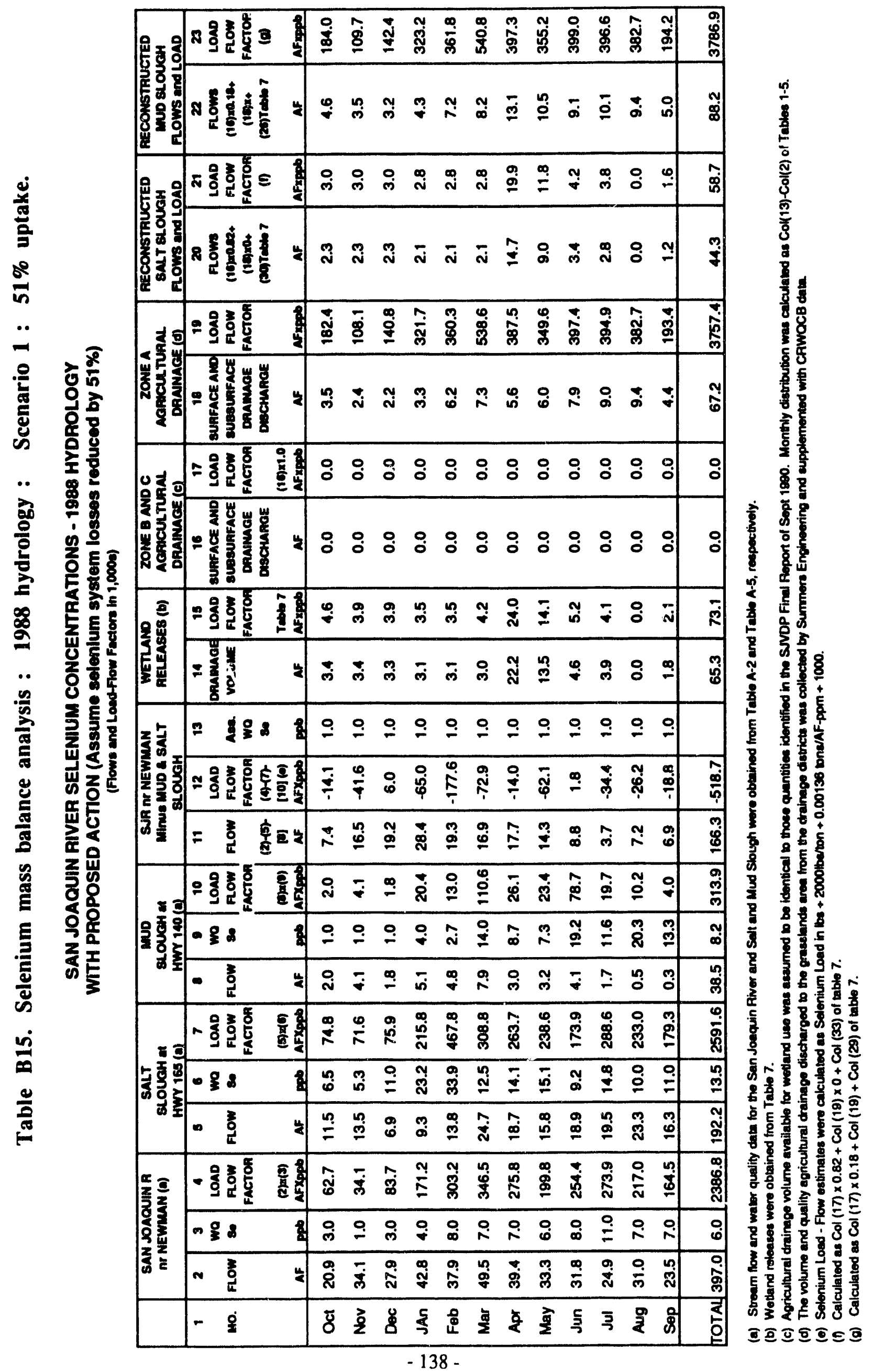




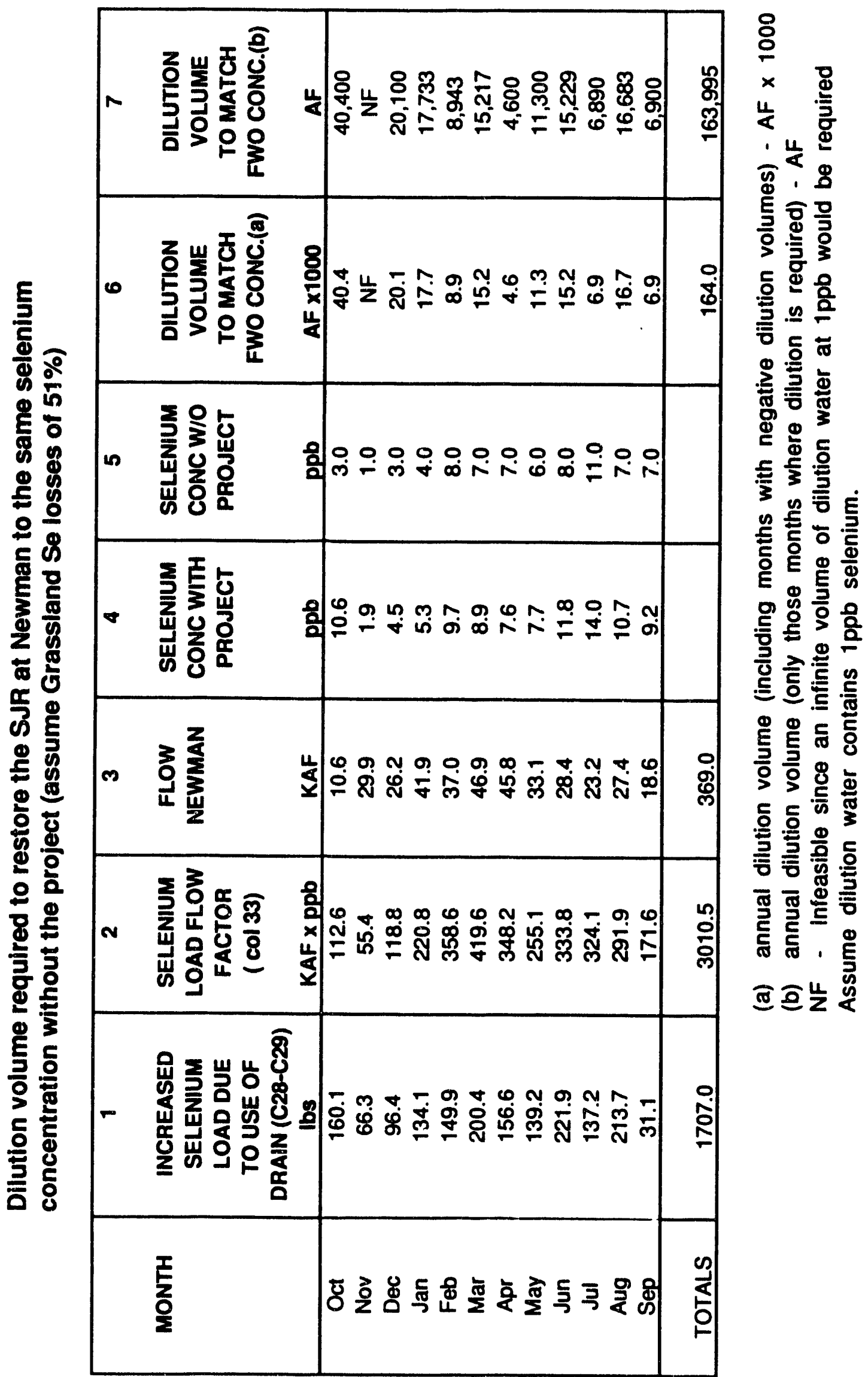




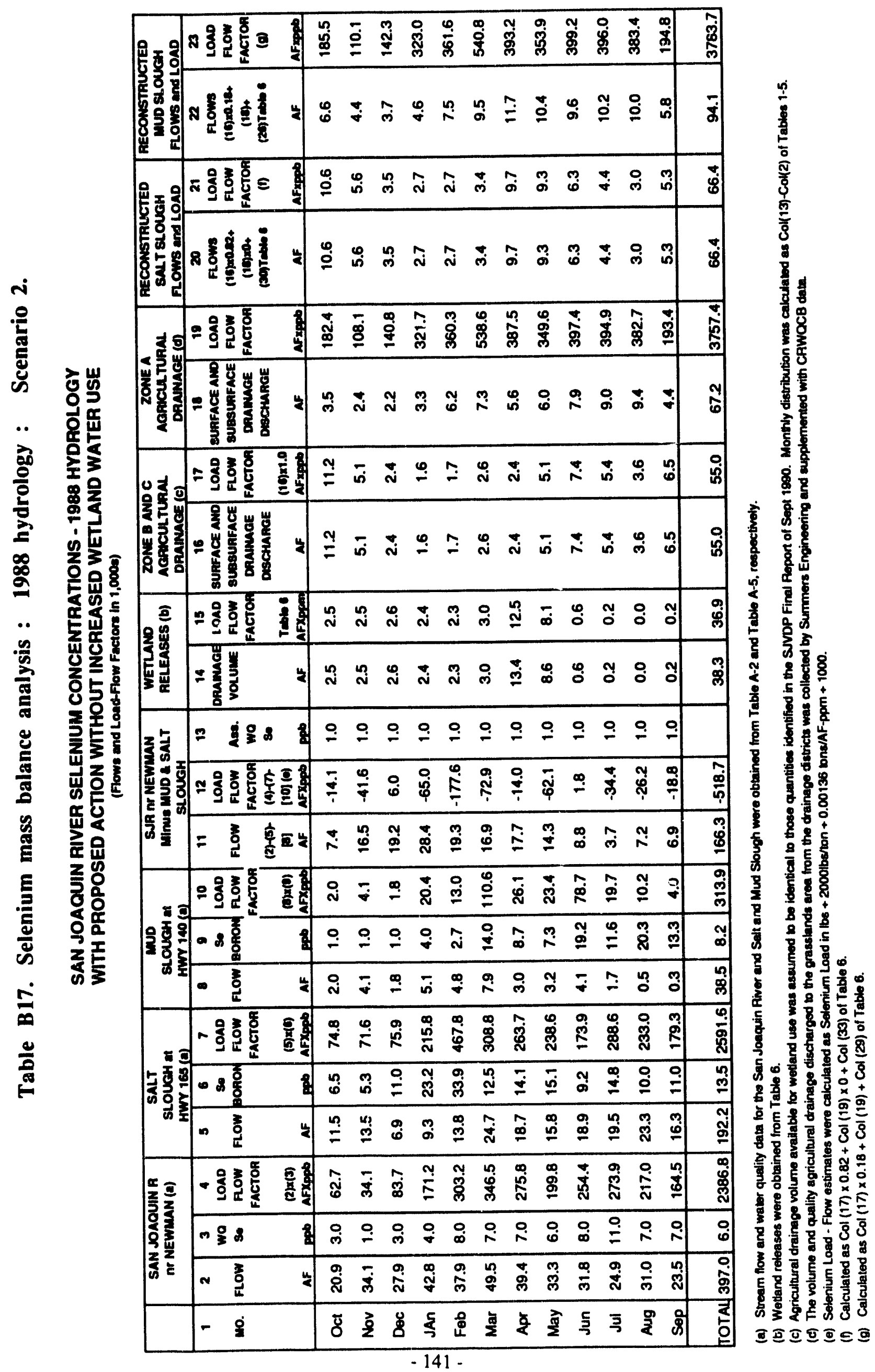




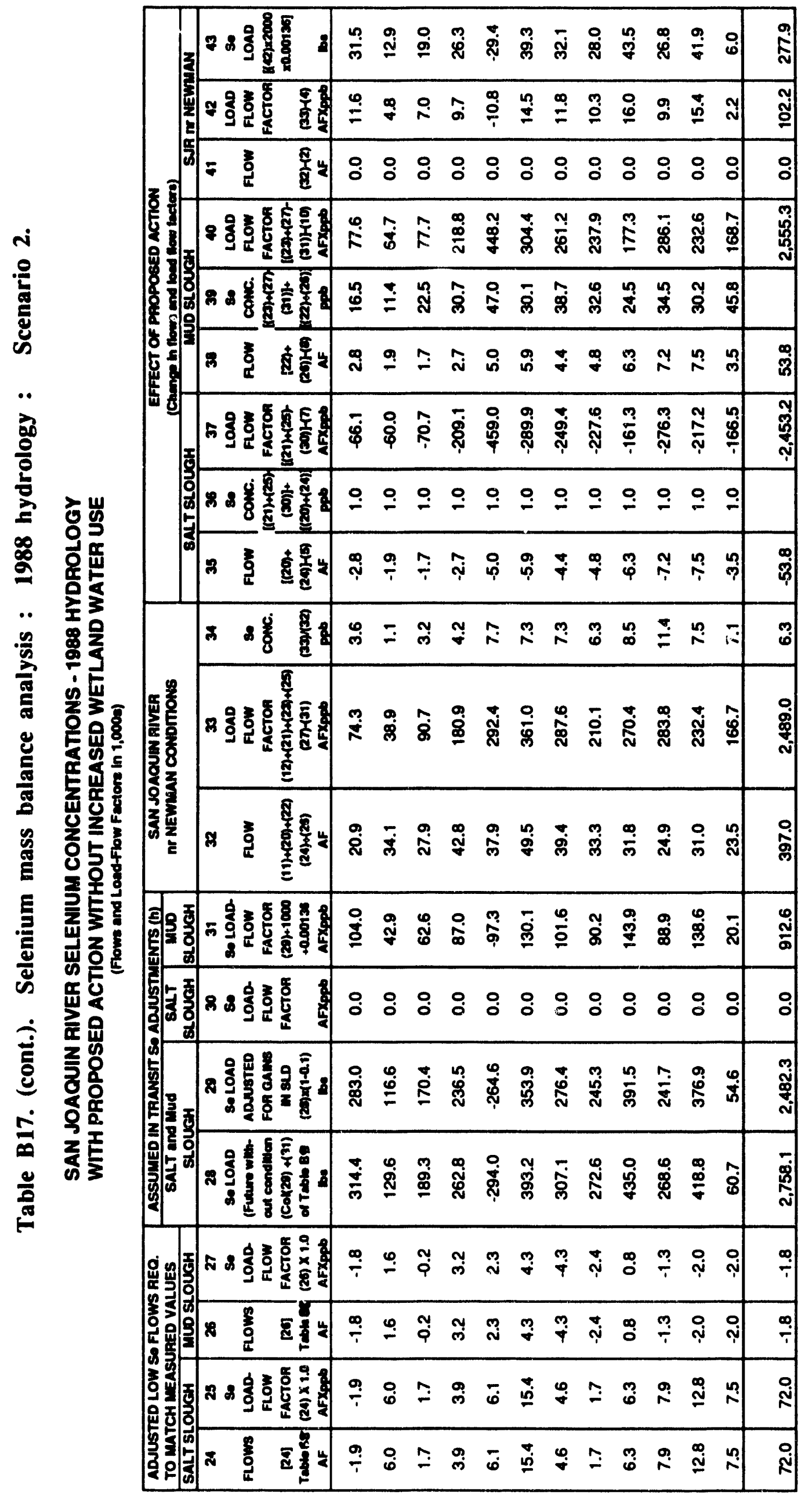




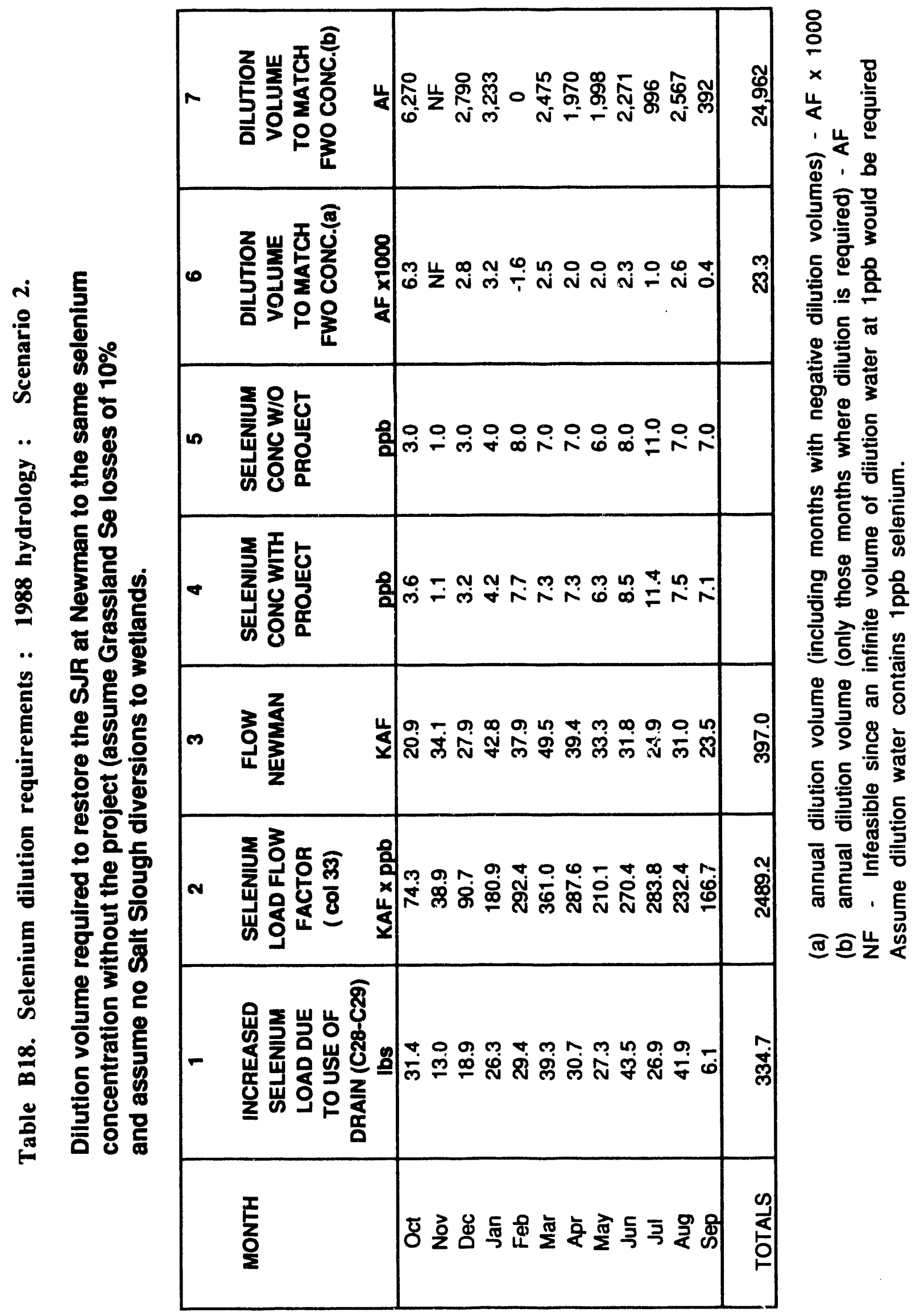




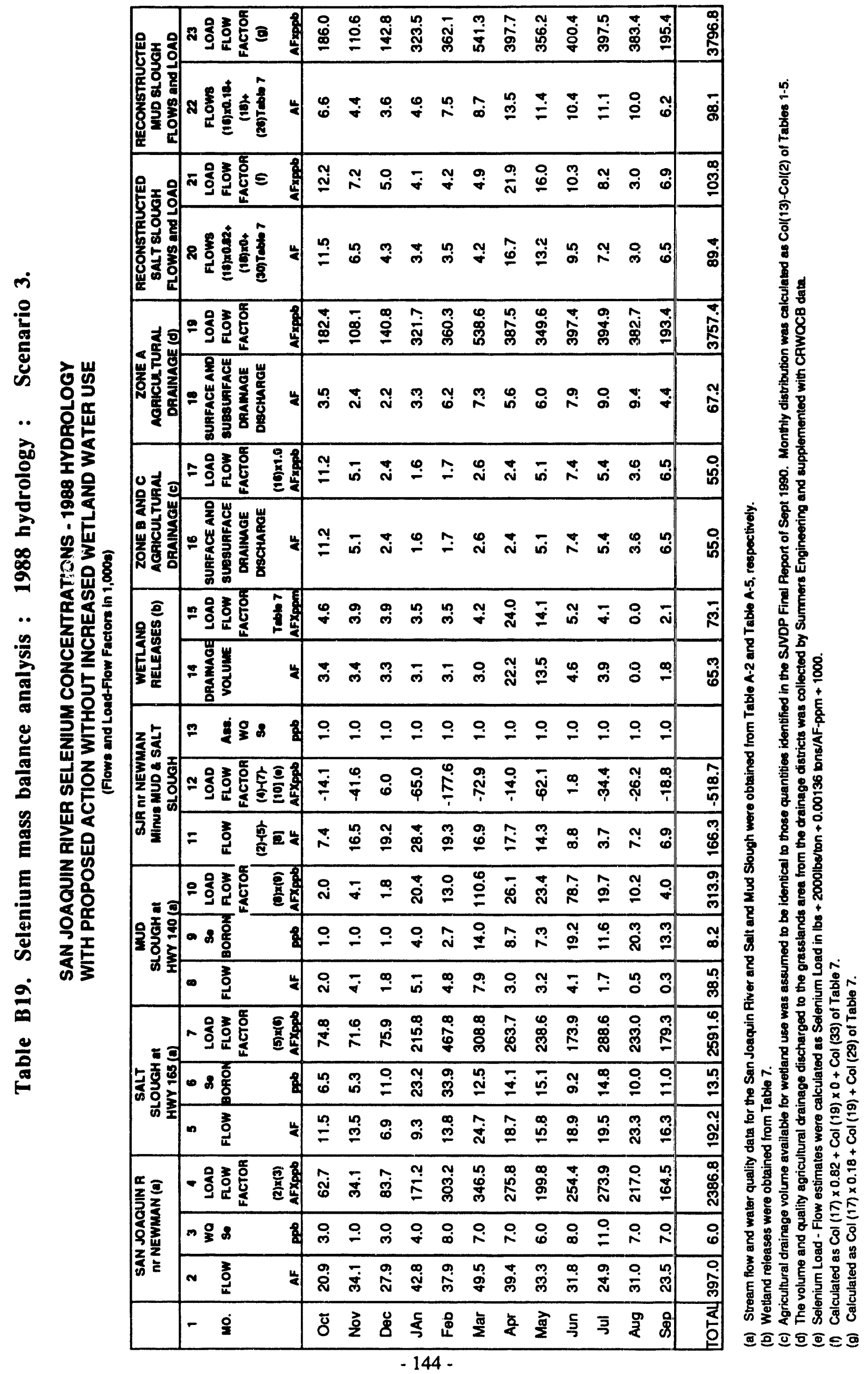




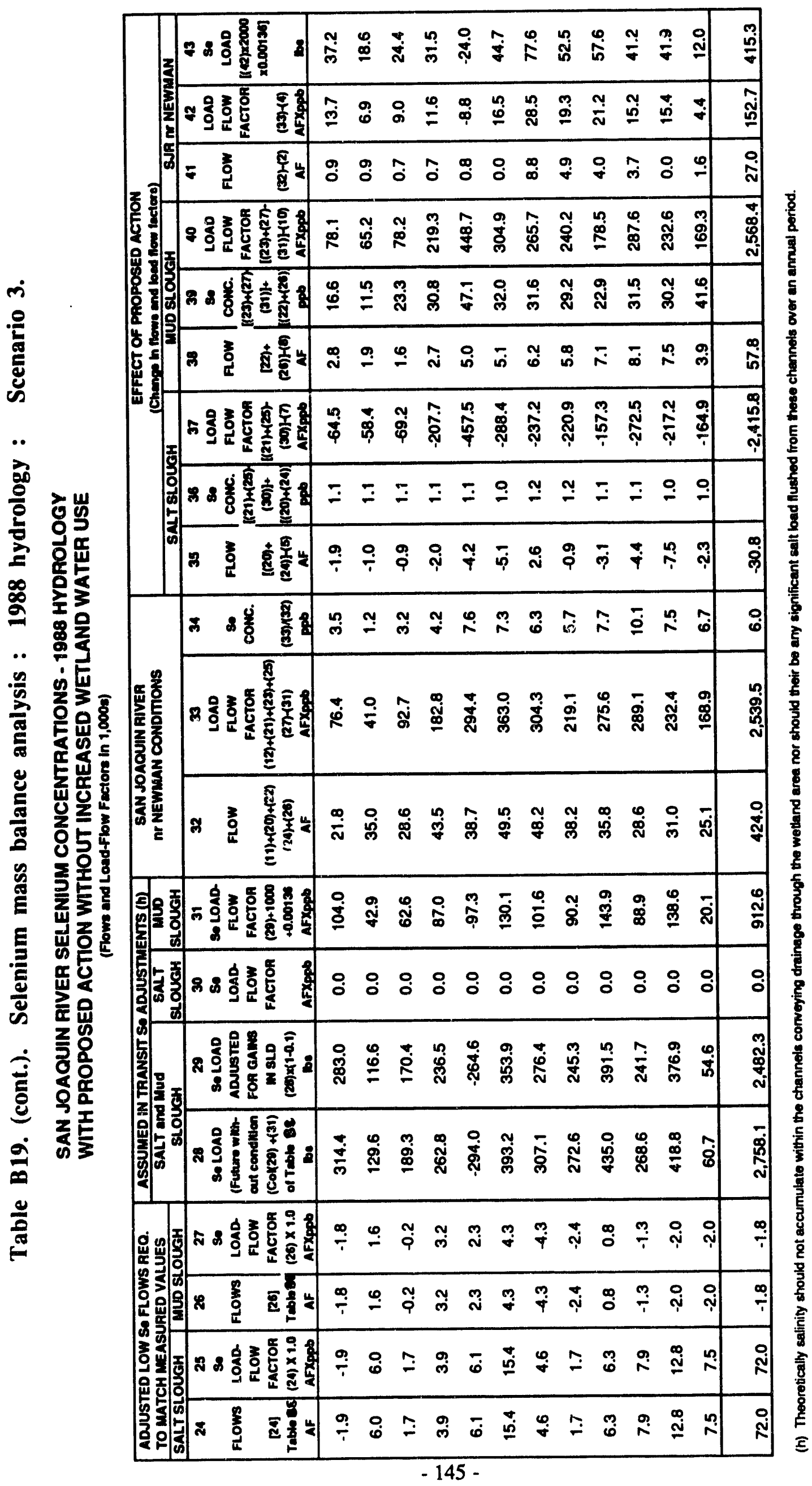


๓่

톨

$\frac{8}{8}$

$\ddot{0}$

$\frac{8}{8}$

롤

胥

홍

竞

$\leftarrow \Phi$

ธ

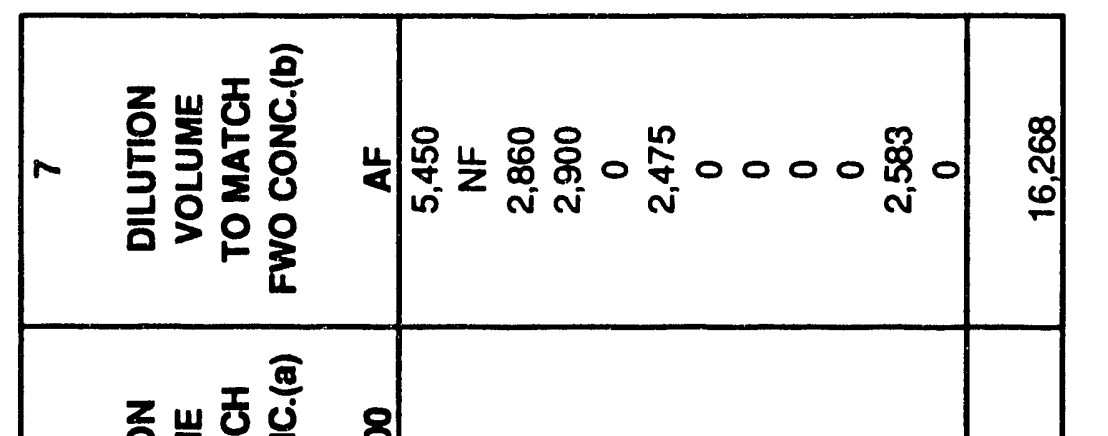

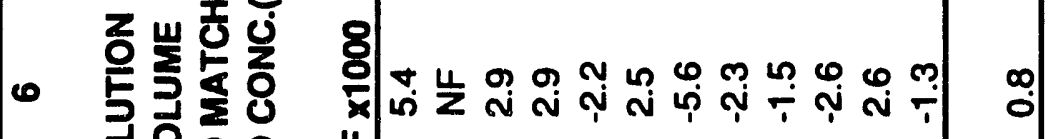
흥요욘 है।

क

\& 8

응

응 훙

응응

은둥

영 옹 옹

光 万

하을

옹

\% 0 。

도은

긍응 홍유

돌

등 행

용

릉응

\begin{tabular}{|c|c|c|}
\hline 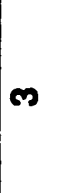 & 咅亭 & 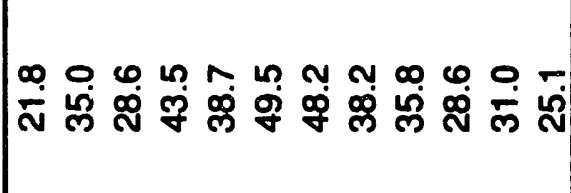 \\
\hline N & 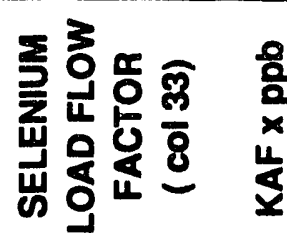 & 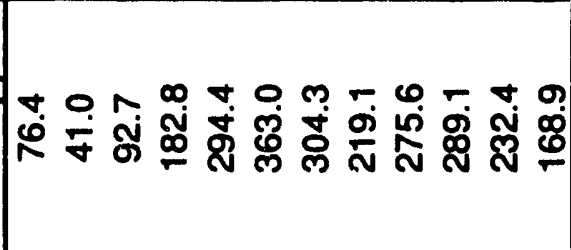 \\
\hline$r$ & 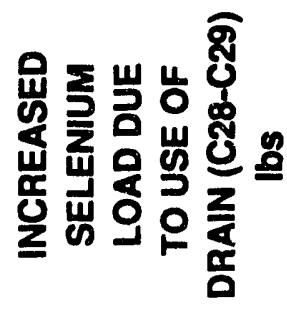 & 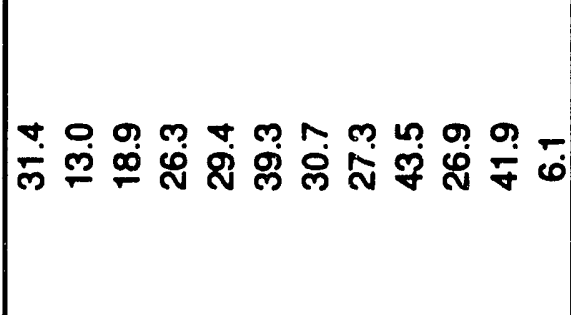 \\
\hline & $\sum_{\mathcal{E}}^{I}$ & రั \\
\hline
\end{tabular}

응

× 옹

क岁

통윽

흥 을

号

은 은 음

금 또는

등

方 京

잉

$\Phi$

든 은

ต

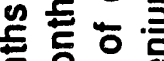

들 웛

올

잏옹 응

옹 음

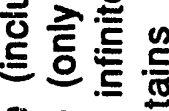

롤 ㄷํㅇ

ํㅡㅇ 웡 혼

등

를 을

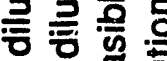

띡 똘

올 올

ह 조른 


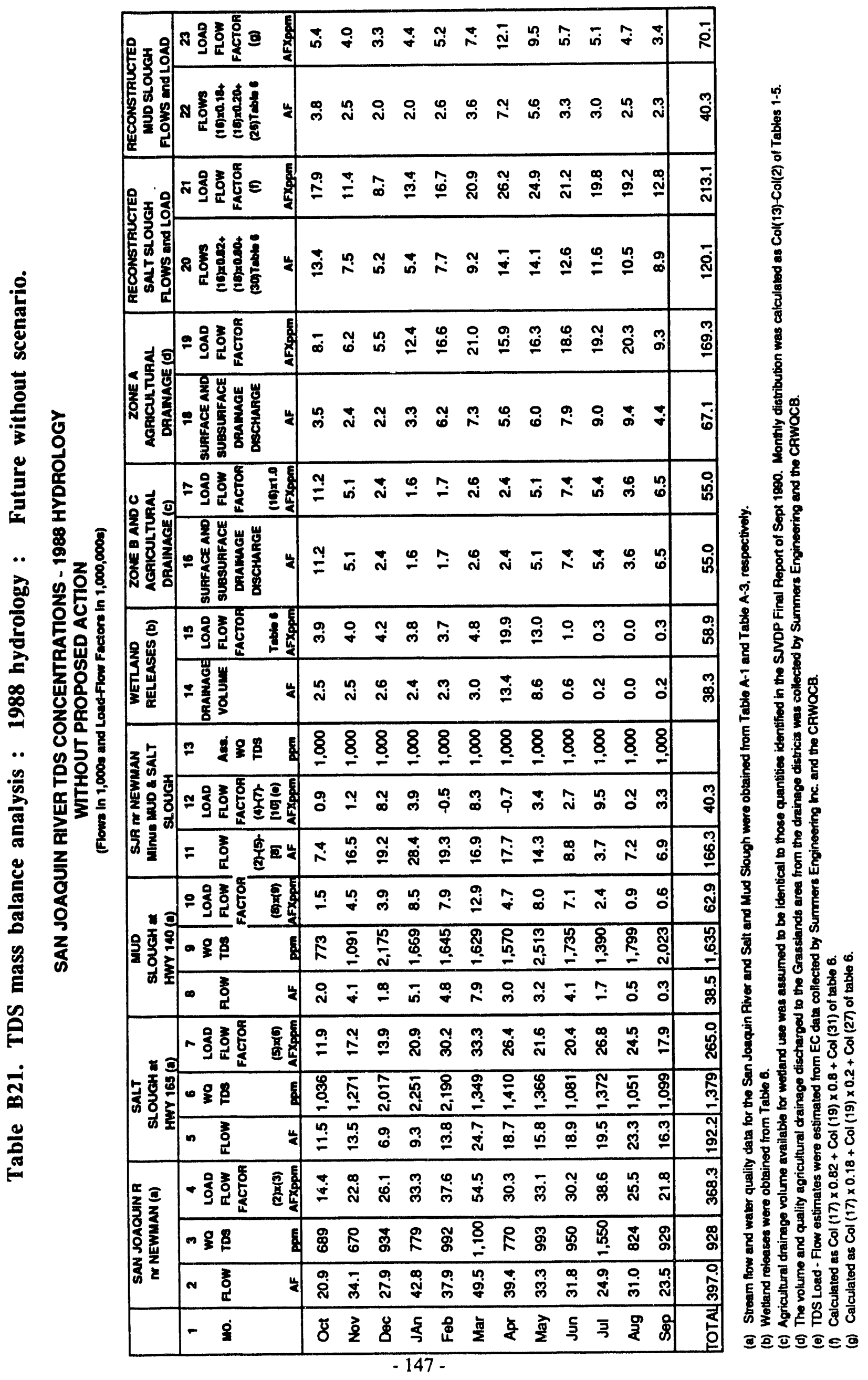




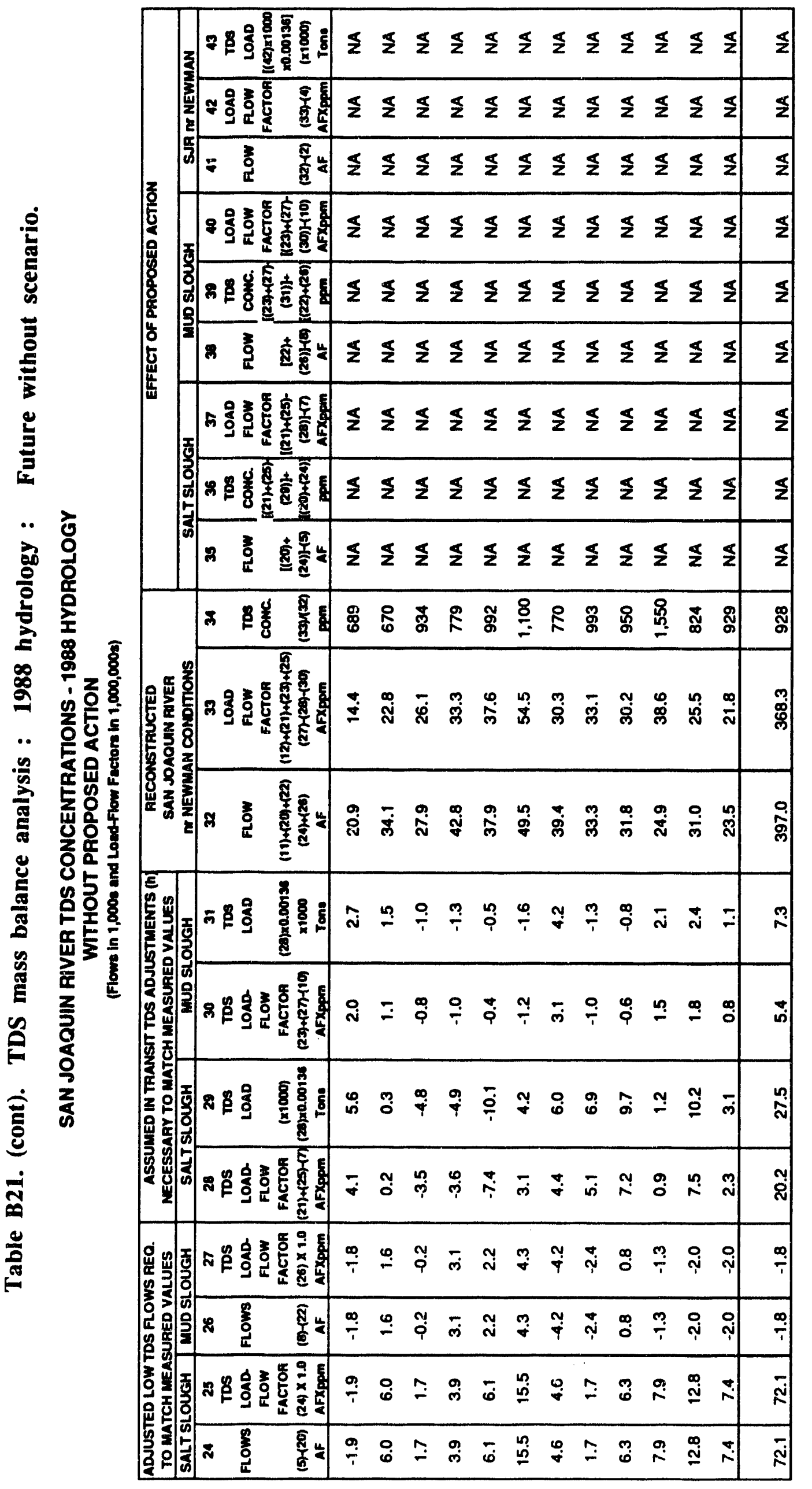




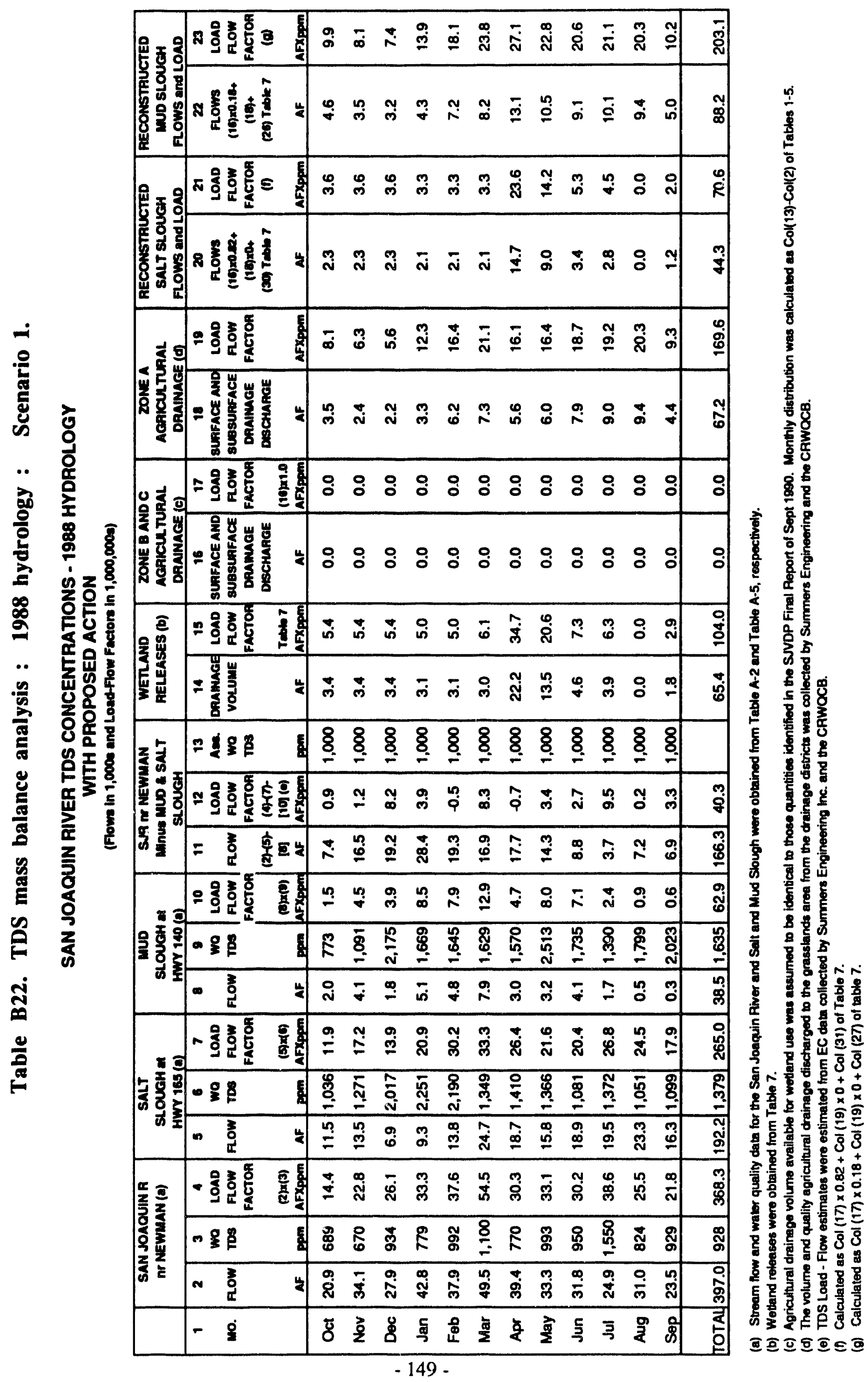




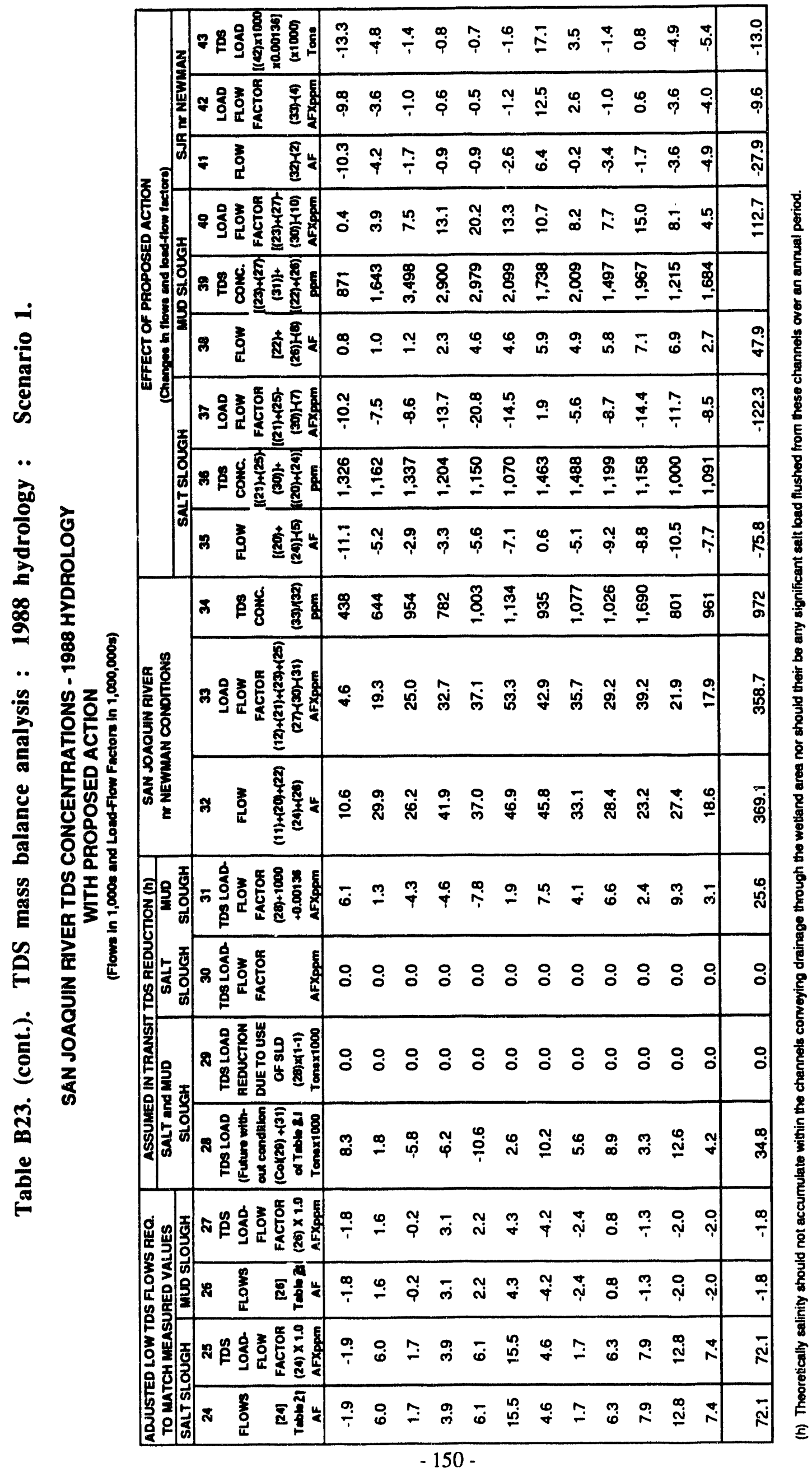




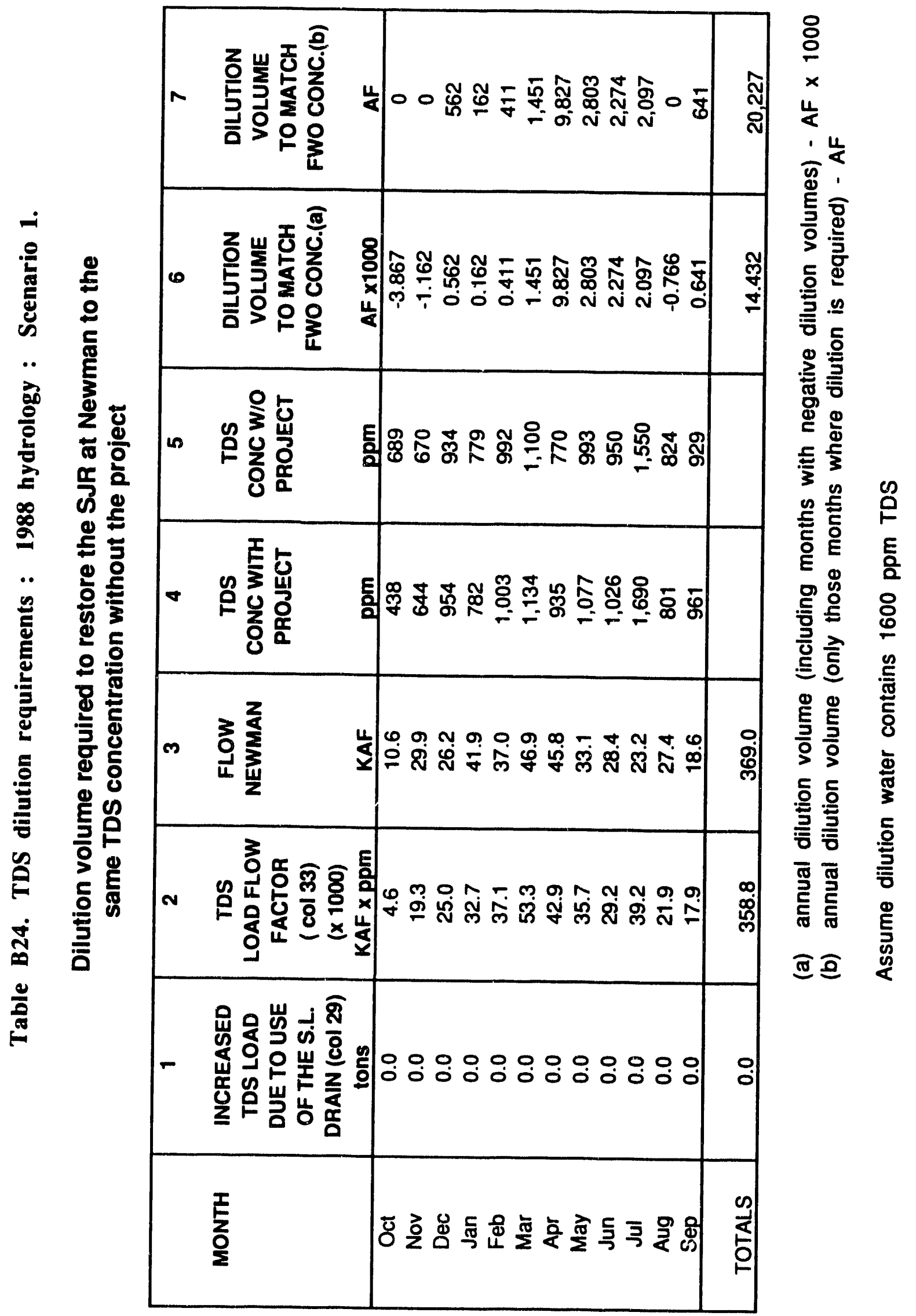




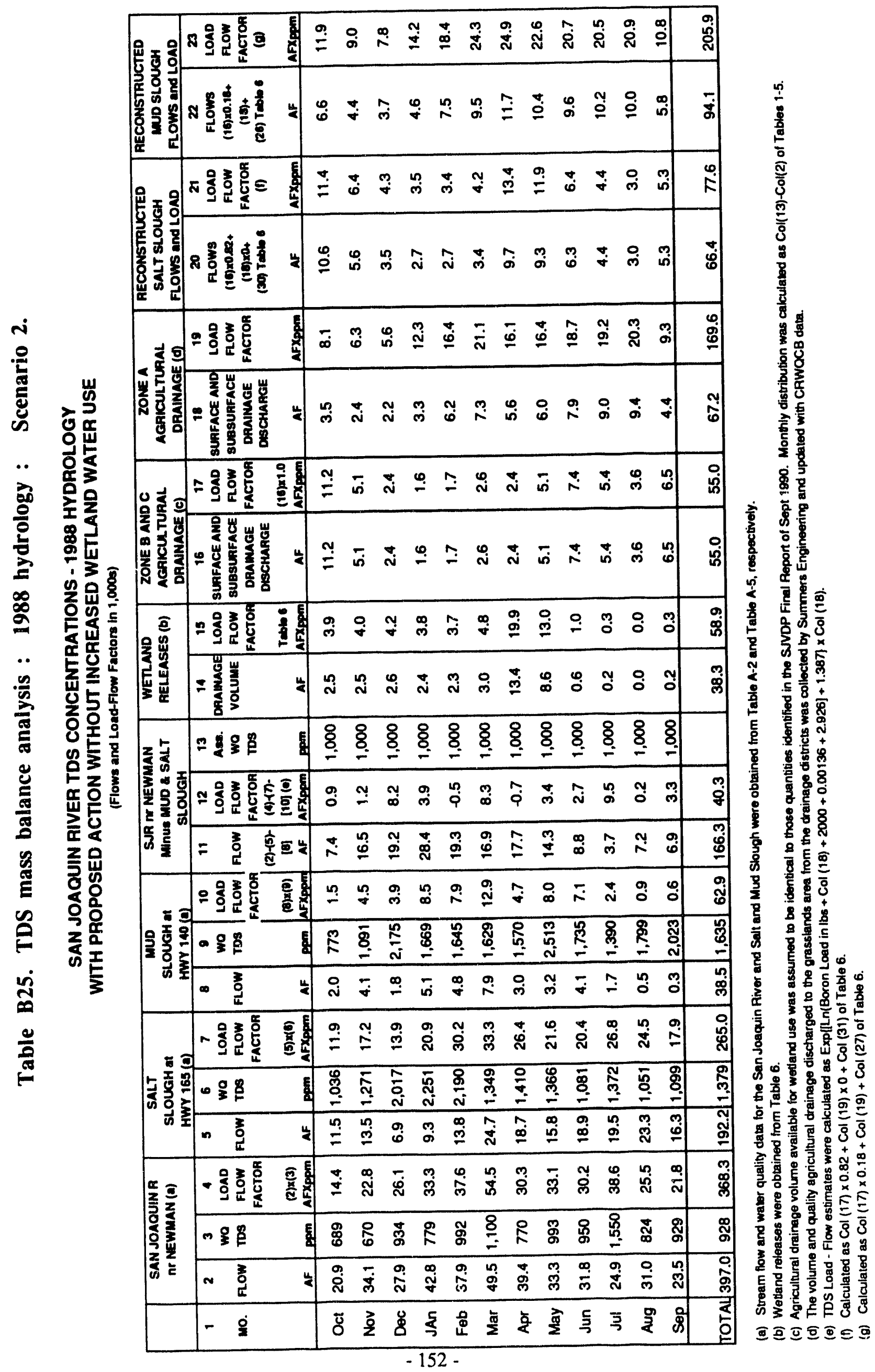




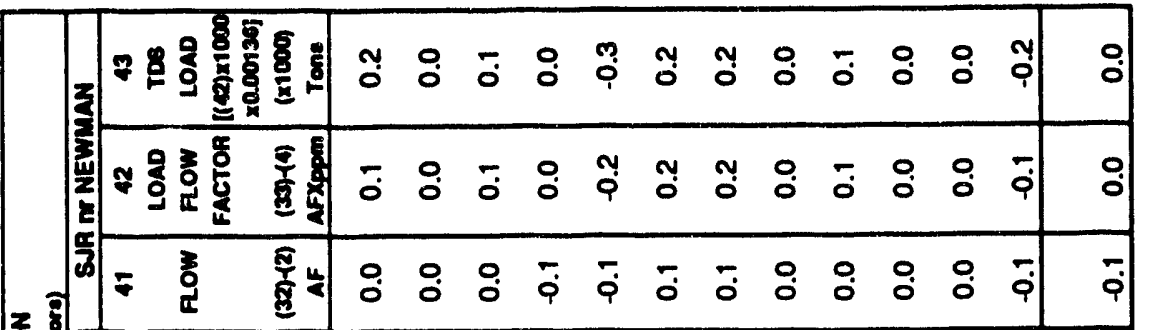

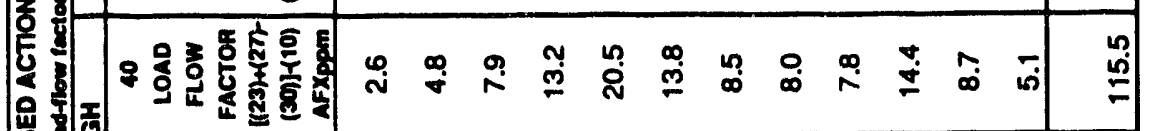

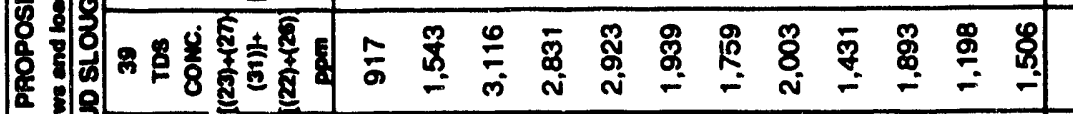

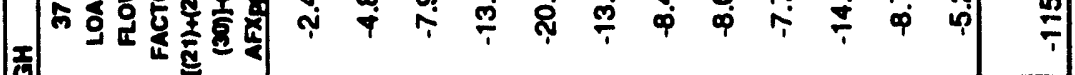

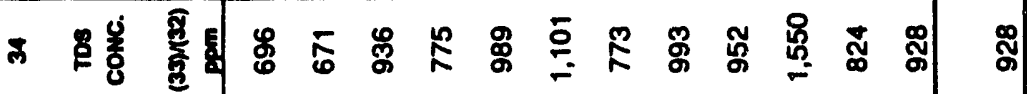

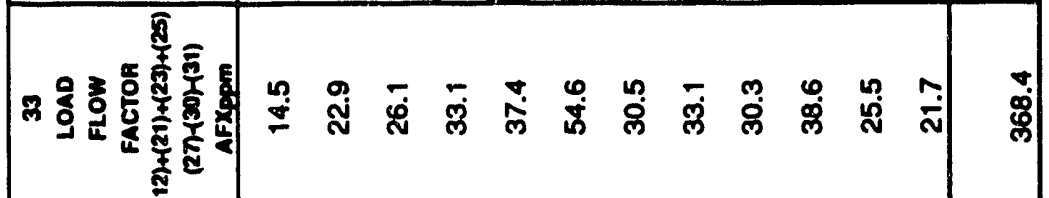

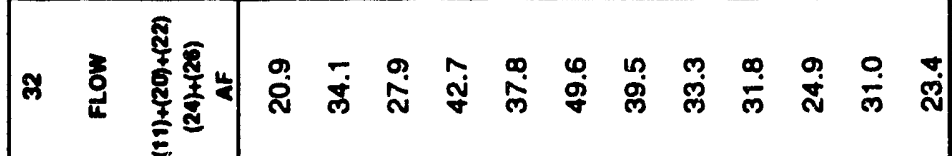

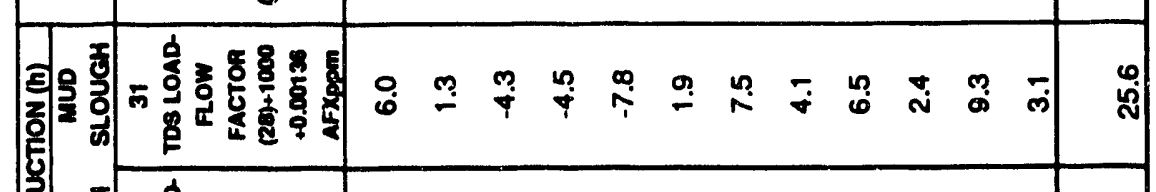

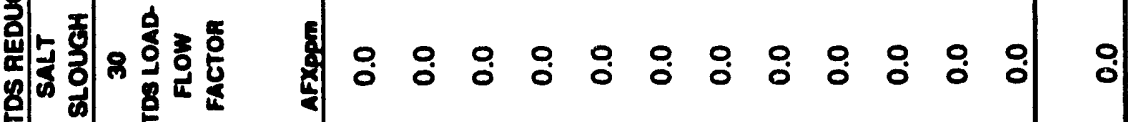
空 


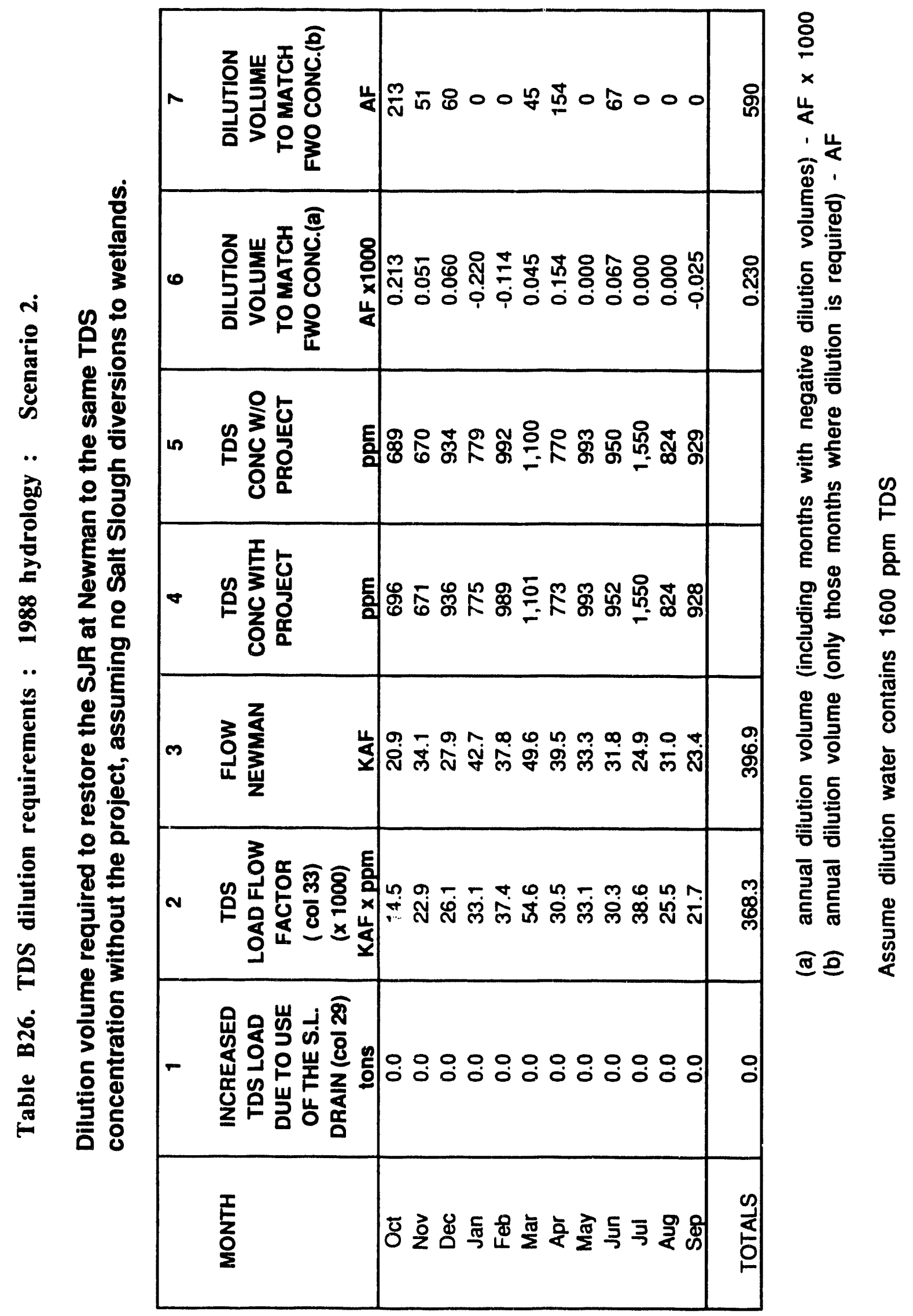




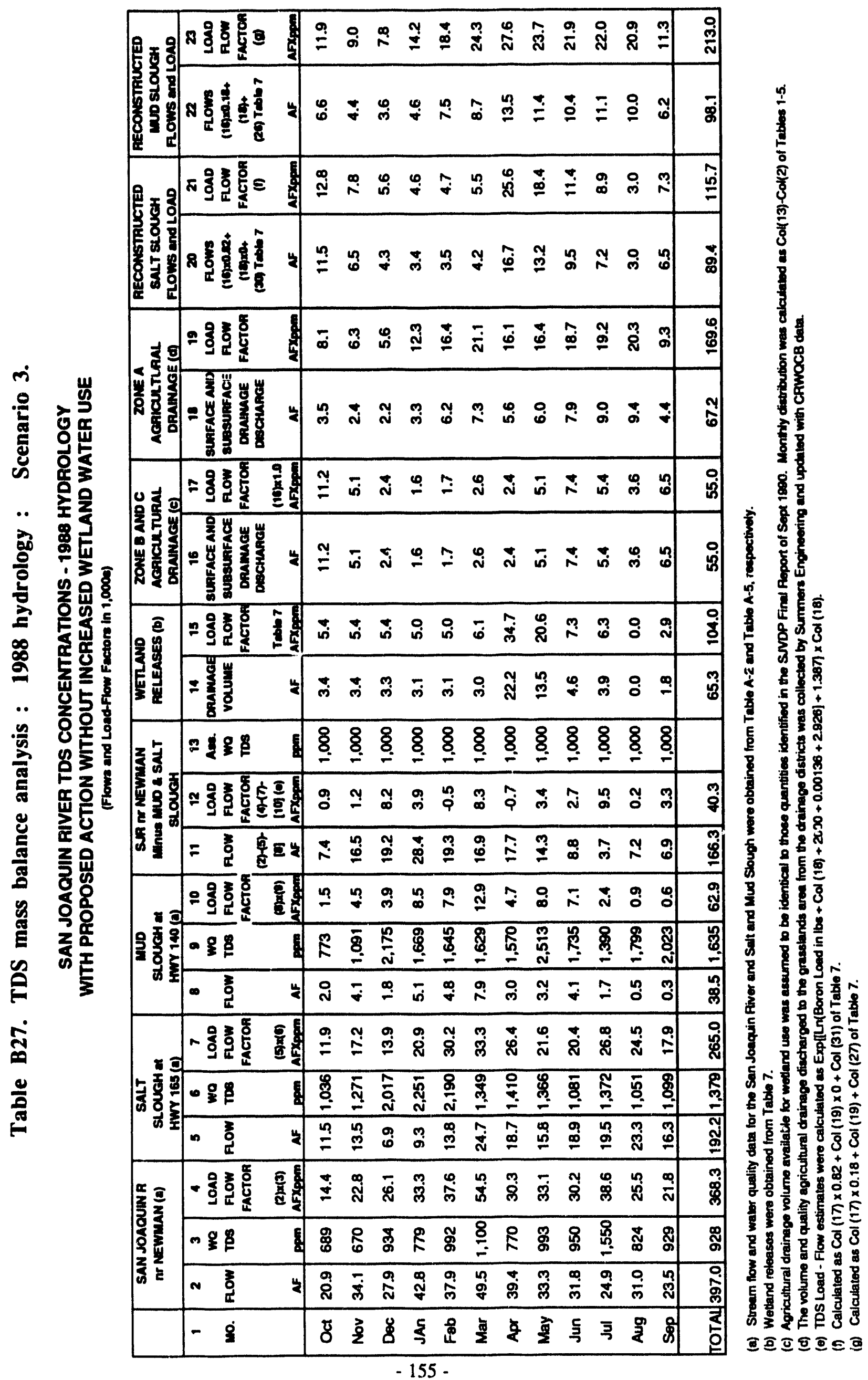




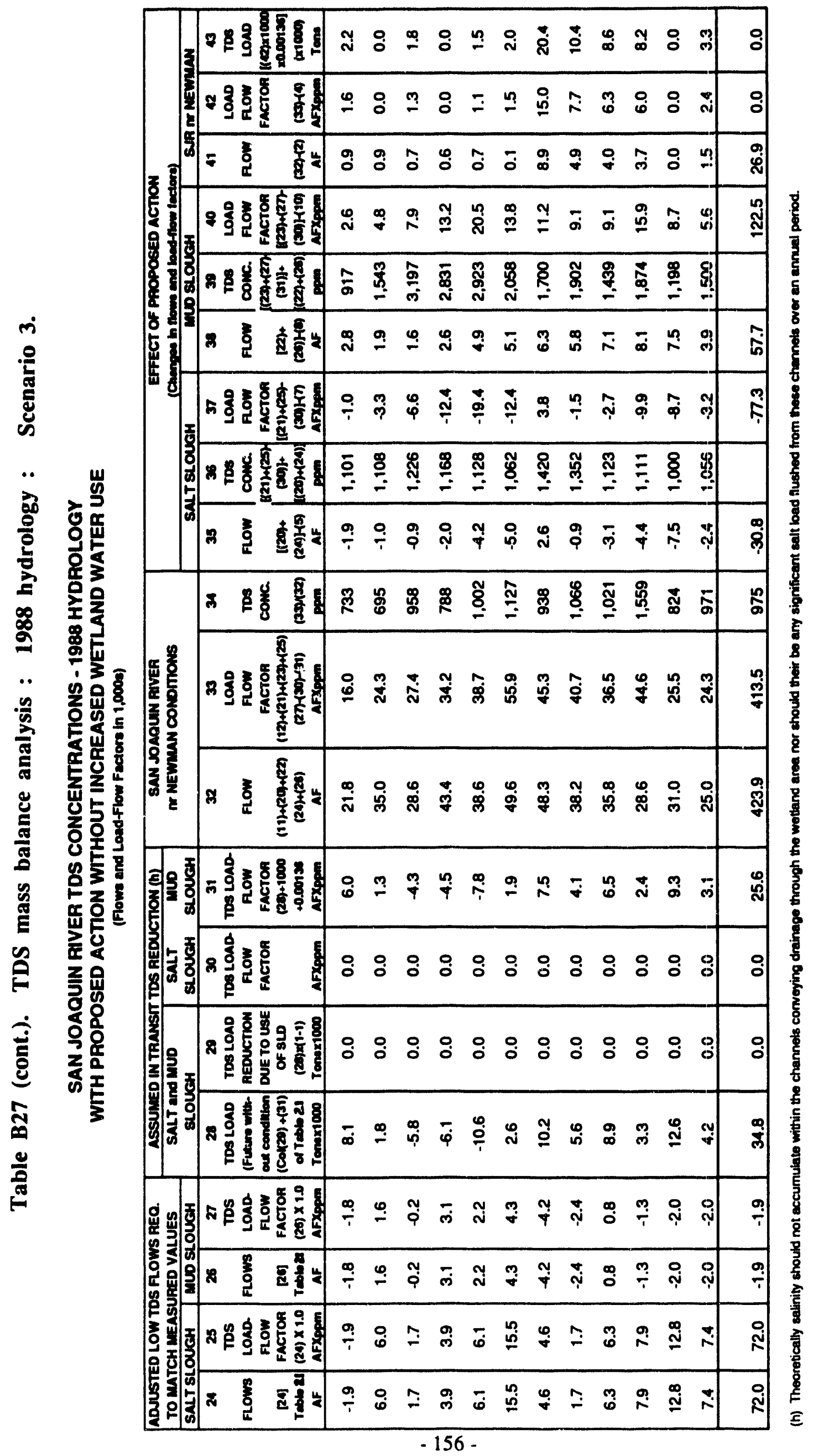




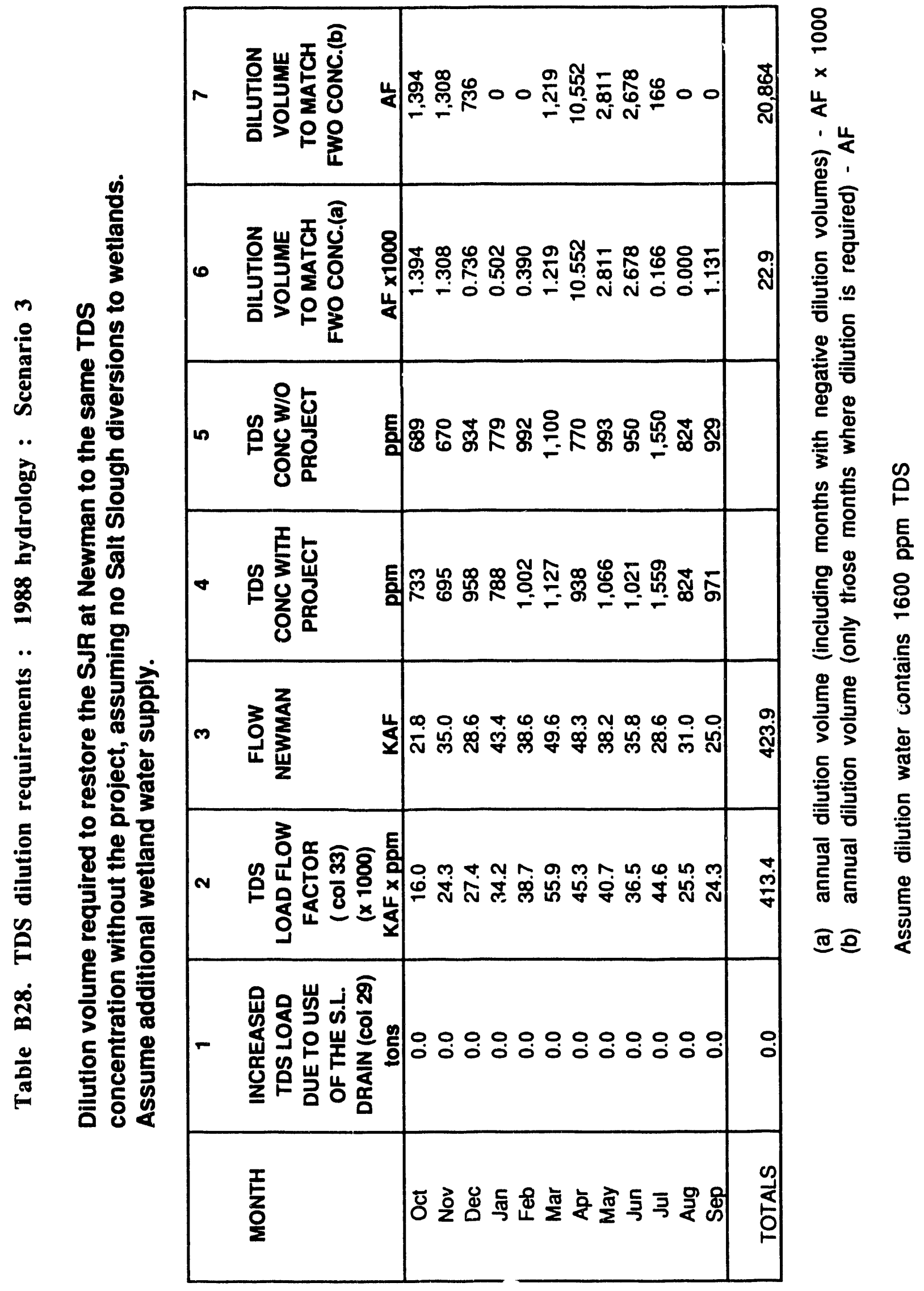




\section{Appendix C}

Mass balance analysis for boron, selenium and TDS

1986 hydrology

C1 - C28 


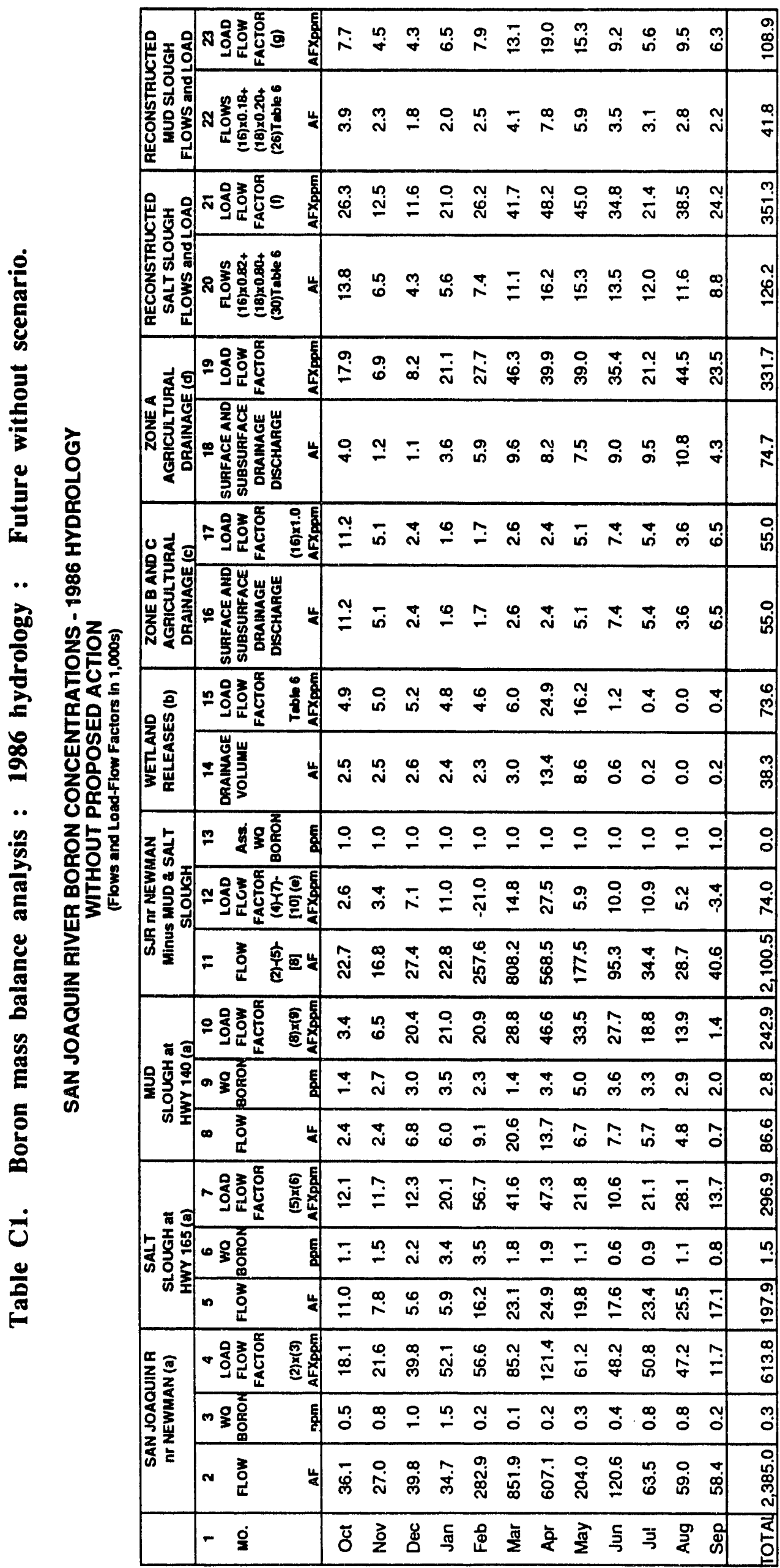

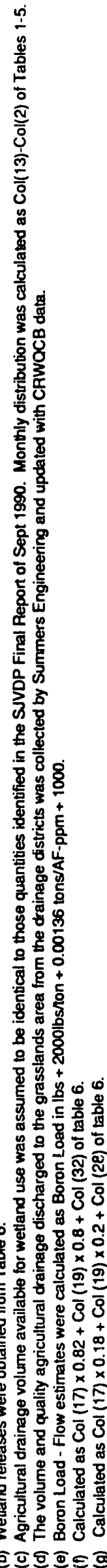




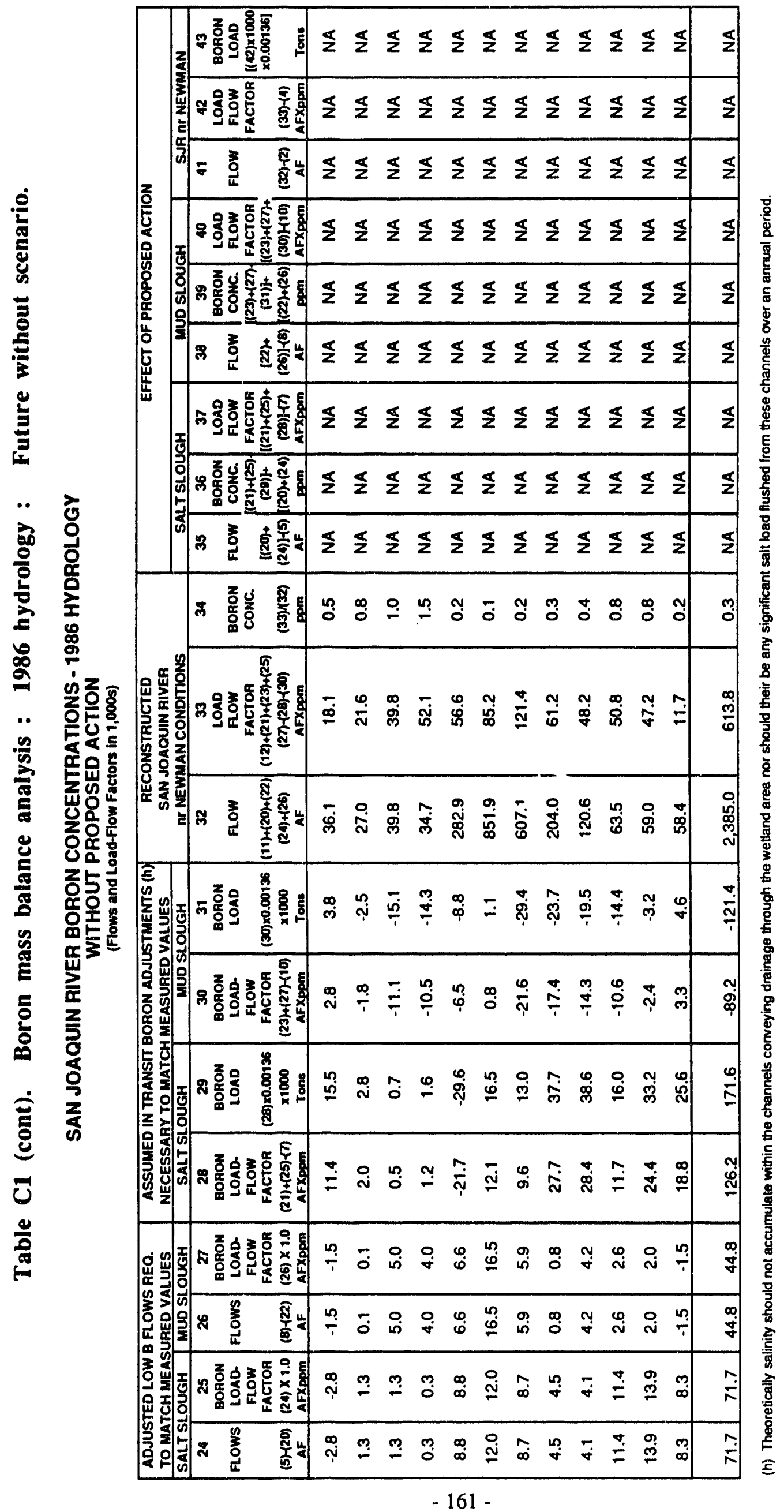




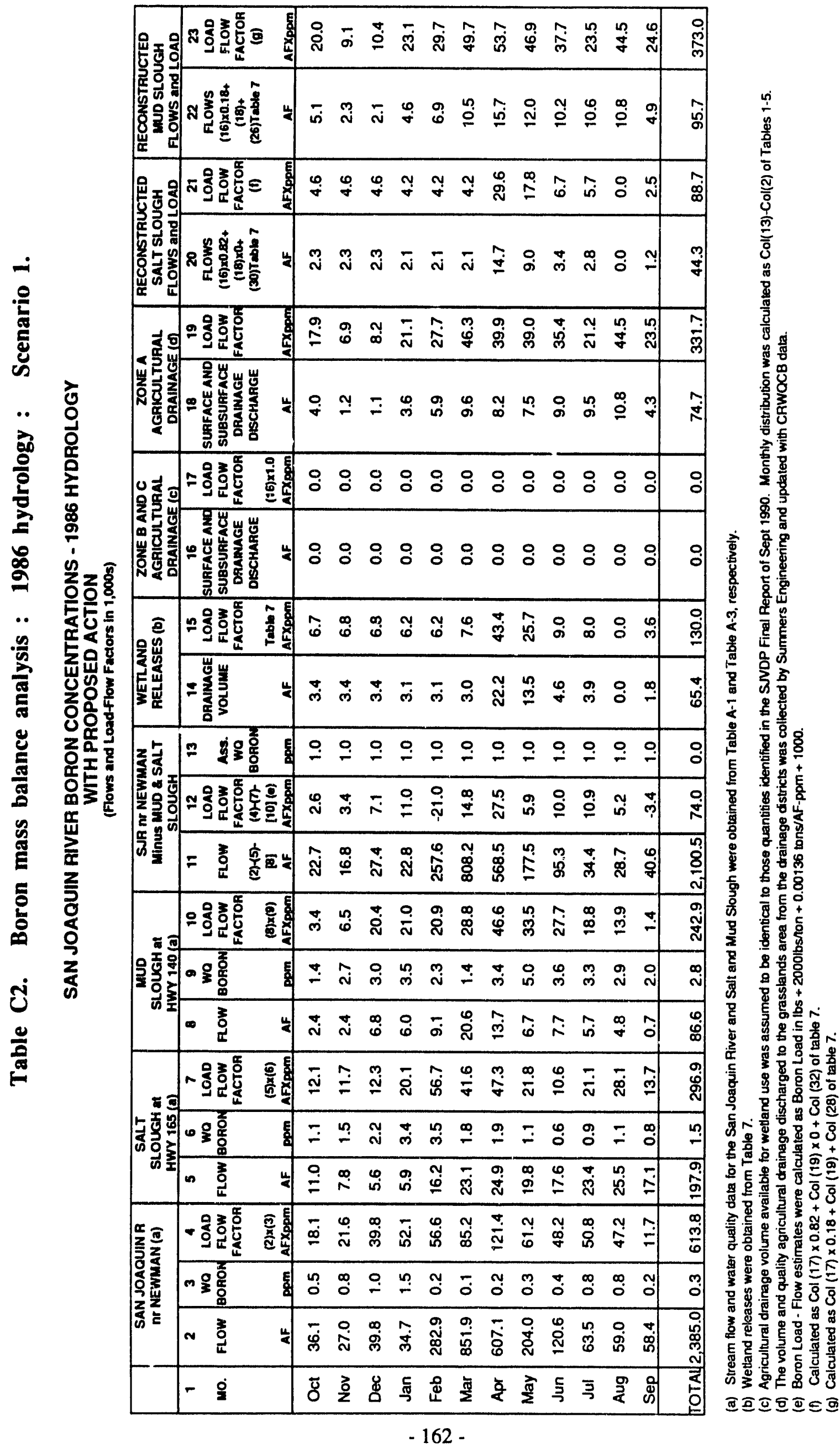




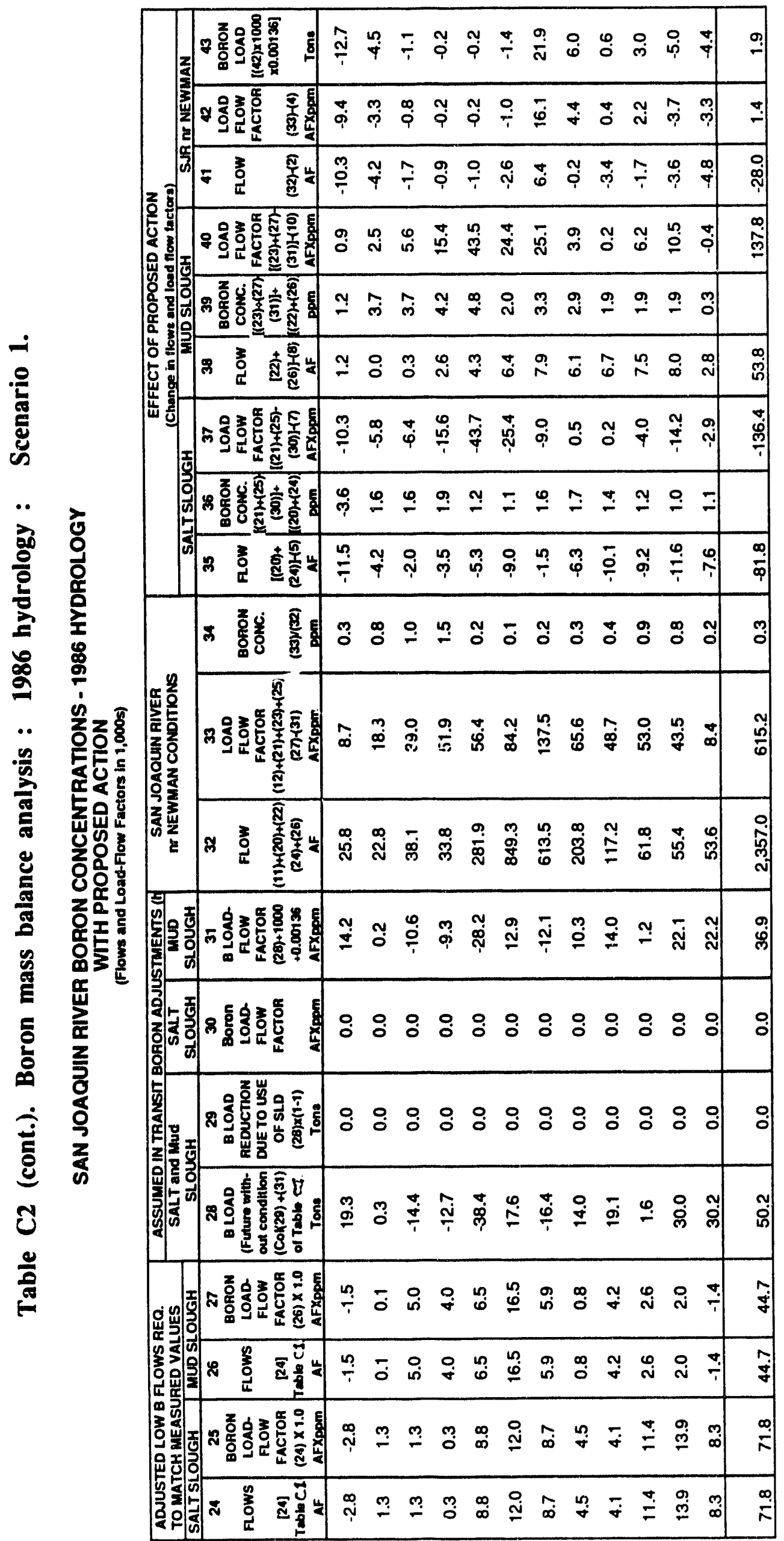




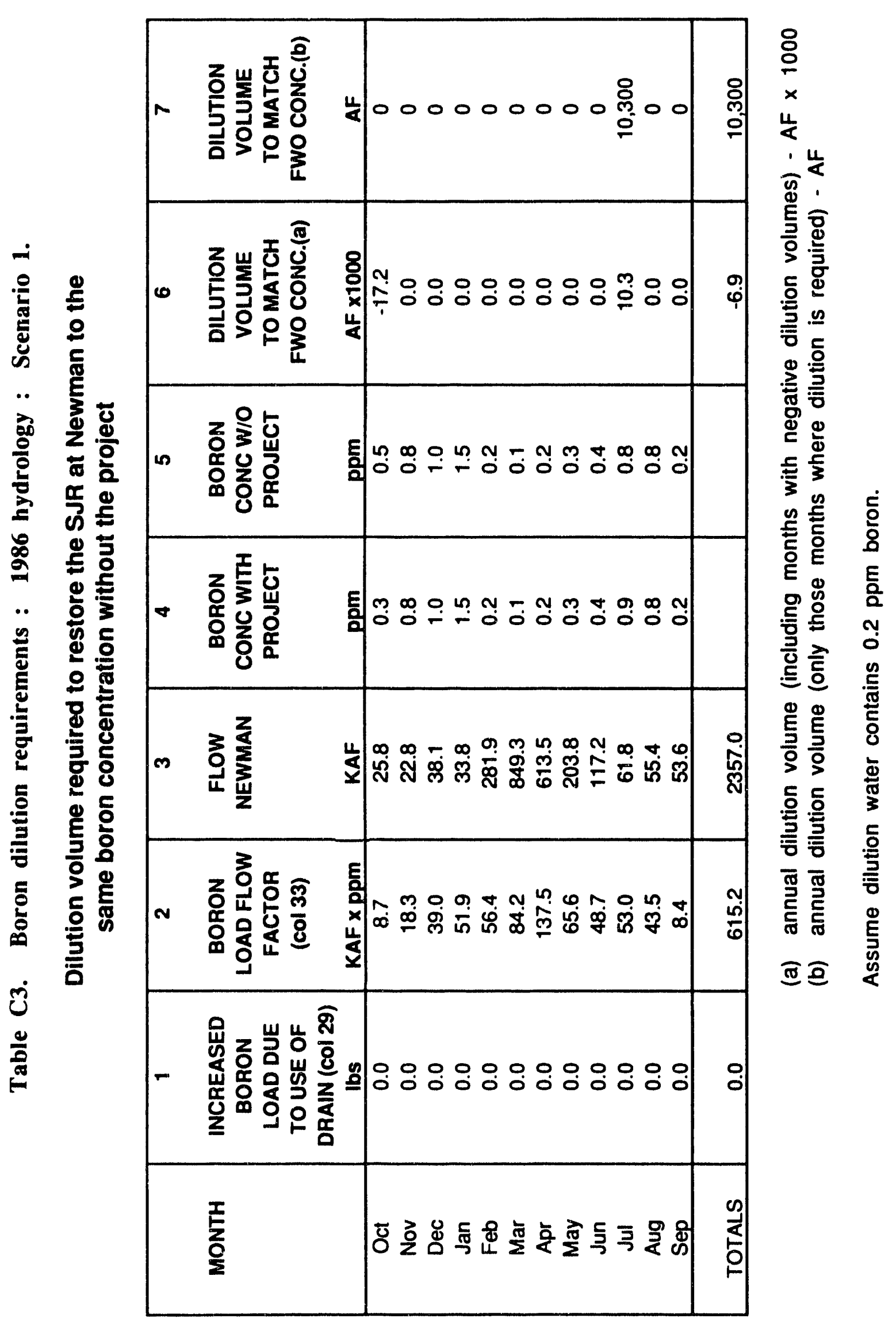




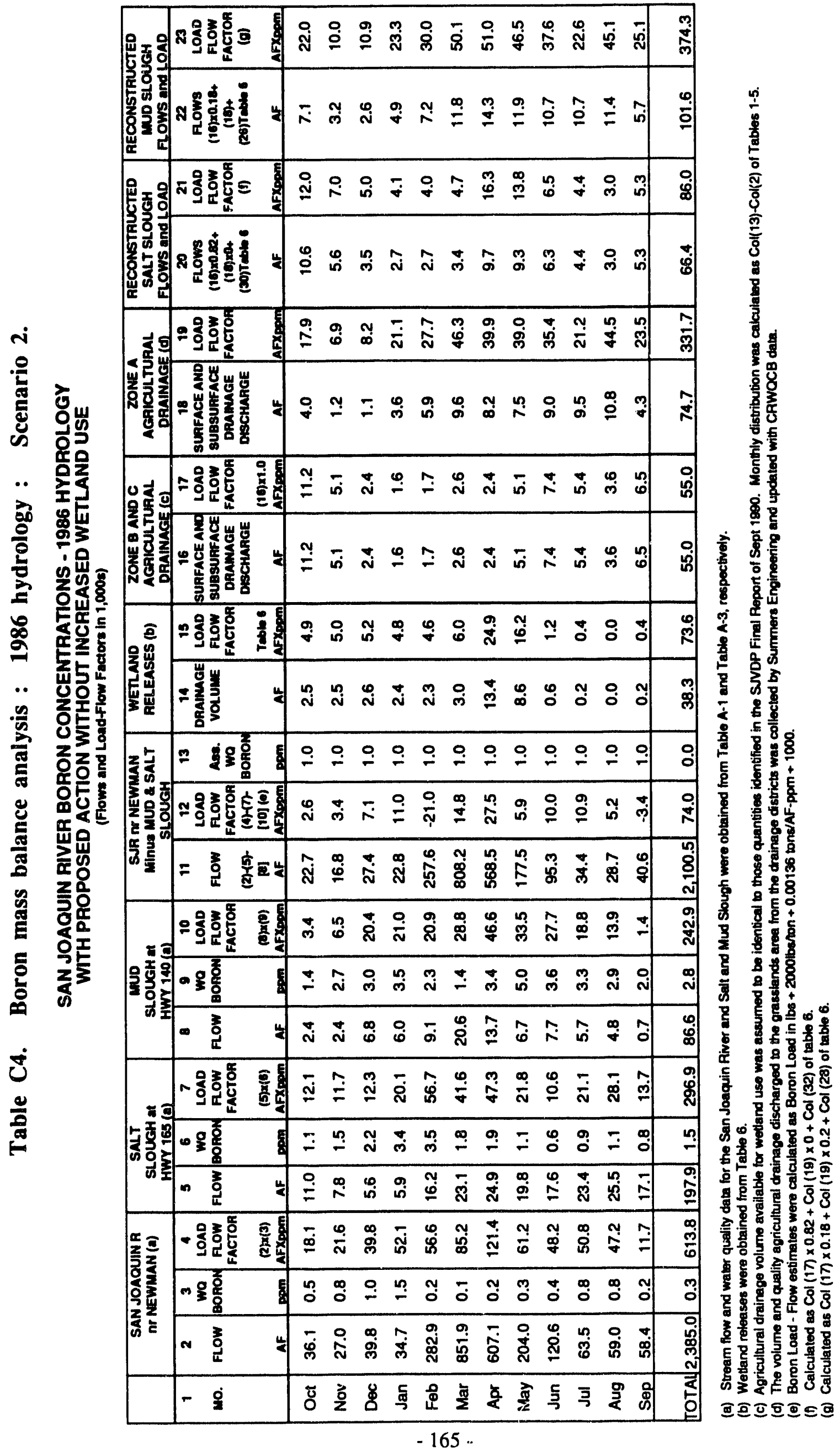




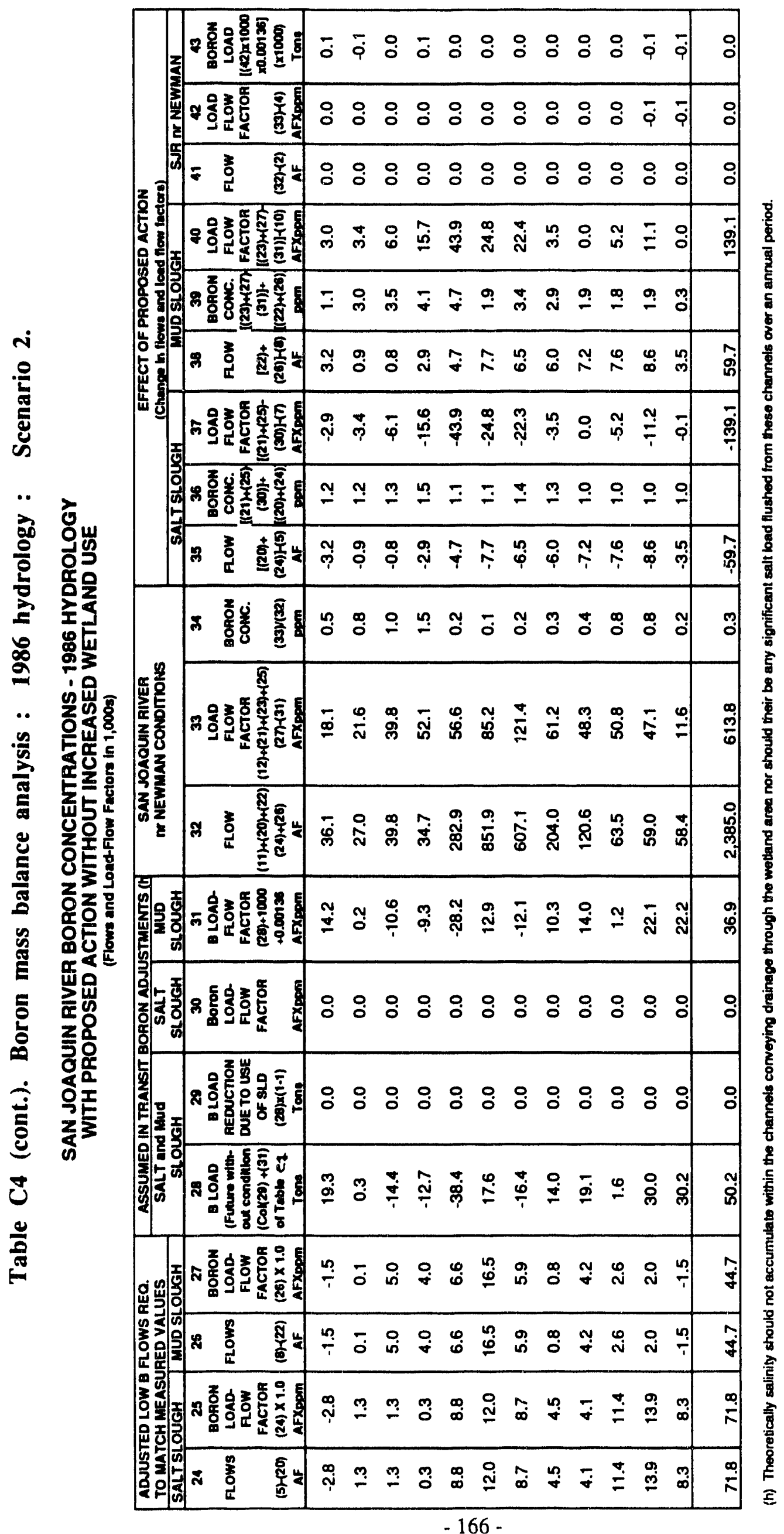




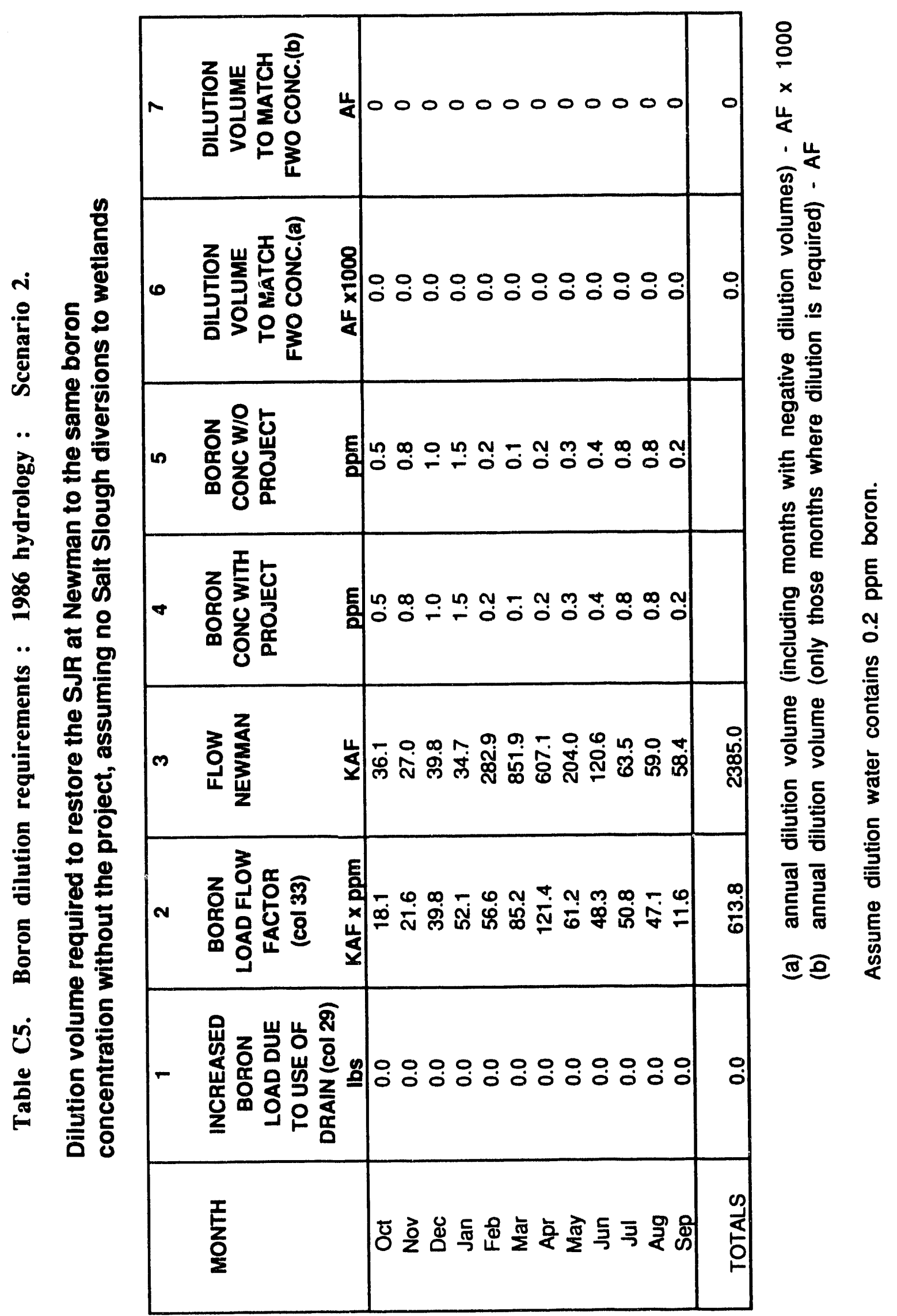




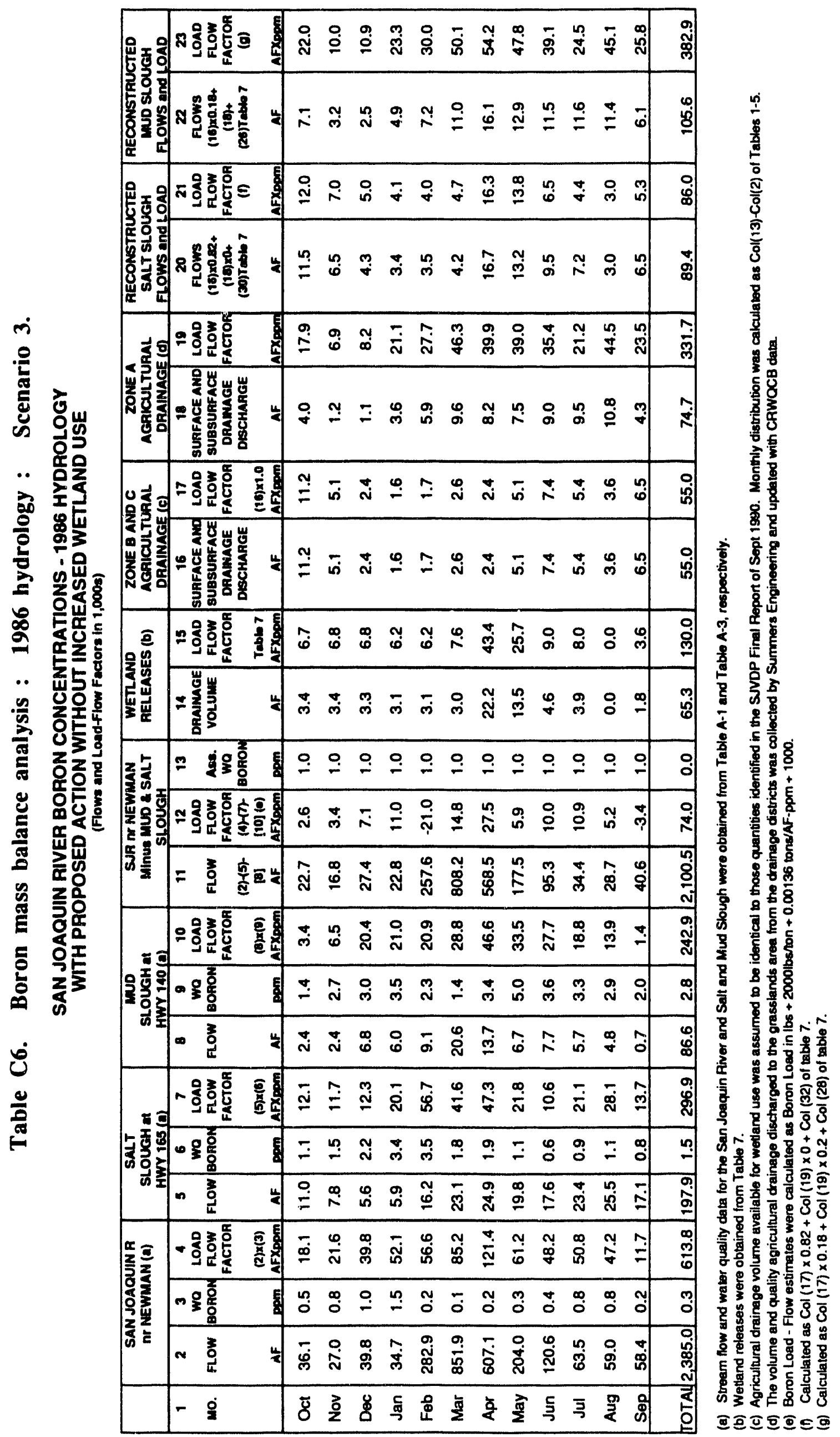




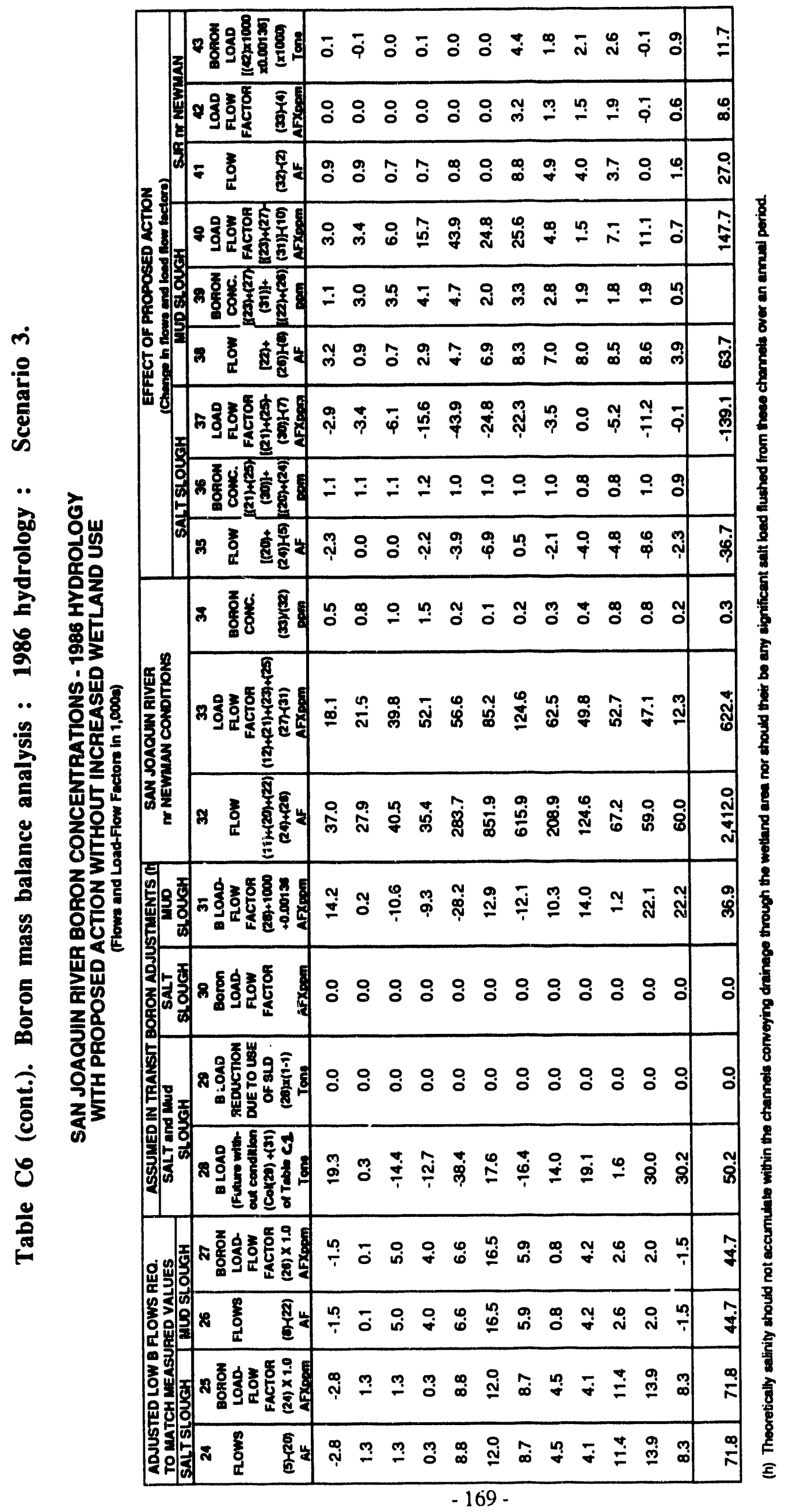




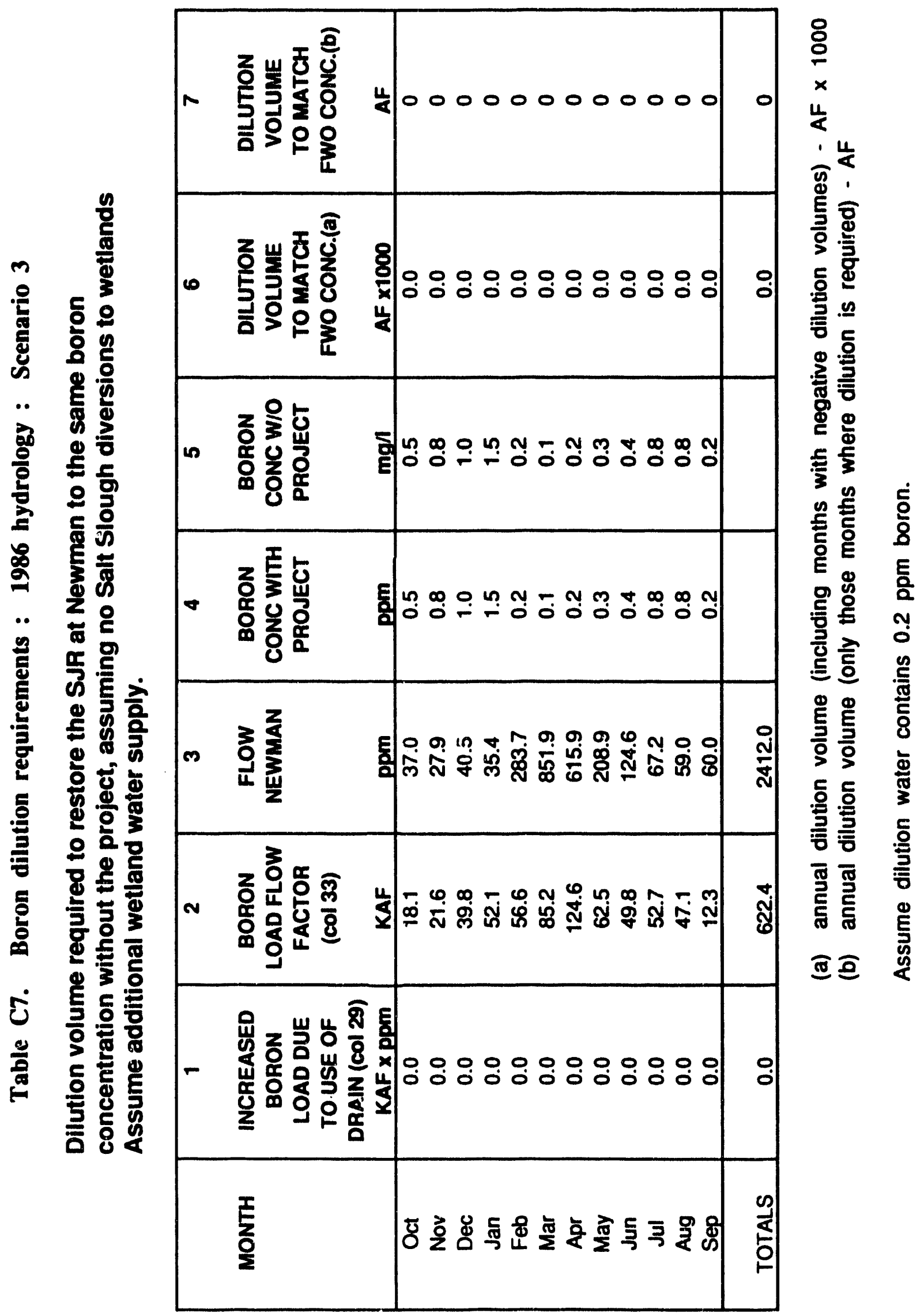




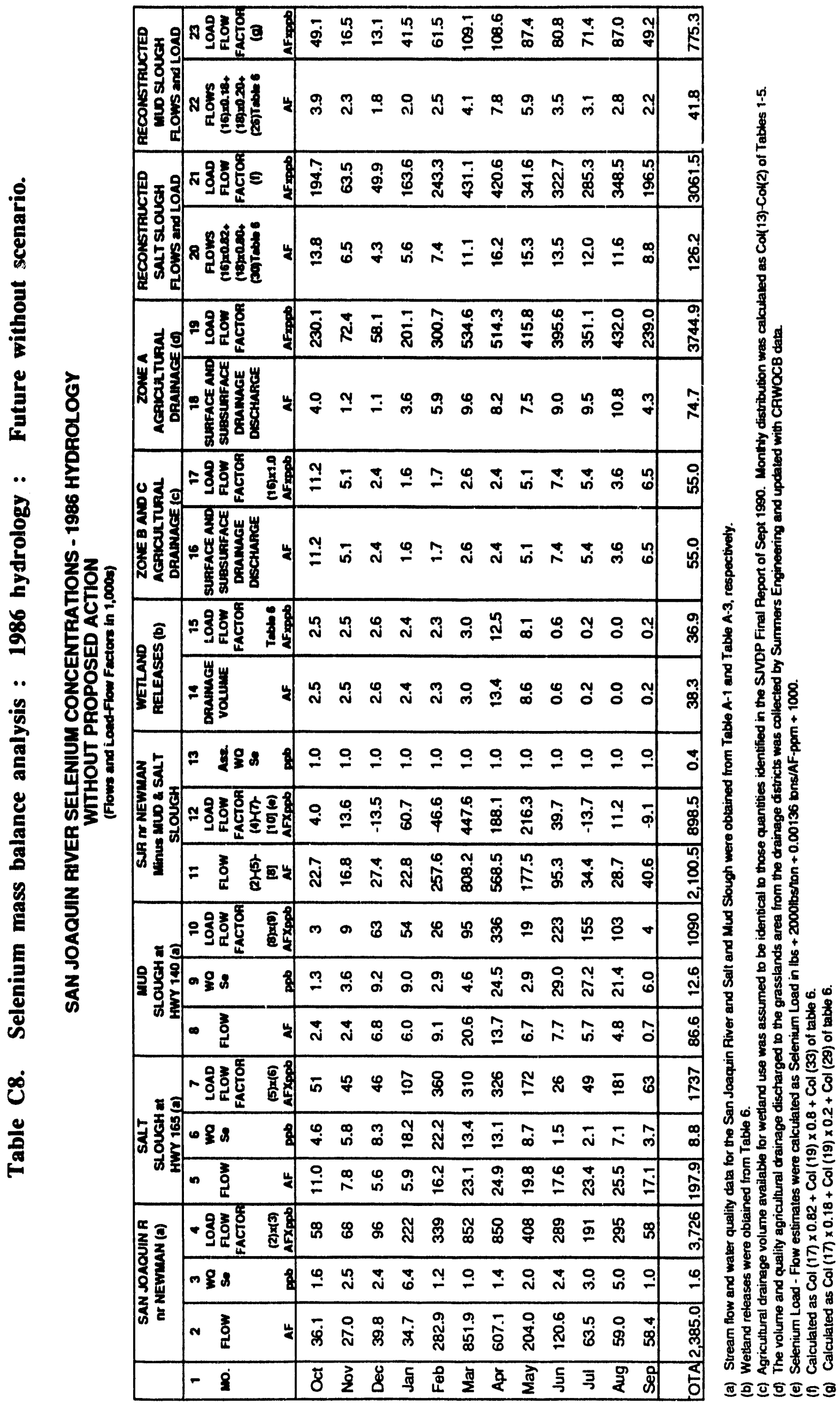




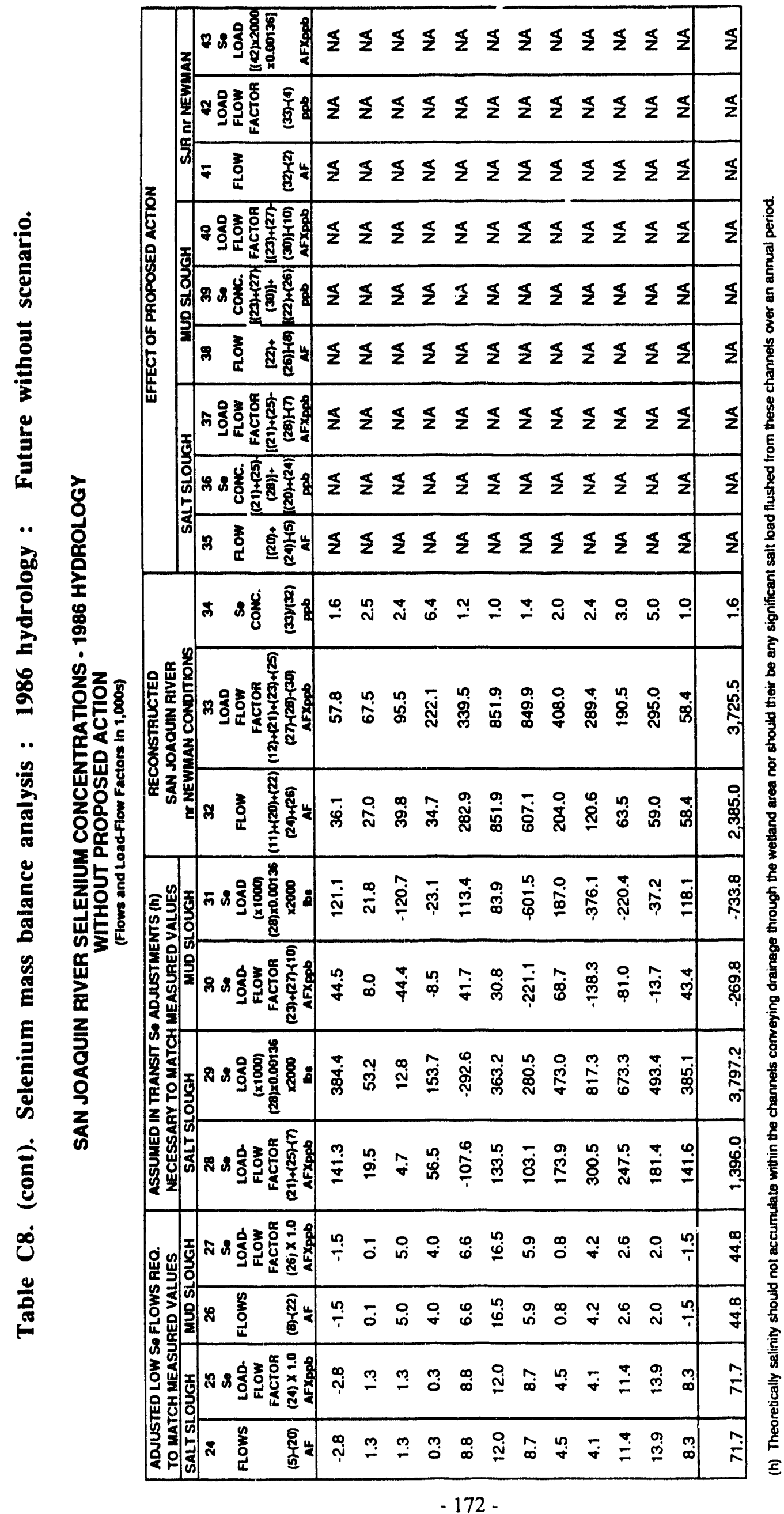




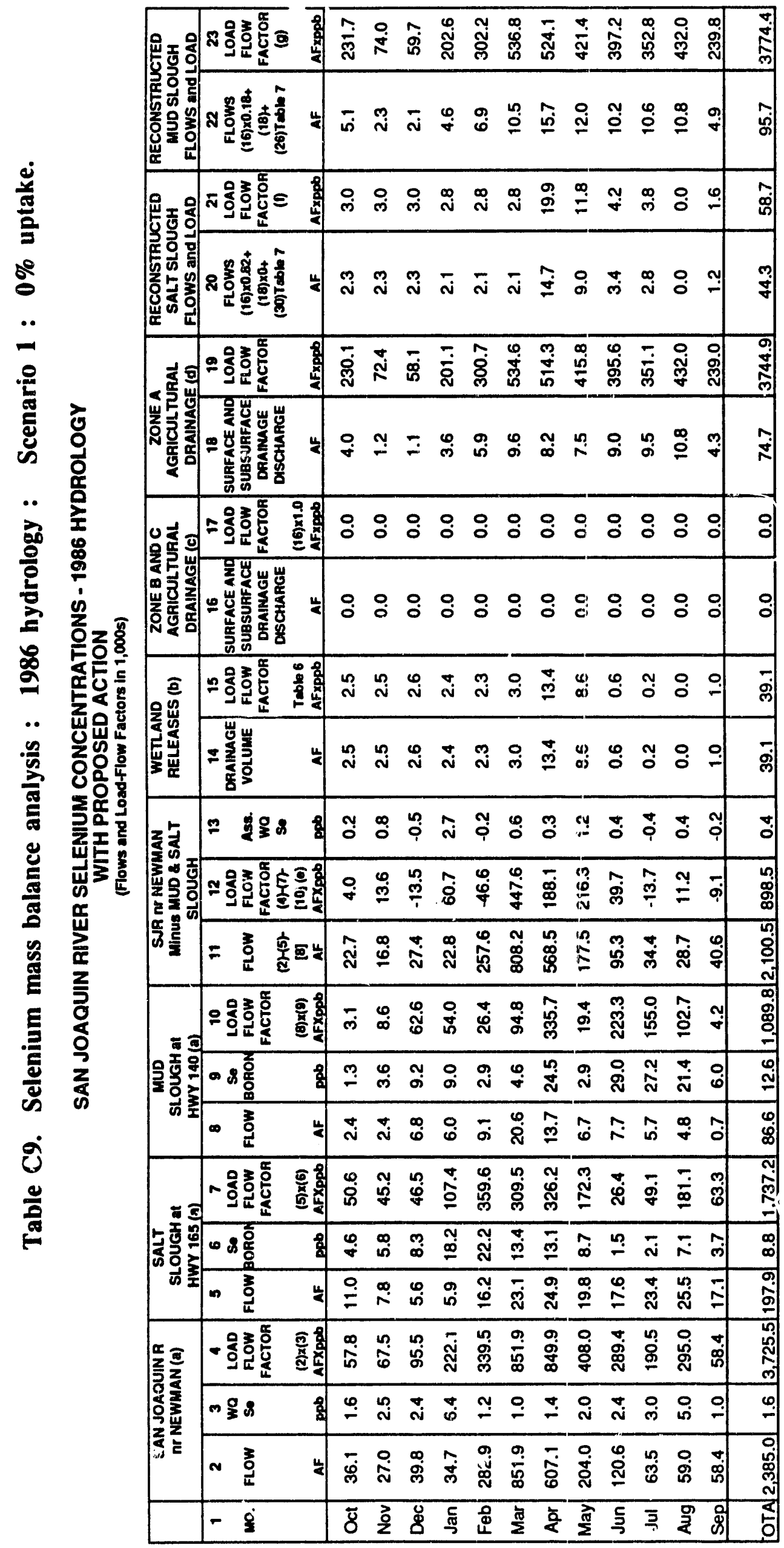

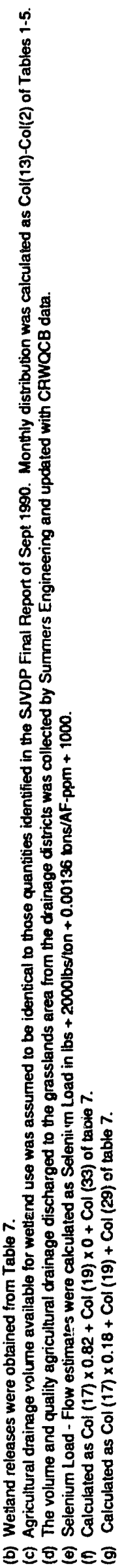




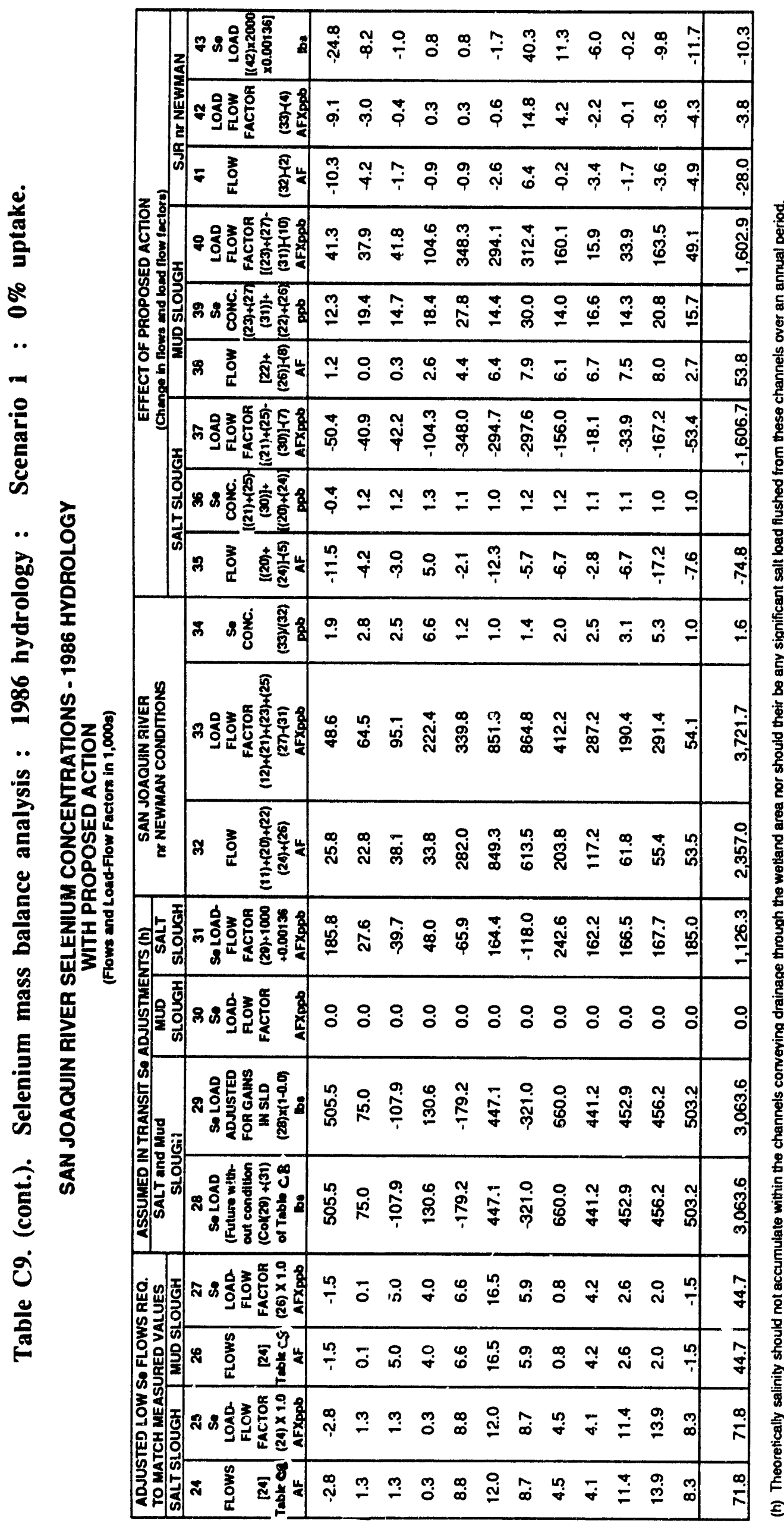




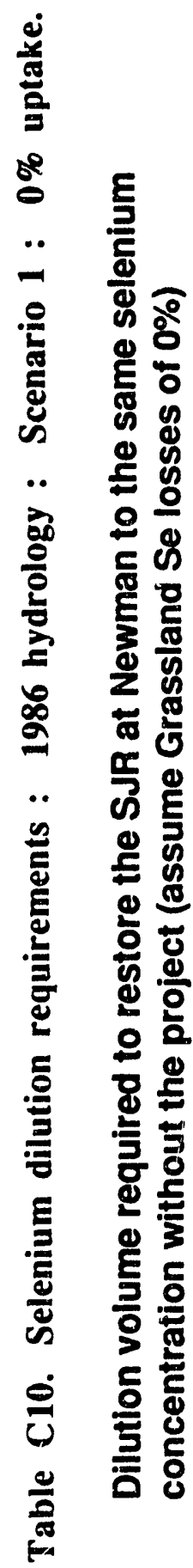

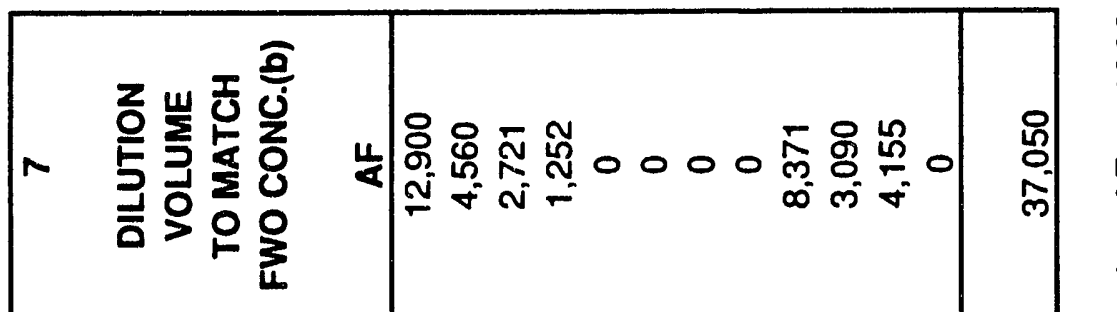

8

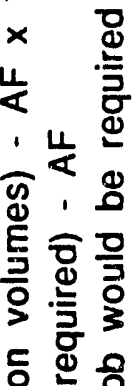

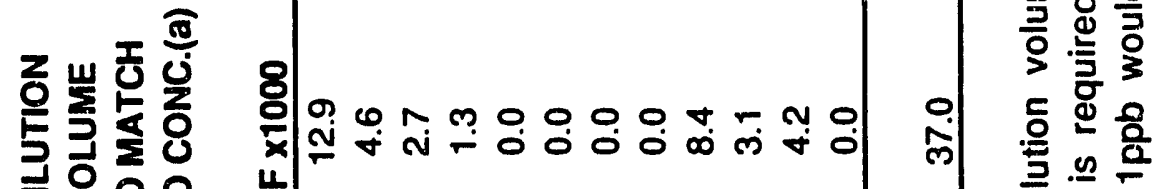

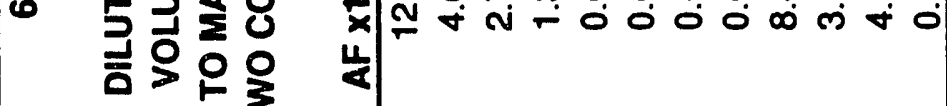

\begin{tabular}{l|l|l|} 
市 & & \\
\hline
\end{tabular}

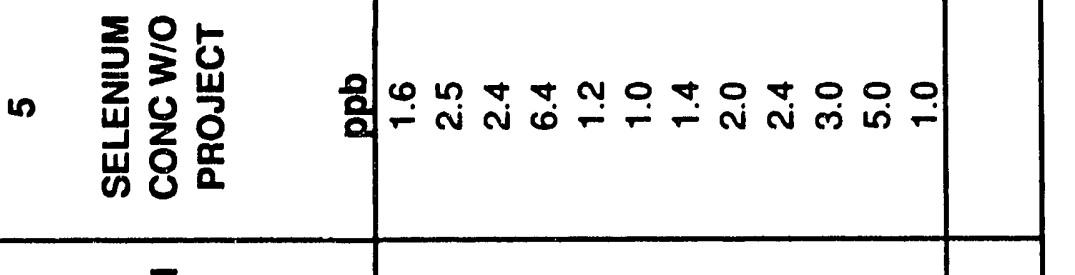

톤

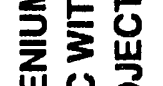

ด

岁各品

ดัด

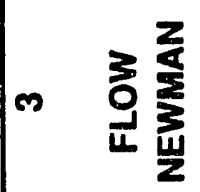

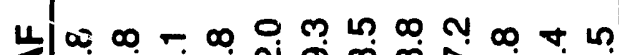

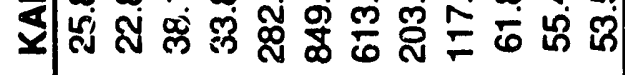

సి.

흥 등

\立

윻

ญ 는

돈 을

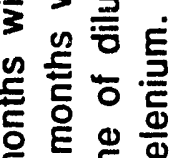

E E

옫유응용

흥호은

흥

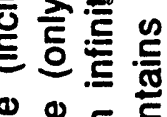

롱ㄷㅇ

흥흥 웡

등ㅎํ

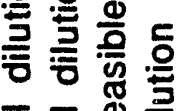

직 똘

륻드

๙

흐는

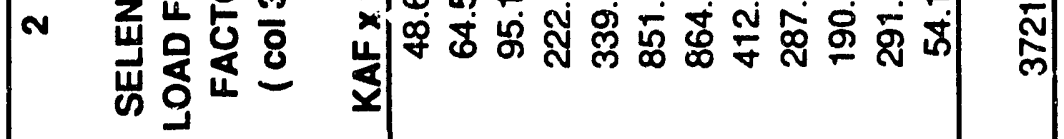

\begin{tabular}{|c|c|}
\hline 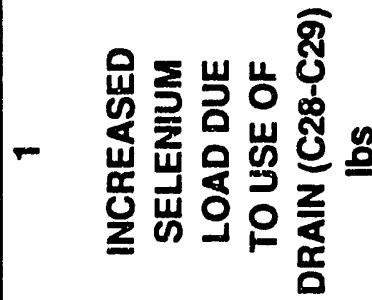 & $\mid \begin{array}{llllllllllll}0 & 0 & 0 & 0 & 0 & 0 & 0 & 0 & 0 & 0 & 0 & 0 \\
0 & 0 & 0 & 0 & 0 & 0 & 0 & 0 & 0 & 0 & 0 & 0\end{array}$ \\
\hline $\begin{array}{l}\text { I } \\
\text { E } \\
\text { 을 }\end{array}$ & 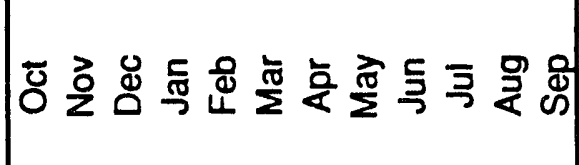 \\
\hline
\end{tabular}




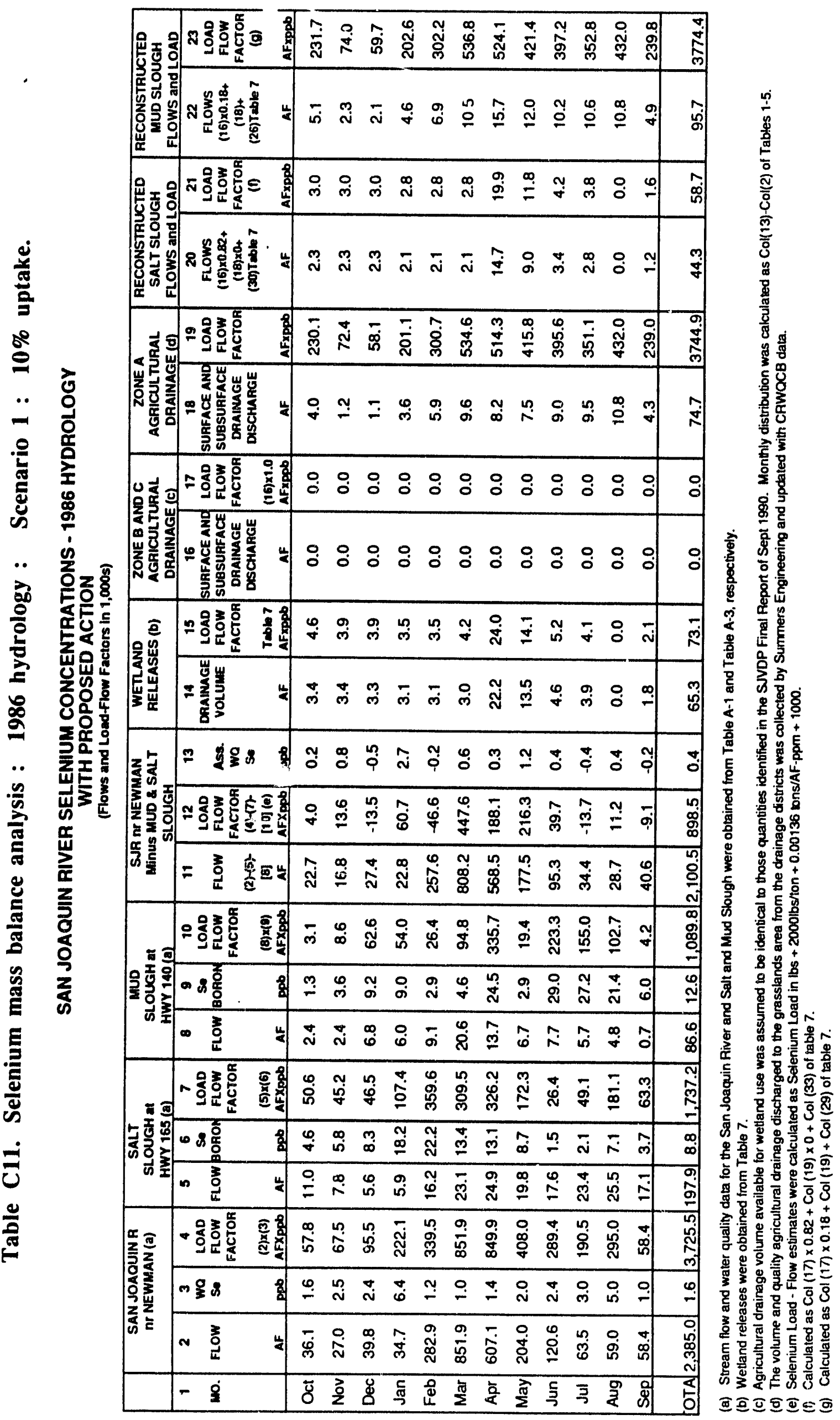




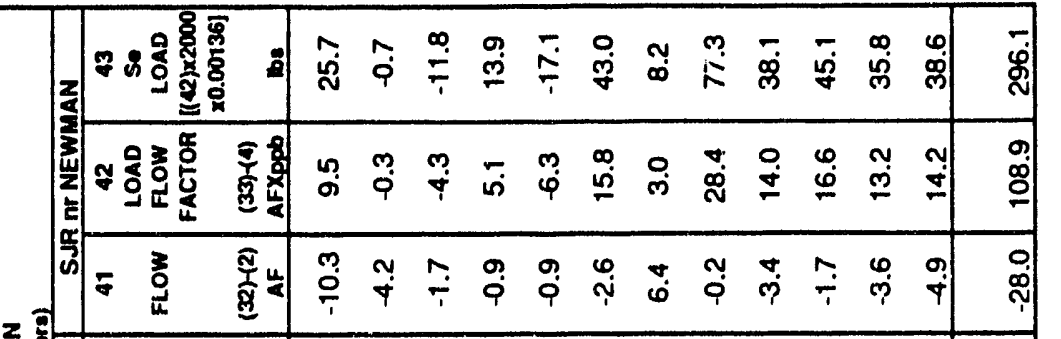

帮 \&

啳

음

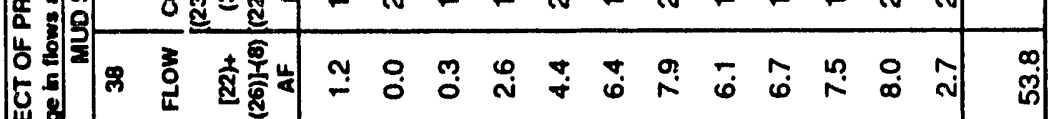

蓆然

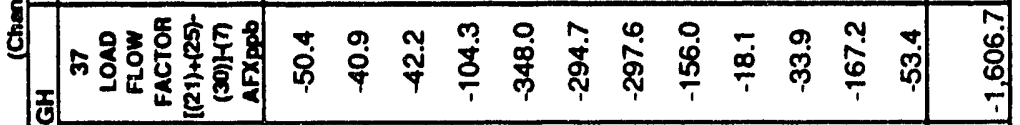

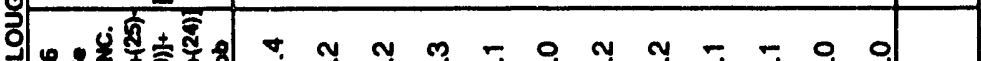

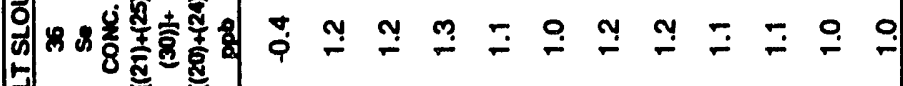

¿े

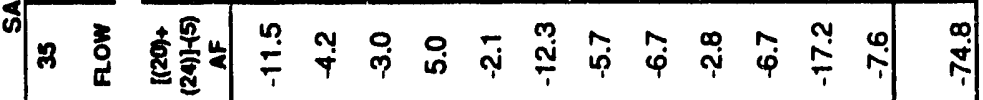

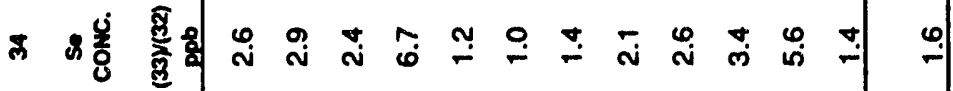

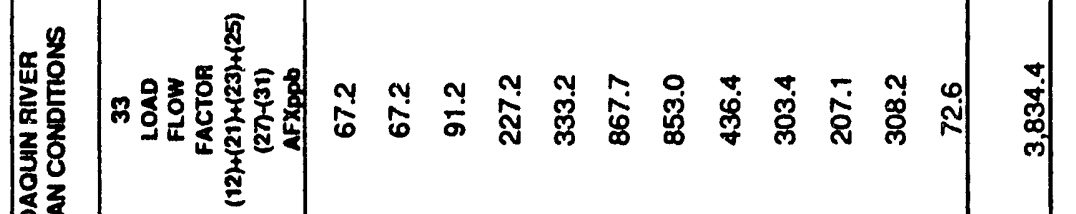

$\because \quad E$

in 政它

离

蒠要

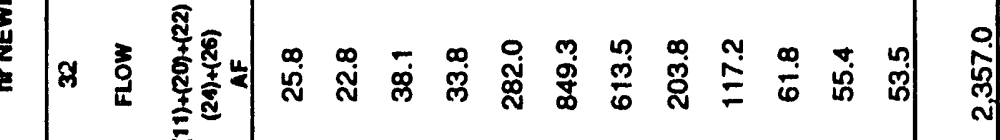

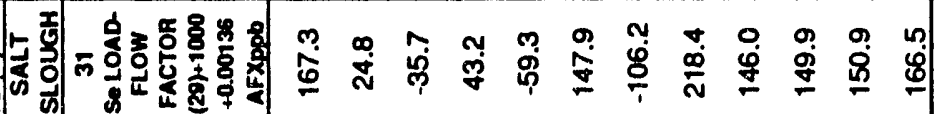

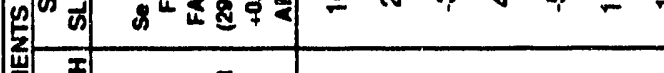

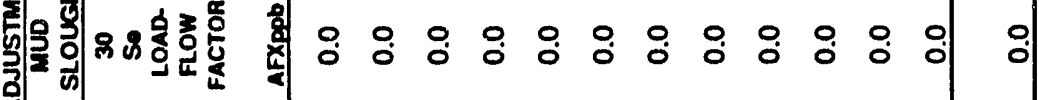

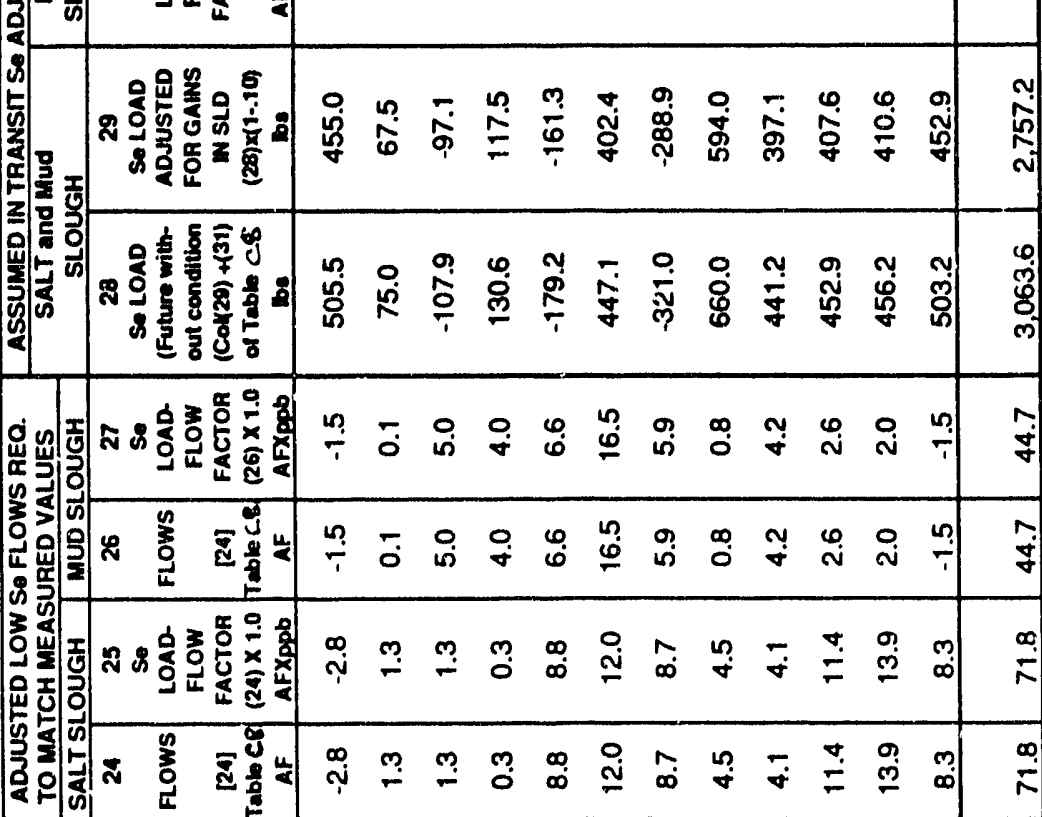




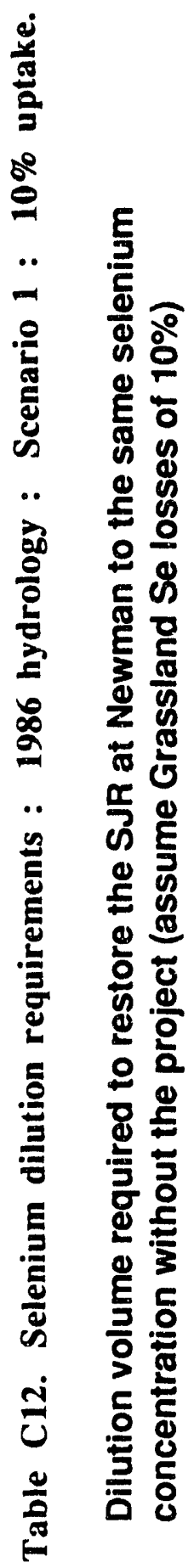

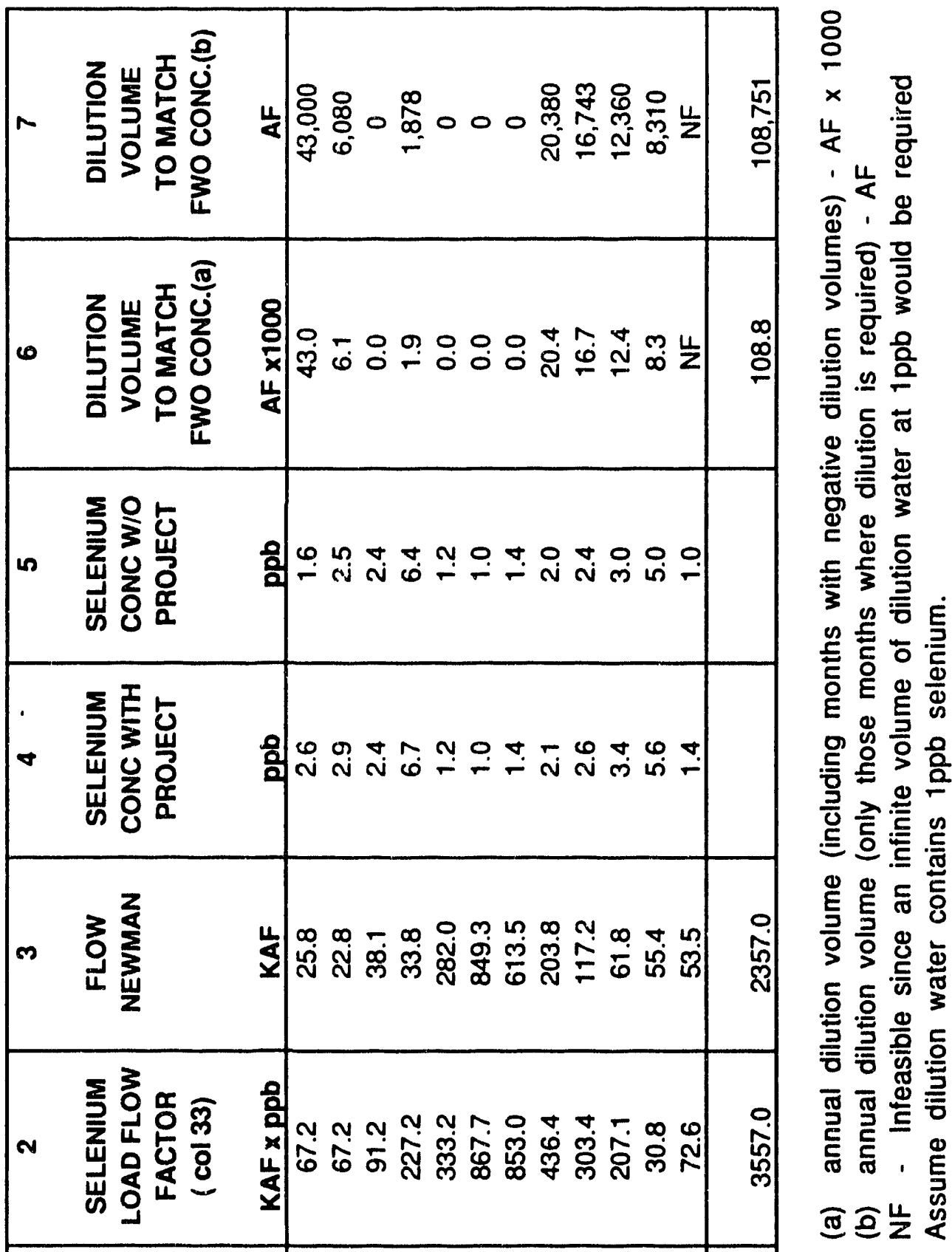

嵌 쓸 岁

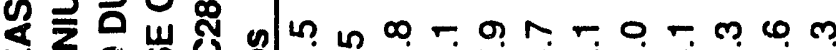

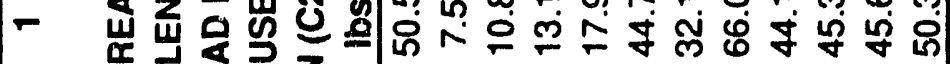

范嵌过은 西

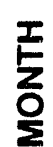

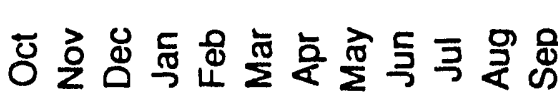




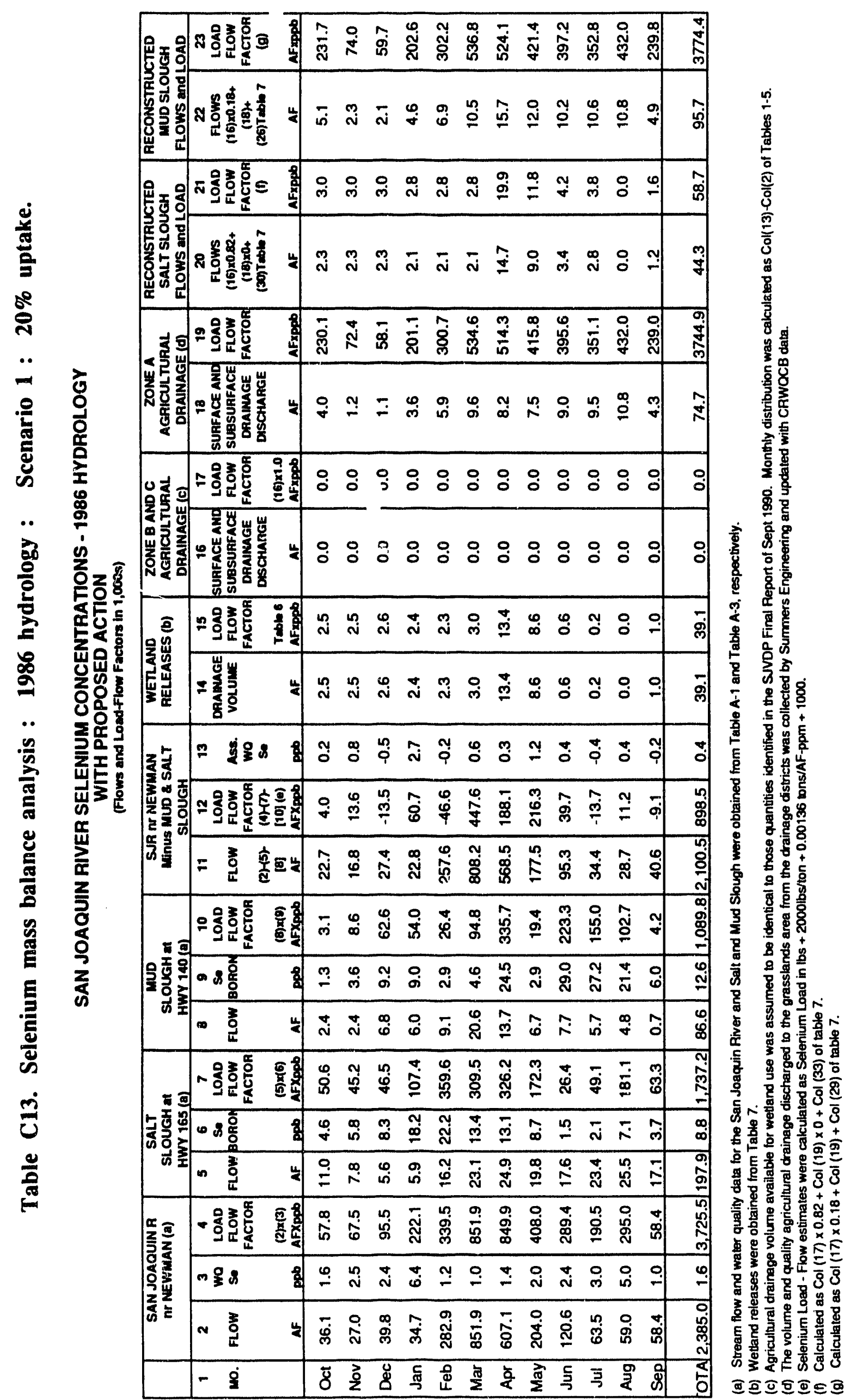




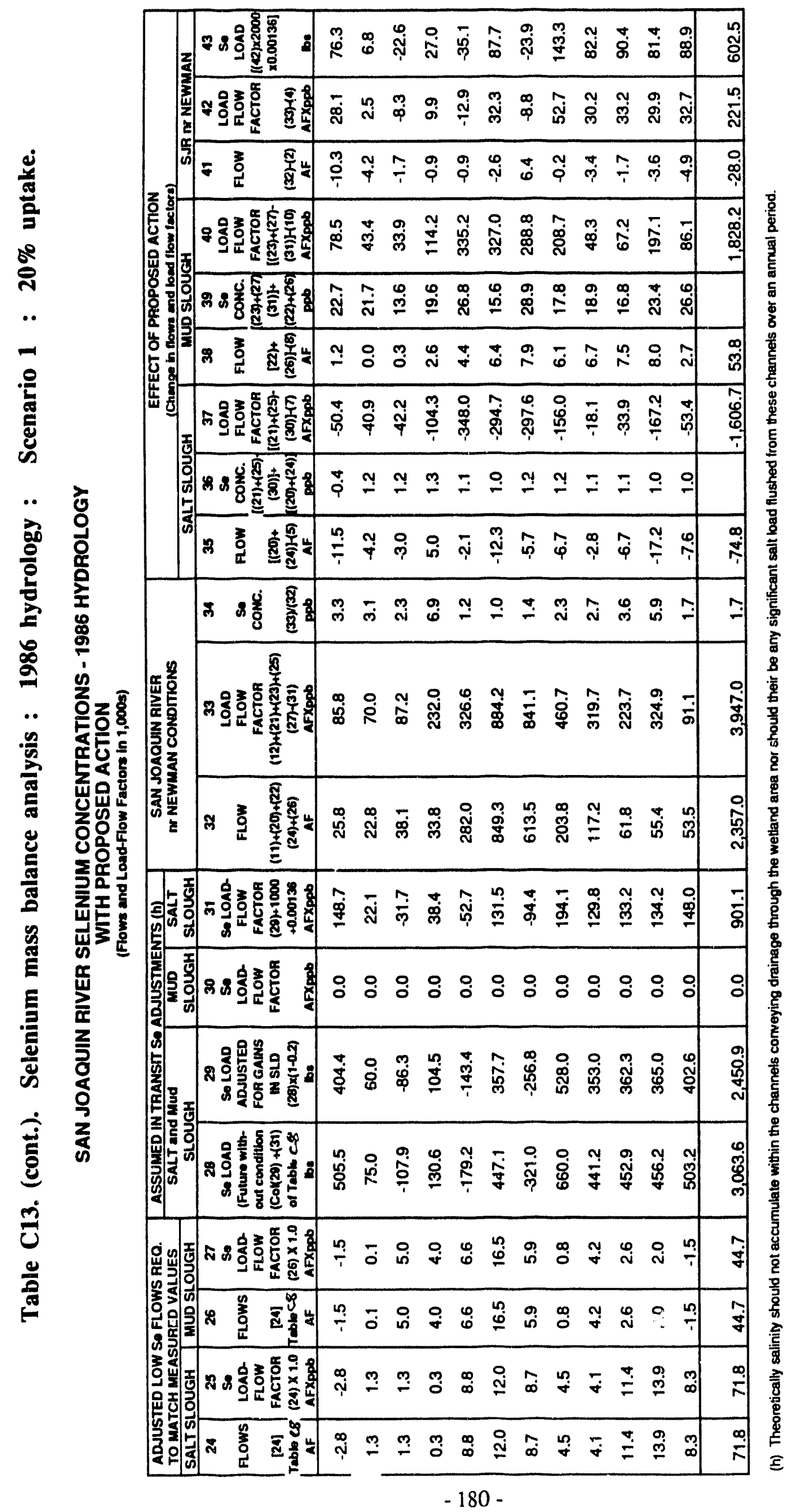




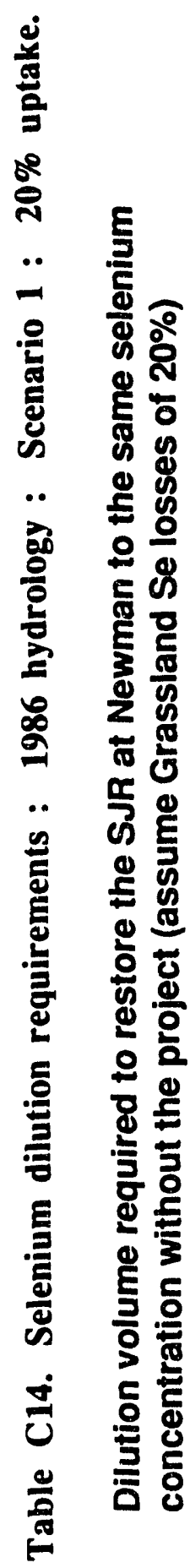

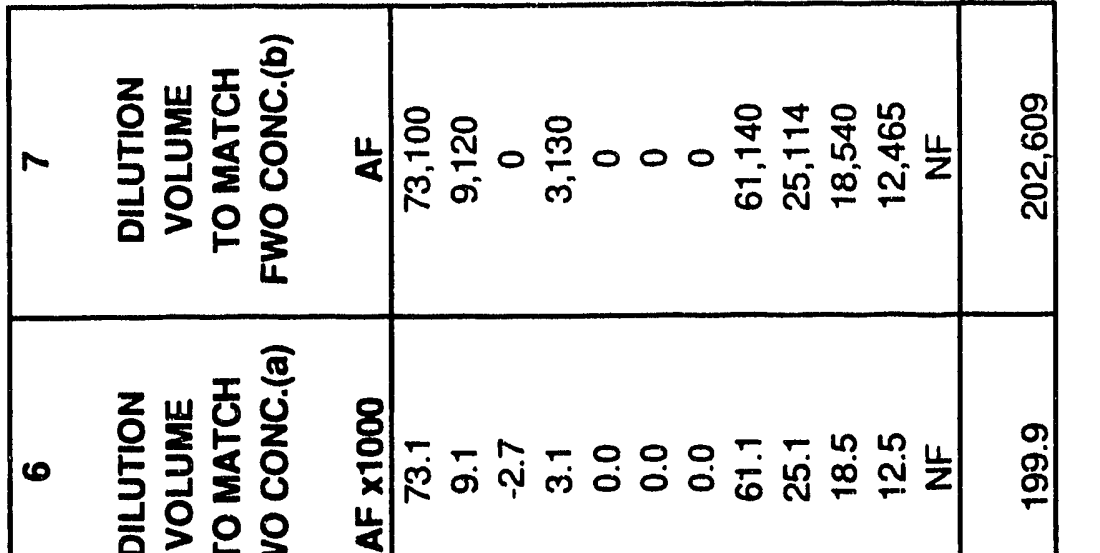

웅

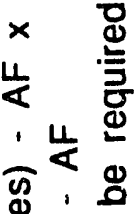

통 웧을

응

든 융

호요음

드 후

竞言离

O

$\Phi$

녹

을 흔

들 옳

E

잉응 응

응

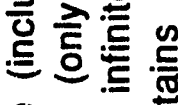

롱ㄷㅇ

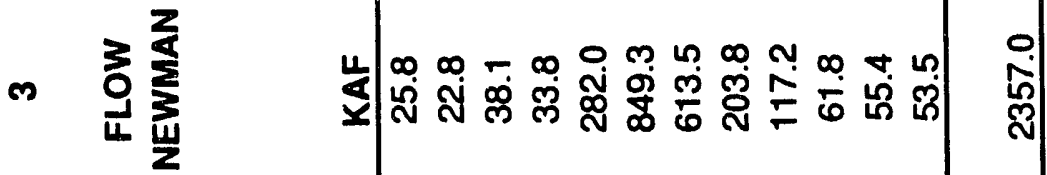

응

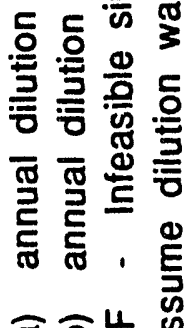

즈는

\begin{tabular}{|c|c|c|}
\hline 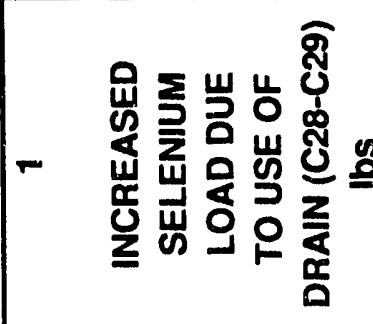 & 遂 & 点 \\
\hline $\begin{array}{l}\text { I } \\
\text { 을 }\end{array}$ & 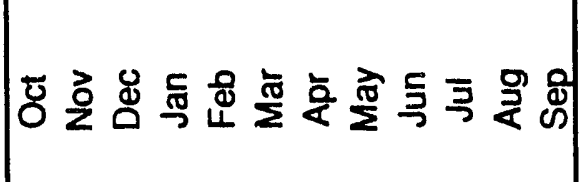 & $\frac{\infty}{\frac{N}{\sigma}}$ \\
\hline
\end{tabular}




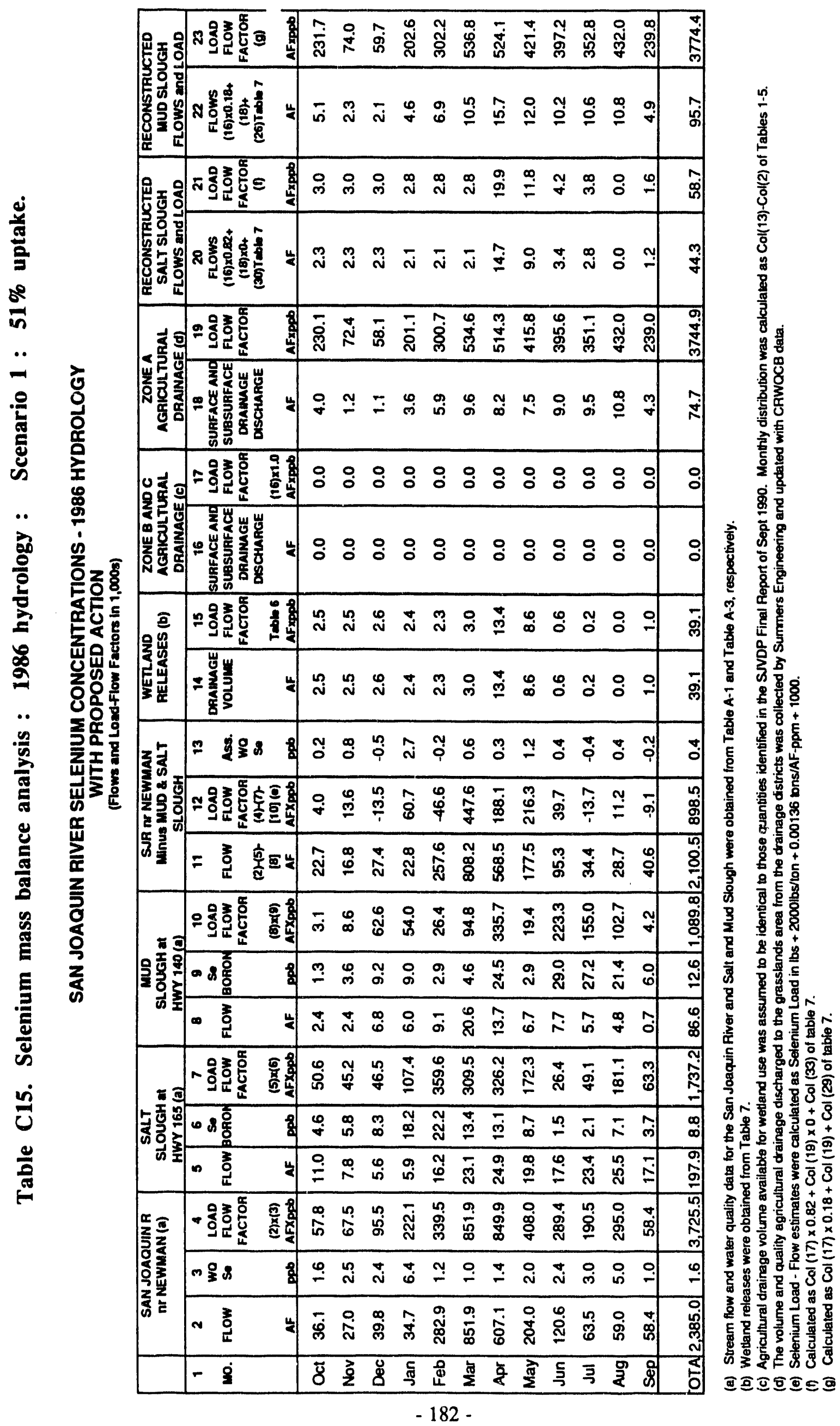




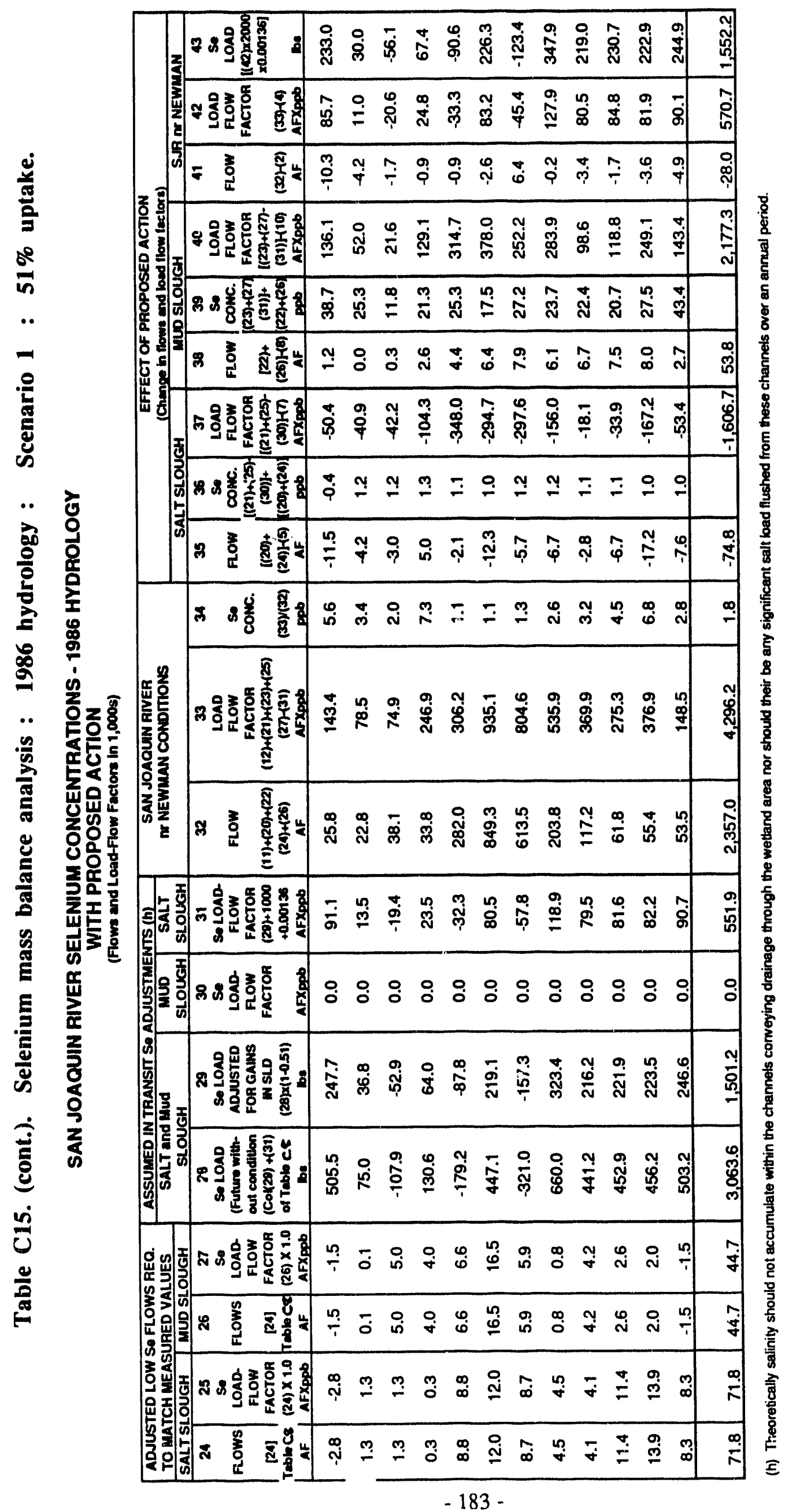


웅 岁离 통ㅎㅀ을

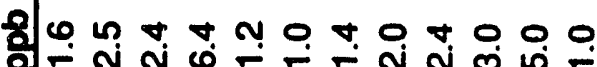

ऊ 8 व

|-

产声卢

竎论

잉 $\forall=-m \omega N$ in $\infty$

ऊั

ดั

\begin{tabular}{|c|c|c|}
\hline 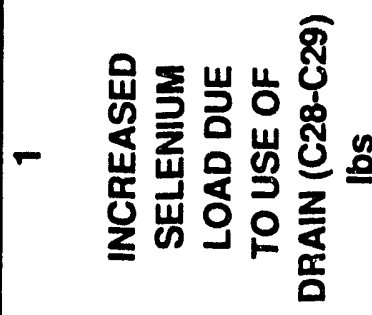 & 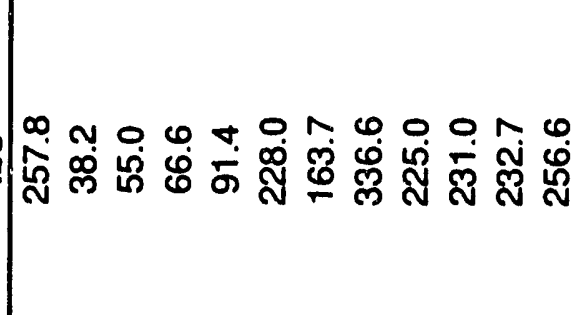 & $\stackrel{\infty}{\infty}$ \\
\hline I & రัర & $\frac{\infty}{5}$ \\
\hline
\end{tabular}




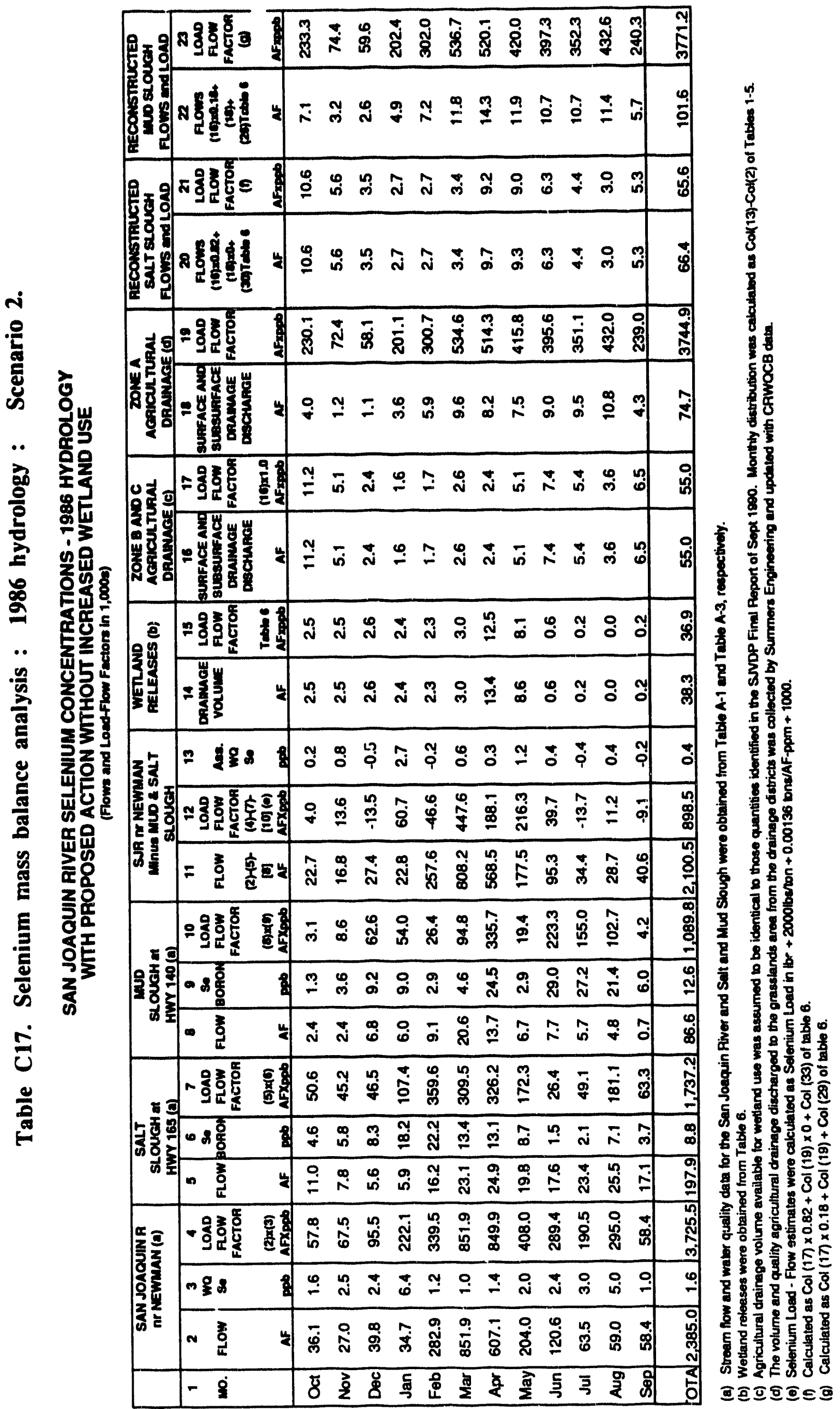




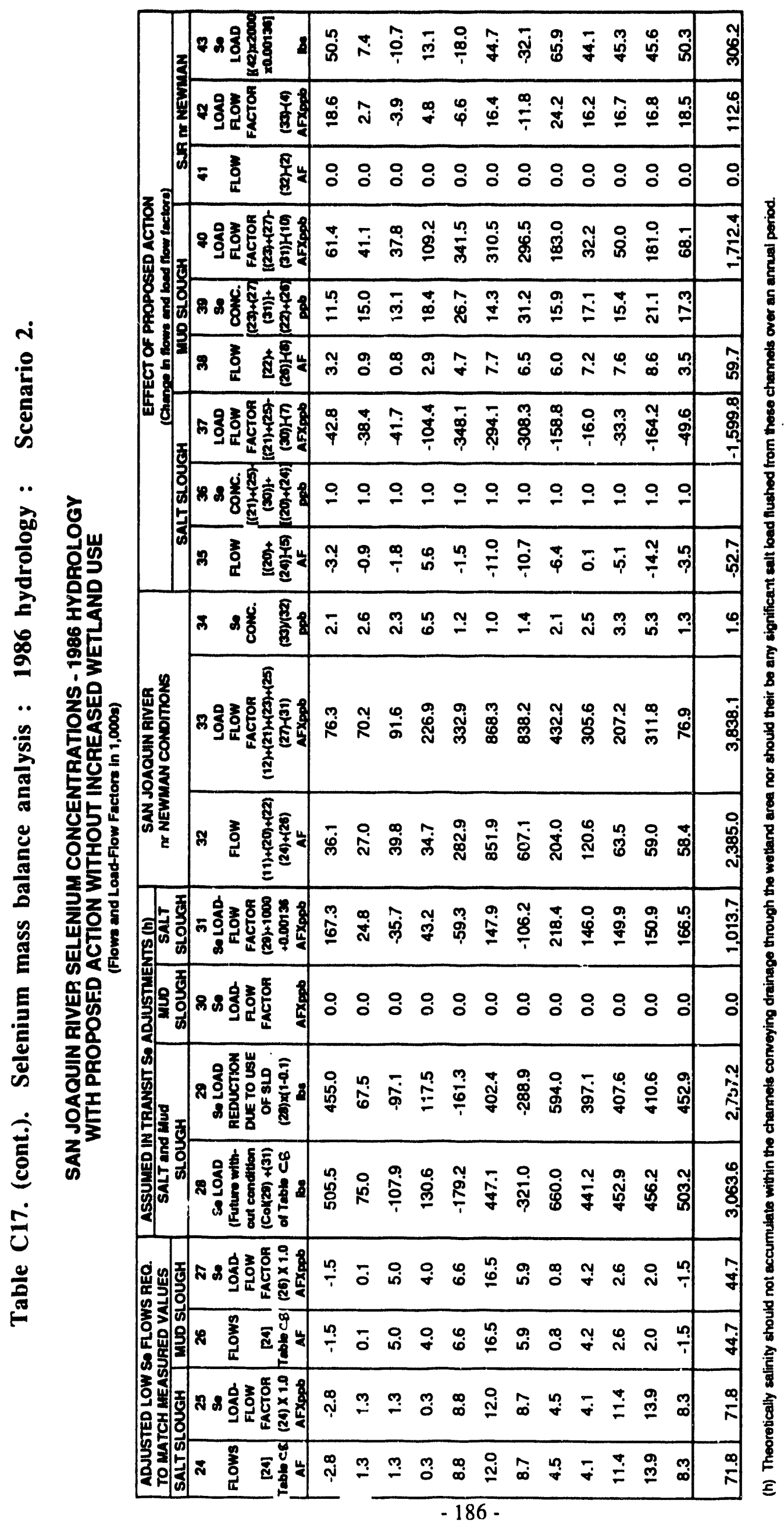




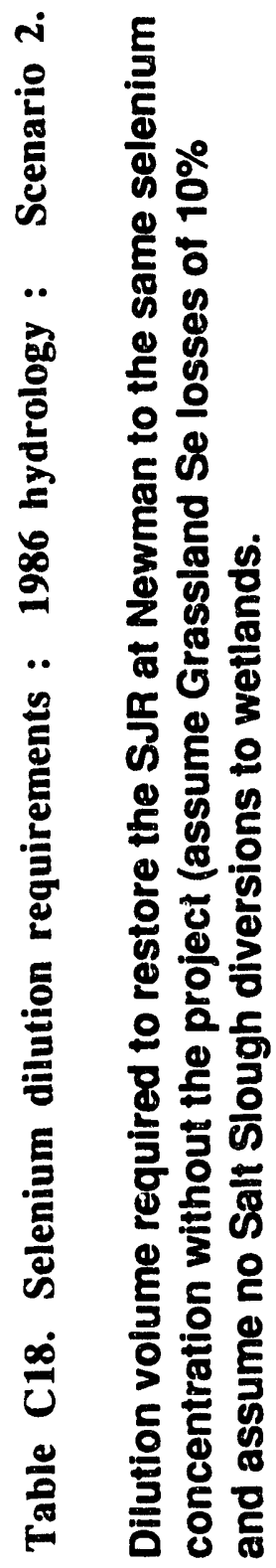

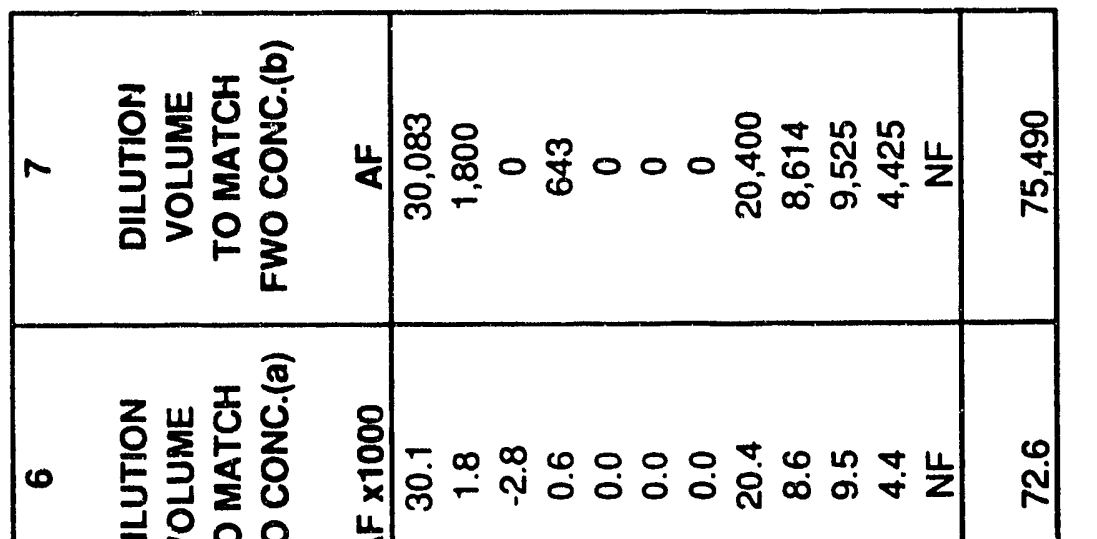

8

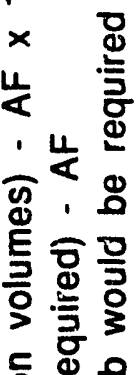

등 융

홓요을

कृ

응

荬 产

잉

¿

돈 $\frac{5}{3} \cdot \frac{0}{\underline{y}}$

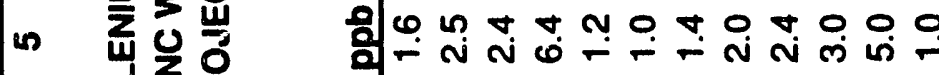
岃 잉

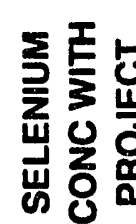

|ring

里

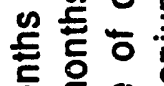

들 ڤ

呅

읗옹 응

응

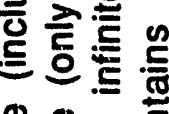

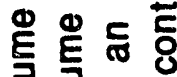

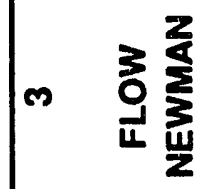

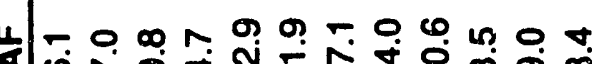

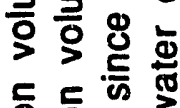

ᄃ 5 क

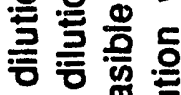

西

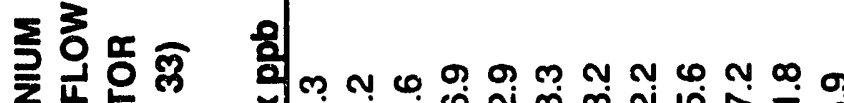

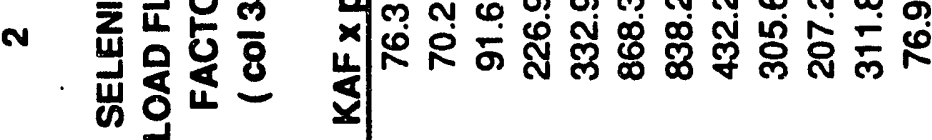

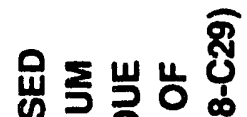

ติว

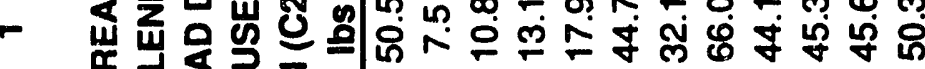

苮岀起

政

ำ

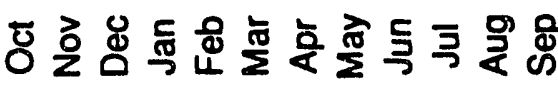




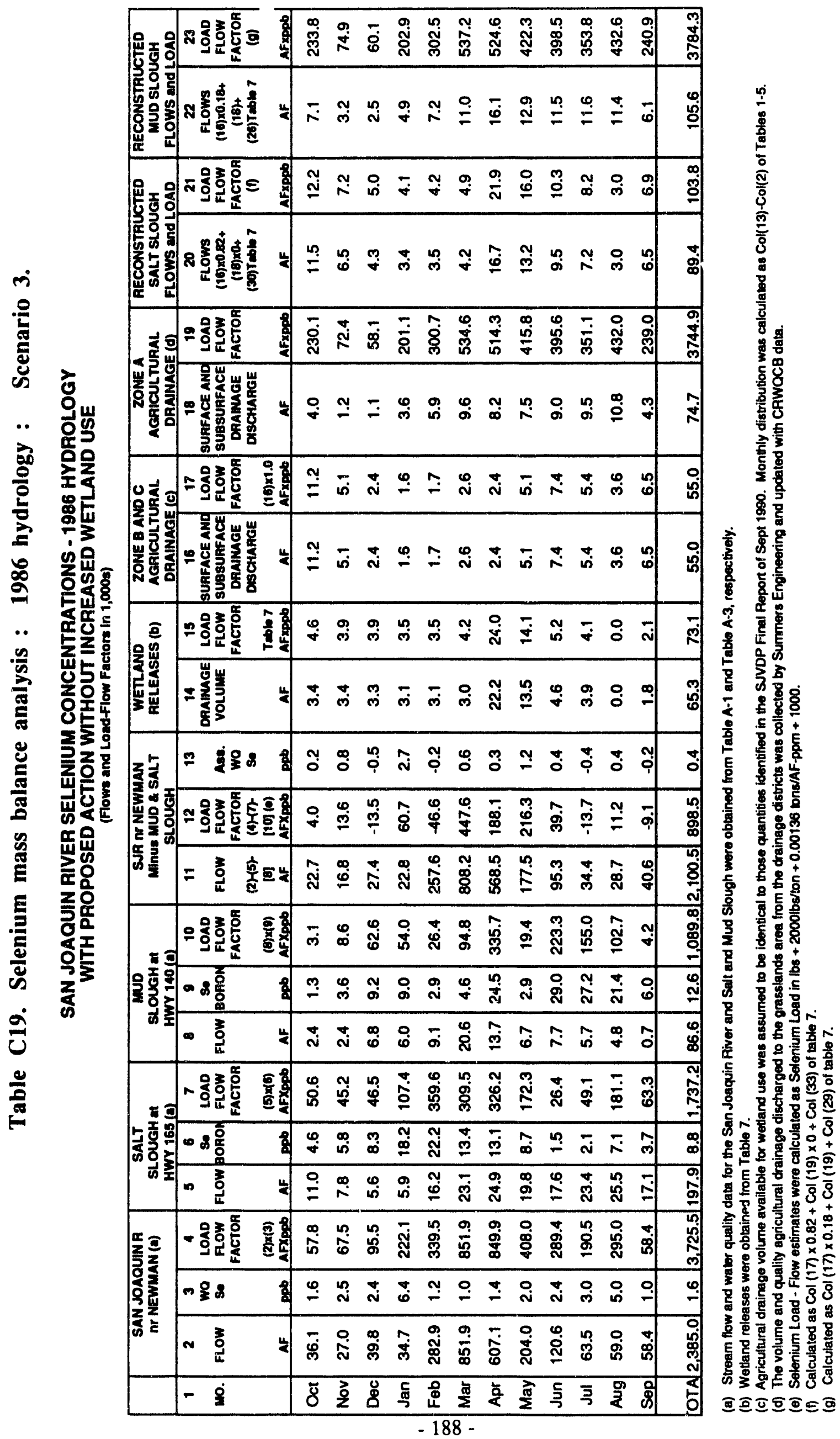




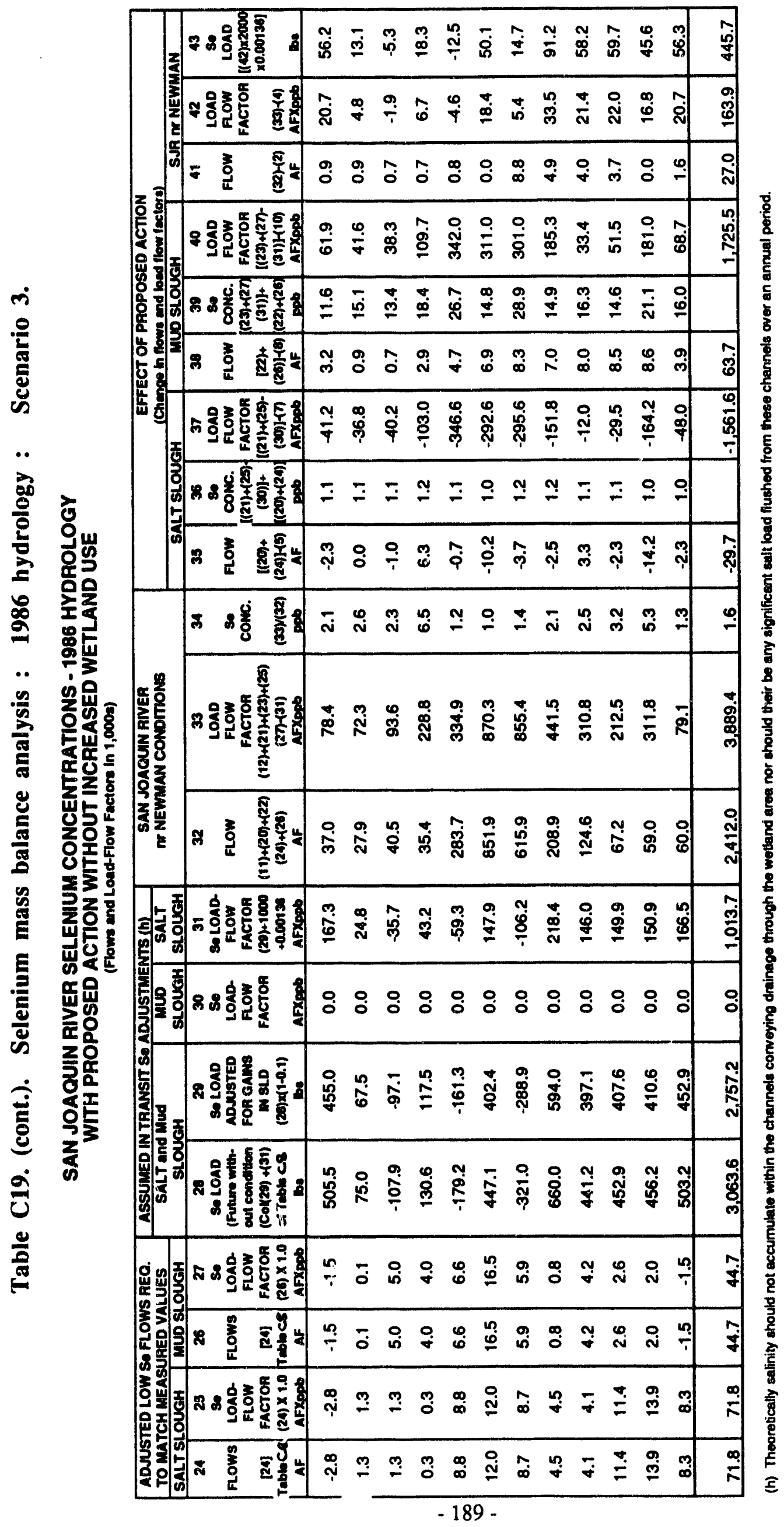


응으응응

힌

흥 ․․ㄹ 드으으등

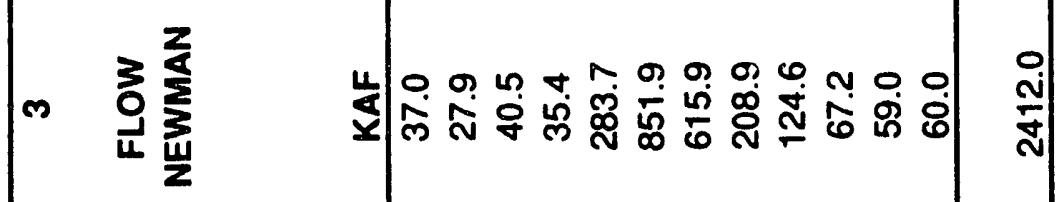
톨 등 รัํํำ 드응 흥 금 읗 응

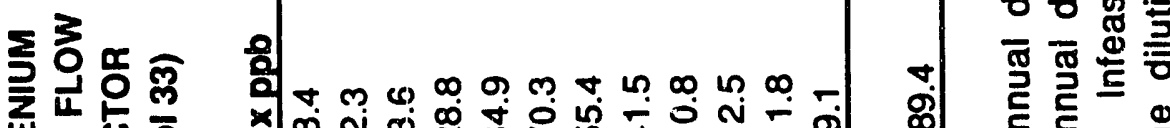

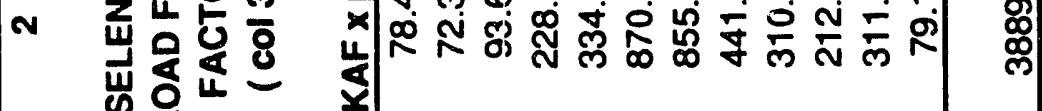

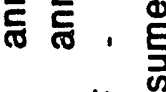
뜨른 


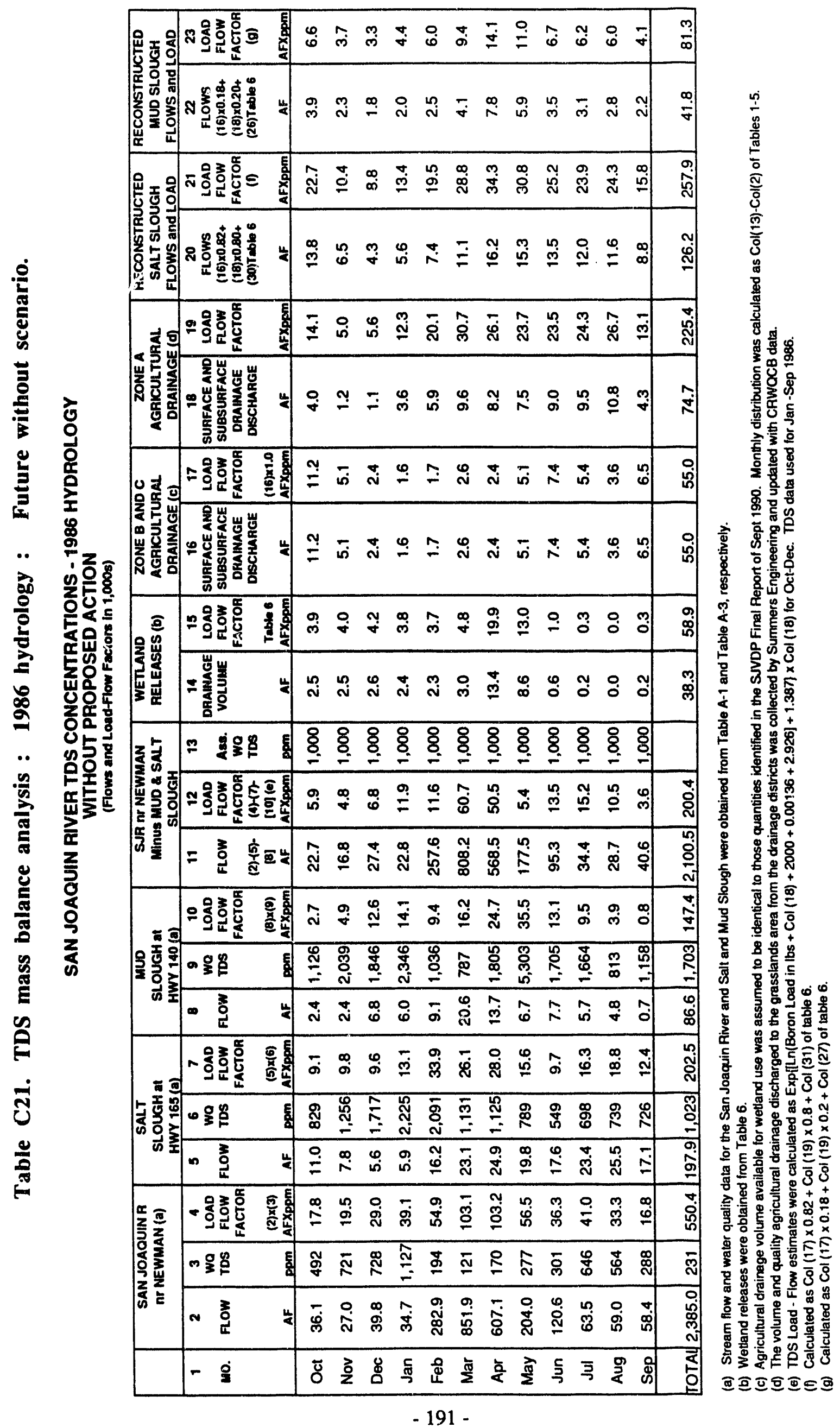




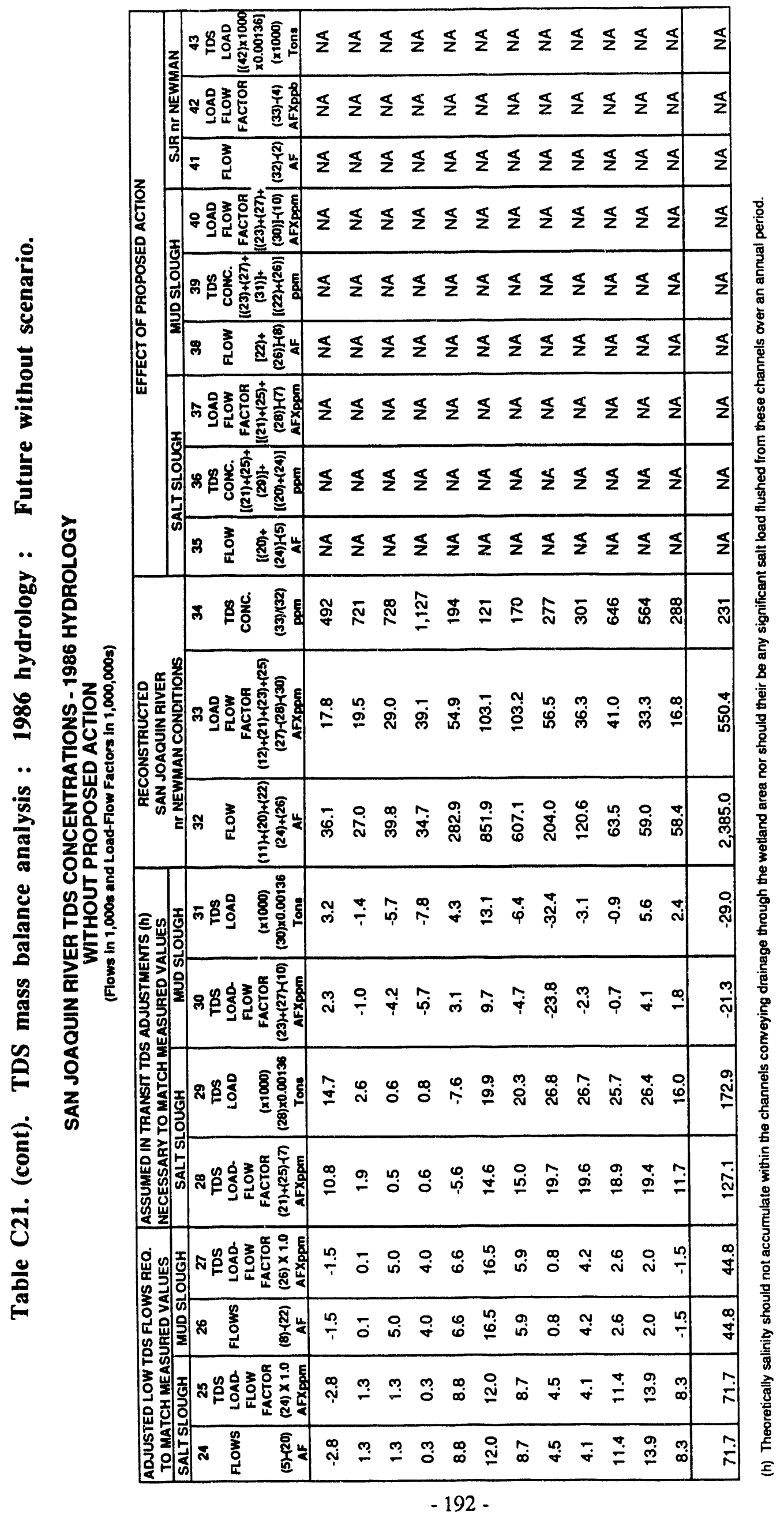




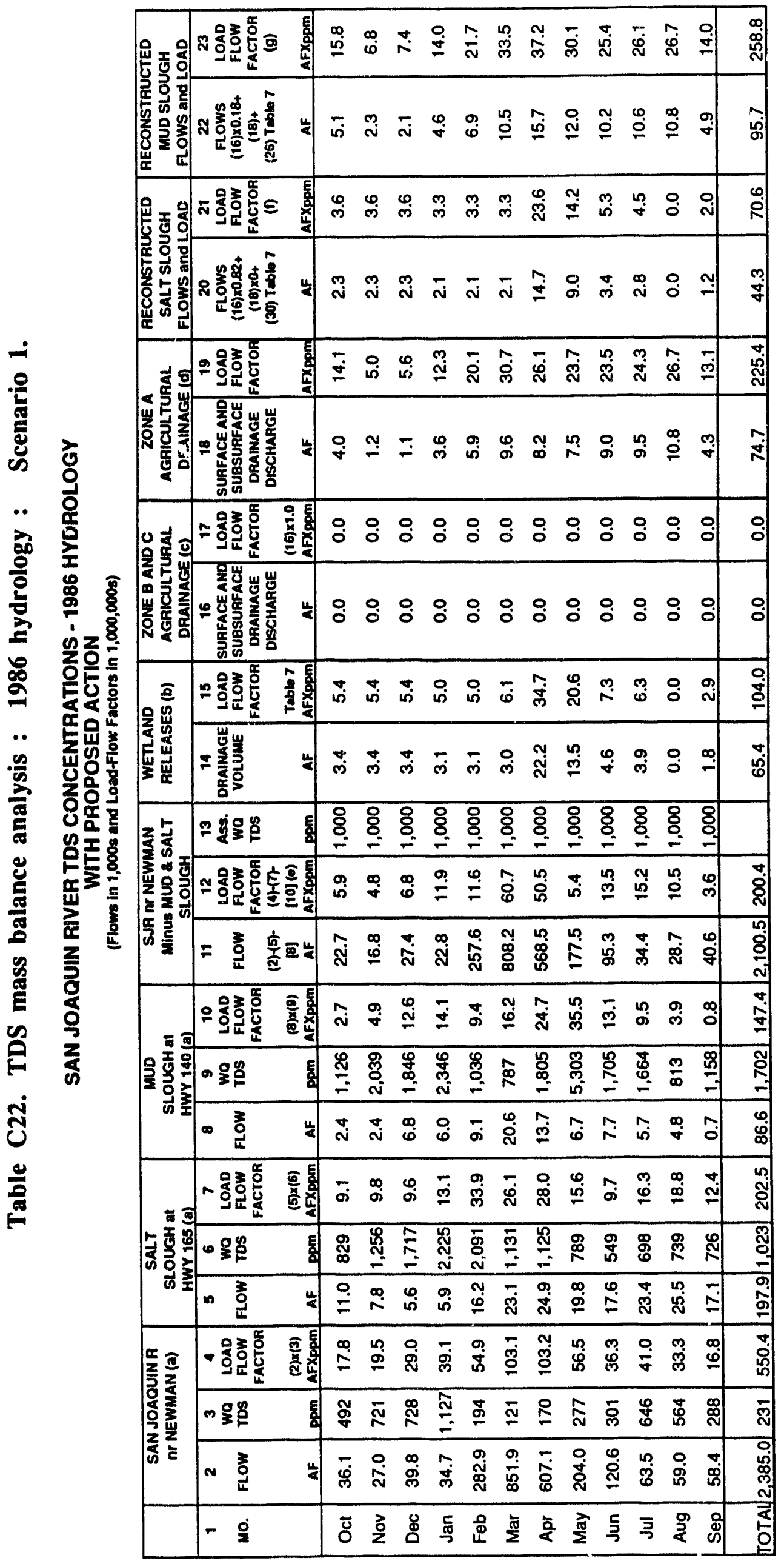

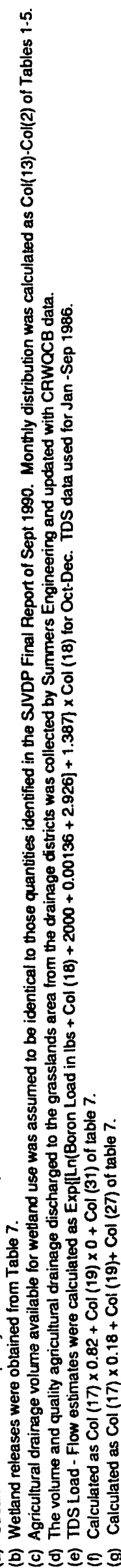




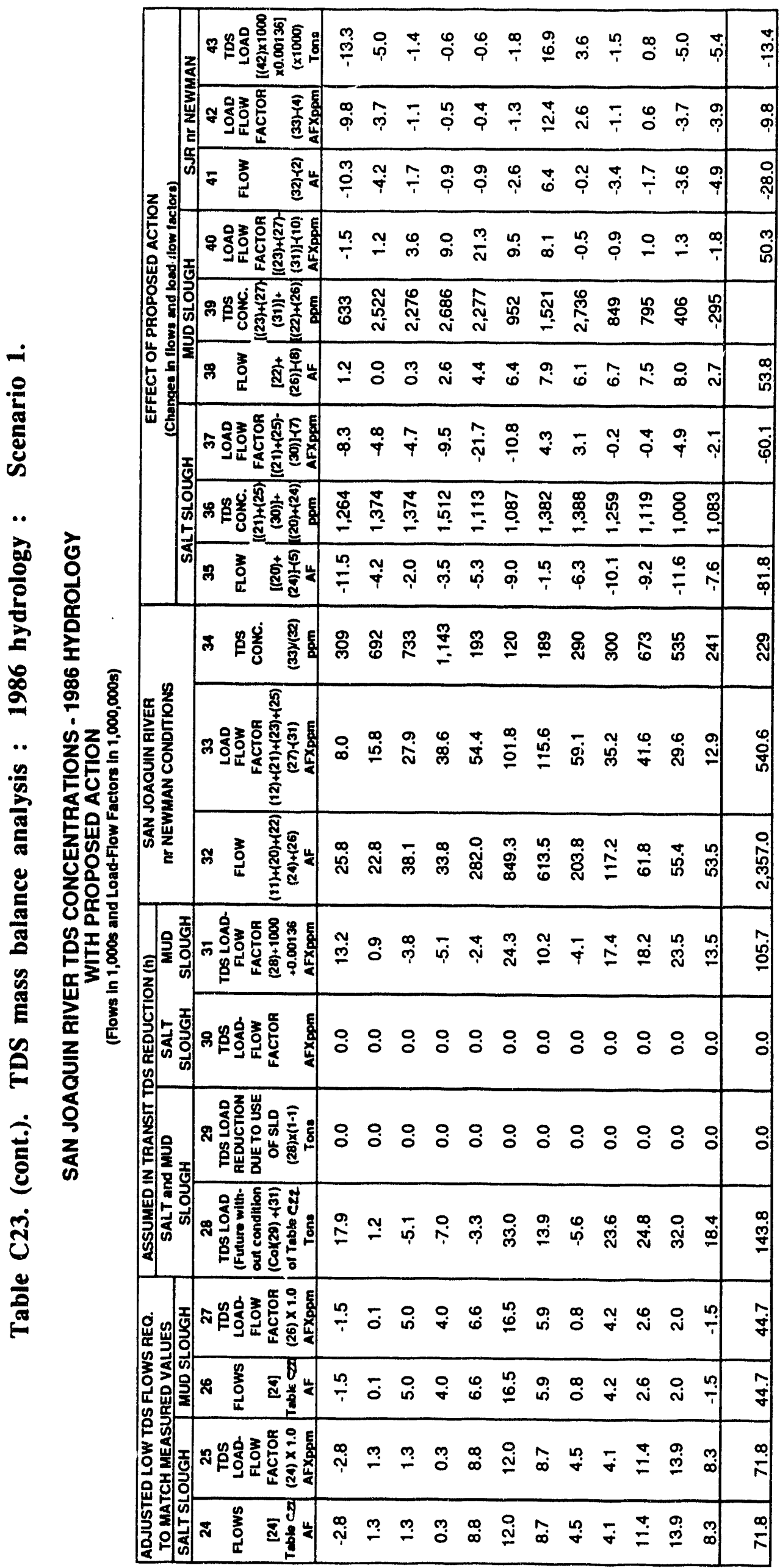




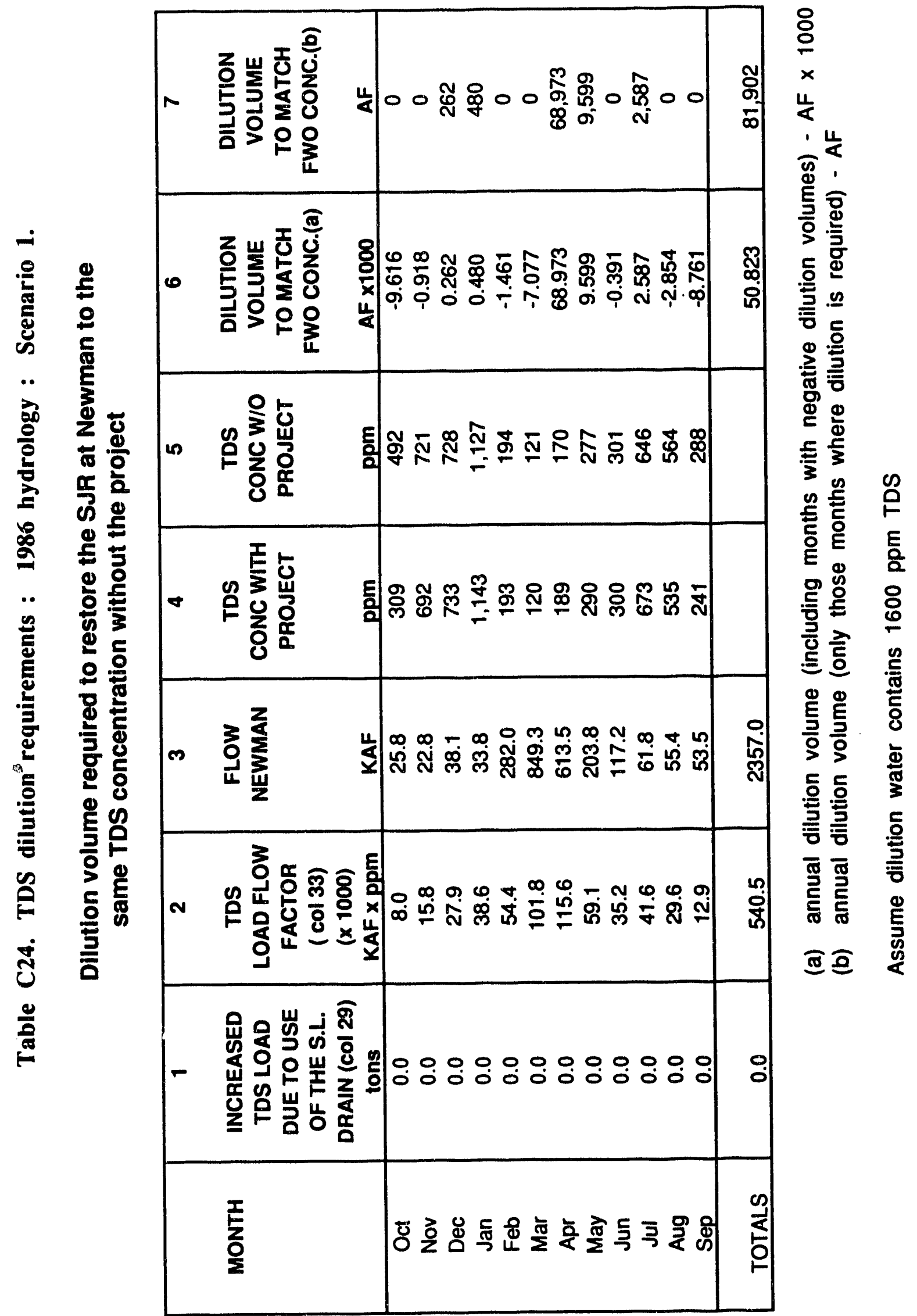




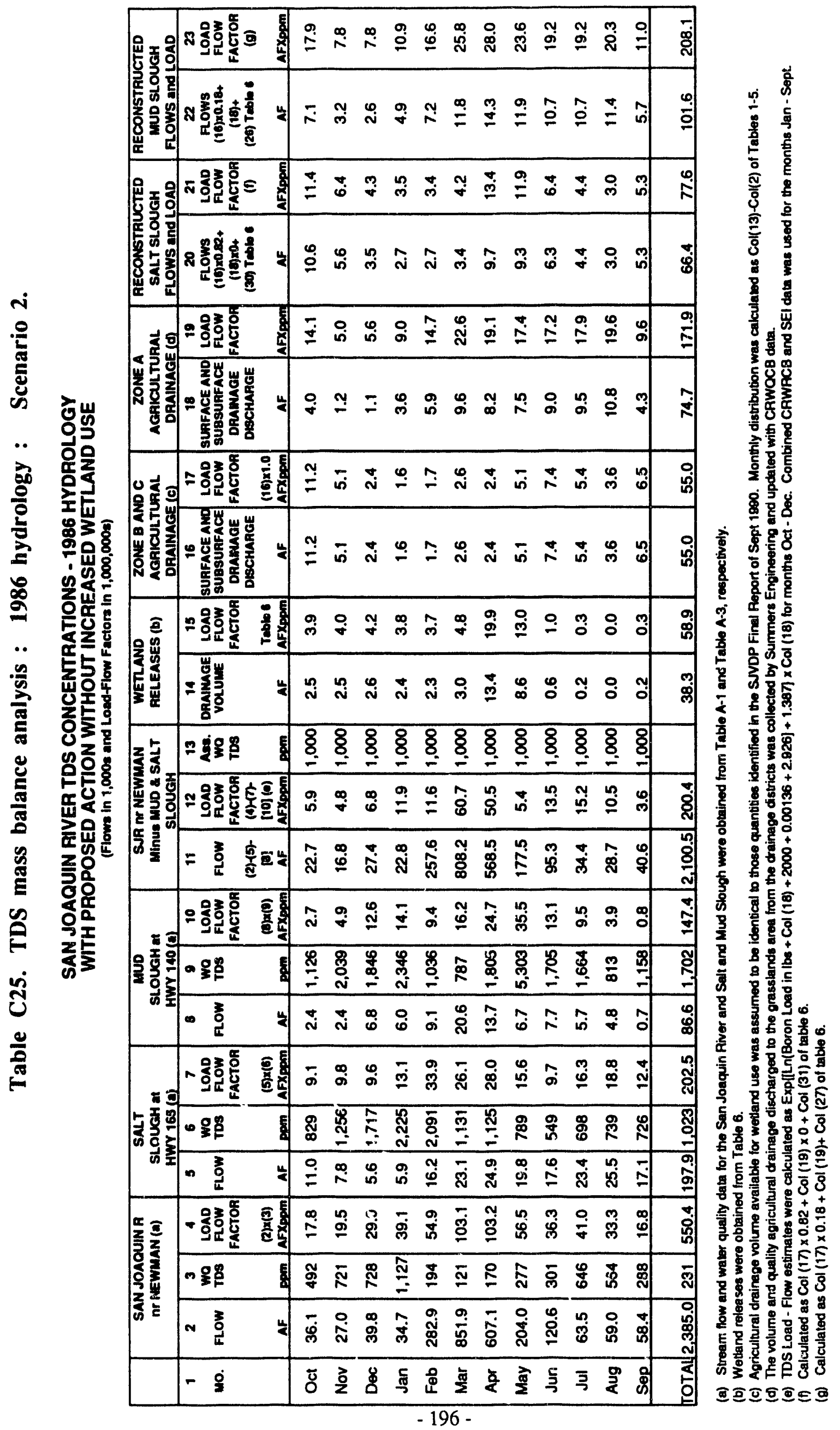




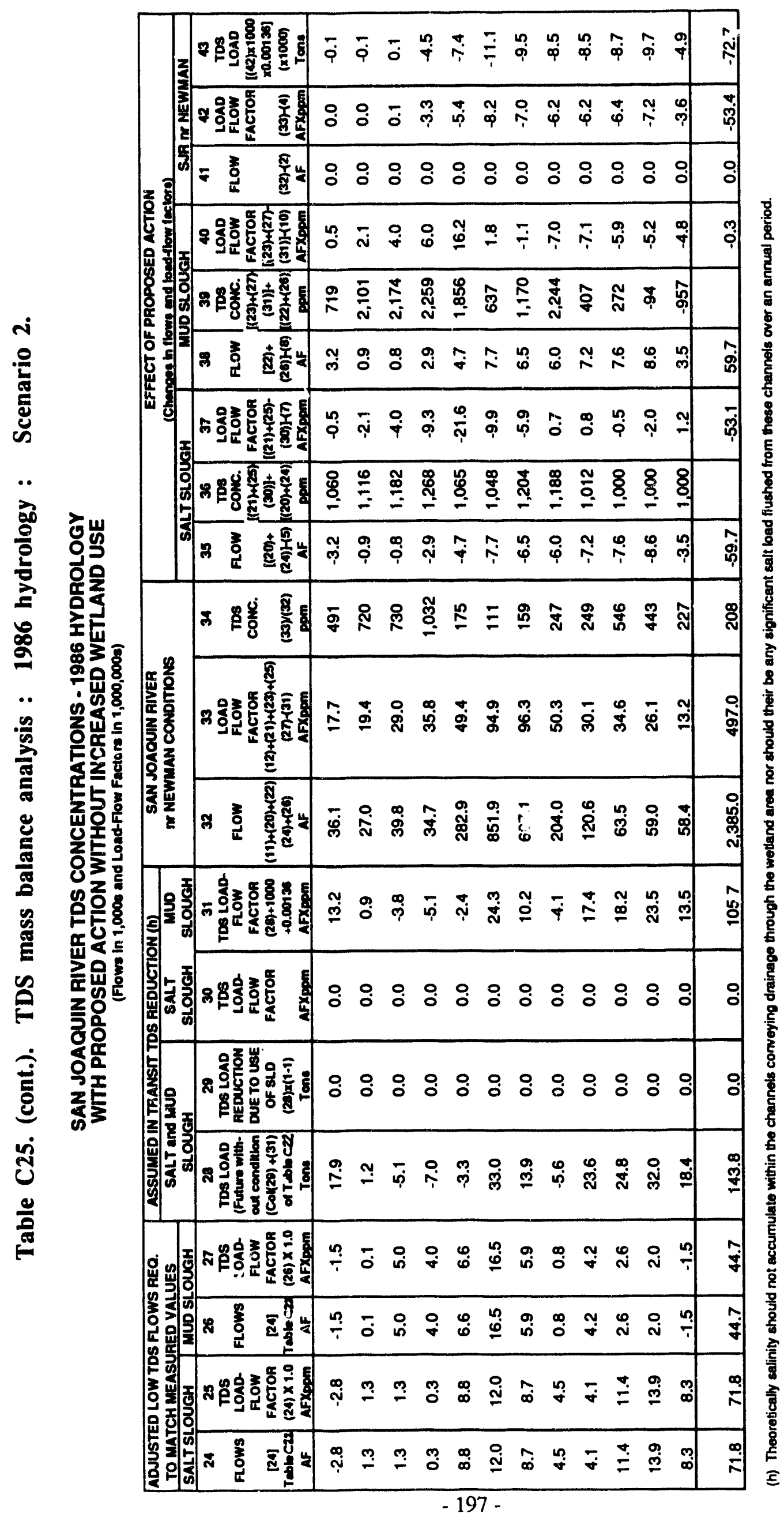




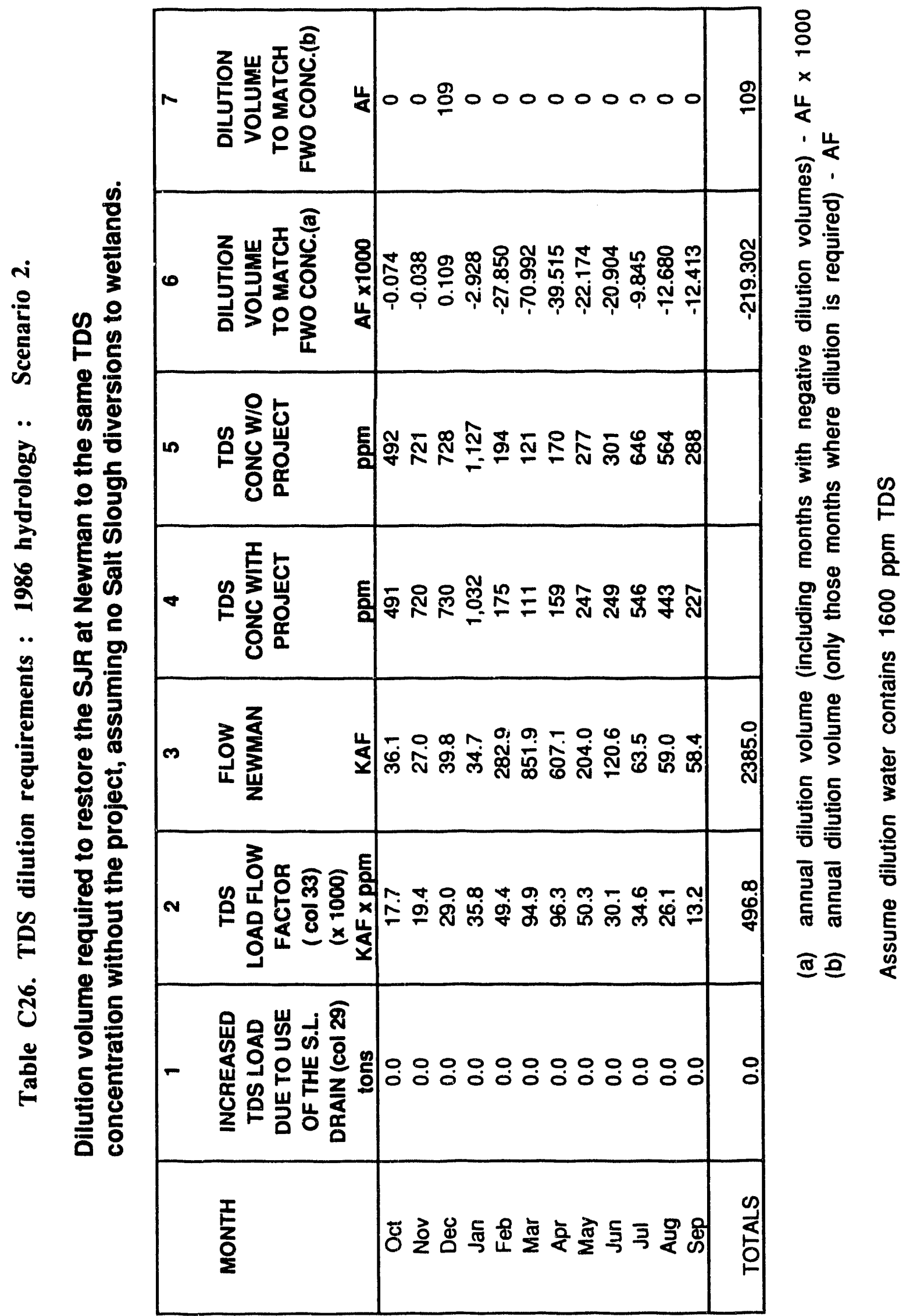




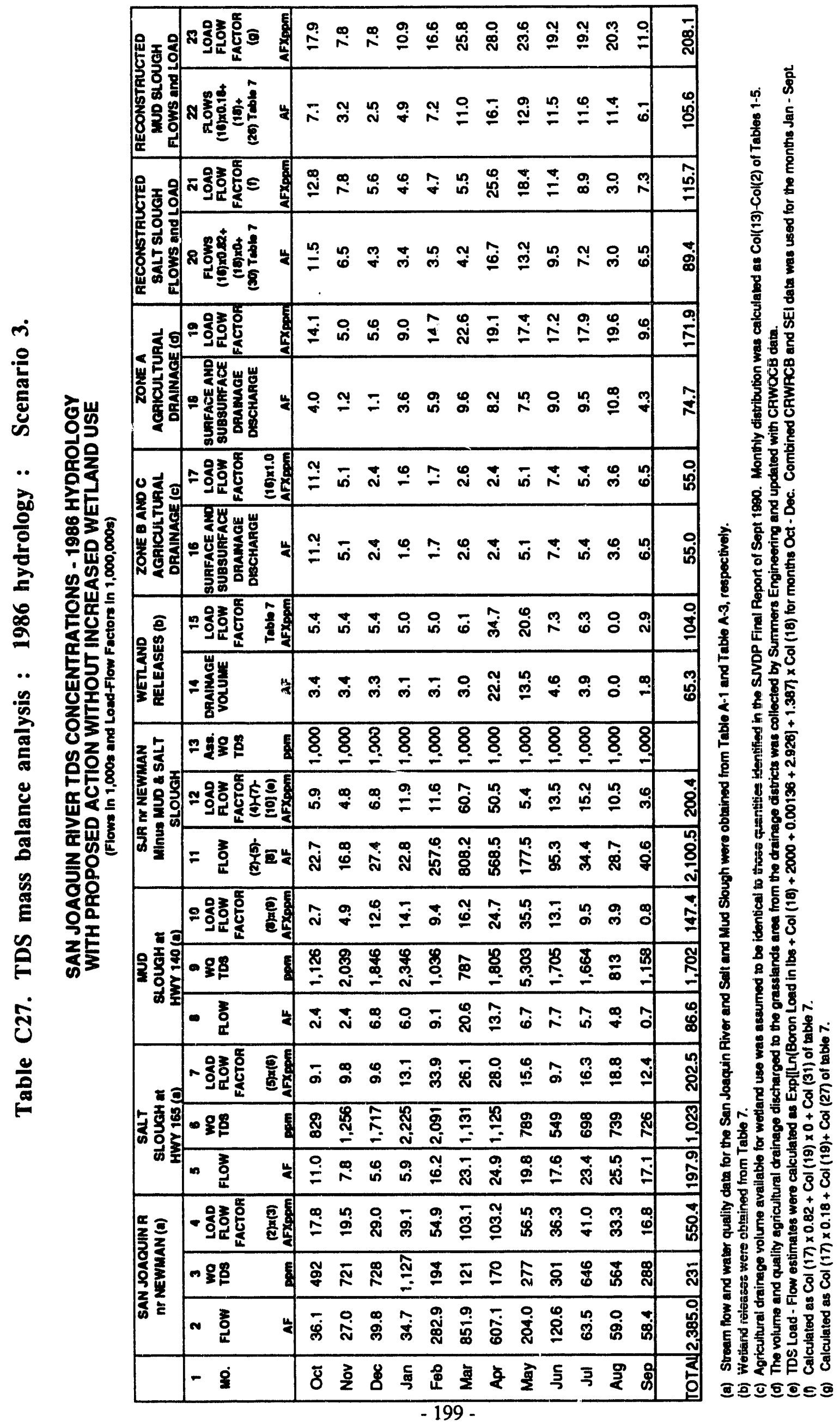




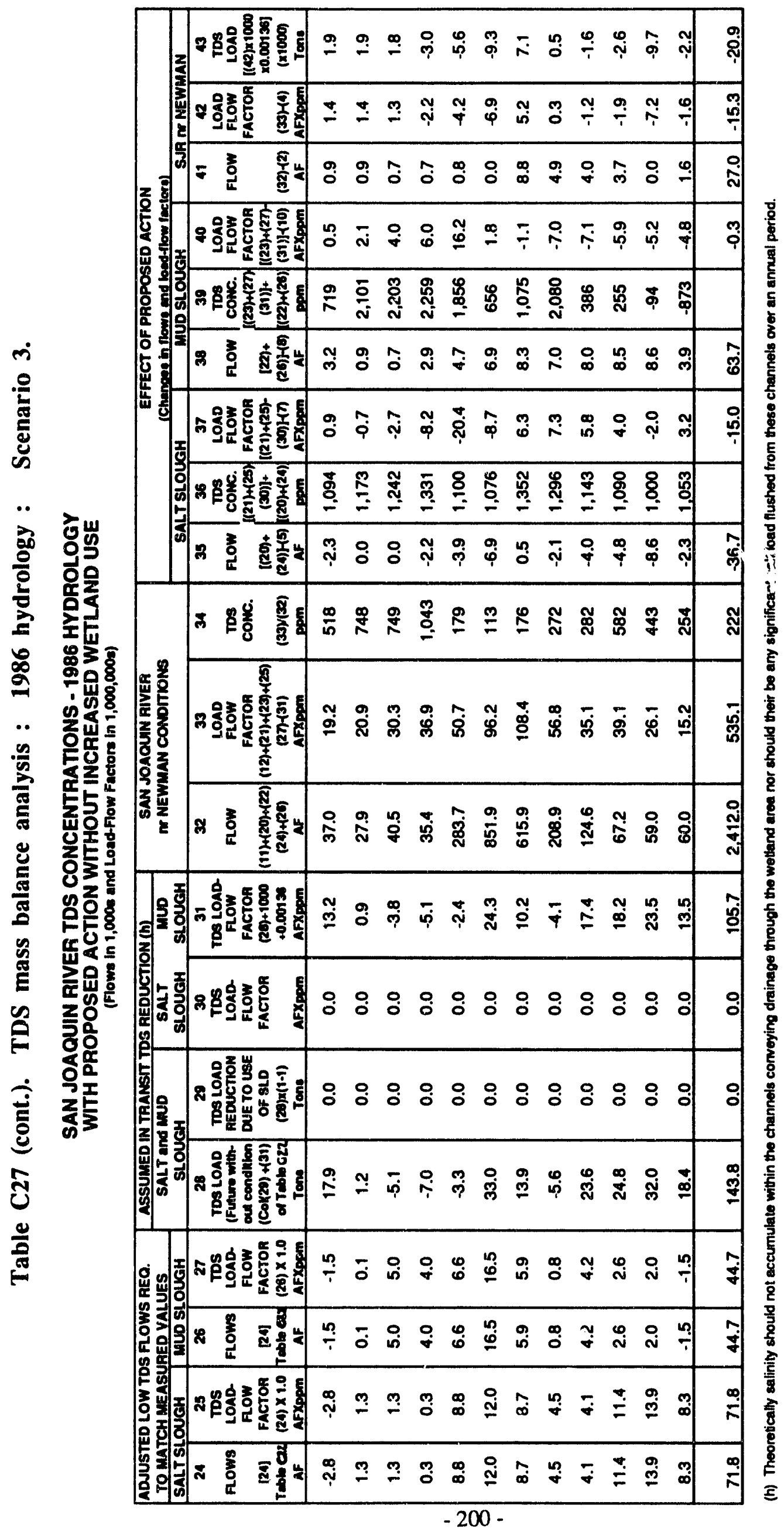




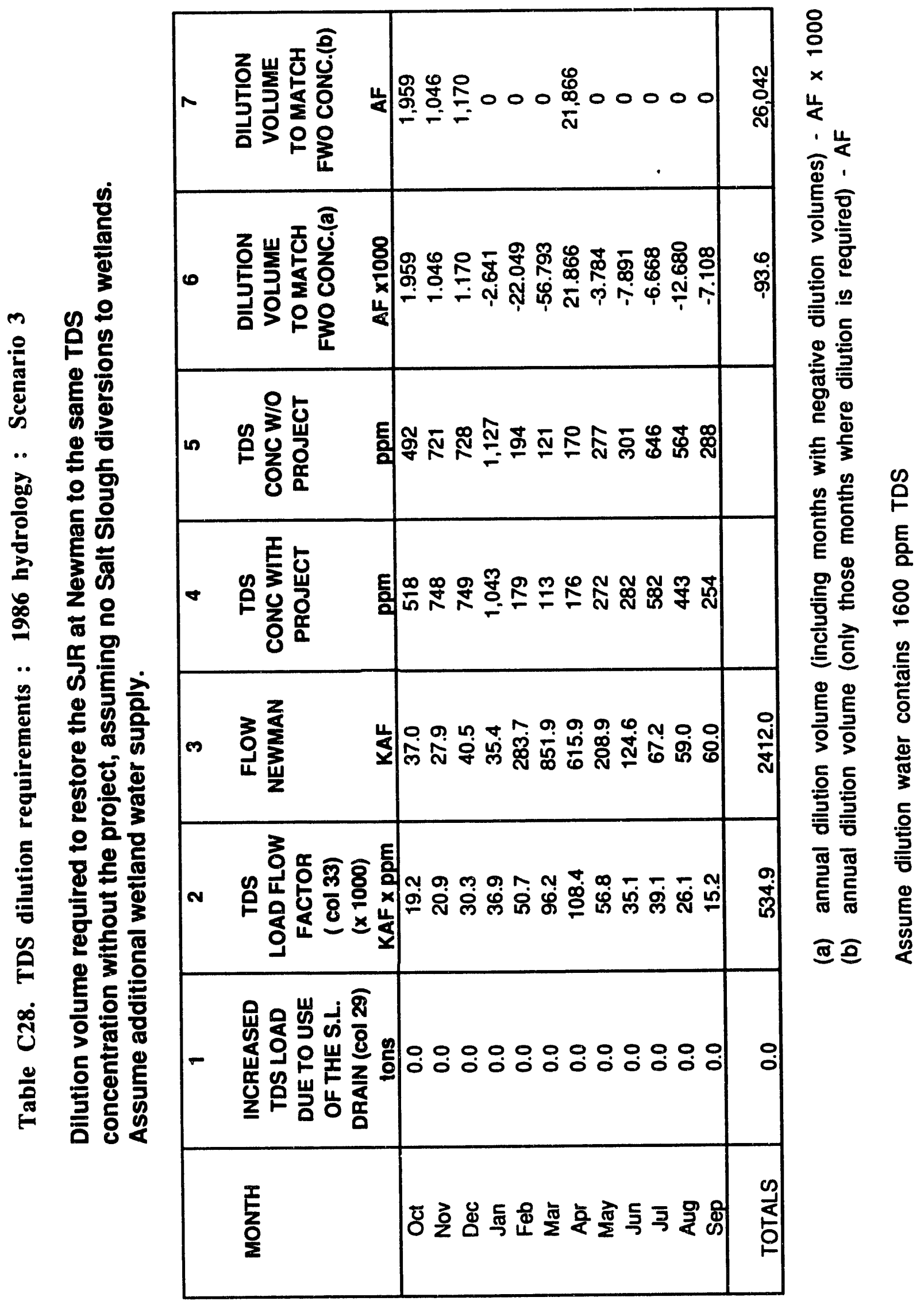




\section{Appendix D}

Flow, boron, selenium and TDS data collected by Summers Eng. Inc. and supplemented with CRWQCB data.

D1 - D2 


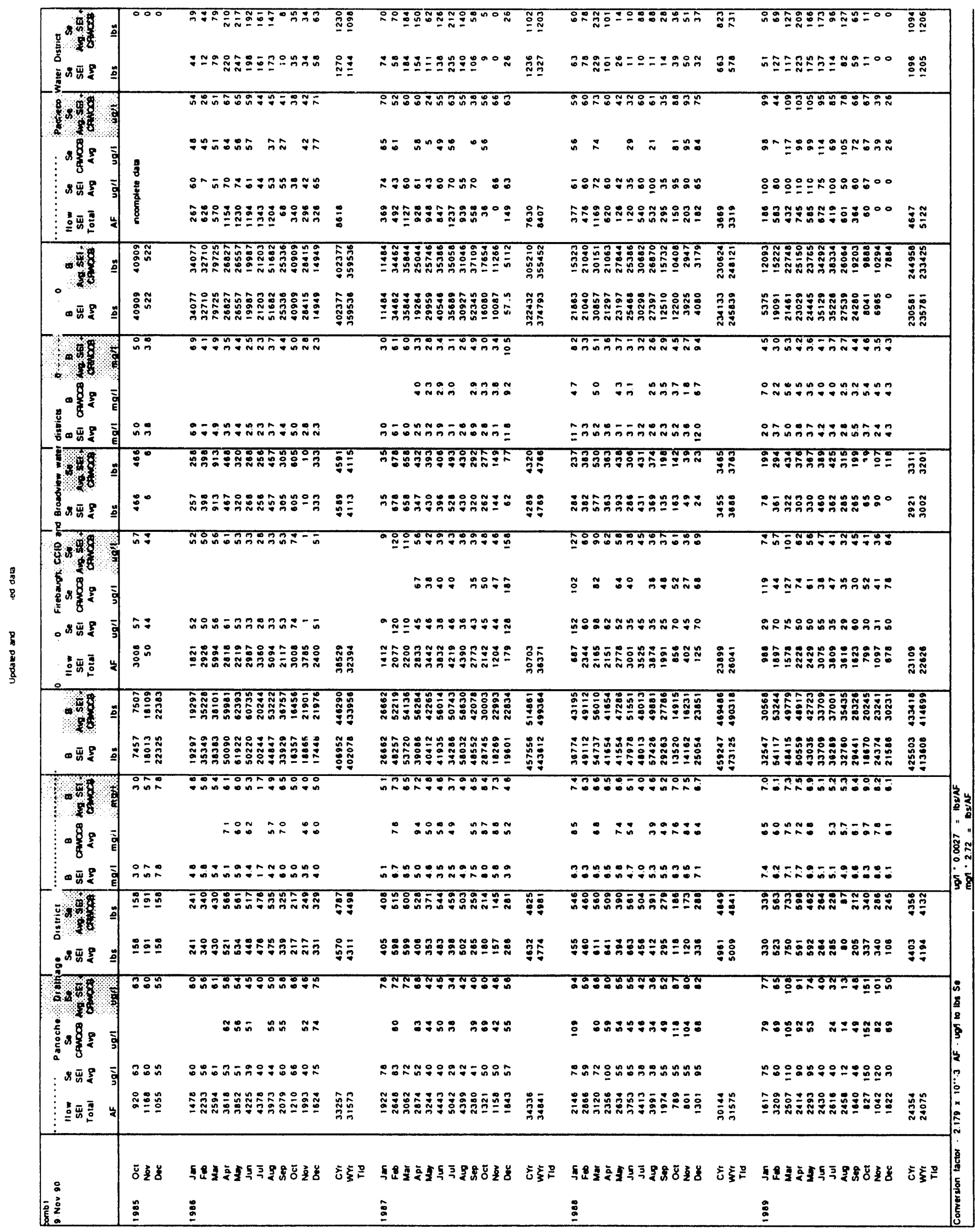




\begin{tabular}{|c|c|c|c|c|c|}
\hline 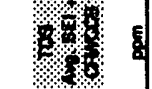 & & 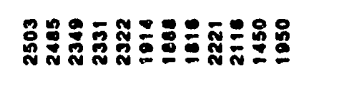 & 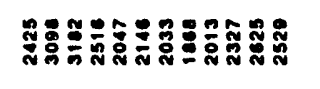 & 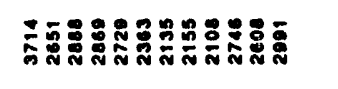 & 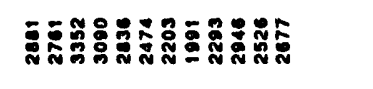 \\
\hline 8 & & 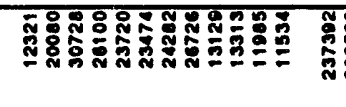 & 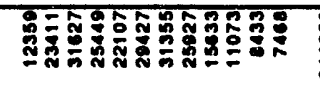 & 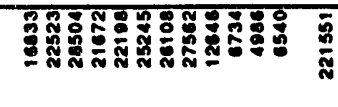 & 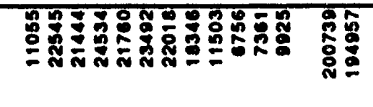 \\
\hline 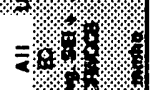 & & 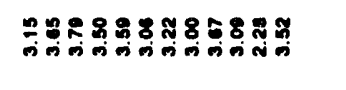 & 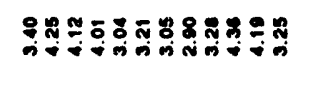 & 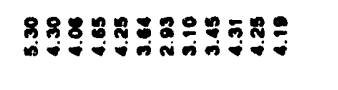 & 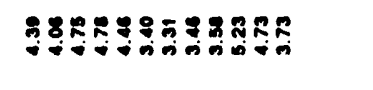 \\
\hline 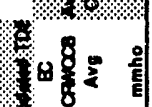 & & 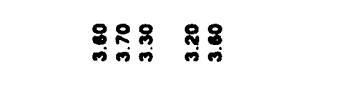 & 它 & ڤั & 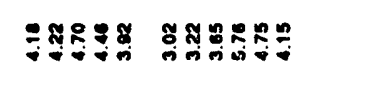 \\
\hline 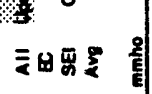 & & 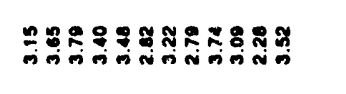 & 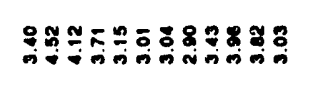 & 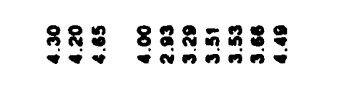 & ํํำ \\
\hline 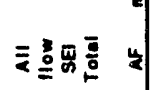 & 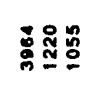 & 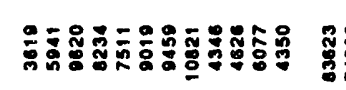 & 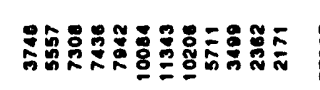 & 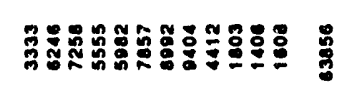 & 天 \\
\hline
\end{tabular}




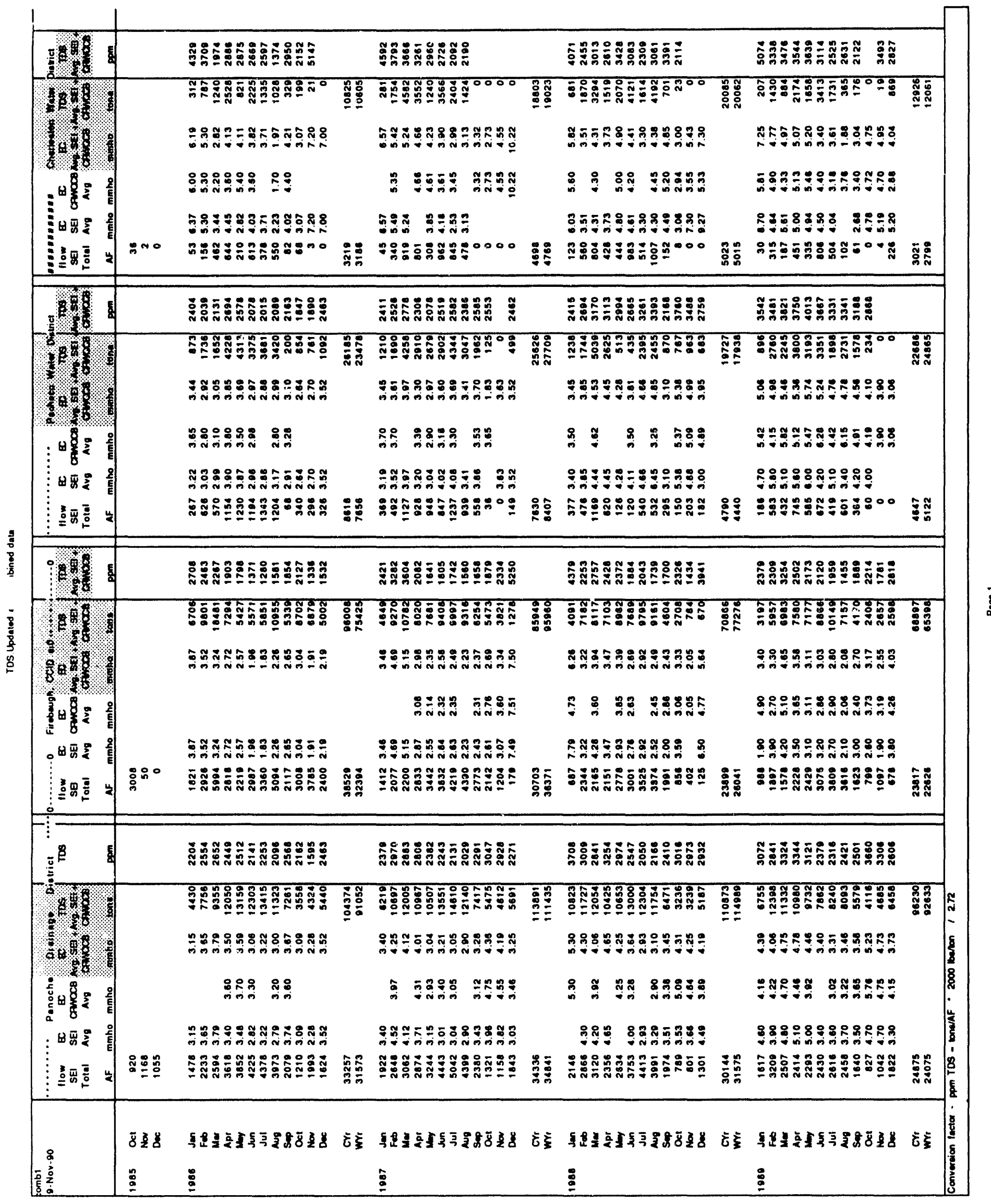




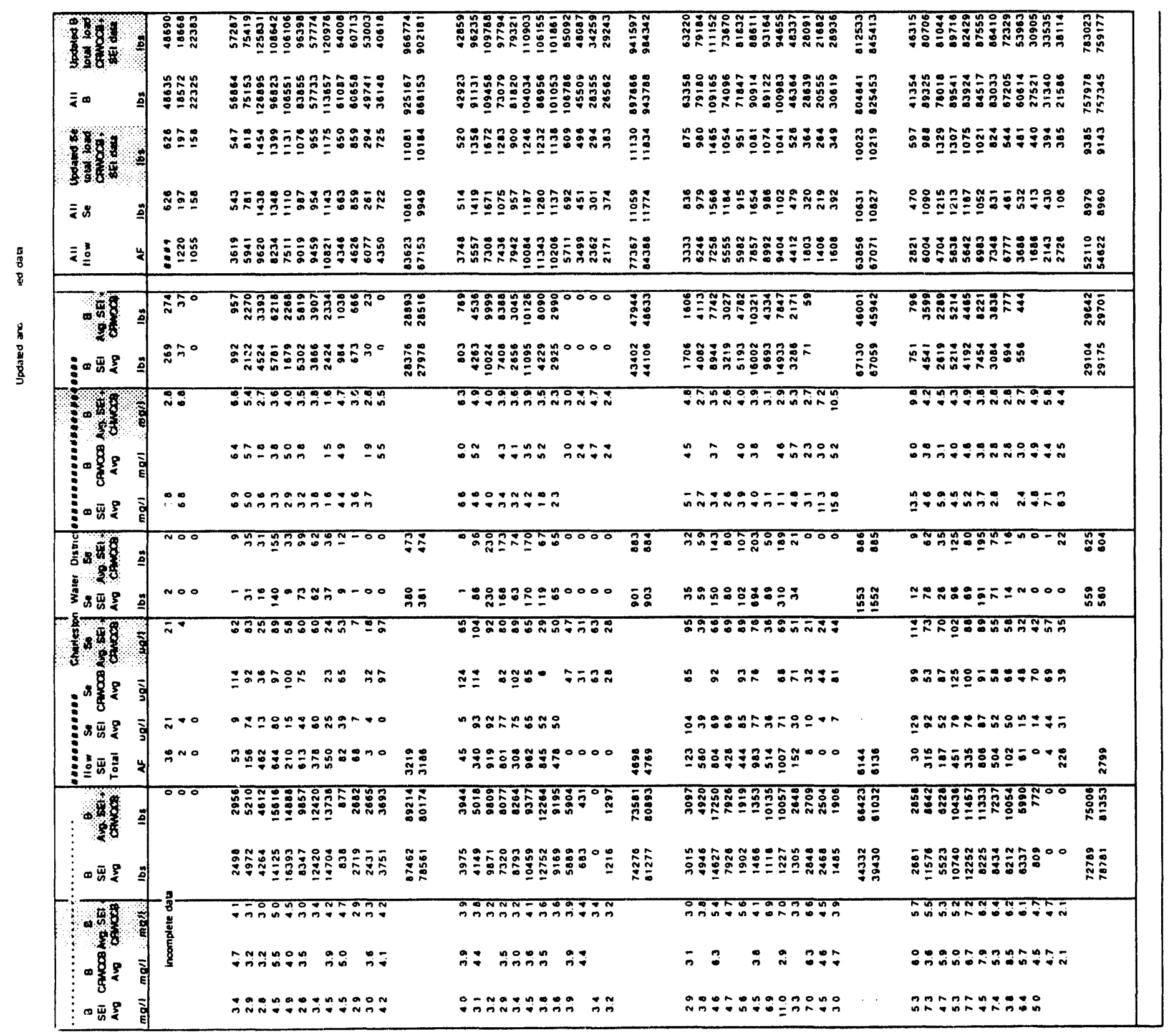


Appendix E

Detailed maps of water supply facilities

in State and Federal Refuges and

Management Areas

E1 - E4 


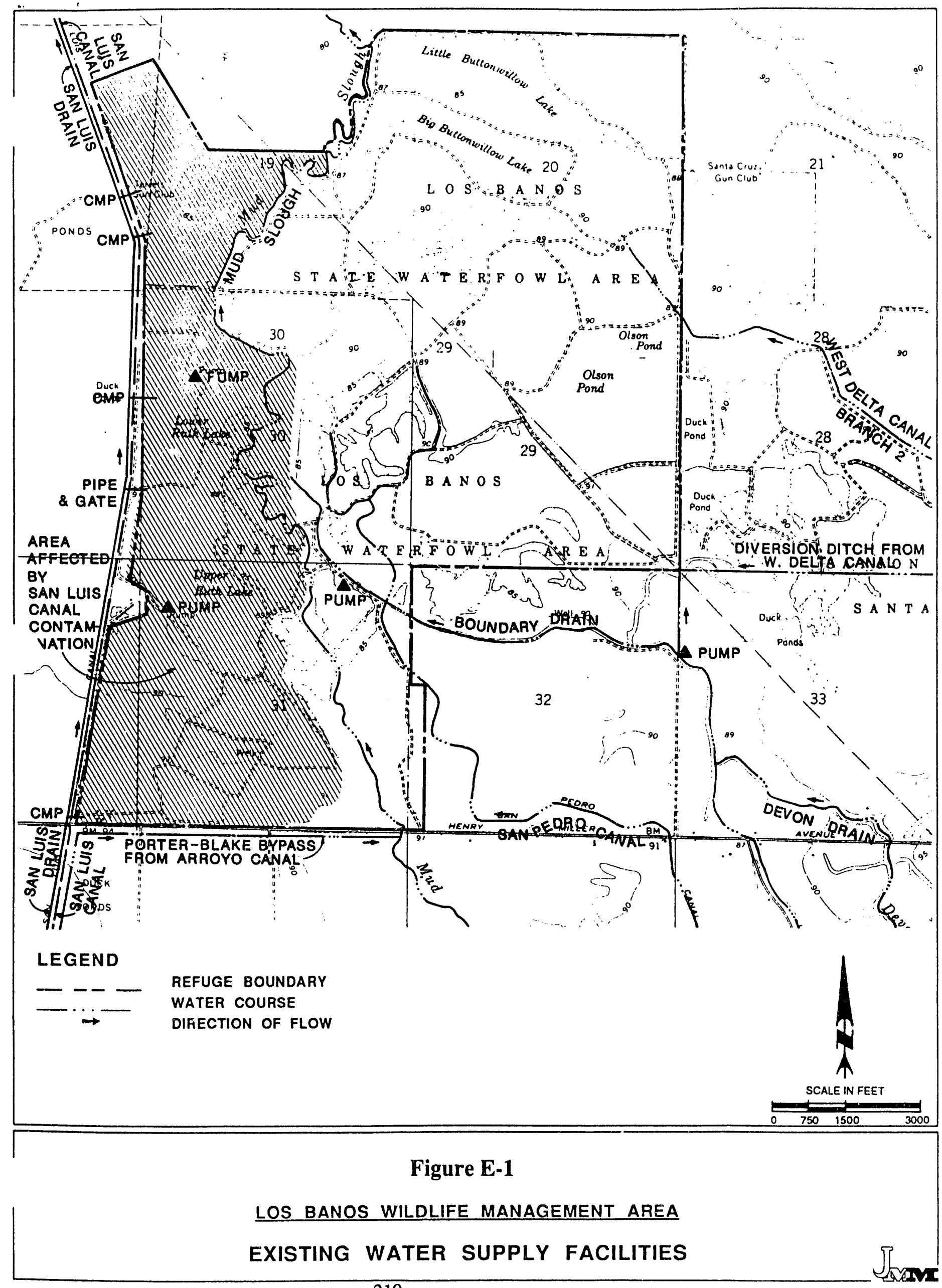




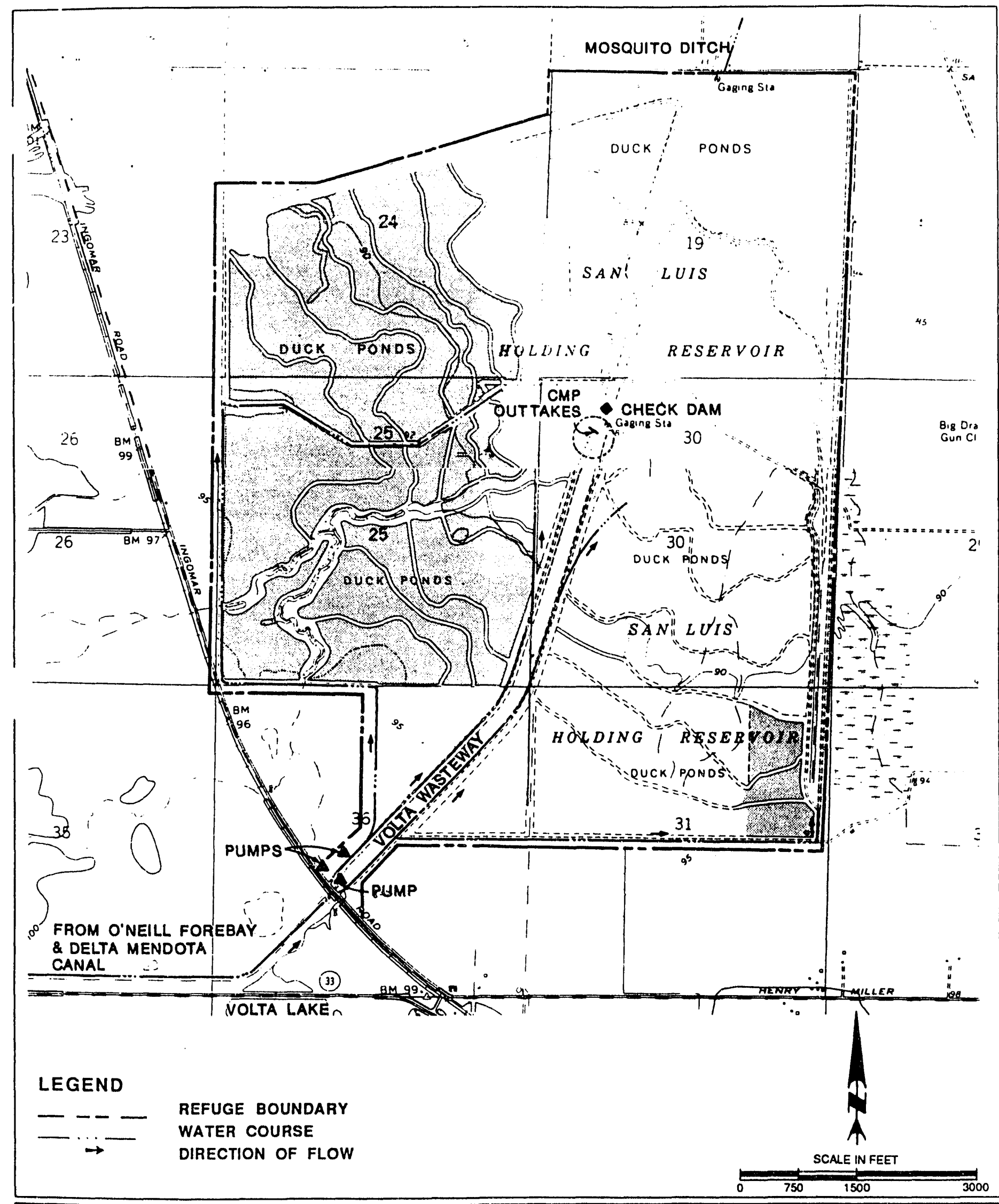

Figure E-2

VOLTA WILDLIFE MANAGEMENT AREA

EXISTING WATER SUPPLY FACILITIES 


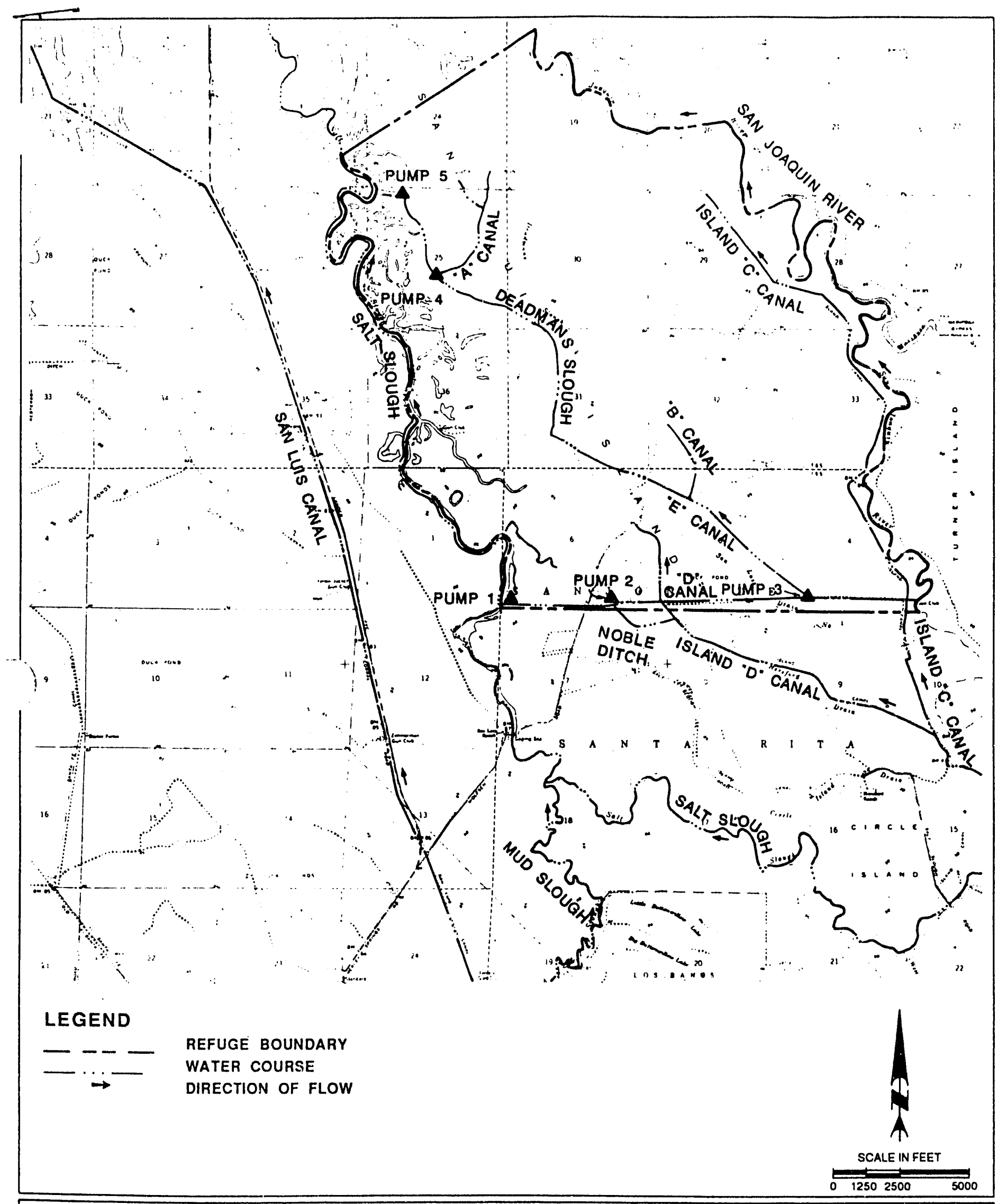

Figure E-3

SAN LUIS NATIONAL WILDLIFE REFUGE

EXISTING WATER SUPPLY FACILITIES 


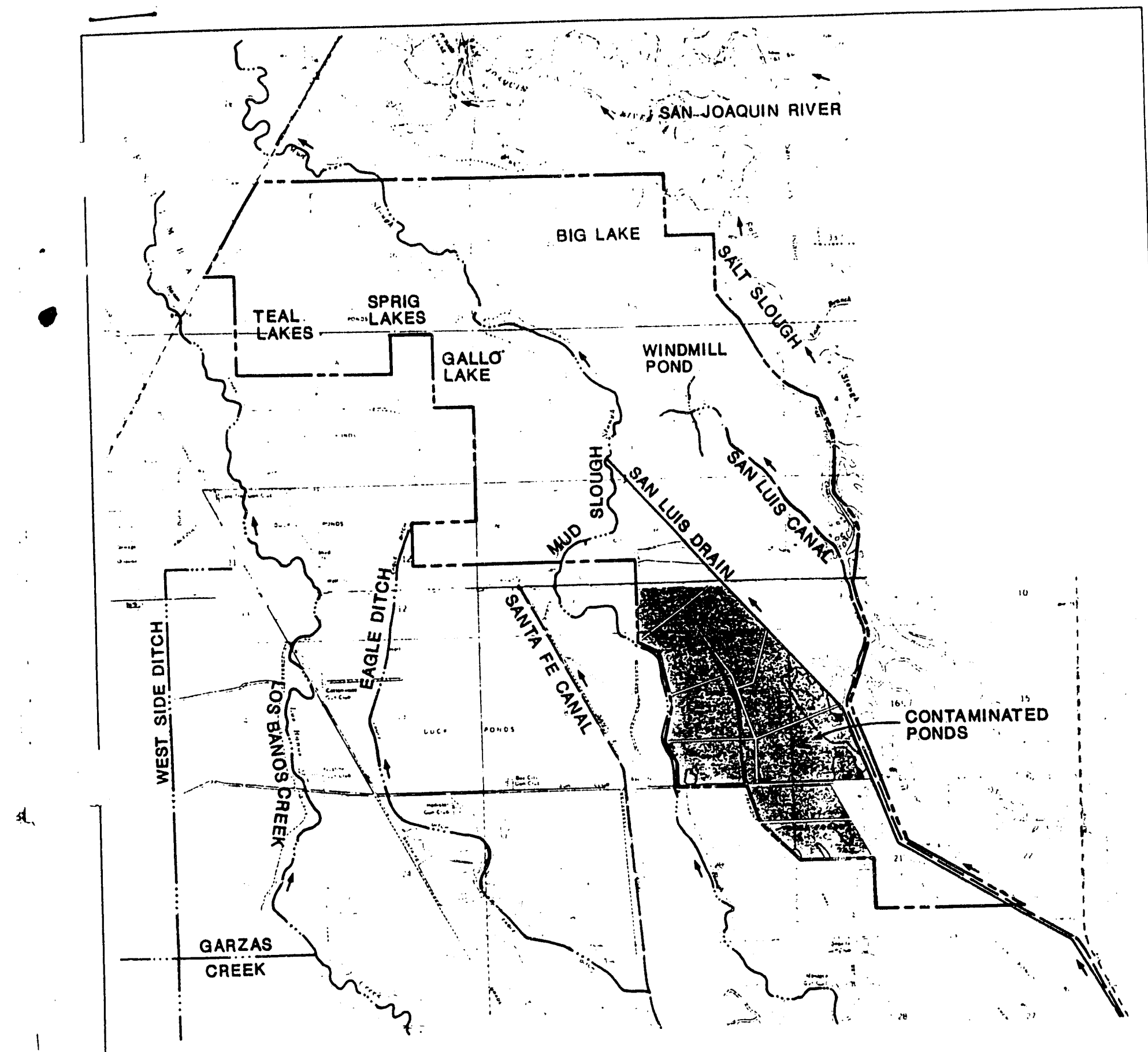

\section{LEGEND}

$\begin{array}{ll}--- & \text { REFUGE BOUNDARY } \\ - & \text { WATER COURSE }\end{array}$

DIRECTION OF FLOW 


\section{Appendix F}

Land use data for management areas defined in GRASDIN model (Philips and Quinn, 1988) 


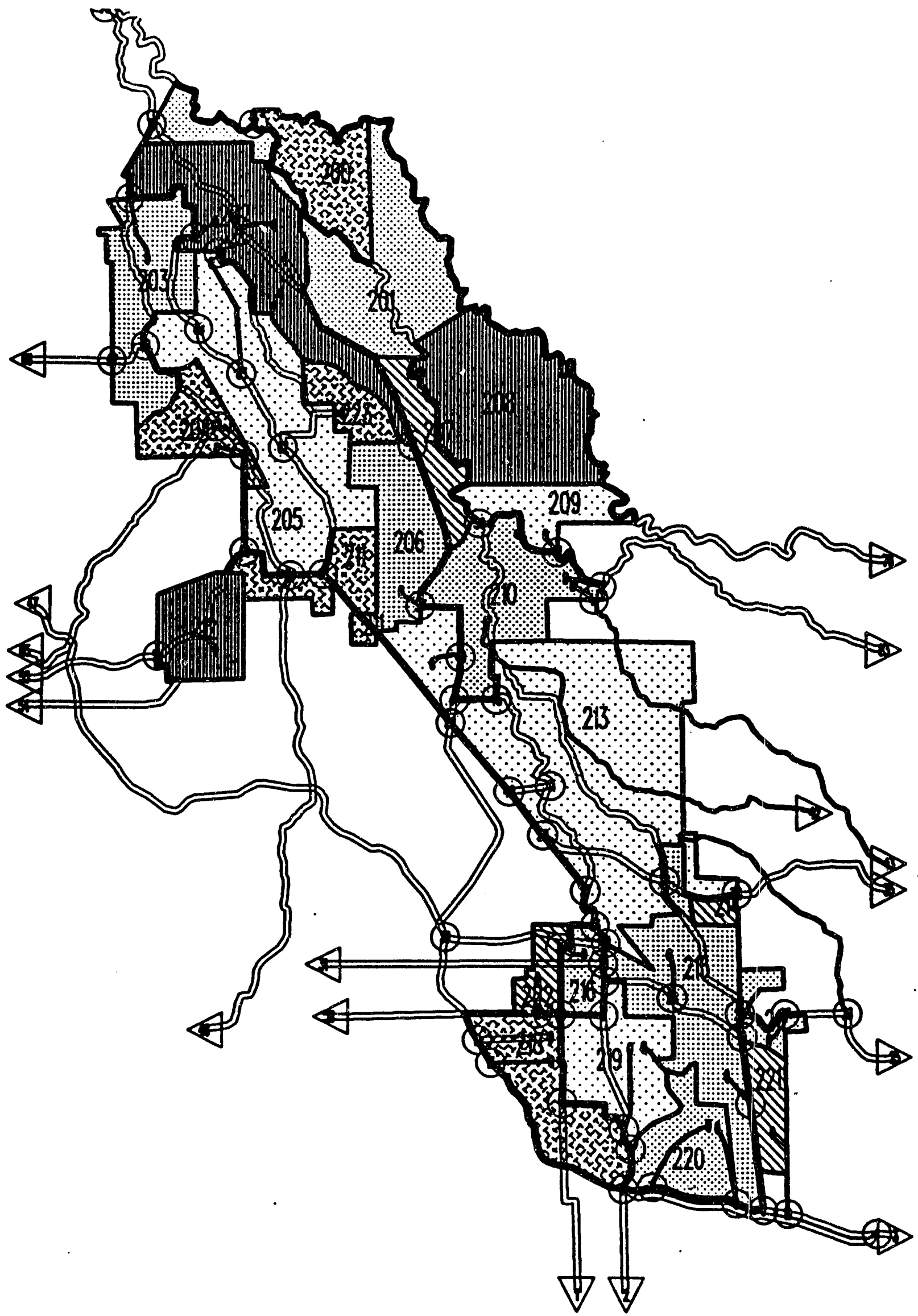

Figure F-1 Map showing the breakdown of the Grassland area into water service subareas (Phillips and Quinn, 1990). The land use data appears in Appendix F. 


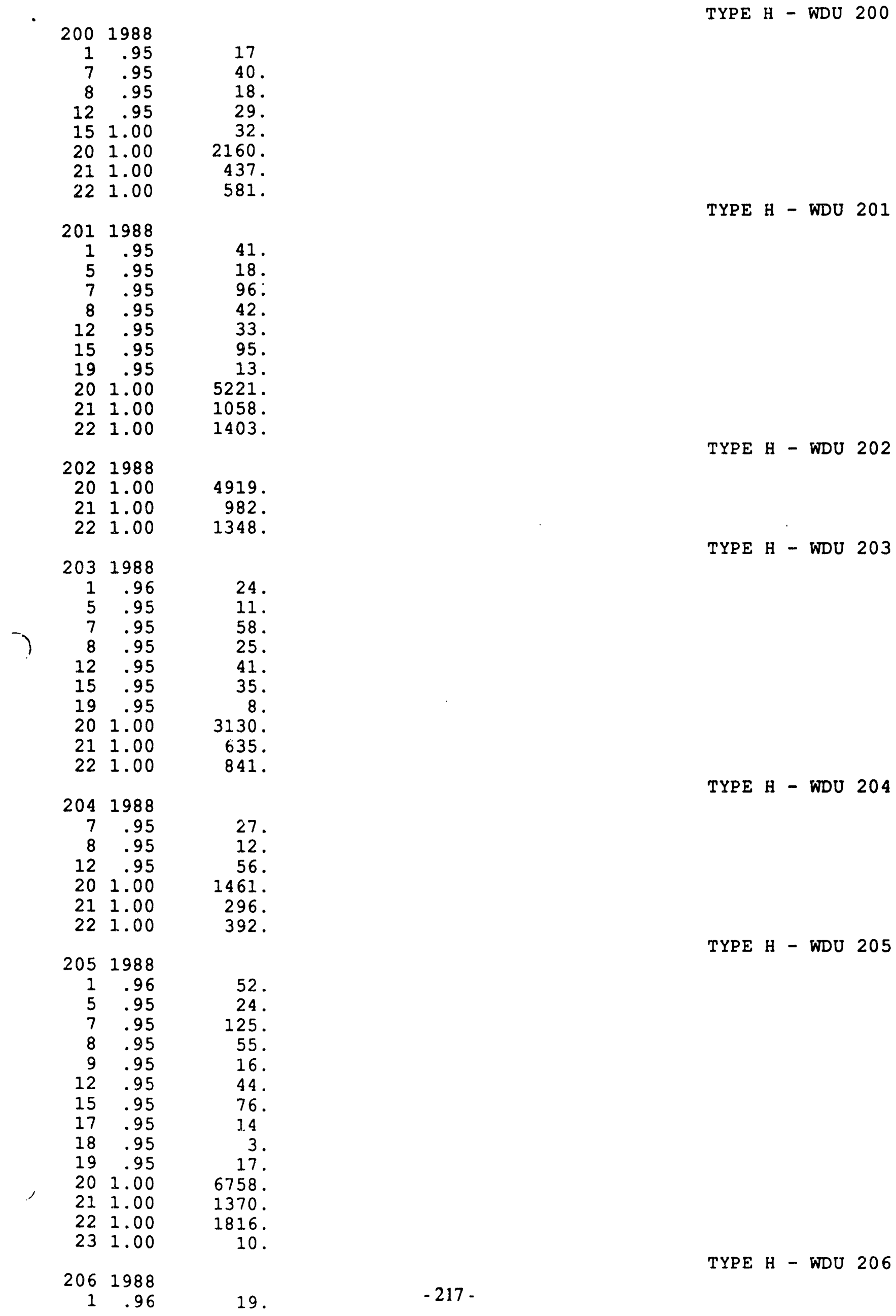




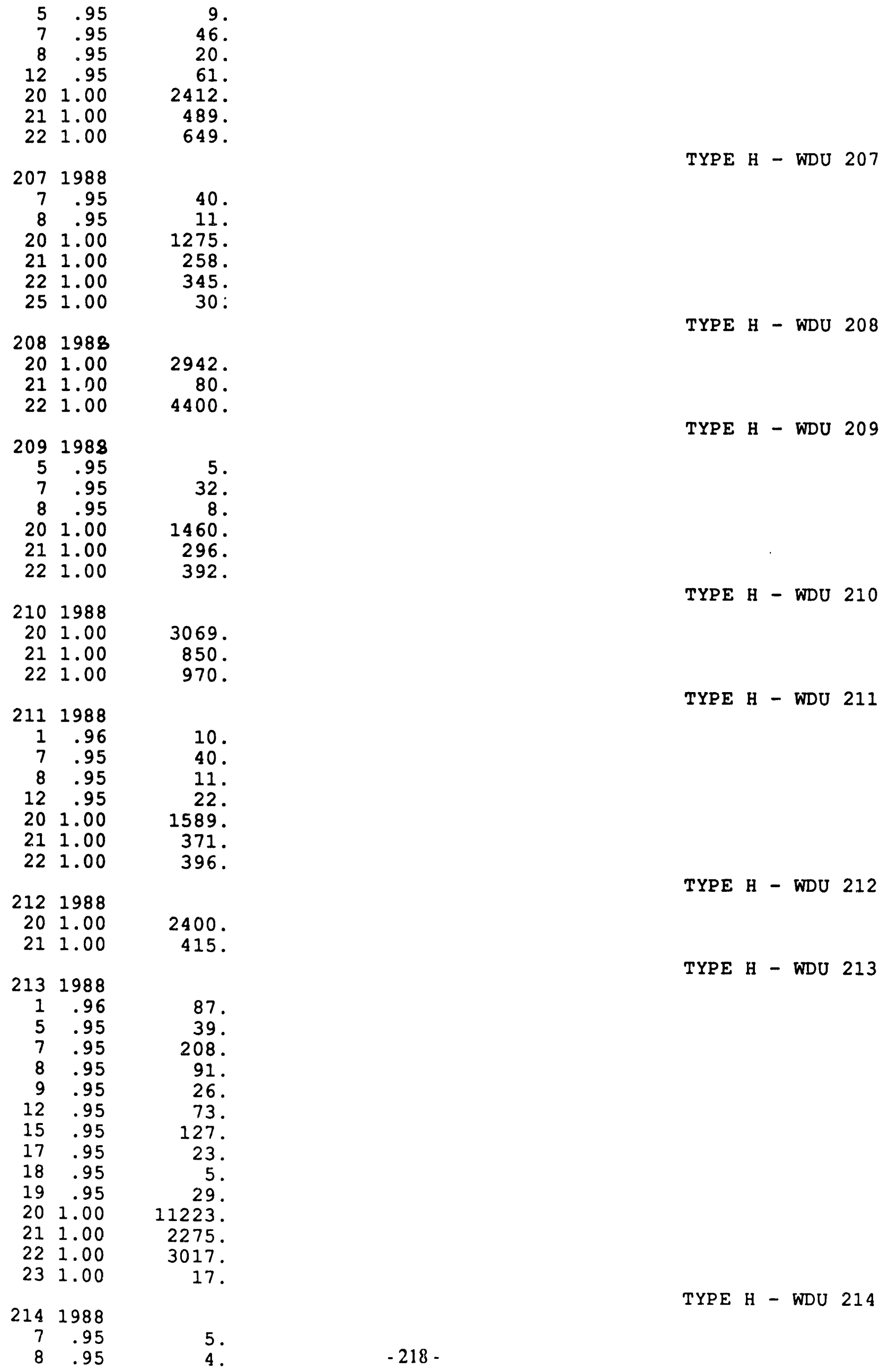




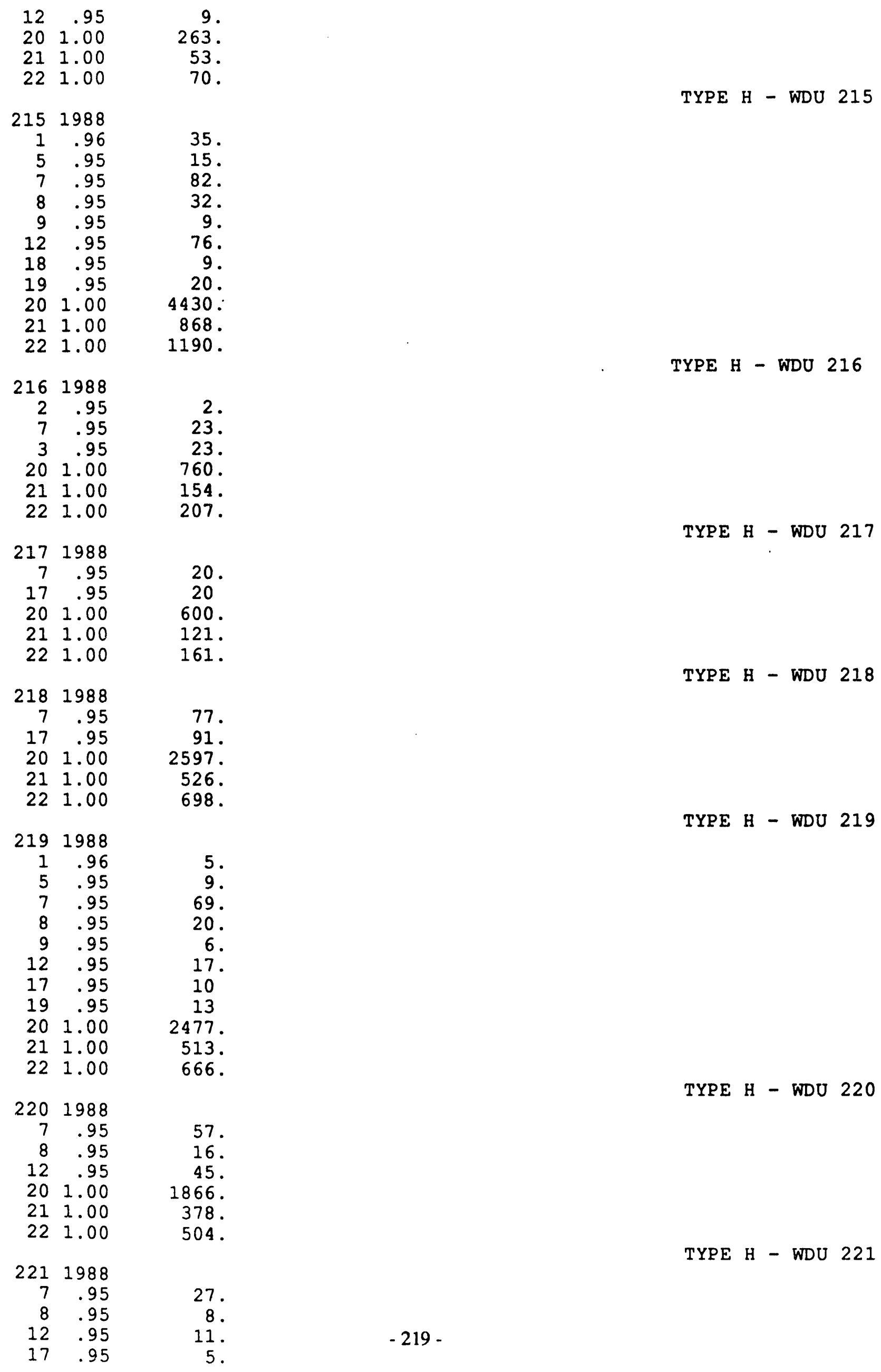




$\begin{array}{rrr}19 & .95 & 8 . \\ 20 & 1.00 & 937 . \\ 21 & 1.00 & 190 . \\ 22 & 1.00 & 252 .\end{array}$

2221982

7.95
77

$17 \quad .95$

19.95

201.00

211.00

221.00

2231982

$3 \quad .95$

7.95

12.95

$17 \quad .95$

$19 \quad .95$

201.00

211.00

221.00

ALFALFA

ALF SEED

BARLEY

BEANS

BEETS

CORN

COTTON

GRAIN

MELONS

MILO

MISC FID

MISC TRK

NATIVE

NURSERY

PASTURE

POTATOES

RICE

SAFFLOWER

TOMATOES

SEASONAL WETLANDS

PERMANENT WETLANDS

MANAGED UPLANDS

OTHER UPLANDS

UNIRRIGATED CROPLANDS

NO CROP
18.

22.

703.

142 .

188.

7 :

25 .

10 .

8.

10 .

926 .

188 .

249 .

TYPE H - WDU 222

TYPE H - WDU 223

TYPE H - END OF DATA

0.96

TYPE I - CROP CODES 
Appendix G

Monitoring stations within the Grassland area and frequency of measurement

(Summers Engineeering, 1991) 


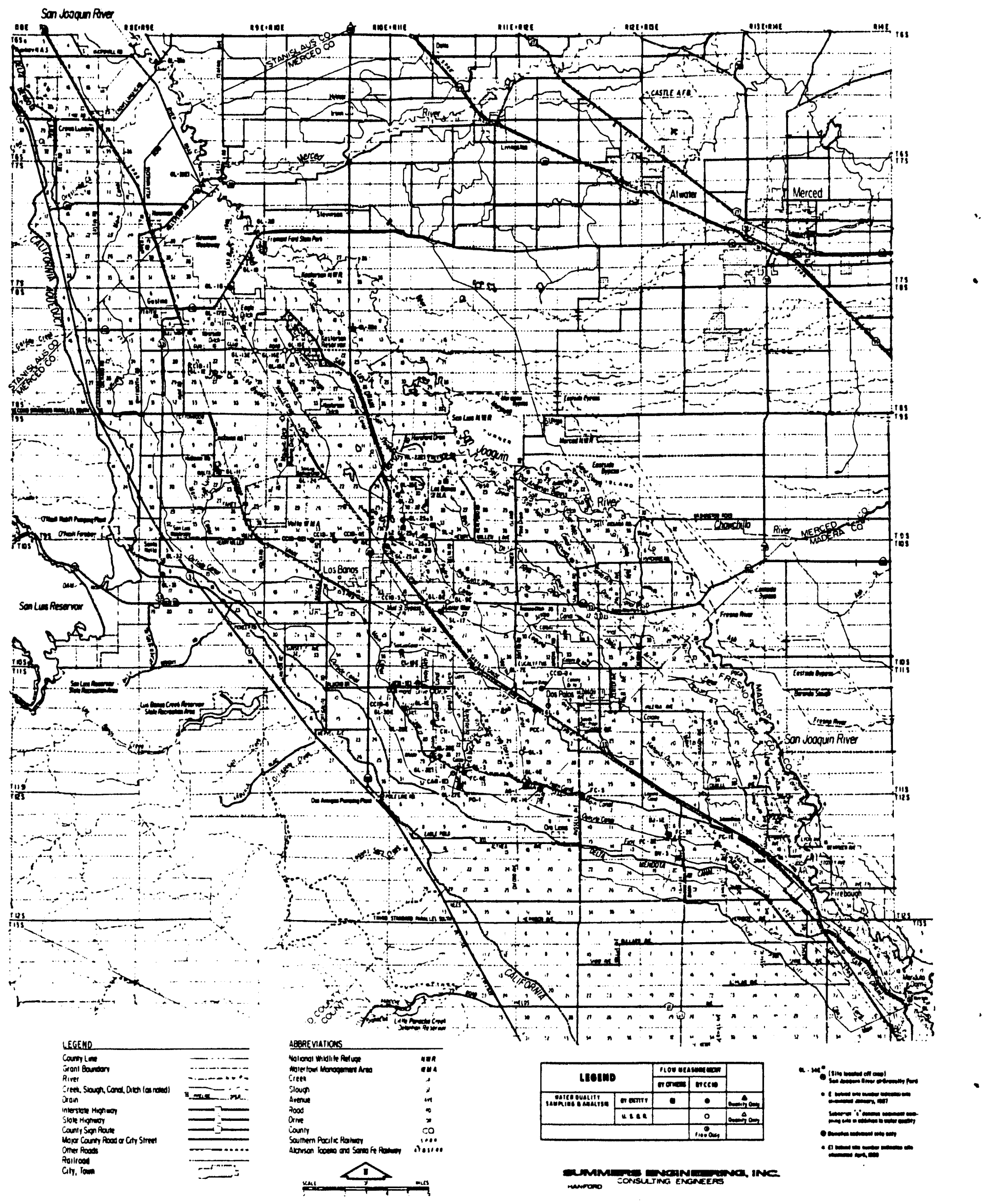

Figure G-1. Monitoring stations within the Grassland area (Summers, 1991). 


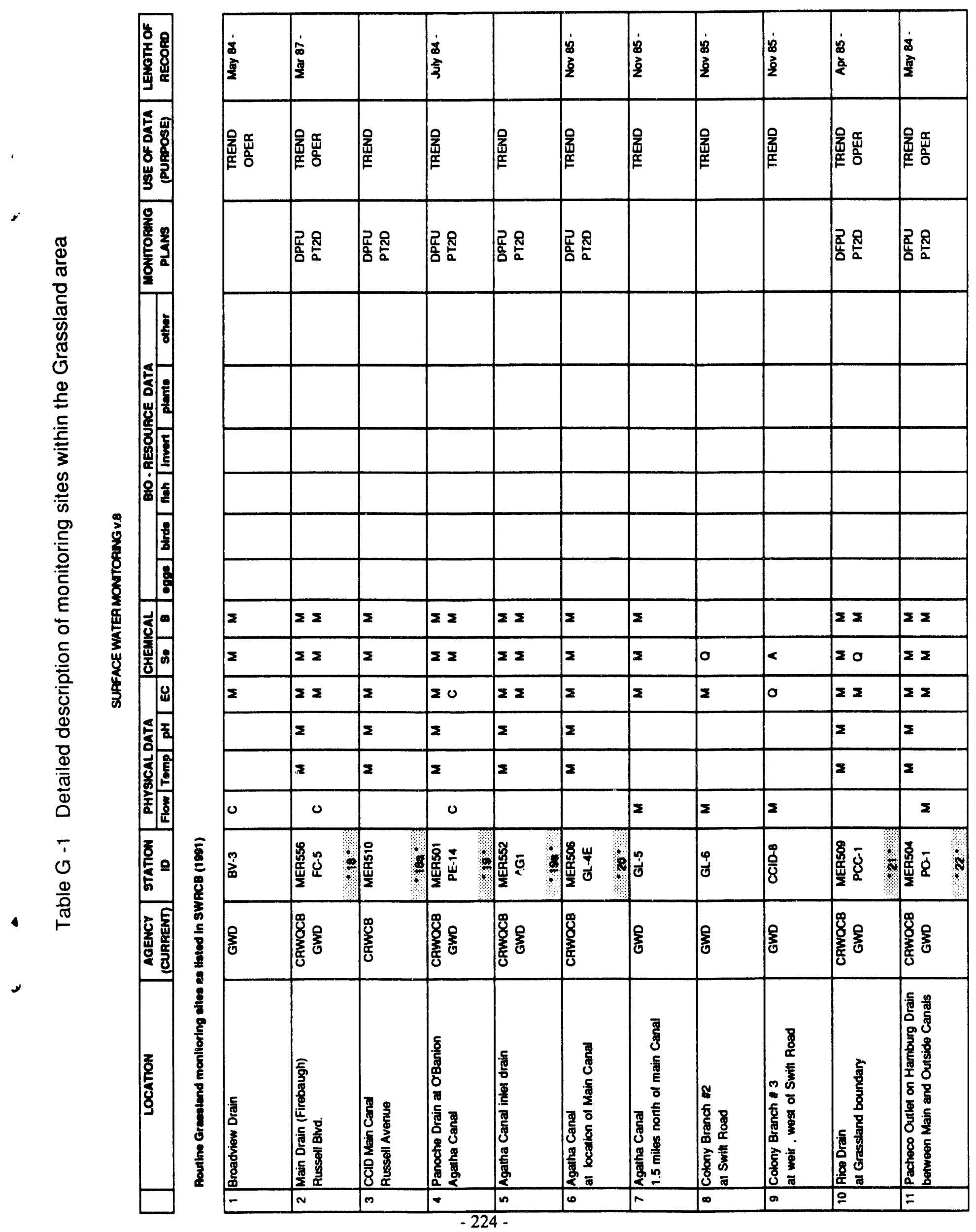




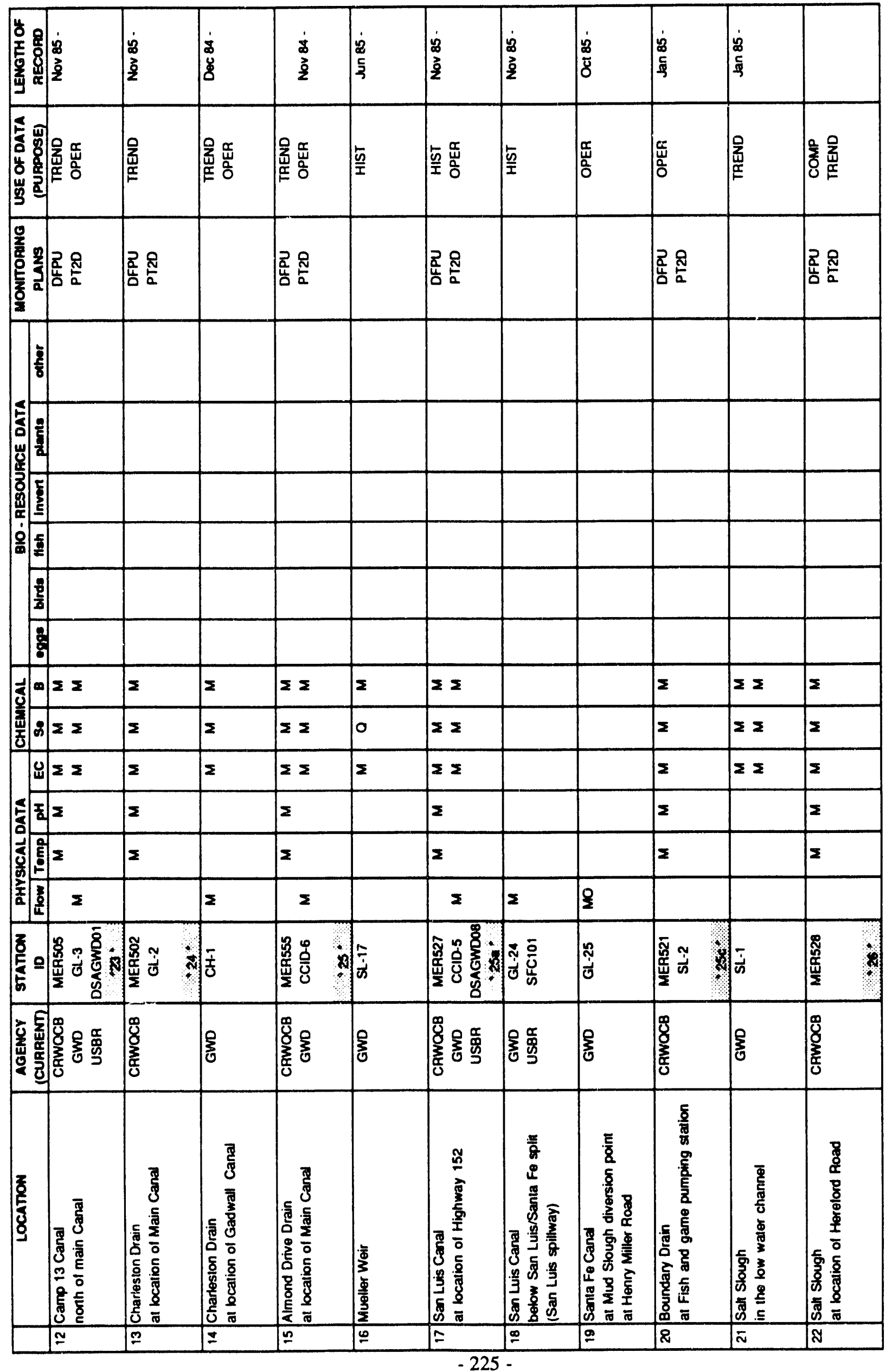




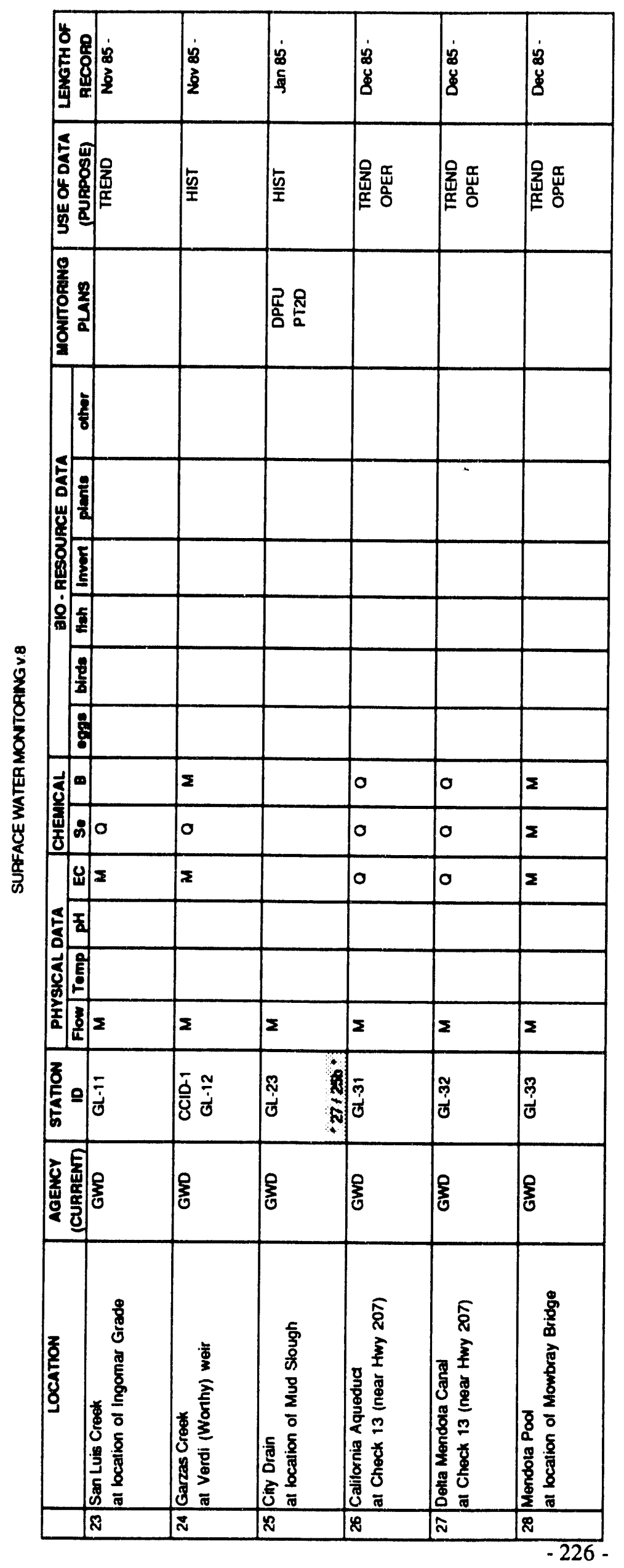

\begin{tabular}{|c|c|c|c|}
\hline & & $\mid \begin{array}{l}\dot{3} \\
\vdots \\
\vdots \\
\vdots\end{array}$ & \\
\hline 参采 & 产 & 恿㤩 & 衰竞 \\
\hline 8릉 옴 & 름옹 & \& & 8 总总 \\
\hline & & & \\
\hline & & & \\
\hline & & & \\
\hline & & & \\
\hline & & & \\
\hline & & & \\
\hline $3 \leqslant$ & $z=$ & 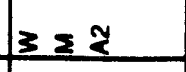 & 3 \\
\hline 32 & 32 & 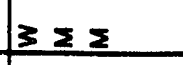 & 3 \\
\hline 300 & 302 & $3 \geq 0$ & 30 \\
\hline 3 & 3 & 3 & 3 \\
\hline 30 & 3 & 3 & 30 \\
\hline 0 & $\begin{array}{lll}0 & 0\end{array}$ & & 0 \\
\hline 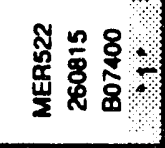 & 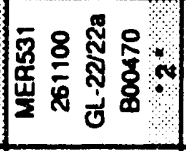 & 䒴 & 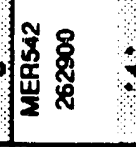 \\
\hline 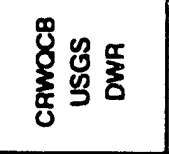 & 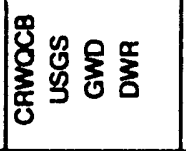 & 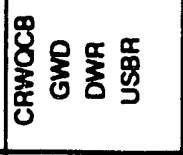 & 焉 \\
\hline 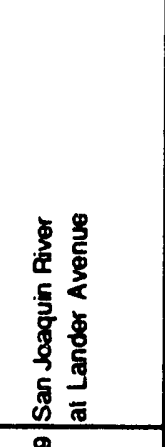 & 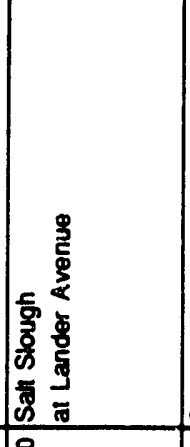 & 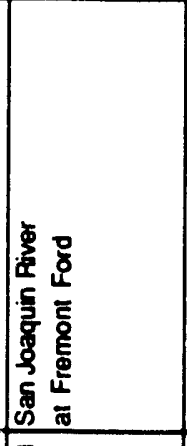 & 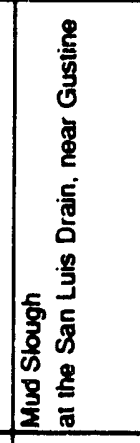 \\
\hline $\mathbb{R}$ & I8 & $\bar{n}$ & I \\
\hline
\end{tabular}

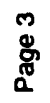




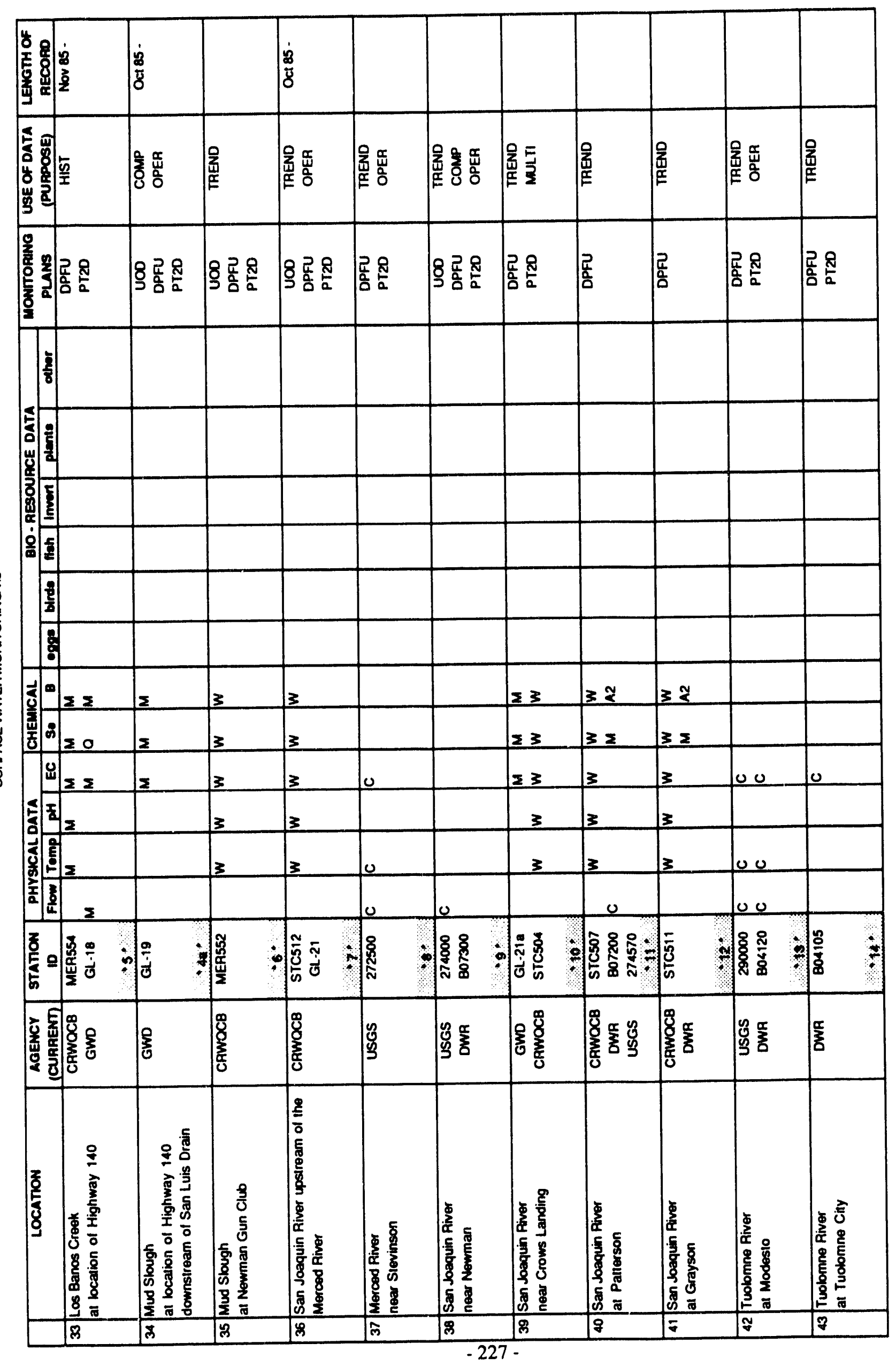



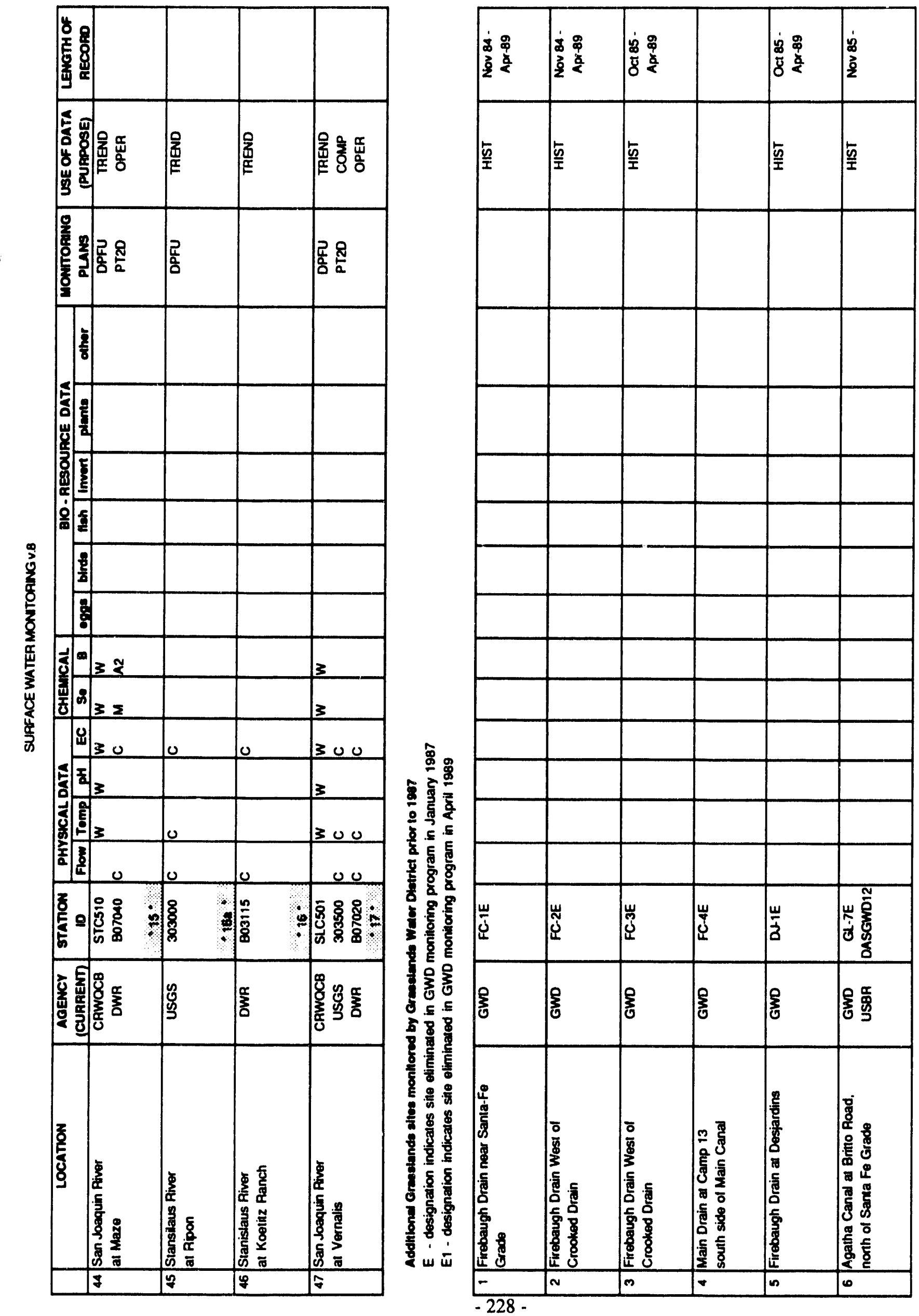


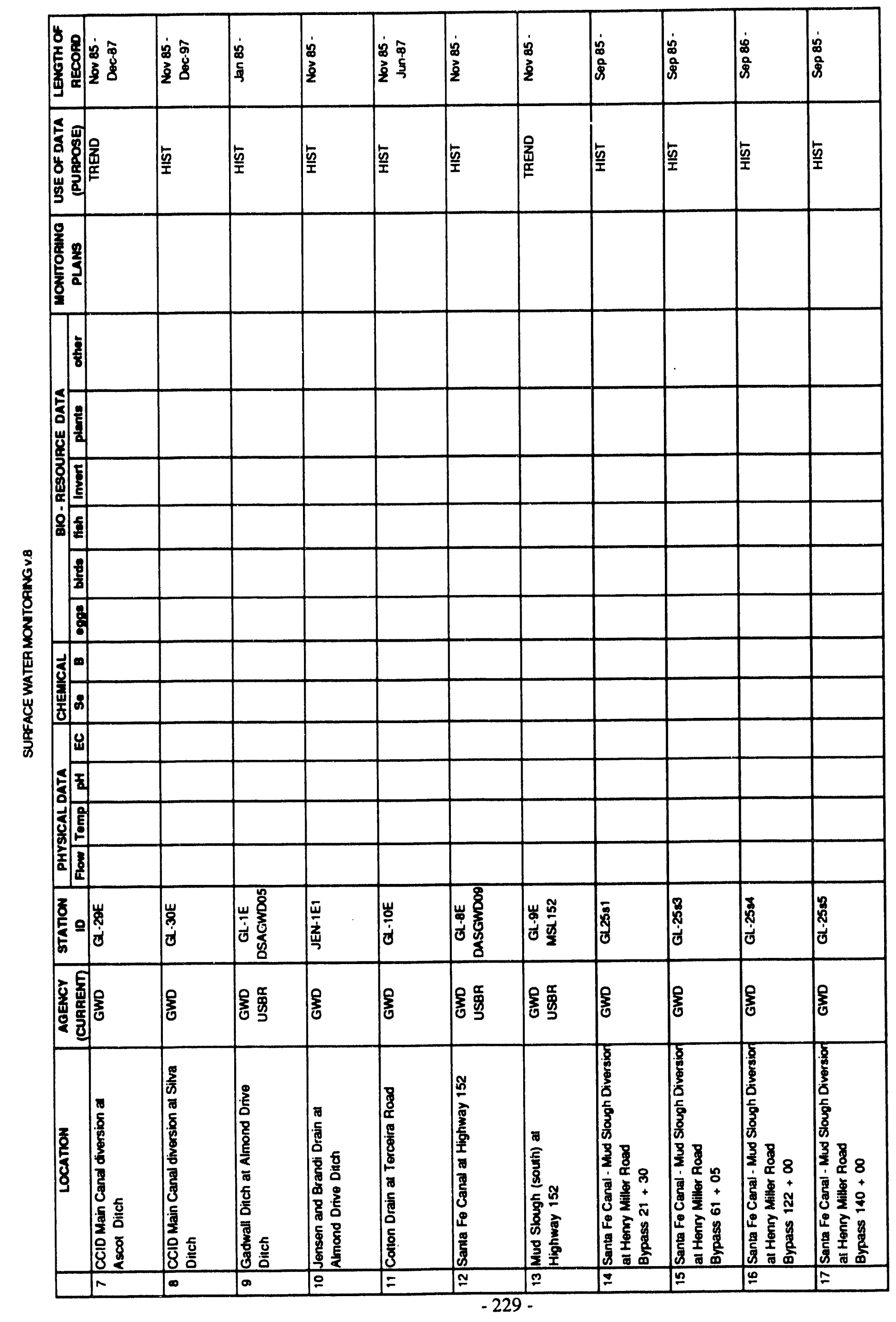

咅 


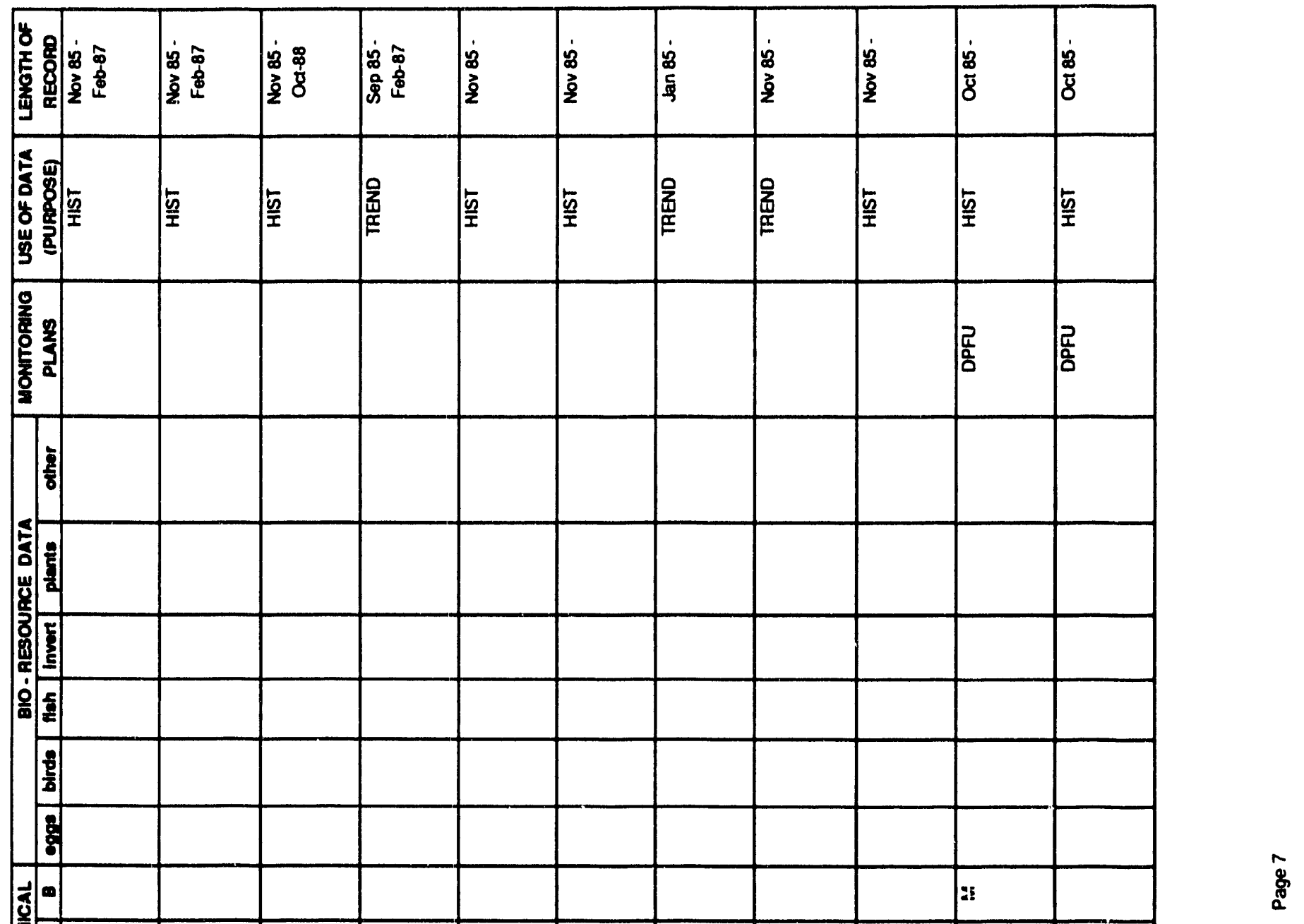




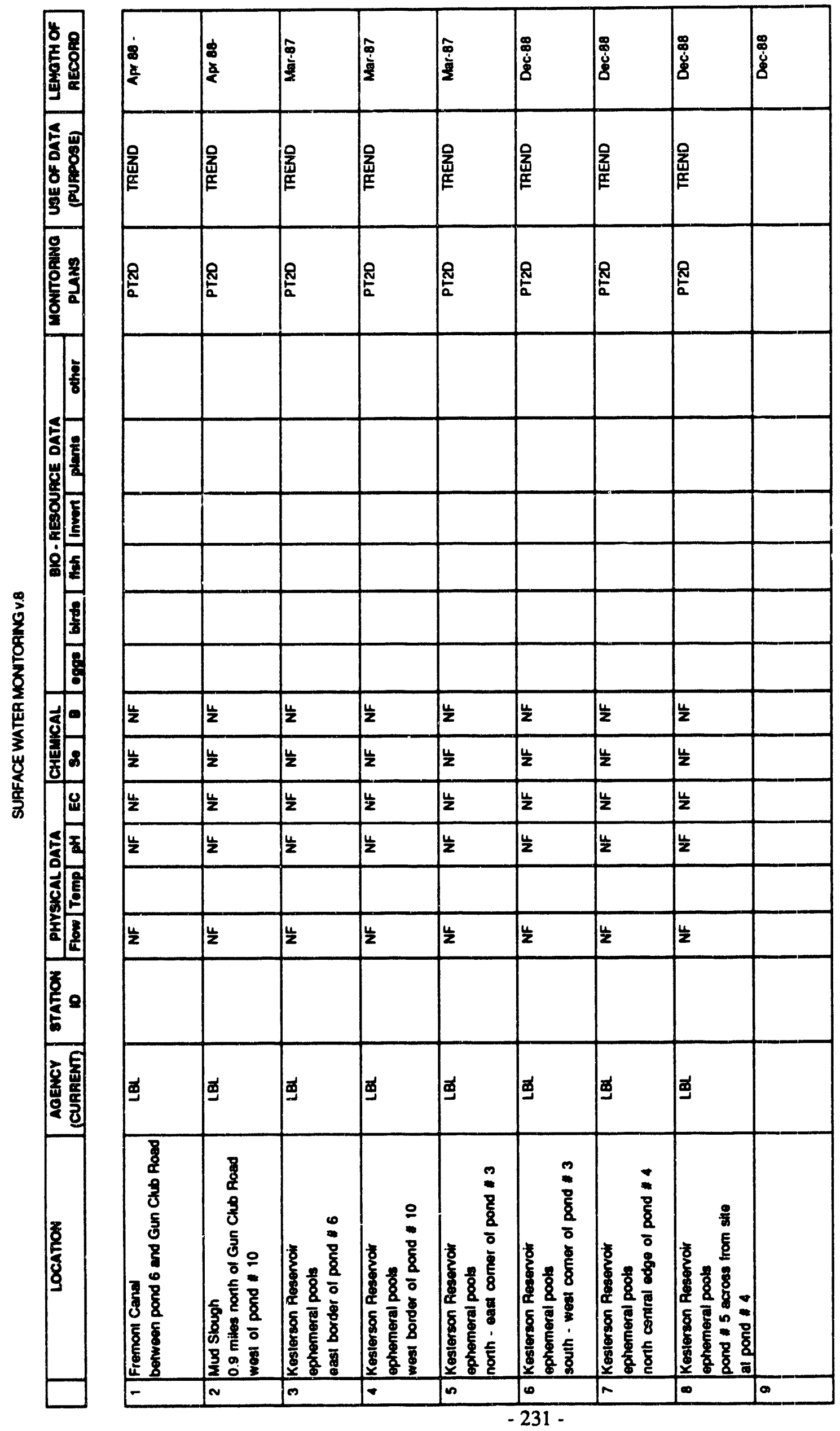

$\dot{z}$ 


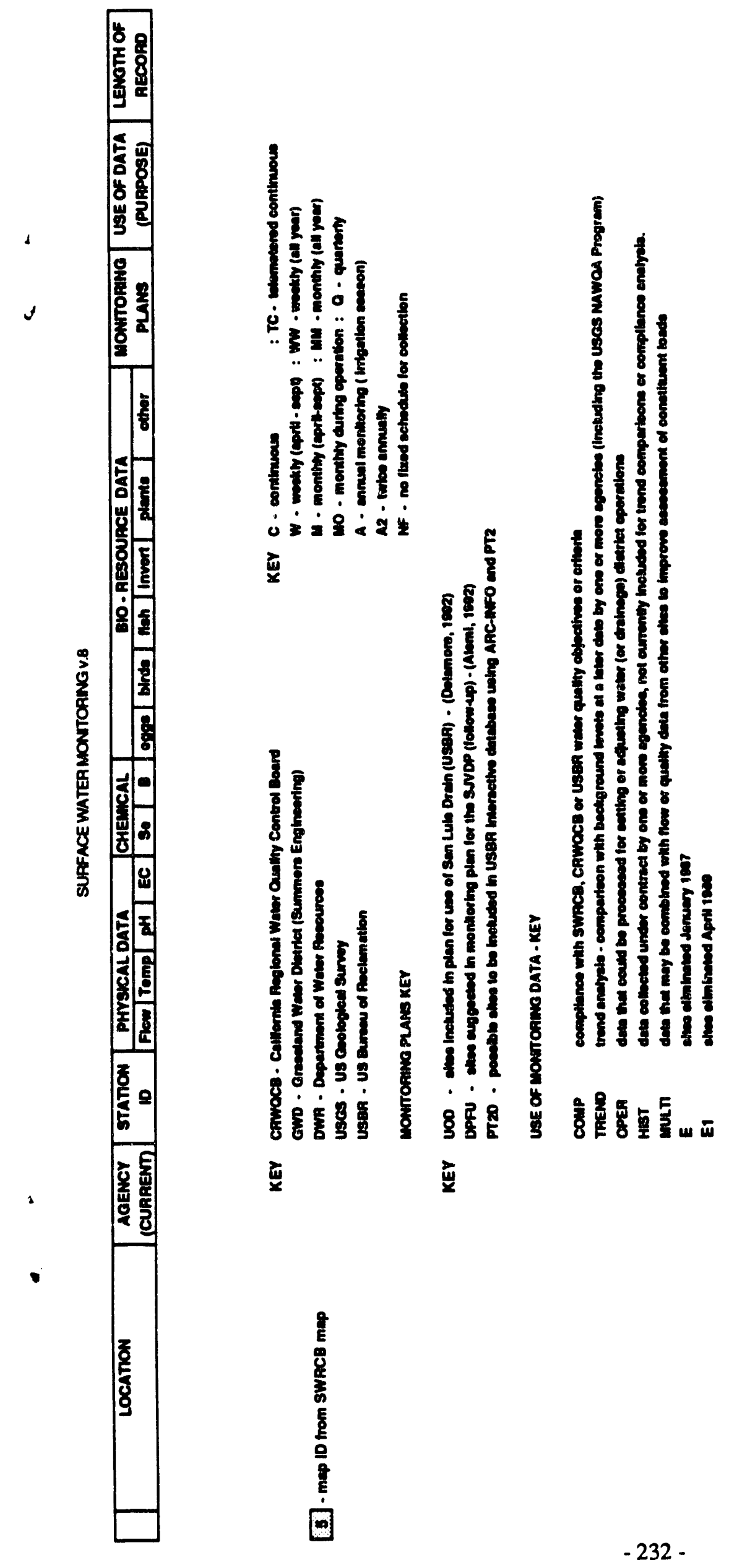

웅
잉 

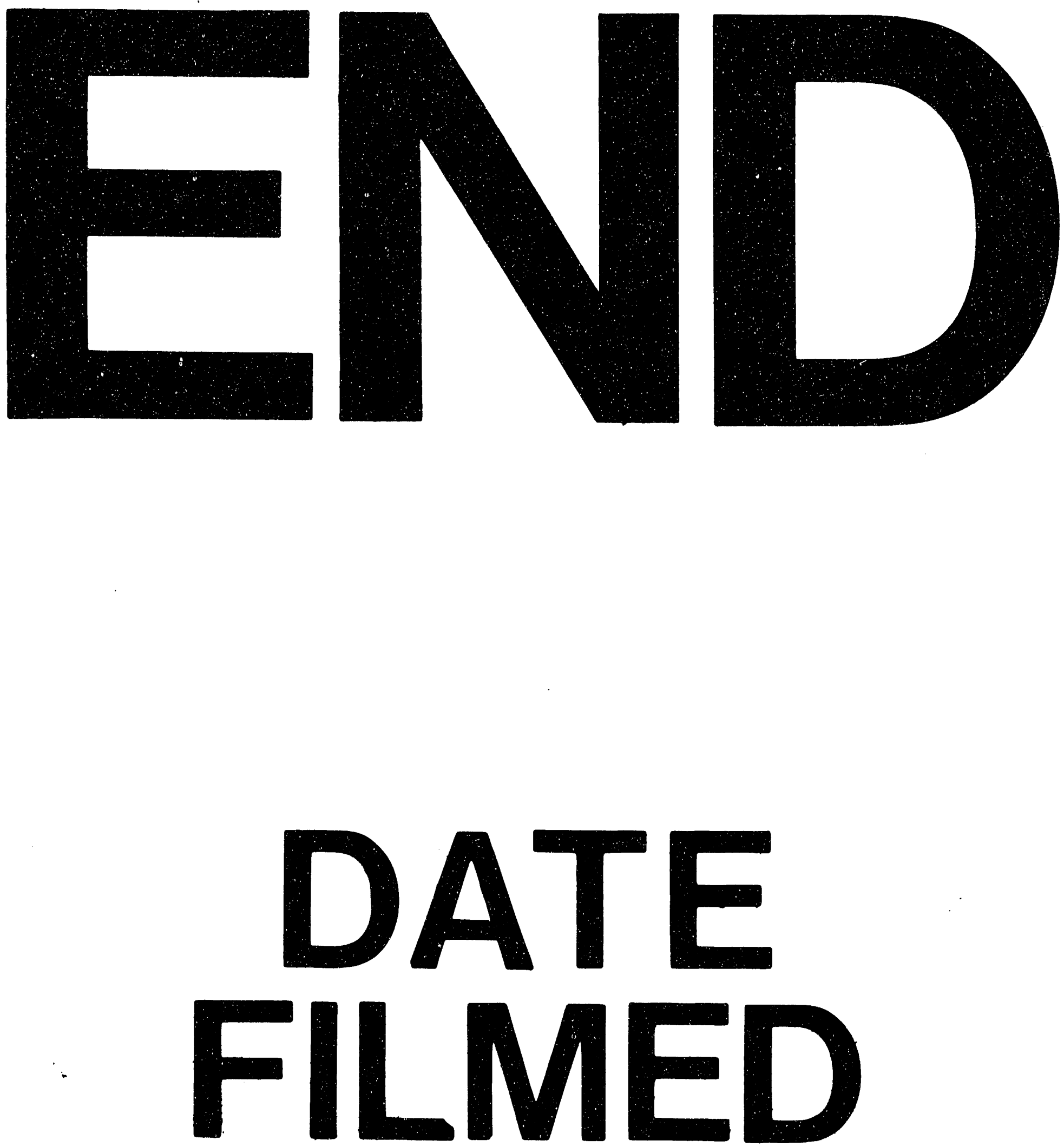

1

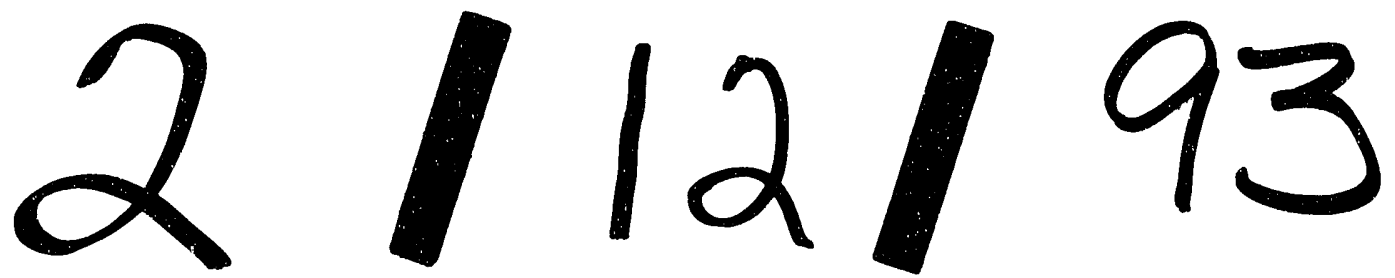


